\title{
No time to waste : a glycogen synthase kinase-3 $\beta$ - glucocorticoid receptor signaling axis illuminated
}

Citation for published version (APA):

Koen Verhees, K. J. P. (2013). No time to waste : a glycogen synthase kinase-3 $\beta$ - glucocorticoid receptor signaling axis illuminated. [Doctoral Thesis, Maastricht University]. Maastricht University. https://doi.org/10.26481/dis.20130619kv

Document status and date:

Published: 01/01/2013

DOI:

$10.26481 / \mathrm{dis} .20130619 \mathrm{kv}$

Document Version:

Publisher's PDF, also known as Version of record

\section{Please check the document version of this publication:}

- A submitted manuscript is the version of the article upon submission and before peer-review. There can be important differences between the submitted version and the official published version of record.

People interested in the research are advised to contact the author for the final version of the publication, or visit the DOI to the publisher's website.

- The final author version and the galley proof are versions of the publication after peer review.

- The final published version features the final layout of the paper including the volume, issue and page numbers.

Link to publication

\footnotetext{
General rights rights.

- You may freely distribute the URL identifying the publication in the public portal. please follow below link for the End User Agreement:

www.umlib.nl/taverne-license

Take down policy

If you believe that this document breaches copyright please contact us at:

repository@maastrichtuniversity.nl

providing details and we will investigate your claim.
}

Copyright and moral rights for the publications made accessible in the public portal are retained by the authors and/or other copyright owners and it is a condition of accessing publications that users recognise and abide by the legal requirements associated with these

- Users may download and print one copy of any publication from the public portal for the purpose of private study or research.

- You may not further distribute the material or use it for any profit-making activity or commercial gain

If the publication is distributed under the terms of Article $25 \mathrm{fa}$ of the Dutch Copyright Act, indicated by the "Taverne" license above, 
No time to waste:

a glycogen synthase kinase-3 $\beta$ - glucocorticoid receptor signaling axis illuminated 
(C) Koen J.P. Verhees, Maastricht, the Netherlands, 2013

All rights reserved. No part of this book may be reproduced or transmitted, in any form or by any means, without written permission from the author.

Cover: Denies Damiaens DQ , 2012

Layout: Tiny Wouters

Production: CPI - Wöhrmann Print Service, Zutphen

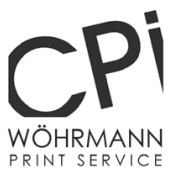

ISBN: 978-94-6203-347-4

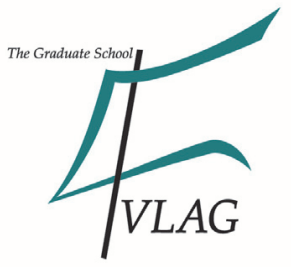

Rution
The study presented in this thesis was performed at the Nutrition and Toxicology Research Institute Maastricht (NUTRIM), which participates in the Graduate School VLAG (Advanced Studies in Food Technology, Agrobiotechnology, Nutrition and Health Sciences), accredited by the Royal Netherlands Academy of Arts and Sciences (KNAW).

K O N I N K L I J K E NE DER L A N D S E
K A D E M I E V A N W E TE N S C H A P P E N

Maastricht UMC+

azm Maastricht University 


\section{No time to waste: \\ a glycogen synthase kinase-3 $\beta$ - glucocorticoid receptor signaling axis illuminated}

\section{PROEFSCHRIFT}
ter verkrijging van de graad van doctor aan de Universiteit Maastricht, op gezag van de Rector Magnificus, Prof. dr. L.L.G. Soete volgens het besluit van het College van Decanen, in het openbaar te verdedigen op woensdag 19 juni 2013 om 14.00 uur

door

Koen J.P. Verhees 


\section{Promotor}

Prof. dr. ir. A.M.W.J. Schols

\section{Copromotor}

Dr. R.C.J. Langen

\section{Beoordelingscommissie}

Prof. dr. L. de Windt (voorzitter)

Prof. dr. L. Koenderman (Department of Respiratory Medicine - UMC Utrecht)

Prof. dr. L. van Loon

Dr. R. Shiri-Sverdlov

Prof. dr. J.P. Thissen (Unité de Diabétologie et Nutrition, Faculté de

Médecine, Université catholique de Louvain (UCL), Bruxelles, Belgique)

The studies described in this thesis were supported by a research grant, project number NAF 3.2.07.017, from the Long foundation (Longfonds), formerly the Netherlands Asthma Foundation (Nederlands Astma Fonds), and from the Transnational University Limburg (tUL). The publication of this thesis was financially supported by: Stichting Pulmonologie (PUL, Maastricht), the Longfonds (NAF 3.2.07.017), GC Biotech (http://www.gcbiotech.com/), Roche Diagnostics, GlaxoSmithKline, Chiesi Pharmaceuticals B.V., and Nutricia Advanced Medical Nutrition, Danone Research - Centre for Specialized Nutrition.
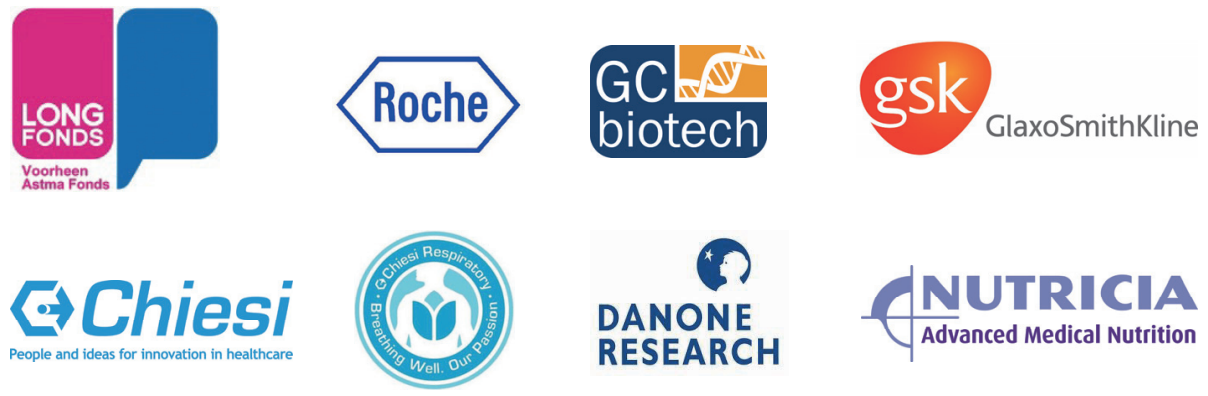
"Once the flesh has disappeared from the body, carrying the bones becomes a burden; it draws you down into the earth"

Atemschaukel, Herta Müller

honestes ante honores 



\section{Contents}

Chapter $1 \quad$ General introduction 9

$\begin{array}{lll}\text { Chapter } 2 & \text { Regulation of skeletal muscle plasticity by glycogen synthase } & 17\end{array}$ kinase-3ß: a potential target for the treatment of muscle wasting

Chapter 3 Glycogen synthase kinase-3 3 is required for the induction of skeletal muscle atrophy

Chapter $4 \quad$ Glucocorticoid-dependent skeletal muscle atrophy requires glycogen synthase kinase- $3 \beta$

Chapter 5 Pulmonary inflammation-induced muscle atrophy involves a glycogen synthase kinase-3 $\beta$ - glucocorticoid receptor signaling axis

Chapter 6 Glycogen synthase kinase-3 inhibition prevents skeletal muscle atrophy in an animal model of pulmonary inflammation

Chapter 7 General discussion and future directions

Layman's summary

Samenvatting

Dankwoord

Curriculum Vitae

List of publications 



\section{Chapter 1}

GENERAL INTRODUCTION 
Chapter 1 


\section{BACKGROUND}

Skeletal muscle is a highly plastic tissue, with the intriguing ability to change its shape or composition upon changes in functional demand. Gain or loss of muscle is essential in adapting to a variety of different (patho)physiological conditions. Under normal circumstances skeletal muscle mass plasticity is exemplified by the loss of muscle mass (muscle atrophy) during disuse and the capacity to restore muscle size when normal physical activity is resumed (regeneration). An increase in functional demand, as seen during resistance training, may subsequently lead to muscle growth (muscle hypertrophy).

Skeletal muscle atrophy is a physiological adaptation of the body to immobility, reduced physical activity, malnutrition and ageing (13). It is also a serious, but often underestimated, complication in cancer (3) and acute and chronic disease including chronic obstructive pulmonary disease (COPD) $(8,24)$, congestive heart failure (CHF) (2), inflammatory bowel disease (IBD) (28), AIDS (29), chronic kidney disease (CKD) (31), and rheumatoid arthritis (RA) (1,22), commonly referred to as cachexia. Cachexia, derived from the Greek words kakós (bad) and hexis (condition or appearance), is defined as a complex metabolic syndrome associated with underlying illness and characterized by loss of muscle with or without loss of fat mass (10). In these disorders, loss of muscle mass is a major contributor to exercise impairment and muscle weakness resulting in a dismal quality of life $(5,6,16,17,20,26)$. Moreover, muscle wasting has been convincingly shown to be a significant determinant of increased morbidity and mortality, irrespective of primary organ failure $(2,19,23)$. The prevalence of cachexia ranges from $5 \%$ to $15 \%$ in COPD or CHF, and up to $80 \%$ in advanced stages of cancer (30). In cancer, cachexia accounts for roughly $20 \%$ of all deaths $(4,27)$, and for cachectic CHF and COPD patients the relative mortality risk is increased to $50 \%$ compared with stable, normal weight patients $(2,24)$, further illustrating the significance of muscle mass maintenance in chronic disease.

It is now abundantly clear that, in view of the wealth of evidence in the literature, there is a need to develop therapeutic strategies to prevent or treat muscle wasting. In contrast to the largely irreversible lung function impairment in COPD, muscle mass and function are reversible components in the prognosis of the disease (24). Both muscle mass and muscle function can be restored or improved by physiological means, an approach which may involve exercise training, either alone or in combination with nutritional support. Several studies have demonstrated the beneficial effects of such rehabilitation programs in patients with COPD, CKD and CHF, and in sarcopenia, however, in a subpopulation of subjects the anabolic response to these interventions is either absent or limited (9). In addition, the efficacy and feasibility of such treatment programs is further complicated or impeded by primary organ impairment in chronic disease, old age or other medical or psychosocial factors. 
As an alternative, or in addition to exercise and nutritional intervention, skeletal muscle atrophy may be targeted by pharmacological treatment approaches using anabolics, such as growth hormone (GH) and insulin-like growth factor (IGF). For example, in patients with advanced COPD a multimodal intervention consisting of exercise, nutritional supplementation and anabolic steroids yielded beneficial effects on muscle mass and physical functioning without causing deleterious side effects $(21,25)$. However, the optimal target(s), timing and risk-benefit ratio of pharmacological treatment of cachexia remains to be determined.

In light of the above, there is a growing demand for the availability of pharmacological compounds aimed at the treatment of skeletal muscle atrophy. These therapeutic interventions will either target the impaired signaling that lies at the basis of disturbed muscle mass homeostasis, or may aim at modulation of master regulators of the molecular processes that govern muscle mass plasticity. It is therefore crucial to investigate the molecular mechanisms that underlie skeletal muscle atrophy, and to identify regulatory molecules as putative candidates for specific pharmacological modulation of muscle atrophy. The overall objective of the work presented in this thesis is to gain insight into the role of GSK-3 $\beta$ in the molecular mechanisms that underlie skeletal muscle atrophy. Here, we postulate that GSK-3 $\beta$ may be considered as a central regulator of skeletal muscle atrophy.

\section{AIMS AND OUTLINE OF THE THESIS}

Under normal physiological conditions muscle mass is constant due to the balance between muscle anabolism (protein synthesis) and muscle catabolism (proteolysis) (15). In skeletal muscle this homeostasis is in large part the result of basal insulin and IGF-I signaling (14). Glycogen synthase kinase-36 (GSK-3ß) is a constitutively active protein kinase which is phosphorylated and inactivated following induction of IGF-I signaling (7).

Chapter 2 provides an extensive overview of our current understanding regarding the role of GSK-3 $\beta$ in various signaling pathways that control skeletal muscle plasticity. Furthermore, a comprehensive outline of the regulation of GSK-3 $\beta$ activity is presented, as well as the potential therapeutic value and applicability of pharmacological GSK-3 inhibitors, aimed at the prevention or reversal of muscle wasting in chronic disease. Few studies have postulated that GSK-3 $\beta$ may be involved in the regulation of muscle protein breakdown during atrophy $(11,12,18)$. To investigate this further, in chapter 3, GSK-3 $\beta$ activity was modulated in cultured muscle cells (myotubes), using pharmacological and genetic approaches, to elucidate its role in myofibrillar protein loss in response to synthetic glucocorticoid (GC)-treatment or reduced IGF-I/Akt signaling. In chapter 4 , the specific contribution of GSK-3 $\beta$ to 
endogenous and synthetic GC-induced muscle proteolysis, and associated signaling, was further dissected in vivo using a muscle-specific GSK-3 $\beta$ knockout mouse line (MGSK-3 $\beta$ KO). The work described in chapter 5 provides mechanistic insights into the in vivo role of GSK-3 $\beta$ in GC-mediated skeletal muscle atrophy following acute pulmonary inflammation. To evaluate the potential pharmacological application of the above-mentioned in vitro and in vivo findings, the possibility of GSK-3 $\beta$ as a therapeutic target to treat muscle wasting was assessed in a guinea pig model of pulmonary inflammation in chapter 6 . The insights resulting from the experimental data presented in this dissertation are integrated and discussed in the light of the most recent literature in chapter 7, as well as the implications of these findings for muscle wasting in COPD and future investigations to further address GSK-3 $\beta$ 's pharmacological potential in the treatment of cachexia. 


\section{References}

1. Altomonte L, Zoli A, Mirone L, Scolieri P, and Magaro M. Serum levels of interleukin-1b, tumour necrosis factor-a and interleukin-2 in rheumatoid arthritis. Correlation with disease activity. Clin Rheumatol 11: 202-205, 1992.

2. Anker SD, Ponikowski P, Varney S, Chua TP, Clark AL, Webb-Peploe KM, Harrington D, Kox WJ, PooleWilson PA, and Coats AJ. Wasting as independent risk factor for mortality in chronic heart failure. Lancet 349: 1050-1053, 1997.

3. Argiles JM and Lopez-Soriano FJ. The role of cytokines in cancer cachexia. Med Res Rev 19: 223-248, 1999.

4. Argiles JM, Moore-Carrasco R, Fuster G, Busquets S, and Lopez-Soriano FJ. Cancer cachexia: the molecular mechanisms. Int J Biochem Cell Biol 35: 405-409, 2003.

5. Baarends EM, Schols AM, Mostert R, and Wouters EF. Peak exercise response in relation to tissue depletion in patients with chronic obstructive pulmonary disease. Eur Respir J 10: 2807-2813, 1997.

6. Brevinge $\mathrm{H}$, Berglund B, Bosaeus I, Tolli J, Nordgren S, and Lundholm K. Exercise capacity in patients undergoing proctocolectomy and small bowel resection for Crohn's disease. Br J Surg 82: 1040-1045, 1995.

7. Cross DA, Alessi DR, Cohen $\mathrm{P}$, Andjelkovich $\mathrm{M}$, and Hemmings $\mathrm{BA}$. Inhibition of glycogen synthase kinase-3 by insulin mediated by protein kinase B. Nature 378: 785-789, 1995.

8. Debigare $\mathrm{R}$, Cote $\mathrm{CH}$, and Maltais F. Peripheral muscle wasting in chronic obstructive pulmonary disease. Clinical relevance and mechanisms. Am J Respir Crit Care Med 164: 1712-1717, 2001.

9. Dela F and Kjaer M. Resistance training, insulin sensitivity and muscle function in the elderly. Essays Biochem 42: 75-88, 2006.

10. Evans WJ, Morley JE, Argiles J, Bales C, Baracos V, Guttridge D, Jatoi A, Kalantar-Zadeh K, Lochs H, Mantovani G, Marks D, Mitch WE, Muscaritoli M, Najand A, Ponikowski P, Rossi Fanelli F, Schambelan M, Schols A, Schuster M, Thomas D, Wolfe R, and Anker SD. Cachexia: a new definition. Clin Nutr 27: 793-799, 2008.

11. Evenson AR, Fareed MU, Menconi MJ, Mitchell JC, and Hasselgren PO. GSK-3beta inhibitors reduce protein degradation in muscles from septic rats and in dexamethasone-treated myotubes. Int J Biochem Cell Biol 37: 2226-2238, 2005.

12. Fang $\mathrm{CH}$, Li BG, James JH, King JK, Evenson AR, Warden GD, and Hasselgren PO. Protein breakdown in muscle from burned rats is blocked by insulin-like growth factor $\mathrm{i}$ and glycogen synthase kinase-3beta inhibitors. Endocrinology 146: 3141-3149, 2005.

13. Fluck $M$ and Hoppeler $H$. Molecular basis of skeletal muscle plasticity--from gene to form and function. Rev Physiol Biochem Pharmacol 146: 159-216, 2003.

14. Glass DJ. Molecular mechanisms modulating muscle mass. Trends Mol Med 9: 344-350, 2003.

15. Glass DJ. Skeletal muscle hypertrophy and atrophy signaling pathways. Int J Biochem Cell Biol 37: 1974-1984, 2005.

16. Gosker HR, Lencer NH, Franssen FM, van der Vusse GJ, Wouters EF, and Schols AM. Striking similarities in systemic factors contributing to decreased exercise capacity in patients with severe chronic heart failure or COPD. Chest 123: 1416-1424, 2003.

17. Harrington D, Anker SD, Chua TP, Webb-Peploe KM, Ponikowski PP, Poole-Wilson PA, and Coats AJ. Skeletal muscle function and its relation to exercise tolerance in chronic heart failure. J Am Coll Cardiol 30: 1758-1764, 1997.

18. Li BG, Hasselgren PO, and Fang CH. Insulin-like growth factor-I inhibits dexamethasone-induced proteolysis in cultured $\mathrm{L} 6$ myotubes through PI3K/Akt/GSK-3beta and PI3K/Akt/mTOR-dependent mechanisms. Int J Biochem Cell Biol 37: 2207-2216, 2005.

19. Marquis K, Debigare R, Lacasse $Y$, LeBlanc P, Jobin J, Carrier G, and Maltais F. Midthigh muscle crosssectional area is a better predictor of mortality than body mass index in patients with chronic obstructive pulmonary disease. Am J Respir Crit Care Med 166: 809-813, 2002.

20. Mostert R, Goris A, Weling-Scheepers C, Wouters EF, and Schols AM. Tissue depletion and health related quality of life in patients with chronic obstructive pulmonary disease. Respir Med 94: 859-867, 2000. 
21. Pison CM, Cano NJ, Cherion C, Caron F, Court-Fortune I, Antonini MT, Gonzalez-Bermejo J, Meziane L, Molano LC, Janssens JP, Costes F, Wuyam B, Similowski T, Melloni B, Hayot M, Augustin J, Tardif C, Lejeune $\mathrm{H}$, Roth $\mathrm{H}$, and Pichard $\mathrm{C}$. Multimodal nutritional rehabilitation improves clinical outcomes of malnourished patients with chronic respiratory failure: a randomised controlled trial. Thorax 66: 953960, 2011.

22. Roubenoff R, Roubenoff RA, Cannon JG, Kehayias JJ, Zhuang H, Dawson-Hughes B, Dinarello CA, and Rosenberg IH. Rheumatoid cachexia: cytokine-driven hypermetabolism accompanying reduced body cell mass in chronic inflammation. J Clin Invest 93: 2379-2386, 1994.

23. Schols AM, Broekhuizen R, Weling-Scheepers CA, and Wouters EF. Body composition and mortality in chronic obstructive pulmonary disease. Am J Clin Nutr 82: 53-59, 2005.

24. Schols AM, Slangen J, Volovics L, and Wouters EF. Weight loss is a reversible factor in the prognosis of chronic obstructive pulmonary disease. Am J Respir Crit Care Med 157: 1791-1797, 1998.

25. Schols AM, Soeters PB, Mostert R, Pluymers RJ, and Wouters EF. Physiologic effects of nutritional support and anabolic steroids in patients with chronic obstructive pulmonary disease. A placebocontrolled randomized trial. Am J Respir Crit Care Med 152: 1268-1274, 1995.

26. Stucki G, Bruhlmann P, Stoll T, Stucki S, Willer B, and Michel BA. Low serum creatine kinase activity is associated with muscle weakness in patients with rheumatoid arthritis. J Rheumatol 23: 603-608, 1996.

27. Tisdale MJ. Cancer cachexia: metabolic alterations and clinical manifestations. Nutrition 13: 1-7, 1997.

28. Tjellesen L, Nielsen PK, and Staun M. Body composition by dual-energy X-ray absorptiometry in patients with Crohn's disease. Scand J Gastroenterol 33: 956-960, 1998.

29. Valdez H and Lederman MM. Cytokines and cytokine therapies in HIV infection. AIDS Clin Rev: 187228, 1997.

30. von Haehling S and Anker SD. Cachexia as a major underestimated and unmet medical need: facts and numbers. J Cachexia Sarcopenia Muscle 1: 1-5, 2010.

31. Workeneh BT and Mitch WE. Review of muscle wasting associated with chronic kidney disease. Am J Clin Nutr 91: 1128S-1132S, 2010. 


\section{Chapter 2}

REGULATION OF SKELETAL MUSCLE PLASTICITY BY GLYCOGEN SYNTHASE KINASE-3ß: A POTENTIAL TARGET FOR THE TREATMENT OF MUSCLE WASTING

Koen JP Verhees, Nicholas AM Pansters, Annemie MWJ Schols, and Ramon CJ Langen 


\section{Abstract}

Muscle wasting is a prevalent and disabling condition in chronic disease and cancer and has been associated with increased mortality and impaired efficacy of surgical and medical interventions. Pharmacological therapies to combat muscle wasting are currently limited but considered as an important unmet medical need. Muscle wasting has been attributed to increased muscle proteolysis, and in particular ubiquitin 26S-proteasome system (UPS)-dependent protein breakdown. However, rates of muscle protein synthesis are also subject to extensive (patho)physiological regulation, and the balance between synthesis and degradation ultimately determines net muscle protein turnover. As multinucleated muscle fibers accommodate threshold changes in muscle protein content by the accretion and loss of muscle nuclei, myonuclear turnover may additionally determine muscle mass. Current insights in the mechanisms dictating muscle mass plasticity not only reveal intricate interactions and cross-talk between these processes, but imply the existence of signaling molecules that act as molecular switchboards, which coordinate and integrate cellular responses upon conditions that evoke changes in muscle mass. These "master regulators" of skeletal muscle mass plasticity are preferred targets for pharmacological modulation of skeletal muscle wasting. In this review glycogen synthase kinase-38 (GSK-3ß) is highlighted as a master regulator of muscle mass plasticity since, in addition to its role in UPS-mediated muscle protein degradation, it also controls protein synthesis, and influences myonuclear accretion and cell death. Moreover, the regulation of GSK-3 $\beta$ activity as well as currently available pharmacological inhibitors are described and discussed in the context of multimodal treatment strategies aimed at the inhibition of GSK-3 $\beta$, and optimal exploitation of its potential role as a central regulator of skeletal muscle mass plasticity for the treatment of muscle wasting. 


\section{General introduction}

A gradual decline in muscle mass is common with aging, and results in decreased physical functioning (284). Muscle wasting is also a prevalent and disabling condition in chronic diseases such as congestive heart failure (CHF) (16), chronic obstructive pulmonary disease (COPD) $(71,297)$ chronic renal failure (CRF), AIDS (333), rheumatoid arthritis (RA) $(12,276)$ and cancer $(17,106)$. In these diseases, muscle wasting has been associated with increased mortality and impaired efficacy of surgical and medical intervention (296). Maintenance of muscle mass is therefore currently considered as an important unmet medical need.

Targeted medical intervention, however, requires a better understanding of the molecular mechanisms underlying the processes of muscle atrophy, muscle hypertrophy and muscle recovery. These processes are determined by the balance between muscle protein synthesis and degradation (muscle protein turnover) and by the balance between myonuclear loss and myonuclear accretion (myonuclear turnover) (128). This review focuses on the role and therapeutic potential of glycogen synthase kinase-36 (GSK-3ß) in the cellular and molecular regulation of skeletal muscle mass plasticity. GSK-3 $\beta$, although originally isolated from muscle $(98,279)$, is ubiquitously expressed (7) and involved in different cellular signaling pathways $(33,168,262)$, which determine tissue growth and metabolism, such as IGF-I/Akt, Wingless/int (Wnt)/ $\beta$-catenin, calcineurin/nuclear factor of activated $T$ cells (NFAT) and apoptosis signaling. GSK-3 $\beta$ is a constitutively active kinase $(59,61,67,154,212)$ and its function in various signaling pathways is determined by regulatory inactivation (65), which makes modulation of GSK-3 $\beta$ activity by inhibitors an interesting pharmacological target $(49,143,229)$. For nearly three decades, a myriad of studies have described GSK-3 $\beta$ in muscle protein and myonuclear turnover, and in this review we postulate that GSK-3 $\beta$ may be considered as a central regulator of muscle mass plasticity.

\section{GSK-3ß}

\subsection{GSK-3 isoforms}

The serine (Ser)/threonine (Thr) kinase GSK-3 was initially described as one of the kinases capable of phosphorylating and inhibiting its namesake substrate glycogen synthase (GS), a rate-limiting enzyme involved in glycogen synthesis (99,111). In vertebrates GSK-3 exists as two highly homologous isoforms encoded by distinct genes known as GSK-3 $\alpha$ and GSK-3 $\beta$ (365). GSK-3 $\alpha$ is the larger of the two isoforms with a molecular weight of $51 \mathrm{kDa}$, whereas GSK-3 $\beta$ is a protein of $47 \mathrm{kDa}$. This size difference is attributable to the presence of a glycine rich extension at the $\mathrm{N}$-terminus 
of GSK-3 $\alpha$ (364,365). GSK-3 has been highly conserved during evolution and orthologs exist in virtually every eukaryotic species investigated to date (265). Intriguingly, in lower eukaryotes (e.g. nematodes, sea squirts) GSK-3 is encoded by a single gene (10). It is believed that in higher eukaryotes the two paralogous GSK-3 isozymes split from a common precursor at the appearance of vertebrates, implying that during evolution one of the isoforms took on unique functions, possibly to compensate for a higher degree of system complexity (10). Avian species, however, have only one copy of the GSK-3 gene and appear to have selectively lost GSK-3 $\alpha$ (10). GSK-3 is officially known as Shaggy (Sgg) (Gene ID 13248) in Drosophila melanogaster although it is also referred to a zeste-white 3 (zw3) and as human tau protein kinase (tPK1) in Homo sapiens. However, for the remainder of this review article we will use the term GSK-3. The overall structure of GSK-3 is shared by many kinases and constitutes a typical twodomain kinase fold with a small $\mathrm{N}$-terminal lobe, consisting mostly of $\beta$-sheets, and a large C-terminal lobe, primarily composed of $\alpha$-helices. Both isoforms share a high degree of sequence similarity within their kinase domains ( $98 \%$ identity), but differ substantially at their $\mathrm{N}$-and C-terminal domains (84\% overall identity) (365). The catalytic domain is located at the interface between the $\alpha$-helical and $\beta$-strand domains $(135,136,244)$ and is folded into a bi-lobal architecture containing the positively charged ATP-binding pocket and the activation loop (T-loop), which is important for kinase activity $(134,325)$.

\subsection{Redundancy of GSK-3 $\alpha$ and $\beta$}

Although GSK-3 was originally isolated from muscle $(99,279)$, this kinase is ubiquitously expressed in all tissues, with particularly high expression levels in the brain (7). Considering the high degree of sequence similarity, it is not surprising that both GSK-3 isoforms share similar functions. Despite this fact, GSK-3 $\alpha$ and GSK-3 $\beta$ are not always functionally redundant. In 2000, Hoeflich and colleagues disrupted the GSK-3 $\beta$ isoform in mice, which gave rise to an embryonically lethal phenotype. Analysis of the GSK-3 $\beta^{-/-}$embryos revealed massive liver degeneration due to hepatocyte apoptosis, thought to be a consequence of a defect in nuclear factor- $K B$ (NF-KB) activation (146). The inability of GSK-3 $\alpha$ to compensate for the loss of GSK-3 $\beta$ implied a specific requirement of GSK-3 $\beta$ in hepatocyte survival. Conversely, it was demonstrated that GSK- $3 \alpha$ and GSK-3 $\beta$ appear to be entirely redundant in regulating $W n t / \beta$-catenin signaling $(81,146)$. This redundancy in function has only recently been appreciated because the role of the $\beta$-isoform has been historically overemphasized. This bias probably originated from reports suggesting that mammalian GSK-3 $\beta$ was more effective than GSK-3 $\alpha$ in rescuing the zw3 mutation in Drosophila melanogaster $(278,308)$. However, it should be noted that in these studies the expression levels of both homologs were not equalized. Recently, experiments done in mouse embryonic stem cells (ESCs) clearly established that the single loss of either GSK-3 $\alpha$ or GSK-3 $\beta$ did not negatively alter $W n t / \beta$-catenin signaling, whereas GSK- $3 \alpha / \beta$ double knockout ESCs displayed hyperactivated $\mathrm{Wnt} / \beta$-catenin signaling, resulting in dramatically skewed 
cell differentiation (81). Gillespie et al. reported that the cartilage-specific deletion of GSK-3 $\beta$ did not negatively affect skeletal growth or development and that the compensatory upregulation of GSK-3 $\alpha$ protein levels in cartilage was the likely cause for the lack of any effect (122). In concordance with the latter study, Itoh and colleagues found that in chondrocytes the function of GSK-3 $\alpha$ and GSK-3 $\beta$ appeared to be redundant or compensatory in the early stage of differentiation, as compound knockout (GSK-3 $\alpha^{-/-}$; GSK-3 $\beta^{+/-}$) mice exhibited dwarfism and impaired chondrocyte differentiation, while single GSK- $3 \alpha^{-/-}$, GSK- $3 \beta^{+/-}$, or cartilage-specific GSK-3 $\beta$ knockout mice appeared phenotypically normal (160). Nevertheless, the two isoforms were shown to have opposite effects on the transcriptional activation of certain transcription factors (203), and GSK-3 $\beta$ is more potent than GSK-3 $\alpha$ in phosphorylating phosphatase inhibitor 2 (347). Furthermore, GSK-3 $\alpha$ and GSK-3 $\beta$ play distinct roles in cardiomyocyte differentiation and cardiovascular development in mice $(51,110,172)$. Interestingly, both GSK-3 isoforms serve distinct tissue-specific roles in glycogen metabolism. MacAulay et al. found that global loss of GSK-3 $\alpha$ improved glucose tolerance and insulin sensitivity in knockout mice, mainly by elevating hepatic glycogen synthesis with no observable difference in glycogen deposition in muscle (215). Previously, it was demonstrated that muscle-specific overexpression of GSK-3 $\beta$ resulted in reduced muscle glycogen deposition (254), and that insulin failed to increase muscle GS activity in constitutively active GSK-3 $\beta$ mice (caGSK-3 $\beta$ ) (225), indicating that GSK-3 $\alpha$ and GSK-3 $\beta$ exhibit divergent physiological roles in muscle and liver tissue. Additional evidence identifying GSK-3 $\beta$ as a major regulator of glucose homeostasis in skeletal muscle came from the group of Woodgett, demonstrating that tissue-specific GSK-3 $\beta$ knockout mice displayed improved glucose tolerance and enhanced insulin sensitivity in muscle (but not liver) (253). In a study from McManus et al., GSK-3 $\beta$ protein expression in human and mouse muscle was found to be three to four times higher than compared with GSK-3 $\alpha$, prompting the authors to conclude that GSK-3 $\beta$, rather than GSK-3 $\alpha$ was the predominant GSK-3 isoform in muscle (225). In conclusion, it appears that GSK-3 $\alpha$ and GSK-3 $\beta$ have both common and nonoverlapping cellular functions, largely depending on the physiological context and the cell type studied. The focus of this review will be specifically on the role of GSK-3 $\beta$ in the regulation of skeletal muscle plasticity.

\subsection{Substrate regulation by GSK-3 $\beta$}

GSK-3 $\beta$ is a unique multi-tasking enzyme involved in a myriad of cellular processes which is subject to multiple complex regulatory mechanisms. Unlike other kinases GSK-3 $\beta$ is constitutively active and may be rapidly and reversibly inactivated in response to various cellular signals, such as growth factors. Another feature that sets it apart from other kinases is that phosphorylation of its substrates generally leads to their inactivation $(82,139)$. As such, many substrates of GSK-3 $\beta$ are targeted for destruction by the ubiquitin 26S-proteasome system (UPS). For example, cyclin D1 is phosphorylated by GSK-3 $\beta$ in the nucleus, resulting in its nuclear export and 
subsequent proteasomal degradation (75). In addition to its regulatory role in cell cycle progression via cyclin D1, GSK-3 $\beta$ can also affect cell growth and proliferation through c-myc. Likewise, phosphorylation of c-myc by GSK-3 results in its ubiquitination and destruction by the UPS (129). Furthermore, GSK-3 $\beta$ plays a key role in canonical Wnt signaling, since its phosphorylation of $\beta$-catenin is essential for $\beta$-catenin's ubiquitinmediated degradation (2). Recently, the physical association of GSK-3 $\beta$ with the transcription factor E2F1 was described and found to constitute a phosphorylationindependent cue for UPS-mediated breakdown (380). As is common with many kinases, GSK-3 $\beta$ catalyzes the phosphorylation of its substrates in the presence of ATP and the cofactor magnesium $\left(\mathrm{Mg}^{2+}\right)$ (224). An intriguing feature of GSK-3 $\beta$ involves its requirements for substrate recognition. In general, the specificity of most kinases is largely dependent on a particular consensus sequence of amino acid residues of their substrates. GSK-3 $\beta$, on the other hand, does not require a strict consensus motif, but instead has the unusual preference for target proteins that are pre-phosphorylated at a "priming" residue located four amino acids C-terminal to the site to be modified by GSK-3 $\beta$ (108). Thus, the consensus sequence for GSK-3 $\beta$ substrates is Ser/Thr-X-X-X-XSer/Thr-P, where the $\mathrm{N}$-terminal Ser/Thr represents the target residue and the $\mathrm{C}$ terminal Ser/Thr constitutes the priming phosphorylation site. Although " $X$ " denotes any amino acid, in the case of GSK-3 $\beta$, this often concerns a proline. The phosphorylated priming site of the substrate binds to a positively charged binding pocket in GSK-3 $\beta$, formed by the residues $\mathrm{Arg}^{96}, \mathrm{Arg}^{180}$ and $\mathrm{Lys}^{205}$. This mechanism allows for proper orientation of the kinase domains, and places the substrate at the correct position within the catalytic groove for optimal kinase activity $(67,112,326)$. Mutation of $\mathrm{Arg}^{96}$ to an uncharged alanine disrupts the positively charged pocket which prevents any interaction with the negatively charged phosphate and sulfate ions, precluding primed substrate binding (112). However, in spite of this mutation the enzyme retains its activity and can still phosphorylate unprimed substrates. Though not strictly required, priming phosphorylation significantly augments the efficiency of GSK-3 $\beta$ substrate phosphorylation by 100 - 1000 fold (327). Nevertheless, several substrates such as $\beta$-catenin, tau and axin do not require a priming step prior to phosphorylation by GSK-3 $\beta$ (139).

\subsection{Regulation of GSK-3 $\beta$ enzymatic activity}

The discovery of the crystal structure of GSK-3 $\beta$ in 2001 has had a profound impact on our understanding of the regulatory mechanisms of this extraordinary molecule $(28,67,326)$. Few enzymes exert more influence over cellular function than GSK-3. In fact, GSK-3 is one of the kinases with the most identified substrates in the cell (207), including a wide variety of metabolic signaling molecules, structural proteins and over a dozen transcription factors $(88,130)$. The ability of GSK-3 $\beta$ to accurately execute this astoundingly diverse set of functions is due to the unique and intricate regulatory mechanisms this kinase is subject to. Tight regulation of GSK-3 $\beta$ 's activity can be achieved by a variety of mechanisms that are each dependent on specific signaling 
pathways. These include regulation mediated by a) phosphorylation b) cellular localization c) protein-protein interactions and d) proteolytic cleavage.

\subsubsection{Regulation by phosphorylation}

The best-defined mode of GSK-3 $\beta$ regulation is inhibition of its activity by phosphorylation of the regulatory $\operatorname{Ser}^{9}$ residue in the N-terminus ( $\mathrm{Ser}^{21}$ in GSK-3 $\alpha$ ) (65). Insulin/IGF-I-mediated activation of the phosphatidylinositol 3-kinase (PI-3K)/Akt signaling pathway is a major regulator of GSK-3 $\beta$ activity in which activated Akt/protein kinase B (PKB) (hereinafter termed Akt) directly phosphorylates GSK-3 $\beta$ on this inhibitory residue $(65,155,338)$. Upon phosphorylation, the $\mathrm{N}$-terminus becomes a primed pseudo-substrate that binds intramolecularly to the positively charged binding pocket and the active site, occupying the same binding site as the priming phosphate of a substrate, thereby hindering substrate phosphorylation $(58,82)$. Important to note is that this inhibition mechanism is competitive, implying that elevated concentrations of primed substrates will outcompete pseudo-substrate inhibition (112). Bioinformatics analyses of pseudo-substrate sequences in GSK-3 $\beta$ have pinpointed two highly conserved amino acid residues, namely $\mathrm{Arg}^{4}$ and $\mathrm{Arg}^{6}$. Mutation of any of these residues to alanine enhanced basal GSK-3 $\beta$ activity and prevented autoinhibition by the pseudo-substrate, even upon phosphorylation at $\operatorname{Ser}^{9}$ (157). More specifically, $\mathrm{Arg}^{4}$ and $\mathrm{Arg}^{6}$ were found to facilitate the interaction of the pseudosubstrate with the catalytic core (157). In addition to insulin and IGF-I, numerous other stimuli lead to GSK-3 $\beta$ inactivation through $\mathrm{Ser}^{9}$ phosphorylation, including growth factors platelet-derived growth factor (PDGF) and epidermal growth factor (EGF) that stimulate the GSK-3 $\beta$ inactivating kinase $\mathrm{p} 90^{\mathrm{RSK}}$ via mitogen-activated protein kinases (MAPK) (130). Moreover, amino acids can activate p70S6 kinase (p70S6K) which in turn reduces GSK-3 $\beta$ activity $(19,260)$ via $\operatorname{Ser}^{9}$ phosphorylation (19). Other kinases capable of phosphorylating GSK-3 $\beta$ at $\mathrm{Ser}^{9}$ include protein kinase $A$ (PKA) and some isoforms of protein kinase $C$ (PKC) (167). Important to note is that each kinase, contributing to the control of GSK-3 $\beta$, may only affect a specific pool of GSK-3 $\beta$, depending on the cellular distribution of GSK-3 $\beta$ and the regulatory kinase, respectively. The binding of GSK-3 $\beta$ to specific scaffolding proteins may constitute a mechanism by which interactions with specific regulatory kinases are warranted. For example, PKA-anchoring protein 220 was demonstrated to bind GSK-3 $\beta$ thereby facilitating its phosphorylation by PKA (324). GSK-3 $\beta$ activity can also be regulated by phosphatases which activate the enzyme by dephosphorylation. The Ser/Thr protein phosphatase 1 (PP1) dephosphorylates the N-terminal Ser residues of GSK-3 $\beta$ (377). In addition, protein phosphatase 2A (PP2A) may activate GSK-3 $\beta$ directly by dephosphorylation, or indirectly by dephosphorylation and subsequent inhibition of Akt (161).

In contrast to the inhibitory effect obtained after GSK-3 $\beta$ phosphorylation at Ser ${ }^{9}$, the enzymatic activity of GSK-3 $\beta$ can be enhanced by a stimulatory phosphorylation on $\mathrm{Tyr}^{216}$ (tyrosine) (154). Recent crystallographic studies and molecular dynamics 
simulation techniques have clearly demonstrated that $\mathrm{Tyr}^{216}$ phosphorylation renders the kinase active by stabilization of the activation loop (T-loop), allowing full substrate accessibility $(44,59)$. Hughes et al. reported that this phosphorylation is constitutive in resting cells (154), and it was suggested that in mammalian species the phosphorylation of $\mathrm{Tyr}^{216}$ was a chaperone-dependent autocatalytic event regulated by Hsp90 (61). Additional support for this intramolecular autophosphorylation model, at least in mammals, was provided by Lochhead et al., who showed that newly synthesized GSK-3 $\beta$ becomes phosphorylated on $\operatorname{Tyr}^{216}$ (212). Overall, it appears that Tloop phosphorylation at $\mathrm{Tyr}^{216}$ may facilitate substrate phosphorylation but it is not strictly mandatory for kinase activity (67). Murai and co-workers reported that prolonged growth factor stimulation decreased both the activity and $\mathrm{Tyr}^{216}$ phosphorylation of GSK-3 $\beta$ (239). However, these findings were contradicted by another report claiming that the insulin-induced decrease in GSK-3 $\beta$ activity was strictly due to increased phosphorylation at $\operatorname{Ser}^{9}$, rather than the involvement of a phosphotyrosine phosphatase acting on GSK-3 $\beta$ (304). In line with the latter study, Simon et al. revealed that pharmacological GSK-3 $\beta$ inhibition using lithium did not alter phosphotyrosine levels, despite effective kinase inhibition (309). Moreover, Bhat et al. reported that in neurons proapoptotic stimuli increased nuclear activity of GSK$3 \beta$ by increasing phosphorylation at $\mathrm{Tyr}^{216}$, arguing against the autophosphorylation model. In concordance with the study by Simon et al. pharmacological GSK-3 $\beta$ inhibition induced $\mathrm{Ser}^{9}$ phosphorylation, resulting in diminished GSK-3 $\beta$ activity without reducing $\mathrm{Tyr}^{216}$ phosphorylation (35). It is evident that due to the conflicting nature of these reported findings more research is needed to unravel the exact role of $\mathrm{Tyr}^{216}$ phosphorylation. In muscle, too, the physiological relevance and the mechanisms regulating $\mathrm{Tyr}^{216}$ phosphorylation remain poorly defined and there is a paucity of data pertaining to the identification of the GSK-3 $\beta$ Tyr kinases and phosphotyrosine phosphatases involved. Recently, two other regulatory phosphorylation sites have been described in GSK-3 $\beta$. First, a phosphorylation event at $\mathrm{Thr}^{43}$ was shown to be catalyzed by Erk and resulted in GSK-3 $\beta$ inhibition (76). Likewise, p38 MAPK-mediated phosphorylation of GSK-3 3 on $\operatorname{Ser}^{389}$ and $\mathrm{Thr}^{390}$ was associated with reduced kinase activity (328). In both instances, phosphorylation of these residues increased the propensity of $\operatorname{Ser}^{9}$ to be phosphorylated, as opposed to promoting direct kinase inhibition.

\subsubsection{Regulation by protein-protein interactions}

GSK-3 $\beta$ activity can also be determined by its presence in protein complexes. The best characterized example is the $W n t / \beta$-catenin, also known as the canonical Wnt signaling pathway (for review see, i.e. (233)). Wnt/ $\beta$-catenin signaling requires, in part, GSK-3 inactivation (81). Under basal conditions, $\beta$-catenin levels are regulated by a protein complex, termed the degradation complex containing axin (the scaffolding protein), adenomatous polyposis coli (APC, also a target of GSK-3 (362)), GSK-3 $\beta$ and casein kinase $1 \alpha(\mathrm{CK} 1 \alpha)$. In this complex CK1 $\alpha$ primes $\beta$-catenin by phosphorylation 
which elicits further N-terminal phosphorylation by GSK-3 (153), thereby marking it for degradation by the UPS (209). Upon binding of canonical Wnts the formation of a complex with membrane receptors Frizzled (Fz), a seven-transmembrane protein, and the low-density lipoprotein receptor-related protein 5/6 (LRP5/6) leads to activation of Wnt/ $\beta$-catenin signaling (322). Disheveled (Dvl) becomes activated and recruits the degradation complex to the membrane (200) where GSK-3 $\beta$ phosphorylates the receptor LRP5/6 (68,376), which prevents subsequent GSK-3 $\beta$-mediated $\beta$-catenin phosphorylation, resulting in $\beta$-catenin stabilization $(15,210,245)$. Accumulated cytoplasmic $\beta$-catenin is involved in cell-cell interactions in a complex with cadherins $(213,246)$, while increased nuclear $\beta$-catenin levels induce the expression of growthassociated genes such as c-Myc and cyclin D1 (Figure 2.3) by interacting with transcriptional co-activators such as members of the T-cell factor/lymphocyteenhancement factor 1 (Tcf/Lef-1) family (243). Thus, GSK-3 appears to play a dual role, being involved in both the activation of $W n t / \beta$-catenin signaling, through activating phosphorylation of LRP5/6, as well as in its inhibition via phosphorylation of $\beta$-catenin, illustrating the intricate regulation of this signaling cascade. GSK-3-binding protein (GBP), also known as FRAT (frequently rearranged in advanced T-cell lymphomas), is another complex that has been associated with GSK-3 $(114,200)$. The formation of such protein complexes enables the cell to control the actions of GSK-3 $\beta$ within subcellular compartments. For instance, the protein-kinase interaction of GSK-3-binding protein GBP with GSK-3 appears to facilitate nuclear export of GSK-3 as a mutant form of GSK3 that cannot bind FRAT accumulates in the nucleus (113). Furthermore, during DNA damage the tumor-suppressor protein p53 directly interacts with and activates GSK$3 \beta$ in the nucleus, which increases the transcriptional and apoptotic actions of p53 (353). Similarly, in mitochondria p53 associates with GSK-3 $\beta$ contributing to p53mediated apoptotic signaling (352).

\subsubsection{Regulation by subcellular localization}

Even though GSK-3 $\beta$ is traditionally viewed as a cytosolic protein, it has also been found in nuclei and mitochondria (36). In contrast, under basal conditions GSK-3 $\alpha$ does not shuttle between the cytosol and the nucleus. Yet, upon activation of the calpain pathway, in response to increased calcium levels or in absence of growth factors, GSK$3 \alpha$ has been shown to accumulate in the nucleus (24). This process was not mediated by N-terminal cleavage of GSK-3 $\alpha$ (vide infra). Instead, nuclear accumulation was governed by binding of the N-terminus of GSK-3 $\alpha$ to a calpain-sensitive protein (24). As mentioned earlier, GSK-3 $\beta$ regulates a host of substrates, many of which are transcription factors. For instance, nuclear GSK-3 $\beta$ is capable of phosphorylating NFATc3, thereby negatively affecting its DNA-binding activity (242). However, surprisingly little is known about the regulation of the intracellular compartmentalization of GSK-3 $\beta$. As early as 1998, Ragano-Caracciolo et al. reported that GSK-3 $\beta$ was enriched in a glycogen fraction associated with the nuclear envelope (268). Not soon thereafter, studies by the group of Diehl demonstrated that there were 
dynamic cell cycle-dependent changes in the intracellular localization of GSK-3 $\beta$. Specifically, they found increased levels of nuclear GSK-3 $\beta$ during the $S$ phase, related to proteasomal degradation of cyclin D1 $(11,75)$. Furthermore, heat shock was shown to evoke nuclear GSK-3 $\beta$ accretion (370). It was also reported that activated Akt decreased nuclear GSK-3 $\beta$ levels (37), while in mitochondria GSK-3 $\beta$ was inactivated in an Akt-dependent fashion without affecting the mitochondrial level of GSK-3 $\beta$ (167). In cardiomyocytes, GSK-3 $\beta$ is present in both the nucleus and the cytosol, and endothelin was reported to enhance nuclear localization of GSK-3 $\beta$ (137). Consistent with the previously established role of GSK-3 $\beta$ in NF-KB activation (146), highly activated GSK-3 $\beta$ was found to accumulate in the nuclei of pancreatic cancer cell lines, positively affecting NF-KB-mediated proliferation of cancer cells (249). Adding further complexity to the regulation of GSK-3 $\beta$ function, was the discovery of a minor splice

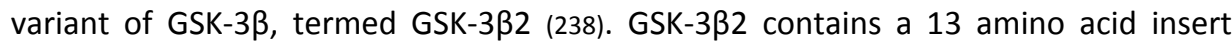
within the catalytic domain and the expression of this splice variant appears to be restricted to neuronal cell bodies, while the unspliced GSK-3 $\beta$ is found in both the soma as well as in neuronal processes. In addition, GSK-3 32 revealed reduced activity towards the microtubule-associated protein tau. These differences in substrate recognition (function) and subcellular localization most likely originate from differential binding to scaffolding proteins, which in turn expose the isoform to a distinct subset of target proteins (238). Although the exact mechanisms regulating the subcellular localization of GSK-3 $\beta$ remain elusive, it appears that several advances in this field (vide supra) have ascribed an important function to GSK-3 $\beta$-binding proteins in the regulation of subcellular trafficking. For instance, the viral latency-associated nuclear antigen (LANA) was shown to compete with axin for binding to GSK-3, consequently resulting in nuclear sequestration of GSK-3 (116).

\subsubsection{Regulation by proteolytic cleavage}

Recently, a novel mechanism of GSK-3 regulation was proposed. It involves calpain-1-mediated truncation of both GSK-3 isoforms. This type of cleavage removes a considerable portion of the $\mathrm{N}$-terminal region including the regulatory $\mathrm{Ser}^{9}$ and $\mathrm{Ser}^{21}$ residues, which results in a non-reversible activation of the enzyme (127). This proteolytic cleavage appeared to be mediated by extracellular calcium levels and could be inhibited by memantine (126), a N-methyl-D-aspartate (NMDA) receptor antagonist which had previously been demonstrated to increase the Ser phosphorylation of both GSK-3 isoforms (70). In the former study, GSK-3 truncation was observed in mouse and human post mortem brain tissue (126). Matrix metalloproteinases (MMPs) are traditionally known for their role in extracellular matrix remodeling. However, several lines of evidence have recently revealed additional substrates and novel biological roles for these proteases $(277,349)$. Interestingly, in cardiomyoblasts matrix metalloproteinase-2 (MMP-2) is capable of cleaving the $\mathrm{N}$-terminal portion of GSK-3 $\beta$, including the regulatory Ser ${ }^{9}$, resulting in increased GSK-3 $\beta$ activity (170). In this study, hydrogen peroxide-induced MMP-2 
activity led to increased GSK-3 $\beta$ activity, which in turn contributed to cardiac dysfunction as a result of oxidative stress injury.

\subsubsection{Pharmacological modulation of GSK-3}

A large body of evidence has confirmed the practicability and therapeutic benefit of pharmaceutical GSK-3 inhibitors, making GSK-3 a prime target in drug discovery. A detailed analysis of all these inhibitors is beyond the scope of this manuscript. Instead, we will focus on the most important types of GSK-3 inhibitors and their modus operandi.

Most GSK-3 inhibitors function either as ATP-competitive, non-ATP-competitive or substrate-competitive inhibitors. GSK-3 inhibitors come in a diversity of chemotypes, including cations, synthetic small molecules and inhibitors isolated from natural sources. The alkali metal lithium $\left(\mathrm{Li}^{+}\right)$was the first GSK-3 inhibitor to be discovered $(178,318)$. Lithium possesses the intriguing capability of inhibiting GSK-3 in both a direct and indirect fashion. As mentioned earlier, enzymatic GSK-3 activity is ATP-dependent and magnesium is required as a cofactor (224). First, lithium functions as a direct reversible inhibitor of GSK-3 by competing for magnesium ions (281). Second, GSK-3 inhibition is achieved indirectly via enhanced Ser phosphorylation and autoregulation $(101,166,176,377)$. Increased phosphorylation of GSK-3 in response to lithium is the result of decreased phosphatase activity, which normally reactivates GSK-3 by removing the inhibitory phosphate from the regulatory Ser residue (Ser ${ }^{9}$ in GSK-3 $\beta$ ) $(166,234)$. When used in cultured cells or in vivo, this dual mode of action of lithium probably accounts for a cumulative suppression of GSK-3 activity.

Of note, regulation of GSK-3 $\beta$ activity by lithium does not always occur through increased GSK-3 $\beta$ phosphorylation (32). This divergence between GSK-3 $\beta$ phosphorylation at $\mathrm{Ser}^{9}$ and GSK-3 $\beta$ kinase activity has also been reported for chemically unrelated GSK-3 $\beta$ inhibitors $(83,101,165)$ and is consistent with other described modes of GSK-3 $\beta$ inactivation (326). Although lithium has been widely used as a GSK-3 inhibitor for decades, it is not completely specific in its actions and high therapeutic concentrations are required (69). The therapeutic range of lithium is $0.5-1.5 \mathrm{mM}$ and its $\mathrm{IC}_{50}$ towards GSK-3 is $1-2 \mathrm{mM}$ (178). Other direct molecular targets of lithium include, amongst others, inositol monophosphatases (IMPAs), cyclooxygenase (COX) and B-arrestin 2 (BArr2) (261). The fact that magnesium and lithium share similar periodic properties, may explain the wide array of biochemical effects exerted by lithium, as magnesium is a cofactor for multiple enzymes (38). In addition to lithium, several other metal ions such as beryllium, zinc, mercury and copper are considered bona fide GSK-3 inhibitors $(156,280)$.

To date, most of the protein kinase inhibitors are ATP-competitors. However, the clinical use of these compounds is limited because of serious limitations in their 
specificity. This is due to the fact that the human kinome constitutes more than $\mathbf{5 0 0}$ kinases that all share a significant degree of sequence homology in the catalytic site, especially within the ATP-binding pocket (93). The quest for optimization of selectivity is therefore one of the most important challenges in the discovery and development of kinase inhibitors $(93,330)$. Some of the first synthetic small molecule GSK-3 inhibitors included the purine analog aminopyrimidines CHIR98014, CHIR98023 and CHIR99021 (273), which together with the maleimides derivatives SB216763 and SB41528 displayed selective inhibition against both GSK-3 isoforms (57). Despite the fact that these are all "less specific" ATP-competitive GSK-3 inhibitors, systematic analysis of profiled kinase inhibitors revealed high selectivity of these compounds toward GSK-3 in the nanomolar concentration range (26). Recent advances in the field have brought forth novel ATP-competitive GSK-3 $\beta$ inhibitors, such as the 7-hydroxy benzimidazole analogs, which show promising therapeutic potential (193).

Generally, physiological inhibition of GSK-3 in response to insulin (217) or IGF-I (336) reduces GSK-3 activity by $40 \%$ and $20 \%$, respectively, indicating that moderate inhibition using pharmacological approaches may be sufficient to correct or influence GSK-3 $\beta$-dependent signaling processes. For example, pharmacological GSK-3 inhibition using lithium was shown to reduce GSK-3 $\beta$ activity by 30 and $35 \%$ in cultured muscle cells and muscle tissue, respectively $(32,336)$. In other words, restoration of physiological GSK-3 activity levels could be sufficient to yield important therapeutic effects in pathologies characterized by aberrant GSK-3 regulation $(59,97)$. Moreover, over-inhibition of GSK-3 under normal circumstances might have detrimental effects, such as tumorigenesis (145), cardiac hypertrophy $(137,138)$ or the induction of neurodegenerative markers (150).

Non-ATP-competitive GSK-3 inhibitors bind to unique regions within the kinase, offering a more selective and subtle mode of enzymatic inhibition, as opposed to simply blocking ATP-binding. Several organic (synthetic) compounds have been reported that do not rely on ATP competition in their action against GSK-3. Some examples include the small heterocyclic thiadiazolidinones (TDZD) inhibitors such as TDZD-8 and NP00111, which were both shown to be potent GSK-3 inhibitors $(220,275)$. Little is known about their exact mechanism of action but it was suggested that these compounds interact with cysteine $199\left(\mathrm{Cys}^{199}\right)$, a key residue located at the entrance to the ATP-binding site of GSK-3 (224). The halomethylketone (HMK) derivatives have recently been described as the first irreversible non-ATP-competitive GSK-3 inhibitors $(63,257)$. The irreversible nature of this inhibition is due to the formation of a covalent sulfur-carbon bond between Cys ${ }^{199}$ of GSK-3 and the HMK moiety (258).

It has proven difficult to identify substrate-competitive inhibitors by means of high-throughput screening, mainly due to the weak binding interaction with the enzyme (similar to the binding properties of the substrate). Nevertheless, substrate- 
competitive inhibitors are more selective than ATP-competitive molecules and may therefore be a more suitable choice for clinical use. In addition, chemical modification of substrate-competitive inhibitors have the potential of improving their specific binding affinity and pharmaceutical applicability (94). Current research efforts focus on the use of peptides as potential protein kinase inhibitors (96). As GSK-3 predominantly binds primed substrates, a set of phosphorylated peptides patterned after known GSK-3 substrates was generated and found to inhibit the enzyme in the micromolar range. The synthesized peptide $\mathrm{L} 803$ is derived from heat shock factor 1 (HSF-1) and displayed the best inhibitory properties (264). Other examples of specific GSK-3 peptide inhibitors include FRATide and axin GID, which were synthesized based on the GSK-3 $\beta$ substrates FRAT and axin, respectively (97).

In conclusion, the use of non-ATP-competitive GSK-3 inhibitors could be relevant for therapeutic use because of better kinase selectivity and lower half maximal inhibitory concentration $\left(\mathrm{IC}_{50}\right)$ values which are paramount to avoid toxicity. The future challenge will be to design selective inhibitors toward GSK-3 $\alpha$ and GSK-3 $\beta$. This effort could prove challenging as both GSK-3 isoforms are highly conserved within their kinase domains (168). An alternative strategic approach could involve exploiting the unique properties of both isozymes, such as cellular localization or specific protein-protein interactions.

\section{GSK-3 $\beta$ in skeletal muscle plasticity}

As mentioned previously, GSK-3 was originally isolated from muscle as a kinase capable of phosphorylating and inactivating GS, a key enzyme that promotes glycogen assimilation (98,366). Apart from a role in muscle metabolism, GSK-3 $\beta$ is also involved in the maintenance and plasticity of skeletal muscle mass. A study by Schakman and coworkers implicated an important role of GSK-3 $\beta$ in skeletal muscle atrophy in vivo (293). Muscle atrophy brought about by the synthetic glucocorticoid (GC) dexamethasone (hereinafter termed Dex) was associated with alterations in the Akt/GSK-3 $\beta$ signal transduction pathway. Previous data from the same group established that GC-induced muscle atrophy and the associated reduction in muscle IGF-I-signaling could be restored by local IGF-I overexpression into muscle (291). In the former study these findings were extended by local overexpression of caAkt which completely blocked Dex-induced atrophy and resulted in marked muscle fiber hypertrophy. This phenotype was associated with increases in the phosphorylation status of p70S6K and GSK-3 $\beta$, indicative of reduced GSK-3 $\beta$ activity. Similarly, overexpression of a dnGSK-3 $\beta$ induced a modest muscle fiber hypertrophy and completely prevented muscle atrophy induced by GCs. A study by the group of Booth investigated the effect of pharmacological GSK-3 $\beta$ inhibition on myotube size (343). Remarkably, lithium supplementation increased the $C_{2} C_{12}$ myotube surface area by 
$85 \%$, while inclusion of IGF-I in the culture medium reduced levels of phosphorylated GSK-3 $\beta$ and caused a similar increase in myotube area (80\%). In order to understand the involvement of GSK-3 $\beta$ in muscle atrophy, hypertrophy and regeneration, the determinants of these processes, i.e. changes in muscle protein- and myonuclear turnover (128) will be briefly discussed below, and subsequently the involvement of GSK-3 $\beta$ in protein synthesis and degradation, myonuclear accretion and apoptosis during muscle mass plasticity will be addressed individually.

\subsection{Processes controlling skeletal muscle mass plasticity}

Muscle protein turnover is determined by the balance between protein synthesis (anabolism) and degradation (catabolism). A shift in favor of synthesis over degradation will result in muscle hypertrophy. Conversely, when muscle protein degradation exceeds depressed or even increased protein synthesis, muscle atrophy may ensue. Initiation of mRNA translation is one of the rate-limiting steps of protein synthesis, and many regulatory pathways of protein synthesis converge at this level, including the IGF-I/Akt/mammalian target of rapamycin (mTOR) and IGF-I/Akt/GSK-3 $\beta$ signaling pathways $(41,169)$. Increased proteolysis during atrophy relies on the orderly activation of three main cellular proteolytic systems including the UPS, the autophagylysosomal pathway (ALP) and the calcium-dependent calpains $(89,128,287,313,361)$. The ALP is involved in clearance of long-lived proteins and dysfunctional organelles $(196,231)$, while the UPS mainly targets myofibrillar and short-lived proteins $(53,60,107,314)$. Interestingly, cross-talk exists at multiple levels in the signaling pathways that determine muscle protein synthesis and degradation, and this reciprocal interaction is essential in the control of protein turnover (Figure 2.1).

The balance between myonuclear accretion and apoptosis determines myonuclear turnover, which is involved in the control of adult muscle fiber hypertrophy, atrophy and regeneration. Multinucleated muscle fibers are formed by the fusion of mononucleated muscle cells and these cells stem from the embryonic myotome (43), which will subsequently form mature muscle fibers (147). The remaining non-fusing single nucleated cells form a specialized cellular niche and are termed "satellite cells" (223). This name is derived from their location in between the epimysium, the membrane surrounding the muscle fibers, and the adult muscle fibers (235). Satellite cells form a reservoir of new myonuclei, which are recruited during muscle plasticity responses (250) and upon activation, these cells proliferate, differentiate and fuse with or into (existing) muscle fibers (Figure 2.1). 


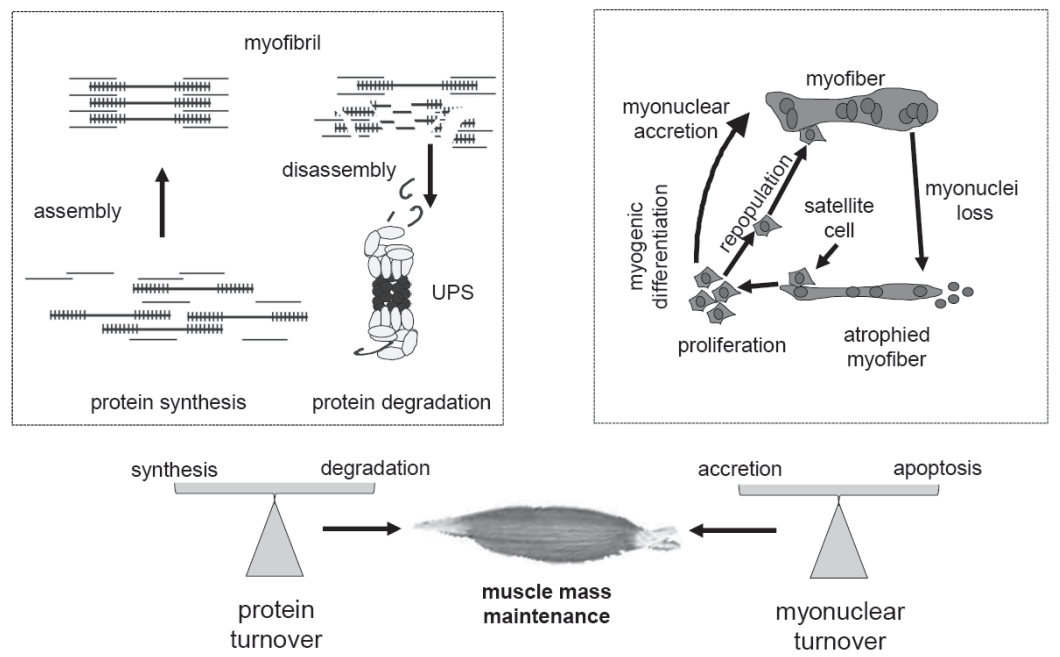

Figure 2.1 Schematic representation of skeletal muscle mass plasticity.

Two important balances regulate skeletal muscle mass plasticity 1) Protein turnover, which comprises protein synthesis and degradation. Disassembly of contractile proteins from the myofibrillar apparatus may involve other proteolytic systems in addition to the UPS prior to their degradation. 2) Myonuclear turnover, which consists of myonuclear accretion and myonuclear loss. Myonuclear accretion occurs upon satellite cell activation and proliferation, which is followed by myogenic differentiation and myonuclear fusion. Loss of myonuclei mediated by apoptosis may occur during myofiber atrophy.

Muscle fiber nuclei (myonuclei) regulate gene expression within a certain cytoplasmic range referred to as the myonuclear domain. The current paradigm implies that when reaching the lower limit, myonuclei disappear from the muscle fiber, while when reaching the upper limit of the domain, nuclei provided by the satellite stem cell pool are incorporated into the myofiber $(9,250)$, although the latter was recently disputed $(39,132,334)$. The loss of myonuclei appears to involve apoptosis, and increased apoptotic signaling in atrophying skeletal muscle has been reported in aging $(14,79,80)$, but has also been linked to conditions such as muscle disuse (310), burn injury (373), muscle denervation (311), unweighting (8) and cancer cachexia (30). Nonetheless, nuclear apoptosis in muscle does not inevitably lead to myofiber cell death (79), as it is unknown how many nuclei may be lost before an entire muscle fiber undergoes apoptosis (104). Further, accretion of new myonuclei may occur during muscle fiber hypertrophy when the upper limit of the myonuclear domain of the present myonuclei in a muscle fiber is exceeded. Alternatively, myonuclear accretion also occurs in regenerating muscle fibers following damage or during recovery from atrophy $(271,374)$. These new myonuclei are provided by the satellite-cell population $(23,285)$ (Figure 2.1). In order to appreciate the role of GSK-3 $\beta$ in the regulation of muscle mass maintenance and plasticity, the current insights of the involvement of 
GSK-3 $\beta$ in the control of muscle protein synthesis and degradation, as well as myonuclear accretion and apoptosis will be individually discussed below.

\subsection{Muscle protein turnover}

\subsubsection{Muscle protein synthesis and GSK-36}

Protein synthesis is a tightly controlled process that requires orderly recruitment and functioning of a plethora of signaling molecules. Protein translation initiation appears to be the rate-limiting step in muscle protein synthesis, and is essentially controlled by eukaryotic initiation factors (elFs). The activity of a number of these elFs is controlled by growth factor (e.g. IGF-I) and hormonal (e.g. insulin) signaling pathways. Protein translation is initiated by the binding of elF2 to the activated initiator methionine transfer RNA ( $\mathrm{RRNA}_{\mathrm{i}}^{\mathrm{Met}}$ ), which leads to the formation of a ternary complex that binds to the $40 \mathrm{~S}$ ribosomal subunit to ultimately form the $43 \mathrm{~S}$ preinitiation complex (173). The ability of elF2 to engage in the formation of this ternary complex depends on the activity of another initiator factor, namely elF2B. elF2B $\varepsilon$ is the largest of the five elF2B subunits and functions as a catalyst responsible for the GDP/GTP exchange reaction of elF2 $(138,173)$. Activated GSK-3 $\beta$ is responsible for an inhibitory phosphorylation on elF2B $\varepsilon$ at $\mathrm{Ser}^{540}$, which results in the loss of guanine nucleotide exchange activity, and is associated with a decrease in the initiation of protein synthesis $(165,355,356)$. Conversely, inactivation of GSK-3 $\beta$ by its upstream kinase Akt leads to decreases in the phosphorylation of elF $2 B \varepsilon$, which facilitates mRNA translation initiation (Figure 2.2). 


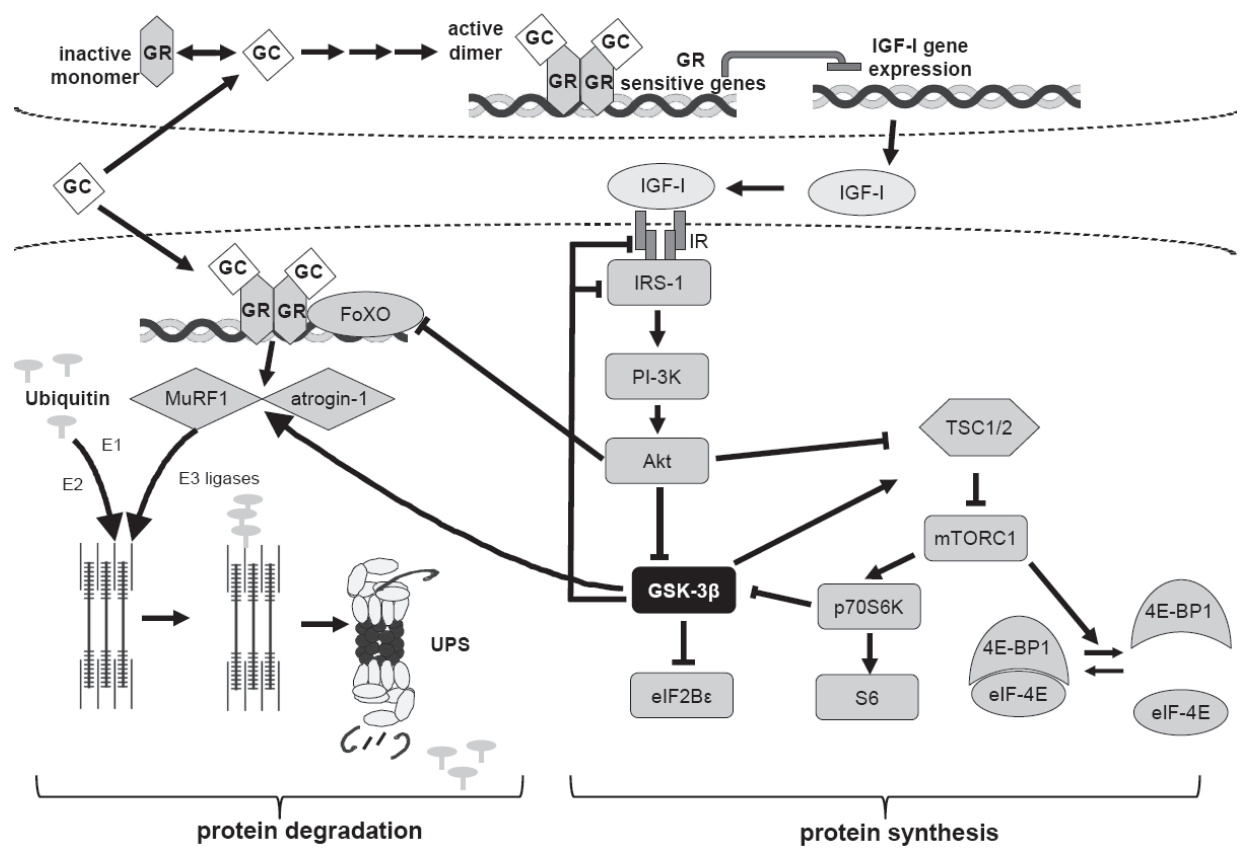

Figure 2.2 Schematic representation of the signaling pathways involved in muscle protein turnover and central role of GSK-3ß.

Anabolic factors such as insulin or IGF-I stimulate PI-3K signaling which results in activation of Akt. Phosphorylated Akt, in turn, inactivates GSK-3 $\beta$ and in parallel stimulates mTORC1 signaling, leading to enhanced protein synthesis. Conversely, under catabolic conditions (which may include glucocorticoid (GC) signaling) Akt activity is reduced, thereby stimulating the expression of the E3 ligases MuRF1 and atrogin-1 through FoXO and GR, leading to enhanced UPS-mediated proteolysis of muscle-specific proteins. Activation of GSK-3 $\beta$, consequent to reduced Akt activity, is required for increases in E3 ubiquitin ligase expression, and may further decrease PI-3K/Akt signaling via a negative feedback loop.

Akt has been identified as a nodal point which transduces extracellular cues (e.g. growth factors, nutrients) and mechanical stimuli to its downstream signaling cascades through the phosphorylation of a myriad of substrates, resulting in the integration of anabolic, catabolic and mechanical responses $(55,369)$. Constitutive Akt1 activation results in pronounced muscle hypertrophy in transgenic mice $(39,188)$, while Akt1/Akt2 double-knockout mice display severe skeletal muscle atrophy (256). Anabolic factors such as insulin or IGF-I stimulate PI-3K signaling resulting in an activating phosphorylation of two Akt residues $(6,45)$. Phosphoinositide-dependent kinase 1 (PDK1) activates Akt by phospholipid binding and activation loop phosphorylation at $\mathrm{Thr}^{308}$, whereas PDK2/rictor-mTOR complex 2 (mTORC2) phosphorylates Akt at $\operatorname{Ser}^{473}(5,162,289)$. Activated Akt, in turn, stimulates the raptormTOR complex 1 (mTORC1) and in parallel inactivates GSK-3 $\beta$ through phosphorylation of $\operatorname{Ser}^{9}$ (139). Of note, phosphorylation of Akt on $\mathrm{Thr}^{308}$ was proven to 
be essential and sufficient for the regulation of GSK-3 $\beta$ by Akt (162). Further, the IGFI/insulin-induced activation of mTORC1 through Akt leads to phosphorylation of its downstream targets p70S6K and elF4E-binding protein 1 (4E-BP1), which contribute to stimulation of protein synthesis by enhancing mRNA translation capacity and mRNA translation initiation via elF4, respectively (mTOR; reviewed in detail by Proud (267) and Glass (123)). Activated p70S6K can in turn inactivate GSK-3 $\beta$ (19). Conversely, in the absence of growth factor signaling activated GSK-3 $\beta$ can cooperate with adenosine monophosphate-activated protein kinase (AMPK) to negatively regulate mTORC1 by activating the mTORC1 inhibitor tuberous sclerosis protein 2 (TSC2) (158). Similarly, activated GSK-3 $\beta$ can hinder Akt signaling by destabilizing the insulin receptor substrate 1 (IRS-1), an essential adaptor molecule for PI-3K, which is required for the relay of Akt activating signals downstream of the IGF-I/insulin receptor (IGF-IR) (IR) $(95,205,351)$. Furthermore, a recent study by Kelly et al. described a novel interaction between GSK-3 $\beta$ and the IGF-IR (171). It was postulated that IGF-IR phosphorylation at $\operatorname{Ser}^{1248}$ was mediated by GSK-3 $\beta$ in the absence of growth factors, resulting in restrained IGF-IR kinase activity. In addition, a kinome wide small interfering RNA (siRNA) screen gave evidence of novel bi-directionality in the Akt/GSK-3 $\beta$ interaction, whereby genetic ablation of GSK-3 $\beta$ significantly reduced Akt phosphorylation (214) (Figure 2.2).

Much of the early evidence pertaining to a role for GSK-3 $\beta$ in muscle protein synthesis was derived from studies in cardiac muscle cells. In 2000, Haq et al.

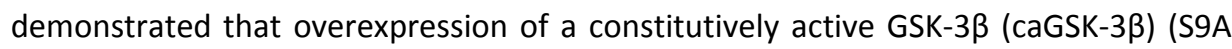
mutant) in neonatal rat cardiomyocytes was sufficient to suppress protein synthesis and to block key features of cardiac hypertrophy (137). By contrast, inhibition of GSK$3 \beta$ with lithium increased protein synthesis, measured by radioactively labeled leucine incorporation. In addition, increased GSK-3 $\beta$ activity appeared to be associated with impaired cardiomyocyte growth, as transgenic mice overexpressing wild-type (WT) GSK-3 $\beta$ developed hypotrophic hearts (228).

In 2001, Bodine et al. demonstrated that both Akt and GSK-3 $\beta$ phosphorylation were increased in a rat model of compensatory skeletal muscle hypertrophy (41). In addition to the decreased phosphorylation status of GSK-3 $\beta$, its specific activity was also reduced upon functional overload of the muscle. Concomitantly, mTORC1 signaling was stimulated, as illustrated by increased phosphorylation of p70S6K and 4E-BP1. Furthermore, overexpression of a constitutively active form of Akt (caAkt) in mice resulted in hypertrophy of normal muscle fibers and prevented muscle fiber atrophy upon denervation (41). The authors contributed the hypertrophy phenotype to increased protein synthesis signaling, based on phosphorylation and subsequent inhibition of GSK-3 $\beta$ and through activation of mTORC1, respectively. In the same year, a report by Rommel et al. extended these findings by showing that expression of

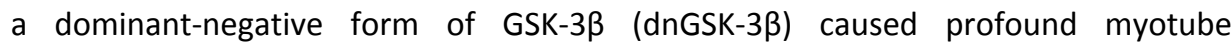


hypertrophy (274). The dnGSK-3 $\beta$ (K85R mutant) is a catalytically inactive (kinase dead) form of GSK-3 $\beta$ where lysine at position 85 (Lys ${ }^{85}$ ) of the ATP-binding site is mutated to arginine $(141,274)$. Treatment of $C_{2} C_{12}$ myotubes with IGF-I resulted in phosphorylation and inactivation of GSK-3 $\beta$, via a mechanism that could be blocked by the PI-3K inhibitor LY294002, but not by rapamycin; a selective mTORC1 inhibitor. It was concluded that GSK-3 $\beta$ constituted a pivotal downstream target of the PI-3K/Akt pathway, and its inhibition contributes to hypertrophy in an mTORC1-independent manner via relief of GSK-3 $\beta$-mediated suppression of the translation initiator factor elF2B, resulting in increased protein synthesis. This was the first study to assess the contribution of the individual Akt/mTORC1 and Akt/GSK-3 $\beta$ pathways to muscle protein synthesis during muscle hypertrophy.

As described below, previous studies investigating the role of lithium and GSK-3 $\beta$ in the regulation of protein turnover in atrophic conditions primarily assessed the role of this kinase in governing muscle protein degradation (101-103). However, there is a paucity of data pertaining to the potential contribution of GSK-3 $\beta$ to muscle atrophy via suppression of the muscle protein synthesis rate. Recent work by Bertsch et al. addressed this gap in the literature (32). In line with previous studies investigating the role of GSK-3 $\beta$ in muscle protein synthesis during hypertrophy $(137,343)$, the incubation of control muscle with lithium significantly increased protein synthesis, measured by incorporation of radioactively labeled phenylalanine in excised muscle tissue, whereas this anabolic effect was absent in muscle tissue from septic rats (32). Further, protein synthesis was decreased in septic muscle, due to diminished phosphorylation of $4 \mathrm{E}$ BP1 and S6. Sepsis increased phosphorylation and inhibition of elF2B $\varepsilon$, consequent to markedly increased GSK-3 $\beta$ activity, thereby decreasing protein translation initiation $(339,356)$. Moreover, lithium was capable of reversing the sepsis-induced increase in elF2B $\varepsilon$ phosphorylation, whereas the phosphorylation of S6 or 4E-BP1 remained unaltered in either control or septic muscles incubated with lithium. Interestingly, lithium decreased GSK-3 $\beta$ activity by $35 \%$ in control muscle, while the sepsis-induced increase in GSK-3 $\beta$ kinase activity was absent in the presence of lithium.

\subsubsection{Muscle proteolysis signaling and GSK-3 $\beta$}

Much of the early evidence linking GSK-3 $\beta$ to the proteolysis of skeletal muscle proteins was collected in models of burn-induced muscle proteolysis. Considering its previously established role as a negative regulator of skeletal muscle hypertrophy (343) Sugita et al. hypothesized that uninhibited increased GSK-3 $\beta$ activity, associated with perturbed Akt signaling, could play a role in muscle wasting in burns (320). Not soon after, a study by the group of Hasselgren clearly established a role for the PI$3 \mathrm{~K} / \mathrm{Akt} / \mathrm{GSK}-3 \beta$ signaling pathway in the anticatabolic effects of IGF-I in a rat model of burn injury, as IGF-I-treatment resulted in pronounced phosphorylation (inactivation) of GSK-3 $\beta$ and inhibition of protein degradation. Likewise, pharmacological GSK-3 $\beta$ inhibition, using lithium or TDZD-8, blocked burn-induced muscle protein breakdown, 
which was quantified by the release of trichloroacetic acid-soluble radioactivity from proteins prelabeled with ${ }^{3} \mathrm{H}$-tyrosine. Concretely, lithium -and TDZD-8-treatment reduced the Tyr release rates, measured ex vivo in extensor digitorum longus (EDL) muscles (103).

In a subsequent study, the potential mechanisms involved in the IGF-I-induced inhibition of protein degradation were examined in vitro. Since increased levels of GCS have been associated with a number of pathological catabolic states $(140,191)$, Li et al. employed the synthetic GC Dex to mimic the catabolic response observed in muscle after burn injury or during sepsis $(198,199)$. Treatment of rat $L 6$ myotubes with Dex resulted in an approximately $20 \%$ increase in protein degradation, determined by reduced radioactively labeled Tyr release rates. Moreover, supplementation of IGF-I to myotubes significantly reduced the basal protein degradation rate and completely abolished the Dex-induced increase in protein breakdown $(198,199)$. Exposure of Dextreated myotubes to the GSK-3 $\beta$ inhibitors lithium or TDZD-8 resulted in a dosedependent reduction of protein degradation comparably to IGF-I, suggesting that IGFI-induced inhibition of protein degradation, at least in part, reflected inhibition of GSK$3 \beta$ (198).

Fang et al. were the first to report that burn injury increased GSK-3 $\beta$ kinase activity in atrophying muscle (102). Formerly, GSK-3 $\beta$ activity was determined indirectly by measuring tissue levels of GSK-3 $\beta$ phosphorylated at Ser ${ }^{9}$, equating reduced GSK-3 $\beta$ phosphorylation in muscle from burned and septic rats with an increase in its activity $(101,103,339)$. Burn injury significantly lowered Akt kinase activity, which was confirmed by reduced levels of phosphorylated Akt. The authors concluded that GSK-3 $\beta$ activation in catabolic conditions reflected reduced phosphorylation of GSK-3 $\beta$ secondary to reduced Akt activity. To support the claim that increased GSK-3 $\beta$ activity could be involved in the regulation of protein degradation in catabolic muscle, siRNA targeted against GSK-3 $\beta$ was used to further investigate its role in Dex-induced proteolysis. Despite a relatively modest reduction of GSK-3 $\beta$ protein (25\%), transfected L6 myoblasts were more refractory to GC-induced protein degradation, providing additional evidence that GSK-3 $\beta$ contributed to muscle proteolysis during skeletal muscle wasting (102). These results were in support of their previous work in which GSK-3 $\beta$ inhibitors blocked burn-induced muscle protein degradation (103). Similarly, in a recent report by Bertsch et al. (32) increased rates of protein breakdown in septic muscle were completely antagonized by lithium, confirming previous findings by the group of Hasselgren (101-103).

\subsubsection{Role of GSK-3 $\beta$ in UPS-mediated muscle proteolysis}

The stimulation of proteolysis observed during skeletal muscle atrophy appears to rely on increased protein degradation via the UPS $(163,164)$. UPS-mediated protein degradation is a selective process and involves two distinct and successive series of 
steps, which include the covalent attachment of multiple ubiquitin molecules to the target protein and the subsequent degradation of the tagged substrate by the 26Sproteasome (300). Conjugation of ubiquitin to the substrate proceeds via a three-step enzymatic mechanism and the E3 ubiquitin ligases catalyze the rate-limiting step in this process (52). Substrate specificity is achieved by several hundred E3s which are expressed in a tissue-specific manner. The expression of the muscle-specific E3s, atrogin-1/muscle atrophy F-box (MAFbx) (hereinafter termed atrogin-1) and musclespecific RING finger protein 1 (MuRF1) is upregulated under a variety of atrophic conditions $(282,367)$ and genetic knockout studies have shown that the null deletion of MuRF1 and atrogin-1 attenuates muscle atrophy following denervation $(40,125)$. Importantly, MuRF1 and atrogin-1 are essential for UPS-mediated proteolysis of myofibrillar proteins (53,60), muscle-specific enzymes (379) and muscle-specific transcription factors (187) (Figure 2.2).

The first report that implicated GSK-3 $\beta$ in the regulation of UPS-mediated protein degradation came from the group of Hasselgren (101). In this study the contribution of GSK-3 $\beta$ activity to increased proteolysis was assessed in vivo in a model of sepsisinduced muscle wasting. Rats were made septic by cecal ligation and puncture (CLP). Remarkably, incubation of EDL muscles of septic rats with either lithium or TDZD-8 significantly reduced basal and sepsis-induced protein breakdown rates (101). To model sepsis-induced skeletal muscle atrophy in vitro, L6 myotubes were exposed to Dex either in the presence or absence of lithium or one of the GSK-3 $\beta$ inhibitors SB216763 or SB415286. In analogy with previous results GSK-3 $\beta$ inhibition markedly decreased myotube proteolysis in response to Dex. Furthermore, lithium-treatment increased GSK-3 $\beta$ phosphorylation at $\mathrm{Ser}^{9}$ in myotubes as well as in incubated muscles. Given the fact that Dex had previously been shown to increase the activity of the UPS (346), the expression of the atrophy markers atrogin-1 and MuRF1 was also assessed. The induction of these E3 ubiquitin ligases in response to Dex was completely prevented by insulin and chemical GSK-3 $\beta$ inhibition at concentrations that inhibited protein degradation (101). Previously, Sandri et al. demonstrated that overexpression of caAkt in cultured myotubes inhibited expression of atrogin-1 (288), while overexpression of caGSK-3 $\beta$ in cultured muscle cells resulted in increased atrogin-1 expression and promoter activation (288), further illustrating the pivotal role of GSK-3ß's kinase activity in the regulation of skeletal muscle proteolysis.

Interestingly, Bertsch et al. reported that incubation of septic muscle with lithium tended to reverse the elevated 26S-proteasome activity, but this reduction failed to reach statistical significance and was not associated with a concomitant decrease in atrogin-1 and MuRF1 mRNA content. Besides, lithium had previously been shown to directly reduce 26S-proteasome activity in a GSK-3 $\beta$-independent fashion (306). Interestingly, recent data from our group suggests that UPS-dependent degradation of myofibrillar proteins requires GSK-3 $\beta$. Genetic ablation of GSK-3 $\beta$ in $\mathrm{C}_{2} \mathrm{C}_{12}$ myotubes 
using siRNA revealed that loss of endogenous GSK-3 $\beta$ protein suppressed both basal and atrophy stimulus-induced atrogin-1 and MuRF1 transcript levels. Moreover, GSK$3 \beta$ ablation resulted in specific sparing of myosin heavy chain fast (MyHC-f), myosin light chains 1 (MyLC-1) and -3 (MyLC-3) protein abundance and myotube size in response to Dex-treatment or impaired IGF-I/Akt signaling, demonstrating that muscle atrophy resulting from increased proteolysis signaling requires GSK-3 $\beta$ (340). Furthermore, gene expression analysis revealed that enzymatic GSK-3 $\beta$ inhibition, using either lithium or CHIR99021, only attenuated atrophy stimulus-induced atrogin1 expression, while MuRF1 expression levels remained unaffected. The notion that atrogin-1 and MuRF1 expression was differentially regulated in response to GSK-3 $\beta$ inactivation was not in agreement with findings by Evenson et al. (101), who found that in response to Dex both atrogin-1 and MuRF1 mRNA levels were suppressed following GSK-3 $\beta$ inhibition. Furthermore, pharmacological suppression of only atrogin-1 expression was not sufficient to prevent or attenuate loss of myofibrillar protein abundance, suggesting that MuRF1 was the predominant E3 ubiquitin ligase responsible for the loss of contractile proteins in both atrophy models. In the light of these findings, it was concluded that the preferential depletion of contractile proteins in response to Dex or LY294002 likely occurred in a UPS-dependent manner, as previous reports by Clarke et al. (53) and Cohen et al. (60) clearly implicated MuRF1 in the targeted destruction of several key myofibrillar proteins during atrophy. Moreover, MuRF1 knockdown studies (sh-MuRF1) confirmed the results in the abovementioned studies as genetic ablation of MuRF1 completely abolished LY294002 -or Dex-induced loss of myofibrillar proteins, similar to the observations made in GSK-3 $\beta$ deficient (sh-GSK-3 $\beta$ ) myotubes in response to these atrophy stimuli (340). These data provided causal evidence to support the hypothesis that in a catabolic state, suppression of GSK-3 $\beta$ exerts a protective effect on myofibrillar protein content by downregulating MuRF1-driven UPS-mediated muscle proteolysis.

\subsubsection{Role of GSK-3 $\beta$ in ALP-mediated muscle proteolysis}

Autophagy is a highly conserved bulk degradation process implicated in the clearance of long-lived proteins and dysfunctional organelles $(196,231)$. This proteolytic system is distinguished by the formation of phagophores, which elongate and fuse while engulfing a portion of the cytoplasm, to ultimately form double-membraned vesicles, called autophagosomes. These structures, in turn, merge with endosomes that later fuse with acidic lysosomes, which degrade the cytosolic contents (270). Autophagosome formation requires the orderly recruitment and assembly of various autophagy-related proteins onto membrane phospholipids, but only the small ubiquitin-like molecules, including microtubule-associated proteins $1 \mathrm{~A} / 1 \mathrm{~B}$ light chain $3 B$ (LC3) and GABA receptor-associated protein 1 (Gabarapl1), bind covalently to phosphatidylethanolamine (286). To date, the contribution of the ALP to skeletal muscle wasting is unclear, despite ample evidence suggesting a clear role for lysosomal degradation in atrophying muscles $(117,286,294)$. Interestingly, basal 
autophagy is constitutively active in skeletal muscle and appears to be necessary to maintain myofibers in a healthy state under normal physiological conditions. Suppression of autophagy by muscle-specific deletion of the essential autophagy gene Atg7 amounts to severe muscle atrophy, and Atg7-null muscles display accumulation of abnormal mitochondria and protein aggregates (221). However, several recent studies have reported that autophagy is strongly induced in skeletal muscle upon starvation $(232,286)$, denervation $(117,294)$ and oxidative stress $(21)$, substantially aggravating muscle loss during these catabolic circumstances. The autophagic flux appears to be a double-edged sword, and tight control of ALP-related gene expression is therefore indispensable to prevent unbalanced autophagy activation and subsequent muscle loss.

In serum-deprived human prostate cancer cells both genetic as well as chemical modulation of GSK-3 $\beta$ activity stimulated an extensive autophagic response, which eventually led to necrotic cell death (372). It was postulated that under serum-free conditions GSK-3 $\beta$ acted as a survival factor with the ability to fine-tune the autophagy process to avoid excessive autodigestion and subsequent cell death (372). Conversely, in mesangial cells it was shown that pharmacological inhibition or genetic ablation of GSK-3 $\beta$ was sufficient to decrease cadmium-induced autophagy (348). Overexpression of GSK-3 $\beta$ potentiated autophagy in the presence of cadmium and, in addition, cadmium-induced increases in reactive oxygen species (ROS) decreased GSK$3 \beta$ phosphorylation at $\mathrm{Ser}^{9}$, indicative of increased GSK-3 $\beta$ activity (348). Sarkar and coworkers demonstrated that pharmacological GSK-3 $\beta$ inhibition attenuated autophagy and mutant huntingtin clearance by activating mTORC1 (290). Recently, an elegant study by Lin et al. unraveled a novel autophagy signaling cascade involving GSK-3 $\beta$ (206). It was reported that GSK-3 $\beta$ was activated upon growth factor withdrawal and that activated GSK-3 $\beta$ catalyzed the phosphorylation of TIP60, which in turn increased acetylation and kinase activity of ULK1, an important autophagy gene (Atg). Similarly, co-expression of GSK-3 increased phosphorylation of TIP60 on Ser ${ }^{86}$, while treatment with the GSK-3 inhibitors SB216763, SB415286 or lithium impeded TIP60 phosphorylation, blocking serum deprivation-induced autophagy (206). Although these recent reports imply regulation of autophagy by GSK-3 $\beta$, currently, there is no convincing evidence to implicate GSK-3 $\beta$ in the regulation of autophagy during muscle proteolysis.

Although discussed separately above, both proteolytic systems, i.e. the ALP and the UPS, may interact to coordinately facilitate muscle protein degradation. For decades both these pathways were viewed as independent of each other. However, it is becoming increasingly more clear that cross-talk between the UPS and the ALP occurs at several levels (183). It was proposed that impairment of the UPS leads to increased autophagic function (78,251). Furthermore, during selective autophagy certain substrates may be specifically targeted for destruction and specificity is 
achieved by substrate ubiquitylation (179). Moreover, the seminal work by the group of Sandri demonstrated that the ALP and the UPS are coordinately regulated during muscle wasting, and that FoXO3a functions as a critical liaison molecule governing transcription of autophagy-related genes (e.g. LC3, Gabarapl1, Bnip3), as well as the UPS-related E3 ligases atrogin-1 and MuRF1 (216,288,378). As GSK-3 $\beta$ appears to regulate UPS-mediated contractile protein breakdown (340), and considering the extensive cross-talk between the UPS and the ALP, it is not improbable that GSK-3 $\beta$ might also converge on the ALP, possibly through a direct or indirect interaction with FoXO3a.

\subsubsection{Role of GSK-3 $\beta$ in calpain and caspase-mediated muscle proteolysis}

The proteasome cannot degrade intact myofibrils, so the first step in the degradation of myofibrillar proteins, such as actin and myosin, during atrophy requires the release of myofilaments from the sarcomere $(314,315)$. These initial steps in myofibrillar proteolysis appear to rely on the calpain and caspase systems. Several lines of evidence have indicated that the activation of the calpain system constitutes an additional mechanism contributing to skeletal muscle proteolysis during atrophy $(27,148,358)$. Although actin and myosin are poor calpain substrates, several proteins important for the structural integrity of the sarcomere, such as nebulin, titin and filamin are readily cleaved by calpain $(152,313)$.

Calpains are non-lysosomal, calcium-dependent Cys proteases, which cover a broad range of physiological functions, including proteolysis of proteins involved in the cell cycle, apoptosis, signal transduction and cytoskeletal organization (124). Under basal conditions calpains are typically in an inactive state, and binding of calcium results in conformational changes which activates the protease (313). Calpain activity can also be regulated by the endogenous inhibitor calpastatin (27). Calpain activity was found to be increased during atrophic conditions like disuse (133), denervation (323), sepsis $(342,358)$ and GC-treatment (148). However, these reports only provided associative support for a role of calpains in muscle wasting. Other data came from studies that employed calpain inhibitors to study the contribution of calpain activity to muscle proteolysis $(25,357)$. However, due to their lack of specificity it was not possible to pronounce upon the direct role of calpains during muscle wasting (85). In contrast, Tidball and Spencer established a causal role for calpains in muscle atrophy by overexpressing calpastatin in mice (329). These transgenic mice exhibited a lower susceptibility to muscle atrophy induced by unloading (329). Although the former study did not verify the contribution of proteolysis to muscle atrophy, transient overexpression of calpastatin in cultured muscle cells reduced protein degradation following Dex-treatment (105).

Caspases are calcium-independent cysteine-aspartic proteases that are wellknown for their essential role as "executioner" proteins in apoptosis (272). Intriguingly, 
besides its role in apoptosis, caspase- 3 has been demonstrated to function during the initial phase of myofibrillar protein degradation $(87,263)$, comparably to calpains. Du et al. proposed that increased caspase-3 activity, following a catabolic insult (e.g. reduced $\mathrm{PI}-3 \mathrm{~K}$ signaling during acute diabetes, sepsis or starvation), plays a critical role in the dissociation of actomyosin complexes, prior to UPS-mediated clearance of myofibrillar proteins (87). Similarly, caspase-3 activity was required during the first two weeks of denervation-induced skeletal muscle atrophy (263). In summary, the current paradigm of skeletal muscle proteolysis encompasses an early "upstream" dissociation of the myofibrils by calpains (possibly acting in concert with caspase-3), resulting in the release myofibrillar proteins which are subsequently ubiquitinated and targeted for destruction by the 26S-proteasome $(27,314)$.

A study by Smith et al. found that increased calpain activity and calpain-dependent protein degradation in calcium-treated muscles was associated with reduced Akt activity (312). Moreover, this reduction in Akt activity was accompanied by reduced phosphorylation of several downstream signaling molecules, including GSK-3 $\beta$. Considering previous evidence demonstrating the essential role of the inhibition of Akt activity during skeletal muscle atrophy $(123,241)$, these findings suggest that calpain-mediated proteolysis not only contributes to muscle atrophy by facilitating myofibrillar protein degradation, but may also affect the control of muscle protein turnover, as reduced Akt activity will allow nuclear translocation and transcriptional activation of FoXO transcription factors, which are vital in regulating the expression and activity of atrogin- 1 and MuRF1, and thus, initiation of UPS-mediated muscle proteolysis $(123,288,319)$. In addition, attenuated Akt signaling, as observed following calpain activation (312), will result in increased GSK-3 $\beta$ activity, which in turn contributes to enhanced protein degradation (101,102,340), and, parallel to decreased mTORC1 activity, will suppress protein synthesis (189). Future studies should address the role of calpain activity in the activation of FoXO and GSK-3 $\beta$, and the inhibition of mTORC1 in the context of skeletal muscle loss during catabolic conditions. Moreover, calpains are renowned for their ability to cleave signaling molecules and transcription factors (27), and several of these substrates such as NF-KB (211), C/EBP- $\beta$ (354) and STAT (247) have been linked to the control of muscle mass. Thus, in addition to the disruption of the sarcomere, increased calpain activity may relay or interrupt cellular signaling cues involved in the regulation of skeletal muscle plasticity.

A recent study by Ebert et al. focused on the role of growth arrest and DNA damage-inducible 45a (Gadd45a) in reprogramming skeletal muscle gene expression during atrophy (91). Gadd45a expression was shown to be under the control of activating transcription factor 4 (ATF-4), a transcription factor whose upregulation had previously been associated with muscle fiber atrophy (92). The authors unraveled a novel stress-induced pathway in which Gadd45a stimulated multiple interconnected atrophy mechanisms (91). Specifically, overexpression of Gadd45a resulted in an 
increase in GSK-3 $\beta$ activity and caspase-3-mediated proteolysis (91). The concurrent activation of GSK-3 $\beta$ and caspase- 3 in this study may concern more than an association, given the previous reports demonstrating a causal role for GSK-3 $\beta$ in caspase-3 activation $(34,174,175)$. Moreover, Hildesheim et al. described an interaction between Gadd45a and GSK-3 $\beta$, i.e. Gadd45a associated with GSK-3 $\beta$ and promoted its dephosphorylation at $\mathrm{Ser}^{9}$, essential for GSK-3 $\beta$ activation (144). Although there is no causal evidence to support a direct link between GSK-3 $\beta$ and caspase-3-dependent protein degradation during muscle wasting, it is conceivable that Gadd45a-mediated increases in GSK-3 $\beta$ activity in response to cellular stress, may enhance caspase-3 activity in muscle, which in turn could cause disruption of the sarcomere.

Of note, several lines of evidence have postulated that there is a cross-talk between the Cys proteases and UPS-mediated proteolysis. As indicated, calpain cleavage products become substrates for UPS-mediated protein breakdown, and the availability of these substrates may enhance UPS-activity (201). Similarly, caspase-3 activation stimulated proteasome activity in differentiated muscle cells, and increased caspase-3 activity exerted a feed-forward amplification of protein degradation in muscle in concert with the UPS (350). It is tempting to suggest that GSK-3 $\beta$ governs an additional level of cross-talk between the UPS and the Cys proteases, as increased GSK-3 $\beta$ activity could either directly or indirectly relay signaling cues to stimulate caspase-3 and calpain-mediated myofibril dissociation, while simultaneously regulating atrogin-1 and MuRF1 expression (340), resulting in enhanced UPS-mediated degradation of myofibrillar proteins.

\subsubsection{Integration of muscle protein synthesis and degradation: regulation by GSK-3B}

As highlighted above, activation of the Akt pathway, and subsequent signaling through its downstream targets GSK-3 $\beta$ and mTORC1, results in increased protein synthesis $(41,169)$. Although this pathway is suppressed in various models of skeletal muscle wasting, this does not simply imply that muscle atrophy is solely due to decreased protein synthesis. Activation of the UPS-mediated protein degradation during muscle atrophy is associated with the induction of a distinct set of genes, including the E3 ubiquitin ligases MuRF1 and atrogin-1, which are inversely regulated by IGF-I/Akt signaling (190). Thus, cross-talk between muscle protein synthesis and the UPS occurs at multiple levels. Based on these and other studies, Akt has been proposed as a central regulator of skeletal muscle plasticity $(41,169,190,319)$.

Coordination between muscle protein synthesis and degradation not only occurs during physiological circumstances, but also appears to be maintained under pathological conditions, and several of these are associated with increased levels of circulating GCs $(192,360)$. The direct effects of GCs on skeletal muscle depend to a large extent on activation of the glucocorticoid receptor (GR) (344), and the administration of synthetic GCs induce muscle atrophy $(293,340)$. Conversely, endogenous GCs appear 
indispensable for the induction of protein degradation in several atrophy models, as adrenalectomy or treatment with the GR antagonist RU-486 attenuates muscle proteolysis and atrophy $(151,227,288,292)$. In addition to its role in proteolysis, GR activation by GCs reduces protein synthesis at multiple levels. A non-genomic mechanism by which the GR impairs protein synthesis involves competition of GR with PI-3K for association with IRS-1, resulting in suppression of Akt/mTORC1 and Akt/GSK-3 $\beta$ signaling $(151,332)$. In addition, GR activation results in the transcriptional repression of muscle IGF-I expression (202), whereas transcriptional activation of regulated in development and DNA damage response 1 (REDD1) (186) concerns another genomic action of GR activation responsible for suppression of protein synthesis via the inhibition of mTORC1. Furthermore, GCs decrease translation initiation through increased availability of dephosphorylated 4E-BP1 (302) and reduced activity of p70S6K (301). Recently, a mutually exclusive signaling cross-talk between GR and MTORC1 was revealed (307), providing further evidence of coordination between the protein synthetic and degradation machinery in response to (pathological) stimuli that affect muscle mass.

Based on its positioning as a direct downstream target of Akt, it is tempting to speculate that, GSK-3 $\beta$ may constitute an additional reciprocal link between the processes that govern muscle protein degradation and synthesis. Interestingly, GSK-3 $\beta$ was shown to directly phosphorylate the human GR, which significantly altered the repertoire of GR-regulated gene expression (119). Since transcriptional regulation of FoXO1 (307) , MuRF1 (344) as well as of REDD1 (186), and suppression of IGF-I expression are dependent on genomic GR actions, its regulation by GSK-3 $\beta$ will coordinately affect UPS-mediated proteolysis and protein synthesis. This warrants further investigation of a potential interaction between GSK-3 $\beta$ and the GR in the control of muscle protein synthesis and degradation during muscle wasting.

\subsection{Myonuclear turnover}

\subsubsection{GSK-3B and myonuclear loss}

Myonuclear apoptosis may contribute to myofiber plasticity. The apoptosis machinery is classically divided into the "mitochondrial, intrinsic apoptotic pathway" and the "death receptor-mediated, extrinsic apoptotic signaling pathway" (33,142), and either internal or external signals can induce caspase activity resulting in cleavage of specific proteins required for cell viability $(90,272)$. The intrinsic pathway may be induced by DNA damage $(352,353)$, ER stress (316), and hypoxia (236) and GSK-3 $\beta$ increases its activity by enhancing signals for mitochondrial disruption like Bax (208), Bim (149), MCL-1 (222) or modulation of transcription factors like $\beta$-catenin (13), p53 (353), and NF-KB (269). 
Conversely, GSK-3 $\beta$ suppresses the extrinsic pathway in response to TNF, Fas ligand, or TRAIL by upstream blockage of caspase-8 $(204,299)$ or caspase-3 $(299,317)$ activation. The molecular bases for these inhibitory actions of GSK-3 on apoptosis are currently unclear. This implies that inhibition of GSK-3 $\beta$ activity may attenuate or prevent apoptosis via the intrinsic pathway, while increasing the susceptibility to apoptosis mediated by the extrinsic pathway. Despite this emerging role for GSK-3 $\beta$ in the regulation of apoptosis, currently no literature exists addressing the involvement of GSK-3 $\beta$ in the regulation of skeletal muscle cell apoptosis. Myonuclear apoptosis has been predominantly described during muscle atrophy in both cachectic patients and models of muscle wasting $(4,197,341)$. Plant et al. demonstrated that denervationinduced muscle atrophy is caspase-3-dependent (263). However, the involvement of caspase-3 in prevention of myofiber atrophy was attributed to caspase-3-dependent degradation of myofibrillar proteins rather than myonuclear apoptosis. Nevertheless, caspase- 3 activity in skeletal muscle is PI-3K-dependent $(120)$ involving GSK-3 $\beta(33,185)$, i.e. phosphorylation of GSK-3 $\beta$ abrogates caspase-3 activation. Moreover, IGF-I/Akt signaling inhibits apoptosis of cardiomyocytes and skeletal muscle cells/myofiber nuclei $(4,240,319)$, implying the potential involvement of GSK-3 $\beta$ (Figure 2.3 ).

\subsubsection{GSK-3B and myonuclear accretion}

GSK-3 $\beta$ plays an integrative role in several signaling pathways that are involved in the cellular processes that direct proliferation and myogenic differentiation following satellite cell activation of and their subsequent incorporation into mature muscle fibers. Notch signaling is active in early satellite cell proliferation (62) and during cell type commitment toward the myoblast lineage, Notch signaling decreases and activation of Wnt/ $\beta$-catenin signaling occurs, which is an essential step in the formation of myocytes capable of fusion $(42,331)$. GSK-3 $\beta$ appears to be involved in both pathways as inhibition of Notch signaling leads to increased GSK-3 $\beta$ activity, while activation of $\mathrm{Wnt} / \beta$-catenin signaling results in GSK-3 $\beta$ inactivation. GSK-3 $\beta$ can associate with Notch thereby decreasing Notch-dependent gene expression (100). However, active GSK-3 $\beta$ has also been positively linked with increased Notchdependent gene expression (131). This dualistic role of GSK-3 $\beta$ in Notch signaling may rely on the cellular context. Wnt/ $\beta$-catenin signaling is essential during embryogenesis $(46,121)$ and appears to be important for postnatal muscle growth and regeneration $(64,118,259)$. In addition to promoting satellite cell proliferation (248), Wnt signaling induces location-specific expression of muscle regulatory factors (MRFs) (321). These MRFs, such as MyoD and myogenin, in turn, induce further muscle-specific gene expression $(31,180,266)$, which results in muscle protein accretion (18). Inhibition of Wnt/ $\beta$-catenin signaling can abrogate myogenic differentiation (74), while increasing Wnt signaling with canonical Wnt-3a leads to enhanced myogenic differentiation (252) (Figure 2.3). 


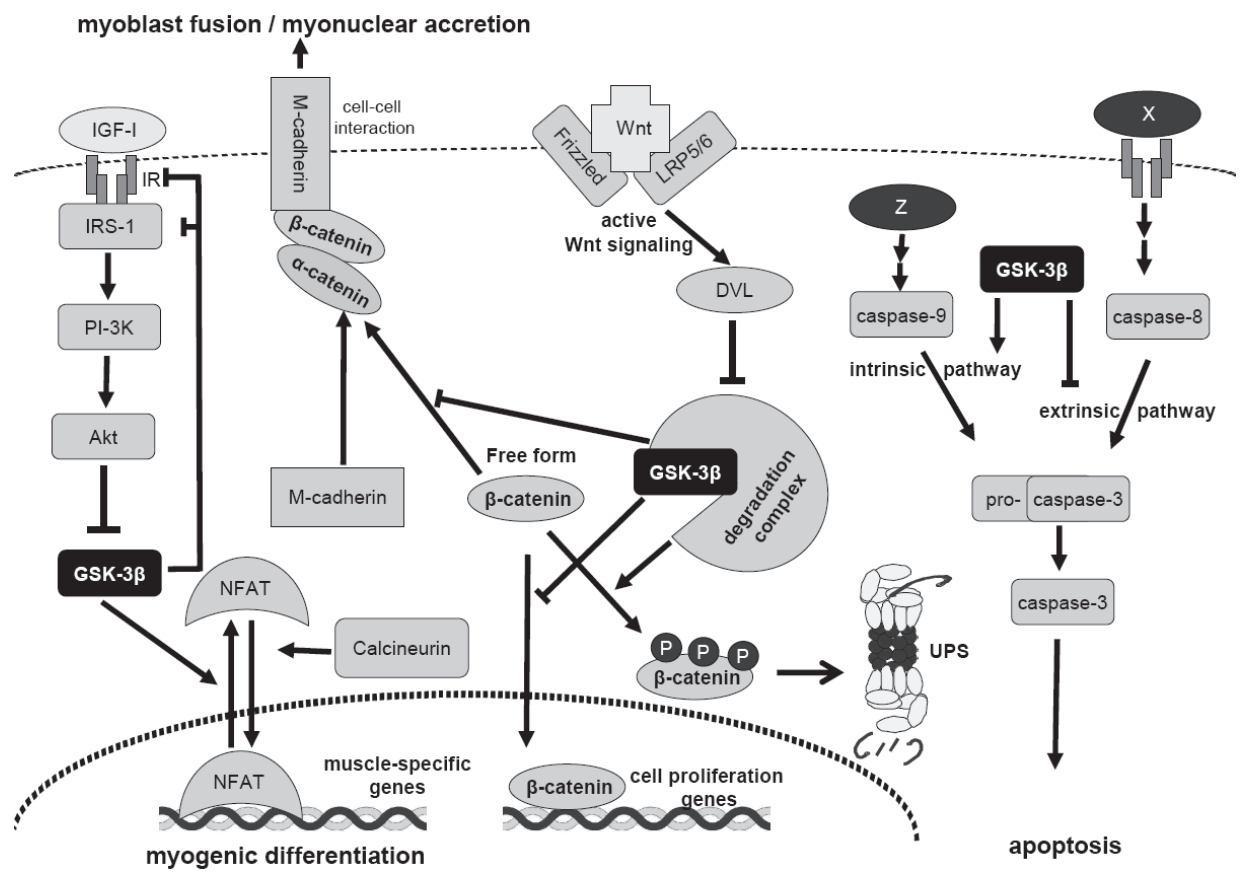

Figure 2.3 Schematic representation of the cellular signaling pathways involved in myonuclear turnover.

IGF-I signaling leads to inactivation of GSK-3 $\beta$ resulting in increased NFAT-dependent gene transcription and myogenic differentiation. Wnt signaling leads to inactivation/relocation of the degradation complex resulting in redistribution of cellular $\beta$-catenin content. This increases $\beta$-catenin-dependent (mitotic) gene transcription as well as its association with (M-) cadherin, thereby improving cell-cell interactions and subsequent myoblast fusion and myonuclear accretion. Apoptosis may contribute to myonuclear loss and GSK-3 $\beta$ differentially affects intrinsic ("Z", e.g. DNA-damage oxidative or ER stress) and extrinsic ("X", e.g. FasL, TRAIL, DR4/5, TNF) apoptosis signaling.

A recent report from our group demonstrated that Wnt-3a supplementation markedly improved myoblast fusion and myotube formation, and incubation of myoblasts with lithium yielded similar results, suggesting that GSK-3 $\beta$ inhibition accounted for these stimulatory effects on morphological differentiation (252). Although inhibition of GSK-3 activity was accompanied by increased $\beta$-catenin protein content and $\beta$-catenin-dependent gene expression, increased $\beta$-catenin-dependent transcriptional activity did not appear to account for improved myoblast fusion upon Wnt-3a -or lithium-treatment (252). Increased myotube formation may rather be a consequence of enhanced myoblast fusion due to increased cell-cell contact sites upon $\beta$-catenin accumulation. $\beta$-catenin is an essential binding partner for cadherin cytoplasmic tail, such as muscle-cadherin (M-cadherin) $(184,255,368)$. $\beta$-catenin colocalizes with $\mathrm{M}$-cadherin at the cell-cell contact sites in membranes which are 
important during myoblast fusion $(159,184,237)$. Interestingly, although pharmacological inhibition of GSK-3 $\beta$ (lithium) increases muscle-specific gene expression in addition to myoblast fusion, the former was not observed in response canonical Wnt-mediated GSK-3 $\beta$ inhibition. Canonical Wnts suppress GSK-3 $\beta$-mediated $\beta$-catenin phosphorylation and degradation through sequestration by axin and Dvl $(177,371,375)$, whereas lithium does not only inhibit GSK-3 $\beta$ associated with the $\beta$-catenin degradation complex, but also the "free" GSK-3 $\beta$ involved in other cellular signaling pathways like the IGF-I/Akt signaling cascade.

Muscle regeneration following injury or during recovery from muscle atrophy involves satellite cell activation, increased autocrine/paracrine IGF-I/Akt signaling (305) and inhibition of GSK-3 $\beta$ enzymatic activity through $\mathrm{Ser}^{9}$ phosphorylation (335). In addition, stimulation with IGF-I has been repeatedly shown to improve myogenic differentiation including enhanced muscle-specific gene expression $(109,295,336)$, and either pharmacological inhibition or genetic ablation of GSK-3 $\beta$ is sufficient to recapitulate this stimulatory effect on myogenic gene expression during differentiation (336,337). Suppression of muscle-specific gene expression by GSK-3 $\beta$ likely occurs through phosphorylation and nuclear exclusion of the transcriptional regulator NFAT $(73,298,337)$ as NFAT transcriptional activity is regulated through dephosphorylation by calcineurin allowing nuclear import $(1,50,230)$, while GSK-3 $\beta$ phosphorylation leads to nuclear export $(29,242)$, thereby preventing NFAT-dependent gene transcription.

Consequently, pharmacological inactivation of GSK-3 $\beta$ will affect both the gene regulatory as well as the cellular remodeling processes involved in myogenic differentiation, by activating/stabilizing two GSK-3 $\beta$ substrates, namely NFAT and $\beta$ catenin, in distinct signaling pathways. However, the cross-talk between these pathways appears to be minimal (303) or absent (252) in skeletal muscle based on studies using either IGF-I or Wnt to accomplish ligand-specific inactivation of GSK-3 $\beta$ $(20,77,200,252,375)$. A possible explanation for these ligand-specific effects of GSK-3 lies in the modus of GSK-3 inactivation by Wnt, i.e. through sequestration by axin and Dvl $(177,371,375)$, which, in contrast to IGF-I signaling, is not dependent on inhibitory Ser ${ }^{9}$ phosphorylation of GSK-3 $\beta$ (20,225). Thus, two distinct signaling routes involved in control of specific aspects of myogenic differentiation, rely on different and independent modes of modulating GSK-3 activity $(252,336)$ reiterating the potential effect of pharmacological inhibition of GSK-3. However, it also indicates that knowledge on the precise role of GSK-3 $\beta$ in the various signaling pathways is of great importance when considering this kinase as a pharmacological target. Therefore, further in vivo dissection of the involvement of GSK-3 $\beta$ in myonuclear turnover and its contribution to skeletal muscle mass plasticity is imperative. 


\section{Therapeutic potential of GSK-3ß modulation}

Recent research efforts have kindled an interest in GSK-3 as an important pharmaceutical target, due to its role in the molecular pathogenesis of various diseases, which currently lack adequate therapeutic treatment. For instance, the chemical GSK-3 inhibitors CT20026 (345) or aminopyrimidine derivatives $(56,273)$ were shown to possess insulin-mimicking properties, which led to improved insulin signaling and glucose homeostasis, and prevented disease progression in several models of diabetes. Furthermore, the recently discovered irreversible non-ATP competitive GSK-3 inhibitor, Tideglusib, is currently in phase II clinical trials for the treatment of Alzheimer's disease and progressive supranuclear palsy (PSP) $(72,84)$. Another recent study reported that the GSK-3 inhibitor AZD2858 could be beneficial in the treatment of osteoporosis (218), as pharmacological GSK-3 inhibition had previously been shown to increase bone mass (54). Similarly, enzymatic GSK-3 inhibition by SB216763 unequivocally abrogated periodontal pathogen-induced alveolar bone loss, which prompted the authors to conclude that GSK-3 inhibition may also be relevant for other chronic inflammatory diseases (3). Motor neuron diseases (MNDs), such as amyotrophic lateral sclerosis (ALS), are characterized by extensive skeletal muscle atrophy. Interestingly, pharmacological inhibition of GSK-3 results in a significant delay in symptom onset and an increase in survival time in an in vivo model of ALS $(181,182)$. Neuroprotection offered by GSK-3 inhibition appears to be a validated therapeutic strategy in the treatment of another MND, namely spinal muscular atrophy (SMA) (48). Chen and co-workers were the first to report that the novel GSK-3 inhibitor BIP-135 exerted a neuroprotective effect, as BIP-135 was found to extend the median survival time of transgenic mice bearing a severe SMA phenotype (48). In conclusion, the above-mentioned studies have clearly established the therapeutic potential of pharmacological GSK-3 $\beta$ inhibitors.

Therapeutic interventions aimed at the treatment of muscle wasting will either target the impaired signaling that lies at the basis of disturbed muscle mass homeostasis, or may aim at modulation of master regulators of the processes that govern muscle mass plasticity. GSK-3 activity levels or its downstream substrates have not systematically been included in the biochemical analyses of muscle tissue obtained in clinical studies that investigate the signaling pathways controlling skeletal muscle mass plasticity. Nevertheless, muscle biopsy analyses have provided some degree of evidence for altered GSK-3 $\beta$ activity in patients with muscle atrophy. Doucet et al. reported similar GSK-3 $\beta$ phosphorylation levels in skeletal muscle of COPD patients with muscle atrophy compared to healthy controls, despite increased Akt phosphorylation, which may suggest aberrant GSK-3 $\beta$ regulation in wasted muscle (86). In chronic complete spinal cord injury, a condition characterized by profound muscle atrophy, muscle biopsy analyses revealed strongly reduced GSK-3 $\beta$ phosphorylation levels, indicative of reduced endogenous inactivation (195). 
Interestingly, similar observations were made in pre-cachectic cancer patients (22). Altogether, there is currently insufficient evidence to conclusively imply or rule out aberrant GSK-3 $\beta$ regulation and signaling during pathological conditions associated with muscle wasting. Apart from the limited number of studies measuring GSK-3 activity and signaling in patient muscle biopsies, this is in part due to methodological limitations including heterogeneity of studied patient populations, timing of muscle biopsies and the variability of biochemical analyses in human muscle tissue subjects (47), cross-sectional study designs could be optimized by careful phenotyping and matching of study groups, and by trying to capture the acute wasting process (66).

Alternatively, rather than comparing GSK-3 $\beta$ signaling under basal conditions, studying it in the context of physiological relevant anabolic responses may be more appropriate and sensitive in order to expose aberrant GSK-3 regulation. One such example is the response to resistance exercise, as several studies have clearly indicated physiological alterations of GSK-3 activity levels post-exercise $(194,283,359)$. Nevertheless, even in absence of conclusive evidence obtained from human muscle biopsies implying impaired GSK-3 $\beta$ regulation and/or signaling as a primary cause of muscle wasting, the pre-clinical research described above may provide sufficient ground to progress into proof of concept clinical trials with GSK-3 $\beta$ inhibitors to reverse muscle atrophy.

Interestingly, pharmacological modulation of GSK-3 $\beta$ has been clinical practice for several decades already, as lithium is an FDA-approved drug for the treatment of psychiatric conditions including bipolar disorder and manic depression (115). Unfortunately, the studies addressing the efficacy of pharmacological GSK-3 inhibitors in these types of disorders and in animal studies do not typically include any parameters related to muscle mass or function. As currently a number of registered clinical trials apply GSK-3 $\beta$ inhibitors in psychiatric disorders, inclusion of muscle mass or muscle strength using simple non-invasive techniques may provide useful information with respect to muscle mass plasticity following systemic pharmacological GSK-3 $\beta$ inhibition.

Thus far, there have been no reports in literature that have associated long term lithium usage to increased incidence of cancer or cancer-related deaths (115). Nevertheless, the treatment time and the dose of pharmacological GSK-3 $\beta$ inhibitors are best kept to a minimum. An important feature of GSK-3 $\beta$ to consider for the purpose of pharmacological inhibition, is that physiological stimuli including insulin, IGF-I or exercise typically reduce GSK-3 activity only to $20-50 \%$ of basal levels in skeletal muscle $(217,336,363)$, indicating that complete inhibition of this molecule may not be needed and desirable. Secondly, the pleiotropic actions of GSK-3 $\beta$, apart from its involvement in muscle plasticity, warrant care with the applied dose of GSK-3 $\beta$ inhibitors considering potential side effects. An important field for further exploration 
concerns the non-ATP-competitive GSK-3 $\beta$ inhibitors because of their superior kinase selectivity and lower $\mathrm{IC}_{50}$ values. Indeed, some preclinical results suggest that prolonged GSK-3 inhibition using TDZDs was not associated with adverse effects $(219,226)$. Substrate-competitive inhibitors also deserve further development and characterization, as these will allow superior specificity towards downstream signaling of GSK-3 $\beta$ related to processes involved in muscle plasticity. Finally, systemically administered inhibitor doses may be further reduced by sensitizing skeletal muscle by means of physical activity or tailored exercise, as the latter enhances local drug delivery due to increased blood flow, and more importantly, in itself already reduces muscle GSK-3 $\beta$ activity levels (194). Therefore, the integration of pharmacological and physical training modalities into a multimodal treatment strategy aimed at inhibition of GSK-3 $\beta$ will allow optimal exploitation of its potential role as a central regulator of skeletal muscle mass plasticity for the treatment of skeletal muscle wasting. 


\section{References}

1. Abbott KL, Friday BB, Thaloor D, Murphy TJ, and Pavlath GK. Activation and cellular localization of the cyclosporine A-sensitive transcription factor NF-AT in skeletal muscle cells. Mol Biol Cell 9: 2905-2916, 1998.

2. Aberle H, Bauer A, Stappert J, Kispert A, and Kemler R. beta-catenin is a target for the ubiquitinproteasome pathway. Embo J 16: 3797-3804, 1997.

3. Adamowicz K, Wang H, Jotwani R, Zeller I, Potempa J, and Scott D. Inhibition of GSK3 abolishes bacterial-induced periodontal bone loss in mice. Mol Med 2012.

4. Adams V, Jiang H, Yu J, Mobius-Winkler S, Fiehn E, Linke A, Weigl C, Schuler G, and Hambrecht R. Apoptosis in skeletal myocytes of patients with chronic heart failure is associated with exercise intolerance. Journal of the American College of Cardiology 33: 959-965, 1999.

5. Alessi DR, Andjelkovic M, Caudwell B, Cron P, Morrice N, Cohen P, and Hemmings BA. Mechanism of activation of protein kinase B by insulin and IGF-1. Embo J 15: 6541-6551, 1996.

6. Alessi DR, and Cohen P. Mechanism of activation and function of protein kinase B. Curr Opin Genet Dev 8: 55-62, 1998.

7. Ali A, Hoeflich KP, and Woodgett JR. Glycogen synthase kinase-3: properties, functions, and regulation. Chem Rev 101: 2527-2540, 2001.

8. Allen DL, Linderman JK, Roy RR, Bigbee AJ, Grindeland RE, Mukku V, and Edgerton VR. Apoptosis: a mechanism contributing to remodeling of skeletal muscle in response to hindlimb unweighting. Am J Physiol 273: C579-587, 1997.

9. Allen DL, Roy RR, and Edgerton VR. Myonuclear domains in muscle adaptation and disease. Muscle Nerve 22: 1350-1360, 1999.

10. Alon LT, Pietrokovski S, Barkan S, Avrahami L, Kaidanovich-Beilin O, Woodgett JR, Barnea A, and EldarFinkelman H. Selective loss of glycogen synthase kinase-3alpha in birds reveals distinct roles for GSK-3 isozymes in tau phosphorylation. FEBS Lett 585: 1158-1162, 2011.

11. Alt JR, Cleveland JL, Hannink M, and Diehl JA. Phosphorylation-dependent regulation of cyclin D1 nuclear export and cyclin D1-dependent cellular transformation. Genes Dev 14: 3102-3114, 2000.

12. Altomonte L, Zoli A, Mirone L, Scolieri $P$, and Magaro M. Serum levels of interleukin-1b, tumour necrosis factor-a and interleukin-2 in rheumatoid arthritis. Correlation with disease activity. Clin Rheumatol 11: 202-205, 1992.

13. Alvarez AR, Godoy JA, Mullendorff K, Olivares GH, Bronfman M, and Inestrosa NC. Wnt-3a overcomes beta-amyloid toxicity in rat hippocampal neurons. Experimental cell research 297: 186-196, 2004.

14. Alway SE, and Siu PM. Nuclear apoptosis contributes to sarcopenia. Exerc Sport Sci Rev 36: 51-57, 2008.

15. Angers S, and Moon RT. Proximal events in Wnt signal transduction. Nat Rev Mol Cell Biol 10: 468477, 2009.

16. Anker SD, Ponikowski P, Varney S, Chua TP, Clark AL, Webb-Peploe KM, Harrington D, Kox WJ, PooleWilson PA, and Coats AJ. Wasting as independent risk factor for mortality in chronic heart failure. Lancet 349: 1050-1053, 1997.

17. Argiles JM, and Lopez-Soriano FJ. The role of cytokines in cancer cachexia. Med Res Rev 19: 223-248, 1999.

18. Armstrong DD, Wong VL, and Esser KA. Expression of beta-catenin is necessary for physiological growth of adult skeletal muscle. Am J Physiol Cell Physiol 291: C185-188, 2006.

19. Armstrong JL, Bonavaud SM, Toole BJ, and Yeaman SJ. Regulation of glycogen synthesis by amino acids in cultured human muscle cells. J Biol Chem 276: 952-956, 2001.

20. Aschenbach WG, Ho RC, Sakamoto K, Fujii N, Li Y, Kim YB, Hirshman MF, and Goodyear LJ. Regulation of dishevelled and beta-catenin in rat skeletal muscle: an alternative exercise-induced GSK-3beta signaling pathway. Am J Physiol Endocrinol Metab 291: E152-158, 2006.

21. Aucello M, Dobrowolny G, and Musaro A. Localized accumulation of oxidative stress causes muscle atrophy through activation of an autophagic pathway. Autophagy 5: 527-529, 2009.

22. Aversa Z, Bonetto A, Penna F, Costelli P, Di Rienzo G, Lacitignola A, Baccino FM, Ziparo V, Mercantini $\mathrm{P}$, Fanelli $\mathrm{FR}$, and Muscaritoli $\mathrm{M}$. Changes in myostatin signaling in non-weight-losing cancer patients. Ann Surg Oncol 19: 1350-1356, 2012. 
23. Aziz A, Sebastian S, and Dilworth FJ. The origin and fate of muscle satellite cells. Stem Cell Rev 8: 609622, 2012.

24. Azoulay-Alfaguter I, Yaffe Y, Licht-Murava A, Urbanska M, Jaworski J, Pietrokovski S, Hirschberg K, and Eldar-Finkelman $\mathrm{H}$. Distinct molecular regulation of glycogen synthase kinase-3alpha isozyme controlled by its $\mathrm{N}$-terminal region: functional role in calcium/calpain signaling. J Biol Chem 286: 13470-13480, 2011.

25. Badalamente MA, and Stracher A. Delay of muscle degeneration and necrosis in mdx mice by calpain inhibition. Muscle Nerve 23: 106-111, 2000.

26. Bain J, Plater L, Elliott M, Shpiro N, Hastie CJ, McLauchlan H, Klevernic I, Arthur JS, Alessi DR, and Cohen P. The selectivity of protein kinase inhibitors: a further update. Biochem J 408: 297-315, 2007.

27. Bartoli M, and Richard I. Calpains in muscle wasting. Int J Biochem Cell Biol 37: 2115-2133, 2005.

28. Bax B, Carter PS, Lewis C, Guy AR, Bridges A, Tanner R, Pettman G, Mannix C, Culbert AA, Brown MJ, Smith DG, and Reith AD. The structure of phosphorylated GSK-3beta complexed with a peptide, FRATtide, that inhibits beta-catenin phosphorylation. Structure 9: 1143-1152, 2001.

29. Beals CR, Sheridan CM, Turck CW, Gardner P, and Crabtree GR. Nuclear export of NF-ATc enhanced by glycogen synthase kinase-3. Science 275: 1930-1934, 1997.

30. Belizario JE, Lorite MJ, and Tisdale MJ. Cleavage of caspases-1, $-3,-6,-8$ and -9 substrates by proteases in skeletal muscles from mice undergoing cancer cachexia. Br J Cancer 84: 1135-1140, 2001.

31. Berkes CA, and Tapscott SJ. MyoD and the transcriptional control of myogenesis. Seminars in cell \& developmental biology 16: 585-595, 2005.

32. Bertsch S, Lang $\mathrm{CH}$, and Vary TC. Inhibition of glycogen synthase kinase 3[beta] activity with lithium in vitro attenuates sepsis-induced changes in muscle protein turnover. Shock 35: 266-274, 2011.

33. Beurel E, and Jope RS. The paradoxical pro- and anti-apoptotic actions of GSK3 in the intrinsic and extrinsic apoptosis signaling pathways. Progress in neurobiology 79: 173-189, 2006.

34. Bhat RV, Leonov S, Luthman J, Scott CW, and Lee CM. Interactions between GSK3beta and caspase signalling pathways during NGF deprivation induced cell death. J Alzheimers Dis 4: 291-301, 2002.

35. Bhat RV, Shanley J, Correll MP, Fieles WE, Keith RA, Scott CW, and Lee CM. Regulation and localization of tyrosine216 phosphorylation of glycogen synthase kinase-3beta in cellular and animal models of neuronal degeneration. Proc Natl Acad Sci U S A 97: 11074-11079, 2000.

36. Bijur GN, and Jope RS. Glycogen synthase kinase-3 beta is highly activated in nuclei and mitochondria. Neuroreport 14: 2415-2419, 2003.

37. Bijur GN, and Jope RS. Proapoptotic stimuli induce nuclear accumulation of glycogen synthase kinase3 beta. J Biol Chem 276: 37436-37442, 2001.

38. Birch NJ. Letter: Lithium and magnesium-dependent enzymes. Lancet 2: 965-966, 1974.

39. Blaauw B, Canato M, Agatea L, Toniolo L, Mammucari C, Masiero E, Abraham R, Sandri M, Schiaffino $S$, and Reggiani C. Inducible activation of Akt increases skeletal muscle mass and force without satellite cell activation. FASEB J 23: 3896-3905, 2009.

40. Bodine SC, Latres E, Baumhueter S, Lai VK, Nunez L, Clarke BA, Poueymirou WT, Panaro FJ, Na E, Dharmarajan K, Pan ZQ, Valenzuela DM, DeChiara TM, Stitt TN, Yancopoulos GD, and Glass DJ. Identification of ubiquitin ligases required for skeletal muscle atrophy. Science 294: 1704-1708, 2001.

41. Bodine SC, Stitt TN, Gonzalez M, Kline WO, Stover GL, Bauerlein R, Zlotchenko E, Scrimgeour A, Lawrence JC, Glass DJ, and Yancopoulos GD. Akt/mTOR pathway is a crucial regulator of skeletal muscle hypertrophy and can prevent muscle atrophy in vivo. Nat Cell Biol 3: 1014-1019, 2001.

42. Brack AS, Conboy IM, Conboy MJ, Shen J, and Rando TA. A temporal switch from notch to Wnt signaling in muscle stem cells is necessary for normal adult myogenesis. Cell Stem Cell 2: 50-59, 2008.

43. Braun $T$, and Gautel M. Transcriptional mechanisms regulating skeletal muscle differentiation, growth and homeostasis. Nat Rev Mol Cell Biol 12: 349-361, 2011.

44. Buch I, Fishelovitch D, London N, Raveh B, Wolfson HJ, and Nussinov R. Allosteric regulation of glycogen synthase kinase 3beta: a theoretical study. Biochemistry 49: 10890-10901, 2010.

45. Burgering BM, and Coffer PJ. Protein kinase B (c-Akt) in phosphatidylinositol-3-OH kinase signal transduction. Nature 376: 599-602, 1995.

46. Cadigan KM, and Nusse R. Wnt signaling: a common theme in animal development. Genes Dev 11: 3286-3305, 1997. 
47. Caron MA, Charette SJ, Maltais F, and Debigare R. Variability of protein level and phosphorylation status caused by biopsy protocol design in human skeletal muscle analyses. BMC Res Notes 4: 488, 2011.

48. Chen PC, Gaisina IN, El-Khodor BF, Ramboz S, Makhortova NR, Rubin LL, and Kozikowski AP. Identification of a Maleimide-Based Glycogen Synthase Kinase-3 (GSK-3) Inhibitor, BIP-135, that Prolongs the Median Survival Time of Delta7 SMA KO Mouse Model of Spinal Muscular Atrophy. ACS Chem Neurosci 3: 5-11, 2012.

49. Cheng H, Woodgett J, Maamari M, and Force T. Targeting GSK-3 family members in the heart: a very sharp double-edged sword. J Mol Cell Cardiol 51: 607-613, 2011.

50. Chin ER, Olson EN, Richardson JA, Yang Q, Humphries C, Shelton JM, Wu H, Zhu W, Bassel-Duby R, and Williams RS. A calcineurin-dependent transcriptional pathway controls skeletal muscle fiber type. Genes Dev 12: 2499-2509, 1998.

51. Cho J, Rameshwar P, and Sadoshima J. Distinct roles of glycogen synthase kinase (GSK)-3alpha and GSK-3beta in mediating cardiomyocyte differentiation in murine bone marrow-derived mesenchymal stem cells. J Biol Chem 284: 36647-36658, 2009.

52. Ciechanover A, Orian A, and Schwartz AL. Ubiquitin-mediated proteolysis: biological regulation via destruction. Bioessays 22: 442-451, 2000.

53. Clarke BA, Drujan D, Willis MS, Murphy LO, Corpina RA, Burova E, Rakhilin SV, Stitt TN, Patterson C, Latres $E$, and Glass DJ. The E3 Ligase MuRF1 degrades myosin heavy chain protein in dexamethasonetreated skeletal muscle. Cell Metab 6: 376-385, 2007.

54. Clement-Lacroix P, Ai M, Morvan F, Roman-Roman S, Vayssiere B, Belleville C, Estrera K, Warman ML, Baron R, and Rawadi G. Lrp5-independent activation of Wnt signaling by lithium chloride increases bone formation and bone mass in mice. Proc Natl Acad Sci U S A 102: 17406-17411, 2005.

55. Clemmons DR. Role of IGF-I in skeletal muscle mass maintenance. Trends Endocrinol Metab 20: 349356, 2009.

56. Cline GW, Johnson K, Regittnig W, Perret P, Tozzo E, Xiao L, Damico C, and Shulman GI. Effects of a novel glycogen synthase kinase-3 inhibitor on insulin-stimulated glucose metabolism in Zucker diabetic fatty (fa/fa) rats. Diabetes 51: 2903-2910, 2002.

57. Coghlan MP, Culbert AA, Cross DA, Corcoran SL, Yates JW, Pearce NJ, Rausch OL, Murphy GJ, Carter PS, Roxbee Cox L, Mills D, Brown MJ, Haigh D, Ward RW, Smith DG, Murray KJ, Reith AD, and Holder JC. Selective small molecule inhibitors of glycogen synthase kinase-3 modulate glycogen metabolism and gene transcription. Chem Biol 7: 793-803, 2000.

58. Cohen P, and Frame S. The renaissance of GSK3. Nature Reviews, Molecular Cell Biology 2: 769-776, 2001.

59. Cohen P, and Goedert M. GSK3 inhibitors: Development and their therapeutic potential. Nature Reviews, Drug Discovery 3: 479-487, 2004.

60. Cohen S, Brault JJ, Gygi SP, Glass DJ, Valenzuela DM, Gartner C, Latres E, and Goldberg AL. During muscle atrophy, thick, but not thin, filament components are degraded by MuRF1-dependent ubiquitylation. J Cell Biol 185: 1083-1095, 2009.

61. Cole A, Frame S, and Cohen P. Further evidence that the tyrosine phosphorylation of glycogen synthase kinase-3 (GSK3) in mammalian cells is an autophosphorylation event. Biochem J 377: 249255, 2004.

62. Conboy IM, Conboy MJ, Smythe GM, and Rando TA. Notch-mediated restoration of regenerative potential to aged muscle. Science 302: 1575-1577, 2003.

63. Conde S, Perez DI, Martinez A, Perez C, and Moreno FJ. Thienyl and phenyl alpha-halomethyl ketones: new inhibitors of glycogen synthase kinase (GSK-3beta) from a library of compound searching. $J$ Med Chem 46: 4631-4633, 2003.

64. Cossu G, and Borello U. Wht signaling and the activation of myogenesis in mammals. EMBO J 18: 6867-6872, 1999.

65. Cross DA, Alessi DR, Cohen P, Andjelkovich M, and Hemmings BA. Inhibition of glycogen synthase kinase-3 by insulin mediated by protein kinase B. Nature 378: 785-789, 1995.

66. Crul T, Testelmans D, Spruit MA, Troosters T, Gosselink R, Geeraerts I, Decramer M, and GayanRamirez G. Gene expression profiling in vastus lateralis muscle during an acute exacerbation of COPD. Cell Physiol Biochem 25: 491-500, 2010. 
67. Dajani R, Fraser E, Roe SM, Young N, Good V, Dale TC, and Pearl LH. Crystal structure of glycogen synthase kinase 3 beta: structural basis for phosphate-primed substrate specificity and autoinhibition. Cell 105: 721-732, 2001.

68. Davidson G, Wu W, Shen J, Bilic J, Fenger U, Stannek P, Glinka A, and Niehrs C. Casein kinase 1 gamma couples Wnt receptor activation to cytoplasmic signal transduction. Nature 438: 867-872, 2005.

69. Davies SP, Reddy H, Caivano M, and Cohen P. Specificity and mechanism of action of some commonly used protein kinase inhibitors. Biochem J 351: 95-105, 2000.

70. De Sarno P, Bijur GN, Zmijewska AA, Li X, and Jope RS. In vivo regulation of GSK3 phosphorylation by cholinergic and NMDA receptors. Neurobiol Aging 27: 413-422, 2006.

71. Debigare $\mathrm{R}$, Cote $\mathrm{CH}$, and Maltais F. Peripheral muscle wasting in chronic obstructive pulmonary disease. Clinical relevance and mechanisms. Am J Respir Crit Care Med 164: 1712-1717, 2001.

72. Del Ser T, Steinwachs KC, Gertz HJ, Andres MV, Gomez-Carrillo B, Medina M, Vericat JA, Redondo P, Fleet D, and Leon T. Treatment of Alzheimer's Disease with the GSK-3 Inhibitor Tideglusib: A Pilot Study. J Alzheimers Dis 2012.

73. Delling U, Tureckova J, Lim HW, De Windt L, Rotwein P, and Molkentin JD. A calcineurin-NFATc3dependent pathway regulates skeletal muscle differentiation and slow myosin heavy-chain expression. Mol Cell Biol 20: 6600-6611, 2000.

74. Descamps S, Arzouk H, Bacou F, Bernardi H, Fedon Y, Gay S, Reyne Y, Rossano B, and Levin J. Inhibition of myoblast differentiation by Sfrp1 and Sfrp2. Cell Tissue Res 332: 299-306, 2008.

75. Diehl JA, Cheng M, Roussel MF, and Sherr CJ. Glycogen synthase kinase-3beta regulates cyclin D1 proteolysis and subcellular localization. Genes Dev 12: 3499-3511, 1998.

76. Ding Q, Xia W, Liu JC, Yang JY, Lee DF, Xia J, Bartholomeusz G, Li Y, Pan Y, Li Z, Bargou RC, Qin J, Lai CC, Tsai FJ, Tsai $\mathrm{CH}$, and Hung MC. Erk associates with and primes GSK-3beta for its inactivation resulting in upregulation of beta-catenin. Mol Cell 19: 159-170, 2005.

77. Ding VW, Chen RH, and McCormick F. Differential regulation of glycogen synthase kinase 3beta by insulin and Wnt signaling. J Biol Chem 275: 32475-32481, 2000.

78. Ding WX, Ni HM, Gao W, Yoshimori T, Stolz DB, Ron D, and Yin XM. Linking of autophagy to ubiquitinproteasome system is important for the regulation of endoplasmic reticulum stress and cell viability. Am J Pathol 171: 513-524, 2007.

79. Dirks-Naylor AJ, and Lennon-Edwards S. Cellular and molecular mechanisms of apoptosis in agerelated muscle atrophy. Curr Aging Sci 4: 269-278, 2011.

80. Dirks A, and Leeuwenburgh C. Apoptosis in skeletal muscle with aging. Am J Physiol Regul Integr Comp Physiol 282: R519-527, 2002.

81. Doble BW, Patel S, Wood GA, Kockeritz LK, and Woodgett JR. Functional redundancy of GSK-3alpha and GSK-3beta in Wnt/beta-catenin signaling shown by using an allelic series of embryonic stem cell lines. Dev Cell 12: 957-971, 2007.

82. Doble BW, and Woodgett JR. GSK-3: tricks of the trade for a multi-tasking kinase. J Cell Sci 116: 11751186, 2003.

83. Dokken BB, Saengsirisuwan V, Kim JS, Teachey MK, and Henriksen EJ. Oxidative stress-induced insulin resistance in rat skeletal muscle: role of glycogen synthase kinase-3. Am J Physiol Endocrinol Metab 294: E615-621, 2008.

84. Dominguez JM, Fuertes A, Orozco L, del Monte-Millan M, Delgado E, and Medina M. Evidence for irreversible inhibition of glycogen synthase kinase-3beta by tideglusib. J Biol Chem 287: 893-904, 2012.

85. Donkor IO. A survey of calpain inhibitors. Curr Med Chem 7: 1171-1188, 2000.

86. Doucet M, Russell AP, Leger B, Debigare R, Joanisse DR, Caron MA, LeBlanc $P$, and Maltais F. Muscle atrophy and hypertrophy signaling in patients with chronic obstructive pulmonary disease. Am J Respir Crit Care Med 176: 261-269, 2007.

87. Du J, Wang X, Miereles C, Bailey JL, Debigare R, Zheng B, Price SR, and Mitch WE. Activation of caspase-3 is an initial step triggering accelerated muscle proteolysis in catabolic conditions. $J$ Clin Invest 113: 115-123, 2004.

88. Dugo L, Collin M, and Thiemermann C. Glycogen synthase kinase 3beta as a target for the therapy of shock and inflammation. Shock 27: 113-123, 2007.

89. Dupont-Versteegden EE. Apoptosis in skeletal muscle and its relevance to atrophy. World journal of gastroenterology : WJG 12: 7463-7466, 2006. 
90. Earnshaw WC, Martins LM, and Kaufmann SH. Mammalian caspases: structure, activation, substrates, and functions during apoptosis. Annual review of biochemistry 68: 383-424, 1999.

91. Ebert SM, Dyle MC, Kunkel SD, Bullard SA, Bongers KS, Fox DK, Dierdorff JM, Foster ED, and Adams CM. Stress-induced Skeletal Muscle Gadd45a Expression Reprograms Myonuclei and Causes Muscle Atrophy. J Biol Chem 287: 27290-27301, 2012.

92. Ebert SM, Monteys AM, Fox DK, Bongers KS, Shields BE, Malmberg SE, Davidson BL, Suneja M, and Adams CM. The transcription factor ATF4 promotes skeletal myofiber atrophy during fasting. $\mathrm{Mol}$ Endocrinol 24: 790-799, 2010.

93. Eglen RM, and Reisine T. The current status of drug discovery against the human kinome. Assay Drug Dev Technol 7: 22-43, 2009.

94. Eldar-Finkelman $\mathrm{H}$, and Eisenstein M. Peptide inhibitors targeting protein kinases. Curr Pharm Des 15: 2463-2470, 2009.

95. Eldar-Finkelman $\mathrm{H}$, and Krebs EG. Phosphorylation of insulin receptor substrate 1 by glycogen synthase kinase 3 impairs insulin action. Proc Natl Acad Sci U S A 94: 9660-9664, 1997.

96. Eldar-Finkelman H, Licht-Murava A, Pietrokovski S, and Eisenstein M. Substrate competitive GSK-3 inhibitors - strategy and implications. Biochim Biophys Acta 1804: 598-603, 2010.

97. Eldar-Finkelman H, and Martinez A. GSK-3 Inhibitors: Preclinical and Clinical Focus on CNS. Front Mol Neurosci 4: 32, 2011.

98. Embi N, Rylatt DB, and Cohen P. Glycogen synthase kinase-3 from rabbit skeletal muscle. Separation from cyclic-AMP-dependent protein kinase and phosphorylase kinase. Eur J Biochem 107: 519-527, 1980.

99. Embi N, Rylatt DB, and Cohen P. Glycogen synthase kinase-3 from rabbit skeletal muscle. Separation from cyclic-AMP-dependent protein kinase and phosphorylase kinase. Eur J Biochem 107: 519-527, 1980.

100. Espinosa L, Ingles-Esteve J, Aguilera C, and Bigas A. Phosphorylation by glycogen synthase kinase-3 beta down-regulates Notch activity, a link for Notch and Wnt pathways. J Biol Chem 278: 3222732235, 2003.

101. Evenson AR, Fareed MU, Menconi MJ, Mitchell JC, and Hasselgren PO. GSK-3beta inhibitors reduce protein degradation in muscles from septic rats and in dexamethasone-treated myotubes. Int $J$ Biochem Cell Biol 37: 2226-2238, 2005.

102. Fang CH, Li B, James JH, Yahya A, Kadeer N, Guo X, Xiao C, Supp DM, Kagan RJ, Hasselgren PO, and Sheriff S. GSK-3beta activity is increased in skeletal muscle after burn injury in rats. Am J Physiol Regul Integr Comp Physiol 293: R1545-1551, 2007.

103. Fang $\mathrm{CH}$, Li BG, James JH, King JK, Evenson AR, Warden GD, and Hasselgren PO. Protein breakdown in muscle from burned rats is blocked by insulin-like growth factor $\mathrm{i}$ and glycogen synthase kinase-3beta inhibitors. Endocrinology 146: 3141-3149, 2005.

104. Fanzani A, Conraads VM, Penna F, and Martinet W. Molecular and cellular mechanisms of skeletal muscle atrophy: an update. J Cachexia Sarcopenia Muscle 2012.

105. Fareed MU, Evenson AR, Wei W, Menconi M, Poylin V, Petkova V, Pignol B, and Hasselgren PO. Treatment of rats with calpain inhibitors prevents sepsis-induced muscle proteolysis independent of atrogin-1/MAFbx and MuRF1 expression. Am J Physiol Regul Integr Comp Physiol 290: R1589-1597, 2006.

106. Fearon K, Strasser F, Anker SD, Bosaeus I, Bruera E, Fainsinger RL, Jatoi A, Loprinzi C, MacDonald N, Mantovani G, Davis M, Muscaritoli M, Ottery F, Radbruch L, Ravasco P, Walsh D, Wilcock A, Kaasa S, and Baracos VE. Definition and classification of cancer cachexia: an international consensus. Lancet Oncol 12: 489-495, 2011.

107. Fielitz J, Kim MS, Shelton JM, Latif S, Spencer JA, Glass DJ, Richardson JA, Bassel-Duby R, and Olson EN. Myosin accumulation and striated muscle myopathy result from the loss of muscle RING finger 1 and 3. J Clin Invest 117: 2486-2495, 2007.

108. Fiol CJ, Mahrenholz AM, Wang Y, Roeske RW, and Roach PJ. Formation of protein kinase recognition sites by covalent modification of the substrate. Molecular mechanism for the synergistic action of casein kinase II and glycogen synthase kinase 3. J Biol Chem 262: 14042-14048, 1987.

109. Florini JR, Ewton DZ, Falen SL, and Van Wyk JJ. Biphasic concentration dependency of stimulation of myoblast differentiation by somatomedins. Am J Physiol 250: C771-778, 1986. 
110. Force $\mathrm{T}$, and Woodgett JR. Unique and overlapping functions of GSK-3 isoforms in cell differentiation and proliferation and cardiovascular development. J Biol Chem 284: 9643-9647, 2009.

111. Frame S, and Cohen P. GSK3 takes centre stage more than 20 years after its discovery. Biochem J 359 : 1-16, 2001.

112. Frame $\mathrm{S}$, Cohen $\mathrm{P}$, and Biondi RM. A common phosphate binding site explains the unique substrate specificity of GSK3 and its inactivation by phosphorylation. Mol Cell 7: 1321-1327, 2001.

113. Franca-Koh J, Yeo M, Fraser E, Young N, and Dale TC. The regulation of glycogen synthase kinase-3 nuclear export by Frat/GBP. J Biol Chem 277: 43844-43848, 2002.

114. Fraser E, Young N, Dajani R, Franca-Koh J, Ryves J, Williams RS, Yeo M, Webster MT, Richardson C, Smalley MJ, Pearl LH, Harwood A, and Dale TC. Identification of the Axin and Frat binding region of glycogen synthase kinase-3. J Biol Chem 277: 2176-2185, 2002.

115. Freland L, and Beaulieu JM. Inhibition of GSK3 by lithium, from single molecules to signaling networks. Front Mol Neurosci 5: 14, 2012.

116. Fujimuro M, Wu FY, ApRhys C, Kajumbula H, Young DB, Hayward GS, and Hayward SD. A novel viral mechanism for dysregulation of beta-catenin in Kaposi's sarcoma-associated herpesvirus latency. Nat Med 9: 300-306, 2003.

117. Furuno K, Goodman MN, and Goldberg AL. Role of different proteolytic systems in the degradation of muscle proteins during denervation atrophy. J Biol Chem 265: 8550-8557, 1990.

118. Galli LM, Willert K, Nusse R, Yablonka-Reuveni Z, Nohno T, Denetclaw W, and Burrus LW. A proliferative role for Wnt-3a in chick somites. Dev Biol 269: 489-504, 2004.

119. Galliher-Beckley AJ, Williams JG, Collins JB, and Cidlowski JA. Glycogen synthase kinase 3betamediated serine phosphorylation of the human glucocorticoid receptor redirects gene expression profiles. Mol Cell Biol 28: 7309-7322, 2008.

120. Gao Y, Ordas R, Klein JD, and Price SR. Regulation of caspase-3 activity by insulin in skeletal muscle cells involves both PI3-kinase and MEK-1/2. Journal of applied physiology 105: 1772-1778, 2008.

121. Geetha-Loganathan $P$, Nimmagadda $S$, and Scaal $M$. Wnt signaling in limb organogenesis. Organogenesis 4: 109-115, 2008.

122. Gillespie JR, Ulici V, Dupuis H, Higgs A, Dimattia A, Patel S, Woodgett JR, and Beier F. Deletion of glycogen synthase kinase-3beta in cartilage results in up-regulation of glycogen synthase kinase3alpha protein expression. Endocrinology 152: 1755-1766, 2011.

123. Glass DJ. Skeletal muscle hypertrophy and atrophy signaling pathways. Int J Biochem Cell Biol 37: 1974-1984, 2005.

124. Goll DE, Thompson VF, Li H, Wei W, and Cong J. The calpain system. Physiol Rev 83: 731-801, 2003.

125. Gomes MD, Lecker SH, Jagoe RT, Navon A, and Goldberg AL. Atrogin-1, a muscle-specific F-box protein highly expressed during muscle atrophy. Proc Natl Acad Sci U S A 98: 14440-14445, 2001.

126. Goni-Oliver P, Avila J, and Hernandez F. Calpain-mediated truncation of GSK-3 in post-mortem brain samples. J Neurosci Res 87: 1156-1161, 2009.

127. Goni-Oliver P, Lucas JJ, Avila J, and Hernandez F. N-terminal cleavage of GSK-3 by calpain: a new form of GSK-3 regulation. J Biol Chem 282: 22406-22413, 2007.

128. Goodman CA, Mayhew DL, and Hornberger TA. Recent progress toward understanding the molecular mechanisms that regulate skeletal muscle mass. Cell Signal 23: 1896-1906, 2011.

129. Gregory MA, Qi Y, and Hann SR. Phosphorylation by glycogen synthase kinase-3 controls c-myc proteolysis and subnuclear localization. J Biol Chem 278: 51606-51612, 2003.

130. Grimes CA, and Jope RS. The multifaceted roles of glycogen synthase kinase 3 beta in cellular signaling. Prog Neurobiol 65: 391-426, 2001.

131. Guha S, Cullen JP, Morrow D, Colombo A, Lally C, Walls D, Redmond EM, and Cahill PA. Glycogen synthase kinase 3 beta positively regulates Notch signaling in vascular smooth muscle cells: role in cell proliferation and survival. Basic Res Cardiol 106: 773-785, 2011.

132. Gundersen K, and Bruusgaard JC. Nuclear domains during muscle atrophy: nuclei lost or paradigm lost? The Journal of physiology 586: 2675-2681, 2008.

133. Haddad F, Roy RR, Zhong H, Edgerton VR, and Baldwin KM. Atrophy responses to muscle inactivity. II. Molecular markers of protein deficits. J Appl Physiol 95: 791-802, 2003.

134. Hanks SK, and Hunter T. Protein kinases 6. The eukaryotic protein kinase superfamily: kinase (catalytic) domain structure and classification. Faseb J 9: 576-596, 1995. 
135. Hanks SK, and Quinn AM. Protein kinase catalytic domain sequence database: identification of conserved features of primary structure and classification of family members. Methods Enzymol 200: 38-62, 1991.

136. Hanks SK, Quinn AM, and Hunter T. The protein kinase family: conserved features and deduced phylogeny of the catalytic domains. Science 241: 42-52, 1988.

137. Haq S, Choukroun G, Kang ZB, Ranu H, Matsui T, Rosenzweig A, Molkentin JD, Alessandrini A, Woodgett J, Hajjar R, Michael A, and Force T. Glycogen synthase kinase-3beta is a negative regulator of cardiomyocyte hypertrophy. J Cell Biol 151: 117-130, 2000.

138. Hardt SE, and Sadoshima J. Glycogen synthase kinase-3 beta: A novel regulator of cardiac hypertrophy and development. Circ Res 90: 1055-1063, 2002.

139. Harwood AJ. Regulation of GSK-3: a cellular multiprocessor. Cell 105: 821-824, 2001.

140. Hasselgren PO. Glucocorticoids and muscle catabolism. Curr Opin Clin Nutr Metab Care 2: 201-205, 1999.

141. He X, Saint-Jeannet JP, Woodgett JR, Varmus HE, and Dawid IB. Glycogen synthase kinase-3 and dorsoventral patterning in Xenopus embryos. Nature 374: 617-622, 1995.

142. Hengartner MO. The biochemistry of apoptosis. Nature 407: 770-776, 2000.

143. Henriksen EJ. Dysregulation of glycogen synthase kinase-3 in skeletal muscle and the etiology of insulin resistance and type 2 diabetes. Curr Diabetes Rev 6: 285-293, 2010.

144. Hildesheim J, Belova GI, Tyner SD, Zhou X, Vardanian L, and Fornace AJ, Jr. Gadd45a regulates matrix metalloproteinases by suppressing DeltaNp63alpha and beta-catenin via p38 MAP kinase and APC complex activation. Oncogene 23: 1829-1837, 2004.

145. Hinoi T, Yamamoto H, Kishida M, Takada S, Kishida S, and Kikuchi A. Complex formation of adenomatous polyposis coli gene product and axin facilitates glycogen synthase kinase-3 betadependent phosphorylation of beta-catenin and down-regulates beta-catenin. J Biol Chem 275: 34399-34406, 2000.

146. Hoeflich KP, Luo J, Rubie EA, Tsao MS, Jin O, and Woodgett JR. Requirement for glycogen synthase kinase-3beta in cell survival and NF-kappaB activation. Nature 406: 86-90, 2000.

147. Hollway G, and Currie P. Vertebrate myotome development. Birth Defects Res C Embryo Today 75: 172-179, 2005.

148. Hong $\mathrm{DH}$, and Forsberg NE. Effects of dexamethasone on protein degradation and protease gene expression in rat L8 myotube cultures. Mol Cell Endocrinol 108: 199-209, 1995.

149. Hongisto V, Smeds N, Brecht S, Herdegen T, Courtney MJ, and Coffey ET. Lithium blocks the c-Jun stress response and protects neurons via its action on glycogen synthase kinase 3. Molecular and cellular biology 23: 6027-6036, 2003.

150. Hu S, Begum AN, Jones MR, Oh MS, Beech WK, Beech BH, Yang F, Chen P, Ubeda OJ, Kim PC, Davies P, Ma Q, Cole GM, and Frautschy SA. GSK3 inhibitors show benefits in an Alzheimer's disease (AD) model of neurodegeneration but adverse effects in control animals. Neurobiol Dis 33: 193-206, 2009.

151. Hu Z, Wang H, Lee IH, Du J, and Mitch WE. Endogenous glucocorticoids and impaired insulin signaling are both required to stimulate muscle wasting under pathophysiological conditions in mice. $J$ Clin Invest 119: 3059-3069, 2009.

152. Huang J, and Forsberg NE. Role of calpain in skeletal-muscle protein degradation. Proc Natl Acad Sci U S A 95: 12100-12105, 1998.

153. Huelsken J, and Behrens J. The Wnt signalling pathway. J Cell Sci 115: 3977-3978, 2002.

154. Hughes K, Nikolakaki E, Plyte SE, Totty NF, and Woodgett JR. Modulation of the glycogen synthase kinase-3 family by tyrosine phosphorylation. EMBO J 12: 803-808, 1993.

155. Hurel SJ, Rochford JJ, Borthwick AC, Wells AM, Vandenheede JR, Turnbull DM, and Yeaman SJ. Insulin action in cultured human myoblasts: contribution of different signalling pathways to regulation of glycogen synthesis. Biochem J 320 ( Pt 3): 871-877, 1996.

156. Ilouz R, Kaidanovich O, Gurwitz D, and Eldar-Finkelman H. Inhibition of glycogen synthase kinase3beta by bivalent zinc ions: insight into the insulin-mimetic action of zinc. Biochem Biophys Res Commun 295: 102-106, 2002.

157. Ilouz R, Pietrokovski S, Eisenstein $M$, and Eldar-Finkelman $H$. New insights into the autoinhibition mechanism of glycogen synthase kinase-3beta. J Mol Biol 383: 999-1007, 2008.

158. Inoki K, Ouyang $\mathrm{H}$, Zhu T, Lindvall C, Wang $\mathrm{Y}$, Zhang X, Yang Q, Bennett C, Harada Y, Stankunas K, Wang CY, He X, MacDougald OA, You M, Williams BO, and Guan KL. TSC2 integrates Wnt and energy 
signals via a coordinated phosphorylation by AMPK and GSK3 to regulate cell growth. Cell 126: 955968, 2006.

159. Ishido M, Uda M, Masuhara M, and Kami K. Alterations of M-cadherin, neural cell adhesion molecule and beta-catenin expression in satellite cells during overload-induced skeletal muscle hypertrophy. Acta Physiol (Oxf) 187: 407-418, 2006.

160. Itoh S, Saito T, Hirata M, Ushita M, Ikeda T, Woodgett JR, Algul H, Schmid RM, Chung UI, and Kawaguchi H. GSK-3alpha and GSK-3beta are involved in early stages of chondrocyte differentiation with functional redundancy through RelA phosphorylation. J Biol Chem 2012.

161. Ivaska J, Nissinen L, Immonen N, Eriksson JE, Kahari VM, and Heino J. Integrin alpha 2 beta 1 promotes activation of protein phosphatase $2 \mathrm{~A}$ and dephosphorylation of Akt and glycogen synthase kinase 3 beta. Mol Cell Biol 22: 1352-1359, 2002.

162. Jacinto E, Facchinetti V, Liu D, Soto N, Wei S, Jung SY, Huang Q, Qin J, and Su B. SIN1/MIP1 maintains rictor-mTOR complex integrity and regulates Akt phosphorylation and substrate specificity. Cell 127: 125-137, 2006.

163. Jackman RW, and Kandarian SC. The molecular basis of skeletal muscle atrophy. Am J Physiol Cell Physiol 287: C834-843, 2004.

164. Jagoe RT, Lecker SH, Gomes M, and Goldberg AL. Patterns of gene expression in atrophying skeletal muscles: response to food deprivation. FASEB J 16: 1697-1712, 2002.

165. Jefferson LS, Fabian JR, and Kimball SR. Glycogen synthase kinase-3 is the predominant insulinregulated eukaryotic initiation factor 2B kinase in skeletal muscle. Int J Biochem Cell Biol 31: 191-200, 1999.

166. Jope RS. Lithium and GSK-3: one inhibitor, two inhibitory actions, multiple outcomes. Trends Pharmacol Sci 24: 441-443, 2003.

167. Jope RS, and Johnson GV. The glamour and gloom of glycogen synthase kinase-3. Trends Biochem Sci 29: 95-102, 2004.

168. Kaidanovich-Beilin O, and Woodgett JR. GSK-3: Functional Insights from Cell Biology and Animal Models. Front Mol Neurosci 4: 40, 2011.

169. Kandarian SC, and Jackman RW. Intracellular signaling during skeletal muscle atrophy. Muscle Nerve 33: 155-165, 2006.

170. Kandasamy $A D$, and Schulz R. Glycogen synthase kinase-3beta is activated by matrix metalloproteinase-2 mediated proteolysis in cardiomyoblasts. Cardiovasc Res 83: 698-706, 2009.

171. Kelly GM, Buckley DA, Kiely PA, Adams DR, and O'Connor R. Serine Phosphorylation of the Insulin-like Growth Factor I (IGF-1) Receptor C-terminal Tail Restrains Kinase Activity and Cell Growth. J Biol Chem 287: 28180-28194, 2012.

172. Kerkela R, Kockeritz L, Macaulay K, Zhou J, Doble BW, Beahm C, Greytak S, Woulfe K, Trivedi CM, Woodgett JR, Epstein JA, Force T, and Huggins GS. Deletion of GSK-3beta in mice leads to hypertrophic cardiomyopathy secondary to cardiomyoblast hyperproliferation. J Clin Invest 118: 3609-3618, 2008.

173. Kimball SR, and Jefferson LS. Control of translation initiation through integration of signals generated by hormones, nutrients, and exercise. J Biol Chem 285: 29027-29032, 2010.

174. King TD, Bijur GN, and Jope RS. Caspase-3 activation induced by inhibition of mitochondrial complex I is facilitated by glycogen synthase kinase-3beta and attenuated by lithium. Brain Res 919: 106-114, 2001.

175. King TD, and Jope RS. Inhibition of glycogen synthase kinase-3 protects cells from intrinsic but not extrinsic oxidative stress. Neuroreport 16: 597-601, 2005.

176. Kirshenboim N, Plotkin B, Shlomo SB, Kaidanovich-Beilin O, and Eldar-Finkelman H. Lithium-mediated phosphorylation of glycogen synthase kinase-3beta involves PI3 kinase-dependent activation of protein kinase C-alpha. J Mol Neurosci 24: 237-245, 2004.

177. Kishida M, Koyama S, Kishida S, Matsubara K, Nakashima S, Higano K, Takada R, Takada S, and Kikuchi A. Axin prevents Wnt-3a-induced accumulation of beta-catenin. Oncogene 18: 979-985, 1999.

178. Klein PS, and Melton DA. A molecular mechanism for the effect of lithium on development. Proc Natl Acad Sci U S A 93: 8455-8459, 1996.

179. Klionsky DJ. Autophagy: from phenomenology to molecular understanding in less than a decade. Nat Rev Mol Cell Biol 8: 931-937, 2007. 
180. Knight JD, and Kothary R. The myogenic kinome: protein kinases critical to mammalian skeletal myogenesis. Skeletal muscle 1: 29, 2011.

181. Koh SH, Baek W, and Kim SH. Brief review of the role of glycogen synthase kinase-3beta in amyotrophic lateral sclerosis. Neurol Res Int 2011: 205761, 2011.

182. Koh SH, Kim Y, Kim HY, Hwang S, Lee CH, and Kim SH. Inhibition of glycogen synthase kinase-3 suppresses the onset of symptoms and disease progression of G93A-SOD1 mouse model of ALS. Exp Neurol 205: 336-346, 2007.

183. Korolchuk VI, Menzies FM, and Rubinsztein DC. Mechanisms of cross-talk between the ubiquitinproteasome and autophagy-lysosome systems. FEBS Lett 584: 1393-1398, 2010.

184. Kramerova I, Kudryashova E, Wu B, and Spencer MJ. Regulation of the M-cadherin-beta-catenin complex by calpain 3 during terminal stages of myogenic differentiation. Mol Cell Biol 26: 8437-8447, 2006.

185. Kuemmerle JF. Endogenous IGF-I protects human intestinal smooth muscle cells from apoptosis by regulation of GSK-3 beta activity. American journal of physiology Gastrointestinal and liver physiology 288: G101-110, 2005.

186. Kumari R, Willing LB, Jefferson LS, Simpson IA, and Kimball SR. REDD1 (regulated in development and DNA damage response 1) expression in skeletal muscle as a surrogate biomarker of the efficiency of glucocorticoid receptor blockade. Biochem Biophys Res Commun 412: 644-647, 2011.

187. Lagirand-Cantaloube J, Cornille K, Csibi A, Batonnet-Pichon S, Leibovitch MP, and Leibovitch SA. Inhibition of atrogin-1/MAFbx mediated MyoD proteolysis prevents skeletal muscle atrophy in vivo. PLoS One 4: e4973, 2009.

188. Lai KM, Gonzalez M, Poueymirou WT, Kline WO, Na E, Zlotchenko E, Stitt TN, Economides AN, Yancopoulos GD, and Glass DJ. Conditional activation of akt in adult skeletal muscle induces rapid hypertrophy. Mol Cell Biol 24: 9295-9304, 2004.

189. Lang $\mathrm{CH}$, and Frost RA. Endotoxin disrupts the leucine-signaling pathway involving phosphorylation of mTOR, 4E-BP1, and S6K1 in skeletal muscle. J Cell Physiol 203: 144-155, 2005.

190. Latres E, Amini AR, Amini AA, Griffiths J, Martin FJ, Wei Y, Lin HC, Yancopoulos GD, and Glass DJ. Insulin-like growth factor-1 (IGF-1) inversely regulates atrophy-induced genes via the phosphatidylinositol 3-kinase/Akt/mammalian target of rapamycin (PI3K/Akt/mTOR) pathway. J Biol Chem 280: 2737-2744, 2005.

191. Lecker SH, Goldberg AL, and Mitch WE. Protein degradation by the ubiquitin-proteasome pathway in normal and disease states. J Am Soc Nephrol 17: 1807-1819, 2006.

192. Lecker SH, Solomon V, Mitch WE, and Goldberg AL. Muscle protein breakdown and the critical role of the ubiquitin-proteasome pathway in normal and disease states. J Nutr 129: 227S-237S, 1999.

193. Lee SC, Shin D, Cho JM, Ro S, and Suh YG. Structure-activity relationship of the 7-hydroxy benzimidazole analogs as glycogen synthase kinase 3beta inhibitor. Bioorg Med Chem Lett 22: 18911894, 2012.

194. Leger B, Cartoni R, Praz M, Lamon S, Deriaz O, Crettenand A, Gobelet C, Rohmer P, Konzelmann M, Luthi $F$, and Russell AP. Akt signalling through GSK-3beta, mTOR and Foxo1 is involved in human skeletal muscle hypertrophy and atrophy. J Physiol 576: 923-933, 2006.

195. Leger B, Senese R, Al-Khodairy AW, Deriaz O, Gobelet C, Giacobino JP, and Russell AP. Atrogin-1, MuRF1, and FoXO, as well as phosphorylated GSK-3beta and 4E-BP1 are reduced in skeletal muscle of chronic spinal cord-injured patients. Muscle Nerve 40: 69-78, 2009.

196. Levine B, and Kroemer G. Autophagy in the pathogenesis of disease. Cell 132: 27-42, 2008.

197. Lewis MI. Apoptosis as a potential mechanism of muscle cachexia in chronic obstructive pulmonary disease. American journal of respiratory and critical care medicine 166: 434-436, 2002.

198. Li BG, Hasselgren PO, and Fang CH. Insulin-like growth factor-I inhibits dexamethasone-induced proteolysis in cultured $\mathrm{L} 6$ myotubes through PI3K/Akt/GSK-3beta and PI3K/Akt/mTOR-dependent mechanisms. Int J Biochem Cell Biol 37: 2207-2216, 2005.

199. Li BG, Hasselgren PO, Fang CH, and Warden GD. Insulin-like growth factor-I blocks dexamethasoneinduced protein degradation in cultured myotubes by inhibiting multiple proteolytic pathways: 2002 ABA paper. J Burn Care Rehabil 25: 112-118, 2004.

200. Li L, Yuan H, Weaver CD, Mao J, Farr GH, 3rd, Sussman DJ, Jonkers J, Kimelman D, and Wu D. Axin and Frat1 interact with dvl and GSK, bridging Dvl to GSK in Wnt-mediated regulation of LEF-1. EMBO J 18: 4233-4240, 1999. 
201. Li Y, Gazdoiu S, Pan ZQ, and Fuchs SY. Stability of homologue of Slimb F-box protein is regulated by availability of its substrate. J Biol Chem 279: 11074-11080, 2004.

202. Li YH, Fan J, and Lang $\mathrm{CH}$. Differential role of glucocorticoids in mediating endotoxin-induced changes in IGF-I and IGFBP-1. Am J Physiol 272: R1990-1997, 1997.

203. Liang $\mathrm{MH}$, and Chuang DM. Differential roles of glycogen synthase kinase- 3 isoforms in the regulation of transcriptional activation. J Biol Chem 281: 30479-30484, 2006.

204. Liao X, Zhang L, Thrasher JB, Du J, and Li B. Glycogen synthase kinase-3beta suppression eliminates tumor necrosis factor-related apoptosis-inducing ligand resistance in prostate cancer. Molecular cancer therapeutics 2: 1215-1222, 2003.

205. Liberman Z, Plotkin B, Tennenbaum T, and Eldar-Finkelman H. Coordinated phosphorylation of insulin receptor substrate- 1 by glycogen synthase kinase- 3 and protein kinase $C$ betall in the diabetic fat tissue. Am J Physiol Endocrinol Metab 294: E1169-1177, 2008.

206. Lin SY, Li TY, Liu Q, Zhang C, Li X, Chen Y, Zhang SM, Lian G, Liu Q, Ruan K, Wang Z, Zhang CS, Chien KY, Wu J, Li Q, Han J, and Lin SC. GSK3-TIP60-ULK1 signaling pathway links growth factor deprivation to autophagy. Science 336: 477-481, 2012.

207. Linding R, Jensen $L$, Ostheimer GJ, van Vugt MA, Jorgensen C, Miron IM, Diella F, Colwill K, Taylor L, Elder K, Metalnikov P, Nguyen V, Pasculescu A, Jin J, Park JG, Samson LD, Woodgett JR, Russell RB, Bork P, Yaffe MB, and Pawson T. Systematic discovery of in vivo phosphorylation networks. Cell 129: 1415-1426, 2007.

208. Linseman DA, Butts BD, Precht TA, Phelps RA, Le SS, Laessig TA, Bouchard RJ, Florez-McClure ML, and Heidenreich KA. Glycogen synthase kinase-3beta phosphorylates Bax and promotes its mitochondrial localization during neuronal apoptosis. The Journal of neuroscience : the official journal of the Society for Neuroscience 24: 9993-10002, 2004.

209. Liu C, Li Y, Semenov M, Han C, Baeg GH, Tan Y, Zhang Z, Lin X, and He X. Control of beta-catenin phosphorylation/degradation by a dual-kinase mechanism. Cell 108: 837-847, 2002.

210. Liu X, Rubin JS, and Kimmel AR. Rapid, Wnt-induced changes in GSK3beta associations that regulate beta-catenin stabilization are mediated by Galpha proteins. Curr Biol 15: 1989-1997, 2005.

211. Liu ZQ, Kunimatsu M, Yang JP, Ozaki Y, Sasaki M, and Okamoto T. Proteolytic processing of nuclear factor kappa B by calpain in vitro. FEBS Lett 385: 109-113, 1996.

212. Lochhead PA, Kinstrie R, Sibbet G, Rawjee T, Morrice N, and Cleghon V. A chaperone-dependent GSK3beta transitional intermediate mediates activation-loop autophosphorylation. Mol Cell 24: 627633, 2006.

213. Logan $\mathrm{CY}$, and Nusse R. The Wnt signaling pathway in development and disease. Annual review of cell and developmental biology 20: 781-810, 2004.

214. Lu Y, Muller M, Smith D, Dutta B, Komurov K, ladevaia S, Ruths D, Tseng JT, Yu S, Yu Q, Nakhleh L, Balazsi G, Donnelly J, Schurdak M, Morgan-Lappe S, Fesik S, Ram PT, and Mills GB. Kinome siRNAphosphoproteomic screen identifies networks regulating AKT signaling. Oncogene 30: 4567-4577, 2011.

215. MacAulay K, Doble BW, Patel S, Hansotia T, Sinclair EM, Drucker DJ, Nagy A, and Woodgett JR. Glycogen synthase kinase 3alpha-specific regulation of murine hepatic glycogen metabolism. Cell Metab 6: 329-337, 2007.

216. Mammucari C, Milan G, Romanello V, Masiero E, Rudolf R, Del Piccolo P, Burden SJ, Di Lisi R, Sandri C, Zhao J, Goldberg AL, Schiaffino S, and Sandri M. FoxO3 controls autophagy in skeletal muscle in vivo. Cell Metab 6: 458-471, 2007.

217. Markuns JF, Wojtaszewski JF, and Goodyear L. Insulin and exercise decrease glycogen synthase kinase-3 activity by different mechanisms in rat skeletal muscle. J Biol Chem 274: 24896-24900, 1999.

218. Marsell R, Sisask G, Nilsson Y, Sundgren-Andersson AK, Andersson U, Larsson S, Nilsson O, Ljunggren $\mathrm{O}$, and Jonsson KB. GSK-3 inhibition by an orally active small molecule increases bone mass in rats. Bone 50: 619-627, 2012.

219. Martinez A. Preclinical efficacy on GSK-3 inhibitors: towards a future generation of powerful drugs. Med Res Rev 28: 773-796, 2008.

220. Martinez A, Alonso M, Castro A, Perez C, and Moreno FJ. First non-ATP competitive glycogen synthase kinase 3 beta (GSK-3beta) inhibitors: thiadiazolidinones (TDZD) as potential drugs for the treatment of Alzheimer's disease. J Med Chem 45: 1292-1299, 2002. 
221. Masiero E, Agatea L, Mammucari C, Blaauw B, Loro E, Komatsu M, Metzger D, Reggiani C, Schiaffino S, and Sandri M. Autophagy is required to maintain muscle mass. Cell Metab 10: 507-515, 2009.

222. Maurer U, Charvet C, Wagman AS, Dejardin E, and Green DR. Glycogen synthase kinase-3 regulates mitochondrial outer membrane permeabilization and apoptosis by destabilization of MCL-1. Molecular cell 21: 749-760, 2006.

223. Mauro A. Satellite cell of skeletal muscle fibers. J Biophys Biochem Cytol 9: 493-495, 1961.

224. Mazanetz MP, and Fischer PM. Untangling tau hyperphosphorylation in drug design for neurodegenerative diseases. Nat Rev Drug Discov 6: 464-479, 2007.

225. McManus EJ, Sakamoto K, Armit LJ, Ronaldson L, Shpiro N, Marquez R, and Alessi DR. Role that phosphorylation of GSK3 plays in insulin and Wnt signalling defined by knockin analysis. Embo J 24: 1571-1583, 2005.

226. Medina M, and Castro A. Glycogen synthase kinase-3 (GSK-3) inhibitors reach the clinic. Curr Opin Drug Discov Devel 11: 533-543, 2008.

227. Menconi M, Fareed M, O'Neal P, Poylin V, Wei W, and Hasselgren PO. Role of glucocorticoids in the molecular regulation of muscle wasting. Crit Care Med 35: S602-608, 2007.

228. Michael A, Haq S, Chen X, Hsich E, Cui L, Walters B, Shao Z, Bhattacharya K, Kilter H, Huggins G, Andreucci M, Periasamy M, Solomon RN, Liao R, Patten R, Molkentin JD, and Force T. Glycogen synthase kinase-3beta regulates growth, calcium homeostasis, and diastolic function in the heart. $J$ Biol Chem 279: 21383-21393, 2004.

229. Miura T, and Miki T. GSK-3beta, a therapeutic target for cardiomyocyte protection. Circ J 73: 11841192, 2009.

230. Miyazaki M, Hitomi Y, Kizaki T, Ohno H, Katsumura T, Haga S, and Takemasa T. Calcineurin-mediated slow-type fiber expression and growth in reloading condition. Med Sci Sports Exerc 38: 1065-1072, 2006.

231. Mizushima N, Levine B, Cuervo AM, and Klionsky DJ. Autophagy fights disease through cellular selfdigestion. Nature 451: 1069-1075, 2008.

232. Mizushima N, Yamamoto A, Matsui M, Yoshimori T, and Ohsumi Y. In vivo analysis of autophagy in response to nutrient starvation using transgenic mice expressing a fluorescent autophagosome marker. Mol Biol Cell 15: 1101-1111, 2004.

233. Moon RT, Kohn AD, De Ferrari GV, and Kaykas A. WNT and beta-catenin signalling: diseases and therapies. Nat Rev Genet 5: 691-701, 2004.

234. Mora A, Sabio G, Risco AM, Cuenda A, Alonso JC, Soler G, and Centeno F. Lithium blocks the PKB and GSK3 dephosphorylation induced by ceramide through protein phosphatase-2A. Cell Signal 14: 557562, 2002.

235. Morgan JE, and Partridge TA. Muscle satellite cells. Int J Biochem Cell Biol 35: 1151-1156, 2003.

236. Mottet D, Dumont V, Deccache Y, Demazy C, Ninane N, Raes M, and Michiels C. Regulation of hypoxia-inducible factor-1alpha protein level during hypoxic conditions by the phosphatidylinositol 3kinase/Akt/glycogen synthase kinase 3beta pathway in HepG2 cells. The Journal of biological chemistry 278: 31277-31285, 2003.

237. Mukai A, Kurisaki T, Sato SB, Kobayashi T, Kondoh G, and Hashimoto N. Dynamic clustering and dispersion of lipid rafts contribute to fusion competence of myogenic cells. Experimental cell research 315: 3052-3063, 2009.

238. Mukai F, Ishiguro K, Sano Y, and Fujita SC. Alternative splicing isoform of tau protein kinase I/glycogen synthase kinase 3beta. J Neurochem 81: 1073-1083, 2002.

239. Murai H, Okazaki M, and Kikuchi A. Tyrosine dephosphorylation of glycogen synthase kinase-3 is involved in its extracellular signal-dependent inactivation. FEBS Lett 392: 153-160, 1996.

240. Musaro A, Giacinti C, Borsellino G, Dobrowolny G, Pelosi L, Cairns L, Ottolenghi S, Cossu G, Bernardi G, Battistini L, Molinaro $M$, and Rosenthal N. Stem cell-mediated muscle regeneration is enhanced by local isoform of insulin-like growth factor 1. Proceedings of the National Academy of Sciences of the United States of America 101: 1206-1210, 2004.

241. Nader GA. Molecular determinants of skeletal muscle mass: getting the "AKT" together. Int J Biochem Cell Biol 37: 1985-1996, 2005.

242. Neal JW, and Clipstone NA. Glycogen synthase kinase-3 inhibits the DNA binding activity of NFATc. J Biol Chem 276: 3666-3673, 2001. 
243. Nelson WJ, and Nusse R. Convergence of Wnt, beta-catenin, and cadherin pathways. Science 303 : 1483-1487, 2004.

244. Noble ME, Endicott JA, and Johnson LN. Protein kinase inhibitors: insights into drug design from structure. Science 303: 1800-1805, 2004.

245. Novak A, and Dedhar S. Signaling through beta-catenin and Lef/Tcf. Cell Mol Life Sci 56: 523-537, 1999.

246. Nusse R. Cell biology: relays at the membrane. Nature 438: 747-749, 2005.

247. Oda A, Wakao $\mathrm{H}$, and Fujita $\mathrm{H}$. Calpain is a signal transducer and activator of transcription (STAT) 3 and STAT5 protease. Blood 99: 1850-1852, 2002.

248. Otto A, Schmidt C, Luke G, Allen S, Valasek P, Muntoni F, Lawrence-Watt D, and Patel K. Canonical Wnt signalling induces satellite-cell proliferation during adult skeletal muscle regeneration. J Cell Sci 121: 2939-2950, 2008.

249. Ougolkov AV, Fernandez-Zapico ME, Bilim VN, Smyrk TC, Chari ST, and Billadeau DD. Aberrant nuclear accumulation of glycogen synthase kinase-3beta in human pancreatic cancer: association with kinase activity and tumor dedifferentiation. Clin Cancer Res 12: 5074-5081, 2006.

250. Pallafacchina G, Blaauw B, and Schiaffino S. Role of satellite cells in muscle growth and maintenance of muscle mass. Nutr Metab Cardiovasc Dis 2012.

251. Pandey UB, Nie Z, Batlevi Y, McCray BA, Ritson GP, Nedelsky NB, Schwartz SL, DiProspero NA, Knight MA, Schuldiner O, Padmanabhan R, Hild M, Berry DL, Garza D, Hubbert CC, Yao TP, Baehrecke EH, and Taylor JP. HDAC6 rescues neurodegeneration and provides an essential link between autophagy and the UPS. Nature 447: 859-863, 2007.

252. Pansters NA, van der Velden JL, Kelders MC, Laeremans H, Schols AM, and Langen RC. Segregation of myoblast fusion and muscle-specific gene expression by distinct ligand-dependent inactivation of GSK-3beta. Cellular and molecular life sciences : CMLS 68: 523-535, 2011.

253. Patel S, Doble BW, MacAulay K, Sinclair EM, Drucker DJ, and Woodgett JR. Tissue-specific role of glycogen synthase kinase 3beta in glucose homeostasis and insulin action. Mol Cell Biol 28: 63146328, 2008.

254. Pearce NJ, Arch JR, Clapham JC, Coghlan MP, Corcoran SL, Lister CA, Llano A, Moore GB, Murphy GJ, Smith SA, Taylor CM, Yates JW, Morrison AD, Harper AJ, Roxbee-Cox L, Abuin A, Wargent E, and Holder JC. Development of glucose intolerance in male transgenic mice overexpressing human glycogen synthase kinase-3beta on a muscle-specific promoter. Metabolism 53: 1322-1330, 2004.

255. Peifer M, McCrea PD, Green KJ, Wieschaus E, and Gumbiner BM. The vertebrate adhesive junction proteins beta-catenin and plakoglobin and the Drosophila segment polarity gene armadillo form a multigene family with similar properties. J Cell Biol 118: 681-691, 1992.

256. Peng XD, Xu PZ, Chen ML, Hahn-Windgassen A, Skeen J, Jacobs J, Sundararajan D, Chen WS, Crawford $\mathrm{SE}$, Coleman KG, and Hay N. Dwarfism, impaired skin development, skeletal muscle atrophy, delayed bone development, and impeded adipogenesis in mice lacking Akt1 and Akt2. Genes Dev 17: 13521365, 2003.

257. Perez DI, Conde S, Perez C, Gil C, Simon D, Wandosell F, Moreno FJ, Gelpi JL, Luque FJ, and Martinez A. Thienylhalomethylketones: Irreversible glycogen synthase kinase 3 inhibitors as useful pharmacological tools. Bioorg Med Chem 17: 6914-6925, 2009.

258. Perez DI, Palomo V, Perez C, Gil C, Dans PD, Luque FJ, Conde S, and Martinez A. Switching reversibility to irreversibility in glycogen synthase kinase 3 inhibitors: clues for specific design of new compounds. J Med Chem 54: 4042-4056, 2011.

259. Petropoulos $\mathrm{H}$, and Skerjanc IS. Beta-catenin is essential and sufficient for skeletal myogenesis in P19 cells. J Biol Chem 277: 15393-15399, 2002.

260. Peyrollier K, Hajduch E, Blair AS, Hyde R, and Hundal HS. L-leucine availability regulates phosphatidylinositol 3-kinase, p70 S6 kinase and glycogen synthase kinase-3 activity in L6 muscle cells: evidence for the involvement of the mammalian target of rapamycin (mTOR) pathway in the Lleucine-induced up-regulation of system A amino acid transport. Biochem J 350 Pt 2: 361-368, 2000.

261. Phiel CJ, and Klein PS. Molecular targets of lithium action. Annu Rev Pharmacol Toxicol 41: 789-813, 2001.

262. Phukan S, Babu VS, Kannoji A, Hariharan R, and Balaji VN. GSK3beta: role in therapeutic landscape and development of modulators. Br J Pharmacol 160: 1-19, 2010. 
263. Plant PJ, Bain JR, Correa JE, Woo M, and Batt J. Absence of caspase-3 protects against denervationinduced skeletal muscle atrophy. J Appl Physiol 107: 224-234, 2009.

264. Plotkin B, Kaidanovich O, Talior I, and Eldar-Finkelman H. Insulin mimetic action of synthetic phosphorylated peptide inhibitors of glycogen synthase kinase-3. J Pharmacol Exp Ther 305: 974-980, 2003.

265. Plyte SE, Hughes K, Nikolakaki E, Pulverer BJ, and Woodgett JR. Glycogen synthase kinase-3: functions in oncogenesis and development. Biochim Biophys Acta 1114: 147-162, 1992.

266. Polesskaya A, Seale $P$, and Rudnicki MA. Wnt signaling induces the myogenic specification of resident CD45+ adult stem cells during muscle regeneration. Cell 113: 841-852, 2003.

267. Proud CG. Regulation of protein synthesis by insulin. Biochem Soc Trans 34: 213-216, 2006.

268. Ragano-Caracciolo M, Berlin WK, Miller MW, and Hanover JA. Nuclear glycogen and glycogen synthase kinase 3. Biochem Biophys Res Commun 249: 422-427, 1998.

269. Rao R, Hao CM, and Breyer MD. Hypertonic stress activates glycogen synthase kinase 3beta-mediated apoptosis of renal medullary interstitial cells, suppressing an NFkappaB-driven cyclooxygenase-2dependent survival pathway. The Journal of biological chemistry 279: 3949-3955, 2004.

270. Ravikumar B, Sarkar S, Davies JE, Futter M, Garcia-Arencibia M, Green-Thompson ZW, JimenezSanchez M, Korolchuk VI, Lichtenberg M, Luo S, Massey DC, Menzies FM, Moreau K, Narayanan U, Renna M, Siddiqi FH, Underwood BR, Winslow AR, and Rubinsztein DC. Regulation of mammalian autophagy in physiology and pathophysiology. Physiol Rev 90: 1383-1435, 2010.

271. Relaix F, and Zammit PS. Satellite cells are essential for skeletal muscle regeneration: the cell on the edge returns centre stage. Development 139: 2845-2856, 2012.

272. Riedl SJ, and Shi Y. Molecular mechanisms of caspase regulation during apoptosis. Nat Rev Mol Cell Biol 5: 897-907, 2004.

273. Ring DB, Johnson KW, Henriksen EJ, Nuss JM, Goff D, Kinnick TR, Ma ST, Reeder JW, Samuels I, Slabiak T, Wagman AS, Hammond ME, and Harrison SD. Selective glycogen synthase kinase 3 inhibitors potentiate insulin activation of glucose transport and utilization in vitro and in vivo. Diabetes 52: 588595, 2003

274. Rommel C, Bodine SC, Clarke BA, Rossman R, Nunez L, Stitt TN, Yancopoulos GD, and Glass DJ. Mediation of IGF-1-induced skeletal myotube hypertrophy by $\mathrm{PI}(3) \mathrm{K} / \mathrm{Akt} / \mathrm{mTOR}$ and $\mathrm{PI}(3) \mathrm{K} / \mathrm{Akt} / \mathrm{GSK} 3$ pathways. Nat Cell Biol 3: 1009-1013, 2001.

275. Rosa AO, Egea J, Martinez A, Garcia AG, and Lopez MG. Neuroprotective effect of the new thiadiazolidinone NP00111 against oxygen-glucose deprivation in rat hippocampal slices: implication of ERK1/2 and PPARgamma receptors. Exp Neurol 212: 93-99, 2008.

276. Roubenoff R, Roubenoff RA, Cannon JG, Kehayias JJ, Zhuang H, Dawson-Hughes B, Dinarello CA, and Rosenberg IH. Rheumatoid cachexia: cytokine-driven hypermetabolism accompanying reduced body cell mass in chronic inflammation. J Clin Invest 93: 2379-2386, 1994.

277. Rouet-Benzineb P, Buhler JM, Dreyfus P, Delcourt A, Dorent R, Perennec J, Crozatier B, Harf A, and Lafuma $C$. Altered balance between matrix gelatinases (MMP-2 and MMP-9) and their tissue inhibitors in human dilated cardiomyopathy: potential role of MMP-9 in myosin-heavy chain degradation. Eur J Heart Fail 1: 337-352, 1999.

278. Ruel L, Bourouis M, Heitzler P, Pantesco V, and Simpson P. Drosophila shaggy kinase and rat glycogen synthase kinase-3 have conserved activities and act downstream of Notch. Nature 362: 557-560, 1993.

279. Rylatt DB, Aitken A, Bilham T, Condon GD, Embi N, and Cohen P. Glycogen synthase from rabbit skeletal muscle. Amino acid sequence at the sites phosphorylated by glycogen synthase kinase- 3 , and extension of the $\mathrm{N}$-terminal sequence containing the site phosphorylated by phosphorylase kinase. Eur J Biochem 107: 529-537, 1980.

280. Ryves WJ, Dajani R, Pearl L, and Harwood AJ. Glycogen synthase kinase-3 inhibition by lithium and beryllium suggests the presence of two magnesium binding sites. Biochem Biophys Res Commun 290: 967-972, 2002.

281. Ryves WJ, and Harwood AJ. Lithium inhibits glycogen synthase kinase-3 by competition for magnesium. Biochem Biophys Res Commun 280: 720-725, 2001.

282. Sacheck JM, Hyatt JP, Raffaello A, Jagoe RT, Roy RR, Edgerton VR, Lecker SH, and Goldberg AL. Rapid disuse and denervation atrophy involve transcriptional changes similar to those of muscle wasting during systemic diseases. FASEB J 21: 140-155, 2007. 
283. Sakamoto K, Arnolds DE, Ekberg I, Thorell A, and Goodyear L. Exercise regulates Akt and glycogen synthase kinase-3 activities in human skeletal muscle. Biochem Biophys Res Commun 319: 419-425, 2004.

284. Sakuma K, and Yamaguchi A. Sarcopenia and cachexia: the adaptations of negative regulators of skeletal muscle mass. J Cachexia Sarcopenia Muscle 3: 77-94, 2012.

285. Salani S, Donadoni C, Rizzo F, Bresolin N, Comi GP, and Corti S. Generation of skeletal muscle cells from embryonic and induced pluripotent stem cells as an in vitro model and for therapy of muscular dystrophies. J Cell Mol Med 16: 1353-1364, 2012.

286. Sandri M. Autophagy in health and disease. 3. Involvement of autophagy in muscle atrophy. Am J Physiol Cell Physiol 298: C1291-1297, 2010.

287. Sandri M. New findings of lysosomal proteolysis in skeletal muscle. Current opinion in clinical nutrition and metabolic care 14: 223-229, 2011.

288. Sandri M, Sandri C, Gilbert A, Skurk C, Calabria E, Picard A, Walsh K, Schiaffino S, Lecker SH, and Goldberg AL. Foxo transcription factors induce the atrophy-related ubiquitin ligase atrogin-1 and cause skeletal muscle atrophy. Cell 117: 399-412, 2004.

289. Sarbassov DD, Guertin DA, Ali SM, and Sabatini DM. Phosphorylation and regulation of Akt/PKB by the rictor-mTOR complex. Science 307: 1098-1101, 2005.

290. Sarkar S, Krishna G, Imarisio S, Saiki S, O'Kane CJ, and Rubinsztein DC. A rational mechanism for combination treatment of Huntington's disease using lithium and rapamycin. Hum Mol Genet 17: 170$178,2008$.

291. Schakman O, Gilson H, de Coninck V, Lause P, Verniers J, Havaux X, Ketelslegers JM, and Thissen JP. Insulin-like growth factor-I gene transfer by electroporation prevents skeletal muscle atrophy in glucocorticoid-treated rats. Endocrinology 146: 1789-1797, 2005.

292. Schakman O, Gilson H, and Thissen JP. Mechanisms of glucocorticoid-induced myopathy. J Endocrinol 197: 1-10, 2008.

293. Schakman O, Kalista S, Bertrand L, Lause P, Verniers J, Ketelslegers JM, and Thissen JP. Role of Akt/GSK-3beta/beta-catenin transduction pathway in the muscle anti-atrophy action of Insulin-like growth factor (IGF)-I in glucocorticoid-treated rats. Endocrinology 2008.

294. Schiaffino S, and Hanzlikova V. Studies on the effect of denervation in developing muscle. II. The lysosomal system. J Ultrastruct Res 39: 1-14, 1972.

295. Schmid C, Steiner T, and Froesch ER. Preferential enhancement of myoblast differentiation by insulinlike growth factors (IGF I and IGF II) in primary cultures of chicken embryonic cells. FEBS Lett 161: 117121, 1983.

296. Schols AM, Broekhuizen R, Weling-Scheepers CA, and Wouters EF. Body composition and mortality in chronic obstructive pulmonary disease. Am J Clin Nutr 82: 53-59, 2005.

297. Schols AM, Slangen J, Volovics L, and Wouters EF. Weight loss is a reversible factor in the prognosis of chronic obstructive pulmonary disease. Am J Respir Crit Care Med 157: 1791-1797, 1998.

298. Schulz RA, and Yutzey KE. Calcineurin signaling and NFAT activation in cardiovascular and skeletal muscle development. Dev Biol 266: 1-16, 2004.

299. Schwabe RF, and Brenner DA. Role of glycogen synthase kinase-3 in TNF-alpha-induced NF-kappaB activation and apoptosis in hepatocytes. American journal of physiology Gastrointestinal and liver physiology 283: G204-211, 2002.

300. Schwartz AL, and Ciechanover A. Targeting proteins for destruction by the ubiquitin system: implications for human pathobiology. Annu Rev Pharmacol Toxicol 49: 73-96, 2009.

301. Shah OJ, Kimball SR, and Jefferson LS. Acute attenuation of translation initiation and protein synthesis by glucocorticoids in skeletal muscle. Am J Physiol Endocrinol Metab 278: E76-82, 2000.

302. Shah OJ, Kimball SR, and Jefferson LS. Glucocorticoids abate p70(S6k) and elF4E function in L6 skeletal myoblasts. Am J Physiol Endocrinol Metab 279: E74-82, 2000.

303. Shanely RA, Zwetsloot KA, Childs TE, Lees SJ, Tsika RW, and Booth FW. IGF-I activates the mouse type Ilb myosin heavy chain gene. Am J Physiol Cell Physiol 2009.

304. Shaw $M$, Cohen $P$, and Alessi DR. Further evidence that the inhibition of glycogen synthase kinase3beta by IGF-1 is mediated by PDK1/PKB-induced phosphorylation of Ser-9 and not by dephosphorylation of Tyr-216. FEBS Lett 416: 307-311, 1997.

305. Shefer G, and Benayahu D. The effect of exercise on IGF-I on muscle fibers and satellite cells. Front Biosci (Elite Ed) 4: 230-239, 2012. 
306. Shim M, and Smart RC. Lithium stabilizes the CCAAT/enhancer-binding protein alpha (C/EBPalpha) through a glycogen synthase kinase 3 (GSK3)-independent pathway involving direct inhibition of proteasomal activity. J Biol Chem 278: 19674-19681, 2003.

307. Shimizu N, Yoshikawa N, Ito N, Maruyama T, Suzuki Y, Takeda S, Nakae J, Tagata Y, Nishitani S, Takehana K, Sano M, Fukuda K, Suematsu M, Morimoto C, and Tanaka H. Crosstalk between glucocorticoid receptor and nutritional sensor mTOR in skeletal muscle. Cell Metab 13: 170-182, 2011.

308. Siegfried E, Chou TB, and Perrimon N. wingless signaling acts through zeste-white 3, the Drosophila homolog of glycogen synthase kinase-3, to regulate engrailed and establish cell fate. Cell 71: 11671179, 1992.

309. Simon D, Benitez MJ, Gimenez-Cassina A, Garrido JJ, Bhat RV, Diaz-Nido J, and Wandosell F. Pharmacological inhibition of GSK-3 is not strictly correlated with a decrease in tyrosine phosphorylation of residues 216/279. J Neurosci Res 86: 668-674, 2008.

310. Siu PM. Muscle apoptotic response to denervation, disuse, and aging. Med Sci Sports Exerc 41: 18761886, 2009.

311. Siu PM, and Alway SE. Response and adaptation of skeletal muscle to denervation stress: the role of apoptosis in muscle loss. Front Biosci 14: 432-452, 2009.

312. Smith IJ, and Dodd SL. Calpain activation causes a proteasome-dependent increase in protein degradation and inhibits the Akt signalling pathway in rat diaphragm muscle. Exp Physiol 92: 561-573, 2007.

313. Smith IJ, Lecker SH, and Hasselgren PO. Calpain activity and muscle wasting in sepsis. American journal of physiology Endocrinology and metabolism 295: E762-771, 2008.

314. Solomon V, and Goldberg AL. Importance of the ATP-ubiquitin-proteasome pathway in the degradation of soluble and myofibrillar proteins in rabbit muscle extracts. J Biol Chem 271: 2669026697, 1996.

315. Solomon V, Lecker SH, and Goldberg AL. The N-end rule pathway catalyzes a major fraction of the protein degradation in skeletal muscle. J Biol Chem 273: 25216-25222, 1998.

316. Song L, De Sarno P, and Jope RS. Central role of glycogen synthase kinase-3beta in endoplasmic reticulum stress-induced caspase-3 activation. J Biol Chem 277: 44701-44708, 2002.

317. Song L, Zhou T, and Jope RS. Lithium facilitates apoptotic signaling induced by activation of the Fas death domain-containing receptor. BMC neuroscience 5: 20, 2004.

318. Stambolic V, Ruel L, and Woodgett JR. Lithium inhibits glycogen synthase kinase-3 activity and mimics wingless signalling in intact cells. Curr Biol 6: 1664-1668, 1996.

319. Stitt TN, Drujan D, Clarke BA, Panaro F, Timofeyva Y, Kline WO, Gonzalez M, Yancopoulos GD, and Glass DJ. The IGF-1/PI3K/Akt pathway prevents expression of muscle atrophy-induced ubiquitin ligases by inhibiting FOXO transcription factors. Mol Cell 14: 395-403, 2004.

320. Sugita $H$, Kaneki M, Sugita M, Yasukawa T, Yasuhara S, and Martyn JA. Burn injury impairs insulinstimulated Akt/PKB activation in skeletal muscle. Am J Physiol Endocrinol Metab 288: E585-591, 2005.

321. Tajbakhsh S, Borello U, Vivarelli E, Kelly R, Papkoff J, Duprez D, Buckingham M, and Cossu G. Differential activation of Myf5 and MyoD by different Wnts in explants of mouse paraxial mesoderm and the later activation of myogenesis in the absence of Myf5. Development 125: 4155-4162, 1998.

322. Tamai K, Semenov M, Kato Y, Spokony R, Liu C, Katsuyama Y, Hess F, Saint-Jeannet JP, and He X. LDLreceptor-related proteins in Wnt signal transduction. Nature 407: 530-535, 2000.

323. Tang H, Cheung WM, Ip FC, and Ip NY. Identification and characterization of differentially expressed genes in denervated muscle. Mol Cell Neurosci 16: 127-140, 2000.

324. Tanji C, Yamamoto H, Yorioka N, Kohno N, Kikuchi K, and Kikuchi A. A-kinase anchoring protein AKAP220 binds to glycogen synthase kinase-3beta (GSK-3beta ) and mediates protein kinase Adependent inhibition of GSK-3beta. J Biol Chem 277: 36955-36961, 2002.

325. Taylor SS, Radzio-Andzelm E, and Hunter T. How do protein kinases discriminate between serine/threonine and tyrosine? Structural insights from the insulin receptor protein-tyrosine kinase. Faseb J 9: 1255-1266, 1995.

326. ter Haar E, Coll JT, Austen DA, Hsiao HM, Swenson L, and Jain J. Structure of GSK3beta reveals a primed phosphorylation mechanism. Nat Struct Biol 8: 593-596, 2001. 
327. Thomas GM, Frame S, Goedert M, Nathke I, Polakis P, and Cohen P. A GSK3-binding peptide from FRAT1 selectively inhibits the GSK3-catalysed phosphorylation of axin and beta-catenin. FEBS Lett 458: 247-251, 1999.

328. Thornton TM, Pedraza-Alva G, Deng B, Wood CD, Aronshtam A, Clements JL, Sabio G, Davis RJ, Matthews DE, Doble B, and Rincon M. Phosphorylation by p38 MAPK as an alternative pathway for GSK3beta inactivation. Science 320: 667-670, 2008.

329. Tidball JG, and Spencer MJ. Expression of a calpastatin transgene slows muscle wasting and obviates changes in myosin isoform expression during murine muscle disuse. J Physiol 545: 819-828, 2002.

330. Traxler $P$, and Furet $P$. Strategies toward the design of novel and selective protein tyrosine kinase inhibitors. Pharmacol Ther 82: 195-206, 1999.

331. Tsivitse S. Notch and Wnt signaling, physiological stimuli and postnatal myogenesis. Int J Biol Sci 6: 268-281, 2010.

332. Ueki K, Fruman DA, Brachmann SM, Tseng YH, Cantley LC, and Kahn CR. Molecular balance between the regulatory and catalytic subunits of phosphoinositide 3-kinase regulates cell signaling and survival. Mol Cell Biol 22: 965-977, 2002.

333. Valdez $\mathrm{H}$, and Lederman MM. Cytokines and cytokine therapies in HIV infection. AIDS Clin Rev 187228, 1997.

334. Van der Meer SF, Jaspers RT, and Degens H. Is the myonuclear domain size fixed? J Musculoskelet Neuronal Interact 11: 286-297, 2011.

335. van der Velden JL, Langen RC, Kelders MC, Willems J, Wouters EF, Janssen-Heininger YM, and Schols AM. Myogenic differentiation during regrowth of atrophied skeletal muscle is associated with inactivation of GSK-3beta. Am J Physiol Cell Physiol 292: C1636-1644, 2007.

336. van der Velden JL, Langen RC, Kelders MC, Wouters EF, Janssen-Heininger YM, and Schols AM. Inhibition of glycogen synthase kinase-3beta activity is sufficient to stimulate myogenic differentiation. Am J Physiol Cell Physiol 290: C453-462, 2006.

337. van der Velden JL, Schols AM, Willems J, Kelders MC, and Langen RC. Glycogen synthase kinase 3 suppresses myogenic differentiation through negative regulation of NFATc3. The Journal of biological chemistry 283: 358-366, 2008.

338. van Weeren PC, de Bruyn KM, de Vries-Smits AM, van Lint J, and Burgering BM. Essential role for protein kinase $B(P K B)$ in insulin-induced glycogen synthase kinase 3 inactivation. Characterization of dominant-negative mutant of PKB. J Biol Chem 273: 13150-13156, 1998.

339. Vary TC, Deiter G, and Kimball SR. Phosphorylation of eukaryotic initiation factor elF2Bepsilon in skeletal muscle during sepsis. Am J Physiol Endocrinol Metab 283: E1032-1039, 2002.

340. Verhees KJ, Schols AM, Kelders MC, Op den Kamp CM, van der Velden JL, and Langen RC. Glycogen synthase kinase-3beta is required for the induction of skeletal muscle atrophy. Am J Physiol Cell Physiol 301: C995-C1007, 2011.

341. Vescovo G, Volterrani M, Zennaro R, Sandri M, Ceconi C, Lorusso R, Ferrari R, Ambrosio GB, and Dalla Libera L. Apoptosis in the skeletal muscle of patients with heart failure: investigation of clinical and biochemical changes. Heart 84: 431-437, 2000.

342. Voisin L, Breuille D, Combaret L, Pouyet C, Taillandier D, Aurousseau E, Obled C, and Attaix D. Muscle wasting in a rat model of long-lasting sepsis results from the activation of lysosomal, Ca2+-activated, and ubiquitin-proteasome proteolytic pathways. J Clin Invest 97: 1610-1617, 1996.

343. Vyas DR, Spangenburg EE, Abraha TW, Childs TE, and Booth FW. GSK-3beta negatively regulates skeletal myotube hypertrophy. Am J Physiol Cell Physiol 283: C545-551, 2002.

344. Waddell DS, Baehr LM, van den Brandt J, Johnsen SA, Reichardt HM, Furlow JD, and Bodine SC. The glucocorticoid receptor and FOXO1 synergistically activate the skeletal muscle atrophy-associated MuRF1 gene. Am J Physiol Endocrinol Metab 295: E785-797, 2008.

345. Wagman AS, Johnson KW, and Bussiere DE. Discovery and development of GSK3 inhibitors for the treatment of type 2 diabetes. Curr Pharm Des 10: 1105-1137, 2004.

346. Wang L, Luo GJ, Wang JJ, and Hasselgren PO. Dexamethasone stimulates proteasome- and calciumdependent proteolysis in cultured L6 myotubes. Shock 10: 298-306, 1998.

347. Wang QM, Park IK, Fiol CJ, Roach PJ, and DePaoli-Roach AA. Isoform differences in substrate recognition by glycogen synthase kinases 3 alpha and 3 beta in the phosphorylation of phosphatase inhibitor 2. Biochemistry 33: 143-147, 1994. 
348. Wang SH, Shih YL, Kuo TC, Ko WC, and Shih CM. Cadmium toxicity toward autophagy through ROSactivated GSK-3beta in mesangial cells. Toxicol Sci 108: 124-131, 2009.

349. Wang W, Schulze CJ, Suarez-Pinzon WL, Dyck JR, Sawicki G, and Schulz R. Intracellular action of matrix metalloproteinase-2 accounts for acute myocardial ischemia and reperfusion injury. Circulation 106: 1543-1549, 2002.

350. Wang XH, Zhang L, Mitch WE, LeDoux JM, Hu J, and Du J. Caspase-3 cleaves specific 19 S proteasome subunits in skeletal muscle stimulating proteasome activity. J Biol Chem 285: 21249-21257, 2010.

351. Waraich RS, Weigert C, Kalbacher H, Hennige AM, Lutz SZ, Haring HU, Schleicher ED, Voelter W, and Lehmann R. Phosphorylation of Ser357 of rat insulin receptor substrate-1 mediates adverse effects of protein kinase C-delta on insulin action in skeletal muscle cells. J Biol Chem 283: 11226-11233, 2008.

352. Watcharasit P, Bijur GN, Song L, Zhu J, Chen X, and Jope RS. Glycogen synthase kinase-3beta (GSK3beta) binds to and promotes the actions of p53. J Biol Chem 278: 48872-48879, 2003.

353. Watcharasit P, Bijur GN, Zmijewski JW, Song L, Zmijewska A, Chen X, Johnson GV, and Jope RS. Direct, activating interaction between glycogen synthase kinase-3beta and p53 after DNA damage. Proc Natl Acad Sci U S A 99: 7951-7955, 2002.

354. Wei W, Yang H, Cao P, Menconi M, Chamberlain C, Petkova V, and Hasselgren PO. Degradation of C/EBPbeta in cultured myotubes is calpain-dependent. J Cell Physiol 208: 386-398, 2006.

355. Welsh GI, Miller CM, Loughlin AJ, Price NT, and Proud CG. Regulation of eukaryotic initiation factor elF2B: glycogen synthase kinase-3 phosphorylates a conserved serine which undergoes dephosphorylation in response to insulin. FEBS Lett 421: 125-130, 1998.

356. Welsh GI, and Proud CG. Glycogen synthase kinase-3 is rapidly inactivated in response to insulin and phosphorylates eukaryotic initiation factor elF-2B. Biochem J 294 ( Pt 3): 625-629, 1993.

357. Whitehouse AS, Smith HJ, Drake JL, and Tisdale MJ. Mechanism of attenuation of skeletal muscle protein catabolism in cancer cachexia by eicosapentaenoic acid. Cancer Res 61: 3604-3609, 2001.

358. Williams AB, Decourten-Myers GM, Fischer JE, Luo G, Sun X, and Hasselgren PO. Sepsis stimulates release of myofilaments in skeletal muscle by a calcium-dependent mechanism. Faseb J 13: 14351443, 1999.

359. Wilson C, Hargreaves M, and Howlett KF. Exercise does not alter subcellular localization, but increases phosphorylation of insulin-signaling proteins in human skeletal muscle. Am J Physiol Endocrinol Metab 290: E341-346, 2006.

360. Wing SS, and Goldberg AL. Glucocorticoids activate the ATP-ubiquitin-dependent proteolytic system in skeletal muscle during fasting. Am J Physiol 264: E668-676, 1993.

361. Wing SS, Lecker SH, and Jagoe RT. Proteolysis in illness-associated skeletal muscle atrophy: from pathways to networks. Crit Rev Clin Lab Sci 48: 49-70, 2011.

362. Wodarz A, and Nusse R. Mechanisms of Wnt signaling in development. Annual review of cell and developmental biology 14: 59-88, 1998.

363. Wojtaszewski JF, Hansen BF, Gade, Kiens B, Markuns JF, Goodyear L, and Richter EA. Insulin signaling and insulin sensitivity after exercise in human skeletal muscle. Diabetes 49: 325-331, 2000.

364. Woodgett JR. cDNA cloning and properties of glycogen synthase kinase-3. Methods Enzymol 200: $564-$ 577, 1991.

365. Woodgett JR. Molecular cloning and expression of glycogen synthase kinase-3/factor A. Embo J 9: 2431-2438, 1990.

366. Woodgett JR, and Cohen P. Multisite phosphorylation of glycogen synthase. Molecular basis for the substrate specificity of glycogen synthase kinase-3 and casein kinase-II (glycogen synthase kinase-5). Biochim Biophys Acta 788: 339-347, 1984.

367. Wray CJ, Mammen JM, Hershko DD, and Hasselgren PO. Sepsis upregulates the gene expression of multiple ubiquitin ligases in skeletal muscle. Int J Biochem Cell Biol 35: 698-705, 2003.

368. Wrobel E, Brzoska E, and Moraczewski J. M-cadherin and beta-catenin participate in differentiation of rat satellite cells. Eur J Cell Biol 86: 99-109, 2007.

369. Wu M, Falasca M, and Blough ER. Akt/protein kinase B in skeletal muscle physiology and pathology. $J$ Cell Physiol 226: 29-36, 2010.

370. Xavier IJ, Mercier PA, McLoughlin CM, Ali A, Woodgett JR, and Ovsenek N. Glycogen synthase kinase 3beta negatively regulates both DNA-binding and transcriptional activities of heat shock factor $1 . J$ Biol Chem 275: 29147-29152, 2000. 
371. Yamamoto H, Kishida S, Kishida M, Ikeda S, Takada S, and Kikuchi A. Phosphorylation of axin, a Wnt signal negative regulator, by glycogen synthase kinase-3beta regulates its stability. J Biol Chem 274: 10681-10684, 1999.

372. Yang J, Takahashi Y, Cheng E, Liu J, Terranova PF, Zhao B, Thrasher JB, Wang HG, and Li B. GSK-3beta promotes cell survival by modulating Bif-1-dependent autophagy and cell death. J Cell Sci 123: 861870, 2010.

373. Yasuhara S, Perez ME, Kanakubo E, Yasuhara Y, Shin YS, Kaneki M, Fujita T, and Martyn JA. Skeletal muscle apoptosis after burns is associated with activation of proapoptotic signals. Am J Physiol Endocrinol Metab 279: E1114-1121, 2000.

374. Yusuf F, and Brand-Saberi B. Myogenesis and muscle regeneration. Histochem Cell Biol 138: 187-199, 2012.

375. Zeman RJ, Bauman WA, Wen X, Ouyang N, Etlinger JD, and Cardozo CP. Improved functional recovery with oxandrolone after spinal cord injury in rats. Neuroreport 20: 864-868, 2009.

376. Zeng X, Tamai K, Doble B, Li S, Huang H, Habas R, Okamura H, Woodgett J, and He X. A dual-kinase mechanism for Wnt co-receptor phosphorylation and activation. Nature 438: 873-877, 2005.

377. Zhang F, Phiel CJ, Spece L, Gurvich N, and Klein PS. Inhibitory phosphorylation of glycogen synthase kinase-3 (GSK-3) in response to lithium. Evidence for autoregulation of GSK-3. J Biol Chem 278: 3306733077, 2003.

378. Zhao J, Brault JJ, Schild A, Cao P, Sandri M, Schiaffino S, Lecker SH, and Goldberg AL. FoxO3 coordinately activates protein degradation by the autophagic/lysosomal and proteasomal pathways in atrophying muscle cells. Cell Metab 6: 472-483, 2007.

379. Zhao TJ, Yan YB, Liu Y, and Zhou HM. The generation of the oxidized form of creatine kinase is a negative regulation on muscle creatine kinase. J Biol Chem 282: 12022-12029, 2007.

380. Zhou F, Zhang L, Wang A, Song B, Gong K, Zhang L, Hu M, Zhang X, Zhao N, and Gong Y. The association of GSK3 beta with E2F1 facilitates nerve growth factor-induced neural cell differentiation. J Biol Chem 283: 14506-14515, 2008. 


\section{Chapter 3}

\section{GLYCOGEN SYNTHASE KINASE-3 $\beta$ IS REQUIRED FOR THE INDUCTION OF SKELETAL MUSCLE}

ATROPHY

Koen JP Verhees, Annemie MWJ Schols, Marco CJM Kelders, Céline MH Op den Kamp, Jos LJ van der Velden, and Ramon CJ Langen 


\section{Abstract}

Skeletal muscle atrophy commonly occurs in acute and chronic disease. The expression of the muscle-specific E3 ligases atrogin-1/MAFbx and muscle RING finger 1 (MuRF1) is induced by atrophy stimuli such as glucocorticoids (GCs) or absence of insulin-like growth factor 1 (IGF-I)/insulin and subsequent Akt signaling. We investigated if glycogen synthase kinase-3B (GSK-3ß), a downstream molecule in IGFI/Akt signaling, is required for basal and atrophy stimulus-induced expression of atrogin-1 and MuRF1, and myofibrillar protein loss in $\mathrm{C}_{2} \mathrm{C}_{12}$ skeletal myotubes. Abrogation of basal IGF-I signaling, using LY294002, resulted in a prominent induction of atrogin-1 and MuRF1 mRNA and was accompanied by a loss of myosin heavy chain fast (MyHC-f) and myosin light chains 1 and 3 (MyLC-1) (MyLC-3). The synthetic GC dexamethasone (Dex) also induced the expression of both atrogenes and likewise resulted in the loss of myosin protein abundance. Genetic ablation of GSK-3 $\beta$ using siRNA resulted in specific sparing of MyHC-f, MyLC-1 and MyLC-3 protein levels after Dex-treatment or impaired IGF-I/Akt signaling. Interestingly, loss of endogenous GSK$3 \beta$ suppressed both basal and atrophy stimulus-induced atrogin-1 and MuRF1 expression, whereas pharmacological GSK-3 $\beta$ inhibition, using CHIR99021 or LiCl, only reduced atrogin-1 mRNA levels in response to LY294002 or Dex. In conclusion, our data reveals that myotube atrophy and myofibrillar protein loss is GSK-3ß-dependent, and demonstrates for the first time that basal and atrophy stimulus-induced atrogin-1 mRNA expression requires GSK-3 $\beta$ enzymatic activity, whereas MuRF1 expression depends solely on the physical presence of GSK-3 ${ }^{\left({ }^{*}\right)}$

* This article is the topic of an editorial focus by Esther E Dupont-Versteegden and Christine Waters (11). 


\section{Introduction}

Skeletal muscle atrophy is a common and disabling feature of chronic degenerative and inflammatory diseases including cancer, congestive heart failure (CHF), chronic kidney disease (CKD) and chronic obstructive pulmonary disease (COPD) (20,31). Furthermore, it is well-established that conditions of disuse (e.g. immobilization, denervation, muscle unloading), aging and semi-starvation also contribute to skeletal muscle atrophy $(15,24)$. Regardless of the initiating trigger, muscle atrophy is characterized by a decrease in muscle protein content, fiber crosssectional area (CSA) and force output $(24,45)$.

Diminished protein content associated with skeletal muscle atrophy is the result of an imbalance between muscle protein synthesis and degradation, in favor of the latter $(25,37)$. Increased muscle proteolysis during atrophy occurs upon the activation of the major cellular proteolytic systems, which include the ATP-dependent ubiquitin 26Sproteasome system (UPS), the autophagy-lysosomal pathway (ALP), and the calciumdependent calpains (19). It should be noted, however, that reduced protein synthesis, besides accelerated breakdown of muscle proteins, also contributes to muscle atrophy under certain conditions $(24,34)$.

It is generally accepted that the "atrophy program" within the muscle is primarily carried out through activation of the UPS (25). This prototypical pathway is characterized by its ability to recognize, ubiquitinate and subsequently target specific protein substrates for destruction. In their quest to elucidate the mechanisms of muscle atrophy, Bodine et al. (2) and Gomes et al. (17) did pioneering work that led to the discovery of two muscle-specific E3 ubiquitin ligases, namely atrogin-1/MAFbx (hereinafter termed atrogin-1) and muscle RING finger 1 (MuRF1), which are considered as rate-limiting enzymes of UPS-mediated muscle protein breakdown, as their absence strongly attenuates muscle atrophy. In fact, atrogin-1 and MuRF1 are induced by a number of atrophy stimuli, including disuse/inactivity (2), nutrient deprivation (fasting) (33) and glucocorticoid (GC)-treatment $(50,60,61)$, and are consequently referred to as atrogenes.

Although myofibrillar proteins are among the most stable in the body (16), during atrophy these proteins of the contractile apparatus are degraded to a greater extent than their cytoplasmic counterparts (36). In recent years, several components of the contractile apparatus, including myosin heavy chain (MyHC) (8), myosin-binding protein $C$ (MyBP-C) and myosin light chains 1 and 2 (MyLC-1 and MyLC-2) (9) were proven to be targets of UPS-mediated protein breakdown, and increased proteolysis of these proteins likely contributes to loss of muscle mass and function in muscle atrophy. Exogenously administered as well as elevated circulating levels of endogenous GCs are a well-described stimulus for muscle proteolysis $(19,22,31)$ and 
physiological levels of endogenous GCs appear indispensable for the induction of protein degradation in several models of atrophy $(23,43)$. Furthermore, treatment of cultured myotubes with the synthetic GC dexamethasone (Dex) has been shown to result in selective loss of MyHC protein (7).

Insulin and insulin-like growth factor 1 (IGF-I) are both anabolic factors, whose ability to promote protein synthesis, and suppress muscle proteolysis have been well documented in the context of muscle maintenance and growth $(15,30,40)$. IGF-I and insulin affect cellular protein turn-over via a well-characterized signaling circuit that includes phosphorylation of phosphatidylinositol-3 kinase (PI-3K), allowing Akt/PKB (hereinafter termed Akt), to translocate to the membrane which in turn facilitates its phosphorylation and activation by the 3-phosphoinositide-dependent protein kinase-1 (PDK-1) (6). Conversely, Akt activation results in the phosphorylation and cytoplasmic retention of the Forkhead box $O$ (FoXO) class of transcription factors, which is required for the suppression of atrogin-1 and MuRF1 gene expression $(43,48)$ and responsible for the subsequent attenuation of proteolysis. In vitro, loss of muscle mass maintenance resulting from impaired IGF-I signaling can be mimicked by LY294002, a selective PI-3K inhibitor, which is able to tip the balance towards protein degradation $(30,40,42)$.

Phosphorylated Akt activates mammalian target of rapamycin complex 1 (mTORC1) and in parallel inactivates glycogen synthase kinase-36 (GSK-3 $\beta$ ), resulting in increased mRNA translation initiation and capacity to promote protein synthesis $(15,38,48)$. As indicated, GSK-3 $\beta$ is a signaling protein directly downstream of Akt. Akt reduces GSK-3 $\beta$ kinase activity through phosphorylation of $\mathrm{Ser}^{9}$ (18), resulting in enhanced mRNA translation due to increased eukaryotic initiation factor $2 B$ (elF2B) activity consequent to reduced inhibitory phosphorylation of elF2B $\varepsilon$ by GSK-3 $\beta$ (59). However, the contribution of GSK-3 $\beta$ to protein turn-over does not appear to be restricted to regulation of protein synthesis. Previously, it was shown that GSK-3 $\beta$ inhibitors decreased general protein degradation comparably to IGF-I in a model of GC-associated muscle proteolysis $(12,13,32)$. Yet it is noteworthy that in these studies the effect of GSK-3 $\beta$ modulation on contractile muscle protein (myofibrillar protein) content was not assessed. Taken together, these findings strongly support the notion that GSK-3 $\beta$ may constitute an additional level at which protein synthesis and degradation are coordinated as, in addition to its inhibitory effect on mRNA translation, GSK-3 $\beta$ activity also appears to be involved in protein degradation. 
In an effort to elucidate a potential role of GSK-3 $\beta$ in the regulation of muscle proteolysis and atrophy, we investigated whether basal and atrophy stimulus-induced expression of atrogin-1 and MuRF1 is affected by inhibition of GSK-3 $\beta$, using pharmacological and genetic approaches in cultured $C_{2} C_{12}$ myotubes. We further sought to examine if GSK-3 $\beta$ is required for the loss of myofibrillar proteins induced by GCs or impaired IGF-I/Akt signaling in vitro. The present study reveals a pivotal role of GSK-3 $\beta$ in the regulation of skeletal muscle atrophy: GSK-3 $\beta$ controls basal and atrophy stimulus-induced expression of atrogin-1 and MuRF1, and conversely, its absence results in specific sparing of MyHC-f, MyLC-1 and MyLC-3 protein levels and myotube size after Dex-treatment or impaired IGF-I/Akt signaling

\section{Materials and Methods}

\section{Cell culture}

The murine skeletal muscle cell line $C_{2} C_{12}$ was obtained from the American Type Culture Collection (ATCC \# CRL1772, Manassas, VA, USA). Myoblasts were cultured in growth medium (GM), composed of low glucose [1 g/l] Dulbecco's Modified Eagle Medium (DMEM) containing antibiotics $[50 \mathrm{U} / \mathrm{ml}$ Penicillin and $50 \mathrm{\mu g} / \mathrm{ml}$ Streptomycin] (all from Gibco, MD, USA) and 9\% (v/v) Fetal Bovine Serum (FBS) (PAA Laboratories $\mathrm{GmbH}$, Austria). The cells were plated at a density of $10^{4} / \mathrm{cm}^{2}$ on $B D$ Matrigel coated [1:50 in DMEM] $35 \mathrm{~mm}$ dishes (both from BD Biosciences, MA, USA) and cultured in $\mathrm{GM}$ for $24 \mathrm{~h}$ prior to induction of differentiation. $\mathrm{C}_{2} \mathrm{C}_{12}$ myoblasts underwent differentiation into myotubes following growth factor withdrawal (62). Differentiation medium (DM) was made by supplementing DMEM with $0.9 \%$ heatinactivated FBS $\left(30 \mathrm{~min}\right.$ at $56^{\circ} \mathrm{C}$ ) and antibiotics $[50 \mathrm{U} / \mathrm{ml}$ Penicillin and $50 \mathrm{\mu g} / \mathrm{ml}$ Streptomycin]. The differentiating cells were provided with fresh DM every $48 \mathrm{~h}$ and $2 \mathrm{~h}$ before stimulation. Murine IGF-I, insulin, $\mathrm{LiCl}$, dexamethasone (Dex), staurosporine (all from Sigma-Aldrich, MO, USA), LY294002 (Calbiochem, CA, USA), Akti-1/2 inhibitor (Merck, Germany) and/or CHIR99021 (kindly provided by Dr. Cohen, MRC Protein Phosphorylation Unit, University of Dundee, UK) were added after 5 days of culture in $\mathrm{DM}$ for the indicated times and concentrations.

\section{RNA isolation and assessment of mRNA abundance for qRT-PCR}

$\mathrm{C}_{2} \mathrm{C}_{12}$ cells were washed twice with ice-cold $1 \mathrm{X}$ PBS, after which total RNA was isolated using the ToTALLY RNA kit (Ambion, TX, USA) according to the manufacturer's instructions. Upon completion of the protocol the RNA was dissolved in $1 \mathrm{mM}$ sodium citrate $\left(\mathrm{pH} \mathrm{6.4)}\right.$ and stored at $-80^{\circ} \mathrm{C}$. The RNA concentrations were measured using a Nanodrop ND-1000 UV-Vis spectrophotometer. Next, 0.4 ug RNA was reverse transcribed into cDNA using the Transcriptor First Strand cDNA Synthesis kit (Roche Diagnostics $\mathrm{GmbH}$, Germany) according to the manufacturer's instructions. Anchored 
oligo-dT primers were used for priming. The mRNA transcript levels of the genes of interest (Supplemental Table S3.1) were determined by real-time quantitative reverse transcription PCR (qRT-PCR). qRT-PCR primers were designed using Primer Express 2.0 software (Applied Biosystems, CA, USA) and obtained from Sigma-Aldrich. qRT-PCR reactions contained $1 X$ Absolute qRT-PCR SYBR Green Fluorescein Mix (Westburg, the Netherlands) and primers [300 nM]. The PCR reaction was performed by a two-step PCR and standards were made by making 5-fold serial dilutions of pooled CDNA. Relative cDNA concentrations of the samples were derived from the standard curve with at least a $R^{2}>0.98$ and an efficiency between $90-110 \%$. The geNorm software package (54) was used to ascertain the most suitable set of reference genes for normalization. The correction factor, calculated by geNorm, was based on a combination of the expression levels of $\beta$-actin, cyclophilin A, GAPDH and calnexin. qRT-PCR reactions were performed on a MyiQ single-color real-time thermocycler and analyzed using MyiQ 2.0 software (all from Bio-Rad, CA, USA).

\section{Western blotting}

$\mathrm{C}_{2} \mathrm{C}_{12}$ cells were washed twice with ice-cold $1 \mathrm{X}$ PBS after which they were scraped using cell scrapers (rubber policemen) and lysed in a whole cell lysate buffer (WCL) [20 mM Tris, pH 7.4; 150 mM NaCl; 1\% Nonidet P40; 1 mM DTT; 1 mM Na $3 V_{4} ; 1$ mM PMSF; $10 \mu \mathrm{g} / \mathrm{ml}$ Leupeptin and 1\% Aprotinin]. Total protein concentration was assessed by the Thermo Scientific Pierce BCA Protein Assay kit (Pierce Biotechnology, IL, USA) according to the manufacturer's instructions. The protein lysates were boiled for $5 \mathrm{~min}$ at $95^{\circ} \mathrm{C}$ after addition of $4 \mathrm{X}$ Laemmli sample buffer [0.25 M Tris- $\mathrm{HCl}$ pH 6.8; $8 \%(\mathrm{w} / \mathrm{v})$ SDS; $40 \%(\mathrm{v} / \mathrm{v})$ glycerol; $0.4 \mathrm{M} \mathrm{DTT}$ and 0.04\% (w/v) Bromophenol Blue]. For the determination of myofibrillar protein abundance cell lysates were sonicated for 10X $1 \mathrm{sec}$ with $10 \mathrm{sec}$ intervals (MSE sonicator, PG784). For SDS-PAGE 0.3 - $20 \mu \mathrm{g}$ of protein was loaded per lane and separated on a Criterion XT Precast 4 - 12\% Bis-Tris gel (Bio-Rad), followed by transfer to a $0.45 \mu \mathrm{m}$ Whatman Protran Nitrocellulose Transfer membrane (Whatman $\mathrm{GmbH}$, Germany) by electroblotting (Bio-Rad Criterion Blotter). For the determination of myofibrillar protein abundance equal volumes of lysate were separated, as correction for total protein would result in an underestimation of potential atrophy effects, since in muscle cells contractile proteins account for the majority of the total protein content. Nitrocellulose blots were incubated overnight $\left(4^{\circ} \mathrm{C}\right)$ with specific antibodies directed against: p-GSK-3 $\beta\left(\operatorname{Ser}^{9}\right)$ (\#9336), GSK-3ß (\#9332), p-Akt (Ser ${ }^{473}$ ) (\#9271), Akt (\#9272), GAPDH (\#2118), cleaved caspase-3 (\#9661) (all from Cell Signaling Technology), MyHC-f (\#M4276), $\alpha$-tubulin (\#T6074) (both from Sigma-Aldrich), p-elF2BE $\left(\right.$ Ser $^{539}$ ) (\#44-530G) (Invitrogen, CA, USA) and MyLC-1 and 3 (\#F310) (Developmental Studies Hybridoma Bank, lowa City, IA, USA) diluted in TBS/0.1\% Tween-20. The blots were probed with a peroxidase conjugated secondary antibody (\#PI-1000) (Vector Laboratories, CA, USA), and visualized using Supersignal WestPico Chemiluminescent Substrate (Pierce Biotechnology) according to the manufacturer's instructions and exposed to Super RX 
film (FUJIFILM). The Western blot films were digitalized using a Bio-Rad GS-800 Densitometer and subsequent quantification was done using Quantity One software (version 4.5) (both from Bio-Rad).

\section{Stable transfection}

Vectors expressing shRNA directed against GSK-3 $\beta$ and MuRF1 were constructed by inserting a duplex of annealed oligonucleotides containing the 19-nt target sequences into the pRetro-Super ( $\mathrm{pRS}$ ) vector $(3,4)$ (kindly provided by Dr. R. Agami, the Netherlands Cancer Institute, Amsterdam). Ecotropic retroviral supernatants were produced by transfection of phoenix packaging cells (kindly provided by Dr. G. Nolan, Stanford University, USA), cultured in high glucose [4.5 g/l] DMEM containing antibiotics [50 U/ml Penicillin and $50 \mu \mathrm{g} / \mathrm{ml}$ Streptomycin] and 9\% (v/v) FBS, with the pRS GSK-3 $3 /$ MuRF1 shRNA vector or the pRS control vector by calcium phosphate precipitation. The tissue culture medium was filtered through a $0.45 \mu \mathrm{m}$ filter $48 \mathrm{~h}$ post-transfection and the supernatant containing the viral particles was used for infection of $\mathrm{C}_{2} \mathrm{C}_{12}$ cells after the addition of Polybrene [4 $\left.\mathrm{\mu g} / \mathrm{ml}\right]$ (Sigma-Aldrich). The cells were infected for at least $6 \mathrm{~h}$ and allowed to recover for $24 \mathrm{~h}$ with fresh GM. Infected cells were selected with Puromycin [2.5 $\mathrm{gg} / \mathrm{ml}]$ for at least $96 \mathrm{~h}$. Of the three target sequences tested, the pRS vector containing the 19-nt target sequences 5'-GTTGTATATGTATCAGCTG-3' and 5'-GATCAACATCTACTGTCTC-3' demonstrated the strongest RNA silencing for GSK-3 $\beta$ and MuRF1. Silencing efficiency was evaluated by qRT-PCR or Western blot analysis for GSK-3ß.

\section{Transient transfection}

GSK-3 $\beta$ mRNA expression was silenced in $\mathrm{C}_{2} \mathrm{C}_{12}$ myotubes that had undergone differentiation for 4 days and were grown in $35 \mathrm{~mm}$ dishes (BD Biosciences). The myotubes were transiently transfected using Stealth RNAi siRNAs (Invitrogen) according to the manufacturer's instructions. The transfection mix was prepared in Opti-MEM reduced serum medium and Lipofectamine RNAiMAX (both from Invitrogen) was used as a transfection agent. The transfection mixture, for both universal control siRNA (low GC\%) and target siRNA [final concentration both at $10 \mathrm{nM}$ ] was incubated at room temperature (RT) for $20 \mathrm{~min}$ after which it was added to the culture dishes containing fresh DM. The post-transfection interval lasted for 24 $h$, before the transfected cells were taken into subsequent experiments. Knockdown of GSK-3 $\beta$ was evaluated by Western blot and qRT-PCR analysis.

\section{May-Grünwald Giemsa staining}

$\mathrm{C}_{2} \mathrm{C}_{12}$ cells were grown on Matrigel coated $35 \mathrm{~mm}$ dishes and underwent differentiation for 5 days, prior to the addition of LY294002 and Dex for $48 \mathrm{~h}$. The cells were washed twice in 1X PBS (RT), fixed in methanol and stained in May-Grünwald 
Giemsa (Sigma-Aldrich) according to the manufacturer's instructions. Pictures were taken at $40 \mathrm{X}$ and $100 \mathrm{X}$ magnifications using a microscope connected to a digital camera (DXM 1200F), both from Nikon (Nikon, Kanagawa, Japan).

\section{Statistical analysis}

The data are represented as means and error bars indicate standard error of the mean (SEM). Comparisons of mean values were tested non-parametrically, using the Mann-Whitney $U$ test. A two-tailed probability value of $p<0.05$ between groups was considered statistically significant.

\section{Results}

\section{Suppression of GSK-3 $\beta$ activity is associated with decreased atrogin-1 and MuRF1 expression}

To investigate the potential regulation of atrogin-1 and MuRF1 expression by GSK$3 \beta$, the mRNA expression pattern of these atrogenes was first determined during myogenic differentiation of $\mathrm{C}_{2} \mathrm{C}_{12}$ myoblasts. atrogin-1 and MuRF1 expression has been shown to be exclusively restricted to cardiac and skeletal muscle $(2,17)$. The mRNA expression of these atrogenes increased during myogenic differentiation $(51,52)$. A strong increase in atrogin-1 and MuRF1 transcript levels was observed when compared with proliferating myoblasts. Atrogin-1 expression levels increased rapidly and peaked at $48 \mathrm{~h}$ post induction of differentiation, whereas MuRF1 mRNA levels increased steadily starting from $24 \mathrm{~h}$ and peaking at $96 \mathrm{~h}$ post induction of differentiation (Figure 3.1A). From $96 \mathrm{~h}$ onwards MuRF1 mRNA expression remained stable, while atrogin-1 mRNA levels stabilized after $72 \mathrm{~h}$ post induction of differentiation. At subsequent time points the fluctuations in atrogin-1 and MuRF1 mRNA were not statistically significant and considered stable (Figure 3.1A). Hence, $\mathrm{C}_{2} \mathrm{C}_{12}$ myoblasts were differentiated for 5 days to address our atrophy-related questions in the remainder of this study.

The addition of IGF-I or insulin to the culture medium significantly decreased the basal mRNA expression levels of both atrogin-1 and MuRF1 in a dose-dependent fashion (Figure 3.1B). The ratio of $\mathrm{p}$-Akt/Akt increased dramatically following incubation with either IGF-I (729\%) or insulin (422\%) compared with vehicle control (Figure 3.1C). 
A

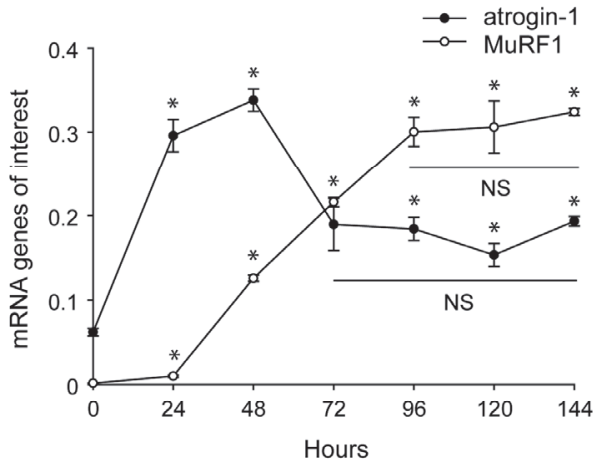

B
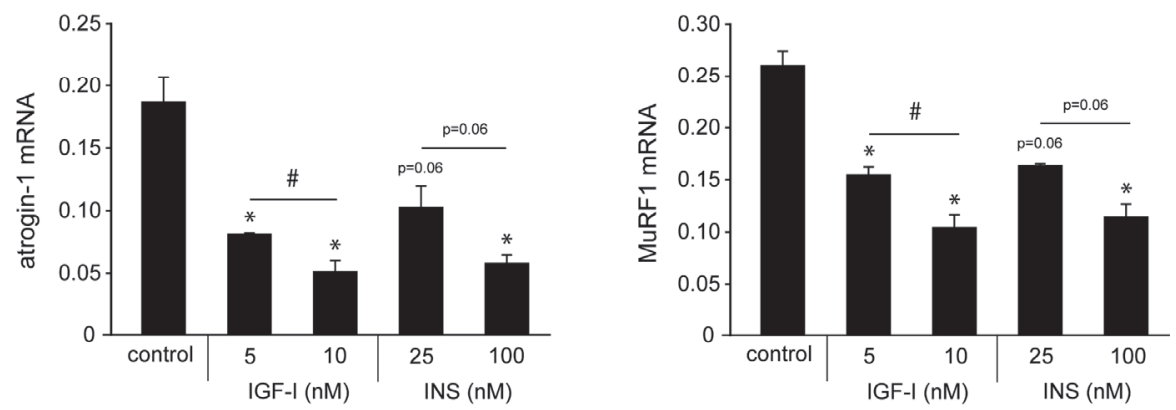

C
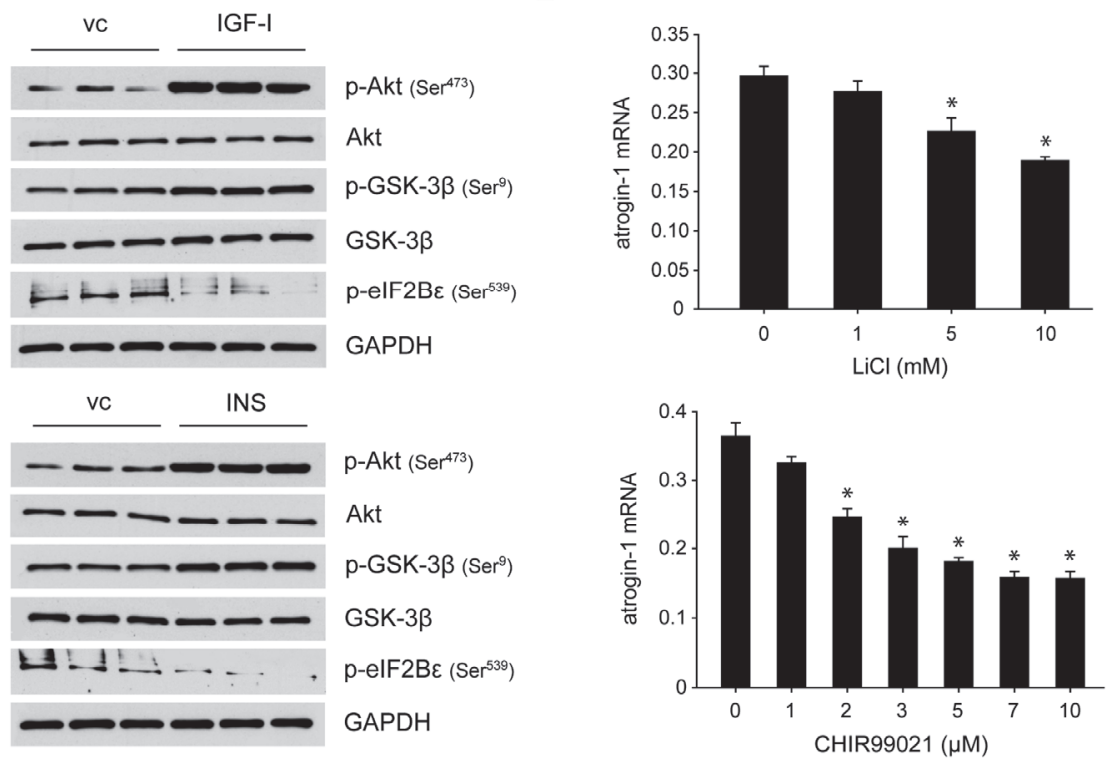
Figure 3.1 Suppression of GSK-3 $\beta$ activity is associated with decreased atrogene expression.

(A) $C_{2} C_{12}$ myoblasts were induced to differentiate in DM for $24,48,72,96,120$ and $144 \mathrm{~h}$ to assess mRNA abundance of atrogin- 1 and MuRF1. Time point 0 represents data for proliferating myoblasts in GM. (B) Fully differentiated $\mathrm{C}_{2} \mathrm{C}_{12}$ myotubes (5 days) were treated for $24 \mathrm{~h}$ with or without IGF-I [5 nM and $10 \mathrm{nM}$ ] or insulin [25 nM and $100 \mathrm{nM}$ ] [vehicle control (vc): $0.1 \%$ (BSA) in HBSS] and mRNA abundance of atrogin-1 and MuRF1 was determined. (C) $\mathrm{C}_{2} \mathrm{C}_{12}$ myotubes were cultured for $2 \mathrm{~h}$ in the presence of IGF-I [5 nM] or insulin [25 nM] and protein levels of phospho-Akt (p-Akt), total Akt (Akt), phospho-GSK-3 3 ( $p$ -

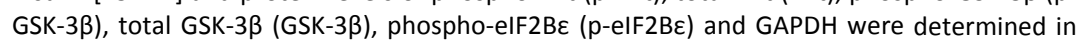
cell lysates by Western blot analysis. Levels of p-elF2B $\varepsilon$ were corrected for GAPDH. (D) $C_{2} C_{12}$ myotubes were treated for $24 \mathrm{~h}$ with $\mathrm{LiCl}$ [1, 5 and $10 \mathrm{mM}$ ] or vc (HBSS), or alternatively with CHIR99021 [1, 2, 3, 5, 7, $10 \mu \mathrm{M}]$ or vc (DMSO), for $18 \mathrm{~h}$ to inhibit GSK-3 $\beta$ activity. mRNA abundance of atrogin-1 and MuRF1 was assessed. All data shown are representative of 3 independent experiments (mean $\pm \mathrm{SEM}, \mathrm{n}=3$ ) (except $\mathrm{A}, \mathrm{n}=4$ ). ${ }^{*} \mathrm{p}<0.05$ compared with control; \# $\mathrm{p}<0.05$ refers to a difference between indicated conditions.

Similarly, supplementation with IGF-I or insulin resulted in a marked increase of

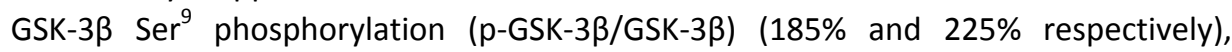
suggesting decreased GSK-3 $\beta$ activity. In addition, supplementing the culture medium with either IGF-I or insulin resulted in lowered levels of p-elF2B $\varepsilon$, the downstream substrate of GSK-3 $\beta$ ( $-92 \%$ and $-84 \%$ respectively), reflecting decreased GSK-3 $\beta$ activity (Figure 3.1C). To investigate the effects of GSK-3 $\beta$ inhibition in the presence of intact Akt signaling on the basal mRNA expression levels of atrogin-1 and MuRF1, $C_{2} C_{12}$ myotubes were treated with LiCl or CHIR99021, a more selective GSK-3 $\beta$ inhibitor (39). Inhibition of GSK-3 $\beta$ resulted in a significant dose-dependent downregulation of atrogin-1 mRNA expression (Figure 3.1D), while MuRF1 expression levels remained unaffected (data not shown). Maximal inhibition of atrogin-1 mRNA expression was noted at concentrations of $10 \mathrm{mM} \mathrm{LiCl}$ concentration (-36\%) or $7 \mu \mathrm{M}$ CHIR99021 ($56 \%)$. No cell death was observed after prolonged treatment with either $\mathrm{LiCl}$ or CHIR99021. Inhibition of GSK-3 $\beta$ enzyme activity therefore recapitulates the inhibition of atrogin-1, but not MuRF1 expression following IGF-I or insulin signaling.

\section{Induction of atrogin-1 but not MuRF1 mRNA expression by blockade of basal IGF-I signaling requires GSK-3 $\beta$ activity}

Next, we investigated how GSK-3 $\beta$ activity and atrogin-1/MuRF1 expression were related under conditions of atrophy induced by abrogation of basal IGF-I signaling. Inhibition of PI-3K using LY294002 resulted in a clear morphological atrophy phenotype (Figure 3.2A) and was characterized by a significant loss of MyHC-f (-65\%) protein levels after $48 \mathrm{~h}$ (Figure 3.2B). Furthermore, MyLC-1 (-52\%) and MyLC-3 (-65\%) protein levels were also diminished after $48 \mathrm{~h}$ exposure to LY294002 (Figure 3.2B). Alongside loss of myofibrillar proteins, LY294002-treatment also caused decreased expression of GAPDH (-66\%) and $\alpha$-tubulin (-60\%, data not shown). A decrease in myosin protein abundance was already apparent after $24 \mathrm{~h}$ (Supplemental Figure S3.1A) but the effects were more evident after $48 \mathrm{~h}$ of LY294002-treatment. 
When using LY294002, a significant reduction of basal p-Akt/Akt (-47\%) was observed, demonstrating effective inhibition of basal IGF-I signaling (Figure 3.2C). Moreover, diminished IGF-I/Akt signaling significantly reduced p-GSK-3 $\beta / G S K-3 \beta$ levels $(-76 \%)$, while levels of $p$-elF2B $\varepsilon$ were elevated $(828 \%)$, indicative of increased GSK-3 $\beta$ activity (Figure $3.2 \mathrm{C}$ ). Similarly, abrogation of basal IGF-I signaling by direct inhibition of Akt using Akti-1/2 (p-Akt/Akt: -94\%) resulted in a lowered p-GSK-3ß/GSK$3 \beta$ ratio $(-57 \%)$ and increased phosphorylation of elF2BE (208\%), suggestive of increased GSK-3 $\beta$ activity (Figure 3.2C). Moreover, incubation with LY294002 caused a dose-dependent induction of atrogin-1 and MuRF1 mRNA levels (Figure 3.2D). LY294002 concentrations greater than $15 \mu \mathrm{M}$ did not further increase atrogene expression, and this concentration is well within the range used for $\mathrm{PI}-3 \mathrm{~K}$ inhibition $(13,30,55)$. Inhibition of Akt kinase activity using Akti-1/2 also significantly induced the expression of atrogin-1 as well as MuRF1 mRNA (Figure 3.2D), confirming the association between increased GSK-3 $\beta$ activity and the induction of atrogene expression observed with LY294002.

To investigate whether GSK-3 $\beta$ activity is required for increased atrogene expression in response to inhibition of Akt signaling, myotubes were simultaneously treated with LY294002 and CHIR99021 to inhibit GSK-3 $\beta$ activity. Interestingly, whereas induction of atrogin-1 expression was fully abrogated by CHIR99021, LY294002-induced MuRF1 mRNA transcript levels were not affected by GSK-3 $\beta$ inhibition (Figure 3.2E).

\section{Induction of atrogin-1 \& MuRF1 mRNA expression by dexamethasone requires GSK-3 $\beta$ activity}

In the clinical setting, GCs are still an important contributor to muscle wasting in acute and chronic disease (44), making Dex-supplementation a relevant in vitro and in vivo model for muscle atrophy $(8,12,21,42)$. To confirm the differential dependency of atrogin-1 and MuRF1 mRNA expression on GSK-3 $\beta$ activity in a second atrophy model, $\mathrm{C}_{2} \mathrm{C}_{12}$ myotubes were exposed to the synthetic GC Dex for $48 \mathrm{~h}$. In analogy with previous findings using LY294002, exposure to Dex gave rise to a clear morphological atrophy phenotype (Figure 3.3A) and likewise resulted in a marked loss of MyHC-f $(-43 \%)$, MyLC-1 (-90\%) and MyLC-3 (-56\%) protein levels (Figure 3.3B), whereas GAPDH protein abundance (-24\%) was only slightly affected by Dex-treatment. A decrease in myosin protein abundance was already apparent after $24 \mathrm{~h}$ (Supplemental Figure S3.2A) but the effects were more pronounced after $48 \mathrm{~h}$ of exposure to Dex. 
A

vc

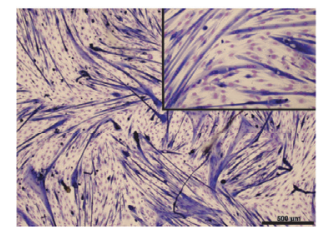

LY294002

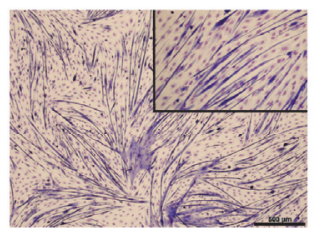

B
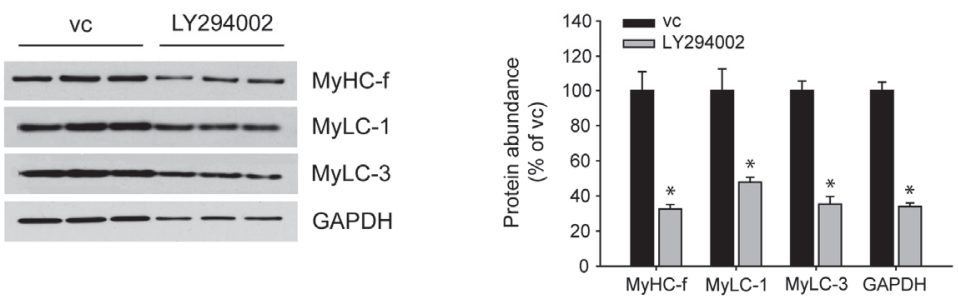

C
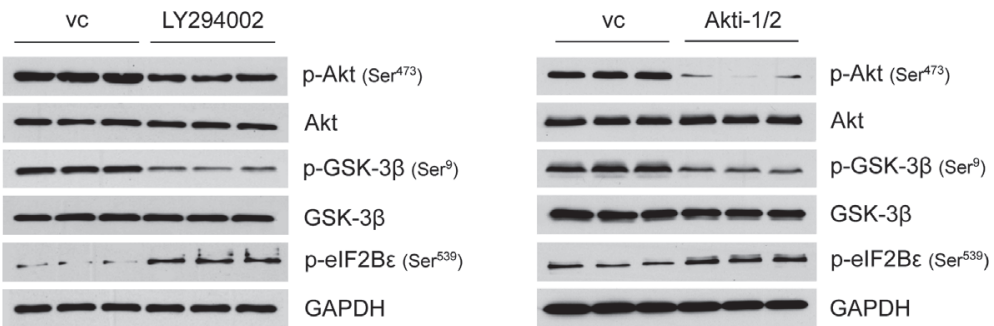

D
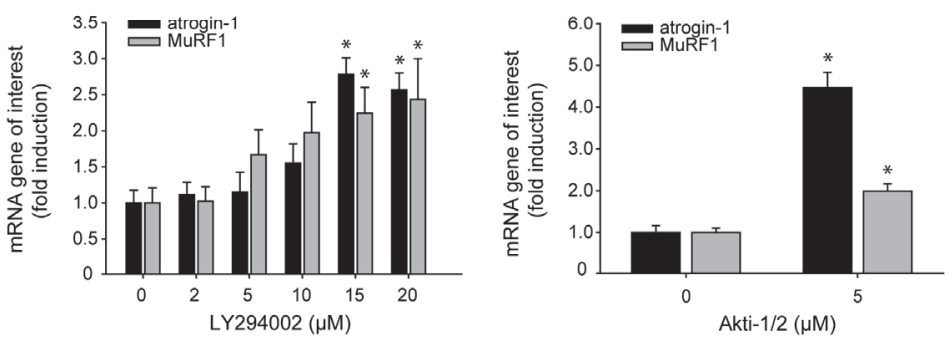

E
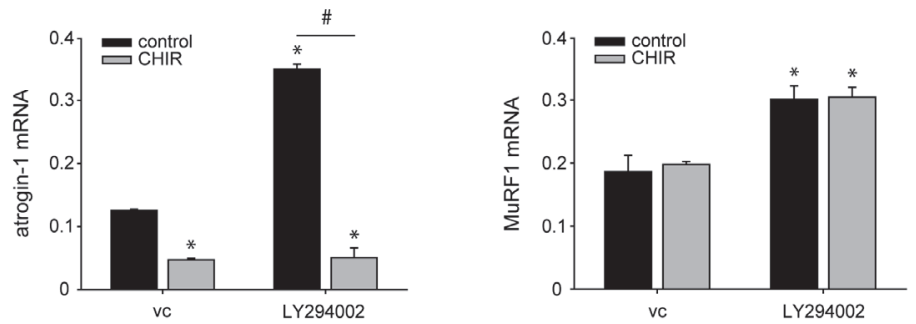
Figure 3.2 Induction of atrogin-1 mRNA expression by blockade of basal IGF-I signaling requires GSK-3 $\beta$ activity.

(A) Myotubes at 5 days of differentiation were treated with LY294002 [15 $\mu \mathrm{M}]$ or vehicle control (vc) (DMSO) for $48 \mathrm{~h}$ and then assessed for morphological changes by staining with May-Grünwald Giemsa (40X magnification, scale bar $=500 \mu \mathrm{m}$; inset $=100 \mathrm{X}$ magnification). (B) $C_{2} C_{12}$ myotubes were exposed to LY294002 [15 $\mu \mathrm{M}$ ] or vc (DMSO) for $48 \mathrm{~h}$. Protein levels of MyHC-f, MyLC-1, MyLC-3 and GAPDH were determined in sonicated cell lysates by Western blot analysis. (C) $C_{2} C_{12}$ myotubes were cultured for $2 \mathrm{~h}$ in the presence of LY294002 [15 $\mu \mathrm{M}$ ] or Akti-1/2 [5 $\mu \mathrm{M}]$ inhibitors or vc (DMSO). Protein levels of phospho-Akt (p-Akt), total Akt (Akt),

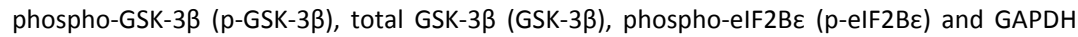
were determined in cell lysates by Western blot analysis. (D) $C_{2} C_{12}$ myotubes were cultured for $18 \mathrm{~h}$ with LY294002 [15 $\mu \mathrm{M}$ ] or Akti-1/2 [5 $\mu \mathrm{M}$ ] inhibitors or vc (DMSO) and the mRNA abundance of atrogin-1 and MuRF1 was determined. (E) $C_{2} C_{12}$ myotubes were treated for $18 \mathrm{~h}$ with LY294002 [15 $\mu \mathrm{M}$ ] or vc (DMSO) and/or CHIR99021 [7 $\mu \mathrm{M}$ ], after which mRNA abundance of atrogin-1 and MuRF1 was assessed. All data shown are representative of 3 independent experiments (mean \pm SEM, n=3) (except C, LY294002 $n=4$ ). * $p<0.05$ compared with control; $\# \mathrm{p}<0.05$ refers to a difference between indicated conditions. NS: not significant.

The Dex concentrations used here have previously been used in the context of atrophy $(8,48)$, and no cell death was observed as a consequence of Dex after 24 or $48 \mathrm{~h}$. Moreover, neither LY294002 nor Dex-treatment increased levels of cleaved caspase-3, which indicated that prolonged exposure to these stimuli did not induce apoptosis in $\mathrm{C}_{2} \mathrm{C}_{12}$ myotubes (Supplemental Figure S3.1B, S3.2B).

Supplementing the culture medium with Dex resulted in a significant dosedependent induction of atrogin-1 mRNA expression (Figure 3.3C). Although less distinct, MuRF1 transcript levels were also upregulated in response to Dex (Figure 3.3D). Inhibition of GSK-3 $\beta$ activity, by CHIR99021 completely abolished Dex-induced increases in atrogin-1 mRNA abundance (Figure 3.3C). However, this dependency on GSK-3 $\beta$ activity was not observed for MuRF1 expression (Figure 3.3D).

\section{Myotube atrophy induced by impaired IGF-I/Akt signaling depends on GSK-3 $\beta$}

To further address whether muscle atrophy and associated atrogene expression are dependent on GSK-3 $\beta$, its expression was transiently silenced using siRNA (vc/sh-GSK-3 3 ) resulting in a $80 \%$ decrease in GSK-3 $\beta$ protein levels compared with myotubes transfected with control siRNA (vc/sh-control) (Figure 3.4A). Decreased levels of p-elF2B $\varepsilon$ (-99\%) further confirmed absence of GSK-3 $\beta$ activity (Figure 3.4A). 
A
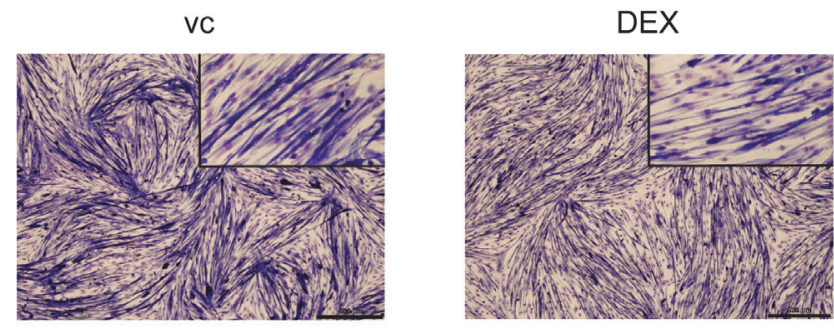

B
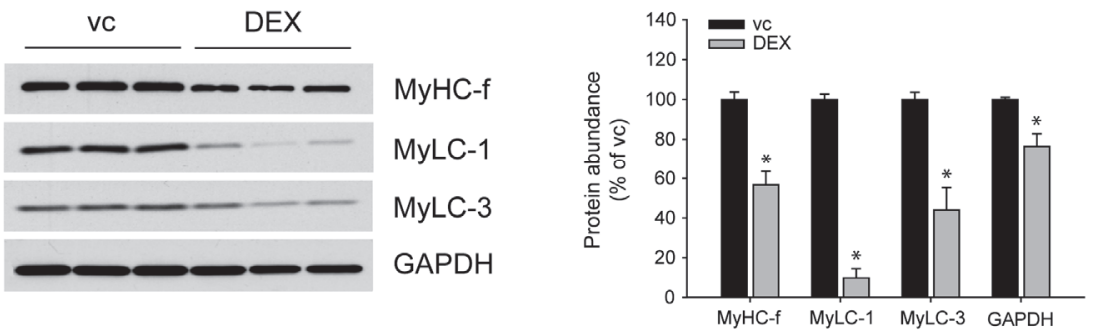

C

D
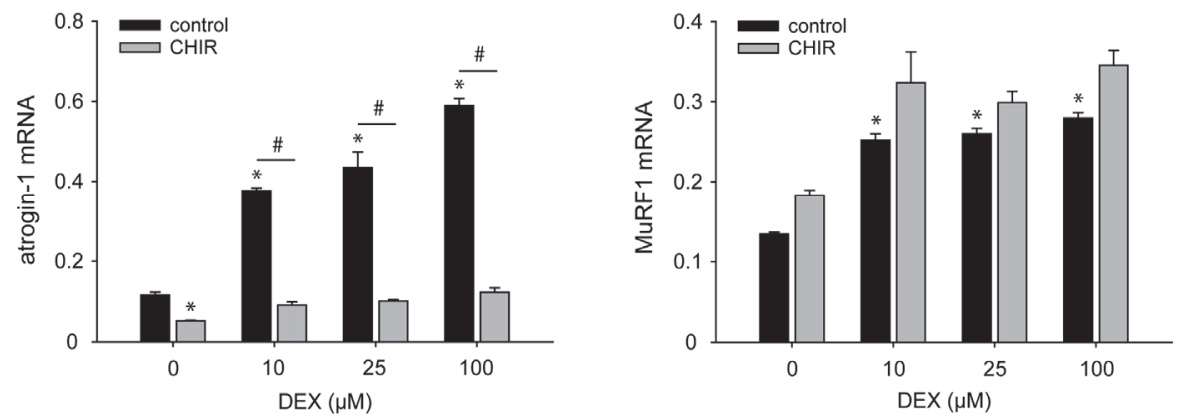

Figure 3.3 Induction of atrogin-1/MuRF1 mRNA expression by dexamethasone requires GSK-3 $\beta$ activity.

(A) Myotubes at 5 days of differentiation were treated with Dex [25 $\mu \mathrm{M}]$ or vehicle control (vc) (DMSO) for $48 \mathrm{~h}$ and then assessed for morphological changes by staining with MayGrünwald Giemsa (40X magnification, scale bar $=500 \mu \mathrm{m}$; inset $=100 \mathrm{X}$ magnification). (B) $\mathrm{C}_{2} \mathrm{C}_{12}$ myotubes were exposed to Dex [25 $\mu \mathrm{M}$ ] or vc (DMSO) for $48 \mathrm{~h}$. Protein levels of MyHC-f, MyLC-1, MyLC-3 and GAPDH were determined in sonicated cell lysates by Western blot analysis. (C)(D) $C_{2} C_{12}$ myotubes were treated for $24 \mathrm{~h}$ with Dex [10, 25 and $100 \mu \mathrm{M}$ ] or vc (DMSO) and/or CHIR99021 [7 $\mu \mathrm{M}$ ] after which mRNA abundance of atrogin-1 (C) and MuRF1 (D) was determined. All data shown are representative of 3 independent experiments (mean \pm SEM, $n=3$ ). * $p<0.05$ compared with control; \# $p<0.05$ refers to a difference between indicated conditions. 
GSK-3 isoform specific knockdown was confirmed by evaluation of GSK-3 $\alpha$ and GSK-3 $\beta$ mRNA expression (Supplemental Figure S3.3A). We next sought to examine the effects of the absence of endogenous GSK-3 $\beta$ on the mRNA expression of atrogin1 and MuRF1. GSK-3 $\beta$-deficient or appropriate control myotubes were subjected to LY294002-treatment for $24 \mathrm{~h}$. Surprisingly, in contrast to former results obtained with the pharmacological inhibitor CHIR99021, genetic ablation of GSK-3 $\beta$ significantly reduced basal expression and induction of atrogin-1 (Figure 3.4B) as well as MuRF1 (Figure 3.4C) mRNA levels in response to LY294002.

To investigate whether the reduced induction of atrogin-1 and MuRF1 mRNA expression after knockdown of GSK-3 $\beta$ corresponded with an attenuated atrophy

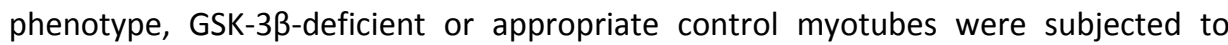
LY294002-treatment for $48 \mathrm{~h}$ to evaluate myofibrillar protein content. Supplementation with LY294002 (LY/sh-control) resulted in a significant loss of MyHC-f (-56\%), MyLC-1 (-43\%) and MyLC-3 (-46\%) protein content compared with control myotubes (vc/sh-control). However, upon genetic ablation of GSK-3 $\beta$ (LY/sh-GSK-3ß), the reduction of MyHC-f (-26\%), MyLC-1 (-7\%) and MyLC-3 (-18\%) was markedly attenuated compared with control myotubes (vc/sh-control) in response to

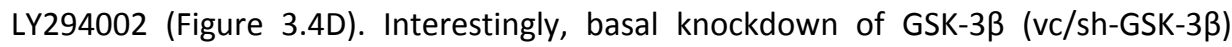
appeared to slightly increase protein levels of MyHC-f (5\%), MyLC-1 (15\%) and MyLC-3 (35\%) compared with myotubes transfected with control siRNA (vc/sh-control) (Figure 3.4D). Importantly, GSK-3 $\beta$ ablation did not prevent decreased GAPDH expression in response to LY294002, suggesting a specific role for GSK-3 $\beta$ in the regulation of myofibrillar protein loss. To investigate whether this attenuated loss of myofibrillar content corresponded to preservation of myotube size in response to LY294002, GSK$3 \beta$-deficient and sh-control myotubes were exposed to LY294002 for $48 \mathrm{~h}$ after which the cells were stained. Indeed, GSK-3ß-deficient myotubes appeared more resistant to LY294002-induced atrophy, characterized by the preservation of myotube size (Supplemental Figure S3.1C).

Myofibrillar protein degradation has been shown to be mediated by MuRF1. So far, no known myofibrillar protein targets have been described for atrogin-1. Therefore, myofibrillar protein content was evaluated in MuRF1-deficient (sh-MuRF1) myotubes and $\mathrm{C}_{2} \mathrm{C}_{12}$ control myotubes following LY294002-treatment for $48 \mathrm{~h}$ (Figure 3.4E). Knockdown of MuRF1 expression was evaluated by qRT-PCR analysis (Supplemental Figure S3.3C). Similar to genetic suppression of GSK-3 $\beta$, ablation of MuRF1 expression largely prevented loss of MyHC-f (-9\%), MyLC-1 (-17\%) and MyLC-3 $(-27 \%)$ protein content compared with $\mathrm{C}_{2} \mathrm{C}_{12}$ control myotubes in response to LY294002 (MyHC-f (-72\%), MyLC-1 (-67\%) and MyLC-3 (-66\%)). 
A

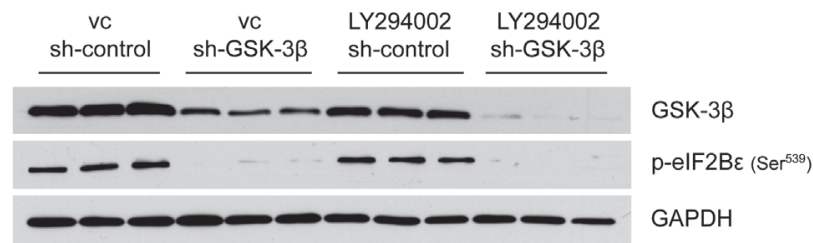

B
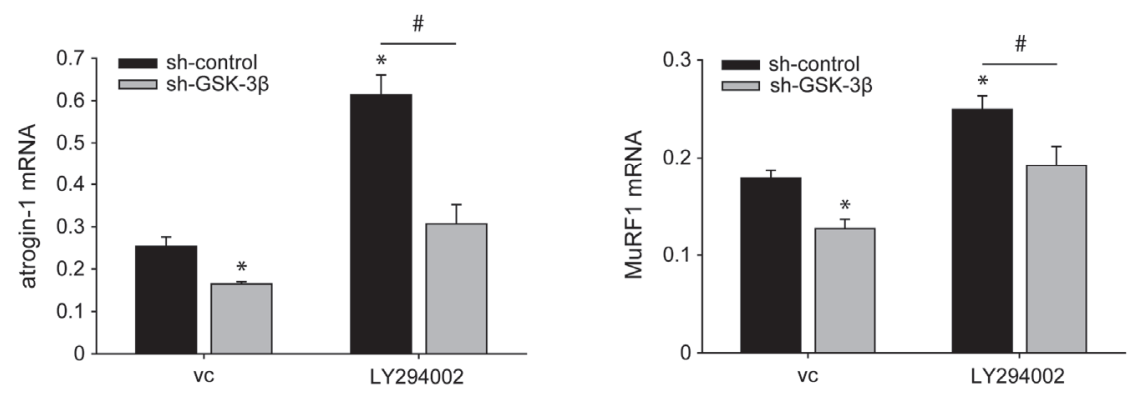

D

E
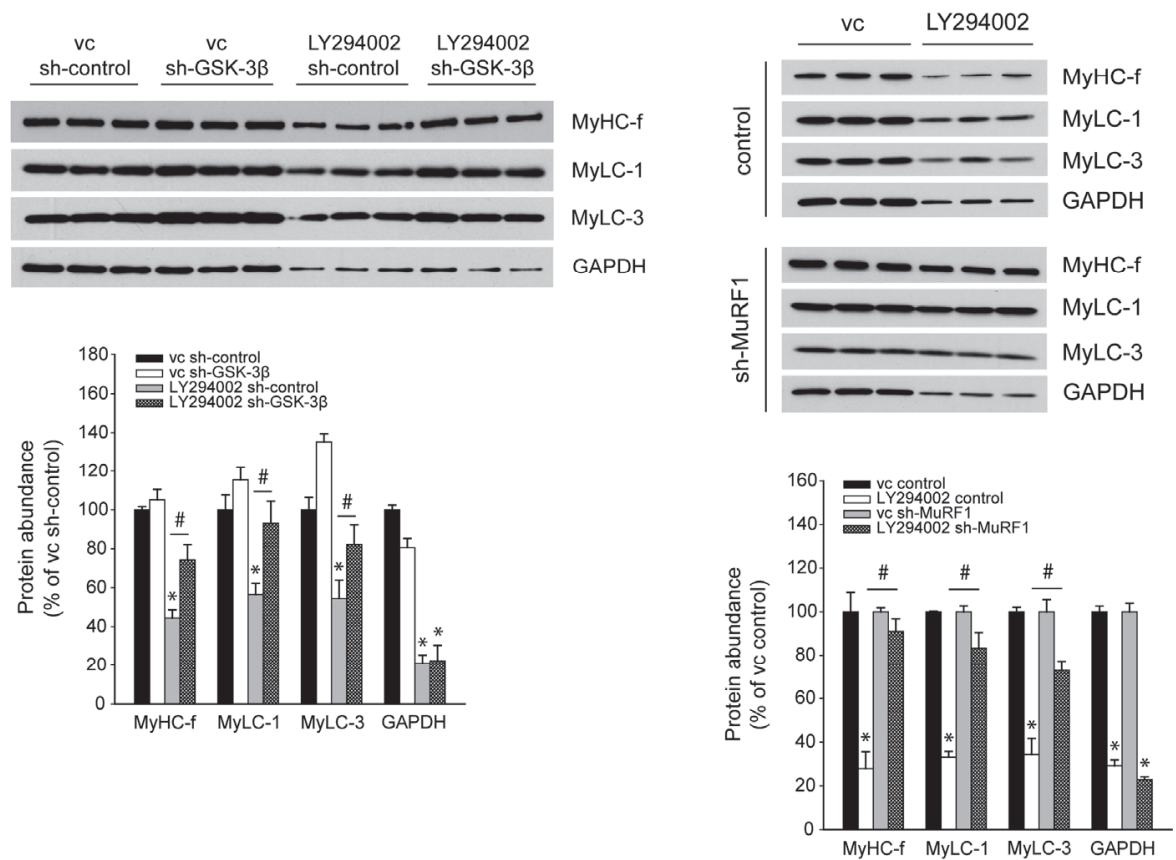
Figure 3.4 Myotube atrophy induced by impaired IGF-I/Akt signaling depends on GSK-3 $\beta$.

(A) $\mathrm{C}_{2} \mathrm{C}_{12}$ myotubes (4 days) were transiently transfected with control siRNA (sh-control), or GSK-3 $\beta$ siRNA (sh-GSK-3 $\beta$ ). $24 \mathrm{~h}$ post-transfection the $\mathrm{C}_{2} \mathrm{C}_{12}$ myotubes ( 5 days) were cultured in the presence of LY294002 [15 $\mu \mathrm{M}$ ] or vehicle control (vc) (DMSO) for $24 \mathrm{~h}$. Protein levels of

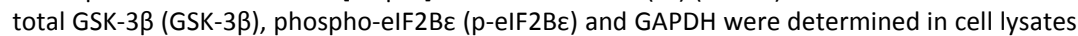
by Western blot analysis. (B)(C) $C_{2} C_{12}$ myotubes (4 days) were transiently transfected with shcontrol, or sh-GSK-3 $\beta$. $24 \mathrm{~h}$ post-transfection the $\mathrm{C}_{2} \mathrm{C}_{12}$ myotubes were cultured in the presence of LY294002 [15 $\mu \mathrm{M}$ ] or vc (DMSO) for $24 \mathrm{~h}$. The mRNA abundance of atrogin-1 (B) and MuRF1 (C) was determined. (D) Alternatively, $\mathrm{C}_{2} \mathrm{C}_{12}$ myotubes (4 days) were transiently transfected with sh-control, or sh-GSK-3 $\beta$. $24 \mathrm{~h}$ post-transfection the $\mathrm{C}_{2} \mathrm{C}_{12}$ myotubes were cultured in the presence of LY294002 [15 $\mu \mathrm{M}$ ] or vc (DMSO) for $48 \mathrm{~h}$. Protein levels of MyHC-f, MyLC-1, MyLC-3 and GAPDH were determined in sonicated cell lysates by Western blot analysis. (E) Stably transfected myoblasts (sh-MuRF1) and native $C_{2} C_{12}$ myoblasts were induced to differentiate for 5 days after which they were cultured in the presence of LY294002 [15 $\mu \mathrm{M}$ ] or vc (DMSO) for $48 \mathrm{~h}$. Protein levels of MyHC-f, MyLC-1, MyLC-3 and GAPDH were determined in sonicated cell lysates by Western blot analysis. All data shown are representative of 3 independent experiments (mean $\pm S E M, n=3$ ). ${ }^{*} p<0.05$ compared with control; \# $\mathrm{p}<0.05$ refers to a difference between indicated conditions. NS: not significant.

\section{Myotube atrophy induced by glucocorticoids depends on GSK-3 $\beta$}

Subsequently, we attempted to confirm the previous findings in the model of GCinduced atrophy. To this end, we employed a stable cell line (sh-control/GSK-3ß) to investigate the effects of ablation of GSK-3 $\beta$ expression on the induction of atrogin-1 and MuRF1 in response to Dex. After differentiation for $72 \mathrm{~h}$ GSK-3 $\beta$-deficient cells displayed enhanced myotube formation compared with sh-control cells (53). At day 5 of differentiation these differences were no longer present. Similar to the results obtained with LY294002, atrogin-1 (Figure 3.5B) as well as MuRF1 (Figure 3.5C) mRNA expression was significantly reduced in GSK-3 $\beta$-deficient compared with control myotubes following treatment with Dex. The isoform specificity of the knockdown was confirmed by mRNA expression analysis of GSK-3 $\beta$ and GSK-3 $\alpha$ (Supplemental Figure S3.3B).

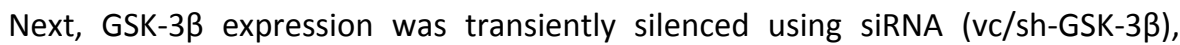
resulting in an $87 \%$ decrease in GSK-3 $\beta$ protein levels compared with myotubes transiently transfected with control siRNA (vc/sh-control) (Figure 3.5A). Decreased levels of p-elF2B $\varepsilon$ further confirmed absence of GSK-3 $\beta$ activity (Figure 3.5A). Supplementation with Dex for $48 \mathrm{~h}$ resulted in a significant loss of MyHC-f (-28\%), MyLC-1 (-47\%) and MyLC-3 (-78\%) protein content compared with control myotubes (vc/sh-control). However, upon genetic ablation of GSK-3 $\beta$, the reduction of MyHC-f was completely prevented (128\% of control), while the decrease in MyLC-1 (-12\%) and MyLC-3 (-6\%) protein abundance was markedly attenuated compared with control

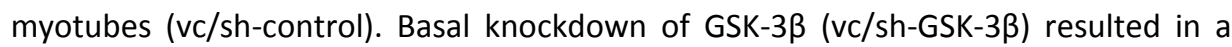
slight increase of MyHC-f (30\%) and MyLC-3 (28\%) protein levels compared with myotubes transfected with control siRNA (vc/sh-control). Here too, GSK-3ß-deficient myotubes appeared more refractory to Dex-induced atrophy compared with vc-control myotubes, based on the preservation of myotube size (Supplemental Figure S3.2C). 
A

\begin{tabular}{|c|c|c|c|}
\hline $\begin{array}{c}\text { vc } \\
\text { sh-control }\end{array}$ & $\begin{array}{c}\text { vc } \\
\text { sh-GSK-3 } \beta\end{array}$ & $\begin{array}{c}\text { DEX } \\
\text { sh-control }\end{array}$ & $\begin{array}{c}\text { DEX } \\
\text { sh-GSK-3 }\end{array}$ \\
\hline
\end{tabular}

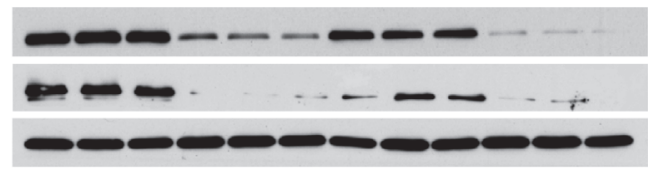

GSK-3ß

p-elF2B $\varepsilon\left(\operatorname{Ser}^{539}\right)$

GAPDH

B

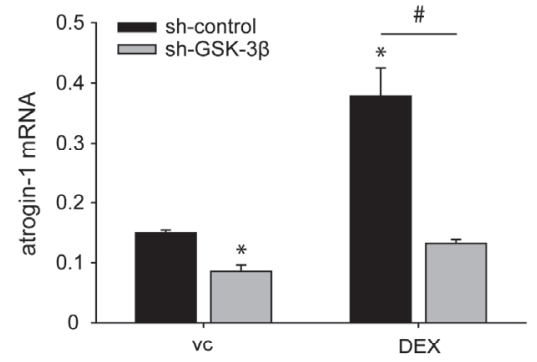

D
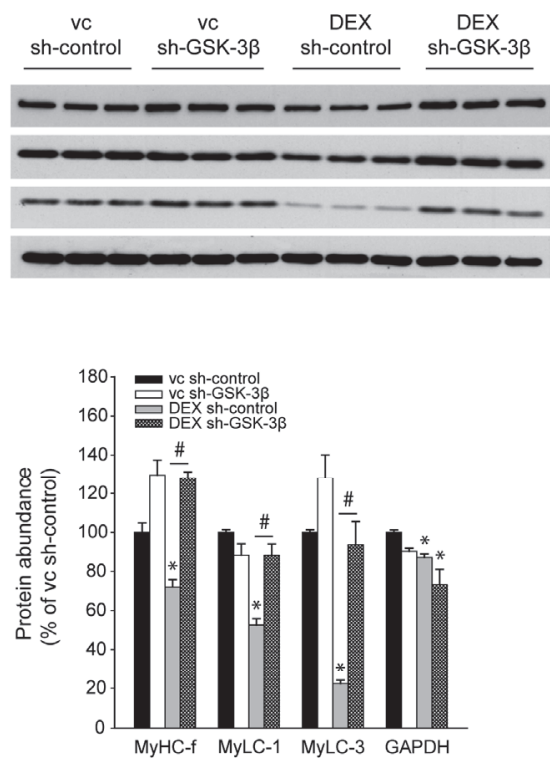

C

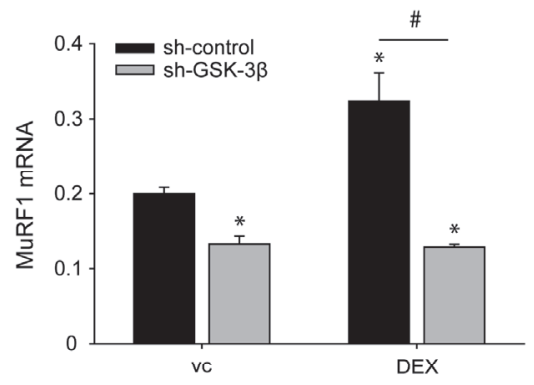

E
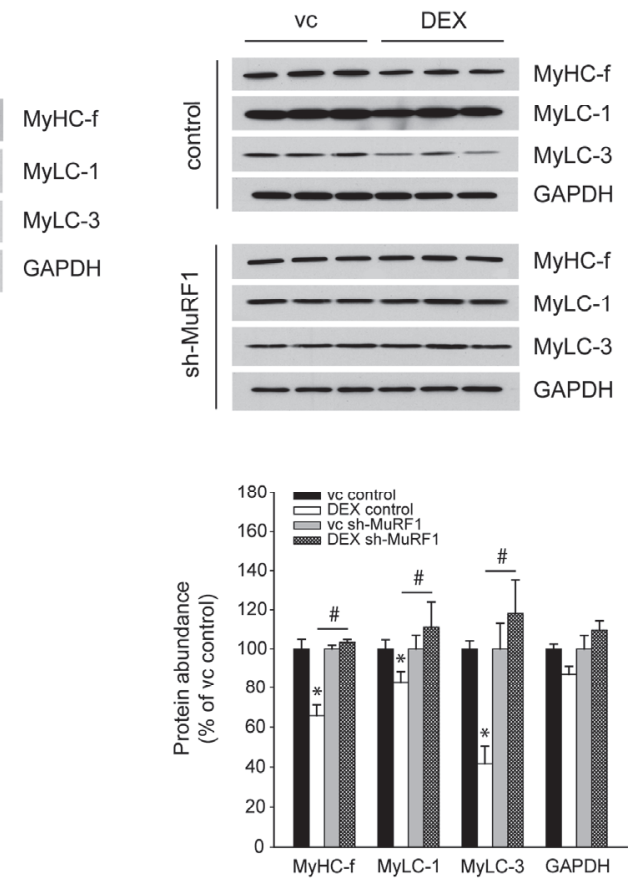
Figure 3.5 Myotube atrophy induced by glucocorticoids depends on GSK-3 3 .

(A) $\mathrm{C}_{2} \mathrm{C}_{12}$ myotubes (4 days) were transiently transfected with control siRNA (sh-control), or GSK-3 3 siRNA (sh-GSK-3 $\beta$ ). $24 \mathrm{~h}$ post-transfection the $\mathrm{C}_{2} \mathrm{C}_{12}$ myotubes ( 5 days) were cultured in the presence of Dex [25 $\mu \mathrm{M}$ ] or vehicle control (vc) (DMSO) for $24 \mathrm{~h}$. Protein levels of total

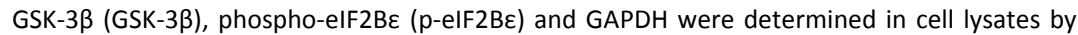
Western blot analysis. GSK-3 3 and p-elF2B $\varepsilon$ were not corrected for GAPDH. (B)(C) Stably transfected myoblasts (sh-control/GSK-3 $\beta$ ) were induced to differentiate for 5 days after which they were cultured in the presence of Dex [25 $\mu \mathrm{M}$ ] or vc (DMSO) for $24 \mathrm{~h}$. Next, the mRNA abundance of atrogin-1 (B) and MuRF1 (C) was determined. (D) Alternatively, $\mathrm{C}_{2} \mathrm{C}_{12}$ myotubes (4 days) were transiently transfected with sh-control, or sh-GSK-3B. $24 \mathrm{~h}$ posttransfection the $\mathrm{C}_{2} \mathrm{C}_{12}$ myotubes were cultured in the presence of Dex [25 $\mu \mathrm{M}$ ] or vc (DMSO) for $48 \mathrm{~h}$. Protein levels of MyHC-f, MyLC-1, MyLC-3 and GAPDH were determined in sonicated cell lysates by Western blot analysis. (E) Stably transfected myoblasts (sh-MuRF1) and native $\mathrm{C}_{2} \mathrm{C}_{12}$ myoblasts were induced to differentiate for 5 days after which they were cultured in the presence of Dex [25 $\mu \mathrm{M}$ ] or vc (DMSO) for $48 \mathrm{~h}$. Protein levels of MyHC-f, MyLC-1, MyLC-3 and GAPDH were determined in sonicated cell lysates by Western blot analysis. All data shown are representative of 3 independent experiments (mean \pm SEM, $n=3$ ). ${ }^{*} p<0.05$ compared with control; \# $\mathrm{p}<0.05$ refers to a difference between indicated conditions. NS: not significant.

Next, MuRF1-deficient (sh-MuRF1) myotubes and $\mathrm{C}_{2} \mathrm{C}_{12}$ control myotubes were exposed to Dex for $48 \mathrm{~h}$ after which myofibrillar protein content was assessed. In analogy with the results obtained using LY294002, ablation of MuRF1 expression completely abolished loss of MyHC-f (103\%), MyLC-1 (111\%) and MyLC-3 (118\%) protein levels compared with $\mathrm{C}_{2} \mathrm{C}_{12}$ control myotubes in response to Dex (MyHC-f, $-34 \%$, MyLC-1, $-58 \%$ and MyLC-3, $-66 \%)$.

\section{Discussion}

Increased proteolysis during muscle atrophy is characterized by the up regulation of a distinct transcriptional program, including the induction of two muscle-specific ubiquitin E3 ligases, namely atrogin-1 and MuRF1 (15). In the present study, we have made use of the $C_{2} C_{12}$ cell culture model to unravel the role of GSK-3 $\beta$ in skeletal muscle atrophy. We found that GSK-3 $\beta$ controls basal and atrophy stimulus-induced expression of atrogin-1 and MuRF1. In addition, we demonstrated that absence of GSK-3 $\beta$ protein results in specific sparing of myofibrillar proteins (MyHC-f, MyLC-1 and MyLC-3) in response to atrophy stimuli such as Dex or impaired IGF-I/Akt signaling.

Decreased expression of atrogin-1 and MuRF1 in response to IGF-I (30) or insulin (42) has been reported previously. This effect has been attributed to Akt-mediated phosphorylation and subsequent cytoplasmic retention of the FoXO transcription factors following IGF-I/insulin signaling $(43,48)$. In parallel, Akt has also been shown to control GSK-3 $\beta$ kinase activity through inhibitory phosphorylation on $\mathrm{Ser}^{9}$ in response to anabolic stimuli (18). Conversely, abrogation of basal IGF-I signaling in myotubes using PI-3K or Akt blockade resulted in increased GSK-3 $\beta$ activity and a pronounced 
induction of both atrogin-1 and MuRF1 mRNA levels, which was in line with previous reports $(30,42)$. This correlation between GSK-3 $\beta$ activity and atrogene expression tempted us to address the requirement of GSK-3 $\beta$ protein and enzymatic activity in basal and atrophy stimulus-induced expression of atrogin-1 and MuRF1.

Several previous studies have postulated that GSK-3 $\beta$ could play a role in the regulation of skeletal muscle atrophy $(12,13,32)$. However, these findings were limited in the sense that GSK-3 $\beta$ was only modulated pharmacologically. We found that ablation of GSK-3 $\beta$ expression, using siRNA, suppressed basal atrogin-1 and MuRF1 mRNA levels and prevented their induction in response to LY294002. Identical results were obtained when Dex was used as an atrophy stimulus. These results confirmed our hypothesis that GSK-3 $\beta$ indeed plays a significant role in the signaling network governing atrogene expression. We next addressed the contribution of GSK-3 $\beta$ enzymatic activity in the regulation of atrogin-1 and MuRF1 expression. Although LiCl has been widely used as a GSK-3 $\beta$ inhibitor for decades (41), this compound is not completely specific and has been shown to affect other metabolic processes as well (10). We therefore employed a second inhibitor, CHIR99021, which has been shown to inhibit GSK-3 with at least 500-fold selectivity against 20 other protein kinases (39). We demonstrated that atrogin-1 mRNA expression was efficiently suppressed by GSK-3 $\beta$ inhibition using CHIR99021 or $\mathrm{LiCl}$, comparable to lowered basal expression of atrogin-1 following IGF-I -or insulin-treatment. These results are in concordance with a previous report by Evenson et al. who found that basal atrogin-1 mRNA expression was significantly lowered in response to insulin or modulation of GSK-3 $\beta$ activity (12). Earlier work by the group of Goldberg demonstrated the converse, i.e. increasing basal GSK-3 $\beta$ activity, by expressing a constitutively active form (caGSK-3 $\beta$ ), stimulated atrogin-1 promoter activity and increased mRNA expression of atrogin-1 (43).

Interestingly, although basal MuRF1 expression was efficiently suppressed by IGF-I or insulin, it was not affected by GSK-3 inhibition using CHIR99021 or LiCl: in contrast to GSK-3 $\beta$ knockdown, disruption of GSK-3 $\beta$ activity did not suppress LY294002 -or Dex-induced MuRF1 expression, despite strongly attenuating atrogin-1 mRNA levels. The notion that atrogin-1 and MuRF1 expression were differentially regulated in response to GSK-3 $\beta$ inactivation, is not consistent with findings by Evenson et al. which demonstrated that in response to Dex, both atrogin-1 and MuRF1 mRNA levels were suppressed after pharmacological inhibition of GSK-3 $\beta$ (12). Nevertheless, considering the fact that we employed two independent atrophy models and used two structurally unrelated GSK-3 inhibitors, our data strongly suggests that induction of atrogin-1, but not MuRF1 expression requires GSK-3 $\beta$ activity. In our own study, the apparent discrepancy between pharmacological inhibition and genetic ablation of GSK-3 $\beta$ with regard to MuRF1 expression unlikely resulted from off-target siRNA effects affecting GSK-3 $\alpha$, since mRNA expression analysis revealed that GSK-3 $\alpha$ mRNA 
levels remained unchanged despite efficient knockdown of GSK-3 $\beta$. Conversely, both $\mathrm{LiCl}\left[\mathrm{IC}_{50}=2 \mathrm{mM}\right]$ and CHIR99021 [IC $\left.\mathrm{C}_{50}=6.7 \mathrm{nM}\right]$ inhibit GSK-3 $\beta$ as well as GSK-3 $\alpha$ potently $(27,39)$. To address whether pharmacological inactivation of GSK-3 $\alpha$ interfered with suppression of MuRF1 despite absence of GSK-3 $\beta$ (kinase activity), GSK-3 $\beta$ deficient myotubes were supplemented with CHIR99021. In these conditions MuRF1 induction was still suppressed, similarly to myotubes treated with sh-GSK-3 $\beta$ only, arguing against non-specific effects of the pharmacological inhibitors masking the effects of GSK-3 $\beta$ enzyme inhibition on regulation of MuRF1 expression (data not shown).

Together these observations suggest a dependency for GSK-3 $\beta$ activity in the case of atrogin-1 mRNA expression following treatment with atrophy stimuli. Induction of MuRF1 mRNA, however, does not appear to require GSK-3 $\beta$ activity. Rather, the mere physical presence of GSK-3 $\beta$ appears to be required for the induction of MuRF1 mRNA upon treatment with either LY294002 or Dex. These observations suggest that GSK-3 $\beta$ controls atrogin-1 and MuRF1 expression by distinct mechanisms of which the exact nature remains to be determined. Differential regulation of atrogin-1 and MuRF1 in response to atrophy stimuli has been described before, since MuRF1 was exclusively increased in a mouse model of nuclear factor- $K B$ (NF-KB)-induced muscle atrophy (5). Moreover, a recent report by Yoshida et al. elegantly demonstrated that IGF-1 prevented angiotensin II-induced atrogin-1 but not MuRF-1 expression (63).

As previously indicated, the mRNA abundance of both E3-ligases was induced by LY294002 and the synthetic GC Dex, which has been described by others $(30,42,49)$. As the phenotypic consequences of GSK-3 $\beta$ modulation on muscle atrophy, e.g. muscle protein content had not yet been defined, we determined whether myofibrillar protein loss associated with up regulation of atrogin-1 and MuRF1 was dependent on GSK-3 $\beta$. Prolonged exposure to either LY294002 or Dex indeed resulted in a marked reduction of MyHC-f, MyLC-1 and MyLC-3 protein abundance. Importantly, absence of GSK-3 $\beta$ was associated with a marked attenuation of the loss of myofibrillar protein abundance and myotube size in response to either LY294002 -or Dex-induced atrophy.

In certain instances LY294002 and Dex have been shown to induce apoptosis $(26,47)$, which could potentially play a role in the onset and progress of loss of myofibrillar proteins. However, these observations were primarily made in cancer cell lines in which the PI3K/Akt pathway was constitutively active. GSK-3 $\beta$ has also been implicated in the regulation of apoptotic signaling (1). We found no increased levels of cleaved caspase-3 in response to LY294002 or Dex, and knockdown of GSK-3 $\beta$ did not increase levels of cleaved caspase-3 either. It is therefore unlikely that loss of myofibrillar proteins and atrophy induced by LY294002 and Dex, and rescue by GSK$3 \beta$ suppression involves modulation of apoptosis. 
Throughout this study the protein abundance of GAPDH and $\alpha$-tubulin (data not shown), both non-myofibrillar proteins, was reduced in response to LY294002, and in a lesser extent to Dex. It is well-known that the rate of protein turnover differs highly between proteins. Considering the low turnover rate of myofibrillar proteins, inhibition of protein synthesis, which likely occurred in response to LY294002, probably affected myosin protein expression to a lesser extent than GAPDH. Despite the protective effect of GSK-3 $\beta$ absence on myofibrillar protein loss, the suppressed levels of atrogin-1 and MuRF1 only provide associative support for the notion that atrophy was reversed by preventing increased proteolysis. Nevertheless, a number of observations in this study provide indirect evidence to suggest that the maintenance of myofibrillar proteins in absence of GSK-3 $\beta$ was rather the result of decreased proteolysis as opposed to increased protein synthesis.

In recent years, numerous reports have attributed an important role for GSK-3 $\beta$ in the regulation of protein synthesis and hypertrophy $(40,56)$. Suppression of endogenous GSK-3 $\beta$ expression resulted in a slight increase of MyHC-f, MyLC-1 and MyLC-3 protein levels. This corresponded with decreased elF2B $\varepsilon$ phosphorylation levels indicative of increased potential for mRNA translation initiation, but as GAPDH levels were not affected, general protein synthesis was likely not increased. Rather, in absence of GSK-3 $\beta$ basal mRNA expression of atrogin-1 and MuRF1 was reduced, which may have resulted in a selective decrease of myofibrillar protein degradation. In case of LY294002 as an atrophy stimulus, general protein synthesis was likely decreased (55) due to blockade of Akt/mTORC1 signaling and Akt-mediated inhibition of GSK-3 $\beta$, which may have contributed to decreased GAPDH protein abundance. However, inhibition of GSK-3 $\beta$ is unlikely to restore general protein synthesis in presence of LY294002, as in absence of mTORC1 activity 4E-BP1 and S6K1 would still be impaired, resulting in low translational activity (46). Moreover, genetic ablation of GSK-3 $\beta$ under these conditions was not sufficient to restore GAPDH protein expression, whereas myofibrillar protein loss was strongly attenuated, suggesting that depletion of GSK-3 $\beta$ preserves contractile proteins through inhibition of proteolysis rather than through stimulation of protein synthesis. This notion is further supported by similar findings when Dex was used. Effects of Dex on myotube protein synthesis are much less pronounced (35), but nevertheless, a marked GSK-3 $\beta$-dependent loss of myofibrillar protein with marginal effects on GAPDH (and $\alpha$-tubulin, data not shown) was observed, suggesting GSK-3 $\beta$-dependent proteolysis. It is noteworthy that in the Dex atrophy model the housekeepers GAPDH and $\alpha$-tubulin were affected to a lesser extent than with $\mathrm{PI}-3 \mathrm{~K}$ blockade, in spite of a distinct loss of myosin protein abundance. The preferential depletion of contractile proteins in response to Dex observed here likely occurred in an UPS-dependent manner, as Clarke et al. demonstrated that MuRF1 is responsible for the targeted destruction of MyHC in a model of GC-associated muscle proteolysis (Dex) (8). In addition, recent data by Cohen et al. revealed that degradation of myosin-binding protein $C$ (MyBP-C) and myosin 
light chains 1 and 2 (MyLC-1 and MyLC-2) was MuRF1-dependent (9). Our MuRF1 shRNA experiments confirm that Dex-induced loss of myofibrillar proteins requires MuRF1 expression, and extend these findings to the MuRF1 dependency of LY294002 myotube atrophy and associated loss of myofibrillar protein abundance. These findings further strengthen the notion that the blockade of MuRF1 expression is responsible for the protective effect of GSK-3 $\beta$ absence on myotube size and myofibrillar protein levels, and further suggest GSK-3 $\beta$ is required for UPS-mediated muscle proteolysis.

As mentioned earlier, gene expression analysis revealed that enzymatic inhibition of GSK-3 $\beta$ attenuated atrophy stimulus-induced atrogin-1 expression, while MuRF1 expression levels remained unaffected. Interestingly, pharmacological inhibition of GSK-3 $\beta$, using CHIR99021 or $\mathrm{LiCl}$, proved insufficient to significantly reverse or attenuate the loss of myofibrillar proteins induced by Dex or LY294002 (Supplemental Figure S3.4A-B). In contrast, earlier studies showed that pharmacological GSK-3 $\beta$ inhibition reduced muscle proteolysis in vitro as well as ex vivo $(12,13,32)$. However these studies did not address reversibility of an atrophy phenotype upon GSK-3 $\beta$ inhibition. Instead, differences in overall protein turn over were presented. Our findings illustrate that suppression of only atrogin-1 expression was not sufficient to prevent myotube atrophy. It is therefore conceivable that MuRF1 was responsible for the loss of contractile proteins in both atrophy models, adding to the belief that MuRF1 is the predominant E3-ligase implicated in the targeted destruction of thick filament myofibrillar proteins $(8,9)$.

To date, there are only two confirmed substrates of atrogin-1, namely elF3f and MyoD (14). It was shown that up regulation of atrogin-1 results in breakdown of the translation initiation factor elF3f, indicating that in addition to protein degradation atrogin-1 is also able to influence protein synthesis $(29,58)$. Loss of MyoD, on the other hand, has detrimental effects on the maintenance of muscle-specific gene transcription and muscle homeostasis (28). Interestingly, our data reveals GSK-3 $\beta$ dependency of atrogin-1 mRNA expression. This suggests a potential role for GSK-3 $\beta$ in the regulation of transcription and mRNA translation via control of atrogin-1 expression, despite the lack of direct evidence to support altered regulation of myofibrillar protein synthesis in absence of GSK-3 $\beta$ in our study. Nevertheless, it remains tempting to speculate that, in analogy to Akt, GSK-3 $\beta$ coordinates contractile protein degradation and synthesis.

While an important role of GSK-3 $\beta$ in skeletal muscle atrophy is emerging, significant gaps still remain in our understanding of the regulation of GSK-3 $\beta$ and its downstream effector molecules. In this context, it would be of great interest to investigate the potential interaction between GSK-3 $\beta$ and the FoXO transcription factors as they have been shown to be key transcriptional regulators of the catabolic 
response during atrophy. It would also be intriguing to investigate a possible interaction between GSK-3 $\beta$ and the glucocorticoid receptor (GR) as the GR has been shown to synergistically cause MuRF1 promoter transactivation with FoXO (57). In addition, GR activation has been shown to impede PI-3K/Akt signaling, allowing FoXO translocation and atrogene expression (23). The data presented in this study sheds new light on the contribution of GSK-3 $\beta$ to skeletal muscle atrophy and future studies may provide a platform for the development of novel therapeutic strategies to prevent or reverse muscle wasting in chronic disease and ageing.

In conclusion, atrogin-1 and MuRF1 expression is regulated by GSK-3 $\beta$-dependent mechanisms, which differentially rely on GSK-3 $\beta$ activity. In addition, the present findings reveal for the first time that the loss of endogenous GSK-3 $\beta$ protein results in specific sparing of myofibrillar proteins and myotube size during atrophy. 


\section{Supplemental table and figures}

Table S3.1 Genes of interest determined by real-time quantitative reverse transcription PCR (qRT-PCR).

\begin{tabular}{|c|c|c|}
\hline Gene name & Forward primer & Reverse primer \\
\hline atrogin-1 & 5'-ACCGGCTACTGTGGAAGAGA-3' & 5'-CCTTCCAGGAGAGAATGTGG-3' \\
\hline MuRF1 & 5'-TGTCTGGAGGTCGTTTCCG-3' & 5'-CTCGTCTTCGTGTTCCTTGC-3' \\
\hline GSK-3 $\alpha$ & 5'-СССТСАССАСТТССТАСААСССА-3' & 5'-TTGTGGCATCAGATGGCTGC-3' \\
\hline GSK-3 $\beta$ & 5'-CCACATGCTCGGATTCAGGC-3' & 5'-TGTCCACGGTCTCCAGCATTAGTAT-3' \\
\hline$\beta$-actin & 5'-CTGAATGGCCCAGGTCTGA-3' & 5'-CCCTCCCAGGGAGACCAA-3' \\
\hline cyclophilin A & 5'-TTCCTCCTTTCACAGAATTATTCCA-3' & 5'-CCGCCAGTGCCATTATGG-3' \\
\hline GAPDH & 5'-CAACTCACTCAAGATTGTCAGCAA-3' & 5'-TGGCAGTGATGGCATGGA-3' \\
\hline calnexin & 5'-GCAGCGACCTATGATTGACAACC-3' & 5'-GCTCCAAACCAATAGCACTGAAAGG-3' \\
\hline
\end{tabular}


A
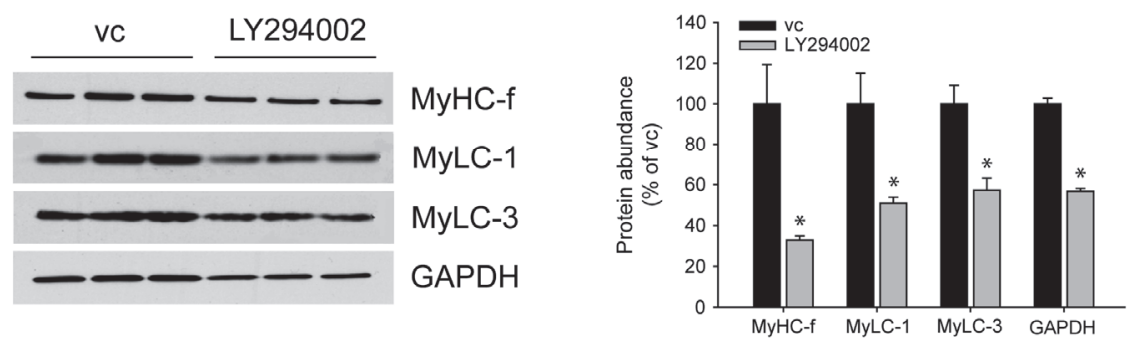

B

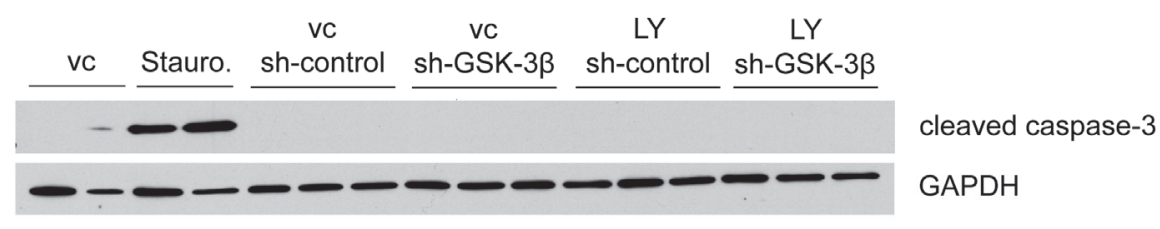

C
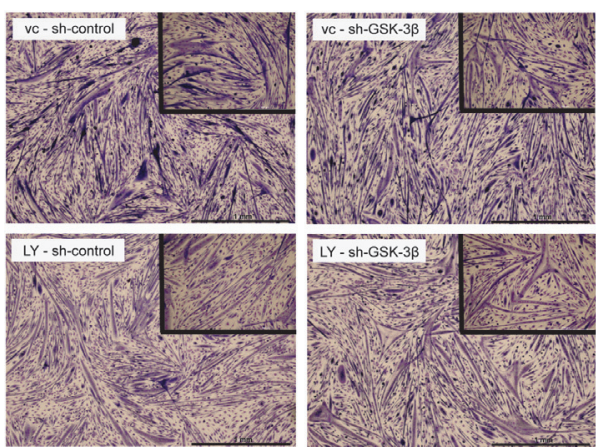

Figure S3.1 LY294002 reduces myofibrillar protein expression and causes atrophy without induction of apoptosis. Genetic deletion of GSK-3 $\beta$ attenuates LY294002-induced myotube atrophy.

(A) $\mathrm{C}_{2} \mathrm{C}_{12}$ myotubes were exposed to LY294002 [15 $\mu \mathrm{M}$ ] or vehicle control (vc) (DMSO) for 24 h. Protein levels of MyHC-f, MyLC-1, MyLC-3 and GAPDH were determined in sonicated cell lysates by Western blot analysis. Myosin protein abundance was not corrected for GAPDH. (B) $\mathrm{C}_{2} \mathrm{C}_{12}$ myotubes (4 days) were transiently transfected with control siRNA (sh-control), or GSK$3 \beta$ siRNA (sh-GSK-3 $\beta$ ). $24 \mathrm{~h}$ post-transfection the $\mathrm{C}_{2} \mathrm{C}_{12}$ myotubes ( 5 days) were cultured in the presence of $\mathrm{LY} 294002[15 \mu \mathrm{M}]$ or vc (DMSO) for $48 \mathrm{~h}$. The sonicated cell lysates were probed for cleaved caspase-3. A positive control for cleaved caspase- 3 was generated by culturing $\mathrm{C}_{2} \mathrm{C}_{12}$ myotubes in the presence of staurosporine $[1 \mu \mathrm{M}]$ for $20 \mathrm{~h}$. (C) Myotubes at 5 days of differentiation were treated with LY294002 [15 $\mu \mathrm{M}$ ] or vehicle control (vc) (DMSO) for $48 \mathrm{~h}$ and then assessed for morphological changes by staining with May-Grünwald Giemsa (40X magnification, scale bar $=1 \mathrm{~mm}$; inset $=100 \mathrm{X}$ magnification). All data shown are representative of 3 independent experiments (mean \pm SEM, $n=3$ ). * $p<0.05$ compared with control. 
A
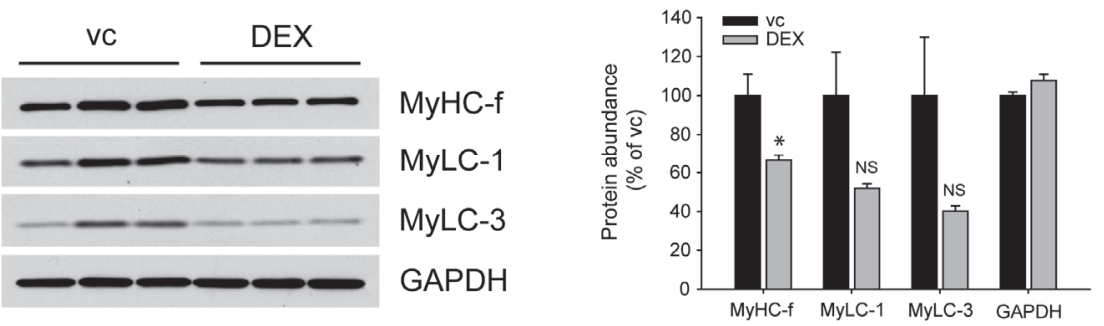

B

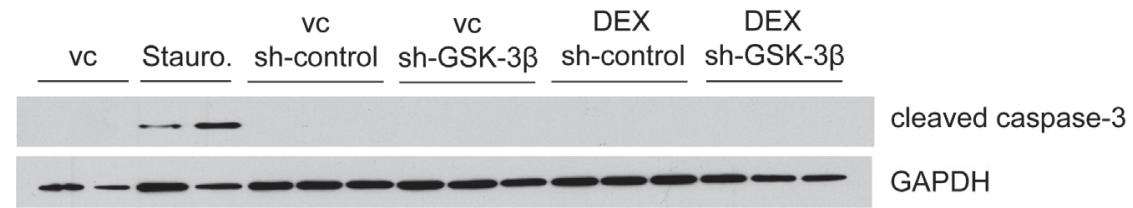

C
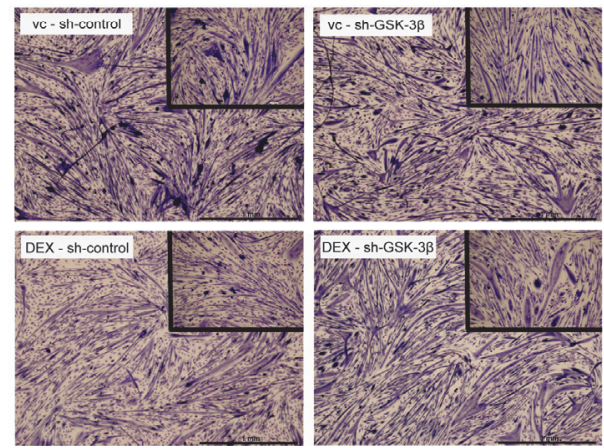

Figure S3.2 Dexamethasone reduces myofibrillar protein expression and causes atrophy without induction of apoptosis. Loss of GSK-3 $\beta$ expression attenuates dexamethasone-induced myotube atrophy.

(A) $\mathrm{C}_{2} \mathrm{C}_{12}$ myotubes were exposed to Dex [25 $\mu \mathrm{M}$ ] or vehicle control (vc) (DMSO) for $24 \mathrm{~h}$. Protein levels of MyHC-f, MyLC-1, MyLC-3 and GAPDH were determined in sonicated cell lysates by Western blot analysis. Myosin protein abundance was not corrected for GAPDH. (B) $\mathrm{C}_{2} \mathrm{C}_{12}$ myotubes (4 days) were transiently transfected with control siRNA (sh-control), or GSK$3 \beta$ siRNA (sh-GSK-3 $\beta$ ). $24 \mathrm{~h}$ post-transfection the $\mathrm{C}_{2} \mathrm{C}_{12}$ myotubes were cultured in the presence of Dex [ $25 \mu \mathrm{M}$ ] or vc (DMSO) for $48 \mathrm{~h}$. The sonicated cell lysates were probed for cleaved caspase-3. A positive control for cleaved caspase- 3 was generated by culturing $C_{2} C_{12}$ myotubes in the presence of staurosporine $[1 \mu \mathrm{M}]$ for $20 \mathrm{~h}$. (C) Myotubes at 5 days of differentiation were treated with Dex [25 $\mu \mathrm{M}$ ] or vehicle control (vc) (DMSO) for $48 \mathrm{~h}$ and then assessed for morphological changes by staining with May-Grünwald Giemsa (40X magnification, scale bar $=1 \mathrm{~mm}$; inset $=100 \mathrm{X}$ magnification). All data shown are representative of 3 independent experiments (mean \pm SEM, $n=3$ ). ${ }^{*} p<0.05$ compared with control. NS: not significant. 
A
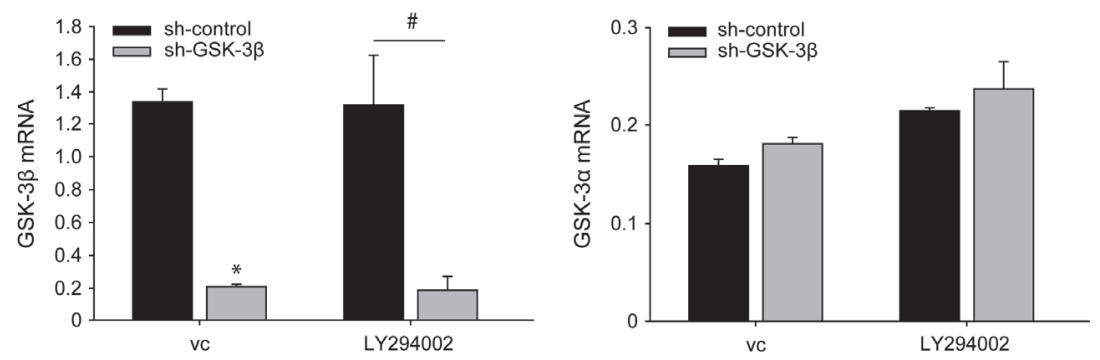

B
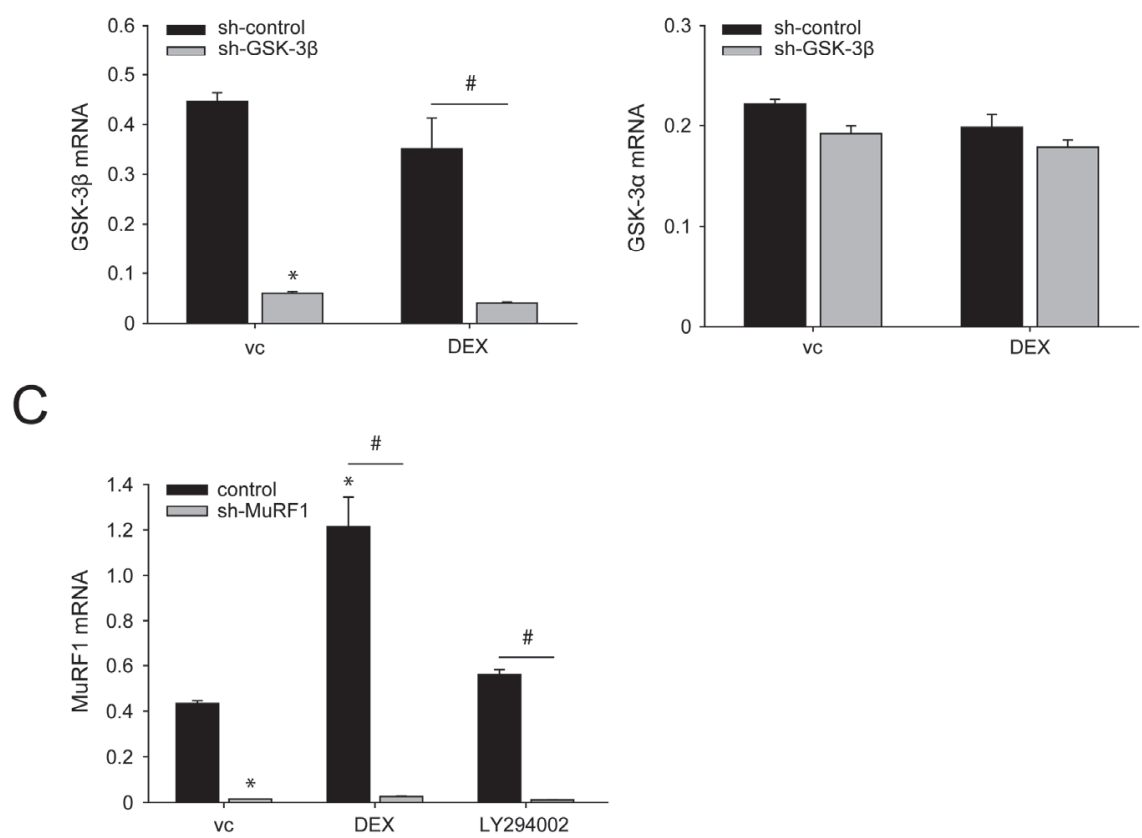

Figure S3.3 Verification of GSK-3 $\beta$ and MuRF1 knockdown by qRT-PCR.

(A) $\mathrm{C}_{2} \mathrm{C}_{12}$ myotubes (4 days) were transiently transfected with control siRNA (sh-control), or GSK-3 $\beta$ siRNA (sh-GSK-3 $\beta$ ). $24 \mathrm{~h}$ post-transfection, the $\mathrm{C}_{2} \mathrm{C}_{12}$ myotubes were cultured in the presence of LY294002 [15 $\mu \mathrm{M}$ ] or vehicle control (vc) (DMSO) for $24 \mathrm{~h}$ after which the mRNA abundance of GSK-3 $\beta$ and GSK-3 $\alpha$ was determined by qRT-PCR. (B) Stably transfected myoblasts (sh-control/GSK-3 $\beta$ ) were induced to differentiate for 5 days after which they were cultured in the presence of Dex [25 $\mu \mathrm{M}$ ] or vc (DMSO) for $24 \mathrm{~h}$. Next, the mRNA abundance of GSK-3 $\beta$ and GSK-3 $\alpha$ was determined by qRT-PCR. (C) Stably transfected myoblasts (sh-MuRF1) and native $\mathrm{C}_{2} \mathrm{C}_{12}$ myoblasts were induced to differentiate for 5 days after which they were cultured in the presence of Dex [25 $\mu \mathrm{M}]$, LY294002 [15 $\mu \mathrm{M}$ ] or vc (DMSO) for $24 \mathrm{~h}$. Next, the mRNA abundance of MuRF1 was determined by qRT-PCR. All data shown are representative of 3 independent experiments (mean $\pm \mathrm{SEM}, \mathrm{n}=3$ ). ${ }^{*} \mathrm{p}<0.05$ compared with control; \# $\mathrm{p}<0.05$ refers to a difference between indicated conditions. 
A
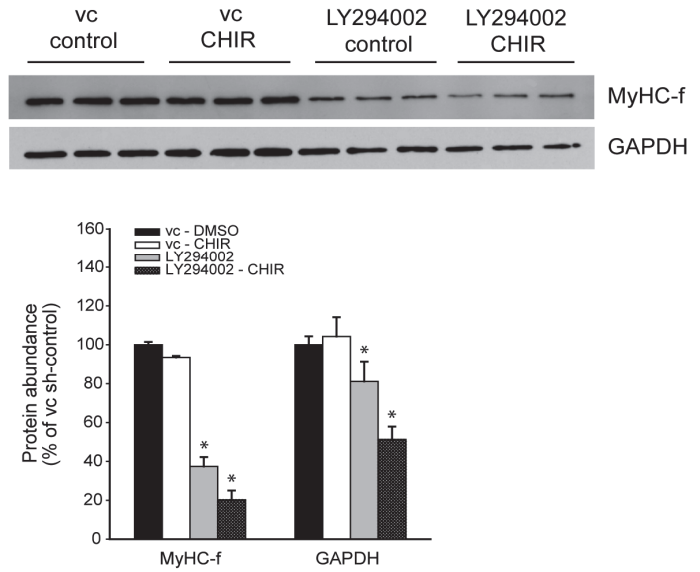

B
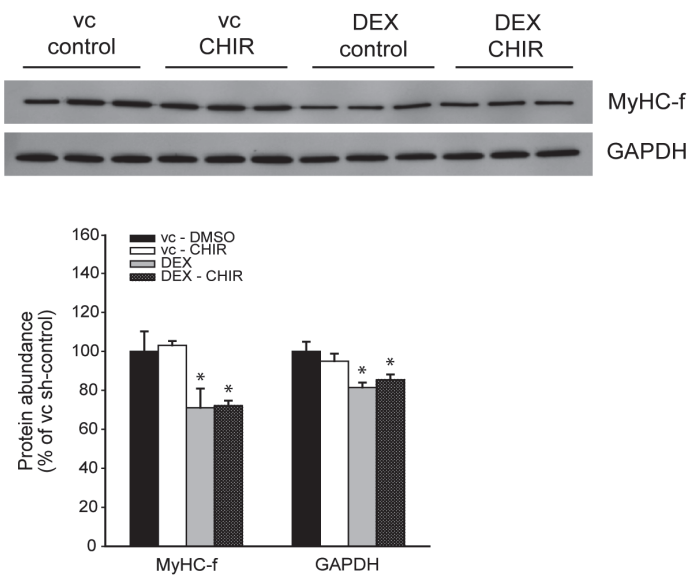

Figure S3.4 Enzymatic GSK-3 $\beta$ inhibition is not sufficient to prevent loss of MyHC-f protein content in response to glucocorticoids or impaired IGF-I/Akt signaling.

(A) $C_{2} C_{12}$ myotubes (5 days) were treated for $48 \mathrm{~h}$ with LY294002 [15 $\mu \mathrm{M}$ ] or vehicle control (vc) (DMSO) and/or CHIR99021 [7 $\mu \mathrm{M}$ ], after which the protein levels of MyHC-f and GAPDH were determined in cell lysates by Western blot analysis. MyHC-f protein abundance was not corrected for GAPDH. (B) $\mathrm{C}_{2} \mathrm{C}_{12}$ myotubes (5 days) were cultured in the presence of Dex [25 $\mu \mathrm{M}]$ or vc (DMSO) and/or CHIR99021 [7 $\mu \mathrm{M}]$ for $48 \mathrm{~h}$. Protein levels of MyHC-f and GAPDH were determined in cell lysates by Western blot analysis. MyHC-f protein abundance was not corrected for GAPDH. All data shown are representative of 3 independent experiments (mean \pm SEM, $n=3$ ). * $p<0.05$ compared with control; \# $\mathrm{p}<0.05$ refers to a difference between indicated conditions. 


\section{References}

1. Beurel E and Jope RS. The paradoxical pro- and anti-apoptotic actions of GSK3 in the intrinsic and extrinsic apoptosis signaling pathways. Prog Neurobiol 79: 173-189, 2006.

2. Bodine SC, Latres E, Baumhueter S, Lai VK, Nunez L, Clarke BA, Poueymirou WT, Panaro FJ, Na E, Dharmarajan K, Pan ZQ, Valenzuela DM, DeChiara TM, Stitt TN, Yancopoulos GD, and Glass DJ. Identification of ubiquitin ligases required for skeletal muscle atrophy. Science 294: 1704-1708, 2001.

3. Brummelkamp TR, Bernards R, and Agami R. Stable suppression of tumorigenicity by virus-mediated RNA interference. Cancer Cell 2: 243-247, 2002.

4. Brummelkamp TR, Bernards R, and Agami R. A system for stable expression of short interfering RNAs in mammalian cells. Science 296: 550-553, 2002.

5. Cai D, Frantz JD, Tawa NE, Jr., Melendez PA, Oh BC, Lidov HG, Hasselgren PO, Frontera WR, Lee J, Glass DJ, and Shoelson SE. IKKbeta/NF-kappaB activation causes severe muscle wasting in mice. Cell 119: 285-298, 2004.

6. Cho JY and Park J. Contribution of Natural Inhibitors to the Understanding of the PI3K/PDK1/PKB Pathway in the Insulin-mediated Intracellular Signaling Cascade. Int J Mol Sci 9: 2217-2230, 2008.

7. Chromiak JA and Vandenburgh HH. Glucocorticoid-induced skeletal muscle atrophy in vitro is attenuated by mechanical stimulation. Am J Physiol 262: C1471-1477, 1992.

8. Clarke BA, Drujan D, Willis MS, Murphy LO, Corpina RA, Burova E, Rakhilin SV, Stitt TN, Patterson C, Latres E, and Glass DJ. The E3 Ligase MuRF1 degrades myosin heavy chain protein in dexamethasonetreated skeletal muscle. Cell Metab 6: 376-385, 2007.

9. Cohen S, Brault JJ, Gygi SP, Glass DJ, Valenzuela DM, Gartner C, Latres E, and Goldberg AL. During muscle atrophy, thick, but not thin, filament components are degraded by MuRF1-dependent ubiquitylation. J Cell Biol 185: 1083-1095, 2009.

10. Davies SP, Reddy H, Caivano M, and Cohen P. Specificity and mechanism of action of some commonly used protein kinase inhibitors. Biochem J 351: 95-105, 2000.

11. Dupont-Versteegden EE and Waters C. No muscle atrophy without GSK-3beta. Focus on "Glycogen synthase kinase-3beta is required for the induction of skeletal muscle atrophy". Am J Physiol Cell Physiol 301: C980-981, 2011.

12. Evenson AR, Fareed MU, Menconi MJ, Mitchell JC, and Hasselgren PO. GSK-3beta inhibitors reduce protein degradation in muscles from septic rats and in dexamethasone-treated myotubes. Int $J$ Biochem Cell Biol 37: 2226-2238, 2005.

13. Fang CH, Li BG, James JH, King JK, Evenson AR, Warden GD, and Hasselgren PO. Protein breakdown in muscle from burned rats is blocked by insulin-like growth factor $\mathrm{i}$ and glycogen synthase kinase-3beta inhibitors. Endocrinology 146: 3141-3149, 2005.

14. Glass DJ. Signaling pathways perturbing muscle mass. Curr Opin Clin Nutr Metab Care 13: 225-229, 2010.

15. Glass DJ. Skeletal muscle hypertrophy and atrophy signaling pathways. Int J Biochem Cell Biol 37: 1974-1984, 2005.

16. Goll DE, Neti G, Mares SW, and Thompson VF. Myofibrillar protein turnover: the proteasome and the calpains. J Anim Sci 86: E19-35, 2008.

17. Gomes MD, Lecker SH, Jagoe RT, Navon A, and Goldberg AL. Atrogin-1, a muscle-specific F-box protein highly expressed during muscle atrophy. Proc Natl Acad Sci U S A 98: 14440-14445, 2001.

18. Harwood AJ. Regulation of GSK-3: a cellular multiprocessor. Cell 105: 821-824, 2001.

19. Hasselgren PO. Glucocorticoids and muscle catabolism. Curr Opin Clin Nutr Metab Care 2: 201-205, 1999.

20. Hasselgren PO and Fischer JE. Muscle cachexia: current concepts of intracellular mechanisms and molecular regulation. Ann Surg 233: 9-17, 2001.

21. Hong DH and Forsberg NE. Effects of dexamethasone on protein degradation and protease gene expression in rat L8 myotube cultures. Mol Cell Endocrinol 108: 199-209, 1995.

22. Hopkinson NS, Tennant RC, Dayer MJ, Swallow EB, Hansel TT, Moxham J, and Polkey MI. A prospective study of decline in fat free mass and skeletal muscle strength in chronic obstructive pulmonary disease. Respir Res 8: 25, 2007. 
23. Hu Z, Wang H, Lee IH, Du J, and Mitch WE. Endogenous glucocorticoids and impaired insulin signaling are both required to stimulate muscle wasting under pathophysiological conditions in mice. J Clin Invest 119: 3059-3069, 2009.

24. Jackman RW and Kandarian SC. The molecular basis of skeletal muscle atrophy. Am J Physiol Cell Physiol 287: C834-843, 2004.

25. Jagoe RT and Goldberg AL. What do we really know about the ubiquitin-proteasome pathway in muscle atrophy? Curr Opin Clin Nutr Metab Care 4: 183-190, 2001.

26. Jiang H, Fan D, Zhou G, Li X, and Deng H. Phosphatidylinositol 3-kinase inhibitor(LY294002) induces apoptosis of human nasopharyngeal carcinoma in vitro and in vivo. J Exp Clin Cancer Res 29: 34, 2010.

27. Jope RS. Lithium and GSK-3: one inhibitor, two inhibitory actions, multiple outcomes. Trends Pharmacol Sci 24: 441-443, 2003.

28. Lagirand-Cantaloube J, Cornille K, Csibi A, Batonnet-Pichon S, Leibovitch MP, and Leibovitch SA. Inhibition of atrogin-1/MAFbx mediated MyoD proteolysis prevents skeletal muscle atrophy in vivo. PLoS One 4: e4973, 2009.

29. Lagirand-Cantaloube J, Offner N, Csibi A, Leibovitch MP, Batonnet-Pichon S, Tintignac LA, Segura CT, and Leibovitch SA. The initiation factor elF3-f is a major target for atrogin1/MAFbx function in skeletal muscle atrophy. Embo J 27: 1266-1276, 2008.

30. Latres E, Amini AR, Amini AA, Griffiths J, Martin FJ, Wei Y, Lin HC, Yancopoulos GD, and Glass DJ. Insulin-like growth factor-1 (IGF-1) inversely regulates atrophy-induced genes via the phosphatidylinositol 3-kinase/Akt/mammalian target of rapamycin (PI3K/Akt/mTOR) pathway. J Biol Chem 280: 2737-2744, 2005.

31. Lecker SH, Solomon V, Mitch WE, and Goldberg AL. Muscle protein breakdown and the critical role of the ubiquitin-proteasome pathway in normal and disease states. J Nutr 129: 227S-237S, 1999.

32. Li BG, Hasselgren PO, and Fang CH. Insulin-like growth factor-I inhibits dexamethasone-induced proteolysis in cultured L6 myotubes through PI3K/Akt/GSK-3beta and PI3K/Akt/mTOR-dependent mechanisms. Int J Biochem Cell Biol 37: 2207-2216, 2005.

33. Medina R, Wing SS, Haas A, and Goldberg AL. Activation of the ubiquitin-ATP-dependent proteolytic system in skeletal muscle during fasting and denervation atrophy. Biomed Biochim Acta 50: 347-356, 1991.

34. Menconi M, Fareed M, O'Neal P, Poylin V, Wei W, and Hasselgren PO. Role of glucocorticoids in the molecular regulation of muscle wasting. Crit Care Med 35: S602-608, 2007.

35. Menconi M, Gonnella P, Petkova V, Lecker S, and Hasselgren PO. Dexamethasone and corticosterone induce similar, but not identical, muscle wasting responses in cultured L6 and C2C12 myotubes. J Cell Biochem 105: 353-364, 2008.

36. Munoz KA, Satarug $\mathrm{S}$, and Tischler ME. Time course of the response of myofibrillar and sarcoplasmic protein metabolism to unweighting of the soleus muscle. Metabolism 42: 1006-1012, 1993.

37. Reid MB. Response of the ubiquitin-proteasome pathway to changes in muscle activity. Am J Physiol Regul Integr Comp Physiol 288: R1423-1431, 2005.

38. Rena G, Guo S, Cichy SC, Unterman TG, and Cohen P. Phosphorylation of the transcription factor forkhead family member FKHR by protein kinase B. J Biol Chem 274: 17179-17183, 1999.

39. Ring DB, Johnson KW, Henriksen EJ, Nuss JM, Goff D, Kinnick TR, Ma ST, Reeder JW, Samuels I, Slabiak T, Wagman AS, Hammond ME, and Harrison SD. Selective glycogen synthase kinase 3 inhibitors potentiate insulin activation of glucose transport and utilization in vitro and in vivo. Diabetes 52: 588595, 2003

40. Rommel C, Bodine SC, Clarke BA, Rossman R, Nunez L, Stitt TN, Yancopoulos GD, and Glass DJ. Mediation of IGF-1-induced skeletal myotube hypertrophy by $\mathrm{PI}(3) \mathrm{K} / \mathrm{Akt} / \mathrm{mTOR}$ and $\mathrm{PI}(3) \mathrm{K} / \mathrm{Akt} / \mathrm{GSK} 3$ pathways. Nat Cell Biol 3: 1009-1013, 2001.

41. Ryves WJ and Harwood AJ. Lithium inhibits glycogen synthase kinase-3 by competition for magnesium. Biochem Biophys Res Commun 280: 720-725, 2001.

42. Sacheck JM, Ohtsuka A, McLary SC, and Goldberg AL. IGF-I stimulates muscle growth by suppressing protein breakdown and expression of atrophy-related ubiquitin ligases, atrogin-1 and MuRF1. Am J Physiol Endocrinol Metab 287: E591-601, 2004.

43. Sandri M, Sandri C, Gilbert A, Skurk C, Calabria E, Picard A, Walsh K, Schiaffino S, Lecker SH, and Goldberg AL. Foxo transcription factors induce the atrophy-related ubiquitin ligase atrogin-1 and cause skeletal muscle atrophy. Cell 117: 399-412, 2004. 
44. Schakman O, Gilson H, Kalista S, and Thissen JP. Mechanisms of muscle atrophy induced by glucocorticoids. Horm Res 72 Suppl 1: 36-41, 2009.

45. Schakman O, Gilson H, and Thissen JP. Mechanisms of glucocorticoid-induced myopathy. J Endocrinol 197: 1-10, 2008.

46. Shah OJ, Anthony JC, Kimball SR, and Jefferson LS. 4E-BP1 and S6K1: translational integration sites for nutritional and hormonal information in muscle. Am J Physiol Endocrinol Metab 279: E715-729, 2000.

47. Sharma S and Lichtenstein A. Dexamethasone-induced apoptotic mechanisms in myeloma cells investigated by analysis of mutant glucocorticoid receptors. Blood 112: 1338-1345, 2008.

48. Stitt TN, Drujan D, Clarke BA, Panaro F, Timofeyva Y, Kline WO, Gonzalez M, Yancopoulos GD, and Glass DJ. The IGF-1/PI3K/Akt pathway prevents expression of muscle atrophy-induced ubiquitin ligases by inhibiting FOXO transcription factors. Mol Cell 14: 395-403, 2004.

49. Sultan KR, Henkel B, Terlou M, and Haagsman HP. Quantification of hormone-induced atrophy of large myotubes from $\mathrm{C} 2 \mathrm{C} 12$ and L6 cells: atrophy-inducible and atrophy-resistant $\mathrm{C} 2 \mathrm{C} 12$ myotubes. Am J Physiol Cell Physiol 290: C650-659, 2006.

50. Tiao G, Fagan J, Roegner V, Lieberman M, Wang JJ, Fischer JE, and Hasselgren PO. Energy-ubiquitindependent muscle proteolysis during sepsis in rats is regulated by glucocorticoids. J Clin Invest 97: 339-348, 1996.

51. Tomczak KK, Marinescu VD, Ramoni MF, Sanoudou D, Montanaro F, Han M, Kunkel LM, Kohane IS, and Beggs $\mathrm{AH}$. Expression profiling and identification of novel genes involved in myogenic differentiation. Faseb J 18: 403-405, 2004.

52. van der Velden JL, Langen RC, Kelders MC, Wouters EF, Janssen-Heininger YM, and Schols AM. Inhibition of glycogen synthase kinase-3beta activity is sufficient to stimulate myogenic differentiation. Am J Physiol Cell Physiol 290: C453-462, 2006.

53. van der Velden JL, Schols AM, Willems J, Kelders MC, and Langen RC. Glycogen synthase kinase 3 suppresses myogenic differentiation through negative regulation of NFATc3. J Biol Chem 283: 358366, 2008.

54. Vandesompele J, De Preter K, Pattyn F, Poppe B, Van Roy N, De Paepe A, and Speleman F. Accurate normalization of real-time quantitative RT-PCR data by geometric averaging of multiple internal control genes. Genome Biol 3: RESEARCH0034, 2002.

55. Vinals F, Chambard JC, and Pouyssegur J. p70 S6 kinase-mediated protein synthesis is a critical step for vascular endothelial cell proliferation. J Biol Chem 274: 26776-26782, 1999.

56. Vyas DR, Spangenburg EE, Abraha TW, Childs TE, and Booth FW. GSK-3beta negatively regulates skeletal myotube hypertrophy. Am J Physiol Cell Physiol 283: C545-551, 2002.

57. Waddell DS, Baehr LM, van den Brandt J, Johnsen SA, Reichardt HM, Furlow JD, and Bodine SC. The glucocorticoid receptor and FOXO1 synergistically activate the skeletal muscle atrophy-associated MuRF1 gene. Am J Physiol Endocrinol Metab 295: E785-797, 2008.

58. Wang H, Liu D, Cao P, Lecker S, and Hu Z. Atrogin-1 affects muscle protein synthesis and degradation when energy metabolism is impaired by the antidiabetes drug berberine. Diabetes 59: 1879-1889, 2010.

59. Welsh GI, Miller CM, Loughlin AJ, Price NT, and Proud CG. Regulation of eukaryotic initiation factor elF2B: glycogen synthase kinase-3 phosphorylates a conserved serine which undergoes dephosphorylation in response to insulin. FEBS Lett 421: 125-130, 1998.

60. Wing SS and Goldberg AL. Glucocorticoids activate the ATP-ubiquitin-dependent proteolytic system in skeletal muscle during fasting. Am J Physiol 264: E668-676, 1993.

61. Wray CJ, Mammen JM, Hershko DD, and Hasselgren PO. Sepsis upregulates the gene expression of multiple ubiquitin ligases in skeletal muscle. Int J Biochem Cell Biol 35: 698-705, 2003.

62. Yaffe D and Saxel O. A myogenic cell line with altered serum requirements for differentiation. Differentiation 7: 159-166, 1977.

63. Yoshida T, Semprun-Prieto L, Sukhanov S, and Delafontaine P. IGF-1 prevents ANG II-induced skeletal muscle atrophy via Akt- and Foxo-dependent inhibition of the ubiquitin ligase atrogin-1 expression. Am J Physiol Heart Circ Physiol 298: H1565-H1570, 2010. 


\section{Chapter 4}

\section{GLUCOCORTICOID-DEPENDENT SKELETAL MUSCLE ATROPHY REQUIRES GLYCOGEN SYNTHASE KINASE-3 $\beta$}

Koen JP Verhees, Annemie MWJ Schols, Nicholas AM Pansters, Frank J Snepvangers, Marco CJM Kelders, Rick HP van Gorp, Tom Houben, Chiel C de Theije, and Ramon CJ Langen

Submitted 


\section{Abstract}

Muscle wasting occurs under a variety of conditions, and in many instances activation of muscle protein degradation requires endogenous glucocorticoids (GCS). The prototypical insulin-like growth factor 1 (IGF-I)/Akt signaling pathway is involved in the regulation of muscle mass. Glycogen synthase kinase-36 (GSK-3 $\beta$ ), a signaling kinase downstream of Akt, has been implicated in the induction of GC-induced skeletal muscle atrophy in vitro. The purpose of this study was to gain further insight into the in vivo role of GSK-3 $\beta$ in GC-induced skeletal muscle atrophy. To this end, we

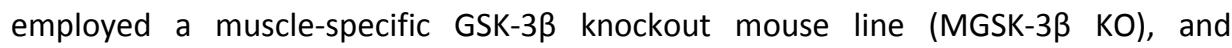
evaluated the direct contribution of this signaling molecule in two different models of GC-associated muscle wasting, i.e. fasting as an endogenous model and synthetic GC administration as an exogenous model. Skeletal muscle-restricted depletion of GSK-3 $\beta$ prevented starvation-induced loss of muscle mass. In addition, the induction of two important mediators of ubiquitin 26S-proteasome system (UPS)-mediated proteolysis, atrogin-1/MAFbx and muscle RING finger 1 (MuRF1) was inhibited, but not completely abrogated, following nutritional deprivation. Similarly, autophagy-related and GCsensitive gene expression were partially dependent on GSK-3ß. Systemic GC signaling mediates muscle atrophy in response to fasting. Muscle-specific deletion of the glucocorticoid receptor (GR) blocked the induction of atrophy signaling in response to synthetic GCs using dexamethasone (Dex). Subsequently, chronic Dex instillation resulted in significant muscle atrophy in WT mice, which was absent in GSK-3 $\beta$ deficient muscle. In conclusion, the data presented in this study indicate that in two distinct models of GC-induced muscle atrophy, GSK-3 $\beta$ functions as a crucial mediator of muscle atrophy, involved in the regulation of two major proteolytic systems, i.e. the ubiquitin $26 \mathrm{~S}$ proteasome system (UPS) and the autophagy-lysosomal pathway (ALP). 


\section{Introduction}

Sustained starvation or nutrient deprivation is characterized by profound skeletal muscle atrophy $(2,38)$. Muscle wasting accompanies a wide range of chronic disease states $(40,51)$, in which it is associated with increased morbidity and mortality $(2,82)$. In addition, malnutrition and semi-starvation may occur as a complication of acute illness or during exacerbations of chronic disease (2). Furthermore, starvation is characterized by elevated circulating glucocorticoids (GCs) $(3,57)$ and decreased insulin and insulin-like growth factor (IGF) levels and signaling $(15,67,71)$. Under conditions of nutrient limitation, GCs are secreted by the adrenal cortex via the hypothalamicpituitary-adrenal (HPA) axis to facilitate hepatic gluconeogenesis (14), which is fueled by the mobilization of amino acids from skeletal muscle.

It has been postulated that the release of endogenous GCs during fasting is required to establish muscle wasting (107). Indeed, adrenalectomized rodents were shown to be refractory to muscle atrophy as a consequence of fasting (4), metabolic acidosis (61) and diabetes mellitus (63). Furthermore, GCs have also been implicated as a causal factor in the onset of muscle wasting during sepsis (98) or following angiotensin II infusion (92), further illustrating the significance of GCs during muscle atrophy. Moreover, synthetic GCs are often administered in the management of acute and chronic pulmonary disease $(70,79)$, and treatment with exogenous GCs is sufficient to induce muscle atrophy in several experimental models $(5,12,21,78,100,104)$. However, the molecular mechanisms by which GCs stimulate muscle wasting have only been partially elucidated. Under normal conditions skeletal muscle is preserved by a balance between protein synthesis and breakdown (49), but during atrophy this balance is disturbed and shifts in favor of degradation $(31,72)$. The direct actions of GC hormones on protein turnover occur through genomic and non-genomic mechanisms (91), and previous studies have demonstrated alterations in both protein degradation $(12,36,100)$ and synthesis $(17,53,83,103)$ following corticosteroid-treatment. Both genomic as well as non-genomic GC actions require the activation of the glucocorticoid receptor (GR) (101). The GR is a ligand-dependent transcription factor that, upon ligand binding, translocates to the nucleus where it dimerises with another ligand bound GR. This homodimer can subsequently regulate the activity of specific GR target genes (28).

Wasting of muscle mass may be attributable to enhanced degradation of myofibrils, which constitute the vast majority of muscle proteins. The targeted destruction of myofibrillar proteins is carried out by the ATP-dependent ubiquitin 26Sproteasome system (UPS) (38,89), which includes two muscle-specific E3 ubiquitin ligases, namely atrogin-1/MAFbx (hereinafter termed atrogin-1) and muscle RING finger 1 (MuRF1), whose expression is induced under several atrophic conditions $(8,32,73,108)$. These ligases appear to be essential for the atrophy process, as their absence strongly attenuates loss of muscle mass following denervation (8), unloading 
(46) or synthetic GC-treatment (5). In addition, the expression of atrogin-1 and MuRF1 was shown to be, at least in part, mediated by GCs as muscle-restricted ablation of the GR blocked the induction of these atrophy-related genes or atrogenes in response to GC-treatment $(104,113)$. However, although GCs have been implicated in the regulation of starvation-induced muscle atrophy $(37,107)$, the exact contribution of GR signaling, and associated atrogene expression remain poorly understood. In contrast to the UPS, the contribution of the autophagy-lysosomal pathway (ALP) to GC-induced muscle proteolysis has received little attention, in spite of evidence which suggests that lysosomal proteolysis adds to muscle atrophy in several models $(6,26,81)$. The ALPassociated genes include, among others, microtubule-associated proteins $1 \mathrm{~A} / 1 \mathrm{~B}$ light chain $3 B$ (LC3b), Bcl-2 and $19 \mathrm{kDa}$ interacting protein 3 (Bnip3), and GABA receptorassociated protein 1 (Gabarapl1), and appear to be tightly regulated at the transcriptional level. Accordingly, Forkhead Box $O$ (FoXO) transcription factors were found to act as critical liaison molecules governing the expression of the ALP-related, as well as the UPS-associated E3 ligases atrogin-1 and MuRF1 $(58,94,111)$.

The classical insulin/insulin-like growth factor 1 (IGF-I) pathway affects cellular protein turnover via a well-characterized signaling conduit where Akt functions as a cardinal nodal point, with the ability to influence both anabolic as well as catabolic signaling cues $(31,48)$. As such, activated Akt can phosphorylate FoXOs, resulting in their cytoplasmic retention, which is required for the suppression of atrogin-1 and MuRF1 gene expression, and thus responsible for the subsequent attenuation of proteolysis $(77,94)$. Conversely, phosphorylated Akt can stimulate protein synthesis by activating mammalian target of rapamycin complex 1 (mTORC1) signaling $(7,9)$. Therefore, both IGF-I/insulin -and GC-associated signaling appear to be involved in the regulation of muscle mass, by affecting cellular protein turnover. Furthermore, in recent years, evidence emerged in support of extensive cross-talk between these signaling pathways $(52,84,101,102)$. Phosphatidylinositol 3-kinase (PI-3K)/Akt signaling may be altered by rapid non-genomic corticosteroid actions $(54,85)$, as the activated GR was recently found to compete with insulin receptor substrate 1 (IRS-1) for association with PI-3K, resulting in impaired IRS-1-associated PI-3K/Akt activity (37). Yet, despite our increased understanding of the intricate interplay between the PI-3K/Akt and GC signaling cascades, the diversity of mediators and the bidirectional interaction between both pathways imply that cross-talk may occur at multiple levels. For instance, in addition to non-genomic actions, GR signaling may also affect IGF-I/insulin receptor signaling through genomic actions, or vice versa. For instance, recently the GR-dependent overexpression of the PI-3K subunit P85 $\alpha$ was found to mimic the effect of GCs, resulting in reduced Akt signaling and myotube atrophy (42).

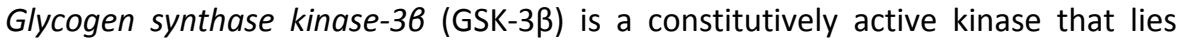
directly downstream of Akt (34), which can inactivate GSK-3 $\beta$ via an inhibitory phosphorylation at $\operatorname{Ser}^{9}(13)$, resulting in enhanced mRNA translation initiation to 
promote protein synthesis $(105,106)$. However, the contribution of GSK-3 $\beta$ to protein turnover is not restricted to the regulation of protein synthesis. Previous work from our group and others established an important role for GSK-3 $\beta$ in the regulation of GC-induced proteolysis $(21,23,100)$. Concretely, genetic ablation or pharmacological inhibition of GSK-3 $\beta$ abrogated the induction of atrogin-1 and MuRF1 mRNA expression in response to synthetic GC-treatment. In addition, previous findings by Schakman et al. clearly showed that overexpression of a dominant-negative GSK-3 $\beta$ (dnGSK-3 $\beta$ ) blocked muscle atrophy in response to synthetic GCs (80). However, the exact workings by which GSK-3 $\beta$ affects GC-induced muscle proteolysis signaling are still unclear. The aim of this current study was to investigate the role of GSK-3 $\beta$ in two distinct models of GC-associated skeletal muscle atrophy. Using muscle-specific GSK$3 \beta$ knockout mice (MGSK-3 $\beta$ KO) we investigated the direct contribution of GSK-3 $\beta$ in skeletal muscle atrophy due to fasting and chronic synthetic GC-treatment. The results presented in this study confirmed previous in vitro findings, and conclusively demonstrate that muscle GSK-3 $\beta$ is an important mediator of GC-dependent skeletal muscle atrophy and associated gene expression.

\section{Materials and methods}

\section{Animal studies}

All mouse studies were carried out under a protocol approved by the Institutional Animal Care Committee of Maastricht University. Male muscle-specific GSK-3 $\beta$ and GR knockout mice (12 weeks of age and designated MGSK-3 $\beta$ KO and MGR KO, respectively) were generated by crossing $\mathrm{MLC}_{1} \mathrm{f}-\mathrm{Cre}^{+/-}$(fast myosin light chain 1 promoter driving (re recombinase) mice with animals bearing GR and GSK-3 $\beta$ alleles flanked with loxP sites (GSK-3 $\beta^{\mathrm{fl} / \mathrm{fl}}$ and $\mathrm{GR}^{\mathrm{fl} / \mathrm{fl}}$ ) on a C57BL/6 background, as described previously $(20,69)$. For both mouse lines, the Cre double negative littermates (MLC1f$\mathrm{Cre}^{-/-}$) served as controls (WT). Genotyping of all mice was performed using genomic DNA from tail tips. The various tissue-specific deletions were determined by PCR, confirming the presence of Cre, and the absence of the deleted floxed GSK-3 $\beta$ and GR alleles. To study the effects on fasting-induced muscle atrophy, MGSK-3 $\beta$ KO and WT control mice were deprived of food for $24 \mathrm{~h}$ or $48 \mathrm{~h}$, allowing free access to drinking water. The control animals (ad libitum group) were given free access to food and water throughout the experiment. Alternatively, MGSK-3 $\beta$ KO, MGR KO and WT control mice were injected subcutaneously (sc) behind the neck just above the scapula with either vehicle (vc) [saline, $0.9 \% \mathrm{NaCl}$ ] or dexamethasone (Dex) dissolved in vc [Sigma-Aldrich, $5 \mathrm{mg} / \mathrm{kg}$ body weight] for $6 \mathrm{~h}, 48 \mathrm{~h}$ or 14 days (d). For the $6 \mathrm{~h}$ time point, the animals received a single bolus of vc or Dex, whereas for the $48 \mathrm{~h}$ and $14 \mathrm{~d}$ studies, the animals were injected every $24 \mathrm{~h}$. The effectiveness of the dosing was verified at the end of the experiment by measuring the spleen mass, which decreased significantly due to GC-induced splenocyte apoptosis. The mice were given ad libitum 
access to food and water throughout the experiment. All animals were housed individually in standard cages, and after completion of the experimental protocol the mice were euthanized and a heart puncture was performed to collect whole blood for glucose measurements and to obtain plasma. Subsequently, the soleus, plantaris, gastrocnemius, tibialis anterior, and extensor digitorum longus (EDL) muscles were collected from both hind limbs using standardized dissection methods. The paired muscle weights of the hind limb musculature were measured and all tissues were flash-frozen in liquid nitrogen.

\section{Tissue processing and histological analyses}

The EDL muscles were embedded in Tissue-Tek (Sakura Finetek, the Netherlands) and sectioned on a Leica CM3050 S cryostat at $-20^{\circ} \mathrm{C}$. Subsequently, serial crosssections $(5 \mu \mathrm{m})$ were stained with the following primary antibodies: anti-Type I MyHC (\#A-4840), anti-Type IIb MyHC (\#BF-F3) (both from Developmental Studies Hybridoma Bank, lowa City, IA, USA), anti-Type Ila MyHC (\#333-7H1) (kindly provided by Dr. A.F.M. Moorman, AMC, Amsterdam, the Netherlands) and anti-laminin (\#L-9393) (Sigma-Aldrich) to determine the myofiber cross-sectional area (CSA) and fiber type distribution. The negatively stained fibers, present after a Type IIb/Ila double-staining, were characterized as Type I/IIx fibers. A subsequent Type I staining revealed that EDL muscle contained virtually no (oxidative) Type I fibers $(<1.5 \%)$ (data not shown), implying that the non-stained fibers were predominantly Type IIx. As such, the glycolytic EDL muscle was abundant in fast-twitch fibers, showing the following distribution: Type IIb, 60\%; Type IIx, 24\%; and Type Ila, 16\% (data not shown). The sections were incubated with the following secondary antibodies: Alexa Fluor 488 (\#A21121), Alexa Fluor 555 (\#A-21426) and Alexa Fluor 350 (\#A-21426) (all from Invitrogen, CA, USA). Digital images of the stained sections were taken under $200 \mathrm{X}$ total magnification using an Eclipse E800 (Nikon, Japan). The fiber cross-sectional area (CSA) was measured after having identified five non-overlapping regions containing a total of 100 - 200 individual fibers per animal, which were then analyzed using Lucia Software (version 4.81).

\section{Corticosterone measurements}

The plasma corticosterone levels were determined by HPLC. Cortisol carboxylic acid was added to the plasma and corticosterone standards as an internal standard (35). Next, the samples and standards were acidified with phosphoric acid, and the steroid hormones were subsequently extracted from the plasma using diethyl ether, and dried with nitrogen gas. The pellet was dissolved in eluens (acetonitrile/ methanol/TFA) and incubated with sulphuric acid for 20 minutes ( $\mathrm{min}$ ) to convert the steroids into fluorescent products. Subsequently, HPLC analysis was performed as described previously (60). All corticosterone values were corrected to the internal standard. 


\section{RNA isolation and assessment of mRNA abundance for qRT-PCR}

Plantaris muscles were homogenized in ice-cold RLT buffer, containing $\beta$ mercaptoethanol, using a rotating blade tissue homogenizer (Polytron PT 1600E, Kinematica, Switzerland). The RNA was isolated using the RNeasy Fibrous Tissue Mini Kit (Qiagen, Germany) according to the manufacturer's instructions. Next, $0.4 \mu \mathrm{g}$ RNA was reverse transcribed into cDNA using the Transcriptor First Strand cDNA Synthesis kit (Roche Diagnostics GmbH, Germany) according to the manufacturer's instructions. Anchored oligo-dT primers were used for priming. The mRNA transcript levels of the genes of interest were determined by real-time quantitative reverse transcription PCR (qRT-PCR). qRT-PCR primers were designed using Primer Express 2.0 software (Applied Biosystems, CA, USA) and obtained from Sigma-Aldrich. The qRT-PCR reactions contained 2X SensiMix SYBR/Fluorescein mix (Bioline, UK) and primers [300 nM]. The PCR reaction was performed by a two-step PCR and standards were made by making 5 -fold serial dilutions of pooled cDNA. Relative cDNA concentrations of the samples were derived from the standard curve with at least a $R^{2}>0.98$ and an efficiency between $90-110 \%$. The geNorm software package was used to ascertain the most suitable set of reference genes for normalization (99). The expression of the genes of interest was normalized to a normalization factor, based on the geometric average of at least three reference genes (ARBP, RPL13A, B2M, GAPDH, calnexin, cyclophilin A, $\beta$ actin and $\alpha$-tubulin). The qRT-PCR reactions were performed on a MyiQ single-color real-time thermocycler and analyzed using MyiQ 2.0 software (all from Bio-Rad, CA, USA).

\section{Western blotting}

Muscle tissue was homogenized in ice-cold $1 \mathrm{X}$ whole cell lysate buffer (WCL) [50 mM Tris, pH 7.4; 150 mM NaCl; 10\% glycerol; 0.5\% Nonidet P-40; 1 mM EDTA; 1 mM

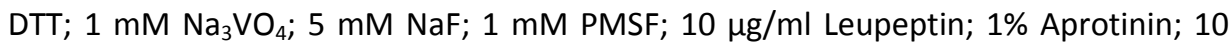
$\mathrm{mM} \beta$-glycerophosphate and $1 \mathrm{mM} \mathrm{Na-pyro-}-\mathrm{PO}_{4}$ ] using a rotating blade tissue homogenizer (Polytron PT 1600E, Kinematica, Switzerland). The total protein concentration was assessed by the Thermo Scientific Pierce BCA Protein Assay kit (Pierce Biotechnology, IL, USA) according to the manufacturer's instructions. The protein lysates were boiled for $5 \mathrm{~min}$ at $95^{\circ} \mathrm{C}$ after the addition of $4 \mathrm{X}$ Laemmli sample buffer [0.25 M Tris-HCl pH 6.8; 8\% (w/v) SDS; 40\% (v/v) glycerol; 0.4 M DTT and 0.04\% $(\mathrm{w} / \mathrm{v})$ Bromophenol Blue]. For SDS-PAGE 1 - $30 \mu \mathrm{g}$ of protein was loaded per lane and separated on a Criterion XT Precast 4 - 12\% Bis-Tris gel (Bio-Rad), followed by transfer to a $0.45 \mu \mathrm{m}$ Whatman Protran Nitrocellulose Transfer membrane (Whatman $\mathrm{GmbH}$, Germany) by electroblotting (Bio-Rad Criterion Blotter). Nitrocellulose blots were incubated overnight $\left(4^{\circ} \mathrm{C}\right)$ with specific antibodies directed against: $\mathrm{GR}(\mathrm{H}-300)$ (Santa

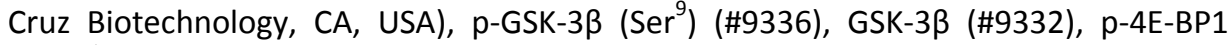
$\left(\mathrm{Thr}^{37 / 46}\right)$ (\#9459), 4E-BP1 (\#9452) and GAPDH (\#2118) (all from Cell Signaling Technology), diluted in $1 \mathrm{X}$ TBS/0.1\% Tween-20. The blots were probed with a 
peroxidase conjugated secondary antibody (\#PI-1000) (Vector Laboratories, CA, USA), and visualized using Supersignal WestPico Chemiluminescent Substrate (Pierce Biotechnology) according to the manufacturer's instructions and exposed to Super RX film (FUJIFILM, Japan). The Western blot films were digitalized using a Bio-Rad GS-800 Densitometer and subsequent quantification was done using Quantity One software (version 4.5.0) (both from Bio-Rad).

\section{Statistical analysis}

Raw data were entered into SPSS (version 20.0) for statistical analysis. All values are represented as means and error bars indicate the standard error of the mean (SEM). The comparisons of mean values were tested parametrically, using a one-way ANOVA followed by a post hoc Fischer's LSD test. A two-tailed probability value of $p<0.05$ between groups was considered statistically significant.

\section{Results}

\section{Starvation-induced skeletal muscle atrophy requires GSK-3 $\beta$}

Nutrient deprivation for $48 \mathrm{~h}$ resulted in a significant and comparable decline in

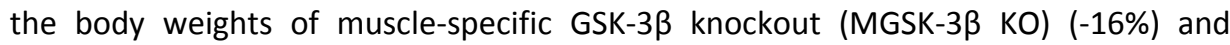
control mice (WT) (-19\%) compared with ad libitum fed animals (Figure 4.1A). Furthermore, irrespective of the genotype, starvation was accompanied by a marked loss in liver weight (Figure 4.1B), and associated with a significant increase in plasma corticosterone levels (Figure 4.1C), which was paralleled by a significant drop in blood glucose concentration (Figure 4.1D). In addition, a concomitant decrease in the wet weights of the hind limb EDL $(-21 \%)$, gastrocnemius $(-14 \%)$, plantaris $(-19 \%)$, tibialis $(-13 \%)$ and soleus $(-15 \%)$ muscles was noted in fasted control mice compared with their non-fasted counterparts. In contrast, in the MGSK-3 $\beta$ KO mice muscle atrophy was strongly attenuated (M. plantaris (-10\%)) or absent (other muscles) (Figure 4.1E). Importantly, there were no genotype-related differences in the levels of circulating corticosterone implying that not the triggers, but rather the signaling of muscle catabolism was affected by muscle GSK-3 $\beta$ deficiency. 
A

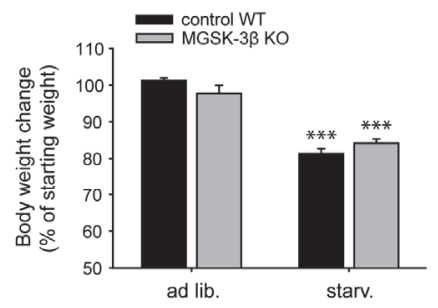

C

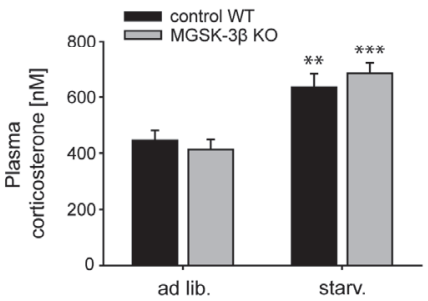

E
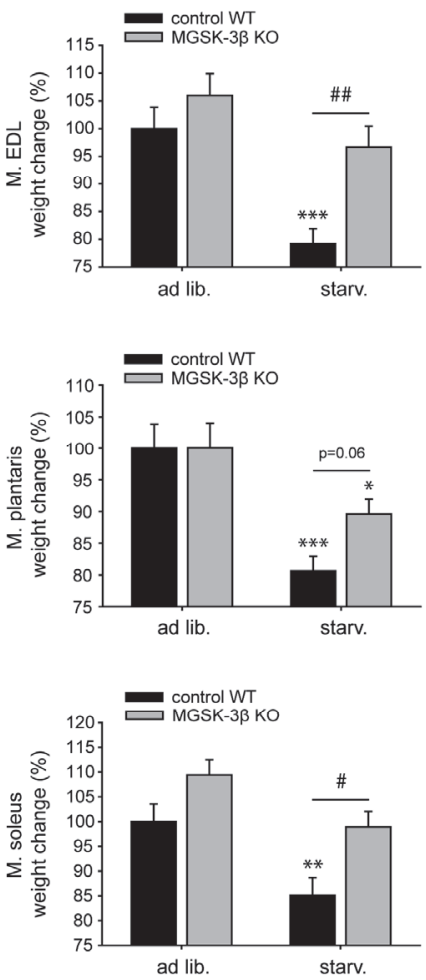

B

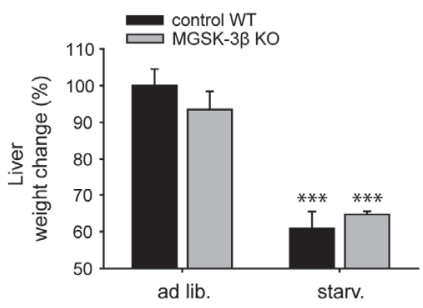

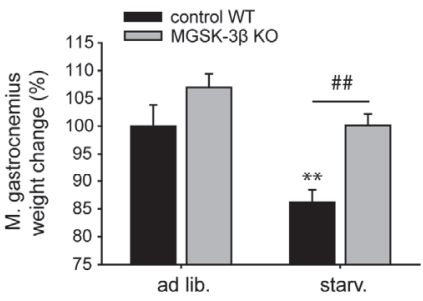

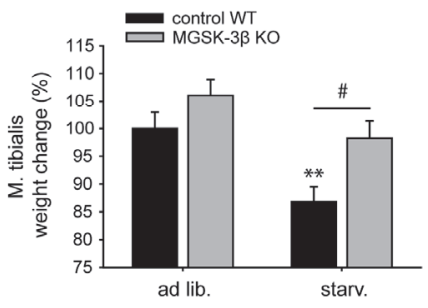


Figure 4.1 Starvation-induced skeletal muscle atrophy requires GSK-3 $\beta$.

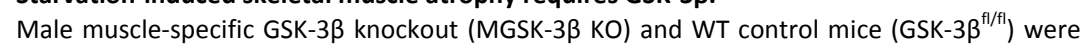
either fasted for $48 \mathrm{~h}$ or fed ad libitum (ad lib.). (A) Body and (B) liver weights were determined and expressed as a \% of weight change over ad libitum WT control. (C) Circulating corticosterone levels [nM] were measured in the plasma of fasted ( $24 \mathrm{~h}$ ) and ad libitum fed mice, and (D) blood glucose concentration [mM] was assessed in whole blood. (E) EDL, gastrocnemius, plantaris, tibialis and soleus muscle mass was assessed and expressed as a \% of weight change over ad libitum WT control. All data shown represent means $\pm S E M, n=5$ animals per group (C: $n=9$ ). ${ }^{* *} \mathrm{p}<0.01, * * * \mathrm{p}<0.001$ compared with ad libitum fed WT control mice; \# $p<0.05$, \#\# $p<0.01$ refers to a difference between indicated conditions.

\section{Starvation-induced UPS -and ALP-related gene expression in muscle is partially dependent on GSK-3 $\beta$}

As MGSK-3 3 KO mice showed significant muscle sparing in response to fastinginduced atrophy, we next assessed the mRNA expression levels of the executioners of muscle atrophy, namely the UPS-associated genes atrogin-1, MuRF1 and E3 $\alpha-I I$. Starvation resulted in significant increases in the transcript levels of these E3 ubiquitin ligases in WT animals (atrogin-1, 3.8 fold; MuRF1, 6.1 fold; E3 $\alpha-I I, 1.3$ fold). Interestingly, the induction of atrogin-1 and MuRF1 was significantly attenuated in GSK-3ß-deficient muscle (2.2 fold and 3.2 fold, respectively), whereas the mRNA expression of E3 $\alpha-I I$ (1.4 fold) remained unaltered (Figure 4.2A). Furthermore, the muscle transcript levels of the ALP-related genes LC3b (1.8 fold), Bnip3 (2.3 fold) and Gabarapl1 (3.4 fold) were all significantly upregulated in fasted WT animals (Figure 2B). However, the induction of LC3b (1.5 fold) and Bnip3 (1.6 fold) mRNA, though still significant, was attenuated in MGSK-3 $\beta$ KO mice, while increases in Gabarapl1 transcript levels appeared completely refractory to the loss of muscle GSK-3 $\beta$ expression (Figure 4.2B).

\section{Fasting-induced FoXO and glucocorticoid-sensitive gene expression in muscle are in part mediated by GSK-3 $\beta$}

Considering the parallel induction of UPS-mediated proteolysis and ALP-related expression programs (Figure 4.2), the mRNA levels of the transcriptional regulators FoXO1 and FoXO3a were investigated next. Notably, FoXO1 and FoXO3a mRNA transcript levels were both markedly upregulated in muscle of starved WT mice (3.4 and 1.6 fold, for FoXO1 and FoXO3a respectively), while their induction was either strongly attenuated (FoXO1, 2.4 fold) or completely blocked (FoXO3a) in MGSK-3 $\beta$ KO muscle in response to fasting (Figure 4.3A). Starvation is a well-established endogenous model of GC-associated muscle atrophy and previous in vitro studies, including our own work, have postulated that GC-induced muscle proteolysis signaling requires $\operatorname{GSK}-3 \beta(22,80,100)$. This tempted us to address the contribution of GSK-3 $\beta$ to GC-sensitive gene expression in this model. Remarkably, increases in GC-sensitive gene expression in response to nutrient deprivation, i.e. glutamate-ammonia ligase 
(Glul) (2.3 fold) and regulated in development and DNA damage responses 1 (REDD1) (3.2 fold), were strongly suppressed (Glul, 1.6 fold) or absent (REDD1) in GSK-3 $\beta$ deficient muscle (Figure 4.3B). However, the induction of Krüppel-like factor 15 (KLF15) $(2.7$ fold) appeared insusceptible to the absence of GSK-3 $\beta$ expression, whereas myostatin mRNA transcript levels were not significantly increased in muscle of fasted WT mice. It is of interest to note that, in spite of this lack of induction, myostatin mRNA abundance was significantly reduced in fasted GSK-3ß-deficient muscle, suggesting a dependency of myostatin gene expression on GSK-3 $\beta$ (Figure 4.3B). In line with an essential role for GCs and associated signaling in starvation-induced skeletal muscle atrophy, our data clearly demonstrates that the increase in circulating corticosterone levels (Figure 4.1C), in response to nutrient deprivation, was paralleled by significantly upregulated mRNA levels of several UPS-related and GC-sensitive genes, which were largely dependent on GSK-3 $\beta$.

\section{Dexamethasone-induced MuRF1 and glucocorticoid-sensitive gene expression in muscle requires the glucocorticoid receptor (GR)}

In line with an essential role for GCs and associated signaling in starvation-induced skeletal muscle atrophy, our data clearly demonstrates that the increase in circulating corticosterone levels (Figure 4.1C) in response to nutrient deprivation, was paralleled by significantly upregulated mRNA levels of several UPS-related and GC-sensitive genes, which were largely dependent on GSK-3 $\beta$. The actions of GCs have been shown to require activation of the GR $(101,110)$. To address the contribution of the GR in steering GC-sensitive and UPS-related gene expression in muscle following exogenously administered GCs, muscle-specific GR KO (MGR KO) and control mice (WT) were injected subcutaneously with Dex or saline for $6 \mathrm{~h}$. Dex instillation increased the mRNA transcript levels of MuRF1 (2.8 fold), in contrast to atrogin-1, whose expression did not respond to Dex (Figure 4A). In addition, Dex induced the transcript levels of the GC-sensitive genes Glul (1.4 fold), KLF-15 (1.8 fold), REDD1 (2.3 fold) and myostatin (1.6 fold) in control animals, while in GR-deficient muscle the induction of these GC-sensitive genes was completely abolished. Furthermore, muscle-specific deletion of the GR significantly reduced the basal expression levels of Glul, KLF-15 and REDD1 (Figure 4.4B). Finally, myostatin expression levels were markedly reduced in GR-depleted muscle in response to Dex (Figure 4.4B). Thus, to a great extent, depletion of endogenous muscle $G R$ expression mirrored the observations made in the MGSK-3 $\beta$ KO mice with regard to GC-sensitive gene expression, suggesting a putative direct or indirect GSK-3 $\beta-$ GR interaction governing transcription. 
A
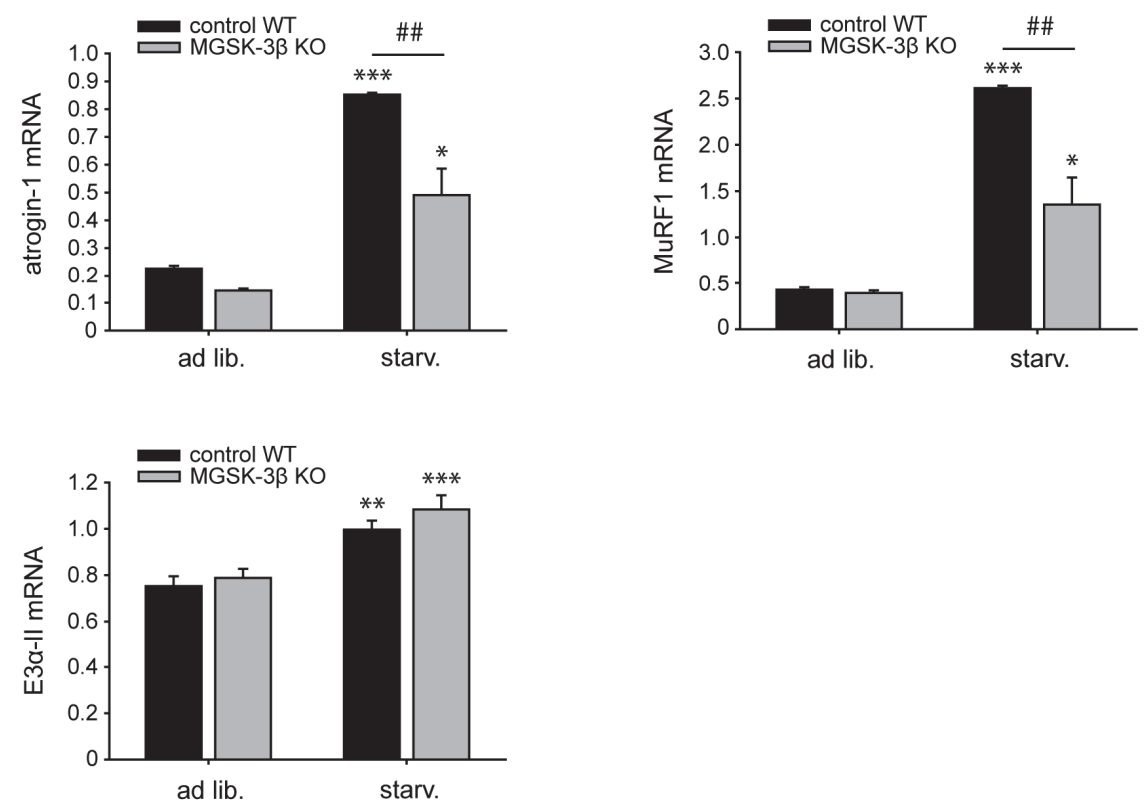

\section{B}
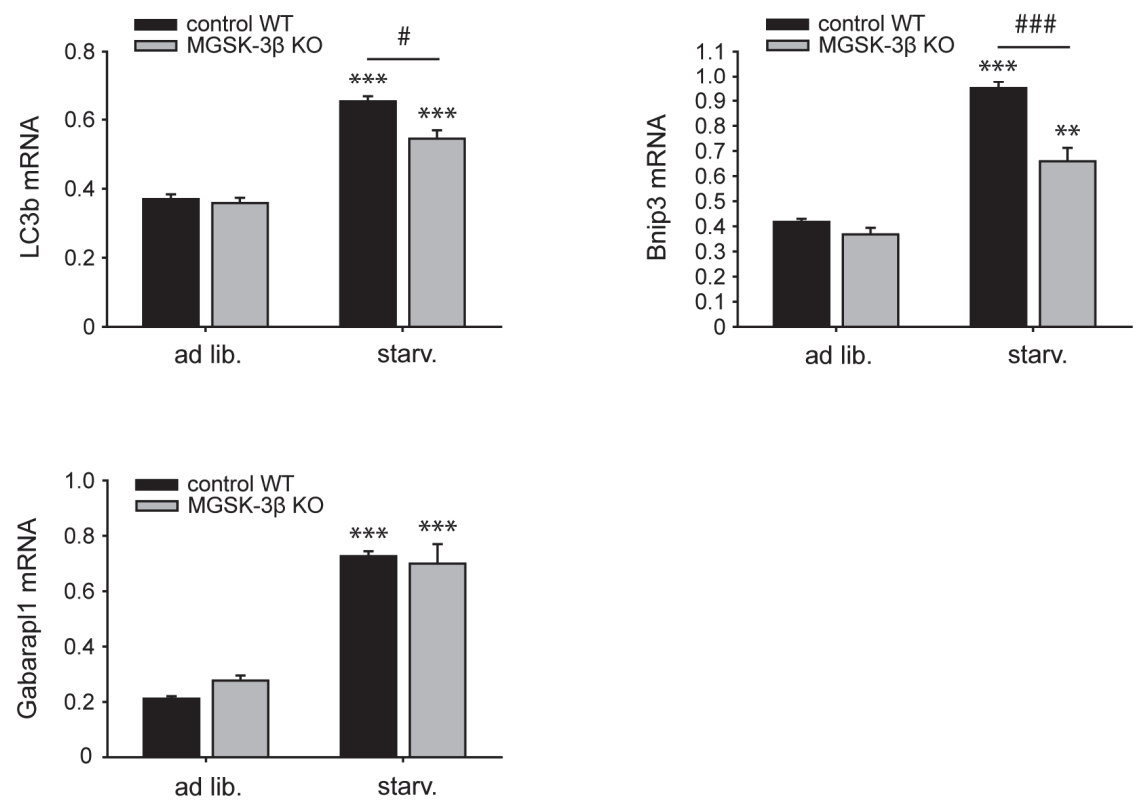
Figure 4.2 Starvation-induced UPS -and ALP-related gene expression in muscle is partially dependent on GSK-3 $\beta$.

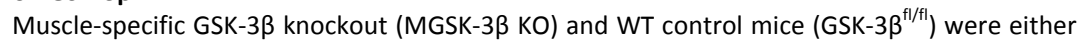
fasted for $24 \mathrm{~h}$ or fed ad libitum. (A) At this time point the mRNA transcript levels of atrogin-1, MuRF1, E3 $\alpha-I I$, and (B) LC3b, Bnip3 and Gabarapl1 were determined in plantaris muscle. All data shown represent means $\pm \mathrm{SEM}, \mathrm{n}=9$ animals per group. ${ }^{*} \mathrm{p}<0.05,{ }^{* *} \mathrm{p}<0.01,{ }^{* * *} \mathrm{p}<0.001$ compared with ad libitum fed WT control mice; \# $p<0.05$, \#\# $p<0.01$, \#\#\# $p<0.001$ refers to a difference between indicated conditions.

A
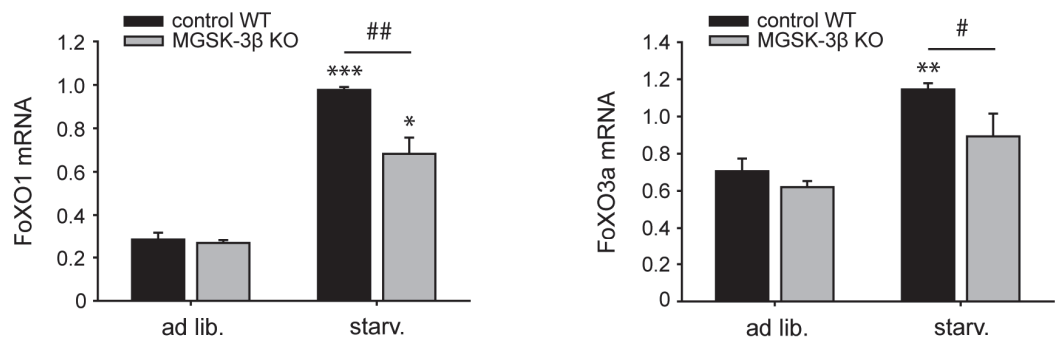

B
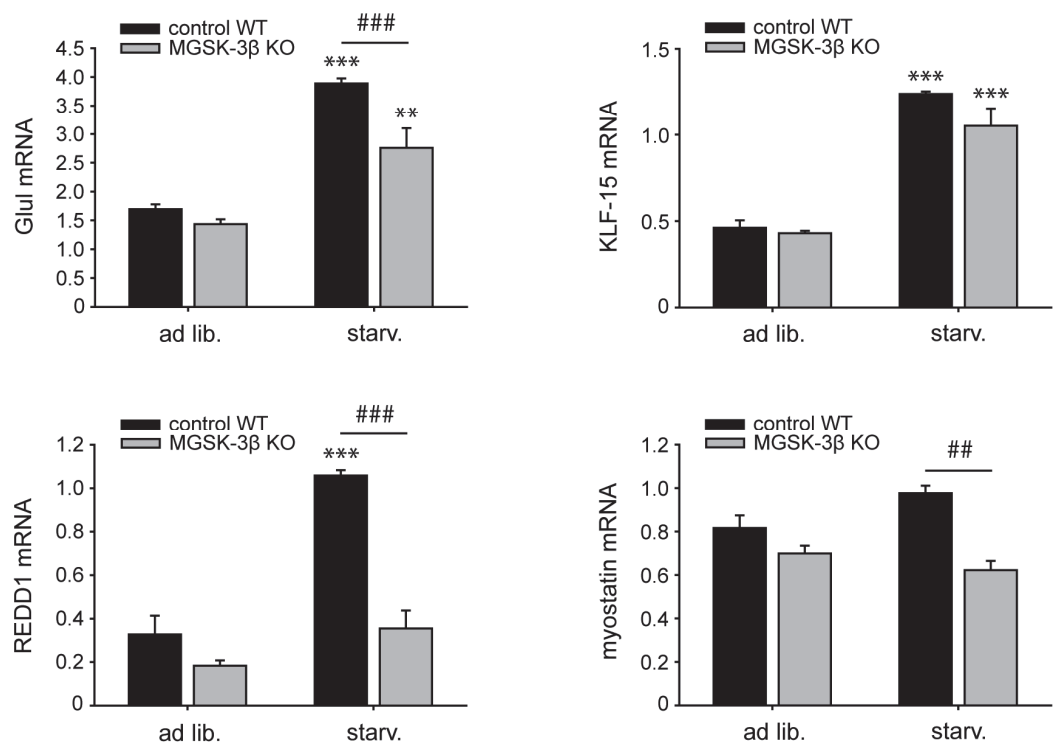

Figure 4.3 Fasting-induced FoXO and glucocorticoid-sensitive gene expression in muscle are in part mediated by GSK-3 $\beta$.

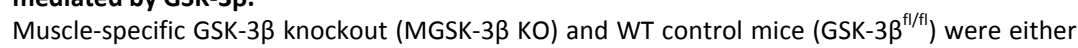
fasted for $24 \mathrm{~h}$ or fed ad libitum, after which the mRNA transcript levels of (A) FoXO1, FoXO3a, (B) Glul, KLF-15, REDD1 and myostatin were determined in plantaris muscle. All data shown represent means $\pm \mathrm{SEM}, \mathrm{n}=9$ animals per group. ${ }^{*} \mathrm{p}<0.05,{ }^{* *} \mathrm{p}<0.01,{ }^{* * *} \mathrm{p}<0.001$ compared with ad libitum fed WT control mice; \# $p<0.05$, \#\# $p<0.01$, \#\#\# $p<0.001$ refers to a difference between indicated conditions. 
A
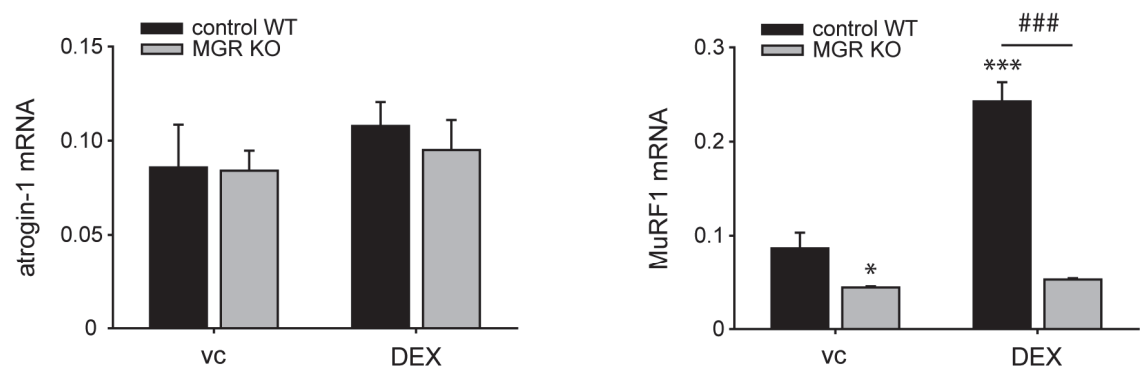

B
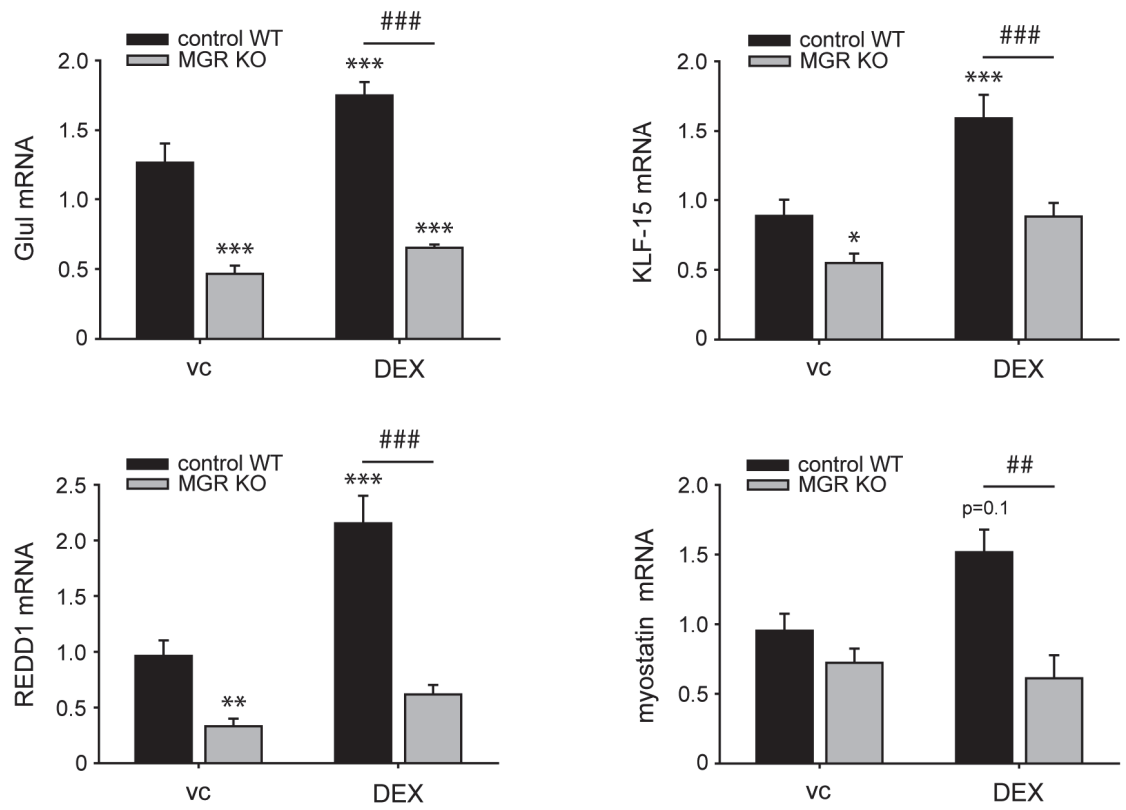

Figure 4.4 Dexamethasone-induced MuRF1 and glucocorticoid-sensitive gene expression in muscle requires the glucocorticoid receptor (GR).

Male muscle-specific GR knockout (MGR KO) and WT control mice $\left(\mathrm{GR}^{\mathrm{fl} / \mathrm{fl})}\right.$ ) were subcutaneously (sc) injected with the synthetic glucocorticoid dexamethasone (Dex) $[5 \mathrm{mg} / \mathrm{kg}$ body weight] or vehicle (vc) [saline, $0.9 \% \mathrm{NaCl}$. After $6 \mathrm{~h}$ mRNA abundance of (A) atrogin-1, MuRF1, (B) Glul, KLF-15, REDD1 and myostatin were determined in gastrocnemius muscle. All data shown represent means $\pm \mathrm{SEM}, \mathrm{n}=6$ animals per group. ${ }^{*} \mathrm{p}<0.05,{ }^{* *} \mathrm{p}<0.01$ compared with vc-treated WT control mice; \# $p<0.05, \# \# p<0.01$ refers to a difference between indicated conditions. NS: not significant. 


\section{ALP- but not UPS-associated gene expression is sustained in skeletal muscle following GC administration and dependent on GSK-3 $\beta$}

We next sought to address whether GC-induced UPS -and ALP-related gene expression was dependent on GSK-3ß. For this purpose, Dex or saline was administered subcutaneously to MGSK-3 $\beta$ KO and WT mice for $48 \mathrm{~h}$. Dex administration resulted in a modest, genotype-independent decrease in body weight (Supplemental Figure S4.2A), and significant losses in spleen mass reflecting its biological activity, regardless of the genotype (Supplemental Figure S4.2A). Unexpectedly, Dex instillation did not induce the mRNA transcript levels of atrogin-1, MuRF1 and E3 $\alpha$-II (Figure 4.5A). MuRF1 expression was even significantly decreased in muscle of MGSK-3 $\beta$ KO and WT mice following $48 \mathrm{~h}$ of corticosteroid exposure (Figure 4.5A). Contrastingly, the ALP-associated genes LC3b and Bnip3 were marginally increased in WT control mice following systemic Dex-treatment, while the induction of Gabarapl1 remained absent (Figure 4.5B). Furthermore, the induction of LC3b and Bnip3 was significantly attenuated in MGSK-3 $\beta$ KO mice, whereas Gabarapl1 transcript levels appeared completely refractory to Dex or the loss of muscle GSK-3 $\beta$ expression (Figure 4.5B).

\section{FoXO -and glucocorticoid-sensitive gene expression is not maintained in skeletal muscle following prolonged glucocorticoid administration}

In agreement with the response of UPS-sensitive gene expression following repeated GC administration, there were no alterations in the expression levels of FoXO1 and FoXO3a, the transcriptional regulators of UPS -and autophagy-related genes (Figure 4.6A). In addition, synthetic GC-treatment did not result in enhanced expression of Glul, KLF-15 and myostatin, all well-established GC-sensitive genes (Figure 4.6B), and even reduced REDD1 transcript levels independently of the presence of GSK-3 $\beta$. 
A
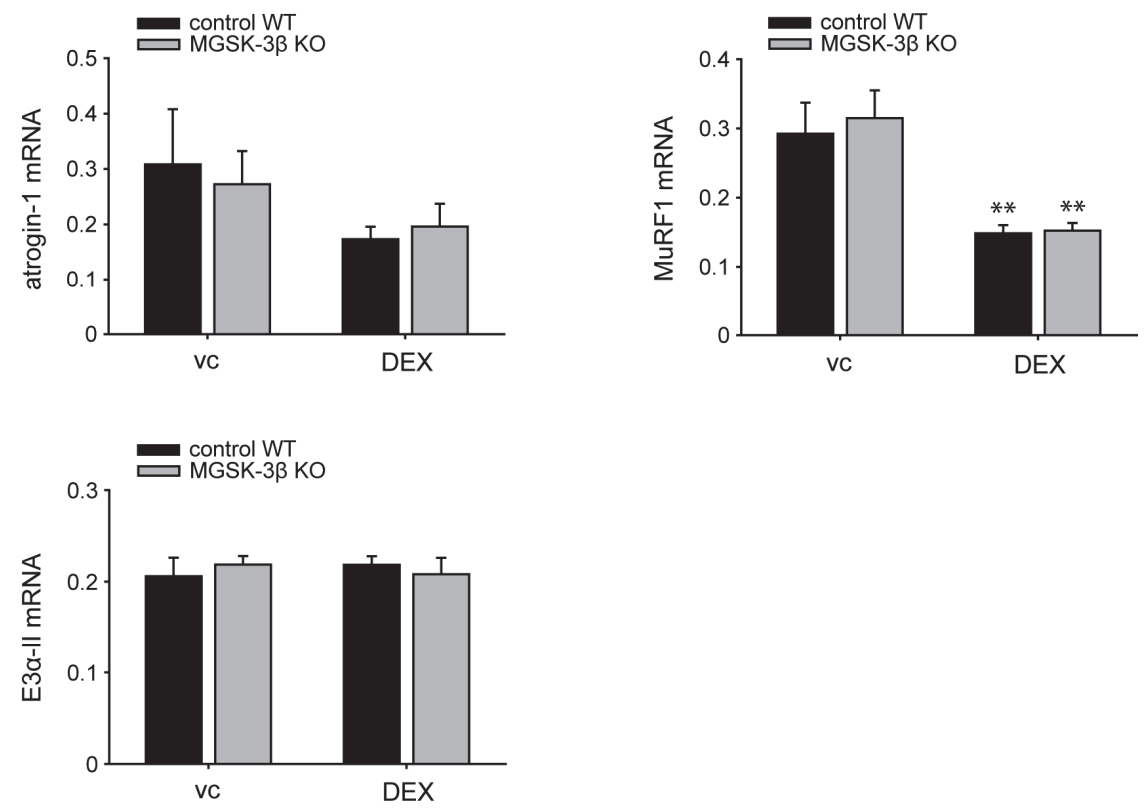

B
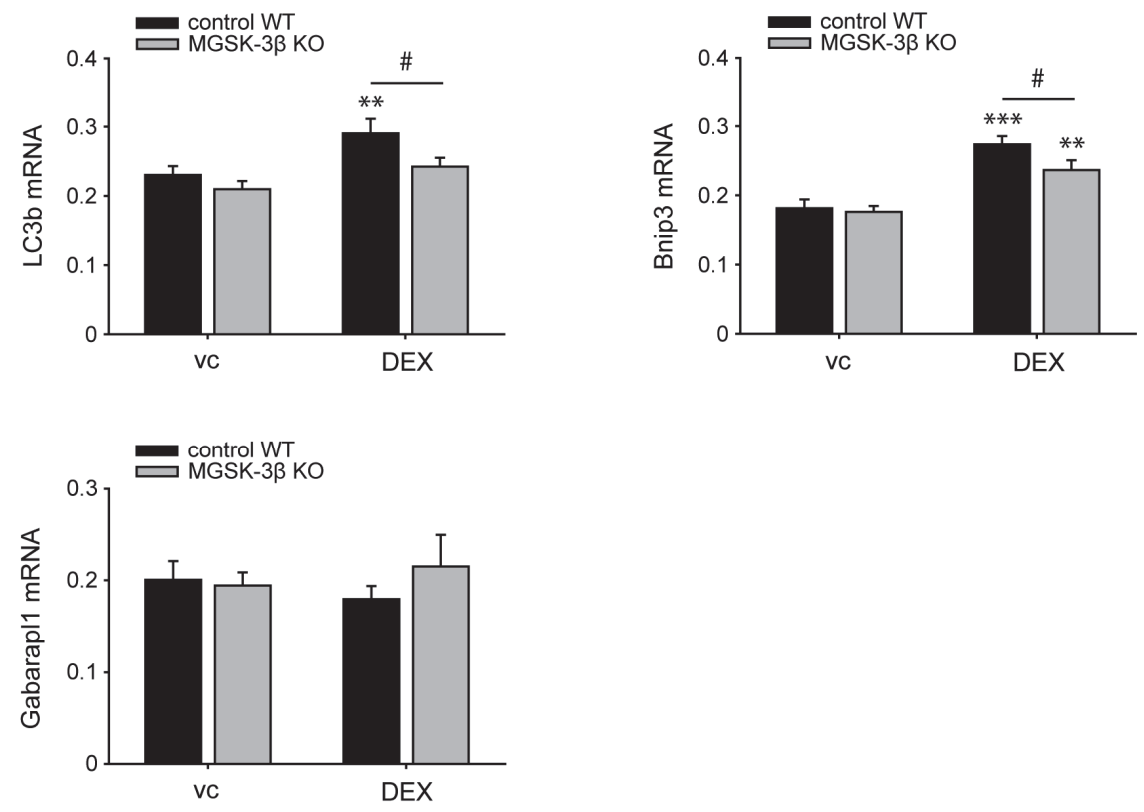
Figure 4.5 ALP -but not UPS-associated gene expression is sustained in skeletal muscle following GC administration, and dependent on GSK-3 $\beta$.

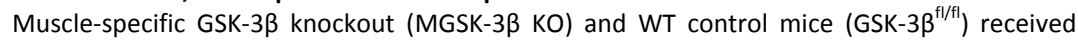
daily injections of Dex or vc for $48 \mathrm{~h}$. (A) At this time point the mRNA transcript levels of atrogin-1, MuRF1, E3 $\alpha-I I$, and (B) LC3b, Bnip3 and Gabarapl1 were determined in plantaris muscle. All data shown represent means \pm SEM, $n=9$ animals per group. $* * p<0.01$, $* * * p<0.001$ compared with vc-treated WT control mice; \# $p<0.05$ refers to a difference between indicated conditions.

A
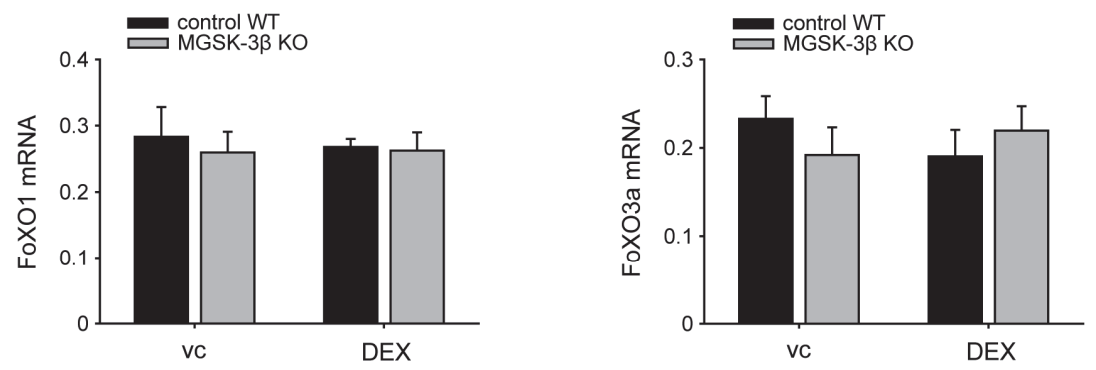

B
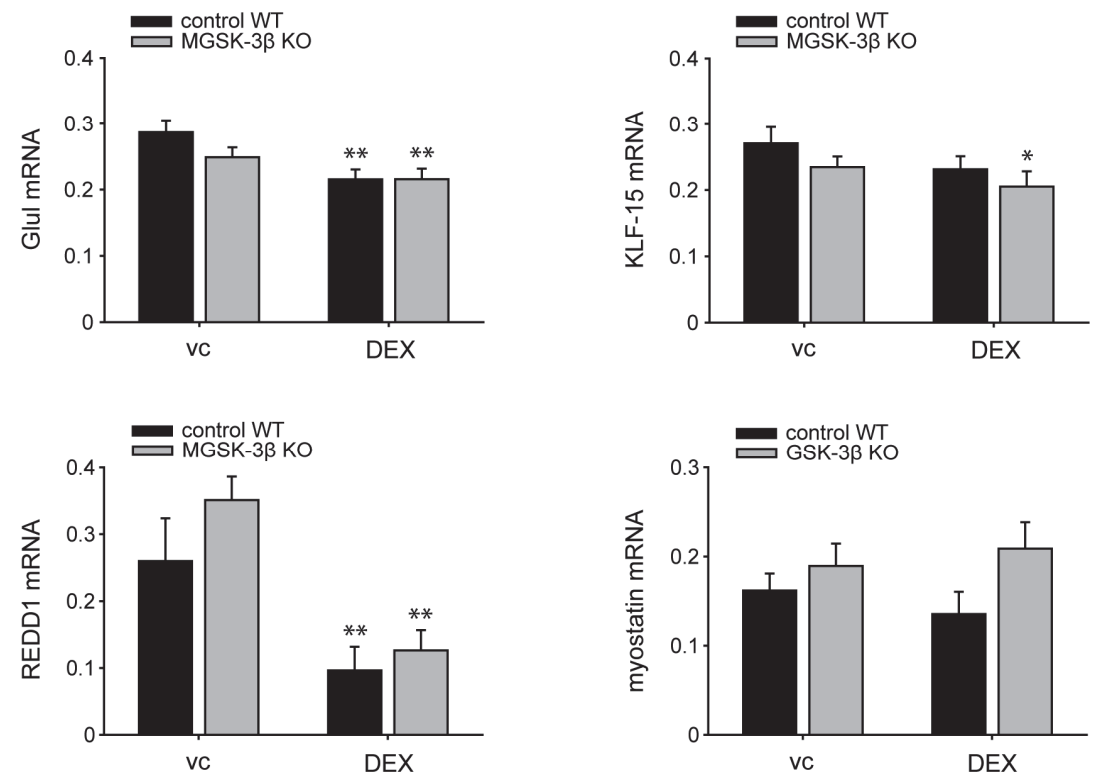

Figure 4.6 FoXO -and glucocorticoid-sensitive gene expression is not maintained in skeletal muscle following prolonged glucocorticoid administration.

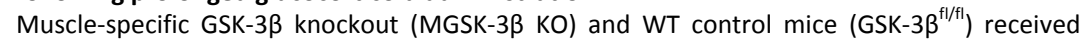
daily injections of Dex or vc for $48 \mathrm{~h}$, after which the mRNA transcript levels of (A) FoXO1, FoXO3a, (B) Glul, KLF-15, REDD1 and myostatin were determined in plantaris muscle. All data shown represent means $\pm \mathrm{SEM}, \mathrm{n}=9$ animals per group. ${ }^{*} \mathrm{p}<0.05, * * \mathrm{p}<0.01$ compared with vc-treated WT control mice. 


\section{Muscle-specific GSK-3 $\beta$ expression is required for glucocorticoid- induced skeletal muscle atrophy}

Considering the dependency of GSK-3 $\beta$ on GC-sensitive and atrogene expression, we next sought to investigate whether GC-induced skeletal muscle atrophy required

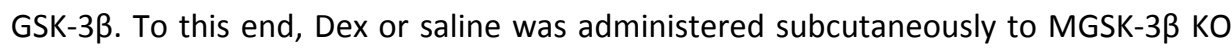
and WT mice for two weeks. A modest, albeit statistically significant, genotypeindependent decline in body weight was observed in response to chronic Dextreatment (Figure 4.7A). Furthermore, repeated Dex challenges resulted in similar losses in spleen mass confirming a similar bioactivity of Dex in both WT and MGSK-3 $\beta$ KO mice (Figure 4.7B). Moreover, a concurrent decrease in the wet weights of EDL $(-10 \%)$, gastrocnemius $(-10 \%)$, plantaris $(-13 \%)$ and tibialis $(-10 \%)$ muscles was found in Dex-treated control mice compared with saline-treated controls. In contrast, in the MGSK-3 $\beta$ KO mice no significant muscle atrophy was observed, while the oxidative M. soleus appeared completely resistant against Dex-induced muscle atrophy (Figure 4.7C). Next, the fiber cross-sectional area (CSA) was measured to determine if the rescued atrophy phenotype, evident from the muscle mass data, was also apparent at the individual fiber level. Indeed, the predominantly glycolytic EDL muscle, i.e. abundant in Type Ilb fast-twitch fibers, of Dex-treated WT control mice atrophied and a showed a significant decrease in mean Type Ilb (-20\%) (data not shown) fiber CSA in contrast to MGSK-3 $\beta$ KO mice, where no significant decrease in CSA was observed. This phenotype was further substantiated by examining the fiber size distribution curves, which revealed a leftward shift, indicating the presence of a larger proportion of smaller fibers in Dex-treated control mice, compared with vehicle-treated control animals (Figure 4.7D). In contrast, there was no observable difference in the fiber size distribution of vehicle-treated and Dex-treated MGSK-3 $\beta$ KO mice (Figure 4.7D). Similar to the observations made in the acute Dex study (Figure 4.5 and Figure 4.6), no increases in the transcript levels of UPS, ALP-related and GC-sensitive genes were detected in response to daily Dex injections for two weeks (Supplemental Figure S4.3 B-D). The $p-G S K-3 \beta$ to GSK-3 $\beta$ ratio in WT muscle following sustained Dex-treatment remained unaltered, and muscle-specific deletion of GSK-3 $\beta$ resulted in >95\% reduction in GSK-3 $\beta$ protein levels. To probe a potential contribution of decreased protein synthesis signaling to the muscle atrophy phenotype observed in WT and MGSK-3 $\beta$ KO mice, the protein levels and phosphorylation status of the rate-limiting translational repressor elF4E-binding protein 1 (4E-BP1) was assessed (Supplemental Figure S4.3E). Dex-treatment resulted in a genotype-independent increase in phosphorylated ( 2.2 fold) as well as total 4E-BP1 levels (1.5 fold). This increase in the $\mathrm{p}-4 \mathrm{E}-\mathrm{BP} 1$ to $4 \mathrm{E}-\mathrm{BP} 1$ ratio was indicative of increased protein synthesis signaling following two weeks of Dex instillation (data not shown). These data indicate that prolonged Dex administration results in a GSK-3ß-dependent muscle atrophy, which is not explained by alterations in UPS -or ALP-associated proteolysis or 4E-BP1-mediated regulation of protein synthesis. 
A

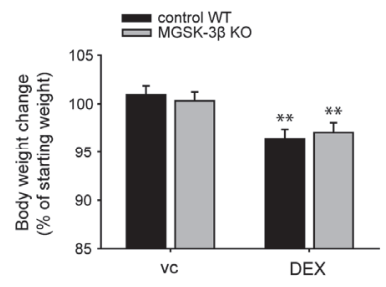

C
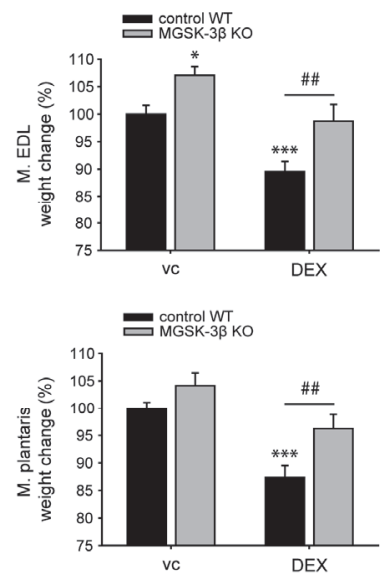

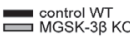

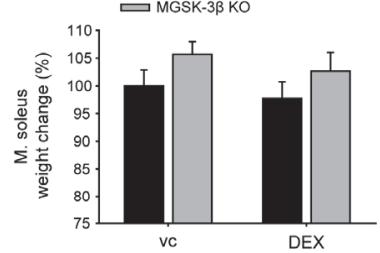

D
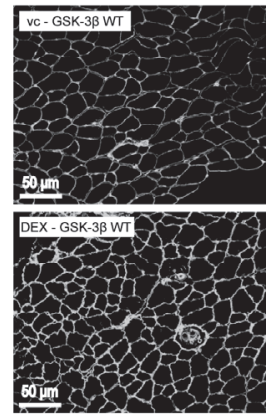
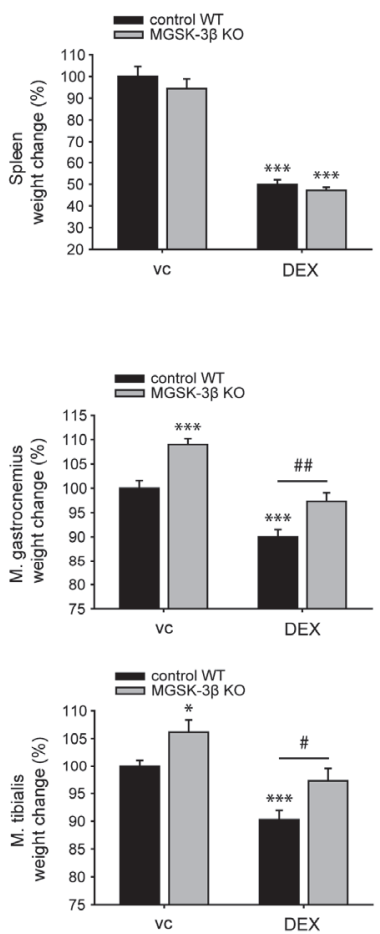
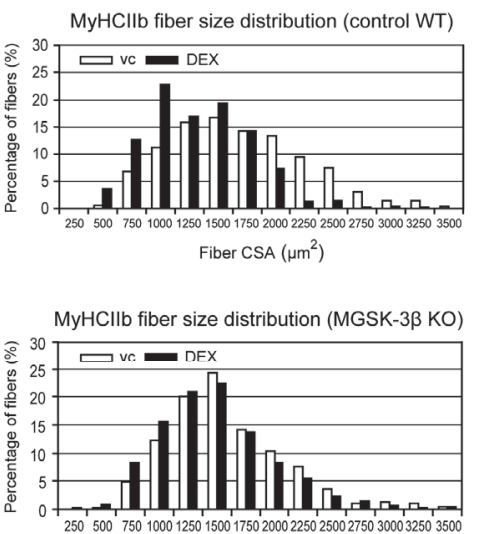
Fiber CSA $\left(\mu \mathrm{m}^{2}\right)$ 
Figure 4.7 Muscle-specific GSK-3 $\beta$ expression is required for glucocorticoid-induced skeletal muscle atrophy.

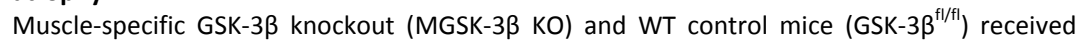
daily injections of Dex or vc for $14 \mathrm{~d}$. (A) End-point body and (B) spleen weights were determined and expressed as a \% of weight change of the vc-treated WT control group. (C) EDL, gastrocnemius, plantaris, tibialis and soleus muscle mass was assessed and expressed as a \% of weight change of the vc-treated WT control group. (D) Muscle fiber cross-sectional areas (CSA) from the EDL muscle of vc -or Dex-treated WT control (left) or MGSK-3 $\beta$ KO (right) mice was determined from laminin-stained cross-sections. Shown are representative lamininstained muscle cross-sections of the same region within the EDL muscle for each experimental group (200X magnification, scale bar $=50 \mu \mathrm{m}$ ), including the corresponding fiber size distribution of Type IIb fiber CSA of WT control (top graph) or MGSK-3 $\beta$ KO (bottom graph) mice following vc or LPS instillation. All data shown represent means $\pm S E M, n=9$ animals per group. ${ }^{*} \mathrm{p}<0.05, * * \mathrm{p}<0.01, * * * \mathrm{p}<0.001$ compared with vc-treated WT control mice; $\# p<0.05, \# \# p<0.01$ refers to a difference between indicated conditions.

\section{Discussion}

Skeletal muscle atrophy is an incapacitating consequence of several pathophysiological conditions characterized by elevated endogenous levels of GCs. However, the exact molecular mechanisms underlying the involvement of GCs in muscle wasting are not completely understood. The research presented in this manuscript aimed at providing new insights into how GC-driven transcriptional cascades are regulated during muscle atrophy, and focused specifically on the role of GSK-3 $\beta$ therein. As mentioned earlier, both IGF-I/insulin and GC-associated signaling are involved in the regulation of muscle mass. However, during catabolic conditions, such as starvation, when insulin and IGF-I levels and associated signaling are generally low, the pro-anabolic PI-3K/Akt pathway is further antagonized by GR-dependent signaling $(37,42)$. GSK-3 $\beta$ is a downstream signaling molecule in the IGF-I/insulin signaling cascade and is activated when Akt activity is suppressed. Previous reports from our group and others clearly delineated an important role for GSK-3 $\beta$ in the regulation of GC-induced muscle proteolysis in vitro, as GSK-3 $\beta$ inactivation inhibited the induction of the atrophy-associated genes atrogin-1 and MuRF1 mRNA, and prevented myotube atrophy in response to synthetic GC-treatment $(21,100)$.

To gain further insight into the in vivo role of GSK-3 $\beta$ during GC-induced muscle

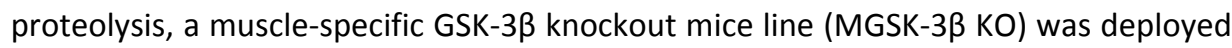
here, to investigate the contribution of GSK-3 $\beta$ to skeletal muscle atrophy in response to fasting and high-dose Dex-treatment. We determined that, in addition to UPSassociated gene expression, GSK-3 $\beta$ is also involved in ALP-related and GR-dependent transcriptional programs. Importantly, the present findings reveal that tissue-specific GSK-3 $\beta$-deficiency results in significant sparing of muscle mass following starvation or synthetic GC-treatment. 
Starvation is a well-established model of GC-mediated muscle atrophy, and has been consistently shown to correlate with increased levels of circulating GCs $(57,66,107)$. In line with this, starvation for $48 \mathrm{~h}$ resulted in a significant genotypeindependent decline in body weight, which was associated with an increase in plasma corticosterone levels. The release of corticosterone is essential for the maintenance of homeostasis, and enables the organism to cope with stress conditions, such as periods of prolonged nutrient deprivation $(10,14)$. Starvation resulted in decreased in liver weights, irrespective of the genotype, which were most likely attributable to enhanced depletion of liver glycogen stores (87). In spite of hepatic glycogenolysis, blood glucose levels decreased following starvation as previously reported (87), independent of muscle GSK-3 $\beta$. A second adaptation to maintain constant blood glucose levels is increased gluconeogenesis. This process is fueled by amino acids, which are mobilized from skeletal muscle, resulting in muscle tissue depletion (24). Indeed, fasted WT control mice displayed extensive atrophy of the lower hind limbs. However, muscle mass of MGSK-3 $\beta$ KO mice was remarkably resistant to starvationinduced skeletal muscle atrophy. This suggests redirection of gluconeogenic precursors other than amino acids such as glycerol (29), as blood glucose in MGSK-3 $\beta$ KO mice was maintained at levels similar to fasted WT control mice.

Atrogin-1 and MuRF1 are both key atrogenes involved in UPS-dependent protein degradation, and fasting-induced increases in their expression have been reported previously $(39,50,76,77)$. Consistent with the observed muscle sparing, and in line with our previous in vitro work (100), the expression of atrogin-1 and MuRF1 was significantly attenuated in starved MGSK-3 $\beta$ KO mice compared with their respective genotypic controls. E3 $\alpha$ (or UBR1) was the first ubiquitin ligase to be implicated in the muscle atrophy process $(44,45,88)$, and mediates ubiquitylation of short-lived proteins by the $\mathrm{N}$-end rule pathway resulting in selective UPS-dependent proteolysis $(88,90,96)$. The expression of E3 $\alpha$ was previously shown to be GC-dependent, as treatment with the GR antagonist RU-38486 significantly reduced its induction in septic muscle $(25,108)$. In this study, we detected a slight, albeit significant, increase in the expression of E3 $\alpha$-II (or UBR2) (43), an E3 $\alpha$ homologue, which, unlike atrogin-1 and MuRF1, was not dependent on muscle GSK-3 $\beta$ expression. However, the exact contribution of the $\mathrm{N}$-end rule pathway in muscle wasting remains unclear, as this system was found to be non-essential for GC-associated muscle catabolism during fasting (1).

In addition to the UPS, the ALP constitutes another major proteolytic system activated during muscle wasting. Although starvation and GC-treatment have been independently linked to the induction of certain autophagic markers $(68,75,95,109)$, the requirement of the GR in mediating ALP-related expression in muscle in response to fasting has not previously been established. Nonetheless, autophagy is thought to be required for the turnover of cellular constituents, particularly during starvationinduced proteolysis (65). In addition, previous studies in skeletal muscle cells suggested 
that the ALP is an essential contributor to muscle atrophy $(64,97)$. Here, we report that fasting significantly upregulated an ALP-related transcriptional program, which was partially dependent on GSK-3 $\beta$, as the induction of Gabarapl1 was refractory to the loss of GSK-3 $\beta$ expression in muscle. Increased autophagic flux following fastinginduced decreases in the activity of the PI-3K/Akt signaling pathway were found to involve FoXO3a activity in skeletal muscle $(58,111)$.

In fact, FoXO transcription factors were found to coordinately regulate both ALPrelated, as well as UPS-associated transcriptional programs in muscle, acting as liaison molecules governing the expression of the E3 ligases atrogin-1 and MuRF1 (77,94), and the critical autophagy-related genes LC3b, Bnip3 and Gabarapl1 $(58,59,111,112)$. The current paradigm of FoXO activation entails its dephosphorylation resulting in nuclear translocation, and subsequent regulation of atrogene expression $(77,94)$. However, several lines of evidence have implied a second non-canonical mode of FoXO activation, involving its de novo expression during skeletal muscle atrophy. In particular, FoXO expression was found to be upregulated in response to GC-treatment $(5,27)$. Furthermore, Waddell et al. demonstrated that GC-induced increases in FoXO mRNA expression were dependent on GR dimerization (101), while Watson et al. described decreases in FoXO1 expression in muscle-specific GR knockout mice (104). In addition, work by Smith and coworkers also established the dependency of FoXO expression on the GR, as the sepsis-induced induction of FoXO1 was attenuated by the GR antagonist RU-38486 (86). Recently, FoXO3a was identified as a direct GR target gene, as it contained functional GREs in its promoter (55). Altogether, these studies suggest that non-genomic actions of GR may control non-canonical FoXO activation in GC-driven muscle atrophy. Interestingly, in our study, fasting resulted in markedly upregulated FoXO1 and -3a mRNA levels, which corresponded with simultaneous increases in GC-sensitive gene expression in skeletal muscle, including Glul, KLF-15, REDD1 and myostatin. In contrast, this induction of both FoXO and GC-sensitive gene expression was significantly attenuated in absence of GSK-3 $\beta$. As such, these results provide in vivo evidence to support a key role for GSK-3 $\beta$ regulation of FoXO expression in control of the proteolytic transcriptional programs of the UPS and ALS, and suggest this may involve genomic actions of the GR.

To more directly assess whether GSK-3 $\beta$ controls GR-dependent muscle atrophy and proteolytic gene expression, the requirement of GSK-3 $\beta$ was tested in a GC (Dex)induced model of muscle atrophy. First we confirmed that Dex-induced GC-sensitive and proteolytic gene expression required muscle GR expression. As indicated, genomic GC actions require the activation of the GR (101). In line with this, skeletal muscle-restricted deletion of the GR blunted the Dex-induced induction of several well-established GC-sensitive genes, including Glul (11), KLF-15 (84), REDD1 (18,41) and myostatin $(30,56)$. Previous work has shown that GCs are sufficient to induce expression of atrogin-1 and MuRF1 in both cell culture and in vivo $(12,74,100,104)$, and 
several studies have indicated that GR-dependent signaling is required for the induction of these ligases $(104,108,113)$. Our data corroborated these findings, since Dex-induced expression of MuRF1 was blocked in GR-deficient muscle. The apparent discrepancy between atrogin-1 and MuRF1 with regard to their induction in response to Dex may have been due to the fact that the MuRF1 gene has a functional glucocorticoid response element (GRE) in its promoter, whereas no GRE has been demonstrated conclusively in the vicinity of the atrogin-1 gene (101). Instead, the GCinduced upregulation of atrogin-1 transcript levels may require non-canonical activation of FoXO driven transcriptional responses (77), providing a possible explanation for the lack of any atrogin-1 induction $6 \mathrm{~h}$ post Dex administration. Consequently, transactivation of the MuRF1 promoter may occur instantaneously following GR activation, whereas non-canonical FoXO activation-mediated atrogin-1 expression may not yet have been completed $6 \mathrm{~h}$ post Dex administration.

As these data confirmed KLF-15, Glul, REDD1 and myostatin as genuine GR-target genes induced by GCs, this supported the notion that the attenuated induction of these genes in absence of muscle GSK-3 $\beta$ following fasting reflects control of GRmediated gene expression by GSK-3 $\beta$ in skeletal muscle. To further address this, WT and MGSK-3 $\beta$ KO mice were treated with the synthetic GC Dex. Similar to the observations made in the starvation study, muscle-specific deletion of GSK-3 $\beta$ resulted in significant sparing of muscle mass following chronic Dex administration. Subsequent examination of the fiber cross-sectional area (CSA) and fiber size distribution curves in WT and MGSK-3 $\beta$ KO mice attenuated muscle fiber atrophy, in line with the sparing of muscle mass. Intriguingly, EDL, gastrocnemius and tibialis muscle wet weights of vehicle-treated MGSK-3 $\beta$ KO mice were modestly, but significantly increased compared with WT animals. The mechanism behind this observation was not determined here since it is beyond the scope of the current study. However, it should be noted that in the starvation study no significant increases in muscle mass were found in ad libitum fed MGSK-3 $\beta$ KO mice compared to WT mice. In addition, increased muscle mass in GSK-3 $\beta$-deficient muscle was not accompanied by increased muscle fiber size, suggesting this increase in muscle mass may not reflect muscle hypertrophy, but changes in interstitial fluid retention which may be inherent to differences between the two experimental models. Interestingly, the oxidative soleus muscle was completely refractory to Dex-induced muscle wasting. Typically, GC-induced muscle atrophy predominantly affects fast-twitch type II glycolytic fibers (particularly IIx and IIb), with little or no impact on oxidative type I fibers $(16,62)$. For this reason, fast-twitch glycolytic muscles, i.e. M. EDL or M. tibialis, are more susceptible to GC-induced atrophy than oxidative muscles, such as M. soleus. The mechanisms behind such fiber specificity are currently unknown. However, Shimizu and colleagues argued that glycolytic muscles have an evolutionary preserved role for the storage of nutrients under the control of the GC-GR axis, and that GR-dependent 
gene expression is a purposeful mechanism for nutrient supply from these muscles, for instance during starvation (84).

In response to Dex administration, $\mathrm{LC} 3 \mathrm{~b}$ and Bnip3 transcript levels were upregulated, and these increases were dependent on GSK-3 $\beta$, similar as observed in response to fasting. However, no increases in the mRNA expression of UPS-related or GC-sensitive genes were detected following $48 \mathrm{~h}$ of Dex exposure. It has been established that proteolytic gene expression is induced early in the atrophy process; generally preceding the onset of muscle loss in several experimental models $(32,73,93)$. It was therefore surprising not to find any increases in atrogene or GC-sensitive gene expression following $48 \mathrm{~h}$ of Dex-treatment, despite confirmation of the biological activity of the water-soluble Dex used in this study, based on the observed decreases in spleen mass, reflecting splenocyte apoptosis (33), as a well-described response to prolonged exposure to excess GC levels.

Similar to the observations made in the acute Dex study, the mRNA expression levels of UPS-related and GC-sensitive genes were not increased following two weeks of Dex administration. In addition to enhanced skeletal muscle proteolysis, decreased protein synthesis may also lie at the basis of muscle atrophy. We therefore assessed the potential contribution of altered protein synthesis to the muscle atrophy phenotype observed in WT and MGSK-3 $\beta$ KO mice. GCs have been shown to negatively modulate translation initiation by dephosphorylation of 4E-BP1 (83), which may result from mTOR inhibition through increased expression of REDD1. In contrast, we observed increased phosphorylation of 4E-BP1 following sustained Dex administration, which was indicative of increased protein synthesis. In the abovementioned study, attenuation of translation initiation was an acute response to GCtreatment (83), and another report suggested that in model of GC-associated muscle atrophy decreases in protein synthesis were of a transient nature (47). However, regardless of whether protein synthesis was reduced or increased following Dextreatment, our data are not in support of a major role of altered protein synthesis in the development of muscle atrophy in this model, due to the fact that any changes in protein synthesis signaling in response to Dex occurred independently of the genotype. Consequently, these observations cannot be reconciled with the differential muscle mass depletion in WT and MGSK-3 $\beta$ KO mice in response to Dex.

The absence of changes in UPS-related gene expression contrasts previous reports by Baehr et al. (5) and Watson et al. (104), in which increased MuRF1 and atrogin-1 expression in skeletal muscle was observed at multiple time points following Dex administration. Slight changes in the experimental model may lie at the basis of this apparent discrepancy, as the total dose may have differed between the studies, as well as the route of administration. As opposed to our treatment regimen of single daily sc-injections with Dex, this was provided by the drinking water in the former 
studies. GC signaling in skeletal muscle may therefore have been of a more continuous nature due to sustained Dex levels, in contrast to the intermittent rises in Dex following sc delivery. Many GC-controlled responses, including gene expression in skeletal muscle are transient in nature, or governed by circadian rhythm (19). This may explain the apparent absence of differentially expressed UPS -and GR-dependent genes $24 \mathrm{~h}$ following the last Dex administration, as these were clearly induced $6 \mathrm{~h}$ post Dex instillation. Nevertheless, our data reveal that increases in ALP-associated gene expression, as well as muscle atrophy induced by GCs requires muscle GSK-3 $\beta$.

In conclusion, our data provide in vivo evidence to support a key role for GSK-3 $\beta$ in GC-dependent muscle atrophy, and suggest GSK-3 $\beta$ controls UPS and ALP transcriptional programs by regulation of genomic actions of the GR. 


\section{Supplemental figures and table}

A

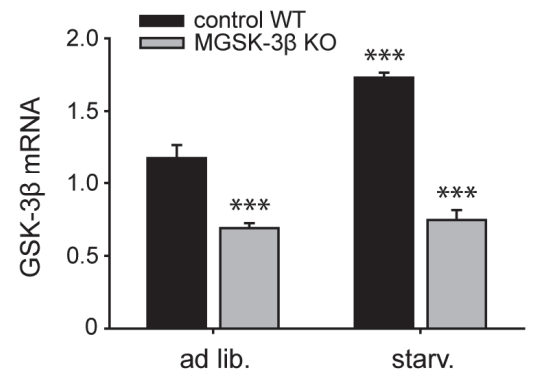

c
B

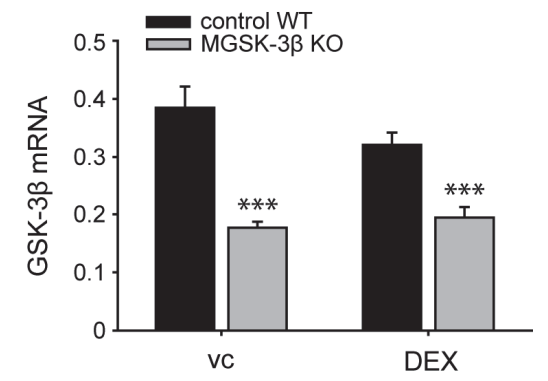

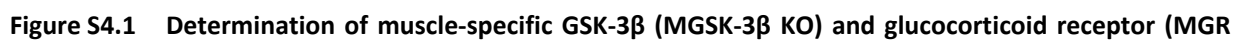
KO) knockout.

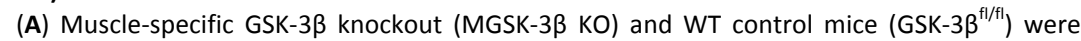
either fasted for $24 \mathrm{~h}$ or fed ad libitum, after which the mRNA transcript levels of GSK-3 $\beta$ were

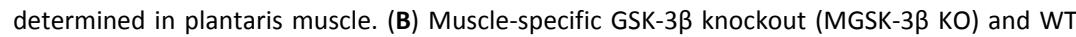
control mice $\left(G S K-3 \beta^{f / f f l}\right)$ received daily injections of Dex or vc for $48 \mathrm{~h}$. At this time point the mRNA transcript levels of GSK-3 $\beta$ were determined in plantaris muscle. (C) Gastrocnemius muscle of WT control and MGR KO mice was collected and lysates were prepared for protein analysis by Western blotting. Shown are representative immunoblots of GR and GAPDH determined in whole muscle homogenates. All data shown represent means $\pm S E M, n=9$ animals per group. ${ }^{* * *} \mathrm{p}<0.001$ compared with vc-treated WT control mice. 
A
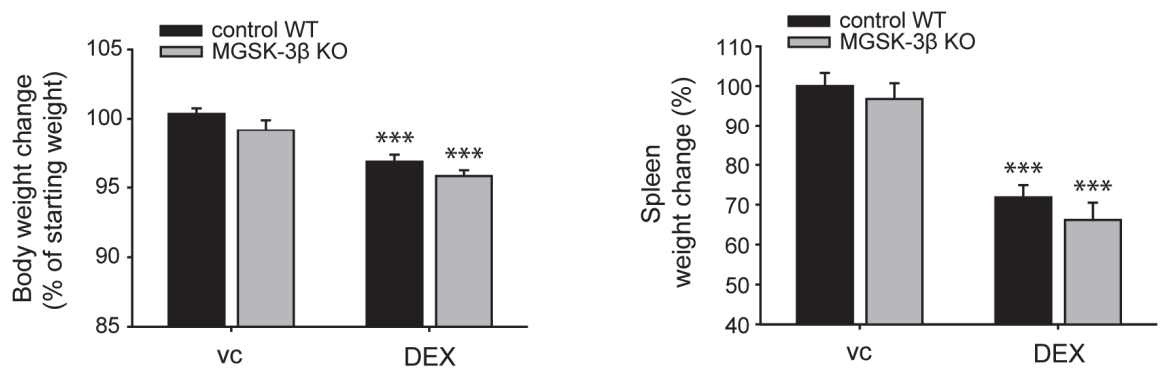

Figure S4.2 Loss of body weight and spleen mass in response to dexamethasone-treatment for $48 \mathrm{~h}$.

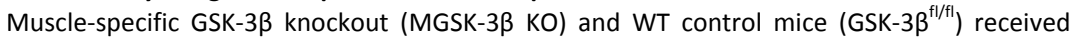
daily injections of Dex or vc for $48 \mathrm{~h}$. (A) End-point body and spleen weights were determined and expressed as a \% of weight change of the vc-treated WT control group. All data shown represent means $\pm \mathrm{SEM}, \mathrm{n}=9$ animals per group. ${ }^{* * *} \mathrm{p}<0.001$ compared with vc-treated WT control mice. 
A
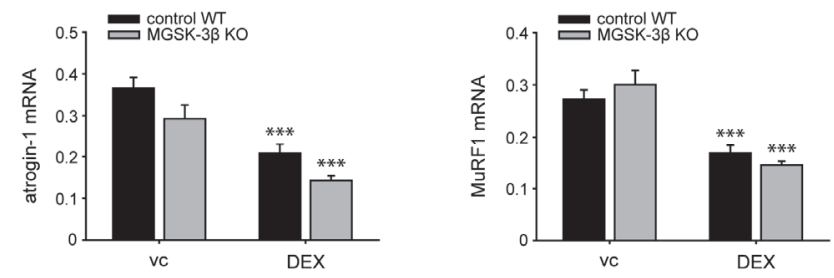

B
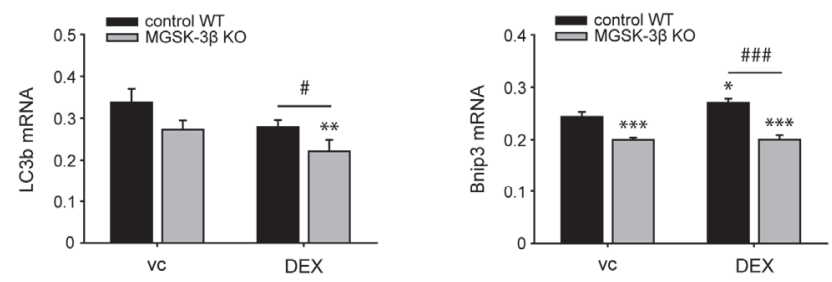

C
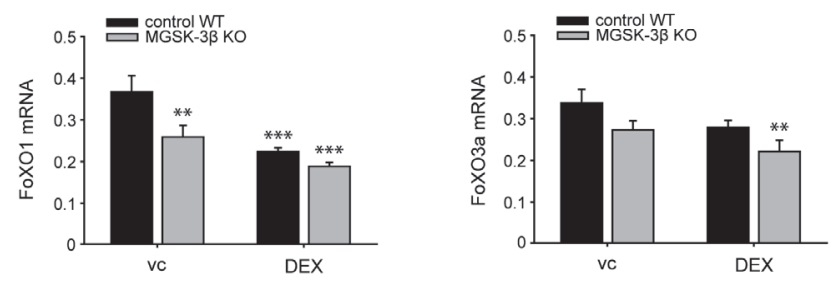

D
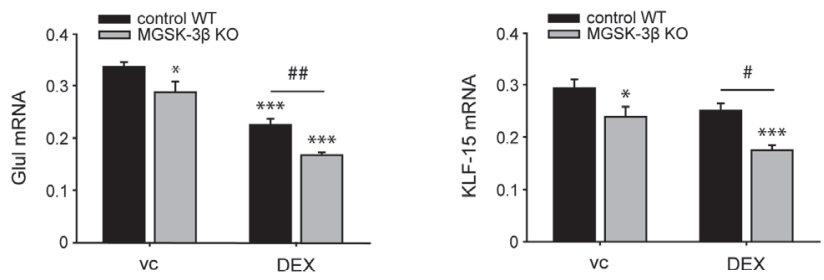

E
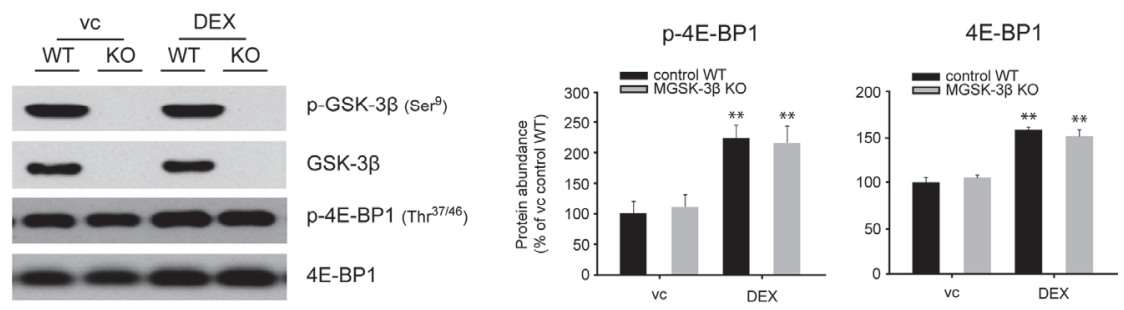
Figure S4.3 Protein synthesis and degradation signaling following chronic dexamethasone-treatment.

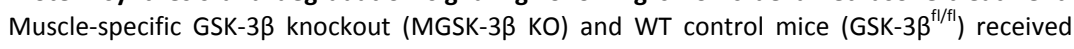
daily injections of Dex or vc for $14 \mathrm{~d}$, after which the mRNA transcript levels of $(\mathbf{A})$ atrogin-1, MuRF1, (B) LC3b, Bnip3, (C) FoXO1, FoXO3a (D) Glul and KLF-15 were determined in plantaris muscle. (E) Gastrocnemius muscle of WT control and MGSK-3 $\beta$ KO mice, subjected to Dex or vc for $14 \mathrm{~d}$, was collected and lysates were prepared for analysis of protein synthesis signaling markers by Western blotting. Representative immunoblots accompanied by quantitative

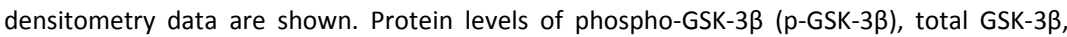
phospho-4E-BP1 (p-4E-BP1) and total 4E-BP1 were determined in whole muscle homogenates. Accompanying bar graphs represent data as a $\%$ of the vc control WT group. All data shown represent means $\pm \mathrm{SEM}, \mathrm{n}=9$ animals per group. ${ }^{*} \mathrm{p}<0.05,{ }^{* *} \mathrm{p}<0.01,{ }^{* * *} \mathrm{p}<0.001$ compared with vc-treated WT control mice; \# $p<0.05$, \#\# $p<0.01, \# \#$ p $<0.001$ refers to a difference between indicated conditions.

Table S4.1 Genes of interest determined by real-time quantitative reverse transcription PCR (qRT-PCR).

\begin{tabular}{|c|c|c|}
\hline Gene name & Forward primer & Reverse primer \\
\hline atrogin-1 & 5'-ACCGGCTACTGTGGAAGAGA-3' & 5'-CCTTCCAGGAGAGAATGTGG-3' \\
\hline MuRF1 & 5'-TGTCTGGAGGTCGTTTCCG-3' & 5'-CTCGTCTTCGTGTTCCTTGC-3' \\
\hline$E 3 \alpha-I I$ & 5'-AGAGAGGAGCGATAAGCTACCCCAGA-3' & 5'-CCACACACGAGGCACAGAGTAGG-3' \\
\hline LC3b & 5'-GAGCAGCACCCCACCAAGAT-3' & 5'-CGTGGTCAGGCACCAGGAA-3' \\
\hline Bnip3 & 5'-AGGTTTTCCTTCCATCTCTGTTACTG-3' & 5'-TGTGTGAACAGAAGTCAGATCCAAA-3' \\
\hline Gabarapl1 & 5'-СССТСССАССАGTGCTACCAT-3' & 5'-TCATCACTGTAGGCCACATACAGAAAA-3' \\
\hline Glul & 5'-GGCCATGCGGGAGGAGA-3' & 5'-GGTGCCTCTTGCTCAGTTTGTCA -3' \\
\hline KLF-15 & 5'-TGCAGCAAGATGTACACCAAGAG-3' & 5'-ATCGCCGGTGCCTTGAC-3' \\
\hline REDD1 & 5'-CGGGCCGGAGGAAGACT-3' & 5'-CTGCATCAGGTTGGCACACA-3' \\
\hline myostatin & 5'-GGCCATGATCTTGCTGTAACCT-3' & 5'-CGGCAGCACCGGGATT-3' \\
\hline FoX01 & 5'-AAGAGCGTGCCCTACTTCAAGGATA-3' & 5'-CCATGGACGCAGCTCTTCTC-3' \\
\hline FoX03a & 5'-TGCTGACGGGTTGGATTTTAACTT-3' & 5'-AAACGGATCACTGTCCACTTGCT-3' \\
\hline GSK-3 $\beta$ & 5'-CCACATGCTCGGATTCAGGC-3' & 5'-TGTCCACGGTCTCCAGCATTAGTAT-3' \\
\hline$\beta$-actin & 5'-CTGAATGGCCCAGGTCTGA-3' & 5'-CCCTCCCAGGGAGACCAA-3' \\
\hline cyclophilin A & 5'-TTCCTCCTTTCACAGAATTATTCCA-3' & 5'-CCGCCAGTGCCATTATGG-3' \\
\hline GAPDH & 5'-CAACTCACTCAAGATTGTCAGCAA-3' & 5'-TGGCAGTGATGGCATGGA-3' \\
\hline calnexin & 5'-GCAGCGACCTATGATTGACAACC-3' & 5'-GCTCCAAACCAATAGCACTGAAAGG-3' \\
\hline ARBP & 5'-GGACCCGAGAAGACCTCCTT-3' & 5'-GCACATCACTCAGAATTTCAATGG-3' \\
\hline RPL13A & 5'-CACTCTGGAGGAGAAACGGAAGG-3' & 5'-GCAGGCATGAGGCAAACAGTC-3' \\
\hline B2M & 5'-CTTTCTGGTGCTTGTCTCACTGA-3' & 5'-GTATGTTCGGCTTCCCATTCTC-3' \\
\hline$\alpha$-tubulin & 5'-CGTAGACCTGGAACCCACGGT-3' & 5'-TGCCTGTGATGAGCTGCTCA-3' \\
\hline
\end{tabular}




\section{References}

1. Adegoke OA, Bedard N, Roest HP, and Wing SS. Ubiquitin-conjugating enzyme E214k/HR6B is dispensable for increased protein catabolism in muscle of fasted mice. Am J Physiol Endocrinol Metab 283: E482-489, 2002.

2. Akner $\mathrm{G}$ and Cederholm T. Treatment of protein-energy malnutrition in chronic nonmalignant disorders. Am J Clin Nutr 74: 6-24, 2001.

3. Allen DL, Cleary AS, Lindsay SF, Loh AS, and Reed JM. Myostatin expression is increased by food deprivation in a muscle-specific manner and contributes to muscle atrophy during prolonged food deprivation in mice. J Appl Physiol 109: 692-701, 2010.

4. Almon RR and Dubois DC. Adrenalectomy eliminates both fiber-type differences and starvation effects on denervated muscle. Am J Physiol 255: E850-856, 1988.

5. Baehr LM, Furlow JD, and Bodine SC. Muscle sparing in muscle RING finger 1 null mice: response to synthetic glucocorticoids. J Physiol 589: 4759-4776, 2011.

6. Bechet D, Tassa A, Taillandier D, Combaret L, and Attaix D. Lysosomal proteolysis in skeletal muscle. Int J Biochem Cell Biol 37: 2098-2114, 2005.

7. Bodine SC. mTOR signaling and the molecular adaptation to resistance exercise. Med Sci Sports Exerc 38: 1950-1957, 2006.

8. Bodine SC, Latres E, Baumhueter S, Lai VK, Nunez L, Clarke BA, Poueymirou WT, Panaro FJ, Na E, Dharmarajan K, Pan ZQ, Valenzuela DM, DeChiara TM, Stitt TN, Yancopoulos GD, and Glass DJ. Identification of ubiquitin ligases required for skeletal muscle atrophy. Science 294: 1704-1708, 2001.

9. Bodine SC, Stitt TN, Gonzalez M, Kline WO, Stover GL, Bauerlein R, Zlotchenko E, Scrimgeour A, Lawrence JC, Glass DJ, and Yancopoulos GD. Akt/mTOR pathway is a crucial regulator of skeletal muscle hypertrophy and can prevent muscle atrophy in vivo. Nat Cell Biol 3: 1014-1019, 2001.

10. Buckingham JC. Glucocorticoids: exemplars of multi-tasking. Br J Pharmacol 147 Suppl 1: S258-268, 2006.

11. Chandrasekhar S, Souba WW, and Abcouwer SF. Identification of glucocorticoid-responsive elements that control transcription of rat glutamine synthetase. Am J Physiol 276: L319-331, 1999.

12. Clarke BA, Drujan D, Willis MS, Murphy LO, Corpina RA, Burova E, Rakhilin SV, Stitt TN, Patterson C, Latres E, and Glass DJ. The E3 Ligase MuRF1 degrades myosin heavy chain protein in dexamethasonetreated skeletal muscle. Cell Metab 6: 376-385, 2007.

13. Cross DA, Alessi DR, Cohen P, Andjelkovich M, and Hemmings BA. Inhibition of glycogen synthase kinase-3 by insulin mediated by protein kinase B. Nature 378: 785-789, 1995.

14. Dallman MF, Strack AM, Akana SF, Bradbury MJ, Hanson ES, Scribner KA, and Smith M. Feast and famine: critical role of glucocorticoids with insulin in daily energy flow. Front Neuroendocrinol 14: 303-347, 1993.

15. Dehoux M, Van Beneden R, Pasko N, Lause P, Verniers J, Underwood L, Ketelslegers JM, and Thissen JP. Role of the insulin-like growth factor I decline in the induction of atrogin-1/MAFbx during fasting and diabetes. Endocrinology 145: 4806-4812, 2004.

16. Dekhuijzen PN, Gayan-Ramirez G, Bisschop A, De Bock V, Dom R, and Decramer M. Corticosteroid treatment and nutritional deprivation cause a different pattern of atrophy in rat diaphragm. J Appl Physiol 78: 629-637, 1995.

17. Desler MM, Jones SJ, Smith CW, and Woods TL. Effects of dexamethasone and anabolic agents on proliferation and protein synthesis and degradation in C2C12 myogenic cells. J Anim Sci 74: 12651273, 1996.

18. DeYoung MP, Horak P, Sofer A, Sgroi D, and Ellisen LW. Hypoxia regulates TSC1/2-mTOR signaling and tumor suppression through REDD1-mediated 14-3-3 shuttling. Genes Dev 22: 239-251, 2008.

19. Dickmeis T. Glucocorticoids and the circadian clock. J Endocrinol 200: 3-22, 2009.

20. Erdmann G, Schutz G, and Berger S. Loss of glucocorticoid receptor function in the pituitary results in early postnatal lethality. Endocrinology 149: 3446-3451, 2008.

21. Evenson AR, Fareed MU, Menconi MJ, Mitchell JC, and Hasselgren PO. GSK-3beta inhibitors reduce protein degradation in muscles from septic rats and in dexamethasone-treated myotubes. Int $J$ Biochem Cell Biol 37: 2226-2238, 2005. 
22. Fang CH, Li B, James JH, Yahya A, Kadeer N, Guo X, Xiao C, Supp DM, Kagan RJ, Hasselgren PO, and Sheriff S. GSK-3beta activity is increased in skeletal muscle after burn injury in rats. Am J Physiol Regul Integr Comp Physiol 293: R1545-1551, 2007.

23. Fang $\mathrm{CH}$, Li BG, James JH, King JK, Evenson AR, Warden GD, and Hasselgren PO. Protein breakdown in muscle from burned rats is blocked by insulin-like growth factor $\mathrm{i}$ and glycogen synthase kinase-3beta inhibitors. Endocrinology 146: 3141-3149, 2005.

24. Felig P, Owen OE, Wahren J, and Cahill GF, Jr. Amino acid metabolism during prolonged starvation. J Clin Invest 48: 584-594, 1969.

25. Fischer D, Sun X, Gang G, Pritts T, and Hasselgren PO. The gene expression of ubiquitin ligase E3alpha is upregulated in skeletal muscle during sepsis in rats-potential role of glucocorticoids. Biochem Biophys Res Commun 267: 504-508, 2000.

26. Furuno K, Goodman MN, and Goldberg AL. Role of different proteolytic systems in the degradation of muscle proteins during denervation atrophy. J Biol Chem 265: 8550-8557, 1990.

27. Furuyama T, Kitayama K, Yamashita H, and Mori N. Forkhead transcription factor FOXO1 (FKHR)dependent induction of PDK4 gene expression in skeletal muscle during energy deprivation. Biochem J 375: 365-371, 2003.

28. Galliher-Beckley AJ and Cidlowski JA. Emerging roles of glucocorticoid receptor phosphorylation in modulating glucocorticoid hormone action in health and disease. IUBMB Life 61: 979-986, 2009.

29. Gerich JE, Meyer C, Woerle HJ, and Stumvoll M. Renal gluconeogenesis: its importance in human glucose homeostasis. Diabetes Care 24: 382-391, 2001.

30. Gilson H, Schakman O, Combaret L, Lause P, Grobet L, Attaix D, Ketelslegers JM, and Thissen JP. Myostatin gene deletion prevents glucocorticoid-induced muscle atrophy. Endocrinology 148: 452460, 2007.

31. Glass DJ. Skeletal muscle hypertrophy and atrophy signaling pathways. Int J Biochem Cell Biol 37: 1974-1984, 2005.

32. Gomes MD, Lecker SH, Jagoe RT, Navon A, and Goldberg AL. Atrogin-1, a muscle-specific F-box protein highly expressed during muscle atrophy. Proc Natl Acad Sci U S A 98: 14440-14445, 2001.

33. Goya RG, Console GM, Spinelli OM, Carino MH, Riccillo F, and Corrons FJ. Glucocorticoid-induced apoptosis in lymphoid organs is associated with a delayed increase in circulating deoxyribonucleic acid. Apoptosis 8: 171-177, 2003.

34. Harwood AJ. Regulation of GSK-3: a cellular multiprocessor. Cell 105: 821-824, 2001.

35. Hermans JJ, van Essen H, Struijker-Boudier HA, Johnson RM, Theeuwes F, and Smits JF. Pharmacokinetic advantage of intrapericardially applied substances in the rat. J Pharmacol Exp Ther 301: 672-678, 2002.

36. Hong DH and Forsberg NE. Effects of dexamethasone on protein degradation and protease gene expression in rat L8 myotube cultures. Mol Cell Endocrinol 108: 199-209, 1995.

37. Hu Z, Wang H, Lee IH, Du J, and Mitch WE. Endogenous glucocorticoids and impaired insulin signaling are both required to stimulate muscle wasting under pathophysiological conditions in mice. $J$ Clin Invest 119: 3059-3069, 2009.

38. Jackman RW and Kandarian SC. The molecular basis of skeletal muscle atrophy. Am J Physiol Cell Physiol 287: C834-843, 2004.

39. Jagoe RT, Lecker SH, Gomes M, and Goldberg AL. Patterns of gene expression in atrophying skeletal muscles: response to food deprivation. Faseb J 16: 1697-1712, 2002.

40. Kandarian SC and Jackman RW. Intracellular signaling during skeletal muscle atrophy. Muscle Nerve 33: 155-165, 2006.

41. Kumari R, Willing LB, Jefferson LS, Simpson IA, and Kimball SR. REDD1 (regulated in development and DNA damage response 1) expression in skeletal muscle as a surrogate biomarker of the efficiency of glucocorticoid receptor blockade. Biochem Biophys Res Commun 412: 644-647, 2011.

42. Kuo T, Lew MJ, Mayba O, Harris CA, Speed TP, and Wang JC. Genome-wide analysis of glucocorticoid receptor-binding sites in myotubes identifies gene networks modulating insulin signaling. Proc Natl Acad Sci U S A 109: 11160-11165, 2012.

43. Kwak KS, Zhou X, Solomon V, Baracos VE, Davis J, Bannon AW, Boyle WJ, Lacey DL, and Han HQ. Regulation of protein catabolism by muscle-specific and cytokine-inducible ubiquitin ligase E3alpha-II during cancer cachexia. Cancer Res 64: 8193-8198, 2004. 
44. Kwon YT, Reiss Y, Fried VA, Hershko A, Yoon JK, Gonda DK, Sangan P, Copeland NG, Jenkins NA, and Varshavsky $A$. The mouse and human genes encoding the recognition component of the $\mathrm{N}$-end rule pathway. Proc Natl Acad Sci U S A 95: 7898-7903, 1998.

45. Kwon YT, Xia Z, Davydov IV, Lecker SH, and Varshavsky A. Construction and analysis of mouse strains lacking the ubiquitin ligase UBR1 (E3alpha) of the N-end rule pathway. Mol Cell Biol 21: 8007-8021, 2001.

46. Labeit S, Kohl CH, Witt CC, Labeit D, Jung J, and Granzier H. Modulation of muscle atrophy, fatigue and MLC phosphorylation by MURF1 as indicated by hindlimb suspension studies on MuRF1-KO mice. J Biomed Biotechnol 2010: 693741, 2010.

47. Lang CH, Frost RA, Jefferson LS, Kimball SR, and Vary TC. Endotoxin-induced decrease in muscle protein synthesis is associated with changes in elF2B, elF4E, and IGF-I. Am J Physiol Endocrinol Metab 278: E1133-1143, 2000.

48. Latres E, Amini AR, Amini AA, Griffiths J, Martin FJ, Wei Y, Lin HC, Yancopoulos GD, and Glass DJ. Insulin-like growth factor-1 (IGF-1) inversely regulates atrophy-induced genes via the phosphatidylinositol 3-kinase/Akt/mammalian target of rapamycin (PI3K/Akt/mTOR) pathway. J Biol Chem 280: 2737-2744, 2005.

49. Lecker SH, Goldberg AL, and Mitch WE. Protein degradation by the ubiquitin-proteasome pathway in normal and disease states. J Am Soc Nephrol 17: 1807-1819, 2006.

50. Lecker SH, Jagoe RT, Gilbert A, Gomes M, Baracos V, Bailey J, Price SR, Mitch WE, and Goldberg AL. Multiple types of skeletal muscle atrophy involve a common program of changes in gene expression. Faseb J 18: 39-51, 2004.

51. Lecker SH, Solomon V, Mitch WE, and Goldberg AL. Muscle protein breakdown and the critical role of the ubiquitin-proteasome pathway in normal and disease states. J Nutr 129: 227S-237S, 1999.

52. Li BG, Hasselgren PO, and Fang CH. Insulin-like growth factor-I inhibits dexamethasone-induced proteolysis in cultured L6 myotubes through PI3K/Akt/GSK-3beta and PI3K/Akt/mTOR-dependent mechanisms. Int J Biochem Cell Biol 37: 2207-2216, 2005.

53. Li YH, Fan J, and Lang CH. Differential role of glucocorticoids in mediating endotoxin-induced changes in IGF-I and IGFBP-1. Am J Physiol 272: R1990-1997, 1997.

54. Limbourg FP, Huang Z, Plumier JC, Simoncini T, Fujioka M, Tuckermann J, Schutz G, Moskowitz MA, and Liao JK. Rapid nontranscriptional activation of endothelial nitric oxide synthase mediates increased cerebral blood flow and stroke protection by corticosteroids. J Clin Invest 110: 1729-1738, 2002.

55. Lutzner $\mathrm{N}$, Kalbacher $\mathrm{H}$, Krones-Herzig A, and Rosl F. FOXO3 is a glucocorticoid receptor target and regulates LKB1 and its own expression based on cellular AMP levels via a positive autoregulatory loop. PLoS One 7: e42166, 2012.

56. Ma K, Mallidis C, Bhasin S, Mahabadi V, Artaza J, Gonzalez-Cadavid N, Arias J, and Salehian B. Glucocorticoid-induced skeletal muscle atrophy is associated with upregulation of myostatin gene expression. Am J Physiol Endocrinol Metab 285: E363-371, 2003.

57. Makimura H, Mizuno TM, Isoda F, Beasley J, Silverstein JH, and Mobbs CV. Role of glucocorticoids in mediating effects of fasting and diabetes on hypothalamic gene expression. BMC Physiol 3: 5, 2003.

58. Mammucari C, Milan G, Romanello V, Masiero E, Rudolf R, Del Piccolo P, Burden SJ, Di Lisi R, Sandri C, Zhao J, Goldberg AL, Schiaffino S, and Sandri M. FoxO3 controls autophagy in skeletal muscle in vivo. Cell Metab 6: 458-471, 2007.

59. Mammucari C, Schiaffino S, and Sandri M. Downstream of Akt: FoxO3 and mTOR in the regulation of autophagy in skeletal muscle. Autophagy 4: 524-526, 2008.

60. Mason SR, Ward LC, and Reilly PE. Fluorimetric detection of serum corticosterone using highperformance liquid chromatography. J Chromatogr 581: 267-271, 1992.

61. May RC, Kelly RA, and Mitch WE. Metabolic acidosis stimulates protein degradation in rat muscle by a glucocorticoid-dependent mechanism. J Clin Invest 77: 614-621, 1986.

62. Minetto MA, Botter A, Lanfranco F, Baldi M, Ghigo E, and Arvat E. Muscle fiber conduction slowing and decreased levels of circulating muscle proteins after short-term dexamethasone administration in healthy subjects. J Clin Endocrinol Metab 95: 1663-1671, 2010.

63. Mitch WE, Bailey JL, Wang X, Jurkovitz C, Newby D, and Price SR. Evaluation of signals activating ubiquitin-proteasome proteolysis in a model of muscle wasting. Am J Physiol 276: C1132-1138, 1999. 
64. Mordier S, Deval C, Bechet D, Tassa A, and Ferrara M. Leucine limitation induces autophagy and activation of lysosome-dependent proteolysis in C2C12 myotubes through a mammalian target of rapamycin-independent signaling pathway. J Biol Chem 275: 29900-29906, 2000.

65. Mortimore GE and Poso AR. Intracellular protein catabolism and its control during nutrient deprivation and supply. Annu Rev Nutr 7: 539-564, 1987.

66. Muir JL and Pfister HP. Corticosterone and prolactin responses to predictable and unpredictable novelty stress in rats. Physiol Behav 37: 285-288, 1986.

67. O'Sullivan U, Gluckman PD, Breier BH, Woodall S, Siddiqui RA, and McCutcheon SN. Insulin-like growth factor-1 (IGF-1) in mice reduces weight loss during starvation. Endocrinology 125: 2793-2794, 1989.

68. Ogata T, Oishi Y, Higuchi M, and Muraoka I. Fasting-related autophagic response in slow- and fasttwitch skeletal muscle. Biochem Biophys Res Commun 394: 136-140, 2010.

69. Patel S, Doble BW, MacAulay K, Sinclair EM, Drucker DJ, and Woodgett JR. Tissue-specific role of glycogen synthase kinase 3beta in glucose homeostasis and insulin action. Mol Cell Biol 28: 63146328, 2008.

70. Pereira RM and Freire de Carvalho J. Glucocorticoid-induced myopathy. Joint Bone Spine 78: 41-44, 2011.

71. Rao RH. Adaptations in glucose homeostasis during chronic nutritional deprivation in rats: hepatic resistance to both insulin and glucagon. Metabolism 44: 817-824, 1995.

72. Reid MB. Response of the ubiquitin-proteasome pathway to changes in muscle activity. Am J Physiol Regul Integr Comp Physiol 288: R1423-1431, 2005.

73. Sacheck JM, Hyatt JP, Raffaello A, Jagoe RT, Roy RR, Edgerton VR, Lecker SH, and Goldberg AL. Rapid disuse and denervation atrophy involve transcriptional changes similar to those of muscle wasting during systemic diseases. Faseb J 21: 140-155, 2007.

74. Sacheck JM, Ohtsuka A, McLary SC, and Goldberg AL. IGF-I stimulates muscle growth by suppressing protein breakdown and expression of atrophy-related ubiquitin ligases, atrogin-1 and MuRF1. Am J Physiol Endocrinol Metab 287: E591-601, 2004.

75. Sandau US and Handa RJ. Glucocorticoids exacerbate hypoxia-induced expression of the proapoptotic gene Bnip3 in the developing cortex. Neuroscience 144: 482-494, 2007.

76. Sandri M, Lin J, Handschin C, Yang W, Arany ZP, Lecker SH, Goldberg AL, and Spiegelman BM. PGC1alpha protects skeletal muscle from atrophy by suppressing FoxO3 action and atrophy-specific gene transcription. Proc Natl Acad Sci U S A 103: 16260-16265, 2006.

77. Sandri M, Sandri C, Gilbert A, Skurk C, Calabria E, Picard A, Walsh K, Schiaffino S, Lecker SH, and Goldberg AL. Foxo transcription factors induce the atrophy-related ubiquitin ligase atrogin-1 and cause skeletal muscle atrophy. Cell 117: 399-412, 2004.

78. Schakman O, Gilson H, de Coninck V, Lause P, Verniers J, Havaux X, Ketelslegers JM, and Thissen JP. Insulin-like growth factor-I gene transfer by electroporation prevents skeletal muscle atrophy in glucocorticoid-treated rats. Endocrinology 146: 1789-1797, 2005.

79. Schakman $\mathrm{O}$, Gilson $\mathrm{H}$, and Thissen JP. Mechanisms of glucocorticoid-induced myopathy. J Endocrinol 197: 1-10, 2008.

80. Schakman O, Kalista S, Bertrand L, Lause P, Verniers J, Ketelslegers JM, and Thissen JP. Role of Akt/GSK-3\{beta\}/\{beta\}-catenin transduction pathway in the muscle anti-atrophy action of Insulin-like growth factor (IGF)-I in glucocorticoid-treated rats. Endocrinology, 2008.

81. Schiaffino S and Hanzlikova V. Studies on the effect of denervation in developing muscle. II. The lysosomal system. J Ultrastruct Res 39: 1-14, 1972.

82. Schols AM, Broekhuizen R, Weling-Scheepers CA, and Wouters EF. Body composition and mortality in chronic obstructive pulmonary disease. Am J Clin Nutr 82: 53-59, 2005.

83. Shah OJ, Kimball SR, and Jefferson LS. Acute attenuation of translation initiation and protein synthesis by glucocorticoids in skeletal muscle. Am J Physiol Endocrinol Metab 278: E76-82, 2000.

84. Shimizu N, Yoshikawa N, Ito N, Maruyama T, Suzuki Y, Takeda S, Nakae J, Tagata Y, Nishitani S, Takehana K, Sano M, Fukuda K, Suematsu M, Morimoto C, and Tanaka H. Crosstalk between glucocorticoid receptor and nutritional sensor mTOR in skeletal muscle. Cell Metab 13: 170-182, 2011.

85. Simoncini T, Hafezi-Moghadam A, Brazil DP, Ley K, Chin WW, and Liao JK. Interaction of oestrogen receptor with the regulatory subunit of phosphatidylinositol-3-OH kinase. Nature 407: 538-541, 2000. 
86. Smith IJ, Alamdari N, O'Neal P, Gonnella P, Aversa Z, and Hasselgren PO. Sepsis increases the expression and activity of the transcription factor Forkhead Box 01 (FOXO1) in skeletal muscle by a glucocorticoid-dependent mechanism. Int J Biochem Cell Biol 42: 701-711, 2010.

87. Sokolovic M, Sokolovic A, Wehkamp D, Ver Loren van Themaat E, de Waart DR, Gilhuijs-Pederson LA, Nikolsky $Y$, van Kampen $A H$, Hakvoort TB, and Lamers WH. The transcriptomic signature of fasting murine liver. BMC Genomics 9: 528, 2008.

88. Solomon V, Baracos V, Sarraf $\mathrm{P}$, and Goldberg AL. Rates of ubiquitin conjugation increase when muscles atrophy, largely through activation of the N-end rule pathway. Proc Natl Acad Sci U S A 95: 12602-12607, 1998.

89. Solomon $\mathrm{V}$ and Goldberg AL. Importance of the ATP-ubiquitin-proteasome pathway in the degradation of soluble and myofibrillar proteins in rabbit muscle extracts. J Biol Chem 271: 2669026697, 1996.

90. Solomon V, Lecker SH, and Goldberg AL. The N-end rule pathway catalyzes a major fraction of the protein degradation in skeletal muscle. J Biol Chem 273: 25216-25222, 1998.

91. Song $\mathrm{IH}$ and Buttgereit F. Non-genomic glucocorticoid effects to provide the basis for new drug developments. Mol Cell Endocrinol 246: 142-146, 2006.

92. Song YH, Li Y, Du J, Mitch WE, Rosenthal N, and Delafontaine P. Muscle-specific expression of IGF-1 blocks angiotensin II-induced skeletal muscle wasting. J Clin Invest 115: 451-458, 2005.

93. Stevenson EJ, Giresi PG, Koncarevic A, and Kandarian SC. Global analysis of gene expression patterns during disuse atrophy in rat skeletal muscle. J Physiol 551: 33-48, 2003.

94. Stitt TN, Drujan D, Clarke BA, Panaro F, Timofeyva Y, Kline WO, Gonzalez M, Yancopoulos GD, and Glass DJ. The IGF-1/PI3K/Akt pathway prevents expression of muscle atrophy-induced ubiquitin ligases by inhibiting FOXO transcription factors. Mol Cell 14: 395-403, 2004.

95. Swerdlow S, McColl K, Rong Y, Lam M, Gupta A, and Distelhorst CW. Apoptosis inhibition by Bcl-2 gives way to autophagy in glucocorticoid-treated lymphocytes. Autophagy 4: 612-620, 2008.

96. Tasaki T, Sriram SM, Park KS, and Kwon YT. The N-end rule pathway. Annu Rev Biochem 81: 261-289, 2012.

97. Tassa A, Roux MP, Attaix D, and Bechet DM. Class III phosphoinositide 3-kinase--Beclin1 complex mediates the amino acid-dependent regulation of autophagy in C2C12 myotubes. Biochem J 376: 577586, 2003.

98. Tiao G, Fagan J, Roegner V, Lieberman M, Wang JJ, Fischer JE, and Hasselgren PO. Energy-ubiquitindependent muscle proteolysis during sepsis in rats is regulated by glucocorticoids. J Clin Invest 97: 339-348, 1996.

99. Vandesompele J, De Preter K, Pattyn F, Poppe B, Van Roy N, De Paepe A, and Speleman F. Accurate normalization of real-time quantitative RT-PCR data by geometric averaging of multiple internal control genes. Genome Biol 3: RESEARCH0034, 2002.

100. Verhees KJ, Schols AM, Kelders MC, Op den Kamp CM, van der Velden JL, and Langen RC. Glycogen synthase kinase-3beta is required for the induction of skeletal muscle atrophy. Am J Physiol Cell Physiol 301: C995-C1007, 2011.

101. Waddell DS, Baehr LM, van den Brandt J, Johnsen SA, Reichardt HM, Furlow JD, and Bodine SC. The glucocorticoid receptor and FOXO1 synergistically activate the skeletal muscle atrophy-associated MuRF1 gene. Am J Physiol Endocrinol Metab 295: E785-797, 2008.

102. Wang H, Kubica N, Ellisen LW, Jefferson LS, and Kimball SR. Dexamethasone represses signaling through the mammalian target of rapamycin in muscle cells by enhancing expression of REDD1. J Biol Chem 281: 39128-39134, 2006.

103. Wang $\mathrm{X}, \mathrm{Hu} \mathrm{J}$, and Price SR. Inhibition of PI3-kinase signaling by glucocorticoids results in increased branched-chain amino acid degradation in renal epithelial cells. Am J Physiol Cell Physiol 292: C18741879, 2007.

104. Watson ML, Baehr LM, Reichardt HM, Tuckermann JP, Bodine SC, and Furlow JD. A Cell Autonomous Role for the Glucocorticoid Receptor in Skeletal Muscle Atrophy Induced by Systemic Glucocorticoid Exposure. Am J Physiol Endocrinol Metab, 2012.

105. Welsh GI, Miller CM, Loughlin AJ, Price NT, and Proud CG. Regulation of eukaryotic initiation factor elF2B: glycogen synthase kinase-3 phosphorylates a conserved serine which undergoes dephosphorylation in response to insulin. FEBS Lett 421: 125-130, 1998. 
106. Welsh GI and Proud CG. Glycogen synthase kinase-3 is rapidly inactivated in response to insulin and phosphorylates eukaryotic initiation factor elF-2B. Biochem J 294 ( Pt 3): 625-629, 1993.

107. Wing SS and Goldberg AL. Glucocorticoids activate the ATP-ubiquitin-dependent proteolytic system in skeletal muscle during fasting. Am J Physiol 264: E668-676, 1993.

108. Wray CJ, Mammen JM, Hershko DD, and Hasselgren PO. Sepsis upregulates the gene expression of multiple ubiquitin ligases in skeletal muscle. Int J Biochem Cell Biol 35: 698-705, 2003.

109. Xia X, Kar R, Gluhak-Heinrich J, Yao W, Lane NE, Bonewald LF, Biswas SK, Lo WK, and Jiang JX. Glucocorticoid-induced autophagy in osteocytes. J Bone Miner Res 25: 2479-2488, 2010.

110. Yudt MR and Cidlowski JA. The glucocorticoid receptor: coding a diversity of proteins and responses through a single gene. Mol Endocrinol 16: 1719-1726, 2002.

111. Zhao J, Brault JJ, Schild A, Cao P, Sandri M, Schiaffino S, Lecker SH, and Goldberg AL. FoxO3 coordinately activates protein degradation by the autophagic/lysosomal and proteasomal pathways in atrophying muscle cells. Cell Metab 6: 472-483, 2007.

112. Zhao J, Brault JJ, Schild A, and Goldberg AL. Coordinate activation of autophagy and the proteasome pathway by FoxO transcription factor. Autophagy 4: 378-380, 2008.

113. Zhao W, Qin W, Pan J, Wu Y, Bauman WA, and Cardozo C. Dependence of dexamethasone-induced Akt/FOXO1 signaling, upregulation of MAFbx, and protein catabolism upon the glucocorticoid receptor. Biochem Biophys Res Commun 378: 668-672, 2009. 


\title{
Chapter 5
}

\author{
A GLYCOGEN SYNTHASE KINASE-3 $\beta$ - \\ GLUCOCORTICOID RECEPTOR SIGNALING AXIS \\ CONTROLS MUSCLE ATROPHY INDUCED BY \\ PULMONARY INFLAMMATION
}

Koen JP Verhees, Annemie MWJ Schols, Nicholas AM Pansters, Astrid Haegens, Frank J Snepvangers, Marco CJM Kelders, Chiel C de Theije, Rick HP van Gorp, Tom Houben, Rob Hermans, Satish Patel, Stefan Berger, and Ramon CJ Langen 


\section{Abstract}

Skeletal muscle atrophy occurs under a variety of acute and chronic conditions and is often associated with increased endogenous levels of glucocorticoids (GCs). The expression of the muscle-specific E3 ubiquitin ligases atrogin-1/MAFbx and muscle RING finger 1 (MuRF1) is induced under multiple catabolic conditions such as systemic inflammation and excess GC levels. We investigated the direct contribution of glycogen synthase kinase-38 (GSK-3ß), a downstream molecule in insulin-like growth factor 1 (IGF-I)/Akt signaling, in pulmonary inflammation-induced skeletal muscle

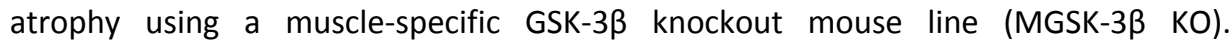
Pulmonary inflammation was induced by intratracheal lipopolysaccharide (IT-LPS) instillation and resulted in increased levels of plasma corticosterone and muscle wasting, which was associated with an induction of the E3 ubiquitin ligases atrogin-1 and MuRF1, GC-sensitive genes, and markers of the autophagy-lysosomal pathway (ALP). Interestingly, MGSK-3 $\beta$ KO mice were protected against pulmonary inflammation-induced muscle atrophy, and loss of muscle GSK-3 $\beta$ significantly attenuated increases in the transcript levels of ubiquitin 26S-proteasome system (UPS), ALP-related and GC-sensitive genes. Similarly, muscle-specific deletion of the glucocorticoid receptor (GR) also conveyed resistance to pulmonary inflammationinduced muscle atrophy and proteolytic signaling, including FoXO1 and -3a expression, implying a requirement for GSK-3 $\beta$ in regulating GR-dependent and associated UPSand ALP-related gene expression. Importantly, these current findings expand upon our earlier observations identifying GSK-3 $\beta$ as an important mediator of GC-induced skeletal muscle atrophy, and support the existence of a GSK-3 $\beta$ - GR signaling axis regulating muscle atrophy, and associated gene expression induced by pulmonary inflammation. 


\section{Introduction}

Skeletal muscle atrophy is a debilitating feature of a wide variety of acute and chronic lung diseases such as sepsis/acute respiratory distress syndrome (ARDS), chronic obstructive pulmonary disease (COPD), and cancer $(67,122)$. Other catabolic conditions, characterized by erosion of lean body mass include semi-starvation, disuse and aging $(33,47)$. Under normal conditions skeletal muscle protein content is maintained by a balance between protein synthesis and degradation (65). Under catabolic circumstances, however, this balance is perturbed and shifts in favor of degradation $(48,85)$.

Enhanced muscle proteolysis during muscle atrophy has been shown to involve activation of the ATP-dependent ubiquitin 26S-proteasome system (UPS) (47). A specific set of atrophy-related genes, commonly referred to as "atrogenes", are upregulated similarly in muscle in several atrophy models, and as such, comprise a common series of transcriptional adaptations leading to accelerated protein breakdown (66,87). The rate-limiting enzymes involved in the UPS-dependent degradation of muscle proteins include two muscle-specific E3 ubiquitin ligases, namely atrogin-1/MAFbx (hereinafter termed atrogin-1) and muscle RING finger 1 (MuRF1), whose expression is upregulated under diverse atrophic conditions (7,34, 87,120). Moreover, genetic studies have shown that the null deletion of MuRF1 abates the loss of muscle mass during denervation (7), unloading (59) and synthetic GCtreatment (5), whereas loss of atrogin-1 expression spares muscle mass following loss of innervation (7). In recent years, it has become apparent that, in addition to the UPS, the autophagy-lysosomal pathway (ALP) plays a key role in the degradation of skeletal muscle proteins $(74,79,91)$. These two major proteolytic systems are subject to intense cross-talk (53), and are tightly regulated at the transcriptional level. Forkhead Box $O$ (FoXO) transcription factors have been demonstrated to act as critical liaison molecules, governing the expression of the autophagy-associated genes microtubuleassociated proteins $1 \mathrm{~A} / 1 \mathrm{~B}$ light chain $3 \mathrm{~A}$ (LC3), Bcl-2 and $19 \mathrm{kDa}$ interacting-protein 3 (Bnip3) and GABA receptor-associated protein 1 (Gabarapl1), as well as the UPSrelated E3 ligases atrogin-1 and MuRF1 $(73,93,105,128)$.

Glucocorticoids (GCs) are a class of steroid hormones that elicit a plethora of biological actions essential for the maintenance of homeostasis (80). GCs are released by the adrenal gland via the hypothalamic-pituitary-adrenal (HPA) axis and contribute to substrate metabolism (11). These hormones are also important regulators of immune and inflammatory processes as they quench the pathophysiological responses to inflammation, for instance in trauma or during acute and severe chronic disease courses (40). Many pathological conditions (e.g. sepsis, fasting, metabolic acidosis and cachexia), characterized by muscle atrophy, are associated with sustained and pronounced elevations in circulating GCs $(41,67,119)$. Physiological levels of 
endogenous GCs, and in particular cortisol in humans and corticosterone in rodents, appear indispensable for the induction of muscle atrophy in several models $(45,93)$. Moreover, in the clinical setting, GCs are often exogenously administered in the management of acute and chronic pulmonary disease $(84,94)$, and exposure to synthetic GCs is sufficient to induce muscle proteolysis in various experimental models $(5,16,22,112,116)$.

The mechanisms by which GCs influence the balance of protein turnover may occur through genomic and non-genomic actions of the glucocorticoid receptor (GR) (104), and functional impairment of the GR markedly reduces GC-induced loss of muscle mass $(52,62,72)$. The $G R$ is a ubiquitously expressed, ligand-dependent transcription factor that governs developmental and metabolic functions in response to GCs. In absence of its ligand, the GR is inactive and sequestered in the cytoplasm by the heat shock protein 90 (Hsp90)-chaperone complex. Upon ligand binding, the GR undergoes a conformational change resulting in its release from Hsp90, allowing it to translocate to the nucleus. GR homodimers can, in turn, regulate the transcription of specific target genes by binding to GC response elements (GREs) of GC-responsive genes (29). The genomic actions of the GR have been implicated in the suppression of protein synthesis in skeletal muscle. For example, repression of mammalian target of rapamycin complex 1 (mTORC1) signaling in response to GCs has recently been demonstrated to involve enhanced transcription of regulated in development and DNA damage responses 1 (REDD1) (18,114). Furthermore, GCs may affect protein synthesis by reducing muscle insulin-like growth factor 1 (IGF-I) expression $(30,69)$, whereas treatment of cultured muscle cells with synthetic GCs was reported to increase the expression of the p85 subunit of phosphatidylinositol 3-kinase (PI-3K) $(55,115)$, leading to suppression of PI-3K activity (109) and myotube atrophy (55). In addition to these genomic effects of GCs, PI-3K/Akt signaling may also be altered by rapid non-genomic corticosteroid actions $(70,100)$. For instance, Hu et al. reported that the activated GR competes with insulin receptor substrate 1 (IRS-1) for association with PI-3K subunits $\mathrm{p} 110$ and $\mathrm{p} 85$, resulting in impaired IRS-1-associated-PI-3K/Akt activity (45). This is likely responsible for reduced protein synthesis signaling by diminishing translation initiation through increased availability of dephosphorylated elF4E-binding protein 1 (4E-BP1) (97), and reduced activity of p70S6 kinase (p70S6K) (96).

Next to their inhibitory role in protein synthesis signaling, GCs also serve an active role in enhanced proteolysis signaling during muscle atrophy. E3 $\alpha$ (or UBR1) was the first ubiquitin ligase to be implicated in the muscle atrophy process $(57,58,102)$, and treatment with the GR antagonist RU-38486 significantly reduced its induction in septic muscle $(25,120)$. Likewise, the expression of atrogin-1 and MuRF1 appeared to be, at least in part, mediated by GCs, as pharmacological inhibition (120) or genetic deletion of the GR $(116,129)$ blunted the induction of these atrogenes during sepsis, or 
following synthetic GC-treatment. In fact, evidence for both genomic and nongenomic GR actions in regulating atrogene expression during GC-mediated muscle atrophy exists. Recently, the direct GR target gene Krüppel-like factor 15 (KLF-15) was found to participate in muscle catabolism by enhancing atrogin-1 and MuRF1 promoter activity, whilst increasing FoXO mRNA expression (98). Furthermore, elevated FoXO1 and FoXO3a transcript levels were demonstrated to coincide with GCinduced muscle wasting $(28,93)$, and Waddell and associates reported that GR and FoXO1 synergistically caused MuRF1 promoter transactivation. Intriguingly, in the latter study, FoXO mRNA levels were reduced in dimerization-deficient mutant GR mice $\left(G R^{\text {dim }}\right.$ ) (113). Currently, the functional implication of FoXO mRNA regulation remains elusive, as FoXO-mediated expression of atrogin-1 and MuRF1 is dependent on its nuclear localization, which is determined by Akt phosphorylation $(93,105)$, and non-genomic GR actions may therefore direct FoXO activity through competition between the GR and IRS-1 for association with PI-3K (45).

Phosphorylation and subsequent activation of Akt via the prototypical IGF-I/insulin pathway has been considered as the nodal point at which the anti-catabolic and proanabolic actions of IGF-I/insulin are integrated $(33,64)$. GSK-3 $\beta$ is a signaling protein directly downstream of Akt and in addition to its well-described role in protein synthesis (118), it is also involved in protein degradation (111). Previously, it was shown that pharmacological GSK-3 $\beta$ inhibition decreased general protein degradation comparably to IGF-I in a model of GC-associated muscle proteolysis $(22,24,68)$, and Schakman et al. reported that overexpression of a dominant-negative GSK-3 $\beta$ prevented GC-induced muscle atrophy (95). Earlier work by our lab delineated a significant role for GSK-3 $\beta$ in the regulation of GC-induced skeletal muscle atrophy, as GC-induced increases in atrogin-1 and MuRF1 transcript levels were blocked in GSK$3 \beta$-deficient myotubes, resulting in specific sparing of myofibrillar proteins (112). However, the exact molecular mechanisms by which GSK-3 $\beta$ contributes to GCinduced muscle proteolysis remain poorly understood. Therefore, the main objective of this current study was to investigate the role of GSK-3 $\beta$ in a model of GC-associated pulmonary inflammation-induced muscle atrophy. Using mice with muscle-specific deletions of GSK-3 $\beta$ or the GR, we determined that GSK-3 $\beta$ regulates GR-dependent, UPS -and ALP-related transcriptional programs. Moreover, we show for the first time that tissue-specific GSK-3 $\beta$-deficiency protects against muscle wasting following lipopolysaccharide (LPS)-induced acute pulmonary inflammation.

\section{Materials and Methods}

\section{Animal studies}

All mouse studies were carried out under a protocol approved by the Institutional Animal Care Committee of Maastricht University. Male muscle-specific GSK-3 $\beta$ and GR 
knockout mice (12 weeks of age and designated MGSK-3 $\beta$ KO and MGR KO, respectively) were generated by crossing $\mathrm{MLC}_{1} \mathrm{f}-\mathrm{Cre}^{+/-}$(fast myosin light chain 1 promoter driving (re recombinase) mice with animals bearing GR and GSK-3 $\beta$ alleles flanked with loxP sites (GSK-3 $\beta^{\mathrm{fl} / \mathrm{fl}}$ and $\mathrm{GR}^{\mathrm{fl} / \mathrm{fl}}$ ) on a $\mathrm{C} 57 \mathrm{BL} / 6$ background, as described previously $(21,82)$. For both mouse lines, the Cre double negative littermates (MLC1f$\mathrm{Cre}^{-/}, \mathrm{GSK}-3 \beta^{\mathrm{fl} / \mathrm{fl}}$ and $\mathrm{GR}^{\mathrm{fl} / \mathrm{fl})}$ served as controls (WT). Genotyping of all mice was performed using genomic DNA from tail tips. The various tissue-specific deletions were determined by PCR, confirming the presence of $\mathrm{Cre}$, and the absence of the deleted floxed GSK-3 $\beta$ and GR alleles. All animals were housed individually in standard cages and were given ad libitum access to food and water throughout the experiment. Acute lung inflammation was induced in anesthetized $[75 \mathrm{mg} / \mathrm{kg}$ ketamine and $3 \mathrm{mg} / \mathrm{kg}$ xylazine] mice by intratracheal (IT) instillation of $60 \mu \mathrm{g}$ lipopolysaccharide (LPS) (Escherichia coli, serotype 055:B5, Sigma-Aldrich, St. Louis, MO, USA) dissolved in $50 \mu \mathrm{l}$ sterile saline [0.9\% $\mathrm{NaCl}]$ as described previously (37). Vehicle (vc)-treated mice were instilled with $50 \mu \mathrm{l}$ LPS-free sterile saline. After intratracheal instillation, the mice were kept in an upright position for 10 minutes ( $\mathrm{min}$ ) to allow the fluid to spread throughout the lungs. Mice ( $n=6$, unless stated otherwise in figure legends) were euthanized 12 hours (h), $24 \mathrm{~h}$ or $48 \mathrm{~h}$ post LPS instillation and a heart puncture was performed to collect whole blood to obtain plasma. The soleus, gastrocnemius, tibialis anterior, plantaris and extensor digitorum longus (EDL) muscles were collected from both hind limbs using standardized dissection methods. The paired muscle weights were measured and all tissues were flash-frozen in liquid nitrogen.

\section{Tissue processing and histological analyses}

The EDL muscle was embedded in Tissue-Tek (Sakura Finetek, the Netherlands) and sectioned on a Leica CM3050 S cryostat at $-20^{\circ} \mathrm{C}$. Subsequently, serial crosssections $(5 \mu \mathrm{m})$ were stained with the following primary monoclonal antibodies: antiType I MyHC (\#A4840), anti-Type Ilb MyHC (\#BF-F3) (both from Developmental Studies Hybridoma Bank, lowa City, IA, USA), anti-Type Ila MyHC (\#333-7H1) (kindly provided by Dr. A.F.M. Moorman, AMC, Amsterdam, the Netherlands) and antilaminin (\#L-9393) (Sigma-Aldrich) to determine fiber cross-sectional area (CSA) and fiber type distribution. The negatively stained fibers, present after a Type Ilb/lla double-staining, were characterized as Type I/IIx fibers. A subsequent Type I staining revealed that the EDL muscle contained virtually no (oxidative) Type I fibers $(<1.5 \%)$ (data not shown), implying that the non-stained fibers were predominantly Type IIx. As such, the glycolytic EDL muscle was abundant in fast-twitch fibers, showing the following distribution: Type IIb, 68\%; Type IIx, 20\%; and Type Ila, 11\% (data not shown). The sections were incubated with the following secondary antibodies: goat anti-mouse IgG Alexa Fluor 488 (\#A-21121), goat anti-mouse IgM Alexa Fluor 555 (\#A21426) and goat anti-rabbit IgG Alexa Fluor 350 (\#A-11069) (all from Invitrogen, CA, USA). Digital images of the stained sections were taken under 200X total magnification using an Eclipse E800 microscope (Nikon, Japan) connected to a digital 
camera (DXM, $1200 \mathrm{NF}$, Nikon, Japan). The fiber CSA was measured after having identified five non-overlapping regions containing a total of 100 - 200 individual fibers per animal, which were then analyzed using Lucia software (version 4.81).

\section{Corticosterone measurements}

The plasma corticosterone levels were determined by HPLC. Cortisol carboxylic acid was added to plasma and corticosterone standards as an internal standard (43). Next, the samples and standards were acidified with phosphoric acid, and the steroid hormones were subsequently extracted from the plasma using diethyl ether, and dried with nitrogen gas. The pellet was dissolved in eluens (acetonitrile/ methanol/TFA) and incubated with sulphuric acid for $20 \mathrm{~min}$ to convert the steroids into fluorescent products. Subsequently, HPLC analysis was performed as described previously (75). All corticosterone values were corrected to the internal standard.

\section{Cell culture}

The murine skeletal muscle cell line $C_{2} C_{12}$ was obtained from the American Type Culture Collection (ATCC \# CRL1772, Manassas, VA, USA). Myoblasts were cultured in growth medium (GM), composed of low glucose [1 g/l] Dulbecco's Modified Eagle Medium (DMEM) containing antibiotics $[50 \mathrm{U} / \mathrm{ml}$ Penicillin and $50 \mathrm{\mu g} / \mathrm{ml}$ Streptomycin] (all from Gibco, MD, USA) and 9\% (v/v) Fetal Bovine Serum (FBS) (PAA Laboratories $\mathrm{GmbH}$, Austria) or differentiation medium (DM), which contained low glucose DMEM with $0.9 \%$ heat-inactivated FBS $\left(30 \mathrm{~min}\right.$ at $\left.56^{\circ} \mathrm{C}\right)$ and antibiotics. Wildtype (WT) $\left(\right.$ GSK-3 $\beta^{+/+}$) and GSK-3 $\beta$-null (GSK-3 $\beta^{-/}$) mouse embryonic fibroblast (MEF) cell lines were generously provided by Dr. J.R. Woodgett (Ontario Cancer Institute, Toronto, Canada) (44) and cultured in GM, composed of high glucose DMEM [4.5 g/l] containing antibiotics and $9 \%$ FBS, or DM, which contained high glucose DMEM supplemented with $0.9 \%$ heat-inactivated FBS and antibiotics. The $\mathrm{C}_{2} \mathrm{C}_{12}$ cells were on Matrigel coated [1:50 in DMEM] $35 \mathrm{~mm}$ dishes (both from BD Biosciences, MA, USA), and all cells were plated at a density of $10^{4} / \mathrm{cm}^{2}$ and cultured in GM for $24 \mathrm{~h}$ prior to transfection or induction of differentiation. The $C_{2} C_{12}$ myoblasts underwent differentiation into myotubes following growth factor withdrawal (124). The differentiating cells were provided with fresh DM every $48 \mathrm{~h}$ and $2 \mathrm{~h}$ before stimulation. Dexamethasone (Dex), LiCl (both from Sigma-Aldrich) and CHIR99021 (kindly provided by Dr. P. Cohen, MRC Protein Phosphorylation Unit, University of Dundee, UK) were added after 5 days $(d)\left(C_{2} C_{12}\right)$ or $1 \mathrm{~d}(\mathrm{MEF})$ of culture in DM for the indicated times and concentrations.

\section{Stable transfection}

Vectors expressing shRNA directed against GSK-3 $\beta$ were constructed by inserting a duplex of annealed oligonucleotides containing the 19-nt target sequences into the 
pRetro-Super (pRS) vector $(9,10)$ (kindly provided by Dr. R. Agami, the Netherlands Cancer Institute, Amsterdam, the Netherlands). Ecotropic retroviral supernatants were produced by transfection of phoenix packaging cells (kindly provided by Dr. G. Nolan, Stanford University, USA), cultured in high glucose [4.5 g/l] DMEM containing antibiotics [50 U/ml Penicillin and $50 \mu \mathrm{g} / \mathrm{ml}$ Streptomycin] and $9 \%(\mathrm{v} / \mathrm{v})$ FBS, with the pRS GSK-3 $\beta$ shRNA vector or the pRS control vector by calcium phosphate precipitation. The tissue culture medium was filtered through a $0.45 \mu \mathrm{m}$ filter $48 \mathrm{~h}$ post-transfection and the supernatant containing the viral particles was used for infection of the $\mathrm{C}_{2} \mathrm{C}_{12}$ cells after the addition of Polybrene [4 $\mu \mathrm{g} / \mathrm{ml}$ ] (Sigma-Aldrich). The cells were infected for at least $6 \mathrm{~h}$ and allowed to recover for $24 \mathrm{~h}$ with fresh GM. The infected cells were selected with Puromycin [2.5 $\mu \mathrm{g} / \mathrm{ml}]$ for at least $96 \mathrm{~h}$. Of the three target sequences tested, the pRS vector containing the 19-nt target sequences 5'-GTTGTATATGTATCAGCTG-3' demonstrated the strongest RNA silencing for GSK-3 $\beta$. Silencing efficiency was evaluated by qRT-PCR or Western blot analysis for GSK-3ß.

\section{Transient transfections and plasmids}

Transient transfections were performed using Nanofectin (PAA, Austria), and in all cases included a co-transfection with pSV- $\beta$-gal to correct for differences in transfection efficiency (Promega, WI, USA). The transfection mix was prepared according to the manufacturer's instructions and contained 3.2 $\mu$ l Nanofectin per $1 \mu \mathrm{g}$ plasmid. For each transfection, 1 - $2.5 \mu \mathrm{g}$ expression plasmid DNA or empty vector controls were used per $35 \mathrm{~mm}$ dish. The transfection mix was added to undifferentiated $\mathrm{C}_{2} \mathrm{C}_{12}$ myoblasts or MEFs at least $6 \mathrm{~h}$ prior to carrying out an experiment. The GRE-luciferase reporter plasmid was used to measure GC-induced transcriptional activity. To determine luciferase and 6 -galactosidase ( $\beta$-gal) activity, the cells were lysed in $1 \mathrm{X}$ luciferase reporter lysis buffer and stored at $-80^{\circ} \mathrm{C}$. Subsequently, luciferase (Promega) and $\beta$-gal (Tropix, MA, USA) activity were measured according to the manufacturer's instructions.

\section{RNA isolation and assessment of mRNA abundance for qRT-PCR}

Muscle tissue was homogenized in ice-cold RLT buffer, containing $\beta$ mercaptoethanol, using a rotating blade tissue homogenizer (Polytron PT 1600E, Kinematica, Switzerland). RNA was isolated using the RNeasy Fibrous Tissue Mini Kit (Qiagen, Germany) according to the manufacturer's instructions. $\mathrm{C}_{2} \mathrm{C}_{12}$ cells were washed twice with ice-cold $1 \mathrm{X}$ PBS, after which total RNA was isolated using the TOTALLY RNA kit (Ambion, TX, USA) according to the manufacturer's instructions. Next, $0.4 \mu \mathrm{g}$ RNA was reverse transcribed into cDNA using the Transcriptor First Strand cDNA Synthesis kit (Roche Diagnostics $\mathrm{GmbH}$, Germany) according to the manufacturer's instructions. Anchored oligo-dT primers were used for priming. The mRNA transcript levels of the genes of interest (Supplemental Table S5.1) were determined by real-time quantitative reverse transcription PCR (qRT-PCR). The qRT- 
PCR primers were designed using Primer Express 2.0 software (Applied Biosystems, CA, USA) and obtained from Sigma-Aldrich. qRT-PCR reactions contained $2 X$ SensiMix SYBR/Fluorescein mix (Bioline, UK) and primers [300 $\mathrm{nM}$ ]. The PCR reaction was performed by a two-step PCR and the standards were made by making a 5 -fold serial dilution of pooled cDNA. Relative cDNA concentrations of the samples were derived from the standard curve with at least $a R^{2}>0.98$ and an efficiency between $90-110 \%$. The geNorm software package was used to ascertain the most suitable set of reference genes for normalization (110). The expression of the genes of interest was normalized to a normalization factor, based on the geometric average of at least three reference genes (ARBP, RPL13A, B2M, GAPDH, calnexin, cyclophilin A, $\beta$-actin and $\alpha$ tubulin). The qRT-PCR reactions were performed on a MyiQ single-color real-time thermocycler and analyzed using MyiQ 2.0 software (all from Bio-Rad, CA, USA).

\section{Nuclear extracts}

Nuclear and cytoplasmic protein extracts of gastrocnemius muscles were fractionated by differential lysis of powered tissue in two consecutive steps. First, the powdered tissue was lysed in Buffer A [20 mM HEPES buffered with $\mathrm{KOH}, \mathrm{pH} 7.8 ; 20$ $\mathrm{mM} \mathrm{KCl} ; 4 \mathrm{mM} \mathrm{MgCl}$; $0.2 \mathrm{mM}$ EDTA, pH 8.0; 1 mM DTT; $0.2 \mathrm{mM} \mathrm{Na}_{3} \mathrm{VO}_{4} ; 0.2 \mathrm{mM} \mathrm{NaF}$; $0.4 \mathrm{mM}$ PMSF; $5 \mu \mathrm{g} / \mathrm{ml}$ Leupeptin], followed by a $1 \mathrm{~h}$ incubation step on a rotating platform at $4^{\circ} \mathrm{C}$ after which Buffer B [10\% Nonidet P-40] was added to separate the nuclei from the cytoplasm. After a short centrifugation step (1 $\mathrm{min} / 14000 \mathrm{rpm}$ ) the supernatant (cytoplasmic fraction) was removed and the pellet, containing the nuclei, was washed (Buffer $\mathrm{A}+\mathrm{B}$ ) to clear away any residual cytoplasmic proteins. Finally, the nuclei were lysed in Buffer $\mathrm{C}$ [100 mM HEPES buffered with $\mathrm{KOH}, \mathrm{pH} 7.8 ; 100 \mathrm{mM} \mathrm{KCl}$; $600 \mathrm{mM} \mathrm{NaCl}$; $0.2 \mathrm{mM}$ EDTA, pH 8.0; 20\% glycerol; $1 \mathrm{mM}$ DTT; $0.2 \mathrm{mM} \mathrm{Na}_{3} \mathrm{VO}_{4} ; 0.2$ $\mathrm{mM} \mathrm{NaF} ; 0.7 \mathrm{mM} \mathrm{PMSF}$ ] and incubated on a rotating platform for $1 \mathrm{~h}$ at $4^{\circ} \mathrm{C}$. Next, the protein lysates were centrifuged $(8 \mathrm{~min} / 14000 \mathrm{rpm})$ and the supernatant was stored at $-80^{\circ} \mathrm{C}$.

\section{Western blotting}

Muscle tissue was homogenized in ice-cold $1 \mathrm{X}$ whole cell lysate buffer (WCL) [50 mM Tris, pH 7.4; 150 mM NaCl; 10\% glycerol; 0.5\% Nonidet P-40; 1 mM EDTA; 1 mM DTT; $1 \mathrm{mM} \mathrm{Na} \mathrm{VO}_{4} ; 5 \mathrm{mM} \mathrm{NaF} ; 1 \mathrm{mM}$ PMSF; $10 \mu \mathrm{g} / \mathrm{ml}$ Leupeptin; $1 \%$ aprotinin; 10 $\mathrm{mM} \beta$-glycerophosphate and $1 \mathrm{mM}$ Na-pyro- $\mathrm{PO}_{4}$ ] using a rotating blade tissue homogenizer (Polytron PT 1600E, Kinematica, Switzerland). The total protein concentration was assessed by the Thermo Scientific Pierce BCA Protein Assay kit (Pierce Biotechnology, IL, USA) according to the manufacturer's instructions. The protein lysates were boiled for $5 \mathrm{~min}$ at $95^{\circ} \mathrm{C}$ after the addition of $4 \mathrm{X}$ Laemmli sample buffer [0.25 M Tris-HCl pH 6.8; 8\% (w/v) SDS; 40\% (v/v) glycerol; 0.4 M DTT and 0.04\% $(\mathrm{w} / \mathrm{v})$ Bromophenol Blue]. For SDS-PAGE 1 - $30 \mu \mathrm{g}$ of protein was loaded per lane and separated on a Criterion XT Precast 4 - 12\% Bis-Tris gel (Bio-Rad), followed by transfer 
to a $0.45 \mu \mathrm{m}$ Whatman Protran Nitrocellulose Transfer membrane (Whatman $\mathrm{GmbH}$, Germany) by electroblotting (Bio-Rad Criterion Blotter). Nitrocellulose blots were incubated overnight $\left(4^{\circ} \mathrm{C}\right)$ with specific antibodies directed against: GR (H-300) (Santa Cruz Biotechnology, CA, USA), p-elF2Be (Ser ${ }^{539}$ ) (\#44-530G) (Invitrogen), p-mTOR

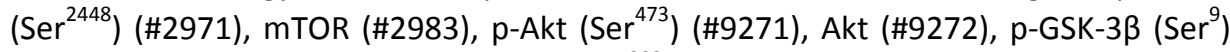
(\#9336), GSK-3ß (\#9332), p-p70S6K (Thr ${ }^{389}$ ) (\#9206), p70S6K (\#2708), p-4E-BP1 $\left(\mathrm{Thr}^{37 / 46}\right)$ (\#9459), 4E-BP1 (\#9452), p-S6 (Ser $\left.{ }^{235 / 236}\right)$ (\#2211), p-FoXO1 (Ser $\left.{ }^{256}\right)(\# 9461)$, FoXO1 (\#2880), p-FoXO3a (Ser ${ }^{253}$ ) (\#9466), FoXO3a (\#2497) p-GR (Ser $\left.{ }^{220}\right)(\# 4161)$ and GAPDH (\#2118) (all from Cell Signaling Technology), diluted in 1X TBS/0.1\% Tween-20. The blots were probed with a peroxidase conjugated secondary antibody (\#PI-1000) (Vector Laboratories, CA, USA), and visualized using Supersignal WestPico Chemiluminescent Substrate (Pierce Biotechnology) according to the manufacturer's instructions and exposed to Super RX film (FUJIFILM, Japan). The Western blot films were digitalized using a Bio-Rad GS-800 Densitometer and subsequent quantification was done using Quantity One software (version 4.5.0) (both from Bio-Rad).

\section{Statistical analysis}

Raw data were entered into SPSS (version 15.0) for statistical analysis. All values are represented as means and error bars indicate the standard error of the mean (SEM). For in vivo data, comparisons of mean values were tested parametrically (unless otherwise indicated in figure legends), using a one-way ANOVA followed by a post hoc Fischer's LSD test. Statistical significance of in vitro data was tested nonparametrically, using the Mann-Whitney $U$ test. A two-tailed probability value of $p<0.05$ between groups was considered statistically significant.

\section{Results}

\section{Pulmonary inflammation-induced muscle atrophy is accompanied by elevated circulating corticosterone levels and glucocorticoid receptor (GR)-signaling in skeletal muscle}

Pulmonary inflammation induced by intratracheal instillation of LPS (IT-LPS) resulted in a progressive and significant decline in body weight of wild-type (WT) mice (Supplemental Figure S5.1A). In addition, a concomitant decrease in hind limb muscle mass (Figure 5.1A, and Supplemental Figure S5.1B) was noted following IT-LPS instillation, which was accompanied by progressive increases in the mRNA transcript levels of the atrophy-related genes atrogin-1, MuRF1 and E3 $\alpha$-II (Figure 5.1A). Furthermore, IT-LPS administration coincided with an increase in circulating GC levels. Increases in plasma corticosterone were already apparent after $4 \mathrm{~h}$, peaked at $24 \mathrm{~h}$ and were maintained $48 \mathrm{~h}$ post instillation (Figure 5.1B). This increase in endogenous GCs was paralleled by significantly upregulated mRNA levels of two GC-sensitive 
genes, glutamate-ammonia ligase (Glul) and Krüppel-like factor 15 (KLF-15), illustrating that elevated circulating corticosterone levels evoke GR signaling in skeletal muscle (Figure 5.1C).

A
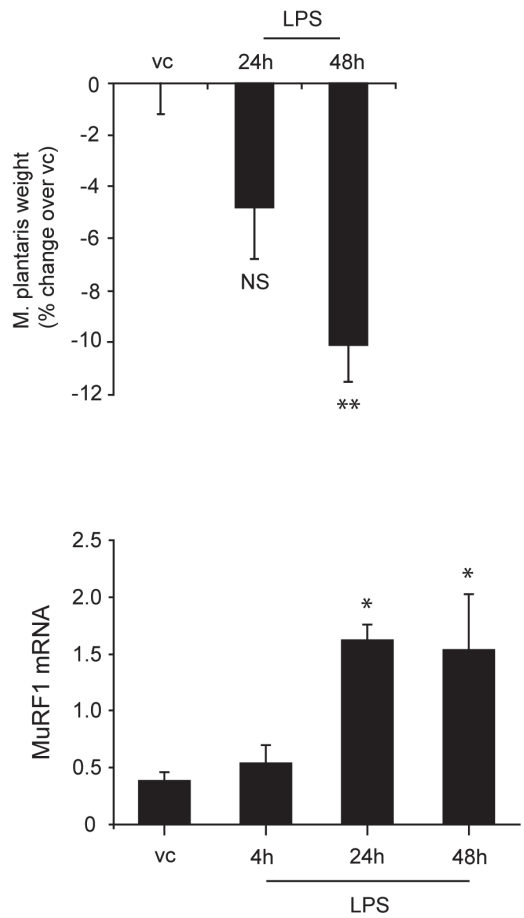
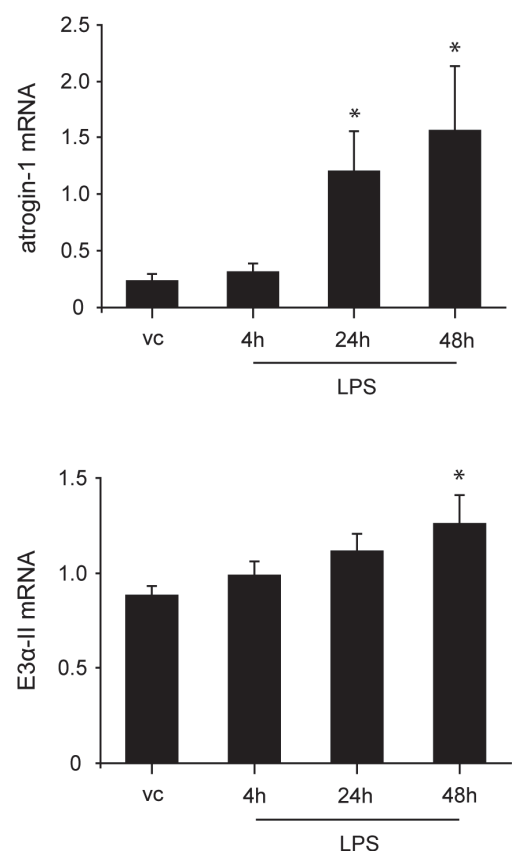
B

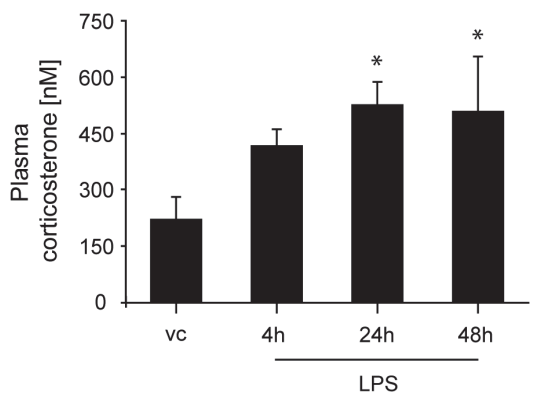

Q
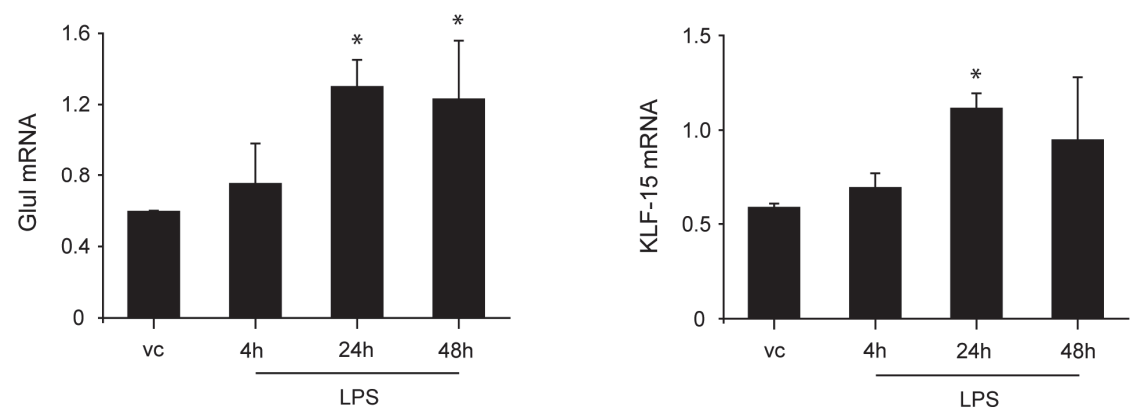

Figure 5.1 Pulmonary inflammation-induced muscle atrophy is accompanied by elevated circulating corticosterone levels and glucocorticoid receptor (GR)-signaling in skeletal muscle.

Male C57BL/6 mice (12 weeks) were subjected to intratracheal (IT) instillation of lipopolysaccharide (LPS) or vehicle (vc) (IT-NaCl). At the indicated time points the mice were terminally anaesthetized for the collection of blood and muscle tissue. (A) Muscle weights were determined, as shown here for plantaris muscle (expressed as \% weight change over vc). In addition, mRNA abundance of atrogin-1, MuRF1 and E3 $\alpha-I I$ was assessed in plantaris muscle. (B) Circulating corticosterone levels [nM] were measured in the plasma of vc (IT-NaCl) and IT-LPS challenged mice at the indicated time points. (C) mRNA expression levels of the glucocorticoid-sensitive genes Glul and KLF-15 were assessed in plantaris muscle, collected at the indicated times of vc -and IT-LPS-treated animals. All mRNA expression data were normalized to geNorm. All data shown represent means $\pm S E M, n=3$ animals per group. The statistical differences were tested non-parametrically, using the Mann-Whitney $U$ test. * $\mathrm{p}<0.05$ compared with the vc-treated group. NS: not significant. 


\section{Muscle GSK-3 $\beta$ is required for pulmonary inflammation-induced skeletal muscle atrophy}

Previous in vitro studies, including our own work, have postulated that GC-induced muscle atrophy requires GSK-3 $\beta$ signaling $(23,95,112)$. To address whether GCassociated pulmonary inflammation-induced skeletal muscle atrophy was dependent on GSK-3 $\beta$ in vivo, muscle-specific GSK-3 $\beta$ knockout (MGSK-3 $\beta$ KO) and control mice (WT) were exposed to IT-LPS or saline for $48 \mathrm{~h}$. LPS induced a significant decline in body weight after $24 \mathrm{~h}$, which further progressed $48 \mathrm{~h}$ post instillation (-15\%) (Supplemental Figure S5.1C). In addition, a decrease in the wet weights of soleus $(-11 \%)$, plantaris $(-11 \%)$, gastrocnemius $(-7 \%)$, tibialis $(-10 \%)$ and EDL $(-8 \%)$ muscles was found in IT-LPS-treated control mice compared with saline-treated controls. In the MGSK-3 $\beta$ KO mice, however, no significant muscle atrophy was observed (Figure 5.2A, and Supplemental Figure S5.2A). Next, the fiber cross-sectional area (CSA) of the EDL muscle was measured to determine if the rescued atrophy phenotype, evident from the muscle mass data, was also apparent at the individual fiber level. Indeed, $M$. EDL of LPS-exposed WT control mice showed a significant decrease in mean Type IIb $(-5 \%)$, Ila (-23\%) and IIx (-19\%) fiber CSA in contrast to IT-LPS-treated MGSK-3 $\beta$ KO mice, where no significant decrease in CSA was observed (Figure 5.2B). LPS instillation even increased the mean Type IIb CSA of GSK-3ß-deficient muscle (Figure 5.2B). This apparent increase in fiber size in MGSK-3 $\beta$ KO muscle following LPS was further substantiated by examining the fiber size distribution curves, which revealed a rightward shift in contrast to the leftward shift observed in LPS-treated WT control mice, when compared with vehicle (vc)-treated WT animals (Figure 5.2C, and Supplemental Figure S5.2C). Moreover, there was no observable difference in Type IIb fiber size distribution of vc-treated animals between both genotypes (Supplemental Figure S5.2B). In addition, the Type Ila and Type I/IIx fiber size distribution reflected the mean CSA data, revealing an increased proportion of smaller fibers in response to IT-LPS in WT mice, whereas muscle fiber size was maintained in MGSK-3 $\beta$ KO animals (Supplemental Figure S5.2C). Here too, there was no observable difference between both genotypes in Type Ila and Type I/Ilx fiber size distribution of vc-treated animals (Supplemental Figure S5.2C). IT-LPS instillation resulted in an increase in circulating plasma GC levels (Figure 2D), and coincided with elevated chemokine ( $C-X-C$ ) motif 1 (CXCL1), chemokine (C-X-C) motif 2 (CXCL2) and tumor necrosis factor- $\alpha$ (TNF- $\alpha$ ) mRNA transcript levels in the lung (Supplemental Figure S5.3A). Importantly, there were no genotype-related differences in the expression pattern of these lung inflammatory markers and circulating corticosterone levels, implying that not the triggers (i.e. inflammation, corticosterone), but rather the signaling of muscle catabolism was affected by muscle GSK-3 $\beta$ deficiency. 
A

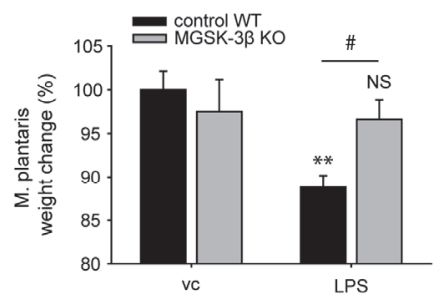

B
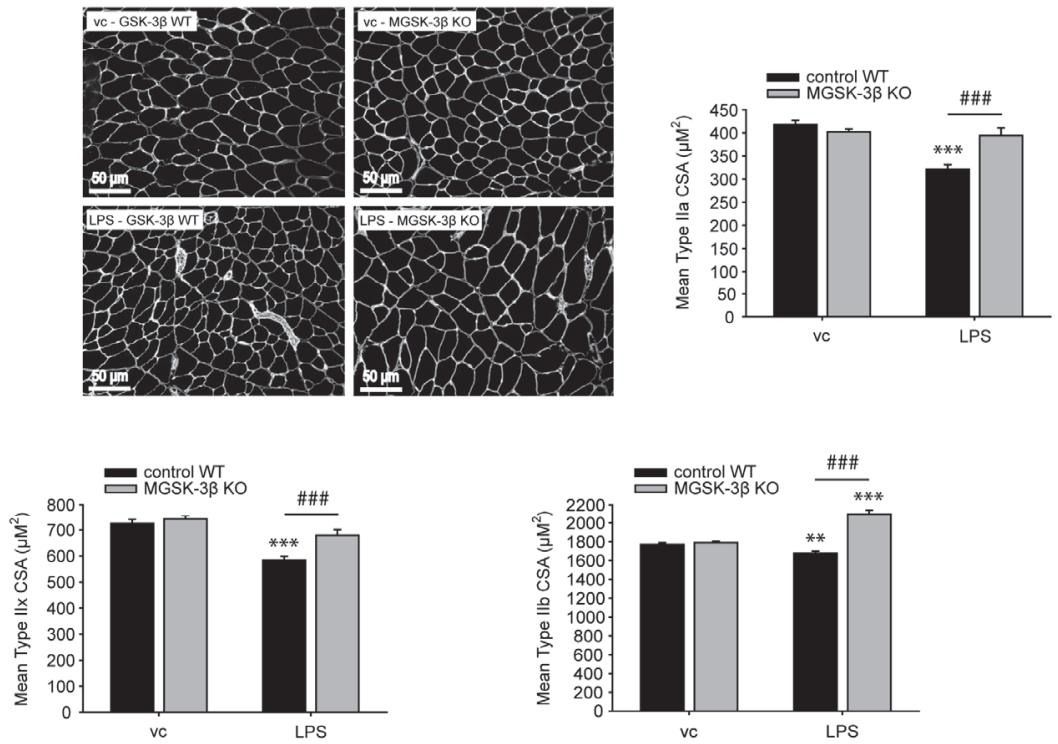

C

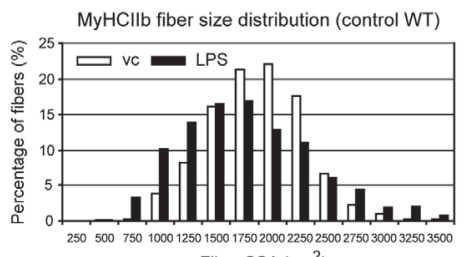
Fiber CSA $\left(\mu \mathrm{m}^{2}\right)$

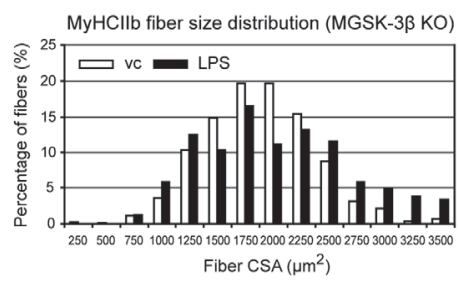

D

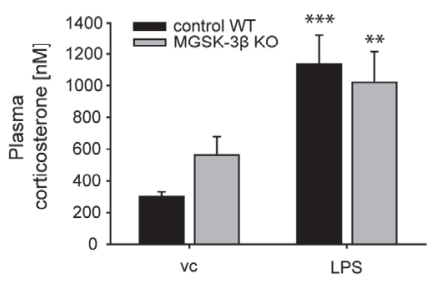


Figure 5.2 Muscle GSK-3 $\beta$ is required for pulmonary inflammation-induced skeletal muscle atrophy.

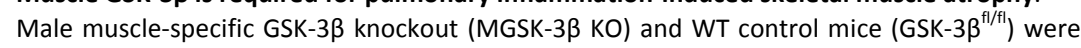
subjected to IT-LPS or vc for $48 \mathrm{~h}$. (A) Plantaris muscle mass was assessed and expressed as a $\%$ of weight change over vc WT control. (B) Muscle fiber cross-sectional areas (CSA) from the EDL muscle of vc or LPS-treated control (left) or MGSK-3 $\beta$ KO (right) mice was determined from laminin-stained cross-sections. Shown are representative laminin-stained muscle crosssections of the same region within the EDL muscle for each experimental group (200X magnification, scale bar $=50 \mu \mathrm{m}$ ), including the corresponding histograms of the mean CSA measurements of EDL Type IIb, Type Ila and Type IIx fibers. (C) Fiber size distribution of Type Ilb fiber CSA of WT control (left) or MGSK-3 $\beta$ KO (right) mice following vc or LPS instillation. (D) Circulating corticosterone levels were measured in the plasma of vc- and IT-LPS challenged WT control and MGSK-3 $\beta$ KO mice following $48 \mathrm{~h}$ of treatment. All data shown represent means \pm SEM, $n=6$ animals per group. ${ }^{* *} \mathrm{p}<0.01, * * * \mathrm{p}<0.001$ compared with the vc-treated WT control group; \# $p<0.05$, \#\#\# $p<0.001$ refers to a difference between indicated conditions. NS: not significant.

\section{Effects of acute pulmonary inflammation on muscle protein synthesis signaling}

To gain insight into the contribution of altered protein synthesis signaling to the muscle atrophy phenotype observed in WT and MGSK-3ß KO mice, the protein levels and phosphorylation state of mTOR and its downstream effectors p70S6K and 4E-BP1 as well as Akt, the upstream activator of mTOR were assessed. The increase in the $p$ Akt to Akt ratio in WT muscle following LPS instillation was indicative of elevated Akt activity, whereas the p-Akt levels in GSK-3 3 -deficient muscle remained unaltered, and was comparable to saline-treated controls. Likewise, $p$-GSK-3 $\beta$ levels were increased in WT muscle of LPS-instilled mice, although this did not correspond with the unaltered phosphorylation state of the GSK-3 $\beta$ substrate eukaryotic initiation factor

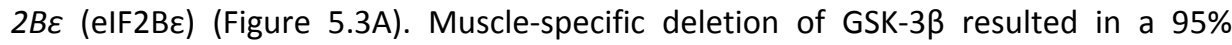
reduction in GSK-3 $\beta$ protein levels which was accompanied by decreased levels of $p$ elF2B $\varepsilon(-62 \%)$, indicative of reduced GSK-3 $\beta$ activity (Figure 5.3A). In contrast to $p$-Akt and $\mathrm{p}$-GSK-3 $\beta, \mathrm{mTOR}, \mathrm{p} 70 \mathrm{~S} 6 \mathrm{~K}$ and $\mathrm{S} 6$ phosphorylation were not affected by LPS exposure or GSK-3 $\beta$ deficiency (Figure 5.3B). Conversely, LPS-treatment decreased 4EBP1 phosphorylation in both WT, as well as GSK-3ß-deficient muscle, and this was further confirmed by a shift of the hyperphosphorylated $\psi$-isoform $(2-3$ fold reduction) to non-phosphorylated 4E-BP1 ( $\alpha$-isoform) (2-3 fold increase; Figure 5.3B); suggestive of decreased protein synthesis signaling $48 \mathrm{~h}$ post instillation. 
A
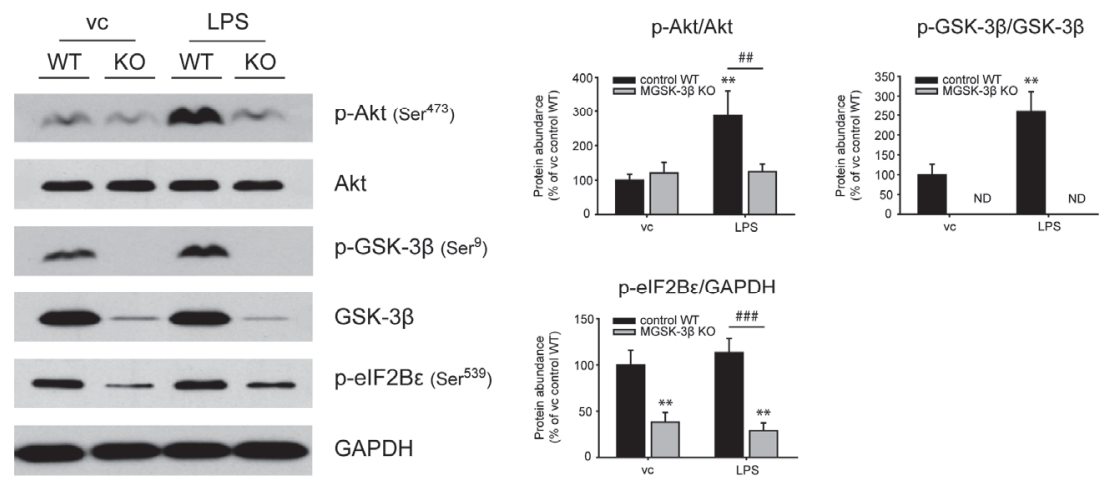

B
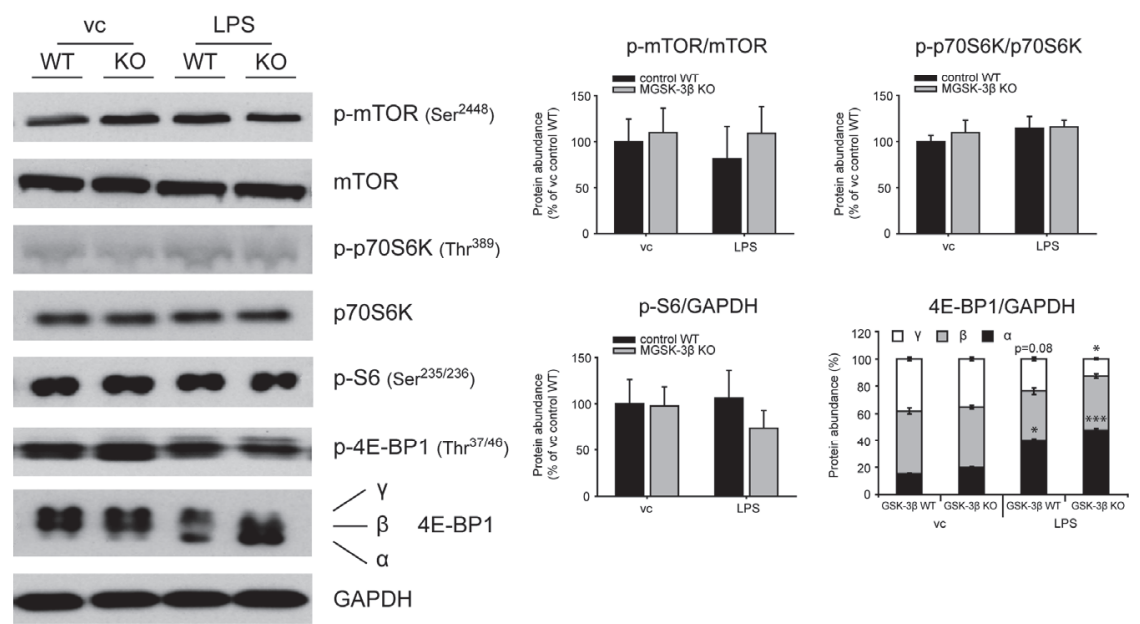

Figure 5.3 Effects of acute pulmonary inflammation on muscle protein synthesis signaling.

Tibialis muscle of WT control and MGSK-3 $\beta$ KO mice, subjected to IT-LPS or vc for $48 \mathrm{~h}$, was collected and lysates were prepared for analysis of protein synthesis signaling markers by Western blotting. Representative immunoblots accompanied by quantitative densitometry data are shown. (A) Protein levels of phospho-Akt (p-Akt), total Akt, phospho-GSK-3 $\beta$ (p-GSK-

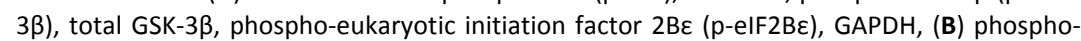
mammalian target of rapamycin (p-mTOR), total mTOR, phospho-p70S6K (p-p70S6K), total p70S6K, phospho-S6 (p-S6), phospho-4E-BP1 (p-4E-BP1), total 4E-BP1 and GAPDH were determined in whole muscle homogenates. Accompanying bar graphs represent data as a \% of the vc control WT group corrected for GAPDH. All data are shown as a ratio of phospho- to total protein for each target (except p-elF2B $\varepsilon, \mathrm{p}$-S6 and (p-) 4E-BP1). All data shown represent means \pm SEM, $n=6$ animals per group. ${ }^{*} p<0.05,{ }^{* *} p<0.01$ compared with the vc-treated WT control group; \#\# $p<0.01$, \#\#\# $p<0.001$ refers to a difference between indicated conditions. ND: not detectable. 


\section{UPS- and ALP-related gene expression in glucocorticoid-associated muscle atrophy is dependent on GSK-3 $\beta$}

While protein synthesis signaling appeared unaffected by genetic ablation of GSK$3 \beta$, increases in the transcript levels of the E3 ubiquitin ligases in WT animals following IT-LPS instillation (atrogin-1, 6.8 fold; MuRF1, 10.6 fold; E3 $\alpha$-II, 1.5 fold) were either strongly attenuated (atrogin-1, 4.5 fold; MuRF1, 6.4 fold) or completely abrogated (E3 $\alpha$-II) in GSK-3 $\beta$-deficient muscle (Figure 5.4A). To model the GC-associated induction of the UPS in vitro, GSK-3 $\beta$-deficient or appropriate control myotubes were exposed to the synthetic GC Dex for $24 \mathrm{~h}$. Genetic ablation of GSK-3 $\beta$ significantly reduced the basal expression and induction of both atrogin-1 and MuRF1 in response to Dex (Supplemental Figure S5.4A). Following IT-LPS instillation, muscle transcript levels of the ALP-related genes microtubule-associated proteins $1 A / 1 B$ light chain $3 B$ (LC3b) (2.4 fold), Bnip3 (2.5 fold) and Gabarapl1 (2.9 fold) were all significantly upregulated in WT animals. However, the induction of LC3b (1.8 fold) and Bnip3 (1.9 fold) mRNA, though still significant, was markedly attenuated in MGSK-3 $\beta$ KO mice. In contrast, increases in Gabarapl1 transcript levels appeared completely refractory to the loss of muscle GSK-3 $\beta$ expression (Figure 5.4B). Similarly, mRNA transcript levels of LC3b, Bnip3 and Gabarapl1 were all significantly upregulated in Dex-treated $\mathrm{C}_{2} \mathrm{C}_{12}$ myotubes, while loss of endogenous GSK-3 $\beta$ expression using siRNA completely blunted the mRNA expression induction of these ALP-related genes (Supplemental Figure S5.4B). Isoform specificity of the knockdown was confirmed by mRNA expression analysis of GSK-3 $\beta$ and GSK-3 $\alpha$ (Supplemental Figure S5.4C). 
A
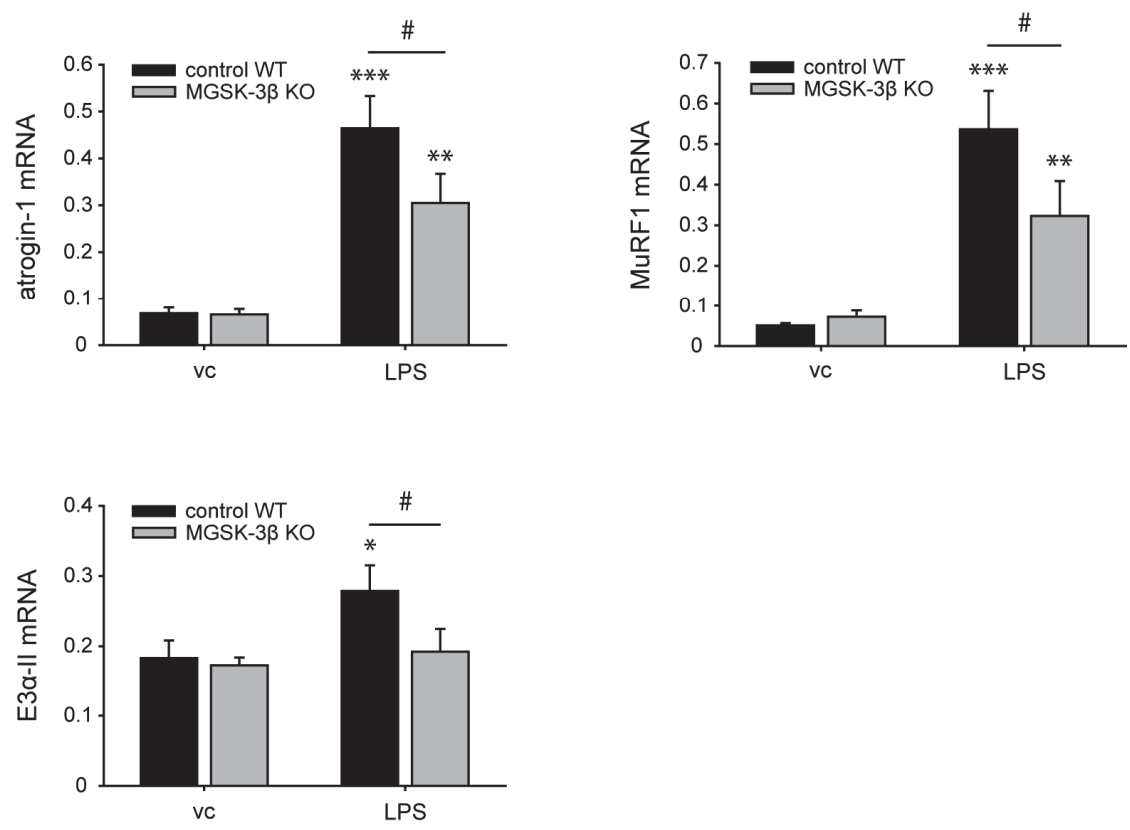

B
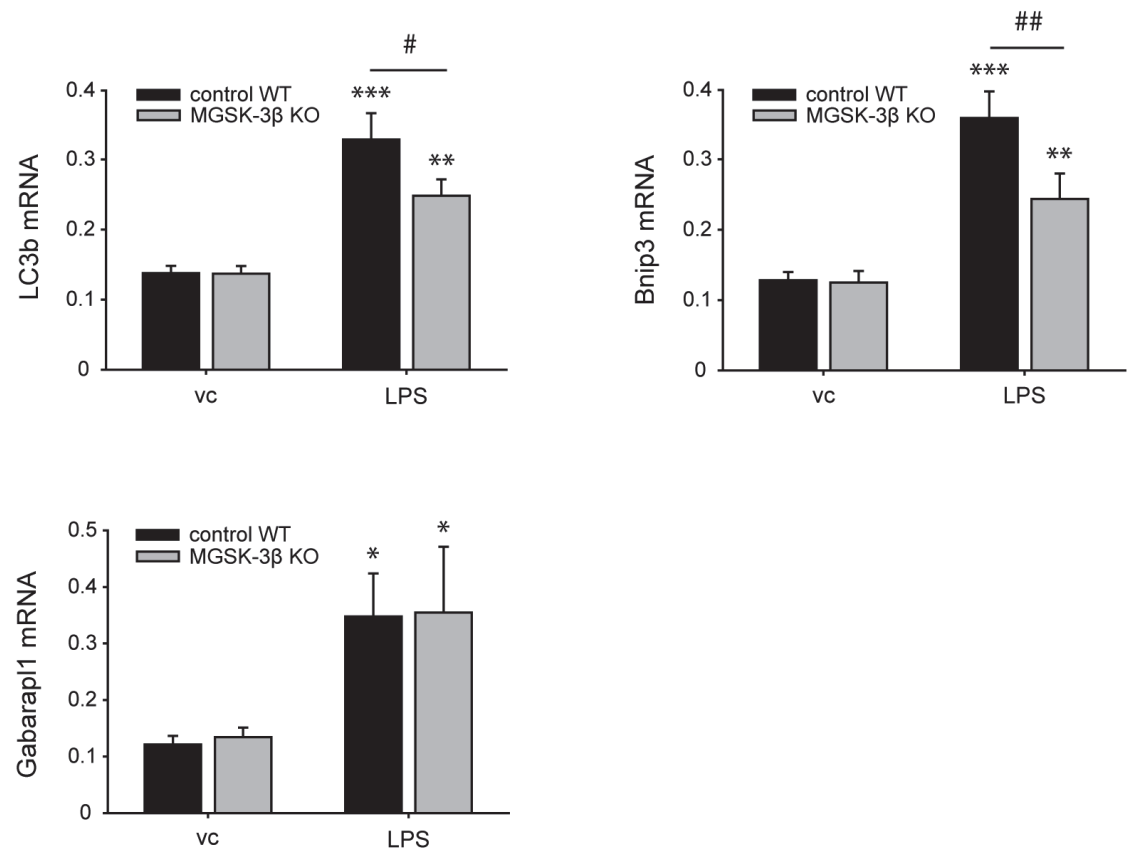
Figure 5.4 UPS- and ALP-related gene expression in glucocorticoid-associated muscle atrophy is dependent on GSK-3ß.

MGSK-3 $\beta$ KO and WT control mice were subjected to IT-LPS or vc for $48 \mathrm{~h}$. (A) At this time point the mRNA transcript levels of the UPS-related atrogin-1, MuRF1, E3 $\alpha-I I$, and (B) autophagy-lysosomal pathway (ALP)-related LC3b, Bnip3 and Gabarapl1 genes were determined in plantaris muscle. All data shown represent means $\pm S E M, n=6$ animals per group. ${ }^{*} \mathrm{p}<0.05, * * \mathrm{p}<0.01,{ }^{* * *} \mathrm{p}<0.001$ compared with the vc-treated WT control group; \# $p<0.05, \# \#<<0.01$ refers to a difference between indicated conditions.

\section{Pulmonary inflammation-induced expression of FoXO1 and -3a requires GSK-3 $\beta$}

Considering the parallel induction of UPS-mediated proteolysis and ALP-related expression programs following LPS administration, FoXO1 and -3a expression levels and post-translational modification by phosphorylation were assessed next. Nuclear levels of FoXO1 (4.3 fold) and FoXO3a (3.6 fold) were significantly elevated in WT muscle following LPS-treatment, and to a lesser extent (FoXO1, 2.9 fold) or absent (FoXO3a) in muscle of MGSK-3 $\beta$ KO animals (Figure $5 \mathrm{~A}$ ). Surprisingly, the protein abundance of phosphorylated FoXO1 and $-3 a$, reflecting cytosolic and hence transcriptionally inactive FoXO, was markedly increased in muscle of LPS-treated animals (12.1 and 2.6 fold, for p-FoXO1 and p-FoXO3a respectively), but to a lesser extent ( $p$-FoXO1, 5.4 fold) or absent ( $p$-FoXO3a) in muscle of MGSK-3 $\beta$ KO mice (Figure 5.5B). Further, total cellular protein levels of both FoXO1 (7.3 fold) and FoXO3a ( 2.7 fold) were significantly increased in response to LPS, albeit less distinct in muscle of IT-LPS-treated MGSK-3 $\beta$ KO animals ( 4.4 fold and 2 fold, for FoXO1 and FoXO3a respectively) (Figure $5.5 \mathrm{C}$ ). Notably, FoXO1 and FoXO3a mRNA transcript levels were both markedly upregulated in WT mice exposed to LPS (4.2 and 2.1 fold, for FoXO1 and FoXO3a respectively), whereas this induction was completely blocked in MGSK-3 $\beta$ $\mathrm{KO}$ muscle in response to LPS (Figure 5.5D). Dependency of FoXO1 and -3a expression in skeletal muscle on GSK-3 $\beta$ was further investigated in cultured myotubes. Likewise, loss of endogenous GSK-3 $\beta$ expression using siRNA (left panels) or physiological GSK$3 \beta$ inhibition, by means of IGF-I-induced serine $9\left(\mathrm{Ser}^{9}\right)$ phosphorylation (right panels), resulted in reduced mRNA expression levels of FoXO1 and FoXO3a (Figure 5.5E). 
A
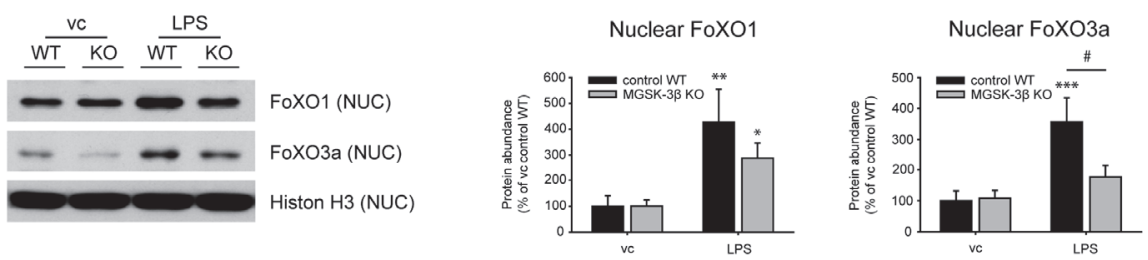

B
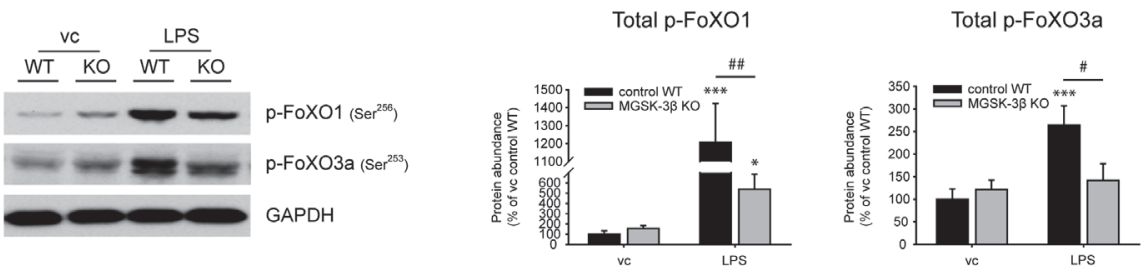

C
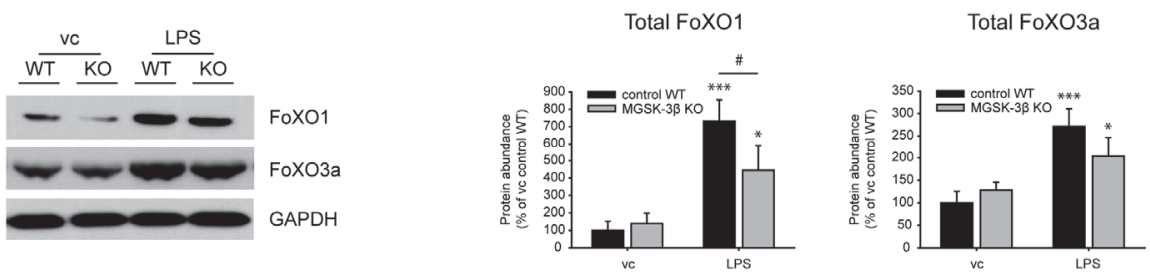

D
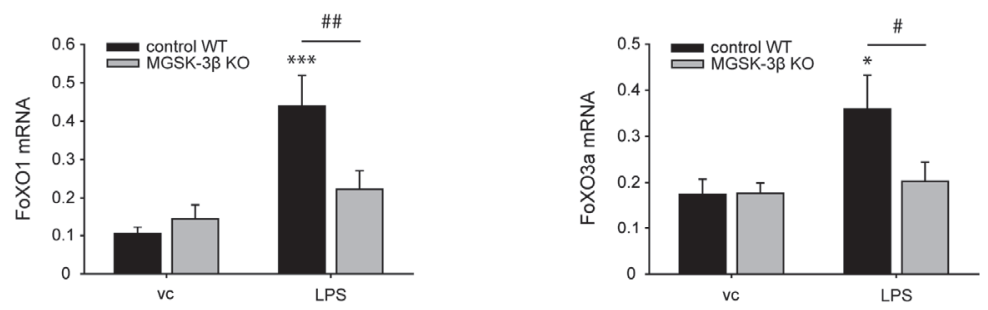

E
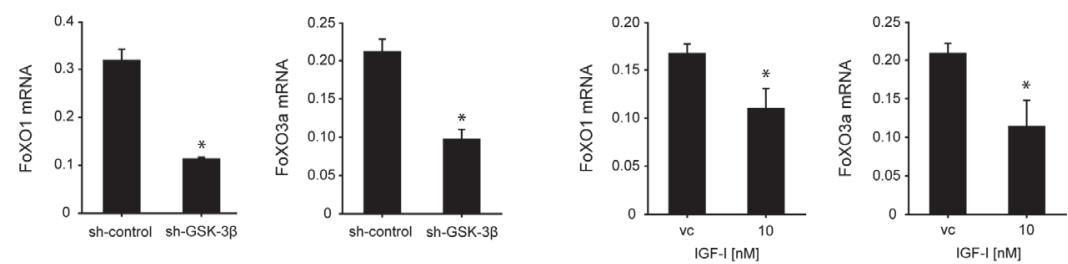
Figure 5.5 Pulmonary inflammation-induced expression of FoXO1 and -3a requires GSK-3 $\beta$.

MGSK-3 $\beta$ KO and WT control mice were subjected to IT-LPS or vc for $48 \mathrm{~h}$, after which (A) nuclear FoXO1 and FoXO3a protein levels were determined by Western blotting in nuclear extracts (NUC) of gastrocnemius muscle. Nuclear FoXO protein abundance was normalized to Histone H3. (B) Next, phospho-FoXO1 -and 3a (p-FoXO1 and p-FoXO3a) and (C) total FoXO1 and $3 a$ protein levels were assessed in whole tibialis muscle homogenates by Western blotting and corrected for GAPDH. All accompanying bar graphs depict densitometric analysis results, represented as a \% of the vc control WT group. (D) FoXO1 and FoXO3a mRNA expression levels were determined in plantaris muscle of MGSK-3 $\beta$ KO and WT control mice subjected to IT-LPS or vc for $48 \mathrm{~h}$. (E) Stably transfected (sh-control/GSK-3ß) or native $\mathrm{C}_{2} \mathrm{C}_{12}$ myoblasts were induced to differentiate for $5 \mathrm{~d}$, after which FoXO1 and FoXO3a mRNA levels were assessed. Alternatively, native $\mathrm{C}_{2} \mathrm{C}_{12}$ myotubes were cultured in the presence of IGF-I for $24 \mathrm{~h}$ prior to the determination of FoXO mRNA abundance. All data shown represent means \pm SEM, $n=6$ animals per group. Cell culture data are representative of 3 independent experiments ( $n=3$ per group). ${ }^{*} p<0.05, * * p<0.01, * * * p<0.001$ compared with the vc-treated WT control group, vc or sh-control; \# $p<0.05$, \#\# $p<0.01$ refers to a difference between indicated conditions.

\section{Glucocorticoid-sensitive gene expression in skeletal muscle is dependent on GSK-3 $\beta$}

The previously reported transcriptional regulation of FoXO expression by the GR (98), tempted us to address the contribution of GSK-3 3 to GC-sensitive gene expression. Remarkably, increases in GR target gene expression in response to IT-LPS in WT muscle, i.e. KLF-15 (2.3 fold), Glul (3.6 fold), REDD1 (7.4 fold) and myostatin (1.7 fold) were strongly suppressed (Glul, 2.3 fold) or absent in GSK-3ß-deficient muscle (Figure 5.6A). The dependency of GC-sensitive gene expression on GSK-3 $\beta$ expression was further examined in vitro. Here too, Dex supplementation significantly increased the mRNA transcript levels of KLF-15 (11 fold), Glul (4.4 fold) and REDD1 (2.3 fold), whereas genetic ablation of GSK-3 $\beta$ markedly attenuated KLF-15 (2.1 fold), or completely prevented the Dex-induced increases in Glul and REDD1 mRNA abundance (Figure 5.6B). In addition, the basal expression of KLF-15 and Glul was significantly reduced in absence of GSK-3 $\beta$ (Figure 5.6B), or by IGF-I or insulin-mediated GSK-3 $\beta$ inactivation via Ser $^{9}$ phosphorylation (Figure 5.6C). Likewise, pharmacological GSK-3 $\beta$ inhibition using CHIR99021 significantly suppressed Dex-induced GR target gene expression, suggesting that enzymatic GSK-3 $\beta$ activity was likely involved in the transcriptional regulation GC-sensitive genes (Supplemental Figure S5.5A). 
A
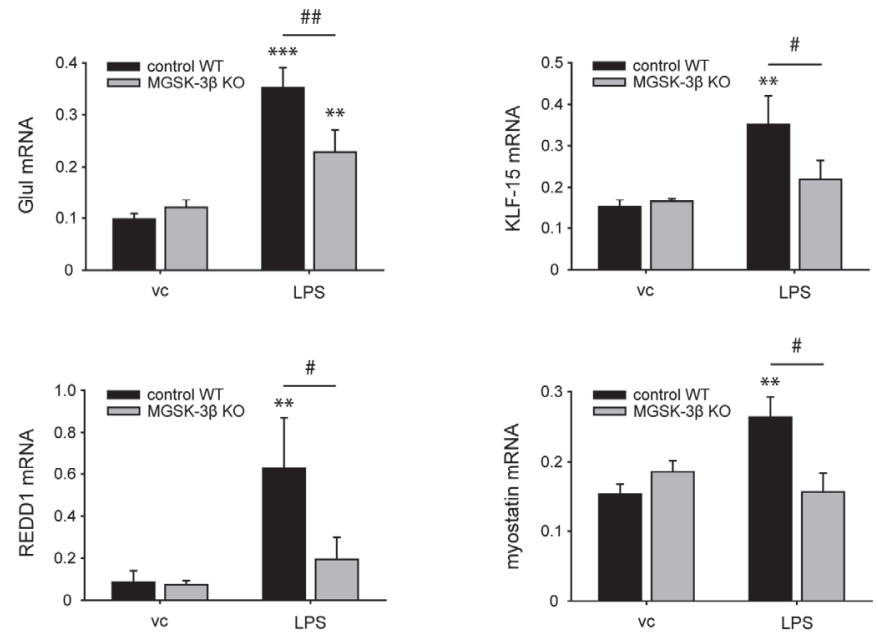

B
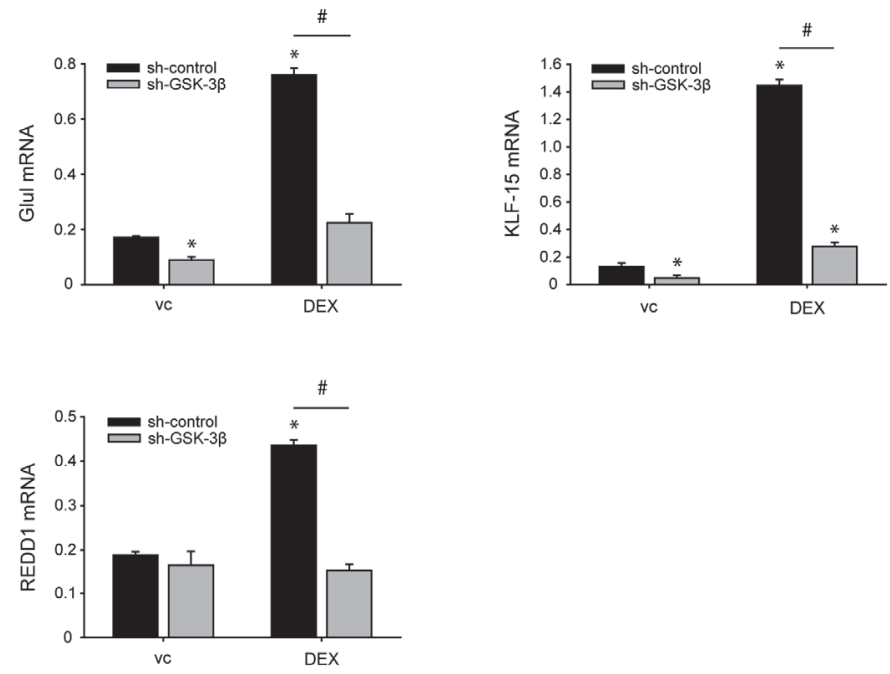

C
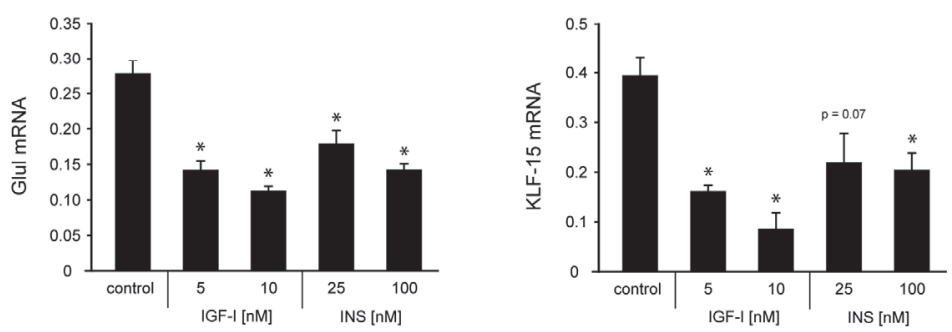
Figure 5.6 Glucocorticoid-sensitive gene expression in skeletal muscle is dependent on GSK-3 $\beta$.

(A) MGSK-3 $\beta$ KO and WT control mice were subjected to IT-LPS or vc for $48 \mathrm{~h}$, after which the mRNA transcript levels of the glucocorticoid-sensitive genes Glul, KLF-15, REDD1 and myostatin were assessed. (B) Alternatively, stably transfected myoblasts (sh-control/GSK-3 $\beta$ ) were induced to differentiate for 5 days, and cultured for an additional $24 \mathrm{~h}$ in the presence of Dex [25 $\mu \mathrm{M}$ ] or vc (DMSO), upon which the mRNA abundance of Glul, KLF-15 and REDD1 was determined. (C) Fully differentiated native $C_{2} C_{12}$ myotubes $(5 \mathrm{~d})$ were cultured for $24 \mathrm{~h}$ with or without IGF-I [5 nM and $10 \mathrm{nM}$ ] or insulin [25 nM and $100 \mathrm{nM}$ ] and vc [0.1\% BSA in HBSS] after which the mRNA expression levels of Glul and KLF-15 were assessed. All data shown represent means \pm SEM, $n=6$ animals per group. Cell culture data are representative of 3 independent experiments ( $n=3$ per group). ${ }^{*} p<0.05, * * p<0.01, * * * p<0.001$ compared with the vc-treated (vc) WT control group or sh-control; \# $p<0.05$, \#\# $p<0.01$ refers to a difference between indicated conditions.

\section{GSK-3 $\beta$ is not required for nuclear translocation of the glucocorticoid receptor (GR) or direct GR-mediated transcriptional activation}

As both pharmacological inhibition and genetic deletion of GSK-3 $\beta$ consistently showed suppression of GC-sensitive gene expression, we next investigated whether reduced GR target gene expression following GSK-3 $\beta$ inhibition correlated with altered phosphorylation and nuclear translocation of GR. Nuclear levels of phosphorylated and total GR corresponded, and nuclear accumulation of (phosphorylated) GR was already apparent after $2.5 \mathrm{~h}$ exposure to Dex. Interestingly, neither pharmacological GSK-3 $\beta$ inhibition, either by LiCl (data not shown) or CHIR99021 (Supplemental Figure S5.5B, top panel), nor genetic ablation of GSK-3 $\beta$, impeded nuclear translocation of GR (Figure 5.7A, top panel), despite effective knockdown of GSK-3 $\beta$ protein expression (75\%) or enzymatic activity; evidenced by decreased phosphorylation of its substrate elF2B $\varepsilon$ : $80 \%$ and $100 \%$ for sh-GSK-3 $\beta$ or CHIR99021, respectively (Figure $5.7 \mathrm{~A}$, bottom panel, and Supplemental Figure S5.5B, bottom panel). There were no alterations in nuclear levels of GR or $\mathrm{p}$-GR in muscle of IT-LPS-treated MGSK-3 $\beta$ KO mice or their WT littermates (Figure 5.7C), despite elevated transcript levels of GR target genes $48 \mathrm{~h}$ post IT-LPS instillation (Figure 5.6A). This may have been due to the transient nature of nuclear GR shuttling, as nuclear GR protein levels were no longer increased upon prolonged exposure to Dex (21 h). Similarly, nuclear p-GR levels were only marginally increased after $21 \mathrm{~h}$ of Dex-treatment (Figure 5.7A, center panel), compared with the explicit increase in $\mathrm{p}-\mathrm{GR}$ nuclear abundance $2.5 \mathrm{~h}$ post Dex supplementation (Figure 5.7A, top panel). To assess whether GR-dependent transactivation capacity relied on GSK-3 $\beta$, sh-GSK-3 $\beta$ and appropriate $\mathrm{C}_{2} \mathrm{C}_{12}$ control myoblasts (sh-control) were transiently transfected with a reporter construct driven by a promoter containing GCsensitive transcriptional response elements (GREs). Alternatively, $C_{2} C_{12}$ myoblasts were transfected with a GRE reporter construct, and either cultured in the presence or absence of CHIR99021. Intriguingly, Dex-induced GR-dependent transcriptional activity was not affected by either genetic deletion or pharmacological inhibition of GSK-3 $\beta$ (Figure 5.7B, top graph and Supplemental Figure S5.5C). Similar observations were made in primary WT and GSK-3ß-null mouse embryonic fibroblasts (MEFs) in 
response to Dex (Figure 5.7B, bottom graph and Supplemental Figure S5.5C). Interestingly, a pronounced accretion in nuclear GSK-3 $\beta$ protein abundance was noted in response to prolonged Dex exposure ( $21 \mathrm{~h}$ ) (Figure 5.7D, bottom panel). In addition to the increase in nuclear GSK-3 $\beta$ protein levels, the phosphorylation status of GSK-3 $\beta$ was significantly reduced, suggestive of elevated nuclear activity of GSK-3 $\beta$ in response to Dex (Figure 5.7D, bottom panel). However, this increase in nuclear GSK$3 \beta$ protein abundance and activity was not yet observed $2.5 \mathrm{~h}$ post Dex supplementation (Figure 5.7D, top panel). In concordance with the in vitro data, nuclear GSK-3 $\beta$ protein abundance was significantly increased in muscle of WT mice challenged with LPS, although nuclear p-GSK-3 $\beta$ levels were also upregulated, implying that $48 \mathrm{~h}$ post IT-LPS instillation nuclear GSK-3 $\beta$ activity was no longer increased (Figure 5.7E).

\section{Pulmonary inflammation-induced muscle atrophy is mediated through the glucocorticoid receptor (GR)}

Considering the dependency of both muscle atrophy and GC signaling on GSK-3 $\beta$, we next addressed whether muscle GR-mediated signaling cues were required for acute pulmonary inflammation-induced muscle atrophy. To this end, muscle-specific GR KO (MGR KO) and control mice (WT) were treated with IT-LPS or saline for $48 \mathrm{~h}$. Protein expression analysis revealed that muscle-specific deletion of GR resulted in a $75 \%$ reduction in GR protein levels, which was accompanied by decreased levels of $p$ GR (-80\%) (Supplemental Figure S5.6A). Further, LPS induced a significant decrease in body weight after $24 \mathrm{~h}$, which further progressed $48 \mathrm{~h}$ post instillation, albeit less pronounced in MGR KO mice $(-10 \%)$ compared with WT control mice (-13\%) (Supplemental Figure S5.6B). In addition, a decrease in the wet weights of soleus $(-4 \%)$, plantaris $(-17 \%)$, gastrocnemius $(-7 \%)$, tibialis $(-6 \%)$ and EDL $(-9 \%)$ muscles was found in IT-LPS-treated control mice compared with saline-treated controls. In the MGR KO mice, however, no significant muscle atrophy was observed (Figure 8A, and Supplemental Figure S5.6C). Furthermore, loss of muscle GR expression resulted in a modest but statistically significant increase in the wet weight of $M$. gastrocnemius (Supplemental Figure S5.6C). The increase in plasma corticosterone levels following ITLPS instillation (Figure 5.8B) coincided with increases in the mRNA transcript levels of Glul (4.8 fold), KLF-15 (2.9 fold), REDD1 (7.5 fold) and myostatin (2.8 fold) in WT animals, while, despite raised corticosterone levels in GR-deficient muscle, the induction of these GC-sensitive genes was either significantly attenuated ( 1.5 fold and 1.67 fold, for KLF-15 and myostatin, respectively) or completely abolished (Glul and REDD1) (Figure 5.8C). 


\section{Muscle protein synthesis signaling is decreased in response to acute pulmonary inflammation independently of muscle GR signaling}

The data revealing increased Akt activity $48 \mathrm{~h}$ following LPS exposure in WT animals are suggestive of an attempt of the muscle to counteract the catabolic effect of LPS, and as such, to re-establish basal Akt signaling (Figure 5.3). To gain further insight into the acute effect of pulmonary inflammation on muscle protein synthesis signaling, MGR KO and control mice (WT) were exposed to IT-LPS for $12 \mathrm{~h}$. In clear contrast with the $48 \mathrm{~h}$ study, the p-Akt to Akt ratio in WT muscle remained unaltered in response to LPS. Likewise, no differences were observed in $p-G S K-3 \beta / G S K-3 \beta$ expression levels in WT muscle of LPS-instilled mice, and this corresponded with an unaltered phosphorylation state of the GSK-3 $\beta$ substrate elF2B $\varepsilon$ (Figure 5.9A, top panel). In contrast to p-Akt and p-GSK-3 $\beta$, mTOR and S6 phosphorylation was clearly reduced following LPS challenge. Remarkably, the LPS-induced decrease in S6 phosphorylation was not accompanied by an altered phosphorylation state of p70S6K, its upstream regulatory kinase (Figure 5.9A, bottom panel). Furthermore, LPStreatment decreased 4E-BP1 phosphorylation in both WT as well as GR-deficient muscle, which was further confirmed by a shift of the hyperphosphorylated $\mathrm{y}$-isoform (3 fold reduction) to non-phosphorylated 4E-BP1 ( $\alpha$-isoform) ( 2 - 3 fold increase; Figure 5.9A, bottom panel). Altogether, it appeared that 12 and $48 \mathrm{~h}$ following IT-LPS instillation muscle protein synthesis signaling was perturbed downstream of mTOR, independent of Akt. Next, the contribution of the GR in the regulation of FoXO protein expression was assessed. In contrast to the increase in FoXO phosphorylation and total protein abundance, observed $48 \mathrm{~h}$ post IT-LPS instillation (Figure 5.5B and 5.5C, respectively), the protein levels of phosphorylated as well as total FoXO were not elevated following $12 \mathrm{~h}$ of IT-LPS instillation (Figure 5.9B). In concordance with the observed reduction in FoXO mRNA expression, loss of muscle-specific GR expression significantly decreased FoXO1 and FoXO3a protein abundance, in control conditions, suggesting that basal FoXO expression may, in part, be regulated by GR (Figure 5.9B). In view of the complete rescue of the muscle atrophy phenotype in the MGSK-3 $\beta$ and MGR KO studies, reductions in protein synthesis did not likely contribute to muscle atrophy, but this was rather the consequence of increased muscle proteolysis signaling. 
A

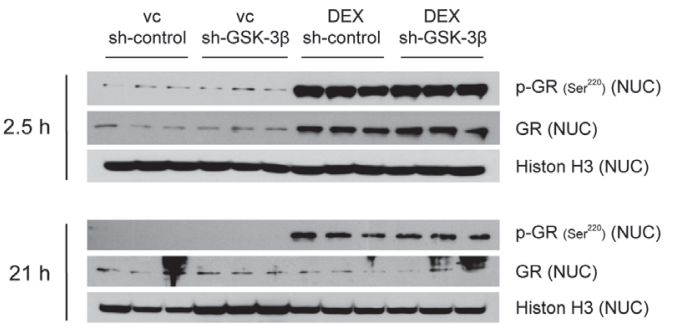

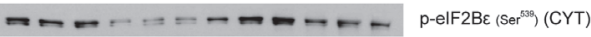

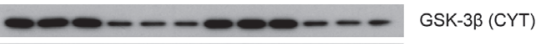

GAPDH (CYT)
B

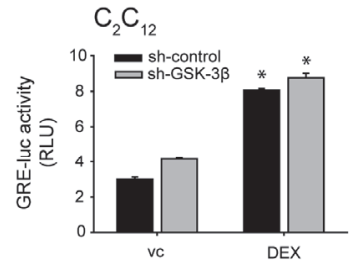

MEF

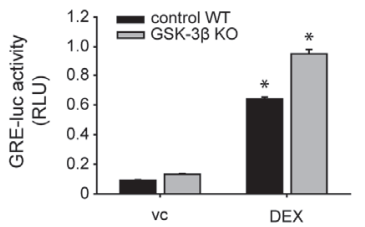

C

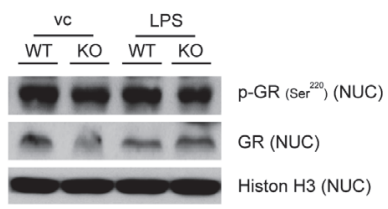

D
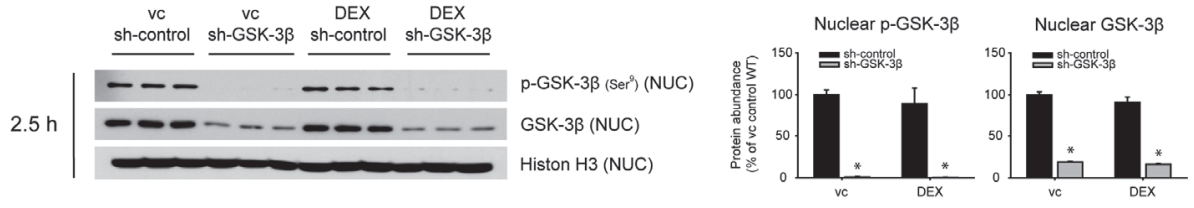

|

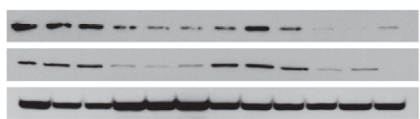

p-GSK-3B (ser) (NUC)

GSK-3B (NUC)

Histon H3 (NUC)

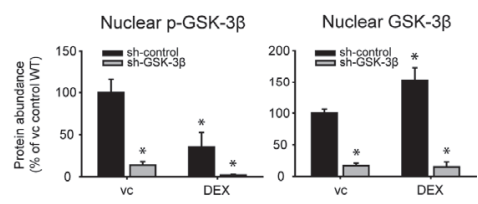

E
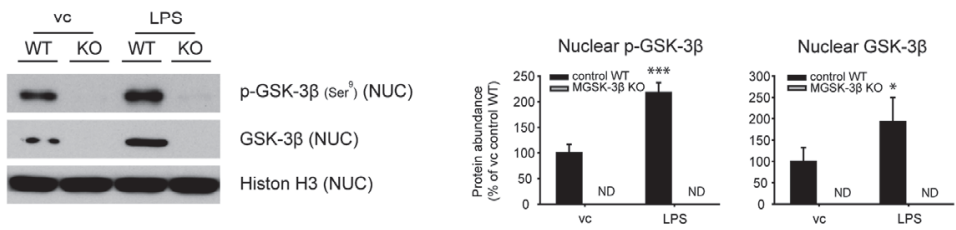
Figure 5.7 GSK-3 $\beta$ is not required for nuclear translocation of the glucocorticoid receptor (GR) or direct GR-mediated transcriptional activation.

Stably transfected myoblasts (sh-control/GSK-3ß) were induced to differentiate for $5 \mathrm{~d}$, after which myotubes were cultured in the presence of Dex [ $25 \mu \mathrm{M}]$ or vc (DMSO) for $2.5 \mathrm{~h}$ or $21 \mathrm{~h}$. (A) Nuclear protein abundance of phosphorylated (p-GR), total GR and (D) phospho-GSK-3 $\beta$

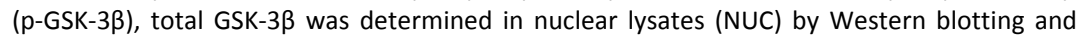
normalized to Histone H3. (A) Phospho-eukaryotic initiation factor $2 B \varepsilon$ (p-elF2B $\varepsilon$ ) and GSK-3 $\beta$ protein expression was assessed in cytoplasmic fractions (CYT) and corrected for GAPDH. (B) Plasmids encoding a luciferase reporter gene controlled by an inducible promoter containing glucocorticoid response elements (GREs) or $\beta$-galactosidase ( $\beta$-gal) were transiently

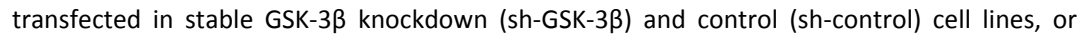
GSK-3 $\beta$-null $\left(\mathrm{GSK}-3 \beta^{-/}\right.$) and WT control $\left(\mathrm{GSK}-3 \beta^{+/+}\right.$) mouse embryonic fibroblasts (MEFs). Transfected cells were cultured in the presence of Dex [25 $\mu \mathrm{M}$ ] or vc (DMSO) for $6 \mathrm{~h}$ after which luciferase and $\beta$-gal activity were measured. Shown are representative graphs of 3 independent experiments $(n=3)$. MGSK-3 $\beta$ KO and WT control mice were subjected to IT-LPS or vc for $48 \mathrm{~h}$, after which nuclear protein abundance of $(C)$ phosphorylated (p-GR), total GR

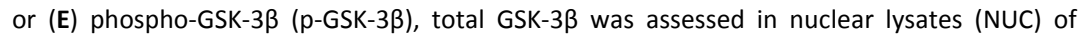
gastrocnemius muscle by Western blot analysis and normalized to Histone $\mathrm{H} 3$. All accompanying bar graphs depict densitometric analysis results, represented as a \% of the vc control WT or vc sh-control group corrected for Histone H3. Cell culture data are representative of 3 independent experiments ( $n=3$ per group), and in vivo data represent means \pm SEM, $n=6$ animals per group. ${ }^{*} \mathrm{p}<0.05, * * * \mathrm{p}<0.001$ compared with the compared with the vc-treated WT control or vc sh-control group. ND: not detectable.

\section{FoXO, UPS and ALP-associated gene expression in glucocorticoid- dependent muscle atrophy require the glucocorticoid receptor (GR)}

Given the potential link between GR, FoXO and GSK-3 $\beta$, highlighted in Figures 5.5 and 5.6, it was tempting to address the contribution of GR to the regulation of FoXO mRNA expression. Similar to the observations made in MGSK-3 $\beta$ KO mice, LPS-induced increases in FoXO1 and FoXO3a mRNA were also completely blunted in GR-deficient muscle (Figure 5.10A). Next, we sought to address the contribution of the GR in the activation of the UPS. The mRNA abundance of the atrophy-associated genes atrogin1 (6.65 fold), MuRF1 (7.22 fold) and E3 $\alpha$-II (2.46 fold) were all significantly upregulated in WT mice in response to LPS. Interestingly, the induction of MuRF1 and E3 $\alpha$-II was completely blocked in GR-deficient muscle, while atrogin-1 mRNA levels, though markedly attenuated (2.53 fold), remained increased following LPS exposure (Figure 5.10B). Given the previously established role of GSK-3 $\beta$ in the regulation of ALP-related and GR target gene expression (Figure 5.4 and Figure 5.6, respectively), the requirement of the GR in the induction of the pulmonary inflammation-associated autophagy program was investigated next. Following IT-LPS instillation, muscle transcript levels of the ALP-related genes LC3b (2.9 fold), Bnip3 (5 fold) and Gabarapl1 (2.9 fold) were all significantly upregulated in WT animals, while their induction was completely abolished in GR-deficient muscle (Figure 5.10 C). 
A
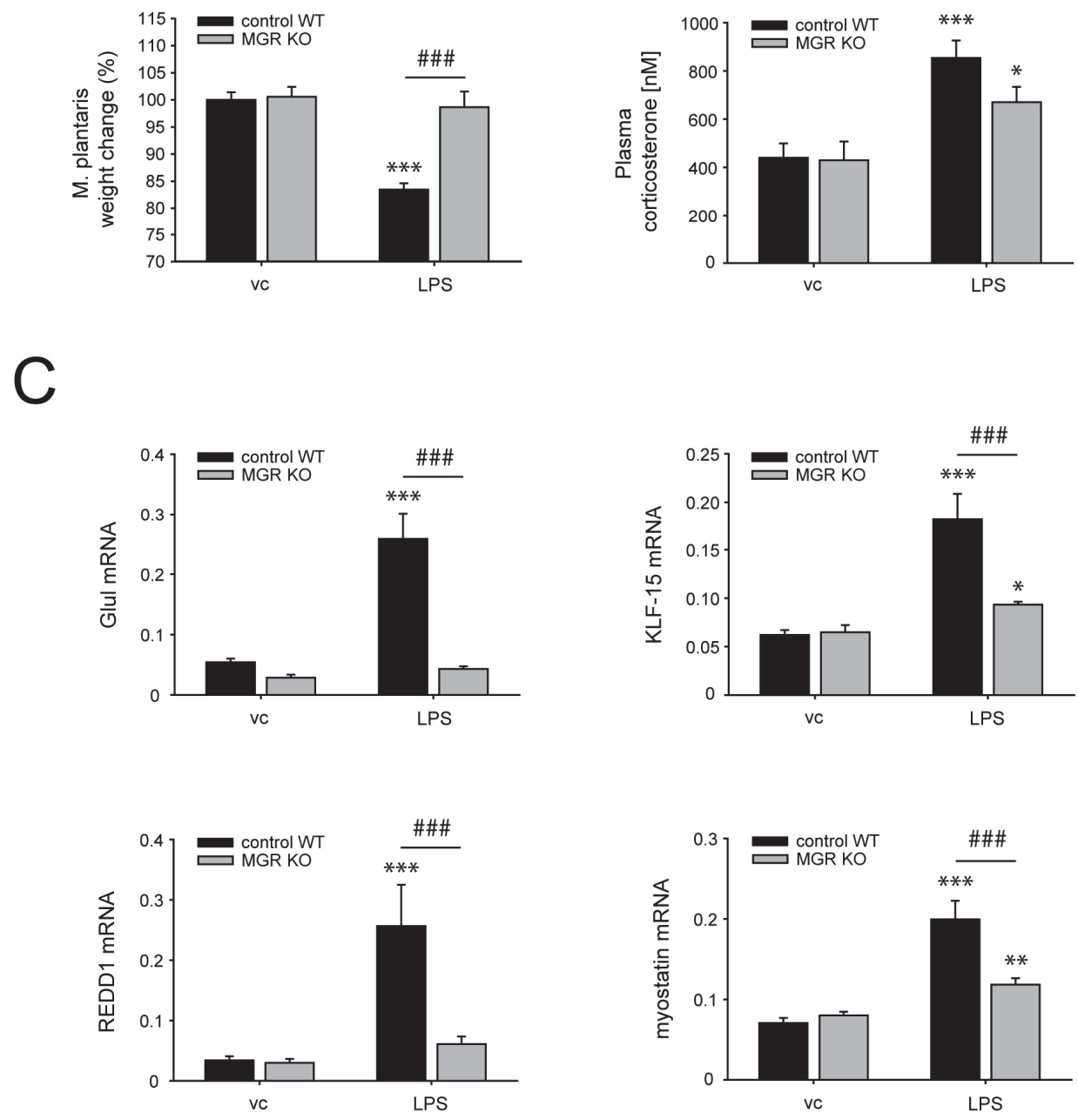

Figure 5.8 Pulmonary inflammation-induced muscle atrophy is mediated through the glucocorticoid receptor (GR).

Male muscle-specific GR knockout (MGR KO) and WT control mice $\left(\mathrm{GR}^{\mathrm{f} / \mathrm{fl}}\right)$ were subjected to IT-LPS or vc for $48 \mathrm{~h}$. (A) Treatment-induced change in plantaris muscle mass expressed as a \% of weight change over vc WT control. (B) Circulating corticosterone levels were measured in the plasma of vc- and IT-LPS challenged WT control and MGR KO mice following $48 \mathrm{~h}$ of treatment. (C) Next, mRNA transcript levels of the glucocorticoid-sensitive genes Glul, KLF-15, REDD1 and myostatin were determined in gastrocnemius muscle. All data shown represent means \pm SEM, $n=8-12$ animals per group. ${ }^{*} p<0.05,{ }^{* *} p<0.01,{ }^{* * *} p<0.001$ compared with the vc-treated WT control group; \#\# $p<0.001$ refers to a difference between indicated conditions. 
A

p-Akt/Akt

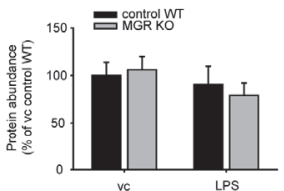

Akt

p-GSK-3 $\beta\left(\operatorname{Ser}^{9}\right)$

GSK-3 $\beta$

p-elF2B $\varepsilon\left(\operatorname{Ser}^{539}\right)$

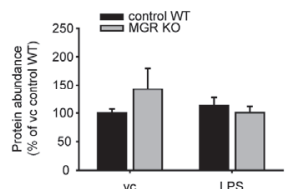

p-S6 $\left(\operatorname{Ser}^{235 / 236}\right)$
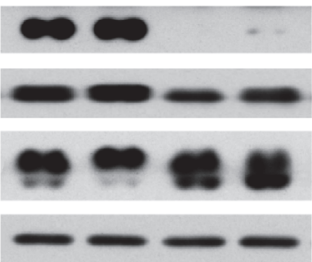

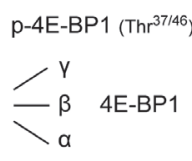

GAPDH

B

$\underline{\mathrm{WT}} \stackrel{\mathrm{KO}}{\mathrm{WT}} \underline{\mathrm{KO}}$

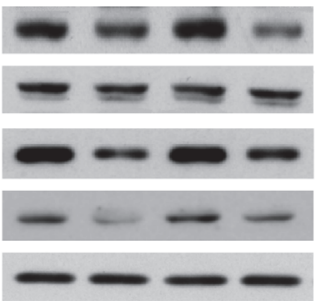

p-FoXO1 $\left(\operatorname{Ser}^{256}\right)$

$\mathrm{p}-\mathrm{FoXO} 3 \mathrm{a}\left(\mathrm{Ser}^{253}\right)$

Fox01

FoXO3a

GAPDH

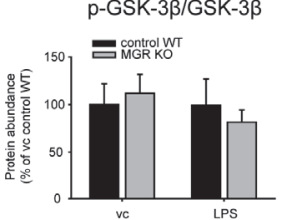

5
p-mTOR/mTOR
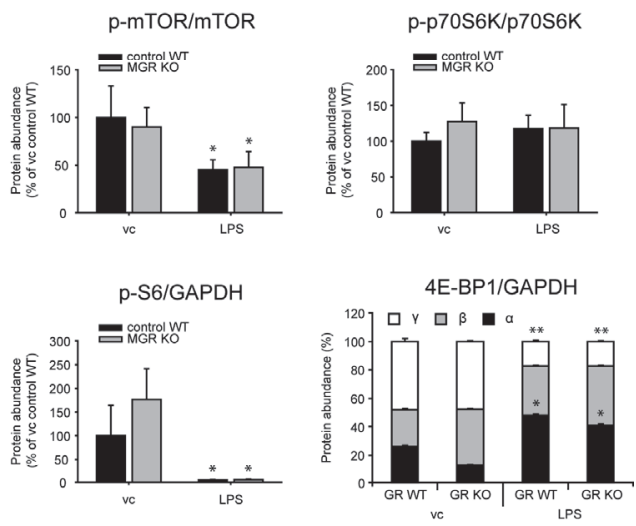

p-FoXO3a/GAPDH

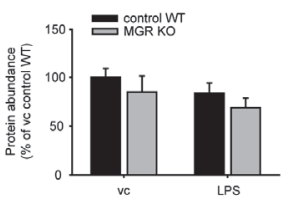

FoXO3a/GAPDH
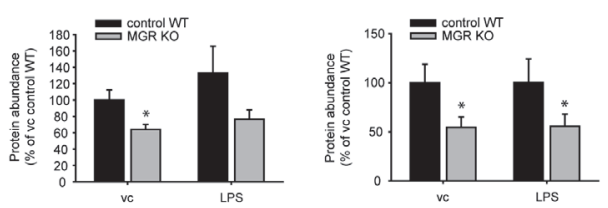
Figure 5.9 Muscle protein synthesis signaling is decreased in response to acute pulmonary inflammation independently of muscle GR signaling.

Plantaris muscle of WT control and MGR KO mice, subjected to IT-LPS or vc for $12 \mathrm{~h}$, was collected and lysates were prepared for analysis of protein synthesis and protein degradationrelated signaling markers by Western blotting. Representative immunoblots accompanied by quantitative densitometry data are shown. (A) Protein levels of phospho-Akt (p-Akt), total

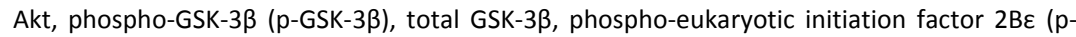
eIF2B 2 ), phospho-mammalian target of rapamycin (p-mTOR), total mTOR, phospho-p70S6K (p-p70S6K), total p70S6K, phospho-S6 (p-S6), phospho-4E-BP1 (p-4E-BP1), total 4E-BP1, GAPDH and (B) phospho-FoXO1 -and $3 a$ (p-FoXO1 and p-FoXO3a) and total FoXO1 -and $3 a$ protein levels were assessed in whole muscle homogenates. Accompanying bar graphs represent data as a \% of the vc control group corrected for GAPDH. All data are shown as a ratio of phospho- to total protein for each target (except p-elF2Be, p-S6, (p-)4E-BP1, ( $p-$ )FoXO1 and ( $p$-)FoXO3a ). All data shown represent means $\pm S E M, n=6$ animals per group. $* p<0.05, * * p<0.01$ compared with the vc-treated WT control group. 
A
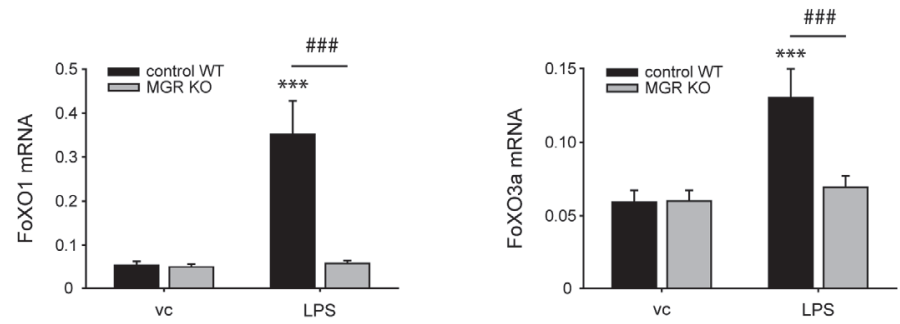

B
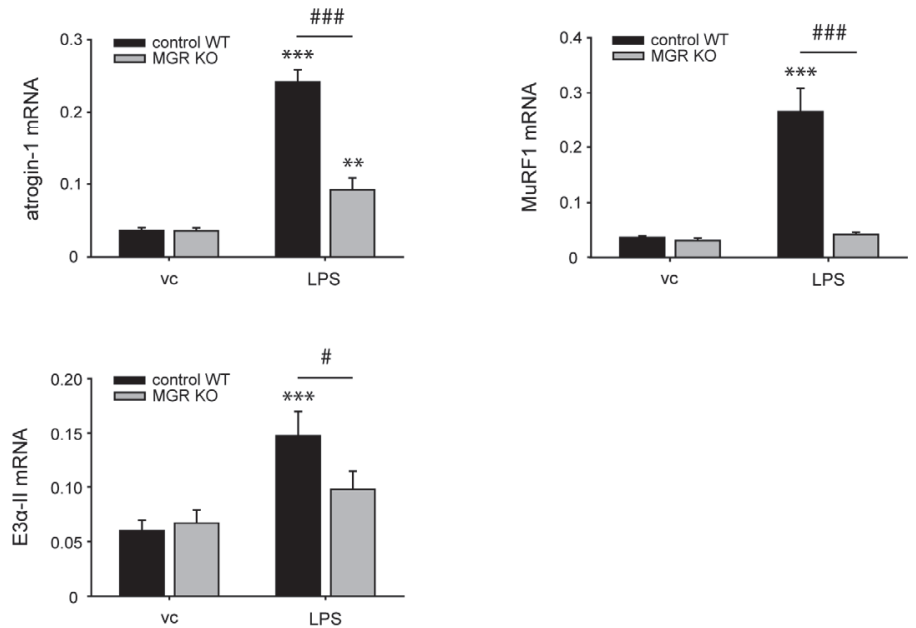

C
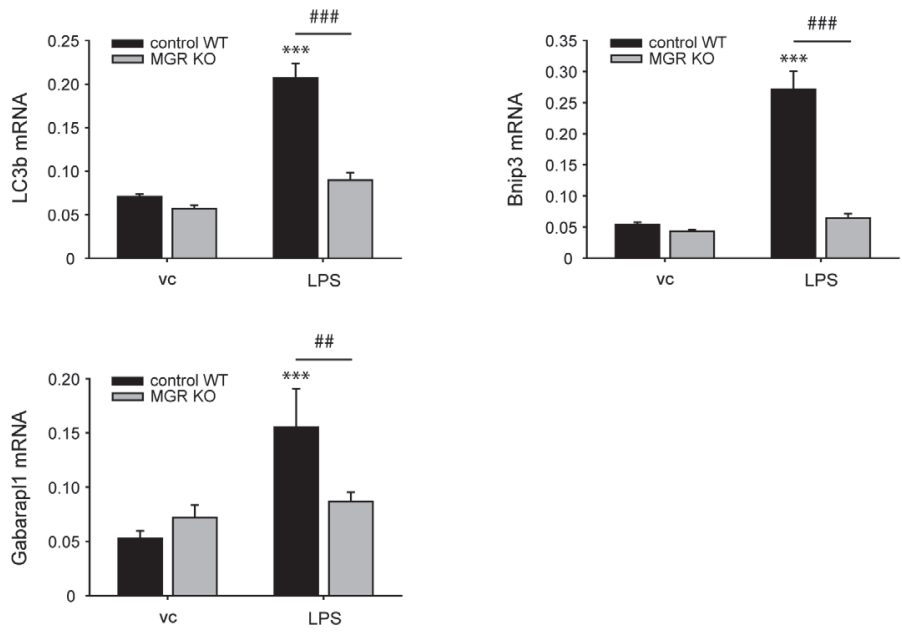
Figure 5.10 FoXO, UPS and ALP-associated gene expression in glucocorticoid-dependent muscle atrophy require the glucocorticoid receptor (GR).

MGR KO and WT control mice were subjected to IT-LPS or vc for $48 \mathrm{~h}$. At this time point the mRNA transcript levels of (A) FoXO1, FoXO3a , (B) the UPS-related atrogin-1, MuRF1, E3 $\alpha-I I$, and (C) the ALP-associated LC3b, Bnip3 and Gabarapl1 genes were determined in gastrocnemius muscle. All data shown represent means $\pm S E M, n=8-12$ animals per group. $* * * \mathrm{p}<0.001$ compared with the vc-treated WT control group; \# $\mathrm{p}<0.05, \# \# \mathrm{p}<0.01$, \#\#\# $\mathrm{p}<0.001$ refers to a difference between indicated conditions.

\section{Discussion}

Although elevated endogenous GC levels have been associated with muscle atrophy in many pathophysiological conditions, the exact molecular mechanisms through which GCs induce skeletal muscle wasting remain largely undefined. The present study provides new insights into how GR -and FoXO-driven transcriptional programs are regulated in response to GCs, and how this affects proteolysis signaling in muscle. Here, we propose a novel GSK-3 $\beta$ - GR signaling axis that controls GCmediated skeletal muscle atrophy in vivo.

Specifically, we investigated the contribution of GSK-3 $\beta$ and GR in a model of GCassociated muscle atrophy induced by pulmonary inflammation. Intratracheal LPS instillation (IT-LPS) is a well-established model of pulmonary inflammation $(37,51,78)$, which is accompanied by a potent systemic inflammatory response (63), and associated with significant muscle wasting $(38,63)$. As indicated, GCs are important physiological inhibitors of the inflammatory response (40), and inflammation following LPS challenge, has been consistently shown to correlate with increased levels of circulating GCs $(36,42,69,99)$. In this study, lung inflammation following topical LPS instillation was accompanied by increases in plasma corticosterone levels, and importantly, muscle-specific deletion of the GR (MGR KO) prevented skeletal muscle atrophy, qualifying this as an appropriate model for studying the involvement of GSK$3 \beta$ in GC-mediated muscle atrophy. Our data demonstrating the prevention of pulmonary inflammation-induced muscle atrophy in MGR KO mice are in line with previous studies showing that administration of GR receptor antagonists prevented or attenuated muscle atrophy $(39,52,62,72)$, and associated signaling (120), in sepsis or following synthetic GC-treatment. However, our current work extends these findings in that GR was specifically targeted in muscle, which circumvents any potential nonspecific (127) or systemic actions other than in muscle by these GR antagonists, and thus provides unequivocal proof to implicate muscle GC-GR signaling in pulmonary inflammation-induced muscle atrophy. Based on previous in vitro findings, suggesting a dependency of GC-induced myotube atrophy on GSK-3 $\beta$ (112), we therefore hypothesized that skeletal muscle-restricted depletion of GSK-3 $\beta$ could protect against pulmonary inflammation-induced muscle atrophy. Using mice with a muscle-

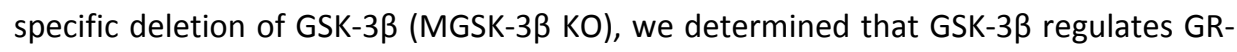


dependent, ubiquitin 26S-proteasome system (UPS) -and autophagy-lysosomal pathway (ALP)-related transcriptional programs, and is required for GC-driven muscle atrophy in vivo. In addition, the findings presented in this manuscript strongly suggest that in the presence of elevated corticosterone levels and sustained pulmonary inflammation, not the triggers, but rather the signaling of muscle catabolism was affected by GSK-3 $\beta$-and GR-deficiency.

MGR KO mice were remarkably resistant to the atrophy-inducing effects of LPS observed in the WT animals. As highlighted earlier, skeletal muscle atrophy may be the consequence of alterations in the balance between muscle protein synthesis and degradation (92). Protein synthesis signaling via IRS-1/PI-3K/Akt is subject to negative regulation by GCs. Specifically, non-genomic actions of the GR following GC-treatment have been described, suppressing Akt activity by competition between the GR and IRS-1 for association with PI-3K (45). Indeed, analyses of muscle protein synthesis signaling markers revealed a decreased activity status of proximal protein synthesis regulators downstream of mTORC1 following $12 \mathrm{~h}$ of IT-LPS. However, considering the unaltered phosphorylation state of Akt, it was unlikely that non-genomic GR actions were responsible for the inhibition of proximal protein synthesis signaling. This was further confirmed, since muscle-specific deletion of the GR did not affect basal -or atrophy stimulus-induced expression or phosphorylation of these critical mediators of protein synthesis.

This suggested that sparing of muscle mass in the MGR KO mice involved altered proteolysis signaling. Acute loss of muscle mass in various catabolic conditions mainly reflects accelerated degradation of muscle proteins $(32,48,65)$. Early reports suggested that a large proportion of muscle proteins are degraded by the $\mathrm{N}$-end rule pathway $(102,103)$, which mediates ubiquitylation of short-lived proteins resulting in selective proteolysis by the UPS (108). In this context, expression of the ubiquitin ligase E3 $\alpha$ was reported to be GC-dependent, as sepsis-induced increases in muscle E3 $\alpha$ transcript levels were blocked by the GR antagonist RU-38486 $(25,120)$. Similarly, we found that the induction of E3 $\alpha$-II (or UBR2) (56), an E3 $\alpha$ homologue, was dependent on GR expression in muscle, suggesting that the upregulation of E3 $\alpha$-II was also mediated by GCs. However, the exact role of the $\mathrm{N}$-end rule pathway is muscle wasting remains unclear, as this system was found to be dispensable for GC-associated muscle catabolism during fasting (1), and is subject to extensive enzyme redundancy (12). ITLPS administration was also associated with upregulated expression of the E3 ubiquitin ligases atrogin-1 and MuRF1. LPS-induced increases of these atrogenes have been reported previously $(26,49,63)$, and both atrogin-1 and MuRF1 are centrally involved in proteasomal degradation of muscle proteins during atrophy $(12,33)$. Several lines of evidence have suggested that GCs can regulate the expression of these ligases in both cell culture and in vivo $(8,16,88,93)$, and recent studies indicated that GRdependent signaling is indispensable for the induction of atrogin-1 and MuRF1 
$(116,120,129)$. Consistent with the observed muscle sparing, skeletal muscle-restricted deletion of the GR blocked the induction of atrogin-1 and MuRF1 following LPS instillation.

The ALP is a second major proteolytic system activated during muscle atrophy. GCtreatment has been linked to the induction of certain autophagic markers $(90,123)$, but to our knowledge the requirement of the GR in regulating ALP-related expression in muscle has not previously been addressed. Similar to the UPS, we demonstrated that ALP-associated gene transcripts required the GR in skeletal muscle. This dependency of UPS -and ALP-related mRNA expression on the GR suggested that these proteolytic genes were regulated by genomic actions of the GR. Interestingly, MuRF1 (113) and Bnip3 (90) are direct targets of the GR, both containing a functional GRE in their promoter. The lack of any MuRF1 and Bnip3 induction in MGR KO mice may have therefore been due to decreased promoter transactivation in absence of direct genomic GR actions. In contrast, no GREs have been identified in the promoters or enhancer regions of the atrogin-1, LC3b and Gabarapl1 genes, thus rendering direct genomic GR actions as an unlikely mechanism in the apparently coordinated expression of UPS -and ALP-related genes. Rather, the transcriptional upregulation of atrogin-1 in response to GCs is thought to be mediated by FoXO (93). FoXO transcription factors are important regulators of UPS -as well as ALP-related gene expression $(73,93,105,128)$. Although a FoXO1-GR interaction was found to synergistically increase MuRF1 promoter transactivation (113), the mechanisms by which GCs regulate FoXO activity remain scantily defined. Moreover, the observed dependency of FoXO-mediated UPS -and ALP-related expression programs on the GR, unlikely involved non-genomic GR actions affecting PI-3K/Akt signaling, since the phosphorylation status of Akt and FoXO remained unaltered in GR-deficient muscle in response to LPS.

Thus far, the reciprocal interaction between IGF-I/insulin and GR signaling has been attributed to non-genomic mechanisms. However, very recently the $p 85 \alpha$ subunit of $\mathrm{PI}-3 \mathrm{~K}$ was identified as a direct GR target gene, and its overexpression was sufficient to cause reductions in $\mathrm{C}_{2} \mathrm{C}_{12}$ myotube diameter, mimicking the effect of GCs (55), suggesting that the interaction between PI-3K/Akt and GR signaling also involves genomic GR actions. In support of this contention, we found that activated PI-3K/Akt signaling reduced basal expression levels of the GR-dependent genes Glul and KLF-15 in cultured muscle cells. PI-3K/Akt signaling inhibits GSK-3 activity (17), and interestingly, enzymatic inhibition or depletion of GSK-3 $\beta$ protein levels was sufficient to reduce basal and block Dex-induced expression of these GR-driven genes. Additional expression analyses in the MGSK-3 $\beta$ KO study corroborated these findings and, as such, provided unequivocal confirmation for the requirement of GSK-3 $\beta$ in the regulation of GC-sensitive genes. Regulation of GC-sensitive gene expression by GSK$3 \beta$ is not entirely without precedent, as enzymatic GSK-3 $\beta$ inhibition abolished the GC- 
induced increase in cyclooxygenase-1 (COX-1) expression in cardiomyocytes (106). Previously, GSK-3 $\beta$ inactivation was demonstrated to inhibit UPS-related gene expression comparably to IGF-I, which resulted in specific sparing of myofibrillar proteins in a model of GC-induced muscle proteolysis (112). Here, we extended these findings by showing that Dex-treatment was sufficient to induce ALP-associated gene expression in vitro, and that this upregulation was dependent on GSK-3 $\beta$, suggesting a role for GSK-3 $\beta$ in the regulation of GC-driven UPS -and ALP-related transcriptional programs. Of note, the physiological relevance of this dependency of GC-sensitive gene expression on GSK-3 $\beta$ was further demonstrated in vivo. Similar to the observations made in the MGR KO study, muscle-specific deletion of GSK-3 $\beta$ prevented pulmonary inflammation-induced loss of muscle mass. Examination of the fiber CSA in WT and MGSK-3 3 KO mice confirmed the phenotype evident from the muscle wet weights. The reduction in mean Type Ila and IIx fiber CSA was abrogated in MGSK-3 $\beta$ KO animals, and LPS instillation even increased the mean Type IIb CSA of GSK-3 $\beta$-deficient muscle. The mechanism responsible for this remarkable finding was not determined here since it is beyond the scope of the current study. In line with the rescued atrophy phenotype, LPS-induced increases in atrogin-1, MuRF1 and E3 $\alpha-I I$ transcript levels were significantly attenuated in GSK-3ß-deficient muscle. In further analogy with the MGR KO study, ALP-associated gene expression, with the notable exception of Gabarapl1, also appeared to be subject to control by GSK-3 $\beta$.

Rather unexpectedly, the phospho- to total ratio of Akt and GSK-3 $\beta$ was dramatically increased in WT mice following $48 \mathrm{~h}$ of IT-LPS. This may have possibly represented an attempt to restore protein synthesis, as this increment in the phosphorylation status of Akt and GSK-3 $\beta$ was not observed $12 \mathrm{~h}$ following LPS administration. In agreement with this, initial LPS studies revealed that muscle atrophy and associated atrogene expression peaked $48 \mathrm{~h}$ post IT-LPS instillation, suggestive of a turning point leading to recovery from atrophy (data not shown). Furthermore, MGSK-3 $\beta$ KO muscle did not reveal enhanced Akt signaling, implying that reduced protein synthesis signaling unlikely contributed to muscle atrophy here, since muscle mass was preserved, nevertheless, in absence of GSK-3 $\beta$. Increased expression of REDD1 is GR-dependent (54) and was previously shown to result in inhibition of mTORC1 signaling $(50,121)$. Interestingly, the LPS-induced induction of REDD1 was prevented in absence of GSK-3 $\beta$ and GR expression in muscle. However, reduction of REDD1 expression did not result in restoration of MTORC1 signaling, as evidenced by similar decreases in 4E-BP1 phosphorylation in muscle of WT and MGSK$3 \beta$ KO and MGR KO animals following LPS challenge. These results therefore suggest that distinct mechanisms, such as inflammation, may lie at the basis of the apparent inconsistency between REDD1 expression and mTORC1 activity observed in absence of GSK-3 $\beta$ or GR. Indeed, sepsis or endotoxin-induced decreases in translation initiation may be mediated by inflammatory cytokines such as TNF- $\alpha(60,61)$, and occur independently of REDD1 in GSK-3 $\beta$-and GR-deficient muscle following IT-LPS. On the 
whole, general protein synthesis signaling was still decreased $48 \mathrm{~h}$ post LPS instillation, best illustrated by enhanced expression and reduced phosphorylation of the rate-limiting translational repressor 4E-BP1 in a genotype-independent fashion. In spite of this, our findings are not in support of a major role of altered protein synthesis in the development of muscle atrophy in this model, as muscle atrophy was prevented in MGSK-3 $\beta$ KO and MGR KO mice, despite reduced muscle protein synthesis signaling.

Previously, both the ALP and UPS proteolytic systems were shown to be coordinately regulated by FoXO transcription factors $(73,93,105,128)$. The current paradigm of FoXO activation entails its dephosphorylation, resulting in nuclear translocation, and subsequent regulation of atrogene expression $(93,105)$. However, counter-intuitively, FoXO1 -and 3a phosphorylation levels were dramatically induced in atrophying WT muscle. Surprisingly, despite these strongly elevated p-FoXO levels, concomitant increases in FoXO nuclear protein abundance were observed following IT-LPS. Simultaneous phosphorylation and nuclear accumulation of FoXO could be explained by de novo FoXO synthesis, capable of overriding Akt-mediated nuclear exclusion of FoXO. Indeed, FoXO mRNA and protein expression were markedly upregulated, implying a second non-canonical mode of FoXO activation in control of GC-mediated muscle atrophy, operating independently of FoXO regulation through phosphorylation. A number of studies support this role for genomic GR-mediated actions in control of FoXO expression. Previously, Waddell et al. demonstrated GCinduced increases in FoXO mRNA expression, which were dependent on GR dimerization (113), and Watson et al. described decreases in FoXO1 expression in muscle-specific GR knockout mice (116). Furthermore, Smith and associates demonstrated that sepsis-induced FoXO1 expression was attenuated by the GR antagonist RU-38486 (101). In agreement with this, FoXO3a was recently identified as a direct GR target gene, as it contained functional GREs in its promoter (71). In addition to direct genomic GR actions, a recent study by Shimizu and co-workers proposed that FoXO expression was also subject to indirect genomic effects (98). Specifically, the transcription factor KLF-15 was identified as a direct GR target gene which subsequently induced FoXO mRNA expression, thereby contributing to the transcription of atrogin-1 and MuRF1 (98).

Here, we report that FoXO expression was dependent on GSK-3 $\beta$ and GR expression. The observed reductions in UPS -and ALP-related gene expression in both studies were likely the result of decreased nuclear FoXO accumulation, consequent to reduced FoXO expression. However, this does not rule out the possibility that GSK-3 $\beta$ may have directly contributed to nuclear translocation of FoXO, since a direct GSK-3 $\beta$ FoXO3a interaction was implicated in the regulation of FoXO3a activity and nuclear translocation in the brain (130). According to another recent report, GSK-3 $\beta$ directly interacts with FoXO1 in kidney cells, regulating the expression of several 
gluconeogenic genes (89). Nonetheless, our data convincingly show that despite effective Akt-mediated FoXO phosphorylation, the nuclear exclusion mechanism was overridden by GR-dependent upregulation of FoXO expression, resulting in sustained elevated levels of nuclear FoXO1 -and 3a controlling UPS -and ALP-related expression programs. As such, activated insulin/IGF-I signaling may act at two levels to inhibit FoXO-dependent gene expression. First, Akt-mediated phosphorylation prevents nuclear accretion of FoXO, and secondly, GSK-3 $\beta$ inactivation by Akt may decrease GRdriven FoXO expression. Although the present study provides compelling in vivo and in vitro evidence to support a key role for GSK-3 $\beta$ in the genomic regulation of FoXO expression, whether IGF-I-mediated decreases in FoXO mRNA transcripts are mediated through GSK-3 $\beta$ inactivation remains to be addressed. In this context, expression of a constitutively active S9A GSK-3 $\beta$ mutant (caGSK-3 $\beta$ ) should negate any inhibitory effects of IGF-I or insulin on FoXO mRNA. The striking similarities between the MGSK-3 $\beta$ KO and MGR KO studies with regard to GC-sensitive, and UPS -and ALPrelated transcriptional programs were suggestive of a GSK-3 $\beta$ - GR signaling mechanism operating upstream of FoXO. We therefore postulate that a GSK-3 $\beta$ - GRmediated signaling axis controls FoXO-dependent UPS -and ALP gene expression by regulation of de novo FoXO expression, which is capable of overruling FoXO phosphorylation and nuclear exclusion mechanisms (Figure 5.11).

To further elucidate the molecular mechanism underlying the requirement of GSK$3 \beta$ on GR-dependent gene expression, we investigated whether GSK-3 $\beta$ deficiency or enzymatic GSK-3 $\beta$ inhibition affected GR nuclear translocation and transactivation capacity. No GR accumulation was observed in nuclear lysates of skeletal muscle $48 \mathrm{~h}$ post IT-LPS, which may have been due to the early and transient nature of GR translocation, as observed in cultured myotubes exposed to the GR agonist Dex. The GR is phosphorylated at multiple Ser residues in a hormone-dependent manner (46), and phosphorylation of the mouse GR at $\operatorname{Ser}^{220}$ is associated with its enhanced nuclear retention and transcriptional activation, promoting a conformational change which facilitates cofactor interaction $(15,46)$. Importantly, genetic or pharmacological inhibition of GSK-3 $\beta$ in these experiments revealed that the nuclear localization or phosphorylation of the GR in response to Dex did not require GSK-3 $\beta$. To assess whether GSK-3 $\beta$ was involved in GR DNA-binding, the GRE transcriptional activity was

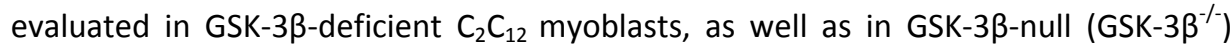
mouse embryonic fibroblasts (MEFs) transiently transfected with a GRE reporter construct. Neither enzymatic inhibition, nor genetic deletion of GSK-3 $\beta$ reduced GRE luciferase reporter activity, despite effective downregulation of GC-sensitive genes. These findings implied that GR DNA-binding was not compromised upon inactivation or genetic deletion of GSK-3ß. Discrepancies between endogenous gene expression/promoter activation and promoter activity measurements using transiently transfected reporter constructs may point at regulation at the level of chromatin remodeling, cofactor recruitment or effects on RNA polymerase II. The 
family of p300/CBP co-activator proteins has been shown to interact with the GR and play a central role in coordinating and integrating multiple signaling-dependent transcriptional events $(13,27)$. The p300/CBP co-activators are endowed with histone acetyl transferase (HAT) activity, and recently GC-induced muscle protein degradation was demonstrated to be p300/HAT-dependent (126). Furthermore, GC-treatment reduces the nuclear expression and activity of histone deacetylases (HDACs) $(2,126)$. Very recently, GSK-3 $\beta$ was demonstrated to be involved in the ligand-dependent activation of the GR, as GSK-3 $\beta$ knockdown impaired the Dex-mediated binding of the GR and RNA polymerase II to the endogenous promoter of GC-sensitive genes (86).

The fact that, neither activity nor physical presence of GSK-3 $\beta$ was required for nuclear localization or transactivation of the GR, prompted us to investigate the possibility of a regulatory role for GSK-3 $\beta$ within the nucleus. GSK-3 $\beta$ nuclear translocation has been reported previously (81), but surprisingly little is known about the regulation of its intracellular compartmentalization. Interestingly, in cultured myotubes Dex-treatment resulted in nuclear accretion of GSK-3 $\beta$, while increased nuclear localization of GSK-3 $\beta$ was also noted in WT animals with pulmonary inflammation. In view of the differences in translocation kinetics between both molecules, it seems improbable that GSK-3 $\beta$ and GR translocated to the nucleus as a complex. Notably, changes in GSK-3 $\beta$ nuclear protein abundance did not reflect increases in total cellular GSK-3 $\beta$ levels. Gene transcription is eventually determined by DNA accessibility and the activity of the basal transcriptional apparatus. The nuclear presence of GSK-3 $\beta$ reported here suggested the potential regulation of chromatin modulation factors and transcription factors by GSK-3 $\beta$. Previously, the expression and DNA-binding activity of the transcription factor CCAAT/enhancerbinding protein $B(\mathrm{C} / \mathrm{EBP} \beta)$ in muscle was found to be dependent on $\mathrm{GCs}(83,125)$. More recent data revealed that $C / E B P \beta$-deficient myotubes were resistant to Dex-induced atrophy, and silencing of C/EBP $\beta$ expression inhibited atrogin-1 and MuRF1 expression in response to Dex (35). Interestingly, GSK-3 $\beta$-dependent phosphorylation of C/EBP $\beta$ in the nucleus resulted in acquisition of DNA-binding activity (107). In addition to enhanced Dex-induced nuclear accumulation of GSK-3 $\beta$, a concomitant reduction in the phosphorylation state of nuclear GSK-3 $\beta$ at Ser ${ }^{9}$ was noted following synthetic GCtreatment. Intriguingly, as phosphorylation at this residue is mediated by Akt, decreased nuclear GSK-3 $\beta$ phosphorylation may therefore reflect reduced Akt activity, possibly through non-genomic actions of the GR inhibiting PI-3K/Akt signaling in response to Dex. Conversely, increased Akt phosphorylation coincided with markedly elevated levels of nuclear p-GSK-3 $\beta$ in skeletal muscle $48 \mathrm{~h}$ post LPS instillation, while nuclear GSK-3 $\beta$ protein abundance remained elevated. Moreover, as phosphorylation at $\mathrm{Ser}^{9}$ is the best-defined mode of GSK-3 $\beta$ activity regulation (17), decreased nuclear phosphorylation of GSK-3 $\beta$ was indicative of elevated enzymatic activity, and therefore suggested that GSK-3 $\beta$ kinase activity may have played a role in the modulatory effects on GR-dependent transcriptional regulation. In agreement with 
this, enzymatic GSK-3 $\beta$ inhibition significantly attenuated basal and abolished GCsensitive gene expression in response to Dex. These results suggest a dynamic regulation of nuclear GSK-3 $\beta$ translocation and activity, which is in line with a previous report revealing rapid and transient increases in nuclear GSK-3 $\beta$ kinase activity (20). Thus, Akt-mediated inactivation of nuclear GSK-3 $\beta$ possibly signifies the end-point of IT-LPS-induced GC-sensitive gene expression, which is in concordance with earlier time-course experiments showing that atrogene expression peaked $48 \mathrm{~h}$ post IT-LPS instillation.

The GR is a liaison molecule involved in a variety of downstream molecular cascades resulting in muscle atrophy. Some of the GR-dependent genes investigated in this study have been implicated in processes related to muscle protein turnover and protein metabolism. Recently, a mutually exclusive cross-talk between the GR and mTORC1 was suggested (98). Specifically, the GR was reported to activate a secondary transcription network driven by KLF-15, which negatively affected mTORC1 activity, by enhancing branched-chain amino acid transaminase 2 (BCAT2) expression resulting in subsequent BCAA degradation (98). Furthermore, GR-driven transcriptional cascades provide integrated cues toward muscle breakdown and coordinated nutrient supply to other organs. Transcriptional upregulation of glutamate-ammonia ligase (Glul) is GCdependent (14), and essential for increased biosynthesis of glutamine to support hepatic gluconeogenesis during muscle wasting (6). LPS-induced increases in Glul mRNA levels were blocked in GSK-3 $\beta$-and GR-deficient muscle, which may have resulted in impaired amino acid secretion by skeletal muscle. Subsequent intracellular accumulation of amino acids could have initiated a negative feedback signal halting further proteolysis. In addition to the KLF-15 - BCAT2 signaling axis, other GC-induced products can also repress mTORC1 activity in skeletal muscle. Myostatin is a cytokine which acts as a master negative regulator of skeletal muscle mass $(19,77)$. It was previously shown to be regulated in a GC-dependent fashion (31,72), and FoXO1 was demonstrated to mediate myostatin expression in conjunction with Smad transcription factors (3). In turn, overexpression of myostatin promotes FoXO1 expression, and leads to increased expression of the atrogenes atrogin-1 and MuRF1, suggesting a functional relationship with myostatin signaling and the regulation of the UPS (76). Notably, in addition to REDD1 and KLF-15, myostatin also contributes to protein synthesis by negatively affecting Akt/mTORC1 signaling $(4,117)$. So beyond a direct role in muscle proteolysis signaling through FoXO, the GSK-3 $\beta$ - GR signaling axis may indirectly control muscle protein synthesis and degradation by regulating REDD1, KLF-15 and myostatin expression in response to GCs.

In summary, we propose a novel GSK-3 $\beta$ - GR signaling axis, which controls a UPS and ALP-related gene expression program and muscle atrophy through non-canonical regulation of FoXO activation (Figure 5.11). The findings presented in this manuscript therefore suggest that GSK-3 $\beta$ may be considered as a central regulator of skeletal 
muscle atrophy, and warrant further investigation into the therapeutic potential of GSK-3 $\beta$ as a pharmacological target to combat muscle wasting.

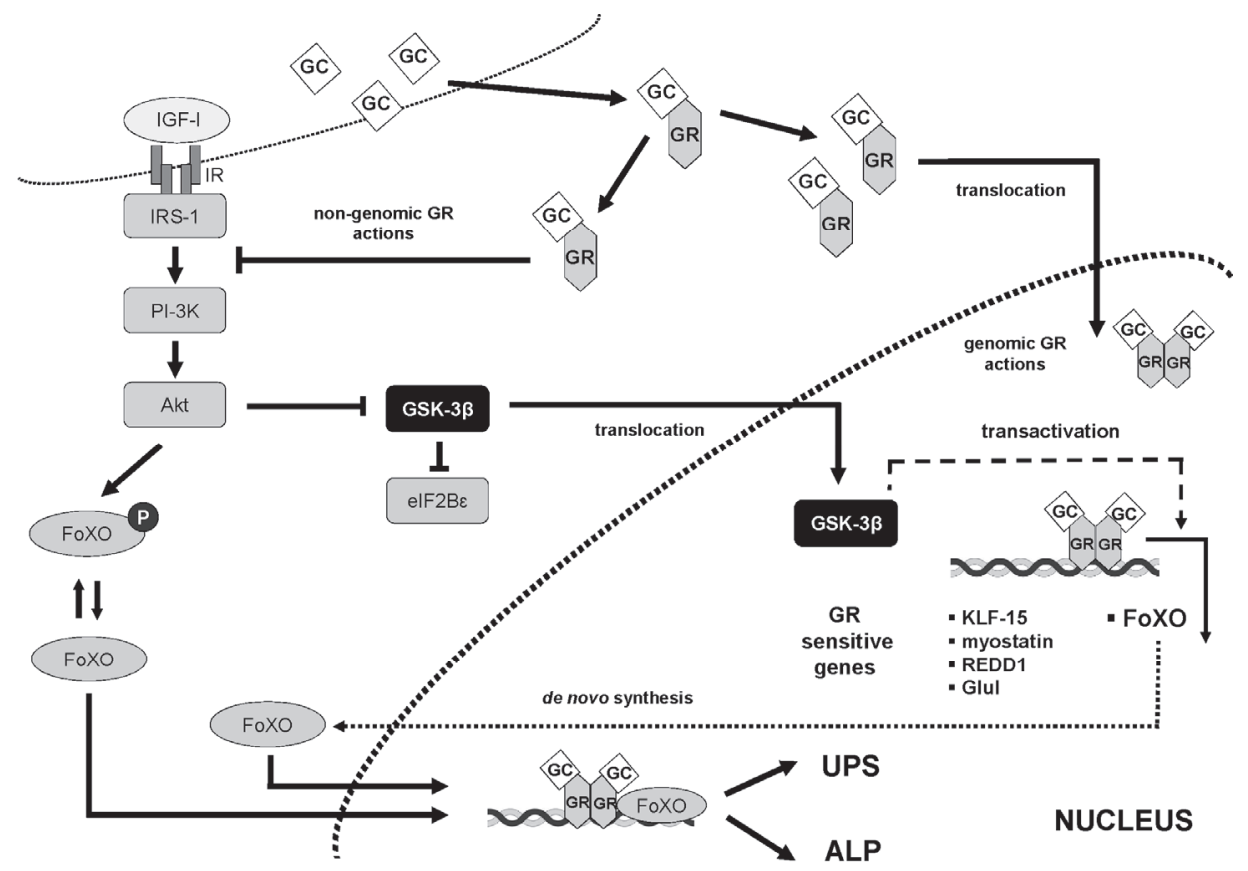

Figure 5.11 A GSK-3 $\beta$ - GR signaling axis controls ubiquitin 26S-proteasome system (UPS) -and autophagy-lysosomal pathway (ALP)-mediated skeletal muscle protein breakdown via de novo synthesis of FoXO transcription factors.

Anabolic factors such as insulin or IGF-I stimulate PI-3K signaling which results in activation of Akt. Phosphorylated Akt, in turn, inactivates GSK-3 $\beta$. Besides steering anabolic signaling, phosphorylated Akt may also regulate cytoplasmic sequestration of FoXO transcription factors (canonical FoXO regulation), resulting in a decrease in proteolysis signaling by downregulating ubiquitin 26S-proteasome system (UPS) and autophagy-lysosomal pathway (ALP)-dependent muscle protein breakdown. Conversely, under catabolic conditions (which may include glucocorticoid (GC) signaling) Akt activity is perturbed, resulting in nuclear translocation of FoXO. GCs may decrease Akt signaling via genomic or non-genomic actions of the glucocorticoid receptor (GR). Inhibition of IGF-l/Akt signaling results in activation of GSK-3 $\beta$. Activated GSK-3 $\beta$ may control GR transactivation, thereby affecting GC-sensitive gene expression, including FoXO. De novo synthesis of FoXO (non-canonical FoXO regulation) via the GSK-3 $\beta$ - GR signaling axis can override Akt-mediated nuclear FoXO exclusion mechanisms and determine UPS -and ALP-related gene expression. 


\section{Supplemental table and figures}

Table S5.1 Genes of interest determined by real-time quantitative reverse transcription PCR (qRT-PCR).

\begin{tabular}{|c|c|c|}
\hline Gene name & Forward primer & Reverse primer \\
\hline atrogin-1 & 5'-ACCGGCTACTGTGGAAGAGA-3' & 5'-CCTTCCAGGAGAGAATGTGG-3' \\
\hline MuRF1 & 5'-TGTCTGGAGGTCGTTTCCG-3' & 5'-CTCGTCTTCGTGTTCCTTGC-3' \\
\hline $\mathrm{E} 3 \alpha-11$ & 5'-AGAGAGGAGCGATAAGCTACCCCAGA-3' & 5'-CCACACACGAGGCACAGAGTAGG-3' \\
\hline LC3b & 5'-GAGCAGCACCCCACCAAGAT-3' & 5'-CGTGGTCAGGCACCAGGAA-3' \\
\hline Bnip3 & 5'-AGGTTTTCCTTCCATCTCTGTTACTG-3' & 5'-TGTGTGAACAGAAGTCAGATCCAAA-3' \\
\hline Gabarapl1 & 5'-CССTCCCACCAGTGCTACCAT-3' & 5'-TCATCACTGTAGGCCACATACAGAAAA-3' \\
\hline Glul & 5'-GGCCATGCGGGAGGAGA-3' & 5'-GGTGCCTCTTGCTCAGTTTGTCA -3' \\
\hline KLF-15 & 5'-TGCAGCAAGATGTACACCAAGAG-3' & 5'-ATCGCCGGTGCCTTGAC-3' \\
\hline REDD1 & 5'-CGGGCCGGAGGAAGACT-3' & 5'-CTGCATCAGGTTGGCACACA-3' \\
\hline myostatin & 5'-GGCCATGATCTTGCTGTAACCT-3' & 5'-CGGCAGCACCGGGATT-3' \\
\hline FoXO1 & 5'-AAGAGCGTGCCCTACTTCAAGGATA-3' & 5'-CCATGGACGCAGCTCTTCTC-3' \\
\hline FoXO3a & 5'-TGCTGACGGGTTGGATTTTAACTT-3' & 5'-AAACGGATCACTGTCCACTTGCT-3' \\
\hline CXCL1 & 5'-CACTGCACCCAAACCGAAG-3' & 5'-TCAGGGTCAAGGCAAGCC-3' \\
\hline CXCL2 & 5'-CCCTGGTTCAGAAAATCATCCAAA-3' & 5'-TTTGGTTCTTCCGTTGAGGGAC-3' \\
\hline TNF- $\alpha$ & 5'-GGGCCACCACGCTCTTC-3' & 5'-TACAGGCTTGTCACTCGAATTTTTG -3' \\
\hline GSK-3 $\alpha$ & 5'-СССТСАССАСТТССТАСААСССА-3' & 5'-TTGTGGCATCAGATGGCTGC-3' \\
\hline GSK-3 $\beta$ & 5'-CCACATGCTCGGATTCAGGC-3' & 5'-TGTCCACGGTCTCCAGCATTAGTAT-3' \\
\hline$\beta$-actin & 5'-CTGAATGGCCCAGGTCTGA-3' & 5'-CCCTCCCAGGGAGACCAA-3' \\
\hline cyclophilin A & 5'-TTCCTCCTTTCACAGAATTATTCCA-3' & 5'-CCGCCAGTGCCATTATGG-3' \\
\hline GAPDH & 5'-CAACTCACTCAAGATTGTCAGCAA-3' & 5'-TGGCAGTGATGGCATGGA-3' \\
\hline calnexin & 5'-GCAGCGACCTATGATTGACAACC-3' & 5'-GCTCCAAACCAATAGCACTGAAAGG-3' \\
\hline ARBP & 5'-GGACCCGAGAAGACCTCCTT-3' & 5'-GCACATCACTCAGAATTTCAATGG-3' \\
\hline RPL13A & 5'-CACTCTGGAGGAGAAACGGAAGG-3' & 5'-GCAGGCATGAGGCAAACAGTC-3' \\
\hline $\mathrm{B} 2 \mathrm{M}$ & 5'-CTTTCTGGTGCTTGTCTCACTGA-3' & 5'-GTATGTTCGGCTTCCCATTCTC-3' \\
\hline$\alpha$-tubulin & 5'-CGTAGACCTGGAACCCACGGT-3' & 5'-TGCCTGTGATGAGCTGCTCA-3' \\
\hline
\end{tabular}


A

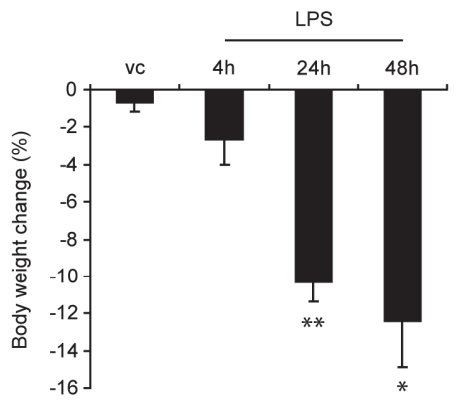

B
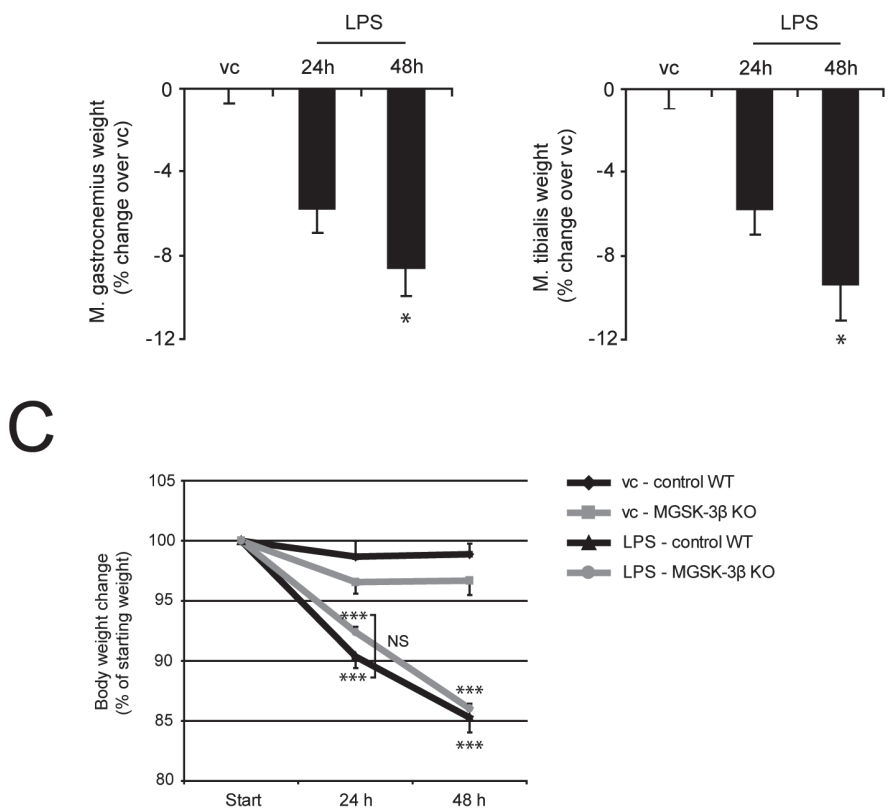

Figure S5.1 LPS-induced pulmonary inflammation results in loss of body weight and is accompanied by skeletal muscle atrophy.

Male C57BL/6 mice were subjected to intratracheal (IT) instillation of lipopolysaccharide (LPS) or vehicle ( $\mathrm{vc}$ ) (IT-NaCl). At the indicated time points the mice were terminally anaesthetized for the collection of blood and muscle tissue. (A) Body weights and (B) muscle weights were determined, as shown here for gastrocnemius and tibialis muscles (expressed as \% weight change over vc). (C) Male muscle-specific GSK-3 $\beta$ knockout (MGSK-3 $\beta$ KO) and WT control mice $\left(\mathrm{GSK}-3 \beta^{\mathrm{fl} / \mathrm{fl}}\right.$ ) were subjected to IT-LPS or vc for $48 \mathrm{~h}$. Body weights were measured every $24 \mathrm{~h}$ and expressed as $\mathrm{a} \%$ of the starting weight. All data shown represent means \pm SEM, (A) (B) $n=3$ and (C) $n=6$ and animals per group. ${ }^{*} p<0.05$, ** $p<0.01, * * * p<0.001$ compared with the vc-treated WT control group. 
A
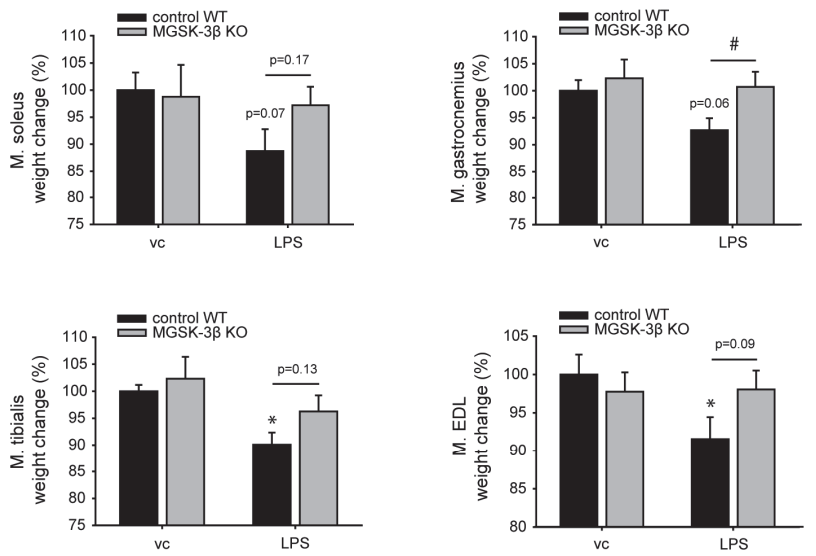

B

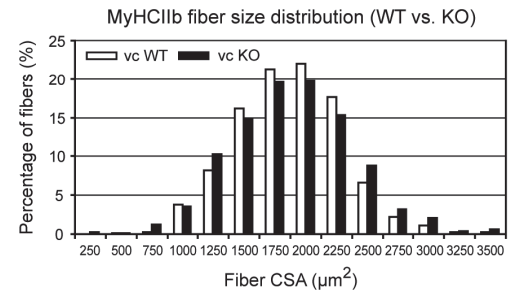

C
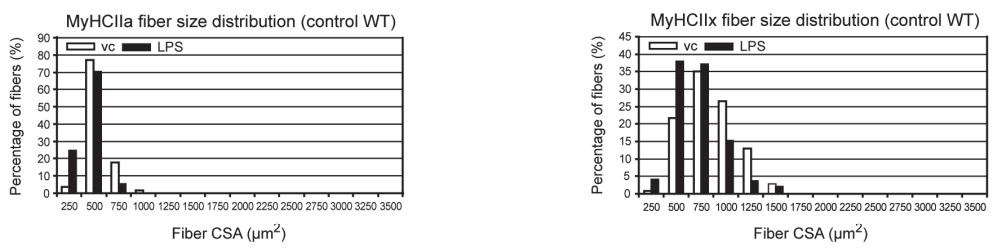

MyHClla fiber size distribution (MGSK-3ß KO)

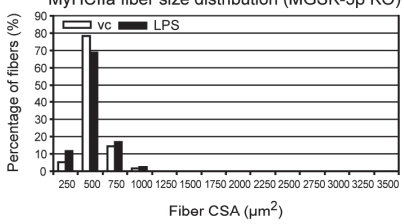

MyHCIlx fiber size distribution (MGSK-3 $\beta$ KO)

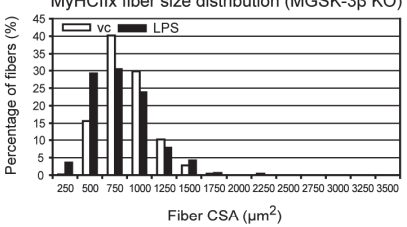

MyHClla fiber size distribution (WT vs. KO)

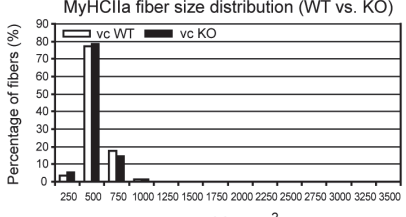

MyHCllx fiber size distribution (WT vs. KO)

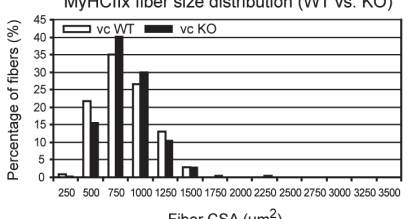

Fiber CSA $\left(\mu \mathrm{m}^{2}\right)$ 
Figure S5.2 Muscle-specific deletion of GSK-3 $\beta$ prevents pulmonary inflammation-induced skeletal muscle atrophy.

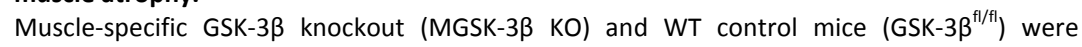
subjected to IT-LPS or vc for $48 \mathrm{~h}$. (A) Soleus, gastrocnemius, tibialis and EDL muscle mass was assessed and expressed as a \% of weight change over vc WT control. (B) Type Ilb fiber size distribution of vc-treated animals between both genotypes (C) Fiber size distribution of Type Ila (left) and Type IIx (right) fiber CSA of WT control or MGSK-3 $\beta$ KO mice following vc or LPS instillation. All data shown represent means $\pm \mathrm{SEM}, \mathrm{n}=6$ animals per group. ${ }^{*} \mathrm{p}<0.05$ compared with the vc-treated WT control group; \# $p<0.05$ refers to a difference between indicated conditions.

A
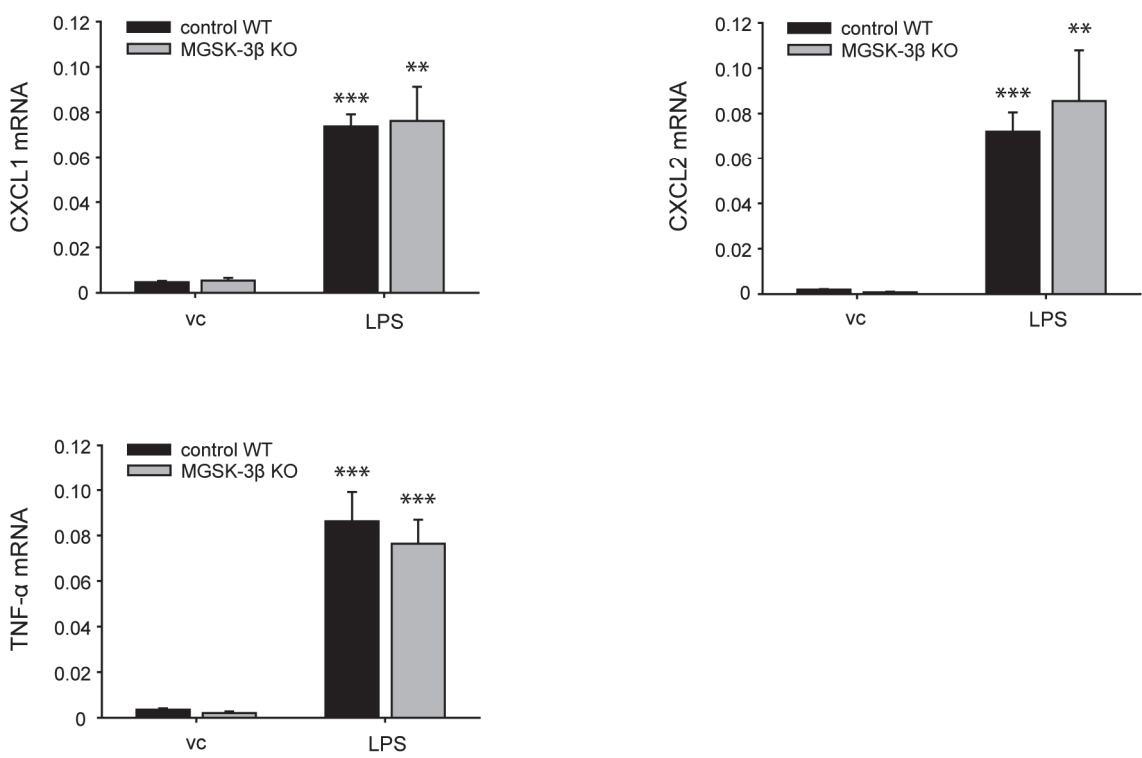

Figure S5.3 LPS-induced pulmonary inflammation is not affected by muscle GSK-3 $\beta$ deficiency. Muscle-specific GSK-3 $\beta$ knockout (MGSK-3 $\beta$ KO) and WT control mice $\left(G S K-3 \beta^{\mathrm{fl} / \mathrm{fl}}\right.$ ) were subjected to IT-LPS or vc for $48 \mathrm{~h}$. (A) At this time point the mRNA transcript levels of CXCL1, CXCL2 and TNF- $\alpha$ were determined in lung tissue and normalized to geNorm. All data shown represent means $\pm \mathrm{SEM}, \mathrm{n}=6$ animals per group. ${ }^{* *} \mathrm{p}<0.01,{ }^{* * *} \mathrm{p}<0.001$ compared with the vc-treated WT control group. 
A
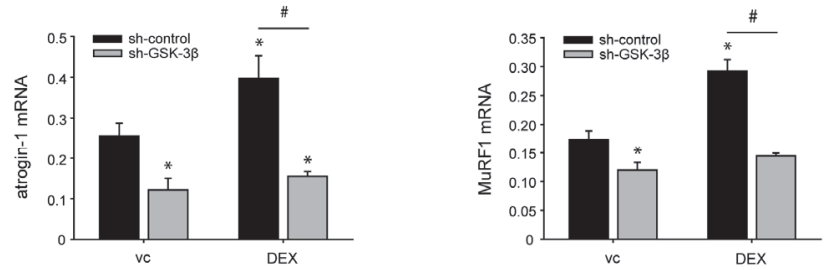

B
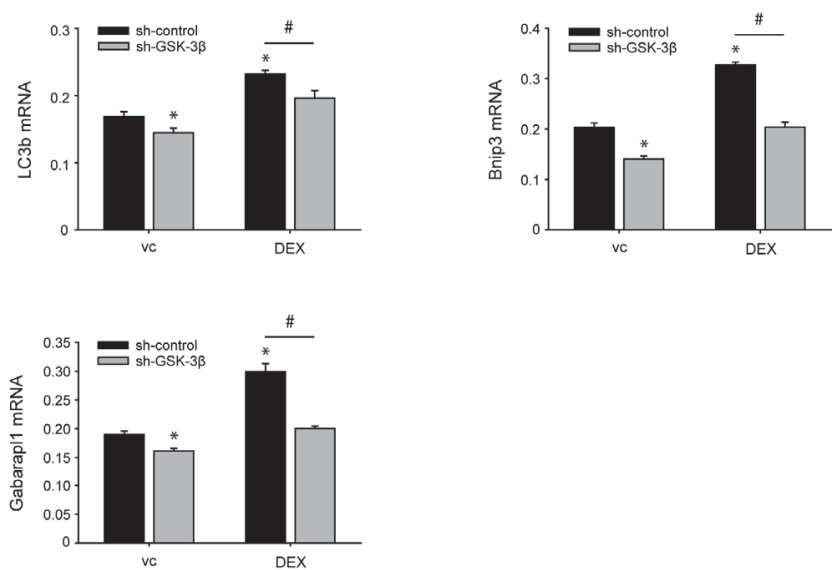

C
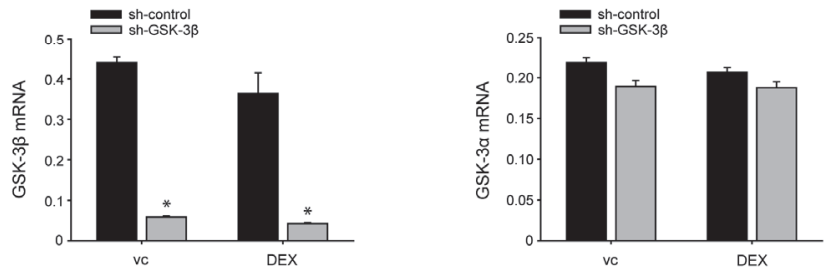

Figure S5.4 UPS -and ALP-related gene expression in glucocorticoid-associated muscle atrophy is dependent on GSK-3 $\beta$ in cultured myotubes.

Stably transfected myoblasts (sh-control/GSK-3ß) were induced to differentiate for $5 \mathrm{~d}$, and cultured for an additional $24 \mathrm{~h}$ in the presence of Dex [25 $\mu \mathrm{M}$ ] or vc (DMSO), after which the mRNA abundance of (A) atrogin-1, MuRF1, (B) LC3b, Bnip3, Gabarapl1, (C) GSK-3 $\beta$ and GSK-3 $\alpha$ was determined. All data shown represent means \pm SEM ( $n=3$ per group) and are representative of 3 independent experiments. ${ }^{*} p<0.05$ compared with the vc-treated sh-control group; \# $p<0.05$ refers to a difference between indicated conditions. 
A
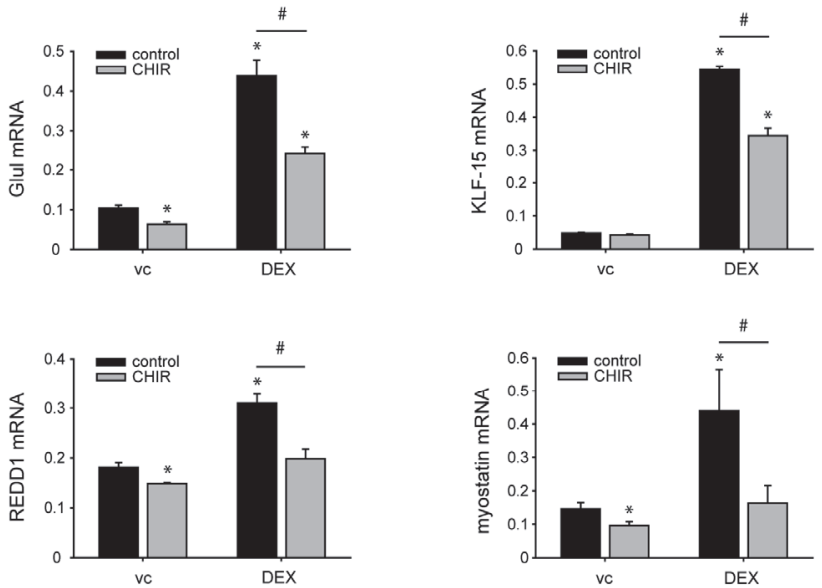

B
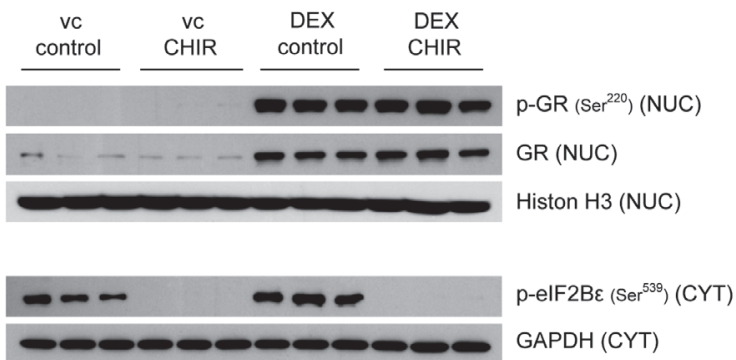

C
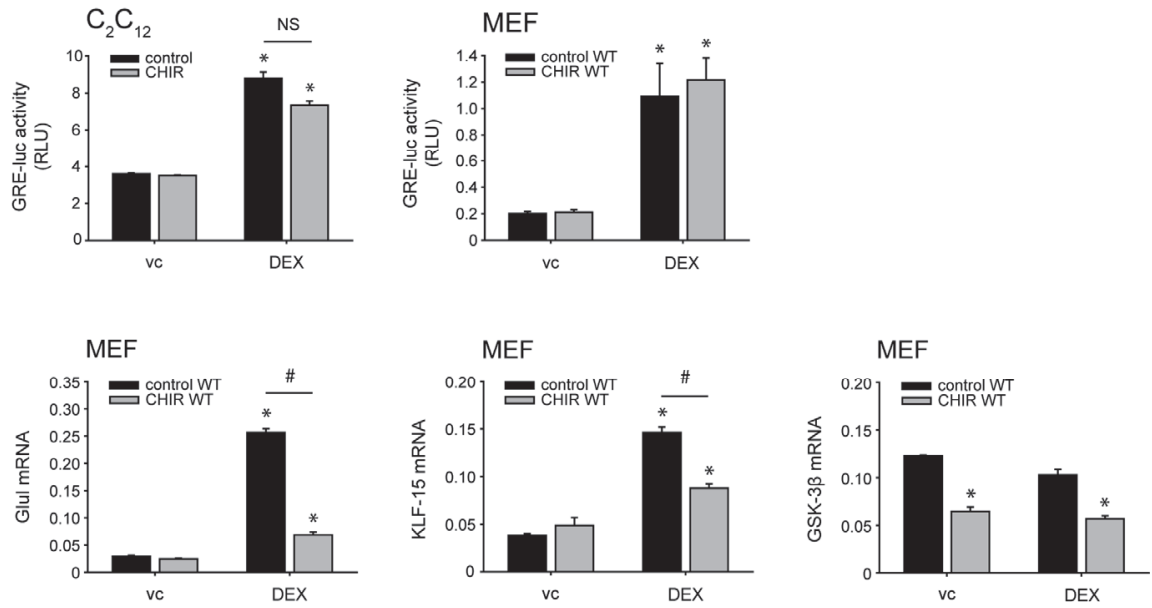
Figure S5.5 Pharmacological GSK-3 $\beta$ inhibition does not affect nuclear translocation of the glucocorticoid receptor (GR) or direct GR-mediated transcriptional activation, despite reduced glucocorticoid-sensitive gene expression.

Fully differentiated native $\mathrm{C}_{2} \mathrm{C}_{12}$ myotubes $(5 \mathrm{~d}$ ) were cultured for $24 \mathrm{~h}$ the presence of Dex [25 $\mu \mathrm{M}]$ or vc (DMSO) and/or CHIR99021 [7 $\mathrm{MM}$ ], after which the mRNA abundance of (A) Glul, KLF-15, REDD1 and myostatin was determined. (B) Alternatively, nuclear protein abundance of phosphorylated ( $p-G R$ ) and total GR was determined in nuclear lysates (NUC) and normalized to Histone $\mathrm{H} 3$ (top panel), while phospho-eukaryotic initiation factor $2 \mathrm{~B} \varepsilon$ ( $\mathrm{p}$ elF2Br) protein expression was assessed in cytoplasmic fractions (CYT) and corrected for GAPDH (bottom panel) by Western blotting. (C) Plasmids encoding a luciferase reporter gene controlled by an inducible promoter containing glucocorticoid response elements (GREs) or $\beta$-galactosidase ( $\beta$-gal) were transiently transfected in native $C_{2} C_{12}$ myoblasts, or GSK-3 $\beta$-null $\left(\right.$ GSK- $3 \beta^{-/-}$) and WT control (GSK-3 $\beta^{+/+}$) mouse embryonic fibroblasts (MEFs). Transfected cells were cultured in the presence of Dex [25 $\mu \mathrm{M}$ ] or vc (DMSO) and/or CHIR99021 [7 $\mu \mathrm{M}$ ] for $6 \mathrm{~h}$ after which luciferase and $\beta$-gal activity were measured (top graphs). Alternatively, mRNA expression levels of Glul, KLF-15 and GSK-3 $\beta$ were determined (bottom graphs). All data shown represent means \pm SEM ( $n=3$ per group) and are representative of 3 independent experiments. * $\mathrm{p}<0.05$ compared with the vc-treated control group; \# $\mathrm{p}<0.05$ refers to a difference between indicated conditions. 
A
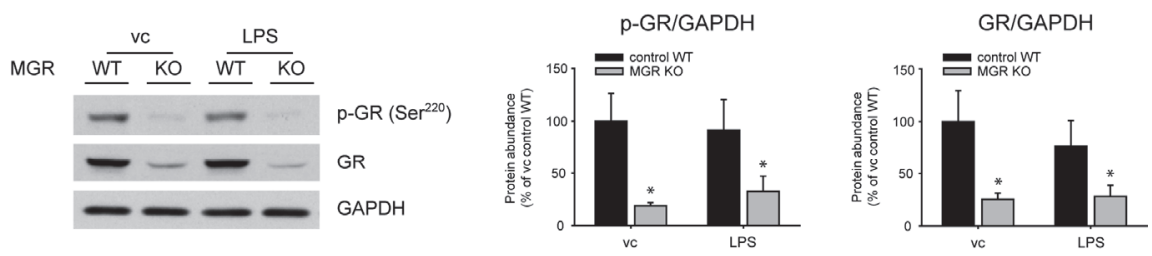

B

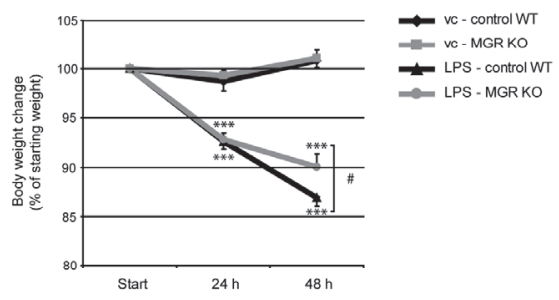

C
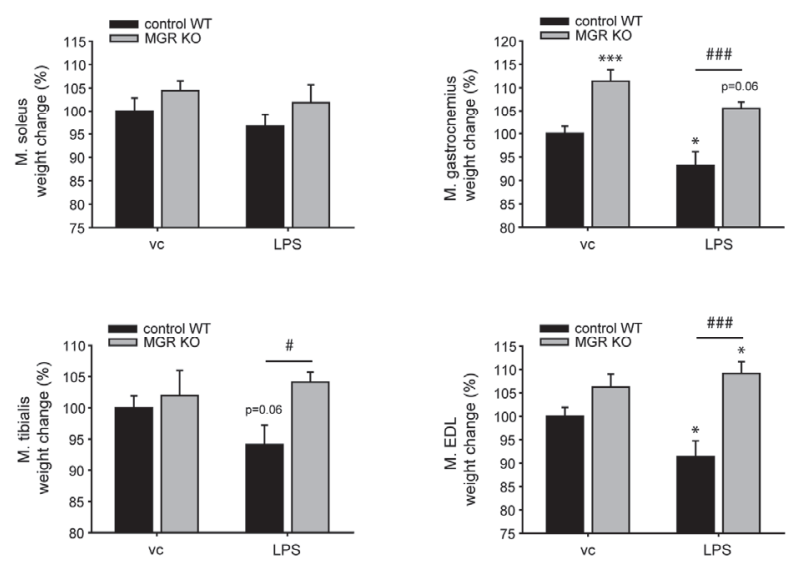

Figure S5.6 Muscle-specific deletion of the glucocorticoid receptor (GR) prevents pulmonary inflammation-induced skeletal muscle atrophy.

Muscle-specific GR knockout (MGR KO) and WT control mice $\left(G R^{\mathrm{fl} / \mathrm{fl}}\right)$ were subjected to IT-LPS or vc for $48 \mathrm{~h}$. (A) Muscle-specific deletion of the GR was confirmed by Western blotting in plantaris muscle and normalized to GAPDH. The accompanying bar graphs depict densitometric analysis results represented as a \% of the vc control WT. (B) Body weights were measured every $24 \mathrm{~h}$ and expressed as a \% of the starting weight. (C) Soleus, gastrocnemius, tibialis and EDL muscle mass was assessed and expressed as a \% of weight change over vc WT control. All data shown represent means \pm SEM, $n=8-12$ animals per group. ${ }^{*} p<0.05$, *** $p<0.001$ compared with the vc-treated WT control group; \# $p<0.05$, \#\#\# $p<0.001$ refers to a difference between indicated conditions. 


\section{References}

1. Adegoke OA, Bedard N, Roest HP, and Wing SS. Ubiquitin-conjugating enzyme E214k/HR6B is dispensable for increased protein catabolism in muscle of fasted mice. Am J Physiol Endocrinol Metab 283: E482-489, 2002.

2. Alamdari N, Smith IJ, Aversa Z, and Hasselgren PO. Sepsis and glucocorticoids upregulate p300 and downregulate HDAC6 expression and activity in skeletal muscle. Am J Physiol Regul Integr Comp Physiol 299: R509-520, 2010.

3. Allen DL and Unterman TG. Regulation of myostatin expression and myoblast differentiation by FoxO and SMAD transcription factors. Am J Physiol Cell Physiol 292: C188-199, 2007.

4. Amirouche A, Durieux AC, Banzet S, Koulmann N, Bonnefoy R, Mouret C, Bigard X, Peinnequin A, and Freyssenet $D$. Down-regulation of $A k t / m a m m a l i a n$ target of rapamycin signaling pathway in response to myostatin overexpression in skeletal muscle. Endocrinology 150: 286-294, 2009.

5. Baehr LM, Furlow JD, and Bodine SC. Muscle sparing in muscle RING finger 1 null mice: response to synthetic glucocorticoids. J Physiol 589: 4759-4776, 2011.

6. Biolo G, Zorat F, Antonione R, and Ciocchi B. Muscle glutamine depletion in the intensive care unit. Int J Biochem Cell Biol 37: 2169-2179, 2005.

7. Bodine SC, Latres E, Baumhueter S, Lai VK, Nunez L, Clarke BA, Poueymirou WT, Panaro FJ, Na E, Dharmarajan K, Pan ZQ, Valenzuela DM, DeChiara TM, Stitt TN, Yancopoulos GD, and Glass DJ. Identification of ubiquitin ligases required for skeletal muscle atrophy. Science 294: 1704-1708, 2001.

8. Bodine SC, Stitt TN, Gonzalez M, Kline WO, Stover GL, Bauerlein R, Zlotchenko E, Scrimgeour A, Lawrence JC, Glass DJ, and Yancopoulos GD. Akt/mTOR pathway is a crucial regulator of skeletal muscle hypertrophy and can prevent muscle atrophy in vivo. Nat Cell Biol 3: 1014-1019, 2001.

9. Brummelkamp TR, Bernards R, and Agami R. Stable suppression of tumorigenicity by virus-mediated RNA interference. Cancer Cell 2: 243-247, 2002.

10. Brummelkamp TR, Bernards R, and Agami R. A system for stable expression of short interfering RNAs in mammalian cells. Science 296: 550-553, 2002.

11. Buckingham JC. Glucocorticoids: exemplars of multi-tasking. Br J Pharmacol 147 Suppl 1: S258-268, 2006.

12. Cao PR, Kim HJ, and Lecker SH. Ubiquitin-protein ligases in muscle wasting. Int J Biochem Cell Biol 37: 2088-2097, 2005.

13. Chan HM and La Thangue NB. p300/CBP proteins: HATs for transcriptional bridges and scaffolds. J Cell Sci 114: 2363-2373, 2001.

14. Chandrasekhar S, Souba WW, and Abcouwer SF. Identification of glucocorticoid-responsive elements that control transcription of rat glutamine synthetase. Am J Physiol 276: L319-331, 1999.

15. Chen W, Dang T, Blind RD, Wang Z, Cavasotto CN, Hittelman AB, Rogatsky I, Logan SK, and Garabedian MJ. Glucocorticoid receptor phosphorylation differentially affects target gene expression. Mol Endocrinol 22: 1754-1766, 2008.

16. Clarke BA, Drujan D, Willis MS, Murphy LO, Corpina RA, Burova E, Rakhilin SV, Stitt TN, Patterson C, Latres $E$, and Glass DJ. The E3 Ligase MuRF1 degrades myosin heavy chain protein in dexamethasonetreated skeletal muscle. Cell Metab 6: 376-385, 2007.

17. Cross DA, Alessi DR, Cohen P, Andjelkovich M, and Hemmings BA. Inhibition of glycogen synthase kinase-3 by insulin mediated by protein kinase B. Nature 378: 785-789, 1995.

18. DeYoung MP, Horak P, Sofer A, Sgroi D, and Ellisen LW. Hypoxia regulates TSC1/2-mTOR signaling and tumor suppression through REDD1-mediated 14-3-3 shuttling. Genes Dev 22: 239-251, 2008.

19. Elkina $Y$, von Haehling S, Anker SD, and Springer J. The role of myostatin in muscle wasting: an overview. J Cachexia Sarcopenia Muscle 2: 143-151, 2011.

20. Elyaman W, Terro F, Wong NS, and Hugon J. In vivo activation and nuclear translocation of phosphorylated glycogen synthase kinase-3beta in neuronal apoptosis: links to tau phosphorylation. Eur J Neurosci 15: 651-660, 2002.

21. Erdmann G, Schutz G, and Berger S. Loss of glucocorticoid receptor function in the pituitary results in early postnatal lethality. Endocrinology 149: 3446-3451, 2008.

22. Evenson AR, Fareed MU, Menconi MJ, Mitchell JC, and Hasselgren PO. GSK-3beta inhibitors reduce protein degradation in muscles from septic rats and in dexamethasone-treated myotubes. Int $J$ Biochem Cell Biol 37: 2226-2238, 2005. 
23. Fang CH, Li B, James JH, Yahya A, Kadeer N, Guo X, Xiao C, Supp DM, Kagan RJ, Hasselgren PO, and Sheriff S. GSK-3beta activity is increased in skeletal muscle after burn injury in rats. Am J Physiol Regul Integr Comp Physiol 293: R1545-1551, 2007.

24. Fang CH, Li BG, James JH, King JK, Evenson AR, Warden GD, and Hasselgren PO. Protein breakdown in muscle from burned rats is blocked by insulin-like growth factor $\mathrm{i}$ and glycogen synthase kinase-3beta inhibitors. Endocrinology 146: 3141-3149, 2005.

25. Fischer D, Sun X, Gang G, Pritts T, and Hasselgren PO. The gene expression of ubiquitin ligase E3alpha is upregulated in skeletal muscle during sepsis in rats-potential role of glucocorticoids. Biochem Biophys Res Commun 267: 504-508, 2000.

26. Frost RA, Nystrom GJ, Jefferson LS, and Lang CH. Hormone, cytokine, and nutritional regulation of sepsis-induced increases in atrogin-1 and MuRF1 in skeletal muscle. Am J Physiol Endocrinol Metab 292: E501-512, 2007.

27. Fryer CJ and Archer TK. Chromatin remodelling by the glucocorticoid receptor requires the BRG1 complex. Nature 393: 88-91, 1998.

28. Furuyama T, Kitayama K, Yamashita H, and Mori N. Forkhead transcription factor FOXO1 (FKHR)dependent induction of PDK4 gene expression in skeletal muscle during energy deprivation. Biochem J 375: 365-371, 2003.

29. Galliher-Beckley AJ and Cidlowski JA. Emerging roles of glucocorticoid receptor phosphorylation in modulating glucocorticoid hormone action in health and disease. IUBMB Life 61: 979-986, 2009.

30. Gayan-Ramirez G, Vanderhoydonc F, Verhoeven G, and Decramer M. Acute treatment with corticosteroids decreases IGF-1 and IGF-2 expression in the rat diaphragm and gastrocnemius. Am J Respir Crit Care Med 159: 283-289, 1999.

31. Gilson H, Schakman O, Combaret L, Lause P, Grobet L, Attaix D, Ketelslegers JM, and Thissen JP. Myostatin gene deletion prevents glucocorticoid-induced muscle atrophy. Endocrinology 148: 452460, 2007.

32. Glass DJ. Molecular mechanisms modulating muscle mass. Trends Mol Med 9: 344-350, 2003.

33. Glass DJ. Skeletal muscle hypertrophy and atrophy signaling pathways. Int J Biochem Cell Biol 37: 1974-1984, 2005.

34. Gomes MD, Lecker SH, Jagoe RT, Navon A, and Goldberg AL. Atrogin-1, a muscle-specific F-box protein highly expressed during muscle atrophy. Proc Natl Acad Sci U S A 98: 14440-14445, 2001.

35. Gonnella P, Alamdari N, Tizio S, Aversa Z, Petkova V, and Hasselgren PO. C/EBPbeta regulates dexamethasone-induced muscle cell atrophy and expression of atrogin-1 and MuRF1. J Cell Biochem 112: 1737-1748, 2011.

36. Greenberg SS, Ouyang J, Zhao X, Parrish C, Nelson S, and Giles TD. Effects of ethanol on neutrophil recruitment and lung host defense in nitric oxide synthase I and nitric oxide synthase II knockout mice. Alcohol Clin Exp Res 23: 1435-1445, 1999.

37. Haegens A, Heeringa P, van Suylen RJ, Steele C, Aratani Y, O'Donoghue RJ, Mutsaers SE, Mossman BT, Wouters EF, and Vernooy JH. Myeloperoxidase deficiency attenuates lipopolysaccharide-induced acute lung inflammation and subsequent cytokine and chemokine production. J Immunol 182: 79907996, 2009.

38. Haegens A, Schols AM, Gorissen SH, van Essen AL, Snepvangers F, Gray DA, Shoelson SE, and Langen RC. NF-kappaB activation and polyubiquitin conjugation are required for pulmonary inflammationinduced diaphragm atrophy. Am J Physiol Lung Cell Mol Physiol 302: L103-110, 2012.

39. Hall-Angeras M, Angeras U, Zamir O, Hasselgren PO, and Fischer JE. Effect of the glucocorticoid receptor antagonist RU 38486 on muscle protein breakdown in sepsis. Surgery 109: 468-473, 1991.

40. Hardy RS, Raza K, and Cooper MS. Endogenous glucocorticoids in inflammation: contributions of systemic and local responses. Swiss Med Wkly 142: w13650, 2012.

41. Hasselgren PO. Glucocorticoids and muscle catabolism. Curr Opin Clin Nutr Metab Care 2: 201-205, 1999.

42. Hawes AS, Rock CS, Keogh CV, Lowry SF, and Calvano SE. In vivo effects of the antiglucocorticoid RU 486 on glucocorticoid and cytokine responses to Escherichia coli endotoxin. Infect Immun 60: 26412647, 1992.

43. Hermans JJ, van Essen H, Struijker-Boudier HA, Johnson RM, Theeuwes F, and Smits JF. Pharmacokinetic advantage of intrapericardially applied substances in the rat. J Pharmacol Exp Ther 301: 672-678, 2002. 
44. Hoeflich KP, Luo J, Rubie EA, Tsao MS, Jin O, and Woodgett JR. Requirement for glycogen synthase kinase-3beta in cell survival and NF-kappaB activation. Nature 406: 86-90, 2000.

45. Hu Z, Wang H, Lee IH, Du J, and Mitch WE. Endogenous glucocorticoids and impaired insulin signaling are both required to stimulate muscle wasting under pathophysiological conditions in mice. J Clin Invest 119: 3059-3069, 2009.

46. Ismaili N and Garabedian MJ. Modulation of glucocorticoid receptor function via phosphorylation. Ann N Y Acad Sci 1024: 86-101, 2004.

47. Jackman RW and Kandarian SC. The molecular basis of skeletal muscle atrophy. Am J Physiol Cell Physiol 287: C834-843, 2004.

48. Jagoe RT and Goldberg AL. What do we really know about the ubiquitin-proteasome pathway in muscle atrophy? Curr Opin Clin Nutr Metab Care 4: 183-190, 2001.

49. Jin B and Li YP. Curcumin prevents lipopolysaccharide-induced atrogin-1/MAFbx upregulation and muscle mass loss. J Cell Biochem 100: 960-969, 2007.

50. Katiyar S, Liu E, Knutzen CA, Lang ES, Lombardo CR, Sankar S, Toth JI, Petroski MD, Ronai Z, and Chiang GG. REDD1, an inhibitor of mTOR signalling, is regulated by the CUL4A-DDB1 ubiquitin ligase. EMBO Rep 10: 866-872, 2009.

51. Knapp S, Florquin S, Golenbock DT, and van der Poll T. Pulmonary lipopolysaccharide (LPS)-binding protein inhibits the LPS-induced lung inflammation in vivo. J Immunol 176: 3189-3195, 2006.

52. Konagaya M, Bernard PA, and Max SR. Blockade of glucocorticoid receptor binding and inhibition of dexamethasone-induced muscle atrophy in the rat by RU38486, a potent glucocorticoid antagonist. Endocrinology 119: 375-380, 1986.

53. Korolchuk VI, Menzies FM, and Rubinsztein DC. Mechanisms of cross-talk between the ubiquitinproteasome and autophagy-lysosome systems. FEBS Lett 584: 1393-1398, 2010.

54. Kumari R, Willing LB, Jefferson LS, Simpson IA, and Kimball SR. REDD1 (regulated in development and DNA damage response 1) expression in skeletal muscle as a surrogate biomarker of the efficiency of glucocorticoid receptor blockade. Biochem Biophys Res Commun 412: 644-647, 2011.

55. Kuo T, Lew MJ, Mayba O, Harris CA, Speed TP, and Wang JC. Genome-wide analysis of glucocorticoid receptor-binding sites in myotubes identifies gene networks modulating insulin signaling. Proc Natl Acad Sci U S A 109: 11160-11165, 2012.

56. Kwak KS, Zhou X, Solomon V, Baracos VE, Davis J, Bannon AW, Boyle WJ, Lacey DL, and Han HQ. Regulation of protein catabolism by muscle-specific and cytokine-inducible ubiquitin ligase E3alpha-II during cancer cachexia. Cancer Res 64: 8193-8198, 2004.

57. Kwon YT, Reiss Y, Fried VA, Hershko A, Yoon JK, Gonda DK, Sangan P, Copeland NG, Jenkins NA, and Varshavsky $A$. The mouse and human genes encoding the recognition component of the $\mathrm{N}$-end rule pathway. Proc Natl Acad Sci U S A 95: 7898-7903, 1998.

58. Kwon YT, Xia Z, Davydov IV, Lecker SH, and Varshavsky A. Construction and analysis of mouse strains lacking the ubiquitin ligase UBR1 (E3alpha) of the N-end rule pathway. Mol Cell Biol 21: 8007-8021, 2001.

59. Labeit S, Kohl CH, Witt CC, Labeit D, Jung J, and Granzier H. Modulation of muscle atrophy, fatigue and MLC phosphorylation by MURF1 as indicated by hindlimb suspension studies on MuRF1-KO mice. J Biomed Biotechnol 2010: 693741, 2010.

60. Lang $\mathrm{CH}$ and Frost RA. Endotoxin disrupts the leucine-signaling pathway involving phosphorylation of mTOR, 4E-BP1, and S6K1 in skeletal muscle. J Cell Physiol 203: 144-155, 2005.

61. Lang $\mathrm{CH}$ and Frost RA. Sepsis-induced suppression of skeletal muscle translation initiation mediated by tumor necrosis factor alpha. Metabolism 56: 49-57, 2007.

62. Lang CH, Nystrom GJ, and Frost RA. Burn-induced changes in IGF-I and IGF-binding proteins are partially glucocorticoid dependent. Am J Physiol Regul Integr Comp Physiol 282: R207-215, 2002.

63. Langen RC, Haegens A, Vernooy JH, Wouters EF, de Winther MP, Carlsen H, Steele C, Shoelson SE, and Schols AM. NF-kappa B Activation is Required for the Transition of Pulmonary Inflammation to Muscle Atrophy. Am J Respir Cell Mol Biol, 2012.

64. Latres E, Amini AR, Amini AA, Griffiths J, Martin FJ, Wei Y, Lin HC, Yancopoulos GD, and Glass DJ. Insulin-like growth factor-1 (IGF-1) inversely regulates atrophy-induced genes via the phosphatidylinositol 3-kinase/Akt/mammalian target of rapamycin (PI3K/Akt/mTOR) pathway. J Biol Chem 280: 2737-2744, 2005. 
65. Lecker SH, Goldberg AL, and Mitch WE. Protein degradation by the ubiquitin-proteasome pathway in normal and disease states. J Am Soc Nephrol 17: 1807-1819, 2006.

66. Lecker SH, Jagoe RT, Gilbert A, Gomes M, Baracos V, Bailey J, Price SR, Mitch WE, and Goldberg AL. Multiple types of skeletal muscle atrophy involve a common program of changes in gene expression. Faseb J 18: 39-51, 2004.

67. Lecker SH, Solomon V, Mitch WE, and Goldberg AL. Muscle protein breakdown and the critical role of the ubiquitin-proteasome pathway in normal and disease states. J Nutr 129: 227S-237S, 1999.

68. Li BG, Hasselgren PO, and Fang CH. Insulin-like growth factor-I inhibits dexamethasone-induced proteolysis in cultured $\mathrm{L} 6$ myotubes through PI3K/Akt/GSK-3beta and PI3K/Akt/mTOR-dependent mechanisms. Int J Biochem Cell Biol 37: 2207-2216, 2005.

69. Li YH, Fan J, and Lang CH. Differential role of glucocorticoids in mediating endotoxin-induced changes in IGF-I and IGFBP-1. Am J Physiol 272: R1990-1997, 1997.

70. Limbourg FP, Huang Z, Plumier JC, Simoncini T, Fujioka M, Tuckermann J, Schutz G, Moskowitz MA, and Liao JK. Rapid nontranscriptional activation of endothelial nitric oxide synthase mediates increased cerebral blood flow and stroke protection by corticosteroids. J Clin Invest 110: 1729-1738, 2002.

71. Lutzner N, Kalbacher H, Krones-Herzig A, and Rosl F. FOXO3 is a glucocorticoid receptor target and regulates LKB1 and its own expression based on cellular AMP levels via a positive autoregulatory loop. PLoS One 7: e42166, 2012.

72. Ma K, Mallidis C, Bhasin S, Mahabadi V, Artaza J, Gonzalez-Cadavid N, Arias J, and Salehian B. Glucocorticoid-induced skeletal muscle atrophy is associated with upregulation of myostatin gene expression. Am J Physiol Endocrinol Metab 285: E363-371, 2003.

73. Mammucari C, Milan G, Romanello V, Masiero E, Rudolf R, Del Piccolo P, Burden SJ, Di Lisi R, Sandri C, Zhao J, Goldberg AL, Schiaffino S, and Sandri M. FoxO3 controls autophagy in skeletal muscle in vivo. Cell Metab 6: 458-471, 2007.

74. Masiero E, Agatea L, Mammucari C, Blaauw B, Loro E, Komatsu M, Metzger D, Reggiani C, Schiaffino S, and Sandri M. Autophagy is required to maintain muscle mass. Cell Metab 10: 507-515, 2009.

75. Mason SR, Ward LC, and Reilly PE. Fluorimetric detection of serum corticosterone using highperformance liquid chromatography. J Chromatogr 581: 267-271, 1992.

76. McFarlane C, Plummer E, Thomas M, Hennebry A, Ashby M, Ling N, Smith H, Sharma M, and Kambadur R. Myostatin induces cachexia by activating the ubiquitin proteolytic system through an NF-kappaB-independent, FoxO1-dependent mechanism. J Cell Physiol 209: 501-514, 2006.

77. McPherron AC, Lawler AM, and Lee SJ. Regulation of skeletal muscle mass in mice by a new TGF-beta superfamily member. Nature 387: 83-90, 1997.

78. Mei SH, McCarter SD, Deng Y, Parker CH, Liles WC, and Stewart DJ. Prevention of LPS-induced acute lung injury in mice by mesenchymal stem cells overexpressing angiopoietin 1. PLoS Med 4: e269, 2007.

79. Mizushima N, Levine B, Cuervo AM, and Klionsky DJ. Autophagy fights disease through cellular selfdigestion. Nature 451: 1069-1075, 2008.

80. Munck A and Naray-Fejes-Toth A. The ups and downs of glucocorticoid physiology. Permissive and suppressive effects revisited. Mol Cell Endocrinol 90: C1-4, 1992.

81. Ougolkov AV, Fernandez-Zapico ME, Bilim VN, Smyrk TC, Chari ST, and Billadeau DD. Aberrant nuclear accumulation of glycogen synthase kinase-3beta in human pancreatic cancer: association with kinase activity and tumor dedifferentiation. Clin Cancer Res 12: 5074-5081, 2006.

82. Patel S, Doble BW, MacAulay K, Sinclair EM, Drucker DJ, and Woodgett JR. Tissue-specific role of glycogen synthase kinase 3beta in glucose homeostasis and insulin action. Mol Cell Biol 28: 63146328, 2008.

83. Penner G, Gang G, Sun X, Wray C, and Hasselgren PO. C/EBP DNA-binding activity is upregulated by a glucocorticoid-dependent mechanism in septic muscle. Am J Physiol Regul Integr Comp Physiol 282: R439-444, 2002.

84. Pereira RM and Freire de Carvalho J. Glucocorticoid-induced myopathy. Joint Bone Spine 78: 41-44, 2011.

85. Reid MB. Response of the ubiquitin-proteasome pathway to changes in muscle activity. Am J Physiol Regul Integr Comp Physiol 288: R1423-1431, 2005. 
86. Rubio-Patino C, Palmeri CM, Perez-Perarnau A, Cosialls AM, Moncunill-Massaguer C, GonzalezGirones DM, Pons-Hernandez L, Lopez JM, Ventura F, Gil J, Pons G, and Iglesias-Serret D. Glycogen synthase kinase-3beta is involved in ligand-dependent activation of transcription and cellular localization of the glucocorticoid receptor. Mol Endocrinol 26: 1508-1520, 2012.

87. Sacheck JM, Hyatt JP, Raffaello A, Jagoe RT, Roy RR, Edgerton VR, Lecker SH, and Goldberg AL. Rapid disuse and denervation atrophy involve transcriptional changes similar to those of muscle wasting during systemic diseases. Faseb J 21: 140-155, 2007.

88. Sacheck JM, Ohtsuka A, McLary SC, and Goldberg AL. IGF-I stimulates muscle growth by suppressing protein breakdown and expression of atrophy-related ubiquitin ligases, atrogin-1 and MuRF1. Am J Physiol Endocrinol Metab 287: E591-601, 2004.

89. Sakamaki J, Daitoku H, Kaneko Y, Hagiwara A, Ueno K, and Fukamizu A. GSK3beta regulates gluconeogenic gene expression through HNF4alpha and FOXO1. J Recept Signal Transduct Res 32: 96$101,2012$.

90. Sandau US and Handa RJ. Glucocorticoids exacerbate hypoxia-induced expression of the proapoptotic gene Bnip3 in the developing cortex. Neuroscience 144: 482-494, 2007.

91. Sandri M. Autophagy in health and disease. 3. Involvement of autophagy in muscle atrophy. Am J Physiol Cell Physiol 298: C1291-1297, 2010.

92. Sandri M. Signaling in muscle atrophy and hypertrophy. Physiology (Bethesda) 23: 160-170, 2008.

93. Sandri M, Sandri C, Gilbert A, Skurk C, Calabria E, Picard A, Walsh K, Schiaffino S, Lecker SH, and Goldberg AL. Foxo transcription factors induce the atrophy-related ubiquitin ligase atrogin-1 and cause skeletal muscle atrophy. Cell 117: 399-412, 2004.

94. Schakman O, Gilson H, and Thissen JP. Mechanisms of glucocorticoid-induced myopathy. J Endocrinol 197: 1-10, 2008.

95. Schakman O, Kalista S, Bertrand L, Lause P, Verniers J, Ketelslegers JM, and Thissen JP. Role of Akt/GSK-3 beta\}/\{beta\}-catenin transduction pathway in the muscle anti-atrophy action of Insulin-like growth factor (IGF)-I in glucocorticoid-treated rats. Endocrinology, 2008.

96. Shah OJ, Kimball SR, and Jefferson LS. Acute attenuation of translation initiation and protein synthesis by glucocorticoids in skeletal muscle. Am J Physiol Endocrinol Metab 278: E76-82, 2000.

97. Shah OJ, Kimball SR, and Jefferson LS. Glucocorticoids abate p70(S6k) and elF4E function in L6 skeletal myoblasts. Am J Physiol Endocrinol Metab 279: E74-82, 2000.

98. Shimizu N, Yoshikawa N, Ito N, Maruyama T, Suzuki Y, Takeda S, Nakae J, Tagata Y, Nishitani S, Takehana K, Sano M, Fukuda K, Suematsu M, Morimoto C, and Tanaka H. Crosstalk between glucocorticoid receptor and nutritional sensor mTOR in skeletal muscle. Cell Metab 13: 170-182, 2011.

99. Silverman MN, Mukhopadhyay P, Belyavskaya E, Tonelli LH, Revenis BD, Doran JH, Ballard BE, Tam J, Pacher P, and Sternberg EM. Glucocorticoid receptor dimerization is required for proper recovery of LPS-induced inflammation, sickness behavior and metabolism in mice. Mol Psychiatry, 2012.

100. Simoncini T, Hafezi-Moghadam A, Brazil DP, Ley K, Chin WW, and Liao JK. Interaction of oestrogen receptor with the regulatory subunit of phosphatidylinositol-3-OH kinase. Nature 407: 538-541, 2000.

101. Smith IJ, Alamdari N, O'Neal P, Gonnella P, Aversa Z, and Hasselgren PO. Sepsis increases the expression and activity of the transcription factor Forkhead Box O 1 (FOXO1) in skeletal muscle by a glucocorticoid-dependent mechanism. Int J Biochem Cell Biol 42: 701-711, 2010.

102. Solomon V, Baracos V, Sarraf P, and Goldberg AL. Rates of ubiquitin conjugation increase when muscles atrophy, largely through activation of the $\mathrm{N}$-end rule pathway. Proc Natl Acad Sci U S A 95 : 12602-12607, 1998.

103. Solomon V, Lecker SH, and Goldberg AL. The N-end rule pathway catalyzes a major fraction of the protein degradation in skeletal muscle. J Biol Chem 273: 25216-25222, 1998.

104. Song IH and Buttgereit F. Non-genomic glucocorticoid effects to provide the basis for new drug developments. Mol Cell Endocrinol 246: 142-146, 2006.

105. Stitt TN, Drujan D, Clarke BA, Panaro F, Timofeyva Y, Kline WO, Gonzalez M, Yancopoulos GD, and Glass DJ. The IGF-1/PI3K/Akt pathway prevents expression of muscle atrophy-induced ubiquitin ligases by inhibiting FOXO transcription factors. Mol Cell 14: 395-403, 2004.

106. Sun $\mathrm{H}$ and Chen QM. Inhibitors of GSK-3 prevent corticosterone from inducing COX-1 expression in cardiomyocytes. Cardiovasc Toxicol 8: 93-100, 2008. 
107. Tang QQ, Gronborg M, Huang H, Kim JW, Otto TC, Pandey A, and Lane MD. Sequential phosphorylation of CCAAT enhancer-binding protein beta by MAPK and glycogen synthase kinase 3beta is required for adipogenesis. Proc Natl Acad Sci U S A 102: 9766-9771, 2005.

108. Tasaki T, Sriram SM, Park KS, and Kwon YT. The N-end rule pathway. Annu Rev Biochem 81: 261-289, 2012.

109. Ueki K, Fruman DA, Brachmann SM, Tseng YH, Cantley LC, and Kahn CR. Molecular balance between the regulatory and catalytic subunits of phosphoinositide 3-kinase regulates cell signaling and survival. Mol Cell Biol 22: 965-977, 2002.

110. Vandesompele J, De Preter K, Pattyn F, Poppe B, Van Roy N, De Paepe A, and Speleman F. Accurate normalization of real-time quantitative RT-PCR data by geometric averaging of multiple internal control genes. Genome Biol 3: RESEARCH0034, 2002.

111. Verhees KJ, Pansters NA, Schols AM, and Langen RC. Regulation of Skeletal Muscle Plasticity by Glycogen Synthase Kinase-3beta: A Potential Target for the Treatment of Muscle Wasting. Curr Pharm Des 19 (18): 3276-98, 2013.

112. Verhees KJ, Schols AM, Kelders MC, Op den Kamp CM, van der Velden JL, and Langen RC. Glycogen synthase kinase-3beta is required for the induction of skeletal muscle atrophy. Am J Physiol Cell Physiol 301: C995-C1007, 2011.

113. Waddell DS, Baehr LM, van den Brandt J, Johnsen SA, Reichardt HM, Furlow JD, and Bodine SC. The glucocorticoid receptor and FOXO1 synergistically activate the skeletal muscle atrophy-associated MuRF1 gene. Am J Physiol Endocrinol Metab 295: E785-797, 2008.

114. Wang H, Kubica N, Ellisen LW, Jefferson LS, and Kimball SR. Dexamethasone represses signaling through the mammalian target of rapamycin in muscle cells by enhancing expression of REDD1. J Biol Chem 281: 39128-39134, 2006.

115. Wang X, Hu J, and Price SR. Inhibition of PI3-kinase signaling by glucocorticoids results in increased branched-chain amino acid degradation in renal epithelial cells. Am J Physiol Cell Physiol 292: C18741879, 2007.

116. Watson ML, Baehr LM, Reichardt HM, Tuckermann JP, Bodine SC, and Furlow JD. A Cell Autonomous Role for the Glucocorticoid Receptor in Skeletal Muscle Atrophy Induced by Systemic Glucocorticoid Exposure. Am J Physiol Endocrinol Metab, 2012.

117. Welle S, Burgess K, and Mehta S. Stimulation of skeletal muscle myofibrillar protein synthesis, p70 S6 kinase phosphorylation, and ribosomal protein $\mathrm{S} 6$ phosphorylation by inhibition of myostatin in mature mice. Am J Physiol Endocrinol Metab 296: E567-572, 2009.

118. Welsh GI, Miller CM, Loughlin AJ, Price NT, and Proud CG. Regulation of eukaryotic initiation factor elF2B: glycogen synthase kinase-3 phosphorylates a conserved serine which undergoes dephosphorylation in response to insulin. FEBS Lett 421: 125-130, 1998.

119. Wing SS and Goldberg AL. Glucocorticoids activate the ATP-ubiquitin-dependent proteolytic system in skeletal muscle during fasting. Am J Physiol 264: E668-676, 1993.

120. Wray CJ, Mammen JM, Hershko DD, and Hasselgren PO. Sepsis upregulates the gene expression of multiple ubiquitin ligases in skeletal muscle. Int J Biochem Cell Biol 35: 698-705, 2003.

121. Wu Y, Zhao W, Zhao J, Zhang Y, Qin W, Pan J, Bauman WA, Blitzer RD, and Cardozo C. REDD1 is a major target of testosterone action in preventing dexamethasone-induced muscle loss. Endocrinology 151: 1050-1059, 2010.

122. Wust RC and Degens $\mathrm{H}$. Factors contributing to muscle wasting and dysfunction in COPD patients. Int J Chron Obstruct Pulmon Dis 2: 289-300, 2007.

123. Xia X, Kar R, Gluhak-Heinrich J, Yao W, Lane NE, Bonewald LF, Biswas SK, Lo WK, and Jiang JX. Glucocorticoid-induced autophagy in osteocytes. J Bone Miner Res 25: 2479-2488, 2010.

124. Yaffe D and Saxel O. A myogenic cell line with altered serum requirements for differentiation. Differentiation 7: 159-166, 1977.

125. Yang H, Menconi MJ, Wei W, Petkova V, and Hasselgren PO. Dexamethasone upregulates the expression of the nuclear cofactor p300 and its interaction with C/EBPbeta in cultured myotubes. $J$ Cell Biochem 94: 1058-1067, 2005.

126. Yang $\mathrm{H}$, Wei W, Menconi $\mathrm{M}$, and Hasselgren PO. Dexamethasone-induced protein degradation in cultured myotubes is p300/HAT dependent. Am J Physiol Regul Integr Comp Physiol 292: R337-334, 2007. 
127. Zhang J, Tsai FT, and Geller DS. Differential interaction of RU486 with the progesterone and glucocorticoid receptors. J Mol Endocrinol 37: 163-173, 2006.

128. Zhao J, Brault JJ, Schild A, Cao P, Sandri M, Schiaffino S, Lecker SH, and Goldberg AL. FoxO3 coordinately activates protein degradation by the autophagic/lysosomal and proteasomal pathways in atrophying muscle cells. Cell Metab 6: 472-483, 2007.

129. Zhao W, Qin W, Pan J, Wu Y, Bauman WA, and Cardozo C. Dependence of dexamethasone-induced Akt/FOXO1 signaling, upregulation of MAFbx, and protein catabolism upon the glucocorticoid receptor. Biochem Biophys Res Commun 378: 668-672, 2009.

130. Zhou W, Chen L, Yang S, Li F, and Li X. Behavioral stress-induced activation of FoxO3a in the cerebral cortex of mice. Biol Psychiatry 71: 583-592, 2012. 
Chapter 5 


\title{
Chapter 6
}

\author{
GLYCOGEN SYNTHASE KINASE-3 INHIBITION \\ PREVENTS SKELETAL MUSCLE ATROPHY IN AN \\ ANIMAL MODEL OF PULMONARY INFLAMMATION
}

Koen JP Verhees, Hoeke A Baarsma, Nicholas AM Pansters, Alexander HV Remels, Annemie MWJ Schols, Reinoud Gosens, and Ramon CJ Langen

submitted 


\section{Abstract}

Pulmonary inflammation in acute and chronic disease is often accompanied by skeletal muscle atrophy. Glycogen synthase kinase-3 (GSK-3) has been implicated in the regulation of muscle protein turnover and myonuclear turnover; two crucial processes that determine skeletal muscle mass. In the present study, we investigated the effect of the selective GSK-3 inhibitor SB216763 on muscle mass and regulatory markers in a guinea pig model of lipopolysaccharide (LPS)-induced pulmonary inflammation. The guinea pigs were pretreated with either intranasally instilled SB216763 or corresponding vehicle 30 minutes prior to each LPS/saline challenge twice weekly. Pulmonary inflammation and indices of muscle mass were determined after 12 weeks. Repeated LPS instillation induced pulmonary inflammation, which was not affected by GSK-3 inhibition using SB216763. Intriguingly, GSK-3 inhibition prevented the LPS-induced loss of skeletal muscle mass and myofiber atrophy. Furthermore, indices of protein synthesis and degradation signaling were not altered in guinea pig muscle homogenates. Additionally, cultured mouse skeletal muscle cells were incubated with tumor necrosis factor- $\alpha$ (TNF- $\alpha$ ) or glucocorticoids (GCS) to model putative triggers of muscle atrophy induced by pulmonary inflammation, in the presence or absence of GSK-3 inhibitors to assess the effects on myogenesis. Interestingly, inhibition of myogenesis of cultured muscle cells by TNF- $\alpha$ or synthetic GCs was completely prevented in the presence of GSK-3 inhibitors. In conclusion, in an animal model of LPS-induced pulmonary inflammation, GSK-3 inhibition prevents skeletal muscle atrophy without affecting pulmonary inflammation. Resistance to inflammation -or GC-induced impairment of myogenic differentiation, imposed by GSK-3 inhibition, suggests that sustained myogenesis contributes to maintenance of muscle mass despite persistent pulmonary inflammation. Collectively, these results indicate that inhibition of GSK-3 may be a novel therapeutic strategy to prevent or reverse muscle wasting in chronic inflammatory disease. 


\section{Introduction}

Skeletal muscle atrophy is a common and disabling feature of several chronic degenerative and inflammatory diseases characterized by an acute or persistent chronic inflammatory response (63). Pulmonary inflammation has been suggested as a trigger and perpetuating factor of muscle wasting in COPD. Skeletal muscle atrophy may be the consequence of a disturbed balance between protein synthesis and degradation in favor of the latter; due to either accelerated breakdown of muscle proteins, or reduced protein synthesis $(20,21,44)$. Insulin-like growth factor 1 (IGF-I) and insulin are both anabolic factors that affect cellular protein turnover via a wellcharacterized signaling conduit that includes phosphorylation of phosphatidylinositol3 kinase (PI-3K), resulting in the activation of Akt/PKB (hereinafter termed Akt) (21). Phosphorylated Akt can, in turn, stimulate protein synthesis by activating mammalian target of rapamycin complex 1 (mTORC1) signaling, characterized by phosphorylation of its downstream substrates elF4E-binding protein 1 (4E-BP1) and p70S6 kinase (p70S6K) (21). Conversely, Akt activation results in the phosphorylation and subsequent cytoplasmic retention of the Forkhead box $O$ (FoXO) class of transcription factors, which have been implicated in the coordination of proteolytic gene expression $(65,71,82)$.

In addition to protein turnover, myonuclear turnover, i.e. the balance between myonuclear loss and myonuclear accretion, may constitute an additional cellular mechanism determining muscle mass (23). Efficient regeneration and restoration of muscle mass following injury or recovery from atrophy requires activation, proliferation and subsequent differentiation of satellite cells into myoblasts that fuse with existing or form new myofibers $(30,51)$. Besides myoblast fusion, myogenic differentiation is characterized by increased transcriptional activity of muscle regulatory factors (MRFs) (e.g. MyoD, myogenin), which promote the expression of muscle-specific genes, including contractile/sarcomeric proteins such as troponin I (Tnl), myosin light chain (MyLC) and myosin heavy chain (MyHC), and enzymes involved in muscle energy metabolism (e.g. muscle creatine kinase (MCK)) (52).

Systemic inflammation in chronic disease manifests itself as increased activation of circulating inflammatory cells and elevated levels of tumor necrosis factor- $\alpha$ (TNF- $\alpha$ ) or interleukin-16 (IL-1 $\beta$ ), as well as increased serum concentrations of acute phase proteins such as C-reactive protein (CRP) $(8,18,66)$, which may directly or indirectly contribute to skeletal muscle atrophy $(1,40)$. In a mouse model of pulmonary inflammation, we recently demonstrated that muscle nuclear factor- $\mathrm{K} B$ (NF-kB) activation was required for the transition from inflammatory- to muscle atrophy signaling (39), suggesting that systemic inflammation contributes to the loss of skeletal muscle mass following acute pulmonary inflammation. Furthermore, the release of glucocorticoids (GCS) as an endogenous response to inflammation, or treatment with synthetic GCs, as a common intervention during acute or endstage chronic respiratory 
disease, may also evoke or aggravate muscle wasting as GCs are potent inducers of muscle atrophy $(3,9,84,86)$.

Currently, pharmacological treatment approaches of muscle atrophy in chronic respiratory diseases are limited $(32,49,62)$. Therapeutic interventions should aim at suppression of triggers of muscle atrophy, e.g. pulmonary inflammation, or at direct modulation of the signaling pathways that regulate muscle mass. Glycogen synthase kinase-3 (GSK-3) is a ubiquitously expressed serine/threonine kinase, occurring in two closely related isoforms, namely GSK-3 $\alpha$ and GSK-3 $\beta$, which share extensive homology in their kinase domains $(61,87,88)$. GSK-3 $\beta$ is a signaling protein directly downstream of Akt, which plays an important role in a myriad of cellular processes, including inflammatory signaling $(10,31)$ and protein synthesis $(85)$, through regulation of mRNA translation initiation via suppression of eukaryotic initiation factor $2 B$ (elF2B) activity. Recent data from our group and others suggest a pivotal role for GSK-3 $\beta$ in the determination of muscle mass, as it is involved in both protein and myonuclear turnover. Concretely, it was established that muscle atrophy, resulting from increased proteolysis signaling following synthetic GC-reatment, requires GSK-3 $\beta$ (80). In another study by our group physiological and pharmacological GSK-3 inhibition enhanced myoblast fusion and myotube formation, in support of an important role of GSK-3 in the regulation of myonuclear turnover (54).

Considering the significance of GSK-3 in the cellular processes controlling inflammatory signaling and muscle mass, the purpose of this study was to assess the potential therapeutic effects of enzymatic GSK-3 inhibition on muscle wasting in an established model of lipopolysaccharide (LPS)-induced pulmonary inflammation, using the selective inhibitor 3-(2,4-dichlorophenyl)-4-(1-methyl-1H-indol-3-yl)-1H-pyrrole2,5-dione (SB216763) (26). The data presented in this study demonstrate that topical application of a GSK-3 inhibitor does not affect pulmonary inflammation, but reduces skeletal muscle atrophy. Subsequent cell culture experiments suggested this may involve maintenance of myogenesis, as GSK-3 inhibition restored muscle differentiation in the presence of effectors of systemic inflammation. Collectively, these current findings indicate that GSK-3 may constitute a novel therapeutic target in the treatment of skeletal muscle atrophy in chronic inflammatory disease.

\section{Materials and Methods}

\section{Animal studies}

Male, outbred specified pathogen-free Dunkin Hartley guinea pigs (Harlan, Heathfield, UK) were used in this study. All protocols described in this manuscript were approved by the University of Groningen Committee for Animal Experimentation. 


\section{Experimental protocol}

Thirty-six guinea pigs were randomly assigned to four experimental groups $(n=9)$, namely: (1) vehicle-treated, saline-challenged; (2) SB216763-treated salinechallenged; (3) vehicle-treated, LPS-challenged, and (4) SB216763-treated, LPS-challenged. The guinea pigs were treated twice per week for 12 consecutive weeks by intranasal instillation of $100 \mu \mathrm{l} \mathrm{SB216763} \mathrm{[2} \mathrm{mM} \mathrm{in} \mathrm{10 \%} \mathrm{(v/v)} \mathrm{DMSO} \mathrm{in} \mathrm{sterile}$ saline] or vehicle [100 $\mu \mathrm{l} 10 \%$ (v/v) DMSO in sterile saline]. After the intranasally instilled solution was aspirated, the animals were kept in an upright position for an additional 2 minutes ( $\mathrm{min}$ ), to allow sufficient spreading of the fluid throughout the lungs. The animals were intranasally instilled with $100 \mu \mathrm{l}$ LPS $[10 \mathrm{mg} / \mathrm{ml}$ in sterile saline] or sterile saline, 30 min post SB216763 or vehicle instillation.

SB216763 is a selective GSK-3 inhibitor (3-(2,4-dichlorophenyl)-4-(1-methyl-1Hindol-3-yl)-1H-pyrrole-2,5-dione) (Tocris Cookson, Bristol, UK) and the LPS was derived from Escherichia coli, serotype 055:B5 (Sigma-Aldrich, MO, USA). Twenty-four hours after the last instillation, the guinea pigs were sacrificed by experimental concussion, followed by rapid exsanguination. Next, the heart, lungs and a series of hind limb muscles including the $M$. gastrocnemius, M. tibialis anterior, M. plantaris and $M$. extensor digitorum longus (EDL) were collected using standardized dissection methods. Independent muscle weights of a single hind limb were measured and all tissues were immediately flash-frozen in liquid nitrogen.

\section{Tissue processing and histological analyses}

The left lung lobe was inflated and fixed with formalin at a constant pressure of $25 \mathrm{~cm} \mathrm{H} \mathrm{H}_{2} \mathrm{O}$ for $24 \mathrm{~h}$. The formalin fixed lungs were embedded in paraffin and subsequently cut in tissue sections $(4 \mu \mathrm{m})$. The granulocytes were identified by staining the sections with diaminobenzidine (DAB) $[0.3 \mathrm{mg} / \mathrm{ml}]$. The inflammatory cells present within a $50 \mu \mathrm{m}$ distance from the airway lumen were quantified and expressed relative to basement membrane length. The airway sections were digitally photographed and all analyses were done in a blinded manner. The EDL muscles were embedded in Tissue-Tek (Sakura Finetek, the Netherlands) and sectioned on a Leica $\mathrm{CM} 3050 \mathrm{~S}$ cryostat at $-20^{\circ} \mathrm{C}$. Subsequently, serial cross-sections $(5 \mu \mathrm{m})$ were stained with the following primary antibodies: anti-Type I MyHC (\#A-4840) (Developmental Studies Hybridoma Bank, lowa City, IA, USA), and anti-laminin (\#L-9393) (SigmaAldrich) to determine the fiber cross-sectional area (CSA) and fiber type distribution. The sections were incubated with the following secondary antibodies: Alexa Fluor 555 (\#A-21426) and Alexa Fluor 350 (\#A-21426) (both from Invitrogen, CA, USA). Digital images of the stained sections were taken under 200X total magnification using an Eclipse E800 microscope (Nikon, Japan) connected to a digital camera (DXM, 1200 NF, Nikon, Japan). The CSA was measured after having identified five non-overlapping 
regions containing a total of 100 - 200 individual fibers per animal, which were then analyzed using Lucia software (version 4.81).

\section{Cell culture}

The murine skeletal muscle cell line $C_{2} C_{12}$ (ATCC \# CRL1772, Manassas, VA, USA) was cultured in growth medium (GM), composed of low glucose [1 g/l] Dulbecco's Modified Eagle Medium (DMEM) containing antibiotics $[50 \mathrm{U} / \mathrm{ml}$ Penicillin and 50 $\mu \mathrm{g} / \mathrm{ml}$ Streptomycin] and 9\% (v/v) Fetal Bovine Serum (FBS) (all from Gibco, MD, USA). The $C_{2} C_{12}$ cells were plated overnight in $\mathrm{GM}$ at $10^{4} / \mathrm{cm}^{2}$ on $\mathrm{BD}$ Matrigel coated [1:50 in DMEM low glucose] $35 \mathrm{~mm}$ dishes as described previously (both from BD Biosciences, MA, USA) (41). Differentiation was induced by growth factor withdrawal (90), replacing GM with differentiation medium (DM) [DMEM, low glucose, with $1 \%$ heat-inactivated FBS and antibiotics]. The synthetic GC dexamethasone (hereinafter referred to as Dex) (Sigma-Aldrich), TNF- $\alpha$ (Calbiochem, CA, USA), with or without LiCl (Sigma-Aldrich) or CHIR99021 [5 $\mu \mathrm{M}$ ] (kindly provided by Dr. Cohen, MRC Protein Phosphorylation Unit, University of Dundee, UK) were directly added to the culture medium upon the induction of differentiation and again $24 \mathrm{~h}$ later when the cells were provided with fresh DM. The myocytes were allowed to differentiate for a total of $72 \mathrm{~h}$, in absence or presence of Dex [10 $\mu \mathrm{M}]$ or TNF- $\alpha[1 \mathrm{ng} / \mathrm{ml}]$.

\section{Stable cell line and luciferase activity determination}

Measurements of troponin I (Tnl) promoter activity during differentiation were performed by creating a stable $\mathrm{C}_{2} \mathrm{C}_{12}$ cell line carrying a genomic $\mathrm{Tnl}$ promoterluciferase reporter gene as described previously (43). To determine the luciferase activity, the cells were washed twice in ice-cold $1 \mathrm{X}$ PBS, lysed in $1 \mathrm{X}$ reporter lysis buffer (Promega, Madison, WI, USA) and stored at $-80^{\circ} \mathrm{C}$. The lysates were spun at $14000 \mathrm{rpm}\left(4^{\circ} \mathrm{C}\right)$ prior to analysis, and the soluble fraction was used to measure the luciferase activity according to the manufacturer's instructions (Promega). The total protein concentration was assessed using a Bio-Rad protein assay kit (Bio-Rad, CA, USA) according to the manufacturer's instructions. All data were corrected for total protein content.

\section{Nuclei count and myogenic index}

The total number of nuclei (100X magnification) in 4 or more fields was counted to determine the amount of nuclei present after $72 \mathrm{~h}$ of differentiation. The myonuclear distribution was assessed by counting all nuclei within four linked images (100X magnification). The nuclei were assigned to one of three classes: (1) single nucleated myoblasts; (2) dividing or fusing bi-nucleated myoblasts, and (3) multi-nucleated (> 2 nuclei) myotubes. Per condition, 1900 or more nuclei were counted and assigned to either of the above-mentioned classes. 


\section{Muscle Creatine Kinase activity}

Myogenic differentiation was assessed biochemically by measuring muscle creatine kinase (MCK) activity. After the induction of differentiation, the $C_{2} C_{12}$ cells were washed twice in ice-cold 1 X PBS, subsequently lysed in $0.5 \%$ Triton X-100, and scraped from the dish with a cell scraper (rubber policeman). The lysates were centrifuged for $2 \mathrm{~min}$ at $14000 \mathrm{rpm}\left(4^{\circ} \mathrm{C}\right)$, and the supernatant was aliquoted and stored at $-80^{\circ} \mathrm{C}$ to determine the protein content or MCK activity in the presence of $1.25 \%$ BSA. The MCK-activity was measured spectrophotometrically (Stanbio Laboratory, TX, USA) (72). The specific activity was calculated after correction for total protein content (7).

\section{May-Grünwald Giemsa Staining}

The $C_{2} C_{12}$ cells were induced to differentiate for $72 \mathrm{~h}$ either in the presence or absence of Dex or TNF- $\alpha$. After $72 \mathrm{~h}$ of differentiation the cells were washed twice in $1 \mathrm{X}$ PBS at room temperature (RT), subsequently fixed in methanol and stained in MayGrünwald Giemsa (Sigma-Aldrich) according to the manufacturer's instructions. Pictures were taken at $40 \mathrm{X}$ and $100 \mathrm{X}$ magnifications using an inverted light microscope (Eclipse E800, Nikon, Japan) connected to a digital camera (DXM, $1200 \mathrm{NF}$, Nikon, Japan). The $100 \mathrm{X}$ magnified images were taken in series of four with a fixed overlap.

\section{Western blotting}

The muscle tissue was homogenized in ice-cold $1 \mathrm{X}$ whole cell lysate buffer (WCL) [50 mM Tris- $\mathrm{HCl}, \mathrm{pH} 7.4 ; 150 \mathrm{mM} \mathrm{NaCl} ; 1 \mathrm{mM}$ EDTA; $1 \mathrm{mM} \mathrm{Na}_{3} \mathrm{VO}_{4} ; 5 \mathrm{mM} \mathrm{NaF}$; 10\% glycerol; 0.5\% Nonidet P-40; $1 \mathrm{mM}$ DTT; $1 \mathrm{mM}$ PMSF; $10 \mu \mathrm{g} / \mathrm{ml}$ Leupeptin; $1 \%$ Aprotinin; $10 \mathrm{mM} \beta$-glycerophosphate and $1 \mathrm{mM} \mathrm{Na-pyro-} \mathrm{PO}_{4}$ ] using a rotating blade tissue homogenizer (Polytron PT 1600E, Kinematica, Switzerland). The $C_{2} C_{12}$ cells were washed twice in ice-cold $1 X$ PBS after which they were lysed in $1 \mathrm{X}$ reporter lysis buffer and scraped of the dish using cell scrapers. The total protein concentration was assessed by the Thermo Scientific Pierce BCA Protein Assay kit (Pierce Biotechnology, IL, USA) according to the manufacturer's instructions. The protein lysates were boiled for $5 \mathrm{~min}$ at $95^{\circ} \mathrm{C}$ after addition of $4 \mathrm{X}$ Laemmli sample buffer [0.25 M Tris- $\mathrm{HCl} \mathrm{pH} \mathrm{6.8;} \mathrm{8 \%} \mathrm{(w/v)} \mathrm{SDS;} \mathrm{40 \%} \mathrm{(v/v)} \mathrm{glycerol;} 0.4 \mathrm{M}$ DTT and 0.04\% (w/v) Bromophenol Blue]. For SDS-PAGE 1 - $25 \mu \mathrm{g}$ of protein was loaded per lane and separated on a Criterion XT Precast 4 - 12\% Bis-Tris gel (Bio-Rad), followed by transfer to a $0.45 \mu \mathrm{m}$ Whatman Protran Nitrocellulose Transfer membrane (Whatman $\mathrm{GmbH}$, Germany) by electroblotting (Bio-Rad Criterion Blotter). The nitrocellulose blots were incubated overnight $\left(4^{\circ} \mathrm{C}\right)$ with specific antibodies directed against: myosin light chains 1 (MyLC-1) and -3 (MyLC-3) (\#F310) (Developmental Studies Hybridoma Bank, lowa City, IA, USA), myosin heavy chain fast (MyHC-f) (\#M4276) (Sigma-Aldrich), p-elF2BE (Ser ${ }^{539}$ ) (\#44-530G) (Invitrogen), p-mTOR (Ser ${ }^{2448}$ ) (\#2971), mTOR (\#2983), 
p-Akt $\left(\operatorname{Ser}^{473}\right)$ (\#9271), Akt (\#9272), p-GSK-3ß (Ser $\left.{ }^{9}\right)$ (\#9336), GSK-3ß (\#9332), p-p70S6K $\left(\mathrm{Thr}^{389}\right.$ ) (\#9206), p70S6K (\#2708), p-4E-BP1 (Thr ${ }^{37 / 46}$ ) (\#9459), 4E-BP1 (\#9452), p-S6 $\left(\mathrm{Ser}^{235 / 236}\right)$ (\#2211), p-FoXO1 (Ser $\left.{ }^{256}\right)$ (\#9461), FoXO1 (\#2880), p-FoXO3a $\left(\mathrm{Ser}^{253}\right)$ (\#9466), FoXO3a (\#2497) and GAPDH (\#2118) (all from Cell Signaling Technology), diluted in $1 \mathrm{X}$ TBS/0.1\% Tween-20. The blots were probed with a peroxidase conjugated secondary antibody (\#PI-1000) (Vector Laboratories, CA, USA), and visualized using Supersignal WestPico Chemiluminescent Substrate (Pierce Biotechnology) according to the manufacturer's instructions and exposed to Super RX film (FUJIFILM, Japan). The Western blot films were digitalized using a Bio-Rad GS-800 Densitometer and subsequent quantification was done using Quantity One software (version 4.5.0) (both from Bio-Rad).

\section{Statistical analysis}

The raw data were entered into SPSS (version 20.0) for statistical analysis. All values are represented as means and error bars indicate the standard error of the mean (SEM). Comparisons of mean values were tested parametrically, using a oneway ANOVA followed by a post hoc Fischer's LSD test. The changes in body weight were tested using a mix-model design ANOVA. Mean value comparisons of in vitro data were tested non-parametrically, using the Mann-Whitney U-test. A two-tailed probability value $(p<0.05)$ between groups was considered statistically significant.

\section{Results}

\section{GSK-3 inhibition does not affect pulmonary inflammation}

Repeated LPS challenges induced an increase in peribronchial inflammation, which was characterized by increased infiltration of granulocytes. The inflammation was most profound in the non-cartilaginous airways. Treatment with SB216763 did not affect the presence of inflammatory cells in and surrounding the airway wall in salinechallenged animals, and had no effect on the peribronchial inflammation seen after LPS instillation (Figure 6.1). 

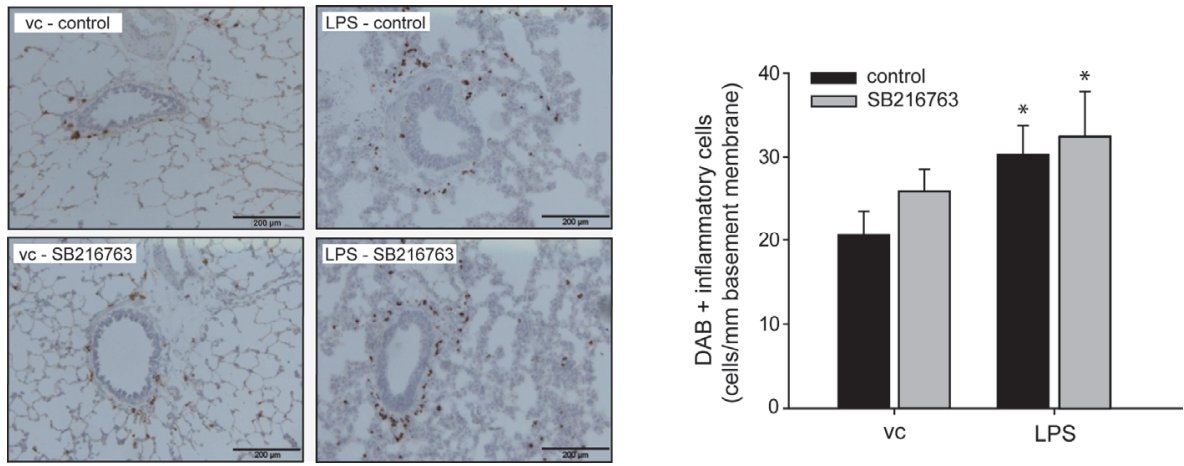

Figure 6.1 LPS-induced pulmonary inflammation is not influenced by enzymatic GSK-3 inhibition. Repeated LPS challenges induced an increase in peribronchial inflammation, characterized by increased infiltration of granulocytes. Granulocytes were identified by staining the sections with diaminobenzidine (DAB). The inflammation was most profound in the non-cartilaginous airways.

\section{Enzymatic GSK-3 inhibition protects against LPS-induced skeletal muscle fiber atrophy}

Throughout the experimental procedures, neither LPS nor the concomitant administration of LPS and SB216763 significantly affected the increase in body weight of the guinea pigs (Figure 6.2A). However, from week 4 onwards the increase in body mass of the SB216763-treated saline-challenged group was significantly lower compared with the vehicle-treated, saline-challenged group ( $p=0.03$ ) (Figure 6.2A). Repeated LPS administration consistently appeared to decrease muscle wet weights (M. plantaris: $-2 \%$, M. gastrocnemius: $-8 \%$, M. tibialis: $-5 \%$, M. EDL: $-7 \%$ ), although this did not reach statistical significance (Figure 2B). Intriguingly, SB216763-treatment significantly reversed the LPS-induced reduction in these skeletal muscle weights (except for M. EDL). To verify the effects on muscle mass, the myofiber CSA of the EDL muscle was determined. The glycolytic EDL muscle predominantly consisted of Type II fibers (96.4\%, data not shown), and immunohistochemical staining revealed that chronic LPS administration significantly decreased the mean Type II fiber CSA compared with vehicle control-treated muscle (Figure 6.2C). The decline in Type II fiber CSA following LPS was further substantiated by examining the fiber size distribution curves, which revealed a leftward shift (smaller fibers) compared with the fiber distribution of vehicle-treated control animals (Figure 6.2D). Strikingly, pharmacological GSK-3 inhibition abrogated the reduction of mean Type II fiber CSA in response to LPS (Figure 6.2C and Figure 6.2D). Unexpectedly, basal enzymatic GSK-3 inhibition caused a significant decrease in mean Type II fiber CSA in EDL muscle of vehicle-treated animals (Figure 2D). Nevertheless, collectively these data indicate that muscle atrophy induced by chronic LPS challenge is prevented by GSK-3 inhibition despite sustained pulmonary inflammation. 
A

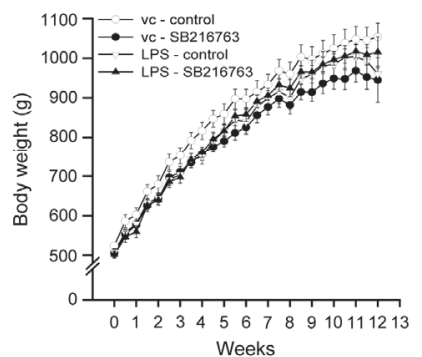

B
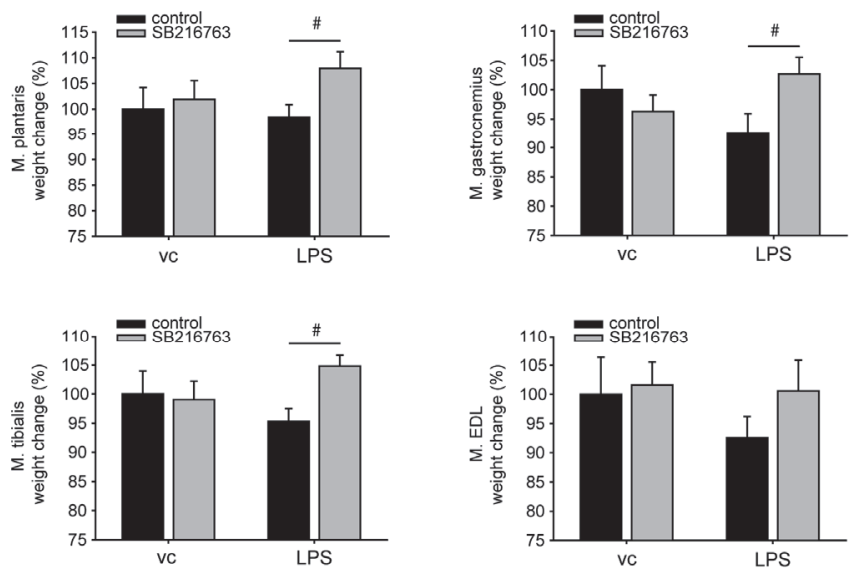

C
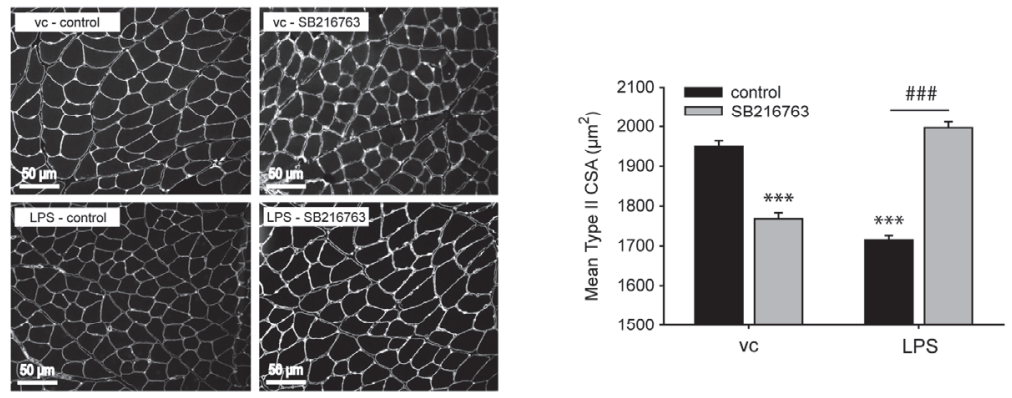

D
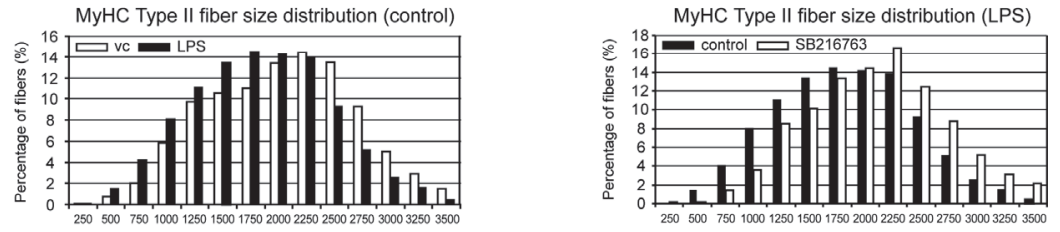

Fiber CSA $\left(\mu \mathrm{m}^{2}\right)$

Fiber CSA $\left(\mu \mathrm{m}^{2}\right)$ 
Figure 6.2 GSK-3 inhibition prevents skeletal muscle fiber atrophy following repeated LPS instillation.

(A) Body weight change of the guinea pigs during the experimental procedures. (B) Effects of repeated LPS exposure and GSK-3 inhibition (SB216763) on skeletal muscle wet weights. (C) The fiber cross-sectional area (CSA) of muscle fibers in the extensor digitorum longus (EDL) muscle of the guinea pigs was determined from laminin-stained cross-sections. Representative laminin-stained (white) cross-sections of the same region within the EDL muscle for each experimental group (20X magnification, scale bar $=50 \mu \mathrm{m}$ ). Histogram of quantitative analysis of the mean Type II cross-sectional area (CSA) ( $n=7$ per group). (D) Fiber size distribution curves of fiber cross-sectional areas of fibers in the EDL. All data shown represent means $\pm \mathrm{SEM}, \mathrm{n}=9$ animals per group. ${ }^{* * *} \mathrm{p}<0.001$ compared with the vc control group; \# $p<0.05$, \#\#\# $p<0.001$ refers to a difference between indicated conditions.

\section{Muscle protein synthesis and degradation signaling responses following chronic LPS-treatment and GSK-3 inhibition}

To address the potential contribution of altered protein synthesis signaling to the muscle atrophy phenotype, the protein levels and the phosphorylation state of mTOR and its downstream effectors p70S6K and 4E-BP1 as well as Akt, the upstream activator of mTOR were assessed. The p-Akt to Akt ratio in LPS control muscle was unchanged following a 12 week treatment regimen with intranasally instilled LPS. Likewise, the p-Akt levels in muscle exposed to SB216763 alone or in combination with LPS remained unaltered, comparable to vehicle/saline-treated controls (Figure 6.3A). Similarly, the phosphorylation state and abundance of GSK-3 $\beta$, a direct downstream substrate of Akt, was unaffected in any of the conditions. Chronic pharmacological GSK-3 inhibition by SB216763 in the lung did not result in detectable alterations in the phosphorylation state of the GSK-3 $\beta$ substrate elF2B $\varepsilon$ (Figure 6.3A).

Furthermore, the ratio of $p$-mTOR over total mTOR was unaffected in any of the conditions. The phosphorylation state of p70S6K, a downstream substrate of mTOR, was unaffected by LPS instillation or GSK-3 inhibition (Figure 6.3B). In contrast, phosphorylation of S6, a substrate of p70S6K, tended to be reduced upon LPS instillation, but these findings did not reach statistical significance (Figure 6.3B). Finally, repeated LPS administration or GSK-3 inhibition did not affect p-4E-BP1 or total 4E-BP1 protein abundance, as another downstream substrate of mTOR (Figure 6.3B). Both phosphorylated levels of FoXO1 as well as total FoXO1 protein abundance remained unaltered following either LPS -or SB216763-treatment (Figure 6.3C). In contrast, the p-FoXO3a to FoXO3a ratio was reduced in response to concomitant LPS and SB216763-treatment, which is indicative of increased FoXO3a activity (Figure 6.3C). Altogether, these data imply that gross alterations in skeletal muscle protein turnover signaling could not account for the muscle atrophy observed in response to chronic pulmonary inflammation, nor the prevention thereof by pharmacological GSK3 inhibition. 
A

$\stackrel{\text { vc }}{\text { control }} \stackrel{\text { LPS }}{ }$ SB

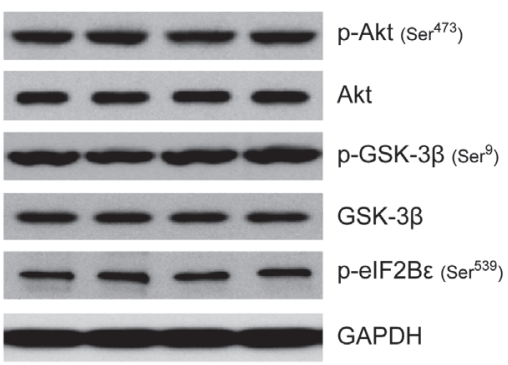

B
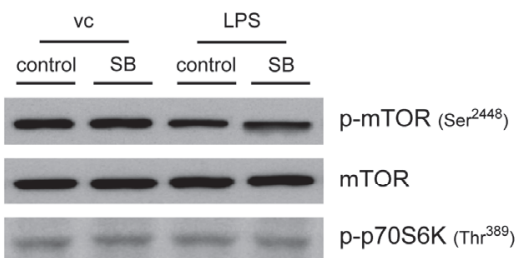

-20 p70S6K

$\longrightarrow \mathrm{p}-\mathrm{S} 6\left(\mathrm{Ser}^{235 / 236}\right)$

$\mathrm{p}-4 \mathrm{E}-\mathrm{BP} 1\left(\mathrm{Thr}^{37 / 46}\right)$

$=20-3 \mathrm{E}-\mathrm{BP} 1$

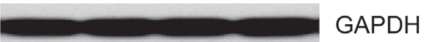

C

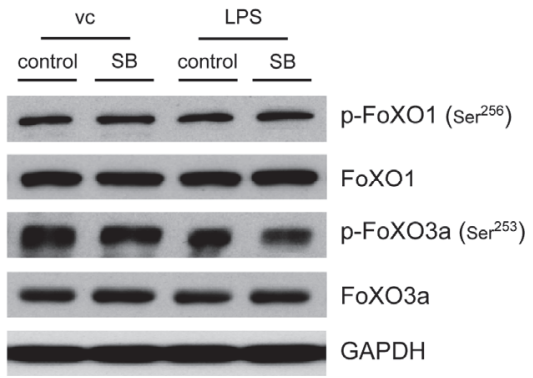

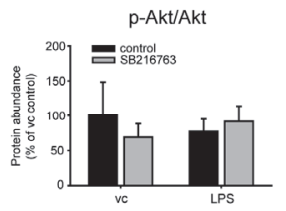
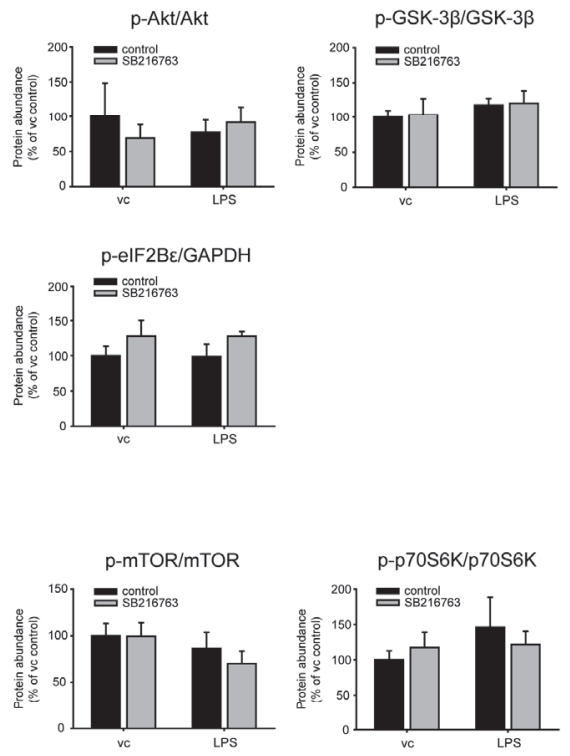

p-p70S6K/p70s6K
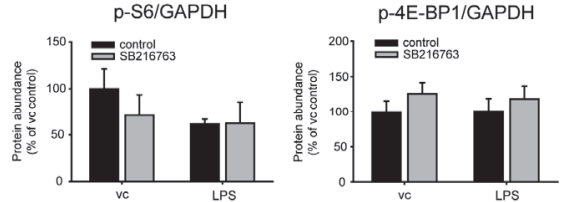

4E-BP1/GAPDH
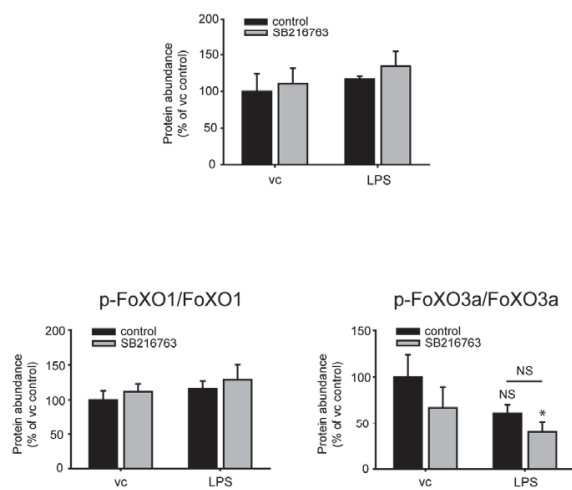
Figure 6.3 Effects of repeated LPS instillation and SB216763-treatment on muscle protein turnover signaling.

Representative immunoblots of protein synthesis and protein degradation-related signaling molecules measured in the extensor digitorum longus (EDL) muscles of guinea pigs that were treated intranasally with LPS or SB216763 for 12 weeks. (A) Protein levels of phospho-Akt

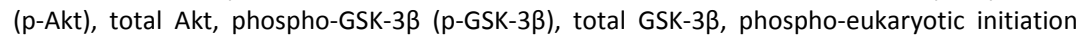
factor $2 \mathrm{~B} \varepsilon$ ( $p$-elF2B $\varepsilon$ ), GAPDH, (B) phospho-mammalian target of rapamycin ( $p$-mTOR), total mTOR, phospho-p70S6K (p-p70S6K), total p70S6K, phospho-S6 (p-S6), phospho-4E-BP1 (p-4E-BP1), total 4E-BP1, GAPDH, (C) phospho-FoXO1 (p-FoXO1), total FoXO1, phosphoFoXO3a (p-FoXO3a), total FoXO3a and GAPDH were determined in whole muscle homogenates by Western blot analysis. The accompanying bar graphs show the densitometric analysis results (means $\pm S E M, n=6$ ), represented as a $\%$ of the vc control group corrected for GAPDH. All data are shown as a ratio of phospho- to total protein for each target (except $\mathrm{p}$ elF2B $\varepsilon, p-S 6$ and (p-)4E-BP1). ${ }^{*} p<0.05$ compared with the vc control group. NS: not significant.

\section{GSK-3 inhibition prevents TNF- $\alpha$-induced impairment of myogenesis}

In addition to alterations in protein turnover, impaired myogenesis may lie at the basis of sustained muscle wasting $(55,60)$. Moreover, systemic inflammation resulting from pulmonary inflammation can trigger muscle atrophy (39), and inflammatory cytokines have been shown to contribute to muscle wasting through the inhibition of myogenic differentiation (41). To investigate whether pharmacological GSK-3 inhibition restores impaired myogenesis, differentiating $\mathrm{C}_{2} \mathrm{C}_{12}$ myoblasts were cultured in the presence or absence of $\mathrm{LiCl}$ and/or TNF- $\alpha$. $\mathrm{LiCl}$ is a direct and indirect inhibitor of GSK-3 and has been widely used to investigate the role of GSK-3 (33,69). TNF- $\alpha$ supplementation resulted in diminished myogenesis of $\mathrm{C}_{2} \mathrm{C}_{12}$ myocytes (Figure 6.4A). Subsequent quantification of myotube formation, by determining the myogenic index, clearly demonstrated that TNF- $\alpha$ reduced myoblast fusion (Figure 6.4B). Conversely, $\mathrm{LiCl}$ increased myotube formation, and importantly, markedly attenuated the TNF- $\alpha$ induced decrease in myotube formation (Figure 6.4B). Identical results were obtained with the structurally unrelated GSK-3 inhibitor CHIR99021 (data not shown). TNF- $\alpha$ significantly decreased the myofibrillar protein abundance, i.e. MyHC-f, MyLC-1 and MyLC-3, whereas LiCl stimulated their expression (Figure 6.4C). Notably, LiCl significantly abrogated the reduction in contractile protein expression in response to TNF- $\alpha$ (Figure 6.4C). In addition to reduced expression of sarcomeric/contractile proteins, TNF- $\alpha$ supplementation markedly decreased MCK activity. Conversely, enzymatic GSK-3 inhibition increased basal MCK activity and prevented the TNF- $\alpha$ induced decline in MCK activity (Figure 6.4D). The differentiation-induced transcriptional activation of the Tnl promoter was diminished in response to TNF- $\alpha$, and increased following GSK-3 inhibition (Figure 6.4E). In line with the other markers of myogenesis, LiCl-treatment significantly reversed the reduction in $\mathrm{Tnl}$ promoter transactivation in response to TNF- $\alpha$. 
A
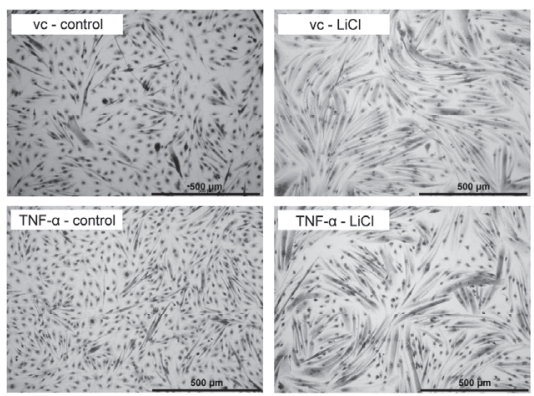

C
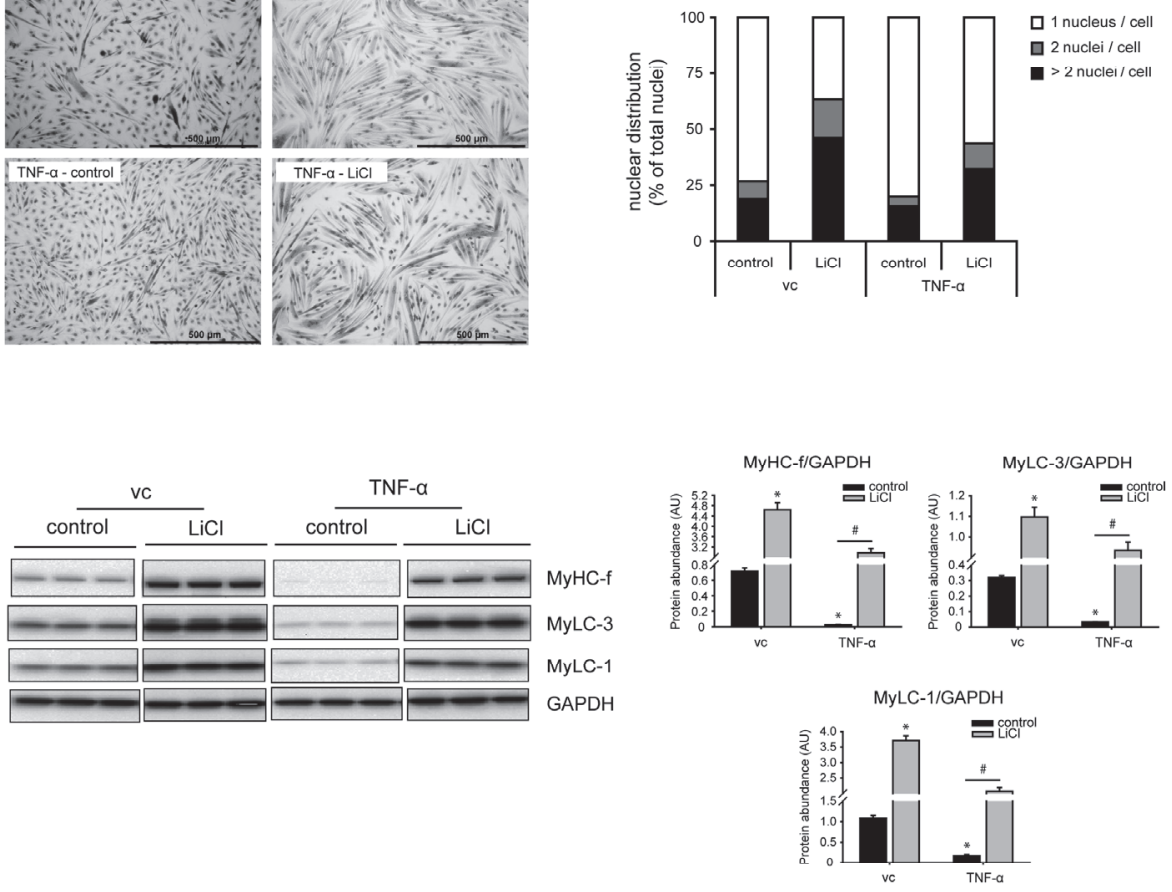

D

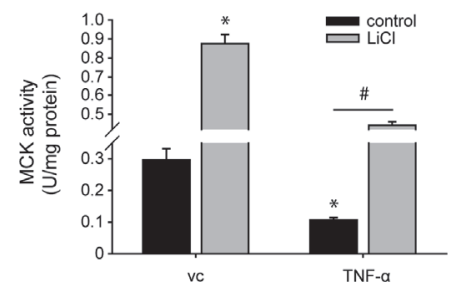

MyHC-f MyLC-3

MyLC-1 GAPDH

B

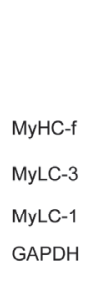

E

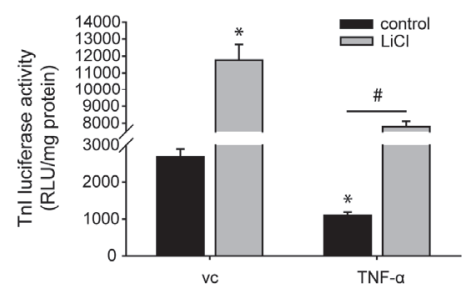


Figure 6.4 Pharmacological GSK-3 inhibition prevents tumor necrosis factor- $\alpha$ (TNF- $\alpha$ )-induced impairment of myogenic differentiation.

(A) Differentiating $\mathrm{C}_{2} \mathrm{C}_{12}$ myoblasts were either cultured in the presence or absence of TNF- $\alpha$ $(1 \mathrm{nM}), \mathrm{LiCl}$ [10 mM] or vc [1.25\% BSA] for $72 \mathrm{~h}$ after which the cells were assessed for morphological changes by staining with May-Grünwald Giemsa (40X magnification, scale bar = $500 \mu \mathrm{m}$ ). (B) Myoblast fusion was quantified by determining the nuclear distribution of 1900 or more nuclei for each separate condition. The data are expressed as a \% of nuclei residing in cells containing 1, 2, or > 2 nuclei; reflecting mononucleated myoblasts (1 nucleus), dividing or fusing myoblasts ( 2 nuclei) or myotubes (> 2 nuclei), respectively. (C) Next, protein levels of myosin heavy chain fast (MyHC-f), myosin light chains 1 (MyLC-1) and -3 (MyLC-3) and GAPDH were determined in whole cell lysates by Western blot analysis, (D) and muscle creatine kinase (MCK) activity was measured spectrophotometrically, expressed as specific enzyme activity (units/mg protein). (E) Differentiating $\mathrm{C}_{2} \mathrm{C}_{12}$ myoblasts containing a stable genomically integrated troponin I (Tnl) luciferase reporter construct were cultured for $72 \mathrm{~h}$ in the presence or absence of $\mathrm{LiCl}$ [10 mM], or TNF- $\alpha$ [1 nM] or vc [1.25\% BSA]. Subsequently, lysates were prepared to measure luciferase activity (RLU/mg total protein). All data shown are representative of 3 independent experiments (means $\pm S E M, n=3$ ). ${ }^{*} p<0.05$ compared with vc control; \# $p<0.05$ refers to a difference between indicated conditions.

\section{GSK-3 inhibition blocks glucocorticoid-induced inhibition of myogenic differentiation}

Systemic inflammation increases circulating levels of cortisol; a potent trigger of muscle atrophy $(28,29)$. Repeated intranasal LPS instillation in guinea pigs resulted in an increase in plasma cortisol levels $(229 \%, \pm$ SEM $48.4 \%)$, which was unaffected by SB213763-treatment (172\%, \pm SEM 51.2\%) (data not shown). Previously it was demonstrated that the synthetic GCs prednisolone as well as Dex strongly impaired myogenesis (53). The addition of Dex to the culture medium during differentiation resulted in impaired $\mathrm{C}_{2} \mathrm{C}_{12}$ myotube formation (Figure 6.5A). Similar to the results obtained with TNF- $\alpha$, pharmacological GSK-3 significantly prevented impairment of myoblast fusion in the presence of Dex (Figure 6.5B). Likewise, pharmacological GSK-3 inhibition using CHIR99021 reversed the Dex-induced impairment of myogenesis (data not shown). Furthermore, Dex significantly decreased the muscle-specific protein expression of MyHC-f, MyLC-1 and MyLC-3, while LiCl supplementation completely reversed this effect (Figure $5 \mathrm{C}$ ). Moreover, Dex markedly reduced MCK activity (Figure 6.5D) and $\mathrm{Tnl}$ promoter transactivation (Figure 6.5E), which was prevented in the presence of $\mathrm{LiCl}$ (Figure 6.5D and Figure 6.5E, respectively). 
A

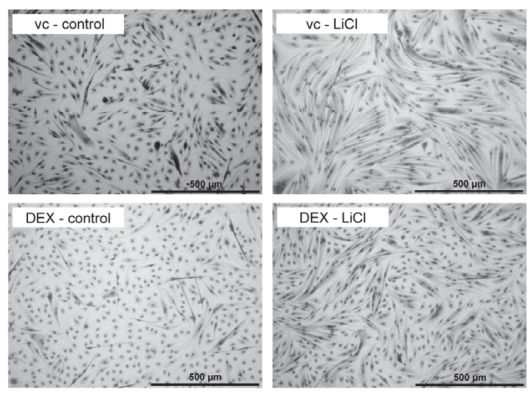

C

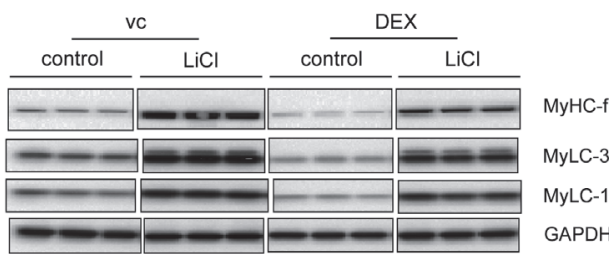

D

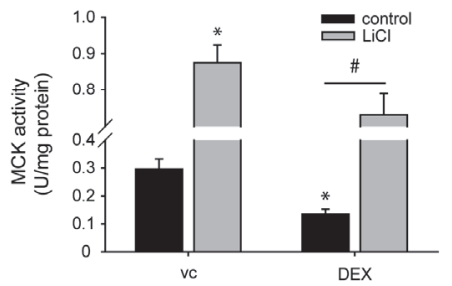

B
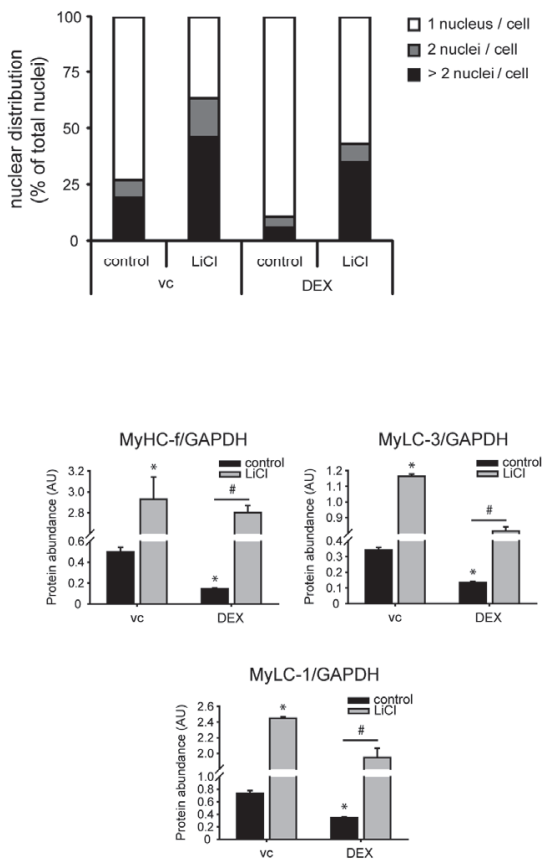

E

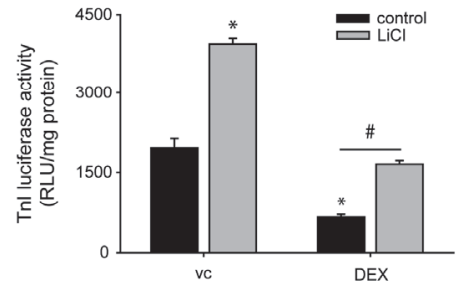


Figure 6.5 Pharmacological GSK-3 inhibition completely blocks glucocorticoid-induced reduction in myogenic differentiation.

(A) Differentiating $\mathrm{C}_{2} \mathrm{C}_{12}$ myoblasts were either cultured in the presence or absence of dexamethasone (Dex) [10 $\mu \mathrm{M}]$, $\mathrm{LiCl}$ [10 mM] or vc (DMSO) for $72 \mathrm{~h}$ after which the cells were assessed for morphological changes by staining with May-Grünwald Giemsa (40X magnification, scale bar $=500 \mu \mathrm{m}$ ). (B) Myoblast fusion was quantified by determining the nuclear distribution of 1900 or more nuclei for each separate condition. The data are expressed as a \% of nuclei residing in cells containing 1, 2, or > 2 nuclei; reflecting mononucleated myoblasts ( 1 nucleus), dividing or fusing myoblasts ( 2 nuclei) or myotubes (> 2 nuclei), respectively. (C) Next, protein levels of MyHC-f, MyLC-1, MyLC-3 and GAPDH were determined in whole cell lysates by Western blot analysis, (D) and MCK activity was measured spectrophotometrically, expressed as specific enzyme activity (units/mg protein). (E) Differentiating $\mathrm{C}_{2} \mathrm{C}_{12}$ myoblasts containing a stable genomically integrated troponin I (Tnl) luciferase reporter construct were cultured for $72 \mathrm{~h}$ in the presence or absence of $\mathrm{LiCl}$ [10 $\mathrm{mM}]$, or Dex [10 $\mu \mathrm{M}]$ or vc (DMSO). Subsequently, lysates were prepared to measure luciferase activity (RLU/mg total protein). All data shown are representative of 3 independent experiments (means $\pm \mathrm{SEM}, \mathrm{n}=3$ ). ${ }^{*} \mathrm{p}<0.05$ compared with vc control; \# $\mathrm{p}<0.05$ refers to a difference between indicated conditions.

\section{Discussion}

Pulmonary inflammation in acute or chronic respiratory disease is commonly associated with skeletal muscle atrophy $(12,73)$. The results presented in this manuscript demonstrate that pharmacological GSK-3 inhibition is beneficial in preventing muscle wasting in an established animal model of pulmonary inflammation, without affecting pulmonary inflammation. Further, impaired myogenic differentiation of cultured muscle cells, in response to TNF- $\alpha$ and GCs as putative mediators of inflammation-induced muscle atrophy, was restored by GSK-3 inhibition, putting forward sustained myogenesis as a basis for the maintenance or muscle mass despite persistent pulmonary inflammation.

Pulmonary inflammation was induced by repeated intranasal instillation of LPS, an endotoxin present in the outer membrane of Gram-negative bacteria, and as a contaminant in environmental pollution, organic dusts and cigarette smoke; all factors that have been associated with the development of COPD $(11,47,59)$. Furthermore, LPS challenge is a well-known in vivo model of neutrophilic inflammation that resembles COPD pathophysiology $(27,35,39)$. Also in guinea pigs, topical LPS challenge resulted in pulmonary inflammation, distinguished by an influx of inflammatory cells in the lung $(34,56,77)$. In addition, pulmonary inflammation is characterized by elevated local levels of the pro-inflammatory cytokines TNF- $\alpha$ and IL-1 $\beta$ (39,45,81), which can activate the transcription factor nuclear factor- $k B$ (NF-KB) $(4,5,57)$. Previously, pharmacological GSK3 inhibition was shown to result in a decrease in NF-KB-dependent gene transcription following stimulation with TNF- $\alpha$ (67), and in another study, NF-KB activation was abrogated in GSK-3 $\beta$-deficient cells in response to LPS (74). Taken together, these 
reports underline the potential of GSK-3 in the regulation of NF-KB activation, and hence, the inflammatory response. In the present study, however, pulmonary inflammation was not affected by enzymatic GSK-3 inhibition. This discrepancy might be due to a tissue-specific dependence of NF-KB and inflammatory signaling on GSK-3 as the above-mentioned studies were conducted in cultured hepatocytes and fibroblasts, whereas in the current report GSK-3 was inhibited in vivo in the lung. Moreover, inflammation is a complex process that, in addition to NF-KB, involves a plethora of transcriptional regulators that may function independently of GSK-3 $(19,75)$. Nevertheless, our data suggest that any effects of local SB216763 instillation on systemic pathology are not accounted for by alterations in the lung inflammatory response.

In addition to sustained inflammation in the lung, chronic LPS-treatment resulted in skeletal muscle atrophy. Similarly, previous work by our group showed that acute pulmonary inflammation was associated with muscle atrophy following intratracheal LPS instillation (IT-LPS) (39). In this study, local inflammation was accompanied by a potent systemic inflammatory response, characterized by elevated circulating levels of inflammatory cytokines, which coincided with increased NF-KB signaling in skeletal muscle (39). Systemic inflammation has been shown to contribute significantly to skeletal muscle atrophy and pro-inflammatory cytokines have been suggested to induce and mediate catabolic responses in muscle via NF-kB $(39,68)$. In the current study circulating cytokine levels were not assessed, rendering it difficult to implicate systemic inflammation as a direct causal trigger in the onset of muscle atrophy. Nevertheless, it is conceivable that, considering the persistent inflammatory state of the lung, systemic inflammation was sustained following repeated LPS challenge, as increased circulating levels of inflammatory cytokines were reported in a mouse model of chronic pulmonary inflammation (40).

During the early onset of inflammation, TNF- $\alpha$ and IL-1 $\beta$ stimulate the release of $\mathrm{GCs}$, as an endogenous reaction to dampen the inflammatory response, via activation of the hypothalamic-pituitary-adrenal (HPA) axis (28). In this study, pulmonary inflammation was associated with increases in plasma cortisol levels, providing indirect evidence to support the notion that systemic inflammation might have occurred in this model. Previously, IT-LPS instillation was reported to increase the plasma concentration of corticosterone; the endogenous GC in mice (24), and in other models of inflammation -or GC-associated muscle atrophy administration of glucocorticoid receptor (GR) antagonists prevented or attenuated muscle atrophy $(48,89)$. Indeed, LPS-induced increases in plasma cortisol were paralleled by a significant decrease in myofiber CSA, and only the latter was prevented by GSK-3 inhibition. Remarkably, basal GSK-3 inhibition likewise resulted in a decrease in myofiber CSA, which may have been the consequence of a blunted increase in body weight in response to SB216763. Over-inhibition of GSK-3 under normal 
circumstances may not be favorable as GSK-3 is essential in the control of various physiological processes such as development and cell proliferation $(50,79)$. As exacerbated GSK-3 activity was previously reported in atrophying muscle (15), our results may indicate that the use of GSK-3 inhibitors should be limited to conditions characterized by aberrant GSK-3 regulation, aimed at restoration of physiological GSK3 activity levels (13,79). Nevertheless, pharmacological GSK-3 inhibition resulted in significant sparing of muscle mass and myofiber CSA, despite sustained pulmonary inflammation and elevated cortisol levels.

Previously reported studies highlighted the efficacy of GSK-3 inhibitors in reducing proteolysis in septic muscle (14), and in muscles from burned rats (16). Furthermore, GSK-3 inhibition was demonstrated to decrease general protein degradation comparably to IGF-I in a model of GC-associated muscle proteolysis (46), and earlier work by our lab delineated a pivotal role for GSK-3 $\beta$ in the induction of skeletal muscle atrophy, as loss of GSK-3 $\beta$ expression in muscle resulted in specific sparing of myofibrillar protein abundance following impaired IGF-I signaling and synthetic GCtreatment (80). Thus, the inability of GSK-3 inhibition to reduce pulmonary inflammation implies that the SB216763 inhibitor may have directly inhibited GSK-3 in muscle.

In view of the significance of GSK-3 signaling in the processes that determine muscle mass $(79,80)$, markers of protein synthesis and degradation were assessed in muscle homogenates. As indicated earlier, Akt activation results in the phosphorylation and cytoplasmic retention of the FoXO transcription factors, and is responsible for the subsequent attenuation of protein breakdown. Conversely, reduced phosphorylation of FoXO, consequent to diminished Akt activity, may increase proteolysis signaling, and hence muscle atrophy. Yet, sustained pulmonary inflammation only appeared to marginally reduce $\mathrm{p}$-FoXO3a protein levels, while the phosphorylation status of FoXO1 remained unaffected. It is noteworthy that suppression of GSK-3 activity did not influence the phosphorylation of FoXO under any conditions. Of note, these moderate effects of pulmonary inflammation and GSK-3 inhibition on FoXO corresponded to the unaltered phosphorylation state of Akt; its upstream regulator. However, pulmonary inflammation tended to reduce the phosphorylation of S6, indicative of decreased protein synthesis. Subsequent analysis of other protein synthesis signaling markers, downstream of Akt, revealed no demonstrable effects of either LPS -or SB216763-treatment. In contrast, several in vivo studies established that LPS-treatment resulted in suppressed protein synthesis in muscle $(37,38)$. However, these pernicious effects on protein synthesis were measured in the acute phase, and a recent report by Tarabees et al. suggested that endotoxins only transiently decrease protein synthesis in skeletal muscle through Akt (76). 
A limitation of this study was the fact that besides FoXO, no additional analyses on muscle protein breakdown signaling were included. Acute loss of muscle mass typically relies on increased proteolysis, a process which is primarily carried out through the activation of the ATP-dependent ubiquitin 26S-proteasome system (UPS), and largely depends on the rate-limiting E3 ubiquitin ligases atrogin-1/MAFbx and muscle RING finger 1 (MuRF1) (6,21,22). Due to limited reagent availability these targets could not be measured in guinea pig muscle. However, in spite of this apparent analytical restriction, it has been established that the expression levels of these executioners of muscle atrophy are induced early in the atrophy process; generally preceding the onset of muscle loss in several experimental models $(22,36,64,70)$. In agreement with this line of thought, the marginal effects on FoXO phosphorylation and expression, following repeated LPS challenge, may correspond with a transient expression of its downstream executioners of proteolysis $(65,82)$. Although our findings are not in support of a major role of altered protein turnover in the development of muscle atrophy in this chronic model, it is difficult to conclusively rule out the contribution protein turnover. First of all, no actual measurements of muscle protein synthesis and degradation were conducted, and the signaling cues of protein turnover, as assessed here, may not always correspond with changes in protein synthesis and degradation $(2,25)$. Secondly, increased proteolysis has been reported in response to acute pulmonary inflammation $(17,39)$. As elevated muscle breakdown signaling requires GSK-3 $\beta$ activity $(14,80)$, SB216763-treatment may have prevented an initial decrease in muscle mass, which subsequently did not recover in the LPS control group despite the normalization of proteolysis signaling.

Altogether, despite a clear role for GSK-3 in the processes that govern protein turnover, our findings illustrate that neither chronic LPS nor pharmacological GSK-3 inhibition had any profound effect on muscle protein synthesis and degradation signaling, suggesting that the sustained muscle atrophy phenotype was not the consequence of gross alterations in protein turnover. Besides protein turnover, myonuclear turnover constitutes another cellular mechanism determining muscle mass (23). The sustained nature of the muscle atrophy phenotype, may have involved impaired regeneration following recovery from atrophy, resulting in impaired restoration of muscle mass. Intriguingly, pharmacological and physiological GSK-3 inhibition was recently shown to enhance myoblast fusion and myotube formation, ascribing an important role to GSK-3 in the process of myogenesis $(54,78)$. In the present study, we made use of the $C_{2} C_{12}$ cell culture model to investigate whether GSK-3 inhibition could prevent impaired myogenesis in response to TNF- $\alpha$ and the synthetic GC Dex. Impaired myogenic differentiation in response to TNF- $\alpha$ (42) has been reported previously, and several lines of evidence, including our own work, have demonstrated that, besides their well-described role as inducers of muscle proteolysis, GCs can also cause muscle atrophy by inhibiting several aspects of myogenesis $(53,58,83)$. 
In agreement with previous findings, TNF- $\alpha$ significantly impaired myogenesis in cultured muscle cells, whereas GSK-3 inhibition improved myogenic differentiation. Importantly, pharmacological GSK-3 inhibition, using two structurally unrelated inhibitors, completely prevented reduced myogenesis in response to TNF- $\alpha$. Similarly, the Dex-induced impairment of myogenesis was completely blocked by GSK-3 inhibition using either $\mathrm{LiCl}$ or CHIR99021. Taken together, interference with myogenic differentiation, as a direct consequence of circulating inflammatory mediators or secondary to increased GC levels, may have resulted in myofiber atrophy by impaired myogenesis, whereas this process was sustained by GSK-3 inhibition, resulting in preservation of muscle mass.

Collectively, our data demonstrate that topical application of the selective GSK-3 inhibitor SB216763 is capable of preventing skeletal muscle atrophy in a guinea pig model of pulmonary inflammation. Pharmacological inhibition of GSK-3 may therefore constitute a novel therapeutic strategy in the treatment of chronic inflammatory diseases characterized by skeletal muscle wasting. 


\section{References}

1. Agusti A, Morla M, Sauleda J, Saus C, and Busquets X. NF-kappaB activation and iNOS upregulation in skeletal muscle of patients with COPD and low body weight. Thorax 59: 483-487, 2004.

2. Atherton PJ, Etheridge T, Watt PW, Wilkinson D, Selby A, Rankin D, Smith K, and Rennie MJ. Muscle full effect after oral protein: time-dependent concordance and discordance between human muscle protein synthesis and mTORC1 signaling. Am J Clin Nutr 92: 1080-1088, 2010.

3. Baehr LM, Furlow JD, and Bodine SC. Muscle sparing in muscle RING finger 1 null mice: response to synthetic glucocorticoids. J Physiol 589: 4759-4776, 2011.

4. Barnes PJ. Transcription factors in airway diseases. Lab Invest 86: 867-872, 2006.

5. Blackwell TS, Lancaster LH, Blackwell TR, Venkatakrishnan A, and Christman JW. Differential NFkappaB activation after intratracheal endotoxin. Am J Physiol 277: L823-830, 1999.

6. Bodine SC, Latres E, Baumhueter S, Lai VK, Nunez L, Clarke BA, Poueymirou WT, Panaro FJ, Na E, Dharmarajan K, Pan ZQ, Valenzuela DM, DeChiara TM, Stitt TN, Yancopoulos GD, and Glass DJ. Identification of ubiquitin ligases required for skeletal muscle atrophy. Science 294: 1704-1708, 2001.

7. Bradford MM. A rapid and sensitive method for the quantitation of microgram quantities of protein utilizing the principle of protein-dye binding. Anal Biochem 72: 248-254, 1976.

8. Di Francia M, Barbier D, Mege JL, and Orehek J. Tumor necrosis factor-alpha levels and weight loss in chronic obstructive pulmonary disease. Am J Respir Crit Care Med 150: 1453-1455, 1994.

9. Dodd SL, Powers SK, Vrabas IS, and Eason JM. Interaction of glucocorticoids and activity patterns affect muscle function. Muscle Nerve 18: 190-195, 1995.

10. Dugo L, Collin M, and Thiemermann C. Glycogen synthase kinase 3beta as a target for the therapy of shock and inflammation. Shock 27: 113-123, 2007.

11. Eduard W, Pearce N, and Douwes J. Chronic bronchitis, COPD, and lung function in farmers: the role of biological agents. Chest 136: 716-725, 2009.

12. Eid AA, Ionescu AA, Nixon LS, Lewis-Jenkins V, Matthews SB, Griffiths TL, and Shale DJ. Inflammatory response and body composition in chronic obstructive pulmonary disease. Am J Respir Crit Care Med 164: 1414-1418, 2001.

13. Eldar-Finkelman $\mathrm{H}$ and Martinez A. GSK-3 Inhibitors: Preclinical and Clinical Focus on CNS. Front Mol Neurosci 4: 32, 2011.

14. Evenson AR, Fareed MU, Menconi MJ, Mitchell JC, and Hasselgren PO. GSK-3beta inhibitors reduce protein degradation in muscles from septic rats and in dexamethasone-treated myotubes. Int $J$ Biochem Cell Biol 37: 2226-2238, 2005.

15. Fang CH, Li B, James JH, Yahya A, Kadeer N, Guo X, Xiao C, Supp DM, Kagan RJ, Hasselgren PO, and Sheriff S. GSK-3beta activity is increased in skeletal muscle after burn injury in rats. Am J Physiol Regul Integr Comp Physiol 293: R1545-1551, 2007.

16. Fang CH, Li BG, James JH, King JK, Evenson AR, Warden GD, and Hasselgren PO. Protein breakdown in muscle from burned rats is blocked by insulin-like growth factor $\mathrm{i}$ and glycogen synthase kinase-3beta inhibitors. Endocrinology 146: 3141-3149, 2005.

17. Files DC, D'Alessio FR, Johnston LF, Kesari P, Aggarwal NR, Garibaldi BT, Mock JR, Simmers JL, DeGorordo A, Murdoch J, Willis MS, Patterson C, Tankersley CG, Messi ML, Liu C, Delbono O, Furlow JD, Bodine SC, Cohn RD, King LS, and Crow MT. A critical role for muscle ring finger-1 in acute lung injury-associated skeletal muscle wasting. Am J Respir Crit Care Med 185: 825-834, 2012.

18. Gan WQ, Man SF, Senthilselvan A, and Sin DD. Association between chronic obstructive pulmonary disease and systemic inflammation: a systematic review and a meta-analysis. Thorax 59: 574-580, 2004.

19. Glass CK and Saijo K. Nuclear receptor transrepression pathways that regulate inflammation in macrophages and T cells. Nat Rev Immunol 10: 365-376, 2010.

20. Glass DJ. Molecular mechanisms modulating muscle mass. Trends Mol Med 9: 344-350, 2003.

21. Glass DJ. Skeletal muscle hypertrophy and atrophy signaling pathways. Int J Biochem Cell Biol 37: 1974-1984, 2005.

22. Gomes MD, Lecker SH, Jagoe RT, Navon A, and Goldberg AL. Atrogin-1, a muscle-specific F-box protein highly expressed during muscle atrophy. Proc Natl Acad Sci U S A 98: 14440-14445, 2001. 
23. Goodman CA, Mayhew DL, and Hornberger TA. Recent progress toward understanding the molecular mechanisms that regulate skeletal muscle mass. Cell Signal 23: 1896-1906, 2011.

24. Greenberg SS, Ouyang J, Zhao X, Parrish C, Nelson S, and Giles TD. Effects of ethanol on neutrophil recruitment and lung host defense in nitric oxide synthase I and nitric oxide synthase II knockout mice. Alcohol Clin Exp Res 23: 1435-1445, 1999.

25. Greenhaff PL, Karagounis LG, Peirce N, Simpson EJ, Hazell M, Layfield R, Wackerhage H, Smith K, Atherton P, Selby A, and Rennie MJ. Disassociation between the effects of amino acids and insulin on signaling, ubiquitin ligases, and protein turnover in human muscle. Am J Physiol Endocrinol Metab 295: E595-604, 2008.

26. Gurrieri C, Piazza F, Gnoato M, Montini B, Biasutto L, Gattazzo C, Brunetta E, Cabrelle A, Cinetto F, Niero R, Facco M, Garbisa S, Calabrese F, Semenzato G, and Agostini C. 3-(2,4-dichlorophenyl)-4-(1methyl-1H-indol-3-yl)-1H-pyrrole-2,5-dione (SB216763), a glycogen synthase kinase-3 inhibitor, displays therapeutic properties in a mouse model of pulmonary inflammation and fibrosis. $J$ Pharmacol Exp Ther 332: 785-794, 2010.

27. Haegens A, Heeringa P, van Suylen RJ, Steele C, Aratani Y, O'Donoghue RJ, Mutsaers SE, Mossman BT, Wouters EF, and Vernooy JH. Myeloperoxidase deficiency attenuates lipopolysaccharide-induced acute lung inflammation and subsequent cytokine and chemokine production. J Immunol 182: 79907996, 2009.

28. Hardy RS, Raza K, and Cooper MS. Endogenous glucocorticoids in inflammation: contributions of systemic and local responses. Swiss Med Wkly 142: w13650, 2012.

29. Hasselgren PO. Glucocorticoids and muscle catabolism. Curr Opin Clin Nutr Metab Care 2: 201-205, 1999.

30. Hawke TJ and Garry DJ. Myogenic satellite cells: physiology to molecular biology. J Appl Physiol 91: 534-551, 2001.

31. Hoeflich KP, Luo J, Rubie EA, Tsao MS, Jin O, and Woodgett JR. Requirement for glycogen synthase kinase-3beta in cell survival and NF-kappaB activation. Nature 406: 86-90, 2000.

32. Jones $\mathrm{R}$ and Ostrem $\mathrm{A}$. Optimising pharmacological maintenance treatment for COPD in primary care. Prim Care Respir J 20: 33-45, 2011.

33. Jope RS. Lithium and GSK-3: one inhibitor, two inhibitory actions, multiple outcomes. Trends Pharmacol Sci 24: 441-443, 2003.

34. Kaneko Y, Takashima K, Suzuki N, and Yamana K. Effects of theophylline on chronic inflammatory lung injury induced by LPS exposure in guinea pigs. Allergol Int 56: 445-456, 2007.

35. Kharitonov SA and Sjobring U. Lipopolysaccharide challenge of humans as a model for chronic obstructive lung disease exacerbations. Contrib Microbiol 14: 83-100, 2007.

36. Komamura K, Shirotani-Ikejima H, Tatsumi R, Tsujita-Kuroda Y, Kitakaze M, Miyatake K, Sunagawa K, and Miyata T. Differential gene expression in the rat skeletal and heart muscle in glucocorticoidinduced myopathy: analysis by microarray. Cardiovasc Drugs Ther 17: 303-310, 2003.

37. Lang $\mathrm{CH}$ and Frost RA. Endotoxin disrupts the leucine-signaling pathway involving phosphorylation of mTOR, 4E-BP1, and S6K1 in skeletal muscle. J Cell Physiol 203: 144-155, 2005.

38. Lang CH, Frost RA, Jefferson LS, Kimball SR, and Vary TC. Endotoxin-induced decrease in muscle protein synthesis is associated with changes in elF2B, elF4E, and IGF-I. Am J Physiol Endocrinol Metab 278: E1133-1143, 2000.

39. Langen RC, Haegens A, Vernooy JH, Wouters EF, de Winther MP, Carlsen H, Steele C, Shoelson SE, and Schols AM. NF-kappa B Activation is Required for the Transition of Pulmonary Inflammation to Muscle Atrophy. Am J Respir Cell Mol Biol, 2012.

40. Langen RC, Schols AM, Kelders MC, van der Velden JL, Wouters EF, and Janssen-Heininger YM. Muscle wasting and impaired muscle regeneration in a murine model of chronic pulmonary inflammation. Am J Respir Cell Mol Biol 35: 689-696, 2006.

41. Langen RC, Schols AM, Kelders MC, Wouters EF, and Janssen-Heininger YM. Inflammatory cytokines inhibit myogenic differentiation through activation of nuclear factor-kappaB. Faseb J 15: 1169-1180, 2001.

42. Langen RC, Van Der Velden JL, Schols AM, Kelders MC, Wouters EF, and Janssen-Heininger YM. Tumor necrosis factor-alpha inhibits myogenic differentiation through MyoD protein destabilization. Faseb J 18: 227-237, 2004. 
43. Langen RCJ, Schols AMWJ, Kelders MCJM, Wouters EFM, and Janssen-Heininger YMW. Enhanced myogenic differentiation by extracellular matrix is regulated at the early stages of myogenesis. In Vitro Cell Dev Biol-Animal 39: 163-169, 2003.

44. Lecker SH, Solomon V, Mitch WE, and Goldberg AL. Muscle protein breakdown and the critical role of the ubiquitin-proteasome pathway in normal and disease states. J Nutr 129: 227S-237S, 1999.

45. Lee KM, Renne RA, Harbo SJ, Clark ML, Johnson RE, and Gideon KM. 3-week inhalation exposure to cigarette smoke and/or lipopolysaccharide in AKR/J mice. Inhal Toxicol 19: 23-35, 2007.

46. Li BG, Hasselgren PO, and Fang CH. Insulin-like growth factor-I inhibits dexamethasone-induced proteolysis in cultured $\mathrm{L} 6$ myotubes through PI3K/Akt/GSK-3beta and PI3K/Akt/mTOR-dependent mechanisms. Int J Biochem Cell Biol 37: 2207-2216, 2005.

47. Liebers $\mathrm{V}$, Raulf-Heimsoth $\mathrm{M}$, and Bruning T. Health effects due to endotoxin inhalation (review). Arch Toxicol 82: 203-210, 2008.

48. Ma K, Mallidis C, Bhasin S, Mahabadi V, Artaza J, Gonzalez-Cadavid N, Arias J, and Salehian B. Glucocorticoid-induced skeletal muscle atrophy is associated with upregulation of myostatin gene expression. Am J Physiol Endocrinol Metab 285: E363-371, 2003.

49. Man WD, Kemp P, Moxham J, and Polkey MI. Skeletal muscle dysfunction in COPD: clinical and laboratory observations. Clin Sci (Lond) 117: 251-264, 2009.

50. Medina M and Wandosell F. Deconstructing GSK-3: The Fine Regulation of Its Activity. Int J Alzheimers Dis 2011: 479249, 2011.

51. Morgan JE and Partridge TA. Muscle satellite cells. Int J Biochem Cell Biol 35: 1151-1156, 2003.

52. Olson EN. Signal transduction pathways that regulate skeletal muscle gene expression. Mol Endocrinol 7: 1369-1378, 1993.

53. Pansters NA, Langen RC, Wouters E, and Schols AM. Synergistic stimulation of myogenesis by glucocorticoid and IGF-I signaling. J Appl Physiol, 2012.

54. Pansters NA, van der Velden JL, Kelders MC, Laeremans H, Schols AM, and Langen RC. Segregation of myoblast fusion and muscle-specific gene expression by distinct ligand-dependent inactivation of GSK-3beta. Cell Mol Life Sci 68: 523-535, 2011.

55. Penna F, Costamagna D, Fanzani A, Bonelli G, Baccino FM, and Costelli P. Muscle wasting and impaired myogenesis in tumor bearing mice are prevented by ERK inhibition. PLoS One 5: e13604, 2010.

56. Pera T, Zuidhof A, Valadas J, Smit M, Schoemaker RG, Gosens R, Maarsingh H, Zaagsma J, and Meurs $\mathrm{H}$. Tiotropium inhibits pulmonary inflammation and remodelling in a guinea pig model of COPD. Eur Respir J 38: 789-796, 2011.

57. Poynter ME, Irvin CG, and Janssen-Heininger YM. A prominent role for airway epithelial NF-kappa B activation in lipopolysaccharide-induced airway inflammation. J Immunol 170: 6257-6265, 2003.

58. Qin W, Pan J, Wu Y, Bauman WA, and Cardozo C. Protection against dexamethasone-induced muscle atrophy is related to modulation by testosterone of FOXO1 and PGC-1alpha. Biochem Biophys Res Commun 403: 473-478, 2010.

59. Rabe KF, Hurd S, Anzueto A, Barnes PJ, Buist SA, Calverley P, Fukuchi Y, Jenkins C, Rodriguez-Roisin R, van Weel $C$, and Zielinski J. Global strategy for the diagnosis, management, and prevention of chronic obstructive pulmonary disease: GOLD executive summary. Am J Respir Crit Care Med 176: 532-555, 2007.

60. Ramamoorthy S, Donohue $M$, and Buck M. Decreased Jun-D and myogenin expression in muscle wasting of human cachexia. Am J Physiol Endocrinol Metab 297: E392-401, 2009.

61. Rayasam GV, Tulasi VK, Sodhi R, Davis JA, and Ray A. Glycogen synthase kinase 3: more than a namesake. Br J Pharmacol 156: 885-898, 2009.

62. Remels AH, Gosker HR, Langen RC, and Schols AM. The mechanisms of cachexia underlying muscle dysfunction in COPD. J Appl Physiol, 2012.

63. Ruegg MA and Glass DJ. Molecular mechanisms and treatment options for muscle wasting diseases. Annu Rev Pharmacol Toxicol 51: 373-395, 2011.

64. Sacheck JM, Hyatt JP, Raffaello A, Jagoe RT, Roy RR, Edgerton VR, Lecker SH, and Goldberg AL. Rapid disuse and denervation atrophy involve transcriptional changes similar to those of muscle wasting during systemic diseases. Faseb J 21: 140-155, 2007. 
65. Sandri M, Sandri C, Gilbert A, Skurk C, Calabria E, Picard A, Walsh K, Schiaffino S, Lecker SH, and Goldberg AL. Foxo transcription factors induce the atrophy-related ubiquitin ligase atrogin-1 and cause skeletal muscle atrophy. Cell 117: 399-412, 2004.

66. Schols AM, Buurman WA, Staal van den Brekel AJ, Dentener MA, and Wouters EF. Evidence for a relation between metabolic derangements and increased levels of inflammatory mediators in a subgroup of patients with chronic obstructive pulmonary disease. Thorax 51: 819-824, 1996.

67. Schwabe RF and Brenner DA. Role of glycogen synthase kinase-3 in TNF-alpha-induced NF-kappaB activation and apoptosis in hepatocytes. Am J Physiol Gastrointest Liver Physiol 283: G204-211, 2002.

68. Spate U and Schulze PC. Proinflammatory cytokines and skeletal muscle. Curr Opin Clin Nutr Metab Care 7: 265-269, 2004.

69. Stambolic V, Ruel L, and Woodgett JR. Lithium inhibits glycogen synthase kinase-3 activity and mimics wingless signalling in intact cells. Curr Biol 6: 1664-1668, 1996.

70. Stevenson EJ, Giresi PG, Koncarevic A, and Kandarian SC. Global analysis of gene expression patterns during disuse atrophy in rat skeletal muscle. J Physiol 551: 33-48, 2003.

71. Stitt TN, Drujan D, Clarke BA, Panaro F, Timofeyva Y, Kline WO, Gonzalez M, Yancopoulos GD, and Glass DJ. The IGF-1/PI3K/Akt pathway prevents expression of muscle atrophy-induced ubiquitin ligases by inhibiting FOXO transcription factors. Mol Cell 14: 395-403, 2004.

72. Szasz G, Gruber W, and Bernt E. Creatine kinase in serum: 1. Determination of optimum reaction conditions. Clin Chem 22: 650-656, 1976.

73. Takabatake N, Nakamura H, Abe S, Inoue S, Hino T, Saito H, Yuki H, Kato S, and Tomoike H. The relationship between chronic hypoxemia and activation of the tumor necrosis factor-alpha system in patients with chronic obstructive pulmonary disease. Am J Respir Crit Care Med 161: 1179-1184, 2000.

74. Takada Y, Fang X, Jamaluddin MS, Boyd DD, and Aggarwal BB. Genetic deletion of glycogen synthase kinase-3beta abrogates activation of IkappaBalpha kinase, JNK, Akt, and p44/p42 MAPK but potentiates apoptosis induced by tumor necrosis factor. J Biol Chem 279: 39541-39554, 2004.

75. Tal TL, Simmons SO, Silbajoris R, Dailey L, Cho SH, Ramabhadran R, Linak W, Reed W, Bromberg PA, and Samet JM. Differential transcriptional regulation of IL-8 expression by human airway epithelial cells exposed to diesel exhaust particles. Toxicol Appl Pharmacol 243: 46-54, 2010.

76. Tarabees R, Hill D, Rauch C, Barrow PA, and Loughna PT. Endotoxin transiently inhibits protein synthesis through Akt and MAPK mediating pathways in C2C12 myotubes. Am J Physiol Cell Physiol 301: C895-902, 2011.

77. Toward TJ and Broadley KJ. Goblet cell hyperplasia, airway function, and leukocyte infiltration after chronic lipopolysaccharide exposure in conscious Guinea pigs: effects of rolipram and dexamethasone. J Pharmacol Exp Ther 302: 814-821, 2002.

78. van der Velden JL, Langen RC, Kelders MC, Wouters EF, Janssen-Heininger YM, and Schols AM. Inhibition of glycogen synthase kinase-3beta activity is sufficient to stimulate myogenic differentiation. Am J Physiol Cell Physiol 290: C453-462, 2006.

79. Verhees KJ, Pansters NA, Schols AM, and Langen RC. Regulation of Skeletal Muscle Plasticity by Glycogen Synthase Kinase-3beta: A Potential Target for the Treatment of Muscle Wasting. Curr Pharm Des 19 (18): 3276-3298, 2013.

80. Verhees KJ, Schols AM, Kelders MC, Op den Kamp CM, van der Velden JL, and Langen RC. Glycogen synthase kinase-3beta is required for the induction of skeletal muscle atrophy. Am J Physiol Cell Physiol 301: C995-C1007, 2011.

81. Vernooy JH, Dentener MA, van Suylen RJ, Buurman WA, and Wouters EF. Long-term intratracheal lipopolysaccharide exposure in mice results in chronic lung inflammation and persistent pathology. Am J Respir Cell Mol Biol 26: 152-159, 2002.

82. Waddell DS, Baehr LM, van den Brandt J, Johnsen SA, Reichardt HM, Furlow JD, and Bodine SC. The glucocorticoid receptor and FOXO1 synergistically activate the skeletal muscle atrophy-associated MuRF1 gene. Am J Physiol Endocrinol Metab 295: E785-797, 2008.

83. Wang H, Kubica N, Ellisen LW, Jefferson LS, and Kimball SR. Dexamethasone represses signaling through the mammalian target of rapamycin in muscle cells by enhancing expression of REDD1. J Biol Chem 281: 39128-39134, 2006. 
84. Watson ML, Baehr LM, Reichardt HM, Tuckermann JP, Bodine SC, and Furlow JD. A Cell Autonomous Role for the Glucocorticoid Receptor in Skeletal Muscle Atrophy Induced by Systemic Glucocorticoid Exposure. Am J Physiol Endocrinol Metab, 2012.

85. Welsh GI, Miller CM, Loughlin AJ, Price NT, and Proud CG. Regulation of eukaryotic initiation factor elF2B: glycogen synthase kinase-3 phosphorylates a conserved serine which undergoes dephosphorylation in response to insulin. FEBS Lett 421: 125-130, 1998.

86. Wing SS and Goldberg AL. Glucocorticoids activate the ATP-ubiquitin-dependent proteolytic system in skeletal muscle during fasting. Am J Physiol 264: E668-676, 1993.

87. Woodgett JR. cDNA cloning and properties of glycogen synthase kinase-3. Methods Enzymol 200: 564577, 1991.

88. Woodgett JR. Molecular cloning and expression of glycogen synthase kinase-3/factor A. Embo J 9: 2431-2438, 1990.

89. Wray CJ, Mammen JM, Hershko DD, and Hasselgren PO. Sepsis upregulates the gene expression of multiple ubiquitin ligases in skeletal muscle. Int J Biochem Cell Biol 35: 698-705, 2003.

90. Yaffe D and Saxel O. A myogenic cell line with altered serum requirements for differentiation. Differentiation 7: 159-166, 1977. 


\section{Chapter 7}

GENERAL DISCUSSION AND FUTURE DIRECTIONS 
Chapter 7 


\section{Prologue}

Intrinsically, skeletal muscle is a highly plastic tissue, referring to its capacity to change in volume or mass, and composition. This ability to adapt is put into action in response to a plethora of stimuli including muscle contractile activity, loading conditions, substrate supply and environmental cues. For instance, with sustained resistance exercise, the muscle hypertrophies, whilst with immobility or starvation, the muscle atrophies (wastes). The mechanisms that govern muscle plasticity may be disturbed in patients suffering from chronic inflammatory disease such as chronic obstructive pulmonary disease (COPD), resulting in impaired muscle growth, re-growth or even loss of skeletal muscle mass.

Chronic obstructive pulmonary disease (COPD) is a lung disorder which is characterized by largely irreversible and progressive airflow obstruction, resulting from inflammation and airway remodeling, often including development of emphysema. Dominant symptoms are dyspnea, and in about $40 \%$ of the patients exercise capacity is limited, due to skeletal muscle weakness, which adversely affects health-related quality of life. Advanced disease stage is characterized by frequent episodes of acute worsening of symptoms referred to as exacerbations. These acute exacerbations accelerate disease progression and negatively affect survival, and therefore warrant additional medical therapy. Although the lung is the primary diseased organ, COPD is increasingly recognized as a systemic disease, due to its clinically significant extrapulmonary manifestations. Muscle wasting is a systemic degenerative manifestation in COPD and the prevalence of muscle atrophy is relatively high, affecting roughly 20 - 40\% of COPD patients, depending on definition and disease stage. Muscle wasting not only contributes to diminished muscle function, reduced exercise capacity and decreased health status, but is also a determinant of mortality in COPD independent of airflow obstruction. A plethora of factors have been suggested to contribute to changes in skeletal muscle structure and function in COPD. Putative triggers of muscle wasting in COPD include disuse, hypoxemia, malnutrition, inflammation and endogenous as well as synthetic GCs. These may be a direct consequence of the diseased lung, e.g. hypoxemia and pulmonary inflammation, or may concern physiological and behavioral maladaptations, e.g. disuse and malnutrition. During acute exacerbations these factors converge and, together with synthetic GCs, may synergize to accelerate muscle wasting.

Clearly, as illustrated in the text box for COPD, combating muscle wasting will benefit the patient by improving quality of life and also the chance of survival, as muscle atrophy is an independent predictor of mortality in chronic disease (144). One notable facet of skeletal muscle plasticity is the existence of signaling molecules that act as molecular switchboards which coordinate and transduce a vast array of stimuli 
into specific transcriptional adaptations that evoke changes in muscle mass $(50,134)$. Glycogen synthase kinase-36 (GSK-3ß) was originally discovered in muscle as one of the kinases responsible for phosphorylation and inactivation of its namesake substrate glycogen synthase (GS) $(43,130)$. However, at present, GSK-3 $\beta$ is known to be ubiquitously expressed throughout the body, involved in a plethora of metabolic and cellular signaling pathways including glycogen accumulation, regulation of mRNA translation, and transcriptional modulation $(25,33,51)$. The overall aim of this thesis was to explore the role of GSK-3 $\beta$ in the molecular mechanisms that underlie skeletal muscle atrophy, in particular the role of GSK-3 $\beta$ in the regulatory processes of skeletal muscle protein turnover during the active muscle wasting process.

\section{Main findings}

Muscle protein turnover is determined by the balance between protein synthesis (anabolism) and degradation (catabolism). Phosphorylation and subsequent activation of Akt via the prototypical phosphatidylinositol 3-kinase (PI-3K)/Akt pathway has been considered as the nodal point at which the anti-catabolic and pro-anabolic actions of insulin-like growth factor 1 (IGF-I) and insulin are integrated (56, 97). Diminished protein content associated with skeletal muscle atrophy is the result of an imbalance between muscle protein synthesis and degradation, in favor of the latter $(55,80,126)$.

In addition to disease specific triggers, including e.g. pulmonary inflammation in COPD, fasting, disuse and aging may also cause erosion of lean muscle mass or contribute to the muscle wasting process in chronic diseases $(56,79)$. Many of these conditions are associated with pronounced and sustained elevations in circulating glucocorticoids (GCs) and diminished IGF-I/Akt signaling (56, 70, 99, 176). Moreover, physiological levels of endogenous GCs are required for the development of muscle atrophy in several experimental models $(76,138)$. Enhanced muscle proteolysis during muscle atrophy involves activation of the ATP-dependent ubiquitin 26S-proteasome system (UPS), the autophagy-lysosomal pathway (ALP), and the calpain and caspase systems $(56,79,135,136)$. Besides stimulating skeletal muscle hypertrophy, activation of the IGF-I/Akt pathway may also dominantly inhibit muscle atrophy signaling $(132,138$, 159). In fact, muscle-specific overexpression of IGF-I has been consistently demonstrated to block atrophy in numerous models of muscle wasting $(13,14,140,145$, 156). However, contrary to the well-defined opposing role of Akt in atrophy signaling, the question on how GCs exactly induce muscle wasting remains largely unaddressed. In addition, it is currently unclear how IGF-I/Akt signaling counteracts the catabolic effects of GCs. GSK-3 $\beta$ is a direct downstream target of Akt, and has previously been shown to be involved in skeletal muscle protein degradation $(45,46,101)$. To ascertain whether GSK-3 $\beta$ could constitute a possible link between IGF-I/Akt and GC signaling in muscle, the contribution of GSK-3 $\beta$ in the regulation of muscle proteolysis and 
atrophy induced by GCs or impaired IGF-I/Akt signaling was established in chapter 3. We found that genetic ablation of GSK-3 $\beta$ in $C_{2} C_{12}$ myotubes, using small interfering RNA (siRNA), suppressed both basal and atrophy stimulus-induced transcript levels of the UPS-related atrogin-1 and MuRF1 genes. Furthermore, loss of endogenous GSK-3 $\beta$ expression resulted in specific sparing of myosin heavy chain fast (MyHC-f) and myosin light chains 1 (MyLC-1) and -3 (MyLC-3) protein abundance and myotube size in response to synthetic GC-treatment (dexamethasone, hereinafter termed Dex), or impaired IGF-I/Akt signaling (LY294002). In contrast to their dependency on GSK-3 $\beta$ expression, induction of atrogin-1 and MuRF1 mRNA transcript levels differentially

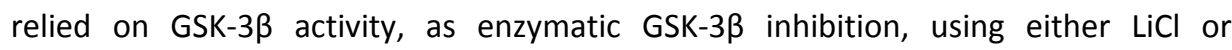
CHIR99021, only attenuated atrophy stimulus-induced atrogin-1 expression, while MuRF1 expression levels remained unaffected (167). In conclusion, the present findings reveal for the first time that the loss of endogenous GSK-3 $\beta$ protein results in specific sparing of myofibrillar proteins and myotube size during atrophy. As such, the results described in chapter 3 attribute a pivotal role to GSK-3 $\beta$ in the regulation of skeletal muscle atrophy.

In chapter 4, we confirmed the dependency of atrogene expression on GSK-3 $\beta$, and gained further insight into the in vivo role of GSK-3 $\beta$ in GC-induced skeletal

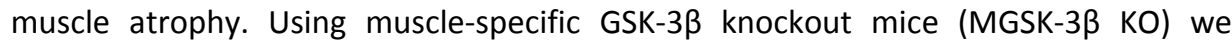
evaluated the direct contribution of GSK-3 $\beta$ in two different models of GC-associated muscle wasting, i.e. fasting as endogenous model, and synthetic GC administration as exogenous model. We demonstrated that skeletal muscle-restricted deletion of GSK$3 \beta$ prevented starvation-induced loss of muscle mass, and inhibited skeletal muscle atrophy following chronic Dex-treatment. However, despite complete inhibition of muscle wasting in response to nutritional deprivation, the induction of atrogin- 1 and MuRF1 was decreased, but not completely abrogated, in GSK-3 $\beta$-deficient muscle. Fasting also significantly upregulated an ALP-related transcriptional program, which was partially dependent on GSK-3 $\beta$. Here too, increases in microtubule-associated proteins $1 A / 1 B$ light chain $3 B(\mathrm{LC} 3 \mathrm{~b})$ and $B c l-2$ and $19 k D a$ interacting-protein 3 (Bnip3) transcript levels were attenuated, but not completely inhibited, whereas GABA receptor-associated protein 1 (Gabarapl1) expression appeared completely refractory to loss of muscle GSK-3 $\beta$. Forkhead Box $O$ (FoXO) transcription factors act as critical liaison molecules coordinately regulating the expression of both ALPrelated, as well as UPS-associated transcriptional programs in muscle (109, 110, 138, 159, 182, 183). Starvation resulted in markedly upregulated FoXO1 and -3a mRNA levels, which were both attenuated in absence of GSK-3 $\beta$. GCs regulate the expression of UPS-related genes including FoXO in both cell culture and in vivo $(24,132,167,170)$, and several studies have indicated that GR-dependent signaling is required for the induction of atrogin-1 and MuRF1 $(170,178,184)$. Our data corroborated these findings, as Dex-induced expression of MuRF1 was blocked in glucocorticoid receptor (GR)deficient muscle. Genetic deletion of the GR demonstrated that intact GC-signaling 
was required for the induction of proteolytic -and GC-sensitive gene expression following Dex-treatment. These data were mirrored by similar observations made in the MGSK-3 $\beta$ KO study in response to fasting. As indicated, muscle-specific deletion of GSK-3 $\beta$ conferred resistance to Dex-induced muscle atrophy, suggesting that blocked muscle atrophy and associated atrogene expression, in response to fasting truly reflected a requirement for GSK-3 $\beta$ in the regulation of GC-induced muscle wasting. Remarkably, despite a clear phenotype, the protective effect of muscle-specific GSK$3 \beta$-deficiency was not evident from UPS-related mRNA expression analyses, since subcutaneous (sc) Dex administration failed to induce sustained proteolytic gene expression. Nonetheless, the striking similarities between the MGSK-3 $\beta$ KO and MGR KO studies with regard to GC-sensitive gene expression, and the dependency of FoXO on GSK-3 $\beta$ and downstream UPS -and ALP-related transcriptional programs, were suggestive of a GSK-3 $\beta$ - GR signaling mechanism operating upstream of FoXO. In conclusion, the findings presented in chapter $\mathbf{4}$ show for the first time that loss of muscle GSK-3 $\beta$ expression in vivo prevents skeletal muscle atrophy in response to starvation or synthetic GC-treatment. Furthermore, this study was the first to show that UPS -and ALP-related transcriptional programs and GC-sensitive gene expression are dependent on GSK-3 $\beta$ in vivo.

The possibility of a GSK-3 $\beta$ - GR interaction during GC-associated muscle atrophy was further investigated in chapter $\mathbf{5}$ in a model of lipopolysaccharide (LPS)-induced pulmonary inflammation, which was accompanied by increases in circulating GCs (corticosterone). Interestingly, skeletal muscle-restricted depletion of GSK-3 $\beta$ and the GR conveyed resistance to pulmonary inflammation-induced muscle atrophy and proteolytic signaling. Pulmonary inflammation resulted in markedly upregulated FoXO1 and -3a mRNA and protein levels in muscle, which were dependent on GR and GSK-3 $\beta$ expression. We postulated that FoXO was a direct GR target gene, and that the observed reductions in UPS -and ALP-related gene expression in the MGSK-3 $\beta$ KO and MGR KO studies were likely the result of decreased nuclear FoXO accumulation, consequent to reduced FoXO expression. Concretely, FoXO expression was GRdependent while GSK-3 $\beta$ operated upstream of the GR, regulating its transcriptional activity. The current paradigm of FoXO activation, i.e. the canonical mode of FoXO activation, entails its dephosphorylation, resulting in nuclear translocation, and subsequent regulation of atrogene expression $(138,159)$. Here, we proposed a novel GSK-3 $\beta$ - GR-mediated signaling axis controlling FoXO-dependent UPS and ALP gene expression by regulation of de novo FoXO expression, capable of overruling FoXO phosphorylation and nuclear exclusion mechanisms, and therefore referred to as noncanonical regulation of FoXO. In addition to introducing a novel GSK-3 $\beta$ - GR signaling axis regulating FoXO expression, the results in chapter $\mathbf{5}$ also show for the first time that genetic deletion of either GSK-3 $\beta$ or the GR results in sparing of muscle mass following acute pulmonary inflammation. 
In chapter 6, the potential therapeutic effects of enzymatic GSK-3 inhibition on muscle wasting was assessed in a guinea pig model of LPS-induced pulmonary inflammation, using the selective GSK-3 inhibitor SB216763. Topical application of this GSK-3 inhibitor did not affect pulmonary inflammation, but inhibited peripheral muscle atrophy. Our findings illustrated that neither chronic LPS-treatment, nor pharmacological GSK-3 inhibition had any profound effect on muscle protein synthesis and degradation signaling, suggesting that the sustained muscle atrophy phenotype was not the consequence of gross alterations in protein turnover. Instead, GSK-3 inhibition may have involved improved regeneration, supporting muscle mass recovery following initial muscle atrophy, which was impaired in vehicle-treated animals characterized by sustained muscle atrophy. Although the possibility of an early SB216763-mediated decrease in proteolytic signaling cannot be excluded, experiments in cultured $\mathrm{C}_{2} \mathrm{C}_{12}$ cells showed that pharmacological GSK-3 inhibition prevented reduced myogenesis in response to tumor necrosis factor- $\alpha$ (TNF- $\alpha$ ) and GCs. Thus, interference with myogenic differentiation, as a direct consequence of circulating inflammatory mediators or secondary to increased GC levels, may have resulted in myofiber atrophy by impaired myogenesis, whereas this process was sustained by GSK-3 inhibition, resulting in preservation of muscle mass. To our knowledge the data described in chapter 6 demonstrates for the first time that topical application of the selective GSK-3 inhibitor SB216763 is able to prevent or reverse skeletal muscle atrophy in vivo, suggesting that pharmacological GSK-3 inhibition could constitute a novel therapeutic strategy in the treatment of chronic inflammatory diseases characterized by skeletal muscle wasting.

\section{Main conclusions}

\section{Regulation of skeletal muscle mass plasticity: GSK-3 $\beta$ steps into the limelight}

\section{The role of GSK-3 $\beta$ in muscle protein synthesis}

As indicated earlier, muscle protein turnover is determined by the balance between protein synthesis (anabolism) and degradation (catabolism). A shift in favor of synthesis over degradation will result in muscle hypertrophy and, conversely, when muscle protein degradation exceeds depressed or even increased protein synthesis, muscle atrophy may ensue. Protein synthesis is a tightly controlled process that requires orderly recruitment and functioning of a plethora of signaling molecules. Initiation of mRNA translation is one of the rate-limiting steps of protein synthesis, and many regulatory pathways of protein synthesis converge at this level, including 
the IGF-I/Akt/mammalian target of rapamycin (mTOR) and IGF-I/Akt/GSK-3 $\beta$ signaling pathways $(19,83)$.

Protein translation initiation is essentially controlled by eukaryotic initiation factors (elFs), whose activity is regulated by growth factor (e.g. IGF-I) and hormonal (e.g. insulin) signaling cascades. Reduced anabolic signaling activates GSK-3 $\beta$, which is responsible for an inhibitory phosphorylation on elF2B $\varepsilon$, resulting in a decrease in the initiation of protein synthesis $(81,173,174)$. Conversely, pro-anabolic signaling activates Akt which, in turn, stimulates the raptor-mTOR complex 1 (mTORC1), and in parallel inactivates GSK-3 $\beta$ through phosphorylation of $\operatorname{Ser}^{9}$ (69). Inhibition of GSK-3 $\beta$ activity leads to decreases in the phosphorylation state of elF2B $\varepsilon$, which facilitates mRNA translation initiation. Further, the IGF-I/insulin-induced activation of mTORC1 through Akt leads to phosphorylation of its downstream targets p70S6 kinase (p70S6K) and elF4E-binding protein 1 (4E-BP1), which contribute to stimulation of protein synthesis by enhancing mRNA translation capacity and mRNA translation initiation via elF4F. In turn, activated p70S6K and its downstream target S6 may inactivate GSK-3 $\beta$, independently of Akt $(10,181)$. Moreover, in the absence of growth factor signaling activated GSK-3 $\beta$ can cooperate with adenosine monophosphate-activated protein kinase (AMPK) to negatively regulate $\mathrm{mTORC1}$ by activating the mTORC1 inhibitor tuberous sclerosis protein 2 (TSC2) (78). Similarly, activated GSK-3 $\beta$ can hinder Akt signaling by destabilizing the insulin receptor substrate 1 (IRS-1), an essential adaptor molecule for $\mathrm{PI}-3 \mathrm{~K}$, which is required for the relay of Akt activating signals downstream of the IGF-I/insulin receptor (IGF-IR) (IR) $(40,104,169)$. Recently, a novel interaction between GSK-3 $\beta$ and the IGF-IR was described, revealing that IGF-IR phosphorylation at Ser ${ }^{1248}$ was mediated by GSK-3 $\beta$ in the absence of growth factors, resulting in restrained IGF-IR kinase activity (85).

These above-mentioned studies have essentially uncovered intricate cross-talk between the IGF-I/Akt/mTORC1 and IGF-I/Akt/GSK-3 $\beta$ sub-pathways of protein synthesis regulation, in which GSK-3 $\beta$ appears to play a central role. For instance, besides regulation via IGF-I and insulin signaling through Akt, GSK-3 $\beta$ activity may also be subject to direct nutrient-dependent regulation via mTORC1 (86), independently of Akt. Furthermore, activation of GSK-3 $\beta$, consequent to reduced Akt activity, may further decrease PI-3K/Akt signaling through a negative feedback loop (Figure 7.1). 


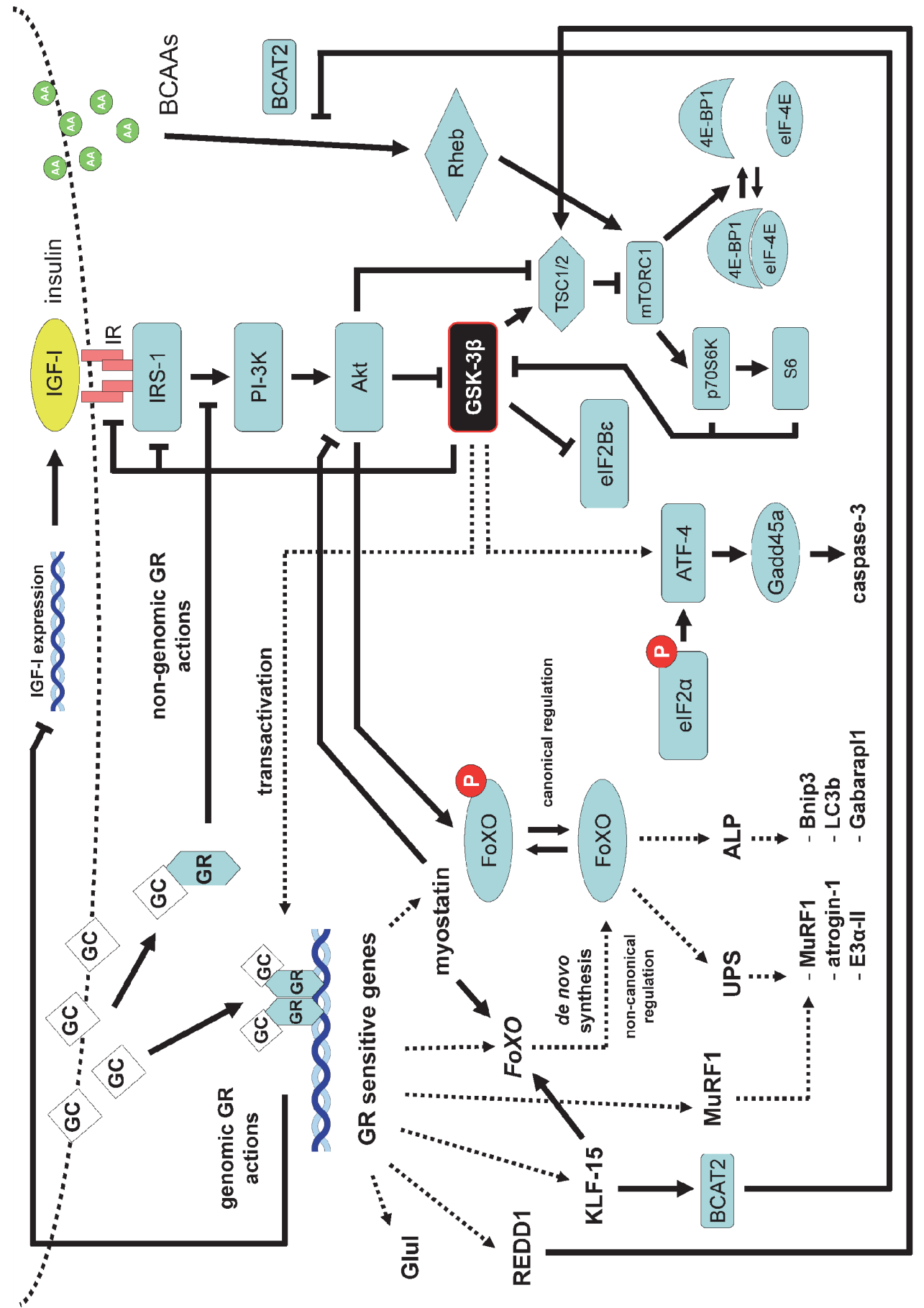


Figure 7.1 GSK-3ß: a central regulator of muscle plasticity: focus on muscle protein turnover

\author{
Non-canonical FoXO regulation by a GSK-3 $\beta$ - GR signaling axis: a new paradigm
}

\begin{abstract}
A schematic representation of the role of GSK-3 $\beta$ in the cellular signaling pathways that govern skeletal muscle protein turnover. The dotted lines represent novelty findings established within the confines of this dissertation. Anabolic factors such as insulin or IGF-I stimulate $\mathrm{PI}-3 \mathrm{~K}$ signaling which results in activation of Akt. Phosphorylated Akt, in turn, inactivates GSK-3 $\beta$ and in parallel stimulates mTORC1 signaling, leading to enhanced protein translation initiation and capacity, and thus, protein synthesis. Besides steering anabolic signaling, phosphorylated Akt may also regulate cytoplasmic sequestration of FoXO transcription factors (canonical FoXO regulation), resulting in a decrease in proteolysis signaling by downregulating ubiquitin 26S-proteasome system (UPS) and the autophagylysosomal pathway (ALP)-dependent muscle protein breakdown. Conversely, under catabolic conditions (which may include glucocorticoid (GC) signaling) Akt activity is perturbed. GCs may decrease Akt signaling via genomic or non-genomic actions of the glucocorticoid receptor (GR). Inhibition of IGF-I/Akt signaling results in activation of GSK-3 $\beta$. Activated GSK-3 $\beta$ may control GR transactivation, thereby affecting GC-sensitive gene expression, including FoXO. De novo synthesis of FoXO (non-canonical FoXO regulation) via the GSK-3 $\beta$ - GR signaling axis can override Akt-mediated nuclear FoXO exclusion mechanisms and determine UPS -and ALPrelated gene expression. Next to direct control of FoXO expression via the GR, GSK-3 $\beta$ may also affect muscle protein turnover indirectly via a set of GC-sensitive genes (KLF-15, myostatin, REDD1; not shown here) or ATF-4 (not shown here).
\end{abstract}

In chapter $\mathbf{5}$, the consequences of loss of muscle GSK-3 $\beta$ expression on protein synthesis signaling were investigated in meticulous detail. Inhibition of GSK-3 $\beta$, by both pharmacological and genetic approaches, consistently resulted in reduced $p$ elF2B $\varepsilon$ levels. As indicated, decreases in the phosphorylation state of elF2B $\varepsilon$ are indicative of increased mRNA translation initiation. However, a net increase in protein synthesis not only relies on enhanced elF2B activity, consequent to reduced elF2B $\varepsilon$ phosphorylation, but is also dependent on the unhindered functioning of the elF4F translation initiation complex, of which elF4E is a rate-limiting member (108). As such, protein synthesis is essentially controlled by two sub-pathways, the Akt/GSK-3ß/elF2B and Akt/mTORC1/eIF4E signaling cascades, respectively, both of which are indispensable for protein translation initiation. Therefore, general protein synthesis was likely not restored in absence of GSK-3 $\beta$, as our data confirmed the previously established segregation of both protein synthesis signaling sub-pathways. Concretely, while the IGF-I/Akt/GSK-3 $\beta$ signaling cascade appeared permissive for increased protein synthesis, the IGF-I/Akt/mTORC1 sub-pathway clearly did not. In response to acute pulmonary inflammation, we noted explicit genotype-independent hypophosphorylation and increases in the expression of 4E-BP1, which binds and inhibits elF4E, the rate-limiting factor of cap-dependent of RNA translational initiation. Sustained inhibition of elF4E would inevitably result in reduced protein synthesis, despite an overall increase in elF2B activity in absence of GSK-3 $\beta$. In contrast, the phosphorylation state of $4 \mathrm{E}-\mathrm{BP} 1$, measured in chapter 4 , was increased following prolonged Dex-treatment, implying that in a more chronic atrophy setting blockade of mRNA translation initiation may be lifted. This delay or lag time in restoration of 
protein synthesis signaling between both sub-pathways may have signified a turning point in the regulation of protein synthesis, and by extension proteolysis signaling (vide infra), following an acute catabolic insult, i.e. pulmonary inflammation. In light of the above, it is tempting to speculate that the first step in restoration of protein synthesis, during recovery from atrophy, involves activation of the IGF-I/Akt/GSK-3 $\beta$ signaling cascade (chapter $\mathbf{5}$ ). In a later stage (chronic atrophy setting), this is followed by relief of translational repression via enhanced activity of the IGF-I/Akt/mTORC1 sub-pathway (chapter 4). Not only will stringent control of GSK-3 $\beta$ activity during the early stages of recovery from atrophy allow for restoration of protein synthesis signaling, tight control of GSK-3 $\beta$ activity will also assure suppression of GR-dependent proteolysis signaling. In other words, Akt-induced inhibition of GSK-3 $\beta$ following an acute catabolic insult may signify the first step in inhibiting muscle proteolysis by blocking the GSK-3 $\beta$ - GR-mediated signaling axis (vide infra).

Nevertheless, in view of the complete rescue of the muscle atrophy phenotype in the MGSK-3 $\beta$ and MGR KO studies, despite impaired protein synthesis signaling, any reductions in the rate of protein synthesis - if any - did not likely contribute to muscle atrophy (chapter 5). Enhanced expression of regulated in development and DNA damage responses 1 (REDD1) was shown to result in inhibition of mTORC1 signaling via TSC1/2 $(42,84,155,179)$. In our studies, the induction of REDD1 was prevented in absence of GSK-3 $\beta$ and GR expression in muscle, but it did not result in restoration of mTORC1 signaling. This suggests that distinct triggers, such as inflammation, may lie at the basis of the apparent inconsistency between REDD1 expression and mTORC1 activity. Sepsis -or endotoxin-induced decreases in translation initiation may be mediated by inflammatory cytokines such as TNF- $\alpha$ (92, 93), and occur independently of REDD1 in GSK-3 $\beta$-and GR-deficient muscle in response to LPS. Similarly, Krüppel-like factor 15 (KLF-15) may negatively affect mTORC1 activity indirectly (150), by enhancing branched-chain amino acid transaminase 2 (BCAT2) expression resulting in subsequent catabolism of branched chain amino acids (BCAAs) $(73,77,150)$. BCAAs are poorly metabolized in the initial phase of the postprandial period, and are therefore in a unique position among amino acids to act as nutrient signals, influencing protein synthesis, degradation and insulin secretion $(27,72,148)$. Recent evidence suggests that elevating blood BCAA levels is sufficient to relieve the catabolic effects of LPS on skeletal muscle protein synthesis by stimulating mTORC1 activity (95).

In addition to REDD1 and KLF-15, myostatin expression was also dependent on GSK-3 $\beta$. Myostatin may contribute to protein synthesis by negatively affecting Akt/mTORC1 signaling $(7,172)$. However, despite the apparent dependency of these genes on GSK-3 $\beta$, our results provided no evidence for restoration of protein synthesis signaling in absence of GSK-3 $\beta$ in response to pulmonary inflammation (chapter 5 ). In conclusion, despite evidence suggesting that GSK-3 $\beta$ plays a broader role in protein synthesis by regulating translation initiation, its function appears to be limited to 
negative regulation of elF2B activity in skeletal muscle under atrophy conditions as investigated here. Our data clearly indicate that any alterations in the IGFI/Akt/mTORC1 sub-pathway occurred independently of GSK-3ß. Therefore, skeletal muscle-restricted deletion of GSK-3 $\beta$ in itself is not decisive in tipping the balance of protein synthesis.

\section{The role of GSK-3ß in muscle proteolysis signaling}

GSK-3 $\beta$-dependent prevention of skeletal muscle atrophy as observed in our in vitro (chapter $\mathbf{3}$ ) and in vivo studies (chapter $\mathbf{4}$, chapter 5 and chapter 6) likely reflected a role of GSK-3 $\beta$ in mediating skeletal muscle protein breakdown. In chapter $\mathbf{5}$, we postulated that a GSK-3 $\beta$ - GR-mediated signaling axis controls FoXO-dependent UPS and ALP gene expression by controlling de novo FoXO expression. Increased FoXO expression was capable of overriding Akt-mediated nuclear exclusion of FoXO, suggestive of a second, non-canonical mode of regulation of FoXO-mediated control of GC-mediated muscle atrophy, operating independently of FoXO regulation through phosphorylation. Our data were in support of a potential regulatory role for GSK-3 $\beta$ within the nucleus, influencing the transcriptional activity of the GR without affecting its nuclear localization. Next to Dex-induced nuclear accumulation of GSK-3 $\beta$, a concomitant reduction in the phosphorylation state of nuclear GSK-3 $\beta$ at $\operatorname{Ser}^{9}$ was indicative of elevated enzymatic activity, and therefore suggested that GSK-3 $\beta$ kinase activity may have played a role in the modulatory effects on GR-dependent transcriptional regulation. As phosphorylation of GSK-3 $\beta$ at $\operatorname{Ser}^{9}$ is mediated by Akt, decreased nuclear GSK-3 $\beta$ phosphorylation may have reflected reduced Akt activity, possibly brought about by non-genomic GR actions inhibiting PI-3K/Akt signaling in response to Dex (76). In addition to facilitating de novo FoXO expression, presumably by enhancing nuclear GSK-3 $\beta$ activity (chapter 5), decreased Akt activity will also result in nuclear accumulation of existing FoXO transcription factors. As such, activated insulin/IGF-I signaling may act at two levels to inhibit FoXO-dependent gene expression. First, Akt-mediated phosphorylation prevents nuclear accretion of FoXO (canonical), and secondly, GSK-3 $\beta$ inactivation by Akt may decrease GR-driven FoXO expression (non-canonical) (Figure 7.1).

Besides FoXO, other GR-dependent genes investigated in this thesis have been implicated in processes related to muscle protein turnover and protein metabolism. In addition to direct genomic GR actions, FoXO expression may also be subject to indirect genomic effects (150). The transcription factor KLF-15 was identified as a direct GR target gene which subsequently induced FoXO mRNA expression, thereby contributing to the transcription of atrogin-1 and MuRF1 (150). As KLF-15 induction in muscle was dependent on GSK-3 $\beta$, reduced KLF-15 expression may have, at least in part, contributed to decreases in atrogin-1 and MuRF1 transcript levels in absence of GSK-3 $\beta$. Furthermore, FoXO1 was demonstrated to mediate myostatin expression in conjunction with Smad transcription factors (6). In turn, overexpression of myostatin 
promotes FoXO1 expression, and results in increased expression of atrogin-1 and MuRF1, implying a functional relationship between myostatin signaling and the regulation of the UPS (114). Beyond a direct role in muscle proteolysis signaling through FoXO, the GSK-3 $\beta$ - GR signaling axis adds an additional layer of complexity to skeletal muscle protein turnover regulation, through indirect control of muscle protein synthesis and degradation by regulating REDD1, KLF-15 and myostatin expression in response to GCs. In analogy to Akt, GSK-3 $\beta$ thus constitutes a central signaling molecule coordinately regulating contractile protein degradation and synthesis (Figure 7.1).

As discussed in chapter 2, the proteasome (UPS) cannot degrade intact myofibrils, so the first step in the degradation of myofibrillar proteins during atrophy requires the release of myofilaments from the sarcomere, which can then be subsequently targeted for UPS-mediated destruction. This early "upstream" dissociation of the myofibril relies on the calpain and caspase systems $(35,57)$. One of the striking observations in this dissertation was the complete prevention of muscle mass loss in absence of GSK-3 $\beta$ following nutrient deprivation (chapter 4) or acute pulmonary inflammation (chapter 5), despite a significant residual increase in atrogin-1, MuRF1 and ALP-related transcript levels. This implies that, next to a role in UPS -and ALPmediated protein degradation, GSK-3 $\beta$ may also be inextricably involved in other cellular mechanisms that control muscle mass, independently of FoXO. Previous work by the group of Hasselgren demonstrated that the calpain inhibitors calpeptin and BN82270 inhibited sepsis-induced muscle proteolysis, without reducing atrogin-1 and MuRF1 mRNA levels (48). Our findings suggest that the complete prevention of muscle atrophy in absence of muscle GSK-3 $\beta$ expression might have signified a direct or indirect role for GSK-3 $\beta$ in mediating caspase -or calpain-dependent muscle proteolysis. Interestingly, calpain activation was found to be associated with attenuated Akt signaling, which in turn resulted in increased GSK-3 $\beta$ and FoXO activity $(153,154)$. Moreover, in a recent study by Ebert et al. growth arrest and DNA damageinducible 45a (Gadd45a) was identified as a critical mediator of muscle atrophy, as it stimulated autophagy and caspase-mediated proteolysis (38). Specifically, following acute stresses such as fasting and muscle disuse, Gadd45a translocates to the nucleus where it alters myonuclear morphology and induces widespread changes in skeletal muscle mRNA expression (38). In this study, increased caspase-3 activity, consequent to Gadd45a overexpression, was associated with enhanced GSK-3 $\beta$ activity (38). The concurrent activation of GSK-3 $\beta$ and caspase- 3 may have concerned more than an association, in particular given previous studies demonstrating a causal role for GSK$3 \beta$ in caspase activation $(17,87,88)$. Could a similar line of reasoning hold true for calpain activation, i.e. implying that increased GSK-3 $\beta$ activity could cause enhanced calpain-mediated muscle degradation? Very recent evidence indeed indicated that independent inhibition of calpain or caspase-3 prevented disuse muscle atrophy. 
Furthermore, inhibition of calpain activity also prevented caspase- 3 activation and vice versa, suggesting a regulatory cross-talk between these proteases (161).

Gadd45a was identified through an unbiased search for potential downstream mediators of the stress-inducible, pro-atrophy transcription factor activating transcription factor 4 (ATF-4) (38, 39), whose expression had been associated with muscle atrophy in response to fasting, denervation, diabetes, cancer and renal failure $(98,131)$. Interestingly, pilot data by our group demonstrated that during pulmonary inflammation-induced muscle atrophy, the induction of ATF-4 mRNA expression was dependent on GSK-3 $\beta$ (Figure 7.2). It tempting to suggest that, as Gadd45a expression requires ATF-4, GSK-3 $\beta$ may play a pivotal regulatory role upstream of ATF-4 thereby determining Gadd45a and, by extension, caspase-3 activation during muscle wasting. Of note, several lines of evidence have postulated that the UPS and cysteine (Cys) proteases (i.e. calpains and caspases) engage in intricate molecular cross-talk. For example, caspase-3 activation stimulated proteasome activity (UPS) (102) in cultured muscle cells (168), which resulted in a feed-forward amplification of muscle protein degradation in concert with the UPS (168). Consequently, it is tempting to suggest that GSK-3 $\beta$ governs an additional level of cross-talk between the UPS, ALP and Cys proteases, as increased GSK-3 $\beta$ activity could either directly or indirectly relay signaling cues to stimulate caspase and calpain-mediated dissociation of the myofibril, while simultaneously regulating atrogin-1, MuRF1 and ALP-related gene expression through transcriptional control of the GR. GR-driven transcriptional cascades provide integrated cues toward muscle breakdown and coordinated nutrient supply to other organs. Transcriptional upregulation of glutamate-ammonia ligase (Glul) is essential for increased biosynthesis of glutamine to support hepatic gluconeogenesis during muscle wasting (18). Gene expression analyses in chapter 5 revealed that increases in Glul transcript levels were blocked in GSK-3 $\beta$-and GR-deficient muscle, which may have prevented impaired amino acid secretion by skeletal muscle. Subsequent intracellular accumulation of amino acids could have initiated a negative feedback signal halting further proteolysis. 


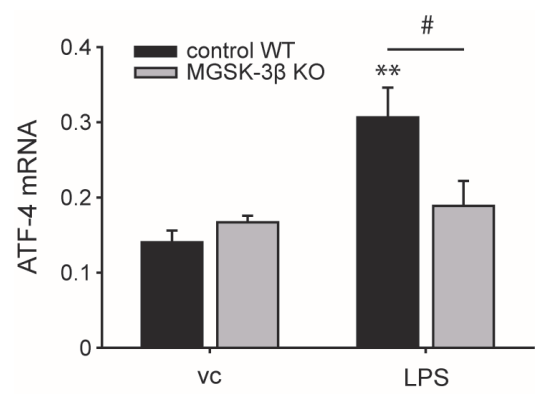

Figure 7.2 Pulmonary inflammation-induced induction of ATF-4 mRNA expression requires GSK-3 $\beta$. MGSK-3 $\beta$ KO and WT control mice were subjected to IT-LPS or vc for $48 \mathrm{~h}$, after which the mRNA transcript levels of the transcription factor ATF-4 were assessed. All data shown represent means \pm SEM, $n=6$ animals per group. ${ }^{* *} p<0.01$ compared with the vc-treated WT control group; \# $\mathrm{p}<0.05$ refers to a difference between indicated conditions.

Similar to the observations made in the MGSK-3 $\beta$ KO studies (chapter 4 and chapter 5), skeletal muscle mass loss was also completely prevented in GR-deficient muscle in response to acute pulmonary inflammation (chapter 5). However, there was a notable difference between both muscle-specific knockout models with regard to proteolysis signaling. As indicated, complete inhibition of muscle atrophy in GSK-3 $\beta$ deficient muscle was accompanied by residual proteolytic signaling, whereas UPS -and ALP-related gene expression was completely blocked upon skeletal muscle-restricted deletion of the GR. An important question that arises from this observation is: how did the residual induction of UPS -and ALP-related genes came into being? In chapter 5, we reported that FoXO expression was dependent on GSK-3 $\beta$ and GR expression. The observed reductions in UPS -and ALP-related gene expression in both studies were likely the result of decreased nuclear FoXO accumulation, consequent to reduced FoXO expression. However, nuclear translocation of the existing pool of FoXO, i.e. canonical regulation, occurs independently of GSK-3 $\beta$ and could explain the partial decrease in UPS -and ALP-related gene expression. It is therefore unlikely that GSK-3 $\beta$ may have directly contributed to nuclear translocation of FoXO in muscle, although a direct GSK-3 $\beta$-FoXO interaction was previously implicated in the regulation of FoXO activity and nuclear translocation in the brain (185) and in kidney cells (133). In clear contrast with the MGR KO study, non-genomic effects of the GR could still have contributed to FoXO translocation by suppression of Akt activity in GSK-3 $\beta$-deficient muscle, providing a possible explanation for the lack of proteolytic signaling in the MGR KO animals only.

Remarkably, inhibition of basal IGF-I/Akt signaling (chapter 3, data not shown), starvation (chapter 4), and pulmonary inflammation (chapter 5, data not shown) resulted in significantly upregulated GSK-3 $\beta$ mRNA levels, suggesting GSK-3 $\beta$ regulation at the transcriptional level in addition to post-translational modification, 
i.e. phosphorylation (Figure 7.3). These findings indicate that, in analogy to FoXO, there may exist an additional, previously unidentified mechanism of GSK-3 $\beta$ activity regulation, based on expression and presumably acting in concert with posttranslational modification via phosphorylation. Nevertheless, these data need to be interpreted with caution, since increases in GSK-3 $\beta$ protein abundance remain to be confirmed. Apparently, this putative novel regulatory mechanism is not subject to direct control by the GR, as Dex-treatment did not result in increases in GSK-3 $\beta$ mRNA levels (data not shown). Instead, increases in GSK-3 $\beta$, but not GSK-3 $\alpha$, mRNA might be regulated by a transcription factor that is embedded in the IGF-I/Akt/GSK-3 $\beta$ signaling path. Increasing GSK-3 $\beta$ expression could be purposeful as part of a positive feedback

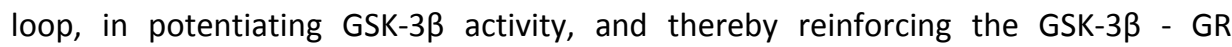
signaling axis.

A
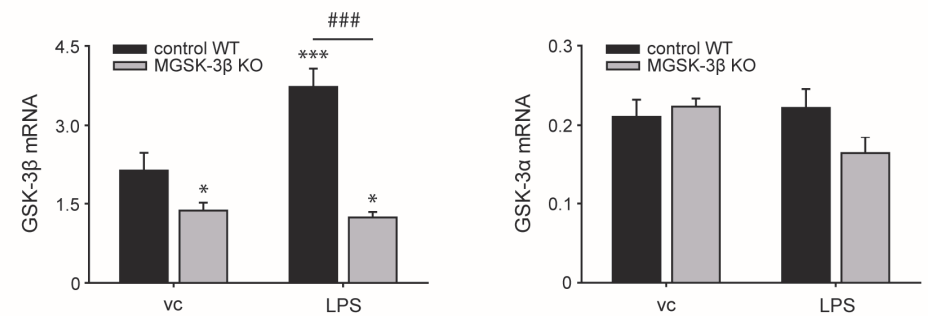

B
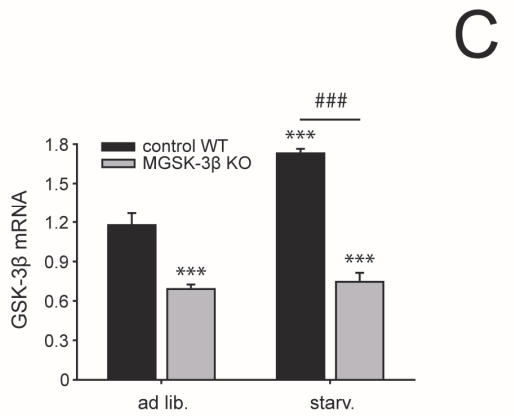

$$
\mathrm{C}_{2} \mathrm{C}_{12}
$$

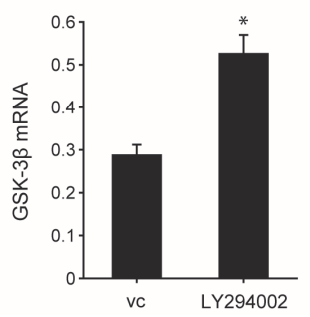

$\mathrm{C}_{2} \mathrm{C}_{12}$

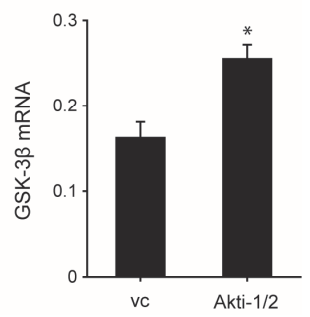

Figure 7.3 Regulation of GSK-3 $\beta$, but not GSK-3 $\alpha$, activity at the transcriptional level.

(A) MGSK-3 $\beta$ KO and WT control mice were subjected to IT-LPS or vc for $48 \mathrm{~h}$, after which the mRNA transcript levels of GSK-3 $\beta$ and GSK-3 $\alpha$ were assessed in plantaris muscle. (B) Musclespecific GSK-3 $\beta$ knockout (MGSK-3 $\beta$ KO) and WT control mice $\left(\right.$ GSK-3 $\beta^{\mathrm{fl} / f \mathrm{l}}$ ) were either fasted for $24 \mathrm{~h}$ or fed ad libitum, after which the mRNA transcript levels of GSK-3 $\beta$ were determined in plantaris muscle. (C) Alternatively, native $\mathrm{C}_{2} \mathrm{C}_{12}$ myotubes were cultured in the presence of LY294002, Akti-1/2 or vc (DMSO) for $24 \mathrm{~h}$ prior to the determination of GSK-3 $\beta$ mRNA abundance. All data shown represent means $\pm S E M, A: n=6, B: n=5$ animals per group. Cell culture data are representative of 3 independent experiments ( $n=3$ per group). ${ }^{*} p<0.05, * * *$ $\mathrm{p}<0.001$ compared with the vc-treated WT control group, or vc-treated myotubes; \# $\mathrm{p}<0.05$, $\# \# \mathrm{p}<0.01$ refers to a difference between indicated conditions. 


\section{GSK-3 $\beta$ and muscle plasticity: beyond control of protein turnover in muscle mass regulation}

In chapter 6 we briefly touched upon the potential contribution of impaired muscle regeneration to sustained skeletal muscle atrophy following LPS-induced chronic pulmonary inflammation, and focused specifically on the role of GSK-3 $\beta$ therein. We established that pharmacological GSK-3 inhibition with either LiCl or CHIR99021 prevented impaired myogenesis in response to TNF- $\alpha$ or synthetic GC-treatment in vitro. As highlighted in chapter $\mathbf{2}$, myogenic differentiation is a process that not only occurs in skeletal muscle development during embryogenesis, but also during postnatal muscle growth or regeneration, making it an essential determinant of skeletal muscle mass plasticity (5). Efficient regeneration and restoration of muscle mass following injury or during recovery from atrophy requires activation, proliferation and subsequent differentiation of satellite cells into myoblasts that fuse with existing or form new myofibers $(71,118)$. An increase in myofiber size is dependent on the accretion of new myonuclei (119), as one myonucleus can only regulate mRNA production for a finite sarcoplasmic volume, designated the myonuclear domain (5). Consequently, an uncompensated loss of myonuclei as a consequence of limitations in myonuclear domain size, will invariably lead to skeletal muscle fiber atrophy (5). Thus, in addition to a balance in protein metabolism (protein turnover), myonuclear turnover, i.e. the balance between myonuclear loss and myonuclear accretion, may constitute an additional cellular mechanism determining skeletal muscle mass plasticity. For instance, muscle disuse atrophy is associated with an imbalance in myonuclear turnover, and, at least in part, depends on a mechanism that involves apoptosis or programmed cell death $(4,116,124)$. Next to activating the UPS, TNF- $\alpha$ can also induce apoptosis in skeletal muscle cells and myoblasts $(16,158)$. Indeed, it was demonstrated that apoptosis played a role during muscle wasting in COPD, in particular in patients with a very low body mass index (BMI) $(3,123)$. As of yet, there are no studies directly implicating GSK-3 $\beta$ in the regulation of myonuclear apoptosis. However, as apoptotic signaling relies heavily on caspase-3, there might be a role reserved for GSK-3 $\beta$ in mediating muscle fiber apoptosis (vide supra).

Myonuclear turnover is also governed by changes in myonuclear accretion. In chapter 6, we established that pharmacological GSK-3 inhibition in differentiating $\mathrm{C}_{2} \mathrm{C}_{12}$ muscle cells prevented reduced myogenesis in response to TNF- $\alpha$ and GCs. These findings were in line with previous work by our group, showing that myogenic differentiation during regrowth of atrophied skeletal muscle was associated with GSK$3 \beta$ inactivation (163). These results concerned more than an association, as subsequent in vitro evidence clearly established that pharmacological GSK-3 $\beta$ inhibition enhanced myogenic differentiation (164). Further modulation of GSK-3 $\beta$ activity by genetic approaches corroborated the above-mentioned results, and revealed that negative regulation of myogenic differentiation by GSK-3 $\beta$ was the direct result of decreased 
nuclear factor of activated T cells c3 (NFATc3)-dependent gene expression (165), due to enhanced GSK-3 $\beta$-dependent nuclear export of NFAT (149). More recent work by our group revealed a segregated regulation of myoblast fusion and muscle-specific gene expression following stimulation of myogenic differentiation in response to distinct ligand-specific signaling routes of GSK-3 $\beta$ inactivation (121). As such, pharmacological inhibition of GSK-3 $\beta$ will affect both gene regulatory as well as the cellular remodeling processes involved in myogenic differentiation, by activating two GSK-3 $\beta$ substrates, namely NFAT and $\beta$-catenin, which are controlled by two distinct cellular pools of GSK$3 \beta$ (166).

\section{GSK-3 $\beta$ and muscle plasticity: a role for GSK-3 $\beta$ in the regulation of cell-intrinsic features determining muscle composition and metabolism?}

Although the scope of this thesis is restricted to the role of GSK-3 $\beta$ in muscle protein turnover, skeletal muscle plasticity is also determined by intrinsic metabolic properties. Besides muscle atrophy, impaired functioning of the remaining muscle contributes significantly to reduced endurance. The cellular processes that maintain muscle size and functional capacity intertwine and are tightly regulated by contractile activity, nutrient supply and hormonal action (15). For instance, exercise can protect against disuse atrophy, and various other systemic causes of muscle wasting (2, 171, 186), whilst simultaneously positively affecting fatigability (muscle endurance). However, the mechanisms by which contractile activity reduces atrophy remain poorly understood. Increased physical activity stimulates expression of the transcriptional coactivator peroxisome proliferator-activated receptor $\gamma$ coactivator $1 \alpha$ (PGC-1 $\alpha$ ). The PGC-1 family of coactivators are prime regulators of oxidative metabolism and mitochondrial content, and they are essential in the maintenance of glucose, lipid and energy homeostasis in muscle (137). It also functions as a metabolic sensor of motor neuron-induced calcium $\left(\mathrm{Ca}^{2+}\right)$ signaling $(28,65)$. The expression of PGC-1 $\alpha$ in muscle increases acutely and chronically with exercise $(11,115,129)$, and its mRNA levels decrease during disuse and various other types of muscle wasting (131, 137). Moreover, data from our group demonstrated that the PGC-1 $\alpha$ pathway was disturbed in muscle of COPD patients (127). On the other hand, transgenic expression of either PGC-1 $\alpha$ or its homolog PGC-1 $\beta$ in muscle results in a substantial increase in muscle mitochondrial content $(9,105,115,157)$ and resistance to fatigue $(9,105)$. Intriguingly, overexpressing PGC-1 $\alpha$ in skeletal muscle blunted the denervation or fasting-induced increase in atrogin-1 and MuRF1 expression (137), and prevented the induction of UPS -and ALP-related gene expression by a constitutively active FoXO3a (caFoXO3a) (20). 
GSK-3 $\beta$ also appears to control cellular muscle oxidative phenotype (OXPHEN) as GSK-3 $\beta$ inhibition was found to promote slow (oxidative) muscle fiber type composition (82), and induced mitochondrial biogenesis in endothelial cells (160). In fact, activated GSK-3 $\beta$ represses PGC-1 $\alpha$ signaling (160) directly by targeting PGC-1 $\alpha$ for intranuclear UPS-mediated degradation, and by inhibiting transcription of the PGC-1 $\alpha$ gene itself (8). Pilot data by our lab confirmed the involvement of GSK-3 $\beta$ in the regulation of PGC-1 $\alpha$ in muscle, as pharmacological or genetic inhibition of GSK-3 $\beta$ greatly increased the expression of PGC-1 $\alpha$ (data not shown). In the light of the above, it is plain to see that regulation of muscle mass and muscle composition should not be viewed as two independent processes. Quite the contrary, although the exact contribution of GSK-3 $\beta$ to regulation of muscle OXPHEN remains incompletely explored, it is tempting to suggest that GSK-3 $\beta$ may function as a nodal point interconnecting the molecular regulation of muscle mass and muscle OXPHEN.

Consequently, GSK-3 $\beta$ inhibition could act as a double-edged therapeutic sword in combating muscle pathology by potentially improving both impairments in muscle OXPHEN as well as muscle atrophy, which may be very relevant for COPD. It is wellestablished that next to the presence of muscle wasting, peripheral skeletal muscle oxidative phenotype (OXPHEN) is disturbed in muscles of COPD patients. Loss of muscle OXPHEN involves a fiber type shift towards a more glycolytic phenotype (Type $\mathrm{I} \rightarrow$ Type II), reduced activity levels of enzymes involved in oxidative metabolism and impaired mitochondrial functioning $(58-60,62,63,117)$. Pharmacological GSK-3 $\beta$ inhibition may therefore represent an attractive therapeutic approach to ameliorate impaired exercise capacity in COPD by simultaneously improving muscle endurance and strength (vide infra).

\section{Muscle wasting in COPD: a role for the GSK-3 $\beta$ - GR signaling axis?}

To efficaciously treat muscle wasting and remodeling during COPD a clear understanding of the etiology and mechanisms of the disease is needed. As indicated above, skeletal muscle atrophy in COPD may be attributable to a multitude of factors, which occur isolated or in concert during different phases of the disease (Table 7.1). Interestingly, almost all of the atrophy triggers listed above, with the notable exception of disuse (inactivity), share a common denominator, namely GCs. GCs are released naturally as an endogenous response to stress conditions including inflammation (68), hypoxia $(54,89,96)$, or during conditions of nutrient limitation (malnutrition) to facilitate hepatic gluconeogenesis (29). Treatment with synthetic GCs is also a common intervention during acute or end stage chronic respiratory disease, and may evoke or aggravate muscle wasting, as GCs are potent inducers of muscle atrophy $(12,34,170,176)$. Considering this, the GSK-3 $\beta$ - GR signaling axis, as postulated 
in this dissertation, directly applies under conditions of malnutrition, inflammation and GC-treatment. Moreover, it may very well be that in absence of raised GC levels, for instance during inactivity-induced atrophy (disuse), the GSK-3 $\beta$ - GR signaling axis also contributes to muscle wasting, as disuse is associated with decreased IGF-I and mechano growth factor (MGF) signaling, which, in turn, allows for unrestrained GSK$3 \beta$ activity. This lack of GSK-3 $\beta$ inhibition may be accompanied by increased sensitivity to basal GC levels, ultimately resulting in muscle atrophy. Furthermore, even though hypoxemia is associated with increased circulating GC levels, it is currently unclear whether GCs are a causal factor in the onset of muscle atrophy in this condition. Nevertheless, it is well-known that in both human as well as animal studies hypoxia reduces appetite and decreases food intake, which may in turn decrease IGF-I/Akt signaling $(22,49,175)$. The GSK-3 $\beta$ - GR signaling axis could therefore play a central role in the interaction and potential synergy between the above-mentioned atrophy triggers. Specifically, low insulin levels, consequent to reduced food intake (malnutrition), will hamper physiological GSK-3 $\beta$ inactivation, thereby increasing the sensitivity to endogenous GCs. Further, COPD patients suffering from acute exacerbations are often hospitalized and treated with high doses of synthetic GCs. Under these circumstances prolonged bed rest (inactivity), reduced food intake (low insulin levels/signaling), and potential insulin resistance (due to inflammation), in combination with elevated levels of exogenous as well as endogenous GC levels may act synergistically to increase skeletal muscle atrophy via the GSK-3 $\beta$ - GR signaling axis.

\section{Therapeutic potential of GSK-3 $\beta$ modulation in COPD: breaking the GSK-3 $\beta$ - GR signaling axis}

Table 7.1 Putative triggers of muscle wasting in COPD. Common antagonism of glucocorticoid and IGF-I/Akt signaling?
- Inflammation
- Hypoxemia
- Malnutrition
- Inactivity
- Glucocorticoids

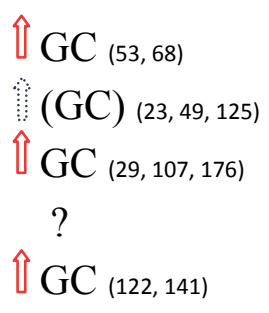

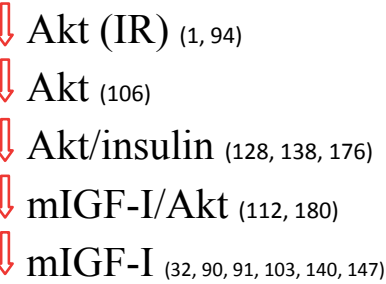

The multifactorial nature of COPD requires a multifaceted intervention. Many studies have addressed the efficacy of exercise training on skeletal muscle and function in $\operatorname{COPD}(52,61,146)$. Combined resistance and endurance training is effective 
in increasing lean muscle mass, strength and exercise capacity, which is associated with an improved quality of life in patients with $\operatorname{COPD}(21,120)$. The beneficial effects of exercise in COPD may be the result of improved muscle regeneration (152), reduction of apoptosis (151), suppression of UPS activity (100), and an increase in protein synthesis $(47,111,180)$. Interestingly, GSK-3 $\beta$ has been implicated in all of these processes. Moreover, exercise training improves local IGF-I expression in muscle (64), and activates Akt signaling, leading to inhibition of GSK-3 $\beta$ activity. As such, increased physical activity may thwart the GSK-3 $\beta$ - GR signaling axis, thereby reducing UPS -and ALP-mediated muscle protein degradation. Importantly, exercise itself results in increased plasma GC levels, thereby stimulating gluconeogenesis and mobilization of amino acids and fatty acids from body stores $(36,162)$. However, exercise-induced release of endogenous GCs is an acute phenomenon, and plasma GCs quickly return to pre-exercise levels after an acute bout of exercise $(37,139)$. Nutritional support has also been demonstrated to result in functional improvements in depleted COPD patients $(142,143)$. Food intake stimulates IGF-I/Akt signaling due to increased insulin levels. Also, specific nutrients such as branched-chain amino acids (BCAAs) may decrease GSK-3 $\beta$ activity independently of Akt by stimulating mTORC1 signaling. Indeed, BCAA supplementation has been demonstrated to result in increased S6K1 phosphorylation via mTORC1 $(30,31)$, which could in turn result in GSK-3 $\beta$ inactivation. Thus, it is tempting to suggest that besides stimulation of protein synthesis, BCAAinduced activation of mTORC1 could also downregulate UPS -and ALP-related transcriptional programs through GSK-3 $\beta$ inhibition, independently of insulin and Akt signaling. A combination of nutritional support and exercise training may be a good approach to obtain improvements in muscle mass and function in patients with COPD $(44,142,143)$. In order to achieve the best outcome for the patient, maximal GSK-3 $\beta$ inhibition should be opted for. Specifically, one could combine a diet rich in BCAAs with a stringent resistance exercise protocol, resulting in both direct as well as indirect GSK-3 $\beta$ inhibition.

Therapeutic interventions aimed at the treatment of muscle atrophy will either target the impaired signaling that lies at the basis of disturbed muscle mass homeostasis, or may aim at pharmacological modulation of central regulators of the processes that govern muscle plasticity. An important feature of GSK-3 $\beta$ to consider for the purpose of pharmacological inhibition, is that physiological stimuli including insulin, IGF-I or exercise typically reduce GSK-3 activity only to $20-50 \%$ of basal levels in skeletal muscle $(113,164,177)$, indicating that complete inhibition of this molecule may not be needed and desirable. Moreover, over-inhibition of GSK-3 under normal circumstances might have detrimental effects, such as tumorigenesis (74), cardiac hypertrophy $(66,67)$ or induction of neurodegenerative markers $(75)$. The potential negative effects of (systemic) GSK-3 inhibition were illustrated in chapter 6, where sustained basal GSK-3 inhibition resulted in a blunted increase in body weight in control animals. In other words, restoration of physiological GSK-3 activity levels could 
be sufficient to yield important therapeutic effects in pathologies characterized by aberrant GSK-3 regulation $(26,41)$.

Furthermore, the pleiotropic actions of GSK-3 3 , apart from its involvement in muscle plasticity, not only warrant care with the applied dose of GSK-3 $\beta$ inhibitors, potential pharmacological intervention also raises questions regarding timing, delivery and specificity. For instance, chronic GSK-3 $\beta$ inhibition could prove useful in preventing muscle wasting, whereas acute GSK-3 $\beta$ inhibition may be suitable option during recovery from atrophy. In terms of drug delivery, local GSK-3 $\beta$ inhibition (in muscle) may be preferable to systemic administration, in view of potential undesirable off-target effects. Targeted drug delivery can be achieved by designing monoclonal antibodies that only target specific cells. These antibodies may be modified to deliver biologically active substances, such as pharmaceuticals. Similarly, nanomedicine has provided the possibility of delivering drugs to specific cells using nanoparticles. Besides timing and delivery, the specificity of GSK-3 $\beta$ inhibitors is of vital importance. In this context, substrate-competitive inhibitors deserve further development and characterization, as these will allow superior specificity towards downstream signaling of GSK-3 $\beta$ related to processes involved in muscle plasticity (chapter 2). In chapter 3, we demonstrated that basal and atrophy stimulus-induced atrogin-1 mRNA expression required GSK-3 $\beta$ enzymatic activity, whereas MuRF1 expression depended solely on the physical presence of GSK-3 $\beta$. These findings are significant because they suggest biological functions of GSK-3 $\beta$ independent of its kinase activity, for which specific inhibitors could be designed. To further investigate the differential dependency of atrogin-1 and MuRF1 expression on GSK-3 $\beta$ 's kinase domain, overexpression of a constitutively active form of GSK-3 $\beta$ (caGSK-3 $\beta$ ) (S9A mutant) in the presence of a GSK-3 $\beta$ inhibitor should only decrease atrogin-1 expression, whereas introducing a kinase-dead GSK-3 $\beta$ (K85R mutant) should exclusively result in MuRF1 induction. These experiments are the first step, and paramount in the quest to further unravel the exact mechanism of the GSK-3 $\beta$ - GR signaling axis and, as such, may shed new light on the differential dependency of atrogin-1 and MuRF1 on GSK-3 $\beta$ activity.

When systemic GSK-3 $\beta$ inhibition is opted for, administered inhibitor doses may be reduced by sensitizing skeletal muscle by means of tailored exercise, as the latter enhances local drug delivery due to increased blood flow, and more importantly, in itself already reduces muscle GSK-3 $\beta$ activity levels (100). Therefore, the integration of pharmacological, nutritional and physical training modalities into a multimodal treatment strategy aimed at inhibition of GSK-3 $\beta$ will allow optimal exploitation of its potential role as a central regulator of skeletal muscle plasticity for the treatment of skeletal muscle wasting. 


\section{References}

1. Aasebo U, Gyltnes A, Bremnes RM, Aakvaag A, and Slordal L. Reversal of sexual impotence in male patients with chronic obstructive pulmonary disease and hypoxemia with long-term oxygen therapy. $J$ Steroid Biochem Mol Biol 46: 799-803, 1993.

2. Adams GR, Haddad F, Bodell PW, Tran PD, and Baldwin KM. Combined isometric, concentric, and eccentric resistance exercise prevents unloading-induced muscle atrophy in rats. J Appl Physiol 103: 1644-1654, 2007.

3. Agusti AG, Sauleda J, Miralles C, Gomez C, Togores B, Sala E, Batle S, and Busquets X. Skeletal muscle apoptosis and weight loss in chronic obstructive pulmonary disease. Am J Respir Crit Care Med 166: 485-489, 2002.

4. Allen DL, Linderman JK, Roy RR, Bigbee AJ, Grindeland RE, Mukku V, and Edgerton VR. Apoptosis: a mechanism contributing to remodeling of skeletal muscle in response to hindlimb unweighting. Am J Physiol 273: C579-587, 1997.

5. Allen DL, Roy RR, and Edgerton VR. Myonuclear domains in muscle adaptation and disease. Muscle Nerve 22: 1350-1360, 1999.

6. Allen DL and Unterman TG. Regulation of myostatin expression and myoblast differentiation by FoxO and SMAD transcription factors. Am J Physiol Cell Physiol 292: C188-199, 2007.

7. Amirouche A, Durieux AC, Banzet S, Koulmann N, Bonnefoy R, Mouret C, Bigard X, Peinnequin A, and Freyssenet $D$. Down-regulation of $A k t / m a m m a l i a n$ target of rapamycin signaling pathway in response to myostatin overexpression in skeletal muscle. Endocrinology 150: 286-294, 2009.

8. Anderson RM, Barger JL, Edwards MG, Braun KH, O'Connor CE, Prolla TA, and Weindruch R. Dynamic regulation of PGC-1alpha localization and turnover implicates mitochondrial adaptation in calorie restriction and the stress response. Aging Cell 7: 101-111, 2008.

9. Arany Z, Lebrasseur N, Morris C, Smith E, Yang W, Ma Y, Chin S, and Spiegelman BM. The transcriptional coactivator PGC-1beta drives the formation of oxidative type IIX fibers in skeletal muscle. Cell Metab 5: 35-46, 2007.

10. Armstrong JL, Bonavaud SM, Toole BJ, and Yeaman SJ. Regulation of glycogen synthesis by amino acids in cultured human muscle cells. J Biol Chem 276: 952-956, 2001.

11. Baar K, Wende AR, Jones TE, Marison M, Nolte LA, Chen M, Kelly DP, and Holloszy JO. Adaptations of skeletal muscle to exercise: rapid increase in the transcriptional coactivator PGC-1. FASEB J 16: 18791886, 2002.

12. Baehr LM, Furlow JD, and Bodine SC. Muscle sparing in muscle RING finger 1 null mice: response to synthetic glucocorticoids. J Physiol 589: 4759-4776, 2011.

13. Barton-Davis ER, Shoturma DI, Musaro A, Rosenthal N, and Sweeney HL. Viral mediated expression of insulin-like growth factor I blocks the aging-related loss of skeletal muscle function. Proc Nat/ Acad Sci U S A 95: 15603-15607, 1998.

14. Barton ER, Morris L, Musaro A, Rosenthal N, and Sweeney HL. Muscle-specific expression of insulinlike growth factor I counters muscle decline in mdx mice. J Cell Biol 157: 137-148, 2002.

15. Bassel-Duby R and Olson EN. Signaling pathways in skeletal muscle remodeling. Annu Rev Biochem 75: 19-37, 2006.

16. Bazzoni $\mathrm{F}$ and Beutler B. The tumor necrosis factor ligand and receptor families. $N$ Engl J Med 334: 1717-1725, 1996.

17. Bhat RV, Leonov S, Luthman J, Scott CW, and Lee CM. Interactions between GSK3beta and caspase signalling pathways during NGF deprivation induced cell death. J Alzheimers Dis 4: 291-301, 2002.

18. Biolo G, Zorat F, Antonione R, and Ciocchi B. Muscle glutamine depletion in the intensive care unit. Int J Biochem Cell Biol 37: 2169-2179, 2005.

19. Bodine SC, Stitt TN, Gonzalez M, Kline WO, Stover GL, Bauerlein R, Zlotchenko E, Scrimgeour A, Lawrence JC, Glass DJ, and Yancopoulos GD. Akt/mTOR pathway is a crucial regulator of skeletal muscle hypertrophy and can prevent muscle atrophy in vivo. Nat Cell Biol 3: 1014-1019, 2001.

20. Brault JJ, Jespersen JG, and Goldberg AL. Peroxisome proliferator-activated receptor gamma coactivator 1alpha or 1beta overexpression inhibits muscle protein degradation, induction of ubiquitin ligases, and disuse atrophy. J Biol Chem 285: 19460-19471, 2010. 
21. Casaburi R. Skeletal muscle dysfunction in chronic obstructive pulmonary disease. Med Sci Sports Exerc 33: S662-670, 2001.

22. Chaudhary P, Suryakumar G, Prasad R, Singh SN, Ali S, and Ilavazhagan G. Chronic hypobaric hypoxia mediated skeletal muscle atrophy: role of ubiquitin-proteasome pathway and calpains. Mol Cell Biochem 364: 101-113, 2012.

23. Chen XQ, Dong J, Niu CY, Fan JM, and Du JZ. Effects of hypoxia on glucose, insulin, glucagon, and modulation by corticotropin-releasing factor receptor type 1 in the rat. Endocrinology 148: 32713278, 2007.

24. Clarke BA, Drujan D, Willis MS, Murphy LO, Corpina RA, Burova E, Rakhilin SV, Stitt TN, Patterson C, Latres $\mathrm{E}$, and Glass DJ. The E3 Ligase MuRF1 degrades myosin heavy chain protein in dexamethasonetreated skeletal muscle. Cell Metab 6: 376-385, 2007.

25. Cohen P and Frame S. The renaissance of GSK3. Nature Reviews, Molecular Cell Biology 2: 769-776, 2001.

26. Cohen P and Goedert M. GSK3 inhibitors: Development and their therapeutic potential. Nature Reviews, Drug Discovery 3: 479-487, 2004.

27. Cota D, Proulx K, Smith KA, Kozma SC, Thomas G, Woods SC, and Seeley RJ. Hypothalamic mTOR signaling regulates food intake. Science 312: 927-930, 2006.

28. Czubryt MP, McAnally J, Fishman GI, and Olson EN. Regulation of peroxisome proliferator-activated receptor gamma coactivator 1 alpha (PGC-1 alpha) and mitochondrial function by MEF2 and HDAC5. Proc Natl Acad Sci U S A 100: 1711-1716, 2003.

29. Dallman MF, Strack AM, Akana SF, Bradbury MJ, Hanson ES, Scribner KA, and Smith M. Feast and famine: critical role of glucocorticoids with insulin in daily energy flow. Front Neuroendocrinol 14: 303-347, 1993.

30. Dann SG, Selvaraj A, and Thomas G. mTOR Complex1-S6K1 signaling: at the crossroads of obesity, diabetes and cancer. Trends Mol Med 13: 252-259, 2007.

31. Dann SG and Thomas G. The amino acid sensitive TOR pathway from yeast to mammals. FEBS Lett 580: 2821-2829, 2006.

32. Desler MM, Jones SJ, Smith CW, and Woods TL. Effects of dexamethasone and anabolic agents on proliferation and protein synthesis and degradation in C2C12 myogenic cells. J Anim Sci 74: 12651273, 1996.

33. Doble BW and Woodgett JR. GSK-3: tricks of the trade for a multi-tasking kinase. J Cell Sci 116: 11751186, 2003.

34. Dodd SL, Powers SK, Vrabas IS, and Eason JM. Interaction of glucocorticoids and activity patterns affect muscle function. Muscle Nerve 18: 190-195, 1995.

35. Du J, Wang X, Miereles C, Bailey JL, Debigare R, Zheng B, Price SR, and Mitch WE. Activation of caspase-3 is an initial step triggering accelerated muscle proteolysis in catabolic conditions. J Clin Invest 113: 115-123, 2004.

36. Duclos M. Evidence on ergogenic action of glucocorticoids as a doping agent risk. Phys Sportsmed 38: 121-127, 2010.

37. Duclos $M$, Gouarne $C$, and Bonnemaison D. Acute and chronic effects of exercise on tissue sensitivity to glucocorticoids. J Appl Physiol 94: 869-875, 2003.

38. Ebert SM, Dyle MC, Kunkel SD, Bullard SA, Bongers KS, Fox DK, Dierdorff JM, Foster ED, and Adams CM. Stress-induced Skeletal Muscle Gadd45a Expression Reprograms Myonuclei and Causes Muscle Atrophy. J Biol Chem 287: 27290-27301, 2012.

39. Ebert SM, Monteys AM, Fox DK, Bongers KS, Shields BE, Malmberg SE, Davidson BL, Suneja M, and Adams CM. The transcription factor ATF4 promotes skeletal myofiber atrophy during fasting. Mol Endocrinol 24: 790-799, 2010.

40. Eldar-Finkelman $\mathrm{H}$ and Krebs EG. Phosphorylation of insulin receptor substrate 1 by glycogen synthase kinase 3 impairs insulin action. Proc Natl Acad Sci U S A 94: 9660-9664, 1997.

41. Eldar-Finkelman $\mathrm{H}$ and Martinez A. GSK-3 Inhibitors: Preclinical and Clinical Focus on CNS. Front Mol Neurosci 4: 32, 2011.

42. Ellisen LW. Growth control under stress: mTOR regulation through the REDD1-TSC pathway. Cell Cycle 4: 1500-1502, 2005. 
43. Embi N, Rylatt DB, and Cohen P. Glycogen synthase kinase-3 from rabbit skeletal muscle. Separation from cyclic-AMP-dependent protein kinase and phosphorylase kinase. Eur J Biochem 107: 519-527, 1980.

44. Engelen MP, Rutten EP, De Castro CL, Wouters EF, Schols AM, and Deutz NE. Altered interorgan response to feeding in patients with chronic obstructive pulmonary disease. Am J Clin Nutr 82: 366372, 2005.

45. Evenson AR, Fareed MU, Menconi MJ, Mitchell JC, and Hasselgren PO. GSK-3beta inhibitors reduce protein degradation in muscles from septic rats and in dexamethasone-treated myotubes. Int $J$ Biochem Cell Biol 37: 2226-2238, 2005.

46. Fang CH, Li BG, James JH, King JK, Evenson AR, Warden GD, and Hasselgren PO. Protein breakdown in muscle from burned rats is blocked by insulin-like growth factor $\mathrm{i}$ and glycogen synthase kinase-3beta inhibitors. Endocrinology 146: 3141-3149, 2005.

47. Fanzani A, Conraads VM, Penna F, and Martinet W. Molecular and cellular mechanisms of skeletal muscle atrophy: an update. J Cachexia Sarcopenia Muscle, 2012.

48. Fareed MU, Evenson AR, Wei W, Menconi M, Poylin V, Petkova V, Pignol B, and Hasselgren PO. Treatment of rats with calpain inhibitors prevents sepsis-induced muscle proteolysis independent of atrogin-1/MAFbx and MuRF1 expression. Am J Physiol Regul Integr Comp Physiol 290: R1589-1597, 2006.

49. Favier FB, Costes F, Defour A, Bonnefoy R, Lefai E, Bauge S, Peinnequin A, Benoit H, and Freyssenet D. Downregulation of Akt/mammalian target of rapamycin pathway in skeletal muscle is associated with increased REDD1 expression in response to chronic hypoxia. Am J Physiol Regul Integr Comp Physiol 298: R1659-1666, 2010.

50. Fluck $\mathrm{M}$ and Hoppeler $\mathrm{H}$. Molecular basis of skeletal muscle plasticity--from gene to form and function. Rev Physiol Biochem Pharmacol 146: 159-216, 2003.

51. Frame $S$ and Cohen P. GSK3 takes centre stage more than 20 years after its discovery. Biochem J 359: 1-16, 2001.

52. Franssen FM, Broekhuizen R, Janssen PP, Wouters EF, and Schols AM. Limb muscle dysfunction in COPD: effects of muscle wasting and exercise training. Med Sci Sports Exerc 37: 2-9, 2005.

53. Gan WQ, Man SF, Senthilselvan A, and Sin DD. Association between chronic obstructive pulmonary disease and systemic inflammation: a systematic review and a meta-analysis. Thorax 59: 574-580, 2004.

54. Gardner DS, Fletcher AJ, Fowden AL, and Giussani DA. Plasma adrenocorticotropin and cortisol concentrations during acute hypoxemia after a reversible period of adverse intrauterine conditions in the ovine fetus during late gestation. Endocrinology 142: 589-598, 2001.

55. Glass DJ. Signaling pathways perturbing muscle mass. Curr Opin Clin Nutr Metab Care 13: 225-229, 2010.

56. Glass DJ. Skeletal muscle hypertrophy and atrophy signaling pathways. Int J Biochem Cell Biol 37: 1974-1984, 2005.

57. Goll DE, Neti G, Mares SW, and Thompson VF. Myofibrillar protein turnover: the proteasome and the calpains. J Anim Sci 86: E19-35, 2008.

58. Gosker HR, Engelen MP, van Mameren H, van Dijk PJ, van der Vusse GJ, Wouters EF, and Schols AM. Muscle fiber type IIX atrophy is involved in the loss of fat-free mass in chronic obstructive pulmonary disease. Am J Clin Nutr 76: 113-119, 2002.

59. Gosker HR, Hesselink MK, Duimel H, Ward KA, and Schols AM. Reduced mitochondrial density in the vastus lateralis muscle of patients with COPD. Eur Respir J 30: 73-79, 2007.

60. Gosker HR, Kubat B, Schaart G, van der Vusse GJ, Wouters EF, and Schols AM. Myopathological features in skeletal muscle of patients with chronic obstructive pulmonary disease. Eur Respir J 22: 280-285, 2003.

61. Gosker HR, Schrauwen P, Broekhuizen R, Hesselink MK, Moonen-Kornips E, Ward KA, Franssen FM, Wouters EF, and Schols AM. Exercise training restores uncoupling protein-3 content in limb muscles of patients with chronic obstructive pulmonary disease. Am J Physiol Endocrinol Metab 290: E976981, 2006.

62. Gosker HR, Wouters EF, van der Vusse GJ, and Schols AM. Skeletal muscle dysfunction in chronic obstructive pulmonary disease and chronic heart failure: underlying mechanisms and therapy perspectives. Am J Clin Nutr 71: 1033-1047, 2000. 
63. Gosker HR, Zeegers MP, Wouters EF, and Schols AM. Muscle fibre type shifting in the vastus lateralis of patients with COPD is associated with disease severity: a systematic review and meta-analysis. Thorax 62: 944-949, 2007.

64. Hambrecht R, Schulze PC, Gielen S, Linke A, Mobius-Winkler S, Erbs S, Kratzsch J, Schubert A, Adams $V$, and Schuler $G$. Effects of exercise training on insulin-like growth factor-I expression in the skeletal muscle of non-cachectic patients with chronic heart failure. Eur J Cardiovasc Prev Rehabil 12: 401-406, 2005.

65. Handschin C, Rhee J, Lin J, Tarr PT, and Spiegelman BM. An autoregulatory loop controls peroxisome proliferator-activated receptor gamma coactivator 1alpha expression in muscle. Proc Natl Acad Sci U S A 100: 7111-7116, 2003.

66. Haq S, Choukroun G, Kang ZB, Ranu H, Matsui T, Rosenzweig A, Molkentin JD, Alessandrini A, Woodgett J, Hajjar R, Michael A, and Force T. Glycogen synthase kinase-3beta is a negative regulator of cardiomyocyte hypertrophy. J Cell Biol 151: 117-130, 2000.

67. Hardt SE and Sadoshima J. Glycogen synthase kinase-3 beta: A novel regulator of cardiac hypertrophy and development. Circ Res 90: 1055-1063, 2002.

68. Hardy RS, Raza K, and Cooper MS. Endogenous glucocorticoids in inflammation: contributions of systemic and local responses. Swiss Med Wkly 142: w13650, 2012.

69. Harwood AJ. Regulation of GSK-3: a cellular multiprocessor. Cell 105: 821-824, 2001.

70. Hasselgren PO. Glucocorticoids and muscle catabolism. Curr Opin Clin Nutr Metab Care 2: 201-205, 1999.

71. Hawke TJ and Garry DJ. Myogenic satellite cells: physiology to molecular biology. J Appl Physiol 91: 534-551, 2001.

72. Hay N and Sonenberg N. Upstream and downstream of mTOR. Genes Dev 18: 1926-1945, 2004.

73. Herman MA, She P, Peroni OD, Lynch CJ, and Kahn BB. Adipose tissue branched chain amino acid (BCAA) metabolism modulates circulating BCAA levels. J Biol Chem 285: 11348-11356, 2010.

74. Hinoi T, Yamamoto H, Kishida M, Takada S, Kishida S, and Kikuchi A. Complex formation of adenomatous polyposis coli gene product and axin facilitates glycogen synthase kinase-3 betadependent phosphorylation of beta-catenin and down-regulates beta-catenin. J Biol Chem 275: 34399-34406, 2000.

75. Hu S, Begum AN, Jones MR, Oh MS, Beech WK, Beech BH, Yang F, Chen P, Ubeda OJ, Kim PC, Davies P, Ma $Q$, Cole GM, and Frautschy SA. GSK3 inhibitors show benefits in an Alzheimer's disease (AD) model of neurodegeneration but adverse effects in control animals. Neurobiol Dis 33: 193-206, 2009.

76. Hu Z, Wang H, Lee IH, Du J, and Mitch WE. Endogenous glucocorticoids and impaired insulin signaling are both required to stimulate muscle wasting under pathophysiological conditions in mice. J Clin Invest 119: 3059-3069, 2009.

77. Ichihara A and Koyama E. Transaminase of branched chain amino acids. I. Branched chain amino acids-alpha-ketoglutarate transaminase. J Biochem 59: 160-169, 1966.

78. Inoki K, Ouyang H, Zhu T, Lindvall C, Wang $Y$, Zhang $X$, Yang $Q$, Bennett $C$, Harada $Y$, Stankunas $K$, Wang CY, He X, MacDougald OA, You M, Williams BO, and Guan KL. TSC2 integrates Wnt and energy signals via a coordinated phosphorylation by AMPK and GSK3 to regulate cell growth. Cell 126: 955968, 2006.

79. Jackman RW and Kandarian SC. The molecular basis of skeletal muscle atrophy. Am J Physiol Cell Physiol 287: C834-843, 2004.

80. Jagoe RT and Goldberg AL. What do we really know about the ubiquitin-proteasome pathway in muscle atrophy? Curr Opin Clin Nutr Metab Care 4: 183-190, 2001.

81. Jefferson LS, Fabian JR, and Kimball SR. Glycogen synthase kinase-3 is the predominant insulinregulated eukaryotic initiation factor 2B kinase in skeletal muscle. Int J Biochem Cell Biol 31: 191-200, 1999.

82. Jiang $\mathrm{H}$, Li H, and DiMario JX. Control of slow myosin heavy chain 2 gene expression by glycogen synthase kinase activity in skeletal muscle fibers. Cell Tissue Res 323: 489-494, 2006.

83. Kandarian SC and Jackman RW. Intracellular signaling during skeletal muscle atrophy. Muscle Nerve 33: 155-165, 2006.

84. Katiyar S, Liu E, Knutzen CA, Lang ES, Lombardo CR, Sankar S, Toth JI, Petroski MD, Ronai Z, and Chiang GG. REDD1, an inhibitor of mTOR signalling, is regulated by the CUL4A-DDB1 ubiquitin ligase. EMBO Rep 10: 866-872, 2009. 
85. Kelly GM, Buckley DA, Kiely PA, Adams DR, and O'Connor R. Serine Phosphorylation of the Insulin-like Growth Factor I (IGF-1) Receptor C-terminal Tail Restrains Kinase Activity and Cell Growth. J Biol Chem 287: 28180-28194, 2012.

86. Kim DH, Sarbassov DD, Ali SM, King JE, Latek RR, Erdjument-Bromage H, Tempst P, and Sabatini DM. mTOR interacts with raptor to form a nutrient-sensitive complex that signals to the cell growth machinery. Cell 110: 163-175, 2002.

87. King TD, Bijur GN, and Jope RS. Caspase-3 activation induced by inhibition of mitochondrial complex I is facilitated by glycogen synthase kinase-3beta and attenuated by lithium. Brain Res 919: 106-114, 2001.

88. King TD and Jope RS. Inhibition of glycogen synthase kinase-3 protects cells from intrinsic but not extrinsic oxidative stress. Neuroreport 16: 597-601, 2005.

89. Kodama T, Shimizu N, Yoshikawa N, Makino Y, Ouchida R, Okamoto K, Hisada T, Nakamura H, Morimoto $\mathrm{C}$, and Tanaka $\mathrm{H}$. Role of the glucocorticoid receptor for regulation of hypoxia-dependent gene expression. J Biol Chem 278: 33384-33391, 2003.

90. Kumari R, Willing LB, Jefferson LS, Simpson IA, and Kimball SR. REDD1 (regulated in development and DNA damage response 1) expression in skeletal muscle as a surrogate biomarker of the efficiency of glucocorticoid receptor blockade. Biochem Biophys Res Commun 412: 644-647, 2011.

91. Kuo T, Lew MJ, Mayba O, Harris CA, Speed TP, and Wang JC. Genome-wide analysis of glucocorticoid receptor-binding sites in myotubes identifies gene networks modulating insulin signaling. Proc Natl Acad Sci U S A 109: 11160-11165, 2012.

92. Lang $\mathrm{CH}$ and Frost RA. Endotoxin disrupts the leucine-signaling pathway involving phosphorylation of mTOR, 4E-BP1, and S6K1 in skeletal muscle. J Cell Physiol 203: 144-155, 2005.

93. Lang $\mathrm{CH}$ and Frost RA. Sepsis-induced suppression of skeletal muscle translation initiation mediated by tumor necrosis factor alpha. Metabolism 56: 49-57, 2007.

94. Lang $\mathrm{CH}$, Frost RA, and Vary TC. Regulation of muscle protein synthesis during sepsis and inflammation. Am J Physiol Endocrinol Metab 293: E453-459, 2007.

95. Lang CH, Lynch CJ, and Vary TC. BCATm deficiency ameliorates endotoxin-induced decrease in muscle protein synthesis and improves survival in septic mice. Am J Physiol Regul Integr Comp Physiol 299: R935-944, 2010.

96. Larsen JJ, Hansen JM, Olsen NV, Galbo H, and Dela F. The effect of altitude hypoxia on glucose homeostasis in men. J Physiol 504 ( Pt 1): 241-249, 1997.

97. Latres E, Amini AR, Amini AA, Griffiths J, Martin FJ, Wei Y, Lin HC, Yancopoulos GD, and Glass DJ. Insulin-like growth factor-1 (IGF-1) inversely regulates atrophy-induced genes via the phosphatidylinositol 3-kinase/Akt/mammalian target of rapamycin (PI3K/Akt/mTOR) pathway. J Biol Chem 280: 2737-2744, 2005.

98. Lecker SH, Jagoe RT, Gilbert A, Gomes M, Baracos V, Bailey J, Price SR, Mitch WE, and Goldberg AL. Multiple types of skeletal muscle atrophy involve a common program of changes in gene expression. Faseb J 18: 39-51, 2004

99. Lecker SH, Solomon V, Mitch WE, and Goldberg AL. Muscle protein breakdown and the critical role of the ubiquitin-proteasome pathway in normal and disease states. J Nutr 129: 227S-237S, 1999.

100. Leger B, Cartoni R, Praz M, Lamon S, Deriaz O, Crettenand A, Gobelet C, Rohmer P, Konzelmann M, Luthi $F$, and Russell AP. Akt signalling through GSK-3beta, mTOR and Foxo1 is involved in human skeletal muscle hypertrophy and atrophy. J Physiol 576: 923-933, 2006.

101. Li BG, Hasselgren PO, and Fang CH. Insulin-like growth factor-I inhibits dexamethasone-induced proteolysis in cultured L6 myotubes through PI3K/Akt/GSK-3beta and PI3K/Akt/mTOR-dependent mechanisms. Int J Biochem Cell Biol 37: 2207-2216, 2005.

102. Li Y, Gazdoiu S, Pan ZQ, and Fuchs SY. Stability of homologue of Slimb F-box protein is regulated by availability of its substrate. J Biol Chem 279: 11074-11080, 2004.

103. Li YH, Fan J, and Lang CH. Differential role of glucocorticoids in mediating endotoxin-induced changes in IGF-I and IGFBP-1. Am J Physiol 272: R1990-1997, 1997.

104. Liberman Z, Plotkin B, Tennenbaum $\mathrm{T}$, and Eldar-Finkelman H. Coordinated phosphorylation of insulin receptor substrate- 1 by glycogen synthase kinase- 3 and protein kinase $C$ betall in the diabetic fat tissue. Am J Physiol Endocrinol Metab 294: E1169-1177, 2008. 
105. Lin J, Wu H, Tarr PT, Zhang CY, Wu Z, Boss O, Michael LF, Puigserver P, Isotani E, Olson EN, Lowell BB, Bassel-Duby R, and Spiegelman BM. Transcriptional co-activator PGC-1 alpha drives the formation of slow-twitch muscle fibres. Nature 418: 797-801, 2002.

106. Liu L, Cash TP, Jones RG, Keith B, Thompson CB, and Simon MC. Hypoxia-induced energy stress regulates mRNA translation and cell growth. Mol Cell 21: 521-531, 2006.

107. Makimura H, Mizuno TM, Isoda F, Beasley J, Silverstein JH, and Mobbs CV. Role of glucocorticoids in mediating effects of fasting and diabetes on hypothalamic gene expression. BMC Physiol 3: 5, 2003.

108. Malys $\mathrm{N}$ and McCarthy JE. Translation initiation: variations in the mechanism can be anticipated. Cell Mol Life Sci 68: 991-1003, 2011.

109. Mammucari C, Milan G, Romanello V, Masiero E, Rudolf R, Del Piccolo P, Burden SJ, Di Lisi R, Sandri C, Zhao J, Goldberg AL, Schiaffino S, and Sandri M. FoxO3 controls autophagy in skeletal muscle in vivo. Cell Metab 6: 458-471, 2007.

110. Mammucari C, Schiaffino S, and Sandri M. Downstream of Akt: FoxO3 and mTOR in the regulation of autophagy in skeletal muscle. Autophagy 4: 524-526, 2008.

111. Man WD, Kemp P, Moxham J, and Polkey MI. Exercise and muscle dysfunction in COPD: implications for pulmonary rehabilitation. Clin Sci (Lond) 117: 281-291, 2009.

112. Marimuthu K, Murton AJ, and Greenhaff PL. Mechanisms regulating muscle mass during disuse atrophy and rehabilitation in humans. J Appl Physiol 110: 555-560, 2011.

113. Markuns JF, Wojtaszewski JF, and Goodyear L. Insulin and exercise decrease glycogen synthase kinase-3 activity by different mechanisms in rat skeletal muscle. J Biol Chem 274: 24896-24900, 1999.

114. McFarlane C, Plummer E, Thomas M, Hennebry A, Ashby M, Ling N, Smith H, Sharma M, and Kambadur R. Myostatin induces cachexia by activating the ubiquitin proteolytic system through an NF-kappaB-independent, FoxO1-dependent mechanism. J Cell Physiol 209: 501-514, 2006.

115. Meirhaeghe A, Crowley V, Lenaghan C, Lelliott C, Green K, Stewart A, Hart K, Schinner S, Sethi JK, Yeo G, Brand MD, Cortright RN, O'Rahilly S, Montague C, and Vidal-Puig AJ. Characterization of the human, mouse and rat PGC1 beta (peroxisome-proliferator-activated receptor-gamma co-activator 1 beta) gene in vitro and in vivo. Biochem J 373: 155-165, 2003.

116. Mitchell PO and Pavlath GK. A muscle precursor cell-dependent pathway contributes to muscle growth after atrophy. Am J Physiol Cell Physiol 281: C1706-1715, 2001.

117. Miyagi K, Asanoi H, Ishizaka S, Kameyama T, Wada O, Seto H, and Sasayama S. Importance of total leg muscle mass for exercise intolerance in chronic heart failure. Jpn Heart J 35: 15-26, 1994.

118. Morgan JE and Partridge TA. Muscle satellite cells. Int J Biochem Cell Biol 35: 1151-1156, 2003.

119. Mozdziak PE, Schultz E, and Cassens RG. Myonuclear accretion is a major determinant of avian skeletal muscle growth. Am J Physiol 272: C565-571, 1997.

120. Ortega F, Toral J, Cejudo P, Villagomez R, Sanchez H, Castillo J, and Montemayor T. Comparison of effects of strength and endurance training in patients with chronic obstructive pulmonary disease. Am J Respir Crit Care Med 166: 669-674, 2002.

121. Pansters NA, van der Velden JL, Kelders MC, Laeremans H, Schols AM, and Langen RC. Segregation of myoblast fusion and muscle-specific gene expression by distinct ligand-dependent inactivation of GSK-3beta. Cell Mol Life Sci 68: 523-535, 2011.

122. Pereira RM and Freire de Carvalho J. Glucocorticoid-induced myopathy. Joint Bone Spine 78: 41-44, 2011.

123. Plataki M, Tzortzaki E, Rytila P, Demosthenes M, Koutsopoulos A, and Siafakas NM. Apoptotic mechanisms in the pathogenesis of COPD. Int J Chron Obstruct Pulmon Dis 1: 161-171, 2006.

124. Powers SK, Kavazis AN, and McClung JM. Oxidative stress and disuse muscle atrophy. J Appl Physiol 102: 2389-2397, 2007.

125. Raff $\mathrm{H}$ and Levy SA. Renin-angiotensin II-aldosterone and ACTH-cortisol control during acute hypoxemia and exercise in patients with chronic obstructive pulmonary disease. Am Rev Respir Dis 133: 396-399, 1986.

126. Reid MB. Response of the ubiquitin-proteasome pathway to changes in muscle activity. Am J Physiol Regul Integr Comp Physiol 288: R1423-1431, 2005.

127. Remels AH, Schrauwen P, Broekhuizen R, Willems J, Kersten S, Gosker HR, and Schols AM. Peroxisome proliferator-activated receptor expression is reduced in skeletal muscle in COPD. Eur Respir J 30: 245252, 2007. 
128. Rommel C, Bodine SC, Clarke BA, Rossman R, Nunez L, Stitt TN, Yancopoulos GD, and Glass DJ. Mediation of IGF-1-induced skeletal myotube hypertrophy by $\mathrm{PI}(3) \mathrm{K} / \mathrm{Akt} / \mathrm{mTOR}$ and $\mathrm{PI}(3) \mathrm{K} / \mathrm{Akt} / \mathrm{GSK} 3$ pathways. Nat Cell Biol 3: 1009-1013, 2001.

129. Russell AP, Feilchenfeldt J, Schreiber S, Praz M, Crettenand A, Gobelet C, Meier CA, Bell DR, Kralli A, Giacobino JP, and Deriaz $O$. Endurance training in humans leads to fiber type-specific increases in levels of peroxisome proliferator-activated receptor-gamma coactivator-1 and peroxisome proliferator-activated receptor-alpha in skeletal muscle. Diabetes 52: 2874-2881, 2003.

130. Rylatt DB, Aitken A, Bilham T, Condon GD, Embi N, and Cohen P. Glycogen synthase from rabbit skeletal muscle. Amino acid sequence at the sites phosphorylated by glycogen synthase kinase-3, and extension of the $\mathrm{N}$-terminal sequence containing the site phosphorylated by phosphorylase kinase. Eur J Biochem 107: 529-537, 1980.

131. Sacheck JM, Hyatt JP, Raffaello A, Jagoe RT, Roy RR, Edgerton VR, Lecker SH, and Goldberg AL. Rapid disuse and denervation atrophy involve transcriptional changes similar to those of muscle wasting during systemic diseases. Faseb J 21: 140-155, 2007.

132. Sacheck JM, Ohtsuka A, McLary SC, and Goldberg AL. IGF-I stimulates muscle growth by suppressing protein breakdown and expression of atrophy-related ubiquitin ligases, atrogin-1 and MuRF1. Am J Physiol Endocrinol Metab 287: E591-601, 2004.

133. Sakamaki J, Daitoku H, Kaneko Y, Hagiwara A, Ueno K, and Fukamizu A. GSK3beta regulates gluconeogenic gene expression through HNF4alpha and FOXO1. J Recept Signal Transduct Res 32: 96101, 2012.

134. Sakamoto K and Goodyear L. Invited review: intracellular signaling in contracting skeletal muscle. J Appl Physiol 93: 369-383, 2002.

135. Sandri M. Autophagy in health and disease. 3. Involvement of autophagy in muscle atrophy. Am J Physiol Cell Physiol 298: C1291-1297, 2010.

136. Sandri M. Signaling in muscle atrophy and hypertrophy. Physiology (Bethesda) 23: 160-170, 2008.

137. Sandri M, Lin J, Handschin C, Yang W, Arany ZP, Lecker SH, Goldberg AL, and Spiegelman BM. PGC1alpha protects skeletal muscle from atrophy by suppressing FoxO3 action and atrophy-specific gene transcription. Proc Natl Acad Sci U S A 103: 16260-16265, 2006.

138. Sandri M, Sandri C, Gilbert A, Skurk C, Calabria E, Picard A, Walsh K, Schiaffino S, Lecker SH, and Goldberg AL. Foxo transcription factors induce the atrophy-related ubiquitin ligase atrogin-1 and cause skeletal muscle atrophy. Cell 117: 399-412, 2004.

139. Sapolsky RM, Romero LM, and Munck AU. How do glucocorticoids influence stress responses? Integrating permissive, suppressive, stimulatory, and preparative actions. Endocr Rev 21: 55-89, 2000.

140. Schakman O, Gilson H, de Coninck V, Lause P, Verniers J, Havaux X, Ketelslegers JM, and Thissen JP. Insulin-like growth factor-I gene transfer by electroporation prevents skeletal muscle atrophy in glucocorticoid-treated rats. Endocrinology 146: 1789-1797, 2005.

141. Schakman O, Gilson H, and Thissen JP. Mechanisms of glucocorticoid-induced myopathy. J Endocrinol 197: 1-10, 2008.

142. Schols A. Nutritional modulation as part of the integrated management of chronic obstructive pulmonary disease. Proc Nutr Soc 62: 783-791, 2003.

143. Schols AM. Nutritional and metabolic modulation in chronic obstructive pulmonary disease management. Eur Respir J Suppl 46: 81s-86s, 2003.

144. Schols AM, Slangen J, Volovics L, and Wouters EF. Weight loss is a reversible factor in the prognosis of chronic obstructive pulmonary disease. Am J Respir Crit Care Med 157: 1791-1797, 1998.

145. Schulze PC, Fang J, Kassik KA, Gannon J, Cupesi M, MacGillivray C, Lee RT, and Rosenthal N. Transgenic overexpression of locally acting insulin-like growth factor-1 inhibits ubiquitin-mediated muscle atrophy in chronic left-ventricular dysfunction. Circ Res 97: 418-426, 2005.

146. Serres I, Gautier V, Varray A, and Prefaut C. Impaired skeletal muscle endurance related to physical inactivity and altered lung function in COPD patients. Chest 113: 900-905, 1998.

147. Shah OJ, Kimball SR, and Jefferson LS. Acute attenuation of translation initiation and protein synthesis by glucocorticoids in skeletal muscle. Am J Physiol Endocrinol Metab 278: E76-82, 2000.

148. She P, Reid TM, Bronson SK, Vary TC, Hajnal A, Lynch CJ, and Hutson SM. Disruption of BCATm in mice leads to increased energy expenditure associated with the activation of a futile protein turnover cycle. Cell Metab 6: 181-194, 2007. 
149. Shen T, Cseresnyes Z, Liu Y, Randall WR, and Schneider MF. Regulation of the nuclear export of the transcription factor NFATc1 by protein kinases after slow fibre type electrical stimulation of adult mouse skeletal muscle fibres. J Physiol 579: 535-551, 2007.

150. Shimizu N, Yoshikawa N, Ito N, Maruyama T, Suzuki Y, Takeda S, Nakae J, Tagata Y, Nishitani S, Takehana K, Sano M, Fukuda K, Suematsu M, Morimoto C, and Tanaka H. Crosstalk between glucocorticoid receptor and nutritional sensor mTOR in skeletal muscle. Cell Metab 13: 170-182, 2011.

151. Siu PM, Bryner RW, Martyn JK, and Alway SE. Apoptotic adaptations from exercise training in skeletal and cardiac muscles. FASEB J 18: 1150-1152, 2004.

152. Siu PM, Donley DA, Bryner RW, and Alway SE. Myogenin and oxidative enzyme gene expression levels are elevated in rat soleus muscles after endurance training. J Appl Physiol 97: 277-285, 2004.

153. Smith IJ and Dodd SL. Calpain activation causes a proteasome-dependent increase in protein degradation and inhibits the Akt signalling pathway in rat diaphragm muscle. Exp Physiol 92: 561-573, 2007.

154. Smith IJ, Lecker SH, and Hasselgren PO. Calpain activity and muscle wasting in sepsis. Am J Physiol Endocrinol Metab 295: E762-771, 2008.

155. Sofer A, Lei K, Johannessen CM, and Ellisen LW. Regulation of mTOR and cell growth in response to energy stress by REDD1. Mol Cell Biol 25: 5834-5845, 2005.

156. Song YH, Li Y, Du J, Mitch WE, Rosenthal N, and Delafontaine P. Muscle-specific expression of IGF-1 blocks angiotensin II-induced skeletal muscle wasting. J Clin Invest 115: 451-458, 2005.

157. St-Pierre J, Lin J, Krauss S, Tarr PT, Yang R, Newgard CB, and Spiegelman BM. Bioenergetic analysis of peroxisome proliferator-activated receptor gamma coactivators 1alpha and 1beta (PGC-1alpha and PGC-1beta) in muscle cells. J Biol Chem 278: 26597-26603, 2003.

158. Stewart CE, Newcomb PV, and Holly JM. Multifaceted roles of TNF-alpha in myoblast destruction: a multitude of signal transduction pathways. J Cell Physiol 198: 237-247, 2004.

159. Stitt TN, Drujan D, Clarke BA, Panaro F, Timofeyva Y, Kline WO, Gonzalez M, Yancopoulos GD, and Glass DJ. The IGF-1/PI3K/Akt pathway prevents expression of muscle atrophy-induced ubiquitin ligases by inhibiting FOXO transcription factors. Mol Cell 14: 395-403, 2004.

160. Struewing IT, Barnett CD, Tang T, and Mao CD. Lithium increases PGC-1alpha expression and mitochondrial biogenesis in primary bovine aortic endothelial cells. FEBS J 274: 2749-2765, 2007.

161. Talbert EE, Smuder AJ, Min K, Kwon OS, and Powers SK. Calpain and capase-3 play required roles in immobilization-induced limb muscle atrophy. J Appl Physiol, 2013.

162. Tharp GD. The role of glucocorticoids in exercise. Med Sci Sports 7: 6-11, 1975.

163. van der Velden JL, Langen RC, Kelders MC, Willems J, Wouters EF, Janssen-Heininger YM, and Schols AM. Myogenic differentiation during regrowth of atrophied skeletal muscle is associated with inactivation of GSK-3 beta. Am J Physiol Cell Physiol 292: C1636-1644, 2007.

164. van der Velden JL, Langen RC, Kelders MC, Wouters EF, Janssen-Heininger YM, and Schols AM. Inhibition of glycogen synthase kinase-3beta activity is sufficient to stimulate myogenic differentiation. Am J Physiol Cell Physiol 290: C453-462, 2006.

165. van der Velden JL, Schols AM, Willems J, Kelders MC, and Langen RC. Glycogen synthase kinase 3 suppresses myogenic differentiation through negative regulation of NFATc3. J Biol Chem 283: 358366, 2008.

166. Verhees KJ, Pansters NA, Schols AM, and Langen RC. Regulation of skeletal muscle plasticity by glycogen synthase kinase-3beta: a potential target for the treatment of muscle wasting. Curr Pharm Des 19 (18): 3276-3298, 2013.

167. Verhees KJ, Schols AM, Kelders MC, Op den Kamp CM, van der Velden JL, and Langen RC. Glycogen synthase kinase-3beta is required for the induction of skeletal muscle atrophy. Am J Physiol Cell Physiol 301: C995-C1007, 2011.

168. Wang XH, Zhang L, Mitch WE, LeDoux JM, Hu J, and Du J. Caspase-3 cleaves specific 19 S proteasome subunits in skeletal muscle stimulating proteasome activity. J Biol Chem 285: 21249-21257, 2010.

169. Waraich RS, Weigert C, Kalbacher H, Hennige AM, Lutz SZ, Haring HU, Schleicher ED, Voelter W, and Lehmann R. Phosphorylation of Ser357 of rat insulin receptor substrate-1 mediates adverse effects of protein kinase C-delta on insulin action in skeletal muscle cells. J Biol Chem 283: 11226-11233, 2008. 
170. Watson ML, Baehr LM, Reichardt HM, Tuckermann JP, Bodine SC, and Furlow JD. A Cell Autonomous Role for the Glucocorticoid Receptor in Skeletal Muscle Atrophy Induced by Systemic Glucocorticoid Exposure. Am J Physiol Endocrinol Metab, 2012.

171. Wehling $M$, Cai $B$, and Tidball JG. Modulation of myostatin expression during modified muscle use. FASEB J 14: 103-110, 2000.

172. Welle S, Burgess K, and Mehta S. Stimulation of skeletal muscle myofibrillar protein synthesis, p70 S6 kinase phosphorylation, and ribosomal protein $\mathrm{S} 6$ phosphorylation by inhibition of myostatin in mature mice. Am J Physiol Endocrinol Metab 296: E567-572, 2009.

173. Welsh GI, Miller CM, Loughlin AJ, Price NT, and Proud CG. Regulation of eukaryotic initiation factor elF2B: glycogen synthase kinase-3 phosphorylates a conserved serine which undergoes dephosphorylation in response to insulin. FEBS Lett 421: 125-130, 1998.

174. Welsh GI and Proud CG. Glycogen synthase kinase-3 is rapidly inactivated in response to insulin and phosphorylates eukaryotic initiation factor elF-2B. Biochem J 294 ( Pt 3): 625-629, 1993.

175. Westerterp-Plantenga MS, Westerterp KR, Rubbens M, Verwegen CR, Richelet JP, and Gardette B. Appetite at "high altitude" [Operation Everest III (Comex-'97)]: a simulated ascent of Mount Everest. J Appl Physiol 87: 391-399, 1999.

176. Wing SS and Goldberg AL. Glucocorticoids activate the ATP-ubiquitin-dependent proteolytic system in skeletal muscle during fasting. Am J Physiol 264: E668-676, 1993.

177. Wojtaszewski JF, Hansen BF, Gade, Kiens B, Markuns JF, Goodyear LJ, and Richter EA. Insulin signaling and insulin sensitivity after exercise in human skeletal muscle. Diabetes 49: 325-331, 2000.

178. Wray CJ, Mammen JM, Hershko DD, and Hasselgren PO. Sepsis upregulates the gene expression of multiple ubiquitin ligases in skeletal muscle. Int J Biochem Cell Biol 35: 698-705, 2003.

179. Wu Y, Zhao W, Zhao J, Zhang Y, Qin W, Pan J, Bauman WA, Blitzer RD, and Cardozo C. REDD1 is a major target of testosterone action in preventing dexamethasone-induced muscle loss. Endocrinology 151: 1050-1059, 2010.

180. Wust RC and Degens $\mathrm{H}$. Factors contributing to muscle wasting and dysfunction in COPD patients. Int $J$ Chron Obstruct Pulmon Dis 2: 289-300, 2007.

181. Zhang HH, Lipovsky Al, Dibble CC, Sahin M, and Manning BD. S6K1 regulates GSK3 under conditions of mTOR-dependent feedback inhibition of Akt. Mol Cell 24: 185-197, 2006.

182. Zhao J, Brault JJ, Schild A, Cao P, Sandri M, Schiaffino S, Lecker SH, and Goldberg AL. FoxO3 coordinately activates protein degradation by the autophagic/lysosomal and proteasomal pathways in atrophying muscle cells. Cell Metab 6: 472-483, 2007.

183. Zhao J, Brault JJ, Schild A, and Goldberg AL. Coordinate activation of autophagy and the proteasome pathway by FoxO transcription factor. Autophagy 4: 378-380, 2008.

184. Zhao W, Qin W, Pan J, Wu Y, Bauman WA, and Cardozo C. Dependence of dexamethasone-induced Akt/FOXO1 signaling, upregulation of MAFbx, and protein catabolism upon the glucocorticoid receptor. Biochem Biophys Res Commun 378: 668-672, 2009.

185. Zhou W, Chen L, Yang S, Li F, and Li X. Behavioral stress-induced activation of FoxO3a in the cerebral cortex of mice. Biol Psychiatry 71: 583-592, 2012.

186. Zinna EM and Yarasheski KE. Exercise treatment to counteract protein wasting of chronic diseases. Curr Opin Clin Nutr Metab Care 6: 87-93, 2003. 
Chapter 7 
LAYMAN'S SUMMARY

$$
251
$$




\section{Layman's summary}

Under normal (healthy) conditions skeletal muscle is characterized by a high degree of plasticity which allows it to adapt easily to changes in functional demand. For example, repeated strength training will result in muscle growth (hypertrophy). Conversely, periods of inactivity - for example during casting of a broken leg or under pathological conditions (bedridden patients) - will result in loss of muscle mass (atrophy). Skeletal muscle atrophy commonly occurs in patients with chronic obstructive pulmonary disease (COPD). Loss of muscle mass is associated with skeletal muscle weakness, exercise impairment, decreased health status and increased mortality, independently of the severity of airflow obstruction. Muscle wasting, however, is not exclusive to COPD but occurs in many chronic diseases, such as congestive heart failure (CHF), rheumatoid arthritis (RA) and cancer. In addition to disease specific triggers - for instance pulmonary inflammation in COPD - fasting (starvation) and disuse (inactivity) may also cause "erosion of lean muscle mass", or contribute to the muscle wasting process in chronic disease. Prevention and treatment of muscle wasting is therefore increasingly recognized as a prerequisite in an integrated disease management approach of these chronic disorders. In order to reach this goal it is essential to comprehend the molecular mechanisms that underlie skeletal muscle atrophy, and to identify potential "key regulators" of skeletal muscle plasticity. Thereupon, it is important to assess whether these regulatory signaling molecules may constitute potential candidates for physiological and/or pharmacological modulation, with the purpose of treating uncontrolled loss of muscle mass during acute and chronic disease.

Muscle protein turnover is essentially determined by the balance between protein synthesis (anabolism) and degradation (catabolism). The prototypical insulin-like growth factor 1 (IGF-I)/Akt pathway is crucial in this process, as it regulates both catabolic as well as anabolic signals in muscle. Reduced protein content associated with skeletal muscle atrophy is the result of an imbalance between muscle protein synthesis and degradation, in favor of the latter. In general, loss of muscle mass is associated with diminished IGF-I/Akt signaling in muscle, and with increased levels of circulating glucocorticoids (GCs). It is well-known that activation of the IGF-I/Akt signaling cascade can counteract the catabolic effects of GCs. However, at this moments it is still largely unclear how GCs exactly cause muscle atrophy, and how increased IGF-I/Akt signaling neutralizes the atrophy-inducing effects of GCs has only been partially been elucidated. Enhanced muscle proteolysis during muscle atrophy involves activation of the ATP-dependent ubiquitin 26S-proteasome system (UPS) and the autophagy-lysosomal pathway (ALP). Glycogen synthase kinase-3B (GSK-3ß) is a direct downstream target in the IGF-I/Akt signaling pathway, and has previously been shown to be involved in skeletal muscle protein degradation. In this dissertation we have discovered that GSK-3 $\beta$ is a central, negative regulator of muscle mass. 
To ascertain whether GSK-3 $\beta$ could constitute a possible link between IGF-I/Akt and $\mathrm{GC}$ signaling in muscle, we made use of the $\mathrm{C}_{2} \mathrm{C}_{12}$ cell culture system (in vitro) of mouse skeletal muscle myoblasts, which can evolve (differentiate) into multinucleated muscle fibers (myotubes). Experiments conducted in chapter 3 showed that genetic deletion of GSK-3 $\beta$ in $C_{2} C_{12}$ myotubes, using small interfering RNA (siRNA), suppressed both basal and atrophy stimulus-induced transcript levels of the essential UPS-related atrogin-1 and MuRF1 genes (atrogenes). Furthermore, loss of GSK-3 $\beta$ expression resulted in specific sparing of several contractile proteins (muscle proteins), including myosin heavy chain fast (MyHC-f) and myosin light chains 1 (MyLC-1) and -3 (MyLC-3), and myotube size in response to synthetic GC-treatment (dexamethasone, hereinafter termed Dex), or blockade of IGF-I/Akt signaling (using LY294002 as an inhibitor). Interestingly, in contrast to their dependency on GSK-3 $\beta$ expression, the increase in atrogin-1 and MuRF1 mRNA transcript levels differentially relied on GSK-3 $\beta$ activity, as enzymatic GSK-3 $\beta$ inhibition, using either LiCl or CHIR99021, only attenuated atrophy stimulus-induced atrogin-1 expression, while MuRF1 expression levels remained unaffected.

In chapter 4, we confirmed the dependency of atrogene expression on GSK-3 $\beta$ in an animal model (in vivo), by using genetically modified mice (knockout mice) lacking GSK-3 $\beta$ expression specifically in skeletal muscle. Using these muscle-specific GSK-3 $\beta$ knockout mice we evaluated the direct contribution of GSK-3 $\beta$ in two different models of GC-associated muscle wasting, i.e. fasting as endogenous model, and synthetic GC administration as exogenous model. In these studies we have convincingly demonstrated that knocking out GSK-3 $\beta$ in muscle prevented starvation-induced loss of muscle mass, and inhibited skeletal muscle atrophy following chronic Dextreatment. Starvation also significantly upregulated an ALP-related transcriptional program, which appeared to be partially dependent on GSK-3ß. Forkhead Box $O$ (FoXO) transcription factors act as critical liaison molecules coordinately regulating the expression of both ALP-related, as well UPS-associated transcriptional programs in muscle. Starvation resulted in markedly upregulated FoXO mRNA levels, which were attenuated in absence of GSK-3 $\beta$. Furthermore, loss of glucocorticoid receptor (GR) expression in muscle (muscle-specific GR knockout) demonstrated that intact GCsignaling was required for the induction of proteolytic -and GC sensitive gene expression following Dex-treatment. These data were mirrored by similar observations made in GSK-3 $\beta$ knockout animals in response to fasting. On the whole, the striking similarities between the GSK-3 $\beta$ and GR knockout studies with regard to GC-sensitive gene expression, and the dependency of FoXO on GSK-3 $\beta$ and downstream UPS -and ALP-related transcriptional programs, were suggestive of a GSK-3 $\beta$ - GR signaling mechanism operating upstream of FoXO.

The possible interplay between GSK-3 $\beta$ and the GR with regard to atrophy signaling in muscle was further investigated in chapter $\mathbf{5}$. In this study we again made 
use of muscle-specific GSK-3 $\beta$ and GR knockout mice, but this time muscle atrophy was brought about by acute pulmonary inflammation, induced by the bacterial endotoxin lipopolysaccharide (LPS). LPS-induced pulmonary inflammation was accompanied by increases in circulating GCs (corticosterone) and associated GCsensitive gene expression. Similar to the observations made in chapter 4 , skeletal muscle-restricted depletion of GSK-3 $\beta$ and the GR conveyed resistance to pulmonary inflammation-induced muscle atrophy and proteolytic signaling. Another important observation was that in addition to proteolytic (UPS and ALP) and GC-sensitive gene expression, also FoXO mRNA and protein expression were dependent on the presence of GR and GSK-3 $\beta$ in muscle. The current paradigm of FoXO regulation is centered around canonical or classical control of FoXO transcription factors, which relies on "inactivation through phosphorylation". As such, dephosphorylation of FoXO results in nuclear translocation, and subsequent regulation of proteolytic gene expression. In contrast, we postulated that FoXO was a direct target gene of the GR, and that the observed reductions in UPS -and ALP-related gene expression in the GSK-3 $\beta$ and GR knockout studies were likely the result of decreased nuclear FoXO accumulation, as a direct consequence of reduced FoXO expression. Concretely, non-canonical, or nonclassical FoXO regulation implies that GSK-3 $\beta$ translocates (moves) to the cell nucleus, where it stimulates GR-dependent gene expression, which, in turn, results in de novo FoXO. We therefore postulate that FoXO expression is GR-dependent, and that GSK-3 $\beta$ operates upstream of the GR, regulating its transcriptional activity. Consequently, regulation of UPS -and ALP-related gene expression occurs downstream of FoXO. In conclusion, in chapter 5 we proposed a novel GSK-3 $\beta$ - GR-mediated signaling axis controlling FoXO-dependent UPS -and ALP-associated gene expression by regulation of de novo FoXO expression, capable of overruling FoXO phosphorylation and nuclear exclusion mechanisms, and therefore referred to as noncanonical regulation of FoXO.

So far our work indicated that GSK-3 $\beta$ may be considered as a central regulator of muscle mass maintenance. In chapter 6, the potential therapeutic effects of enzymatic GSK-3 inhibition on muscle wasting were assessed in vivo. By making use of a highly selective GSK-3 inhibitor we showed that enzymatic GSK-3 inhibition could be a promising treatment strategy to prevent loss of muscle mass and to stimulate muscle growth in chronic diseases such as COPD. Similar to the study design in chapter 5, LPS was used to induce pulmonary inflammation. However, this time guinea pigs were chronically exposed to LPS, as opposed to the acute LPS model in mice employed in chapter 5. Here too, LPS-treatment resulted in pulmonary inflammation and loss of peripheral muscle mass. Interestingly, our findings illustrated that neither chronic LPS-treatment, nor pharmacological GSK-3 inhibition had any profound effect on muscle protein synthesis and degradation signaling (FoXO). Nevertheless, chronic lung inflammation was associated with a decrease in muscle mass and size of the individual muscle fiber diameter. However, topical (local) 
application of the GSK-3 inhibitor (in the lung) inhibited peripheral muscle atrophy without affecting pulmonary inflammation. Subsequent in vitro experiments clearly showed that pharmacological GSK-3 inhibition could improve the differentiation of muscle cells (as part of muscle regeneration) in the presence of GCs and the inflammatory mediator tumor necrosis factor- $\alpha$ (TNF- $\alpha$ ). Our data seem in line with the presumption that improved muscle regeneration, following GSK-3 inhibition, after an initial period of muscle atrophy, may have led to protection against loss of muscle mass. However, it cannot be ruled out that GSK-3 inhibition may have decreased proteolytic signaling during the early phase of muscle atrophy. On the whole, the results in this study indicate that treatment with a selective GSK-3 inhibitor could prevent or reverse skeletal muscle atrophy, suggesting that GSK-3 could constitute a novel therapeutic target to combat muscle loss in chronic diseases such as COPD.

Based on the above-mentioned findings, enclosed in the research chapters $\mathbf{3}, \mathbf{4}, \mathbf{5}$ and 6, we conclude that the signaling protein GSK-3 $\beta$ is a central, negative regulator of muscle mass maintenance. Finally, in chapter 7 we inquired into the possibility of targeting GSK-3 $\beta$ activity by physiological, nutritional and pharmacological means, with the purpose of fighting the often complex and multifactorial phenomenon of muscle atrophy in COPD. We conclude that breaking through the GSK-3 $\beta$ - GR signaling axis could constitute an important and promising treatment strategy to prevent loss of muscle mass and enhance muscle growth in COPD and other chronic diseases. 
SAMENVATTING 


\section{Samenvatting}

De gezonde skeletspier heeft een enorm vermogen om zich aan te passen aan veranderingen in het type en intensiteit van spieractiviteit, en voedseltoestand, alsook de capaciteit om zich te herstellen na spierschade (regeneratie). Dit aanpassingsermogen van de spier wordt ook wel spierplasticiteit genoemd. Deze aanpassingen betreffen de massa, het uithoudingsvermogen en de stofwisseling van de spier. Zo zal bij krachttraining (weerstandstraining), omwille van het verhoogde spiergebruik, na een bepaalde periode een toename in spieromvang waar te nemen vallen. Op celniveau betekent dit meestal dat de spiervezels in grootte zijn toegenomen (spierhypertrofie). Daartegenover staat dat bijvoorbeeld tijdens starvatie (uithongering) of tijdens langdurige inactiviteit (immobiliteit) de spiermassa in omvang afneemt (spieratrofie). Skeletspieratrofie treedt ook vaak op bij chronische inflammatoire ziektebeelden, waaronder chronische obstructieve longziekten (COPD), chronisch hartfalen, bepaalde ontstekingsziekten van de darm, reumatoïde artritis en kanker. Atrofie leidt tot spierzwakte, een verlaagde inspanningstolerantie, een verminderde levenskwaliteit, én zelfs tot een verhoogd sterfterisico, onafhankelijk van de primaire aandoening. Preventie en behandeling van spiermassaverlies worden daarom in toenemende mate onderkend als belangrijke pijlers in een geïntegreerde aanpak van deze chronische ziekten. Hiertoe is het essentieel om de moleculaire mechanismen van spierafbraak in kaart te brengen, en op zoek te gaan naar mogelijke "centrale schakelstations" van skeletspierplasticiteit. Vervolgens is het interessant om na te gaan of deze centrale regulatoire signaleringseiwitten geschikte kandidaten zijn voor fysiologische en/of farmacologische modulatie, teneinde spiermassaverlies in acute en chronische ziekten in te perken.

De regulatie van spiermassa wordt in grote mate bepaald door de balans tussen enerzijds eiwitopbouw (eiwitsynthese) en eiwitafbraak (eiwitdegradatie) anderzijds. In dit proces is een belangrijke rol weggelegd voor de insulin-like growth factor 1 (IGFI)/Akt signaleringsroute, die in staat is zowel anabole (eiwitsynthese) als katabole (eiwitdegradatie) prikkels in de spier te reguleren. Zoals eerder aangegeven kan spieratrofie op verschillende manieren tot stand komen. Over het algemeen gaat verlies aan spiermassa gepaard met verminderde IGF-I/Akt signalering in de spier, en verhoogde niveaus van circulerende glucocorticoiden (GCs). Het is tevens bekend dat het stimuleren van IGF-I/Akt signalering de nefaste (katabole) effecten van GCs kan teniet doen. Op dit moment is het echter nog steeds onduidelijk hoe GCs precies spieratrofie veroorzaken, en hoe activatie van IGF-I/Akt signalering de katabole effecten van GCs kan neutraliseren. Verhoogde spiereiwitafbraak verloopt via de activatie van het 26S-proteasoom (UPS) en het lysosomale autofagie systeem (ALP). Glycogeen synthase kinase-36 is een signaleringseiwit dat deel uitmaakt van de IGFI/Akt signaleringsroute, en in dit proefschrift hebben we ontdekt dat GSK-3 $\beta$ een centrale, negatieve regulator is van spiermassaregulatie. 
Om te achterhalen of GSK-3 $\beta$ mogelijk een link zou kunnen zijn tussen IGF-I/Akt en GC signalering in de spier, hebben we gebruik gemaakt van een celkweeksysteem (in vitro) van muizen skeletspier myoblasten $\left(C_{2} C_{12}\right.$ cellen) die zich kunnen omvormen (differentiëren) tot meerkernige spiervezels (myotubes). Experimenten in hoofdstuk 3 toonden aan dat genetisch deletie (siRNA) van GSK-3 $\beta$ een toename in de mRNA niveaus van atrogin-1 en MuRF1, beiden essentiële UPS-gerelateerde genen (atrogenen), na behandeling met een synthetisch GC (Dex), of na inhibitie van IGFI/Akt signalering (LY294002 inhibitor), kon voorkomen. De afwezigheid van GSK-3 $\beta$ remde tevens de afbraak van verschillende contractiele eiwitten (spiereiwitten), waaronder myosin heavy chain fast (MyHC-f) en myosin light chains 1 (MyLC-1) en 3 (MyLC-3), en beschermde de myotubes tegen atrofie. Een hoogst interessante bevinding was dat farmacologische remming van GSK-3 activiteit, in tegenstelling tot genetische inhibitie, enkel de toename in atrogin-1 mRNA kon onderukken, terwijl MuRF1 expressie niveaus ongevoelig waren voor de inhibitie van GSK-3 enzym activiteit.

In hoofdstuk 4 van dit proefschrift is de afhankelijkheid van atrogenen expressie (atrogin-1 en MuRF1) voor het GSK-3 $\beta$ signaleringseiwit bevestigd in een diermodel (in vivo). Dit hebben we gedaan door gebruik te maken van genetisch gewijzigde muizen waarbij het GSK-3 $\beta$ gen specifiek in de spier werd uitgeschakeld (ook wel een spierspecifieke GSK-3 $\beta$ knockout muis genoemd). Door GSK-3 $\beta$ expressie in de spier te inhiberen waren we in staat de rol van dit signaleringsmolecule te onderzoeken in een endogeen (starvatie) en exogeen (Dex) model van GC-geassocieerde skeletspieratrofie. In deze studies hebben we overtuigend aangetoond dat het uitschakelen van GSK-3 $\beta$ in de spier het verlies aan spiermassa, ten gevolge van starvatie of behandeling met een synthetisch GC (Dex), kan tegengaan. Verder kwam uit vervolganalyses naar voren dat genetische inhibitie van GSK-3 $\beta$ ook de toename van ALP-gerelateerde genen deels kon onderdrukken. Uit de starvatiestudie bleek tevens dat de stijging in mRNA expressie van de Forkhead Box $O$ (FoXO) transcriptiefactoren ook onderhevig was aan de afwezigheid van GSK-3 $\beta$. Daarnaast was de inductie van aantal GC-gevoelige genen onderdrukt in GSK-3 $\beta$ en GR knockout muizen. Zowel UPS als ALP-geassocieerde expressie programma's staan onder controle van FoXOs, en ook is het bewezen dat intacte GC signalering - via de glucocorticoid receptor (GR) - vereist is voor de totstandkoming van proteolytische genexpressie (UPS en FoXO). Het groot aantal overeenkomstigheden tussen de GSK-3 $\beta$ en GR knockout studies, met betrekking tot proteolytische genexpressie, deden het vermoeden rijzen dat deze bevindingen indicatief waren voor een GSK-3 $\beta$ - GR signaleringsmechanisme dat upstream, oftewel boven FoXO opereerde.

De mogelijke relatie tussen GSK-3 $\beta$ en GR met betrekking tot atrofiesignalering werd in hoofdstuk $\mathbf{5}$ in meer detail onderzocht. Voor deze vraagstelling werden opnieuw spierspecifieke GSK-3 $\beta$ en GR knockout muizen gebruikt. Ditmaal echter, 
werd spieratrofie bewerkstelligd door het induceren van een acute longontsteking met behulp van lipopolysaccharide (LPS), een bacterieel endotoxine. Acute longinflammatie ging gepaard met een toename in circulerende GCs (corticosterone) niveaus, en de daarbij horende GC-gevoelige genexpressie. Vergelijkbaar met de bevindingen in hoofdstuk 4, waren spierspecifieke GSK-3 $\beta$ en GR knockout muizen volledig beschermd tegen longinflammatie-geïnduceerde skeletspieratrofie. Een andere belangrijke observatie was dat naast proteolytische (UPS en ALP) en GCgevoelige genexpressie ook FoXO mRNA -en eiwitexpressie afhankelijk bleken te zijn van GR én GSK-3 $\beta$ aanwezigheid in de spier. Het huidige paradigma van FoXO regulatie is gecentreerd rond "inactivatie door fosforylatie" van FoXO transcriptie factoren (canonical of klassieke FoXO regulatie). Wij, daarentegen, hebben gesteld dat FoXO een direct target of doel-gen was van de GR, en dat de geobserveerde afname in UPS -en ALP-gerelateerde genexpressie, in de GSK-3 $\beta$ en GR knockout muizen, waarschijnlijk het resultaat was van verminderde FoXO activiteit in de celkern, als een direct gevolg van verminderde FoXO expressie (non-canonical, oftewel niet-klassieke FoXO regulatie). Non-canonical, oftewel niet-klassieke FoXO regulatie houdt in dat GSK-3 $\beta$ naar de celkern transloceert (zich verplaatst), om aldaar GR-afhankelijke genexpressie te stimuleren, hetgeen resulteert in de novo FoXO expressie. FoXO expressie is met andere woorden GR-afhankelijk, en GSK-3 $\beta$ opereert upstream van de $G R$, en reguleert als dusdanig zijn transcriptionele activiteit. Regulatie van UPS -en ALP-gerelateerde genen gebeurt vervolgens downstream, oftewel onder FoXO. Over het geheel genomen hebben we in hoofdstuk 5 het bestaan van een nieuwe GSK-3 $\beta$ GR signaleringsroute voorgesteld, die proteolytische genexpressie aanstuurt via de novo synthese van FoXO transcriptiefactoren.

Uit het werk zoals hier voorgesteld blijkt dat GSK-3 $\beta$ centraal staat in de regulatie van spierbehoud. In hoofdstuk 6 hebben we de mogelijkheid getoetst om GSK-3 $\beta$ farmacologisch te moduleren in vivo. Door gebruik te maken van een reeds beschikbare hoog selectieve farmacologische remmer van GSK-3 $\beta$ hebben we getoond dat GSK-3 $\beta$ inhibitie mogelijk een veelbelovende behandelingsstrategie zou kunnen worden om spiermassaverlies te voorkomen en spiergroei te bevorderen in chronische ziekten zoals COPD. In deze studie werd opnieuw een LPS model gehanteerd zoals beschreven in hoofdstuk 5, hoewel het ditmaal geen acuut maar een chronisch model betrof. Niet muizen, maar cavia's ondergingen een chronische LPS-behandeling hetgeen resulteerde in een longontsteking en verlies aan perifeer spierweefsel. Onze data toonden geen bewijs van verhoogde eiwitdegradatie (FoXO), noch van verlaagde eiwitsynthese niveaus. Desalniettemin ging chronische longontsteking gepaard met een afname van spiermassa en de grootte van individuele spiervezeldoorsnede. Lokale inhibitie (in de long) van GSK-3, daarentegen, verhinderde spieratrofie zonder de long inflammatie te beïnvloeden. Verder toonden in vitro experimenten aan dat farmacologische GSK-3 inhibitie de differentiatie van spiercellen (onderdeel van spierregeneratie) kon verbeteren in het bijzijn van GCs en 
de ontstekingsstof tumor necrosis factor- $\alpha$ (TNF- $\alpha$ ). Onze data lijken in lijn met de veronderstelling dat verbeterde spierregeneratie met behulp van een GSK-3 inhibitor, na een initiële periode van spieratrofie, al dan niet verhinderd door GSK-3 inhibitie, heeft geleid tot de bescherming tegen spiermassaverlies. De resultaten uit deze studie tonen dus aan dat GSK-3 $\beta$ een therapeutisch doelwit zou kunnen zijn in de strijd tegen spierverlies in chronische ziekten zoals COPD.

Gebaseerd op de bovenstaande bevindingen, omsloten in de onderzoekshoofdstukken 3, 4, 5 en 6 concluderen we dat het signaleringseiwit GSK-3 $\beta$ een centrale, negatieve regulator is van spiermassabehoud. Ten slotte werd in hoofdstuk 7 de mogelijkheid om door middel van fysiologische, nutritionele of farmacologische modulatie van GSK-3 $\beta$ activiteit een krachtig antwoord te bieden tegen het vaak complexe, en multifactoriële verschijnsel van spieratrofie bij COPD, besproken. We besluiten dat het doorbreken van de GSK-3 $\beta$ - GR signaleringsas een veelbelovende behandelingsstrategie lijkt om spiermassaverlies te voorkomen en spiergroei te bevorderen in COPD en andere chronische aandoeningen. 
(6) 


\section{Dankwoord}

Het kan niet anders dan dat ik bij de aanvang van dit dankwoord enkele clichés van stal haal. Immers, een cliché zou geen cliché zijn mocht deze geen grond van waarheid bevatten. Cliché 1: "Eindelijk". Na 5 lange jaren kan ik eindelijk, moe geschreven maar voldaan, mijn proefschrift verdedigen. Het was een lange weg met hier en daar wat putten, niet-conflictvrije stoplichten en wegenwerken, maar uiteindelijk ben ik toch op mijn bestemming geraakt. Such is life denk ik dan. Meer nog, zouden we niet kunnen stellen dat de Belgische snelwegen een metafoor zijn voor het leven? Niet altijd even veilig, en bezaaid met obstakels en gaten. Maar als je dan eens, op een zeldzaam moment, het voorrecht hebt om op een perfecte strook asfalt te rijden, dan weet je die strook ook naar waarde te schatten. Cliché 2: "Promoveren doe je niet alleen". Een waarheid als een koe, als je het mij vraagt. Ik wil met dit schrijven dan ook enkele mensen van harte bedanken.

Hoewel u niet rechtstreeks betrokken was bij mijn onderzoeksproject wil ik u bedanken, Prof. Wouters, om mij de mogelijkheid te bieden om te promoveren op de afdeling Pulmonologie. Ook zou ik u via deze weg graag nogmaals willen bedanken voor de financiële steun die ik van $u$ mocht ontvangen, hetgeen leidde tot de totstandkoming van dit boekje.

Woorden schieten tekort om uit te drukken hoe belangrijk mijn promotieteam is geweest in het realiseren van deze thesis. Beste Annemie, als ik jou in 2 woorden zou moeten omschrijven dan zou ik gaan voor: streng maar rechtvaardig. Het zijn deze karaktereigenschappen die jou aan het hoofd hebben gebracht van deze succesvolle onderzoeksgroep. Ik begrijp nog steeds niet hoe je in staat bent de dagelijkse leiding van onze spierlijn te combineren met die resem andere taken en verplichtingen binnen het MUMC+ en daarbuiten. Als geen ander slaag je erin de aurea mediocritas, oftewel de gulden middenweg, te vinden tussen het formele en het informele. Ik heb enorm van onze interacties (al dan niet werkgerelateerd) genoten. Tegen een bijzondere dame zoals jij zeg ik: Respect. Ramon "The Chief” Langen. Keer op keer verbaas je me weer met je kennis en inzichten. Ik had me in feite geen betere begeleider kunnen wensen. Ondanks je steeds drukkere agenda heb ik nooit de indruk gehad dat ik met vragen bleef zitten. Altijd stond je klaar om teksten na te kijken of om op verbluffende wijze jouw visie op de voortgang van het project met mij te delen; dit alles uiteraard steeds op jouw typerende stoïcijnse, doch humoristische, wijze. Ramon, je bent een groot man. Annemie en Ramon, nogmaals bedankt en laat dit geen écht afscheid zijn.

De collega's van de longlijn mogen uiteraard ook niet ontbreken in dit dankwoord. De "Longlijn Ladies": Niki Sr., Niki Jr., Renske, Irene, Claudia, Gonda, Poornima, Juanita en Mieke. Bedankt voor de gezellige sfeer de afgelopen jaren. Zijn jullie nu niet blij 
dat, sedert mijn vertrek, de "hemelse" keelgeluiden van de "Koen en Sander show" niet meer onderbroken worden door StuBru? Tegenover al dit vrouwelijk geweld staan slechts 2 mannen. Slechts?! Nou ja, volgens mij leveren zij voldoende testosteron om het schijnbaar onevenwicht in deze hormonale balans te herstellen. Pol en Tim, het was altijd gezellig met jullie in het lab of tijdens een feestje! Voor de AIOs onder jullie: moge de wetenschappelijke successen groot zijn en resulteren in prachtige boekjes!

Vele handen maken licht(er) werk. Het is daarom niet onlogisch dat ik in dit dankwoord de namen van de volgende studenten opneem: Tom, Rick en Olivia. Jullie hebben allen op positieve wijze bijgedragen aan dit proefschrift, en uiteraard óók aan de goede sfeer binnen de groep. Ik wens jullie veel succes met jullie verdere academische carrière. Een welverdiende merci!

Frank "Frenk" "The Tank" "Monsieur" Snepvangers. Ik heb je wel eens de "Laatste der Mohikanen" genoemd. Jij was in staat om naast je reguliere labverplichtingen ook andere taken op je te nemen. Een echte duizendpoot die het lab deed draaien, en tijd vrijmaakte voor anderen; dit alles gelardeerd met een bijzondere gelatenheid en gevoel voor humor. Ik wil je daarom ook op gepaste wijze bedanken voor jouw bijdrage aan dit verhaal. Ik heb enorm van onze samenwerking genoten, en ik kan alleen maar vaststellen dat jouw vertrek een fikse aderlating is geweest voor de vakgroep. Anon "Anonius" van Essen: jij bent ondertussen ook niet meer werkzaam binnen de vakgroep, want je kon aan de slag bij de Burger King afdeling binnen de Unie (en wie zou nu niet op zo'n aanbod ingaan?). Het ga je daar goed. Je was gedurende lange tijd mijn bench buurman, hetgeen vaak tot komische situaties leidde, vooral als je weer eens een Chuck Norris stelling poneerde. Chiel "Chielius" "The Man, the Legend" de Theije: dankzij jou kent het muizenplasma van mijn verschillende in vivo studies geen geheimen meer, althans geen glucocorticoid-gerelateerde geheimen (-). Bedankt voor die cruciale analyses! Je bent een meer dan competente analist, en in die hoedanigheid heb je de leemte die Frank achterliet goed weten in te vullen. Daarnaast ben je ook een getalenteerd onderzoeker, hetgeen zal verzilverd worden met een puik boekje. Daar ben ik van overtuigd. Marco "Kobus" "Het Orakel" Kelders. Vooral in de laatste fase van dit traject kon ik op jouw steun rekenen. Zoals een geoliede machine schud jij de ene dataset na de andere uit je mouw, steeds voorzien van het Kobus Quality Label. Bedankt voor al die aanvullende qPCR analyses.

Pascal "P-man" Hommelberg. Jij mocht zeker niet ontbreken in dit dankwoord, ook al ben je al verschillende jaren actief in Groningen. Met weemoed denk ik terug aan onze gesprekken over muziek, cultuur en geschiedenis. Ongelofelijk het aantal feiten die er zich in jouw hoofd bevinden. Weet wel dat we nog een trappistenavond van jou te goed hebben! Dit soort zaken vergeet ik niet :-). All the best. Beste Astrid, een generatiegenootje van Pascal, en de grote roerganger van het muizenwerk. Als een 
ware moederkloek waakte je over je kroost (Nicky en mijzelf). Bedankt om onze beider projecten mee in goede banen te helpen leiden. Je stond altijd klaar om steun te bieden bij zowel onze professionele als persoonlijke besognes. Dit zal ik niet vergeten. Graag had ik ook nog mijn collega AIOs Céline en Bram bedankt voor de aangename tijd zowel binnen als buiten het lab. Bram, nog een extra merci voor het aanleveren van de juiste sponsoringadressen.

Céline: ook het einde van jouw beproeving is in zicht. Zoals Lambik zou zeggen: Geef nog even "verkwistend gas" en voordat je het weet ben je voorbij de meet. Judith "no nickname" Ceelen. Niet in de herfst, maar eerder in de Hongerwinter van mijn carrière te Maastricht vervoegde je onze spierlijn. We hebben met andere woorden niet erg nauw met elkaar samengewerkt, maar ik had je al eerder leren kennen als hardwerkende student onder Chiel's Spartaans bewind. De spierlijn is momenteel licht atrofisch te noemen, en ik beschouw jou als een geschikte GSK-3 inhibitor met als taak verder spierverlies tegen te gaan en regeneratie te bespoedigen. Breng die Spaanse bevalligheid, passie en furie die je hanteert op de dansvloer eenvoudigweg over in het lab, en klaar is kees.

Nicky "Nicolaas" "The Gun" "Het Machien" Pansters: collega van het eerste uur! Samen namen we ruim 5 jaar geleden de "GSK-3 $\beta$ fakkel" over van Jos. De complementariteit tussen ons beiden was uitstekend. Ik stond bij wijlen versteld van je enorm logisch denkvermogen en literatuurkennis. Je was altijd bereid om te helpen waar nodig. Samen hebben we zowel binnen het lab, alsook daarbuiten (zij het op café of in de fitnesszaal), een enorm fijne tijd gehad in Maastricht. Het kan dan ook niet anders dat ik de significante belangrijke bijdrage aan de totstandkoming van dit werk hier op gepaste wijze apart in de verf zet. Ik wens je veel succes met het afronden van je boekje én, niet onbelangrijk, met het uitzetten van de juiste krijtlijnen voor de toekomst. Ik ben er zeker van dat dit eerder een "auf Wiedersehen" is dan een "Goodbye". Ilse, het lijkt me logisch dat ik jou in deze alinea vernoem. Ik sta echt te kijken van jouw computer skills. Net als ik op het punt stond om mijn PC uit het raam te kletteren, daalde jij, als een ware deus ex machina, neder om het een en ander terug recht te zetten. In het bijzonder doel ik hier op de wijze waarop je SPSS machtig bent, en me geholpen hebt met een aantal belangrijke statistische toetsen. Thanks! Ik wil hiermee Harry zijn computer vaardigheden absoluut niet onder de mat vegen. Integendeel. Harry, bedankt voor jouw onmisbare technische ondersteuning de afgelopen jaren. Over technische assistentie gesproken. Tiny, je hebt dit proefschrift vakkundig in elkaar gedraaid. Dankzij jou ben ik staat geweest om nog voor de zomer te promoveren. Ik wil hier nogmaals benadrukken hoe belangrijk dit voor mij is. 
Dear Ana, you deserve a special thanks. For exactly three years we called room 1.340 our home. We hit it off immediately. Honestly, I could not have asked for a better roomie. You read my mind like no other, and were always willing, and able to "jump-start" me whenever I needed it. What I enjoyed most was your sense of humor. We fueled each others creativity, which more than often resulted in a massive laughter-induced endorphin boost! It really helped to alleviate some of the job-related stress. I think that's called coping, right $;$ ? ? consider you as a great friend and our paths will surely cross again in the future.

A-man. Ik denk wel dat je weet waarom je achter mij staat op de Minderbroedersberg. Ellenlange beschrijvingen of verklaringen zijn hier echt niet van toepassing. Bedankt voor de vriendschap en de bijzonder leerrijke tijd die we samen hebben gehad. Naast de personality match, bleken we op professioneel vlak ook een goed team te zijn. Dit blijkt uit de succesvolle GSK-3 $\beta$ spin-off die je uit de grond hebt gestampt. Je bent een gretige wetenschapper, en dat is goed. Bedankt voor alle koffiekes en Duvelkes, dude! Ik wilde het volgende nog met je delen: "True friendship is clear like water, false friendship is sweet like honey". Veel geluk met het levenspad dat je samen met Bettine zal gaan bewandelen. Santé en tot snel!

Yo G. Remember those days in Wageningen? It seems like ages ago, doesn't it? I am very fortunate to have met you in that little Global Village. For years now, we have stayed in contact, city trippin' across Europe, contemplating life and all its amenities. You and your family took me in as one of their own. Needless to say, choosing you as my best man was not exactly rocket science. All the best, bro! Now and in all your future endeavors.

Dear Dongni. In Amsterdam, you convinced me to send an email to Nutrim and to inquire about a job opening at the department of Respiratory Medicine, even though that meant we had to live over $200 \mathrm{~km}$ apart. Our time together opened floodgates of new insights and information in my mind, and I am grateful for that. I am sorry things didn't work between us. You did, however, set the stage for the next act. It is now up to Asia to make a move. I wish you the happiness you crave for, and off course, good luck with concretizing that chocolate dream of yours.

Moeke. Ik wil je bedanken voor de liters koffie en de duizenden $k c a l$ aan eigen gemaakt gebak. Vooral tijdens het schrijven van de verschillende discussies kwam ik vaak langs, en je wist me steeds weer af te leiden, maar vooral te boeien, met je gedetailleerde beschrijving van de gebeurtenissen uit de periode 1940-1944 te Houthalen. Ik wens je een goede gezondheid en laten we vooral het boventaande blijven doen! Ik wil je nog een anekdote van een Schots buschauffeur meegeven: "Er bestaat niet zoiets als slecht weer, alleen maar slecht aangepaste kledij". Oma: je woont misschien iets verder dan 200 meter van me verwijderd, maar dat hield me 
niet tegen om je geregeld te bezoeken; vooral als het me allemaal wat te veel werd. Ik vind het geweldig hoe je op je $90^{\text {ste }}$ nog steeds zo energiek en gezond bent. Dit moet vooral zo blijven. Ik hoop dat we nog vaak op stap kunnen gaan, zodat je me weer kan trakteren op de obligatoire "Achelse Kluis" van 't vat. De kans is reëel dat ik je verjaardagsfeestje zal missen, maar ik beloof dat we samen nog een privé-uitstap zullen doen.

Tant. You still got it! Is het niet met glas, dan wel met verf, klei of bits and bytes. Kortom, bedankt voor het mooie ontwerp. Een belangrijk feit in de afgelopen jaren was dat we elkaar terug hebben ontdekt. Welcome back to the fold. Veel geluk! Beste Eliane. Bedankt voor de vriendschap en je immer luisterend oor. Veel succes met deze nieuwe fase in je leven, daar in je paleis aan de Maas. Het is zoals je zei, met de bijna profetische Maaslandse wijsheid: "Et kump good";). Bart "Arnold" "Jay Cutler" Ruttens. Samen groeiden we op in Wurfeld, en sindsdien zijn we altijd goede vrienden gebleven. Je belichaamt de term "spierhypertrofie", en bent als dusdanig het levende bewijs dat de BMI, in sommige gevallen, een maat voor niets is. Bedankt voor het aanleveren van het didactisch materiaal voor mijn eindpresentatie. Deze kende je al neem ik aan: "Whatever life throws at you, put it on the bar and press it!". Ella, jou wilde ik ook graag vermelden. Bedankt voor de jarenlange vriendschap. Jouw eigenzinnige kijk op het leven heeft me vaak kritisch doen nadenken over mijn eigen situatie. Ik wens jou samen met Mike alle geluk, voorspoed en stabiliteit toe in de toekomst.

Kris. Ik hoop dat jij samen met Isabelle een goede toekomst tegemoet zult gaan. Alles lijkt nu ineens in een stroomversnelling terecht gekomen, maar je bent een waterrat, dus dat komt wel goed! Ma, T. De duizenden woorden die samen dit proefschrift vormen staan alleen maar op de juiste volgorde (althans daar ga ik van uit) dankzij jullie. Dit is geen overdrijving. Bedankt om me van kinds af aan altijd een podium te bieden om al mijn passies en interesses ten volle te kunnen uitwerken, en op tijd in te zien welke bijzondere noden ik had bij de aanvang van mijn schoolcarrière. Maak je maar geen zorgen om mij. Het volgende hoofdstuk mag dan wel nog niet volledig uitgeschreven zijn, ik ben er zeker van dat alles uiteindelijk in zijn plooi zal vallen. 
CURRICULUM VITAE 


\section{Curriculum vitae}

Koen Verhees was born on May 31 1983 in Maaseik, Belgium. In 2001 he graduated from the Koninklijk Atheneum in Maaseik. Later that year he enrolled into a BSc program Biotechnology (specialization: cellular genetics) at the Provinciale Hogeschool Limburg, Belgium. Both his BSc internship and thesis project were carried out at Hasselt University (campus Diepenbeek), at the department of environmental sciences (CMK), where he focused on cadmium toxicity and oxidative stress in Arabidopsis thaliana. In November 2005 he began his MSc in Biotechnology at Wageningen University, the Netherlands. Thesis work was conducted at the Laboratory of Molecular Recognition and Antibody technology (LMA) of Wageningen University, where he participated in the transient production of human and mouse cytokine TGF- $\beta 1$ in Nicotiana benthamiana. To complete his MSc program, an internship was done at the phagocyte laboratory of Sanquin Research Amsterdam. In Amsterdam Koen worked on the role of SIRP $\alpha$-CD47 interaction in antibodydependent cellular cytotoxicity (ADCC) in macrophages. In January 2008 he obtained his MSc degree biotechnology with a specialization in medical biotechnology. After his graduation he briefly worked as a PhD student at the phagocyte laboratory of Sanquin Research Amsterdam, where he studied SNPs in human SIRP $\alpha$ and their implications in the immunological response. In April 2008 he joined the department of Respiratory Medicine at the University of Maastricht. His PhD project was aimed at elucidating the molecular mechanisms that underlie skeletal muscle atrophy and focused specifically on the role of GSK-3 $\beta$ in this process. 
LIST OF PUBLICATIONS 


\section{List of publications}

1. Verhees KJP, Pansters NAM, Schols AMWJ, Langen RCJ. Regulation of skeletal muscle plasticity by glycogen synthase kinase-3 $\beta$ : a potential target for the treatment of muscle wasting. Curr. Pharm. Des. 2013; 19 (18): 3276-3298.

2. Verhees KJP, Schols AMWJ, Kelders MCJM, Op den Kamp CMH, van der Velden $\mathrm{JJJ}$, Langen RCJ. Glycogen synthase kinase-3 $\beta$ is required for the induction of skeletal muscle atrophy. Am. J. Physiol. - Cell Physiol. 2011; 301: C995-C1007.

3. Verhees KJP, Schols AMWJ, Pansters NAM, Snepvangers FJ, Kelders MCJM, van Gorp RHP, Houben T, de Theije CC, Langen RCJ. Glucocorticoid-dependent skeletal muscle atrophy requires glycogen synthase kinase-3 $\beta$. (submitted)

4. Verhees KJP, Schols AMWJ, Pansters NAM, Haegens A, Snepvangers FJ, Kelders MCJM, de Theije CC, van Gorp RHP, Houben T, Hermans R, Patel S, Berger S, Langen RCJ. A glycogen synthase kinase- $3 \beta$ - glucocorticoid receptor signaling axis controls muscle atrophy induced by pulmonary inflammation. (submitted)

5. Verhees KJP, Baarsma HA, Pansters NAM, Remels AHV, Schols AMWJ, Gosens R, Langen RCJ. Glycogen synthase kinase-3 inhibition prevents skeletal muscle atrophy in an animal model of pulmonary inflammation. (submitted) 
LIST OF ABBREVIATIONS

$$
279
$$




\section{List of abbreviations}

4E-BP1

AIDS

Akti-1/2

ALP

AMPK

ANOVA

APC

ARBP

ARDS

ATF-4

Atg

ATP

B2M

Bax

BCAA

BCAT2

$\mathrm{Bcl}-2$

Bim

Bnip3

BSA

$\mathrm{C} / \mathrm{EBP} \beta$

$\mathrm{C}_{2} \mathrm{C}_{12}$

$\mathrm{ca}$

CDNA

$\mathrm{CHF}$

CHIR

CK1 $\alpha$

CKD

CLP

COPD

COX

CRF

CRP

CSA

CXCL

Cys

CYT

DAB

Dex

DM
elF4E-binding protein 1

acquired immunodeficiency syndrome

Akt inhibitor

autophagy-lysosomal pathway

adenosine monophosphate-activated protein kinase

analysis of variance

adenomatous polyposis coli

attachment region binding protein

acute respiratory distress syndrome

activating transcription factor 4

autophagy gene

adenosine-5'-triphosphate

$\beta 2$ microglobulin

Bcl-2-associated $X$ protein

branched-chain amino acid

branched-chain amino acid transaminase 2

Beclin-2

$\mathrm{Bcl}$-2-binding protein

$\mathrm{Bcl}-2$ and $19 \mathrm{kDa}$ interacting protein 3

bovine serum albumin

CCAAT/enhancer-binding protein $\beta$

$\mathrm{C}_{2} \mathrm{C}_{12}$ skeletal muscle cell line derived from Mus musculus

constitutively active (e.g. caGSK-3 3 )

copy DNA

congestive heart failure

CHIR99021, GSK-3 $\beta$ inhibitor

casein kinase $1 \alpha$

chronic kidney disease

cecal ligation and puncture

chronic obstructive pulmonary disease

cyclooxygenase

chronic renal failure

c-reactive protein

cross-sectional area

chemokine ( $\mathrm{C}-\mathrm{X}-\mathrm{C}$ ) motif

cysteine

cytoplasmic extract

diaminobenzidine

dexamethasone

differentiation medium 


\begin{tabular}{|c|c|}
\hline DMEM & Dulbecco's modified eagle medium \\
\hline DMSO & dimethyl sulfoxide \\
\hline $\mathrm{dn}$ & dominant-negative (e.g. dnGSK-3 $\beta$ ) \\
\hline DNA & deoxyribonucleic acid \\
\hline DTT & dithiothreitol \\
\hline Dvl & dishevelled \\
\hline$E 3 \alpha-I I$ & ubiquitin ligase (a.k.a. UBR2) \\
\hline EDL & extensor digitorum longus \\
\hline EGF & epidermal growth factor \\
\hline elF & eukaryotic initiation factor \\
\hline ER & endoplasmatic reticulum \\
\hline ERK & extracellular signal regulated kinase \\
\hline ESC & embryonic stem cells \\
\hline FBS & fetal bovine serum \\
\hline FDA & food and drug administration \\
\hline FoXO & Forkhead Box O \\
\hline FRAT & frequently rearranged in advanced T-cell lymphomas (a.k.a GBP) \\
\hline $\mathrm{Fz}$ & frizzled \\
\hline Gabarapl1 & GABA receptor associated protein 1 \\
\hline Gadd45a & growth arrest and DNA damage-inducible 45a \\
\hline GAPDH & glyceraldehyde 3-phosphate dehydrogenase \\
\hline GBP & GSK-3-binding protein \\
\hline GC & glucocorticoid \\
\hline GDP & guanosine diphosphate \\
\hline Glul & glutamate-ammonia ligase \\
\hline GM & growth medium \\
\hline GR & glucocorticoid receptor \\
\hline$G R^{\operatorname{dim}}$ & dimerization-deficient mutant GR \\
\hline GRE & glucocorticoid responsive element \\
\hline GS & glycogen synthase \\
\hline GSK-3 & glycogen synthase kinase-3 \\
\hline GSK-3 $\beta^{-1-}$ & 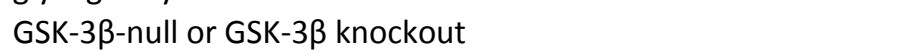 \\
\hline GSK-3 $\beta^{+/-}$ & retaining 1 GSK-3 $\beta$ allele \\
\hline GSK-3 $\beta^{+/+}$ & GSK-3 $\beta$ WT \\
\hline GSK-3 $\beta^{\mathrm{fl} / \mathrm{fl}}$ & double floxed GSK-3 $\beta$ \\
\hline GTP & guanosine triphosphate \\
\hline $\mathrm{h}$ & hour \\
\hline HAT & histone acetyl transferase \\
\hline HDAC & histone deacetylase \\
\hline HEPES & 4-(2-hydroxyethyl)-1-piperazineethanesulfonic acid \\
\hline HMK & halomethylketone \\
\hline HPA & hypothalamic-pituitary-adrenal \\
\hline
\end{tabular}




\begin{tabular}{|c|c|}
\hline HPLC & high-pressure liquid chromatography \\
\hline HSF-1 & heat shock factor 1 \\
\hline Hsp90 & heat shock protein 90 \\
\hline IBD & inflammatory bowel disease \\
\hline $\mathrm{IC}_{50}$ & half maximal inhibitory concentration \\
\hline IGF & insulin-like growth factor \\
\hline IGF-IR & IGF-I receptor \\
\hline IL-1 $\beta$ & interleukin-1 $\beta$ \\
\hline IMPA & inositol monophosphatase \\
\hline IR & insulin receptor \\
\hline IRS-1 & insulin receptor substrate 1 \\
\hline IT & intratracheal \\
\hline $\mathrm{kDa}$ & kilodalton \\
\hline KLF-15 & Krüppel-like factor 15 \\
\hline L6 & L6 skeletal muscle cell line derived from Rattus norvegicus \\
\hline LANA & viral latency-associated nuclear antigen \\
\hline $\mathrm{LC} 3 \mathrm{~b}$ & microtubule-associated proteins $1 \mathrm{~A} / 1 \mathrm{~B}$ light chain $3 \mathrm{~B}$ \\
\hline LPS & lipopolysaccharide \\
\hline LRP5/6 & lipoprotein receptor-related protein $5 / 6$ \\
\hline LSD & least statistical difference \\
\hline LY & LY294002, PI-3K inhibitor \\
\hline Lys & lysine \\
\hline MAFbx & muscle atrophy F-box (a.k.a. atrogin-1) \\
\hline MAPK & mitogen-activated protein kinase \\
\hline MCK & muscle creatine kinase \\
\hline MCL-1 & induced myeloid leukemia cell differentiation protein \\
\hline MEF & mouse embryonic fibroblast \\
\hline MGF & mechano growth factor \\
\hline MGR KO & muscle-specific GR knockout \\
\hline MGSK-3 $\beta$ KO & muscle-specific GSK-3ß knockout \\
\hline $\min$ & minute \\
\hline $\mathrm{mM}$ & millimolar \\
\hline MMP & matrix metalloproteinase \\
\hline MND & motor neuron disease \\
\hline MRF & muscle regulatory factor \\
\hline mRNA & messenger RNA \\
\hline mTOR & mammalian target of rapamycin \\
\hline mTORC1 & raptor-mTOR complex 1 \\
\hline mTORC2 & rictor-mTOR complex 2 \\
\hline MuRF1 & muscle-specific RING finger protein 1 \\
\hline MyHC-f & myosin heavy chain fast \\
\hline MyLC-1 & myosin light chain 1 \\
\hline
\end{tabular}




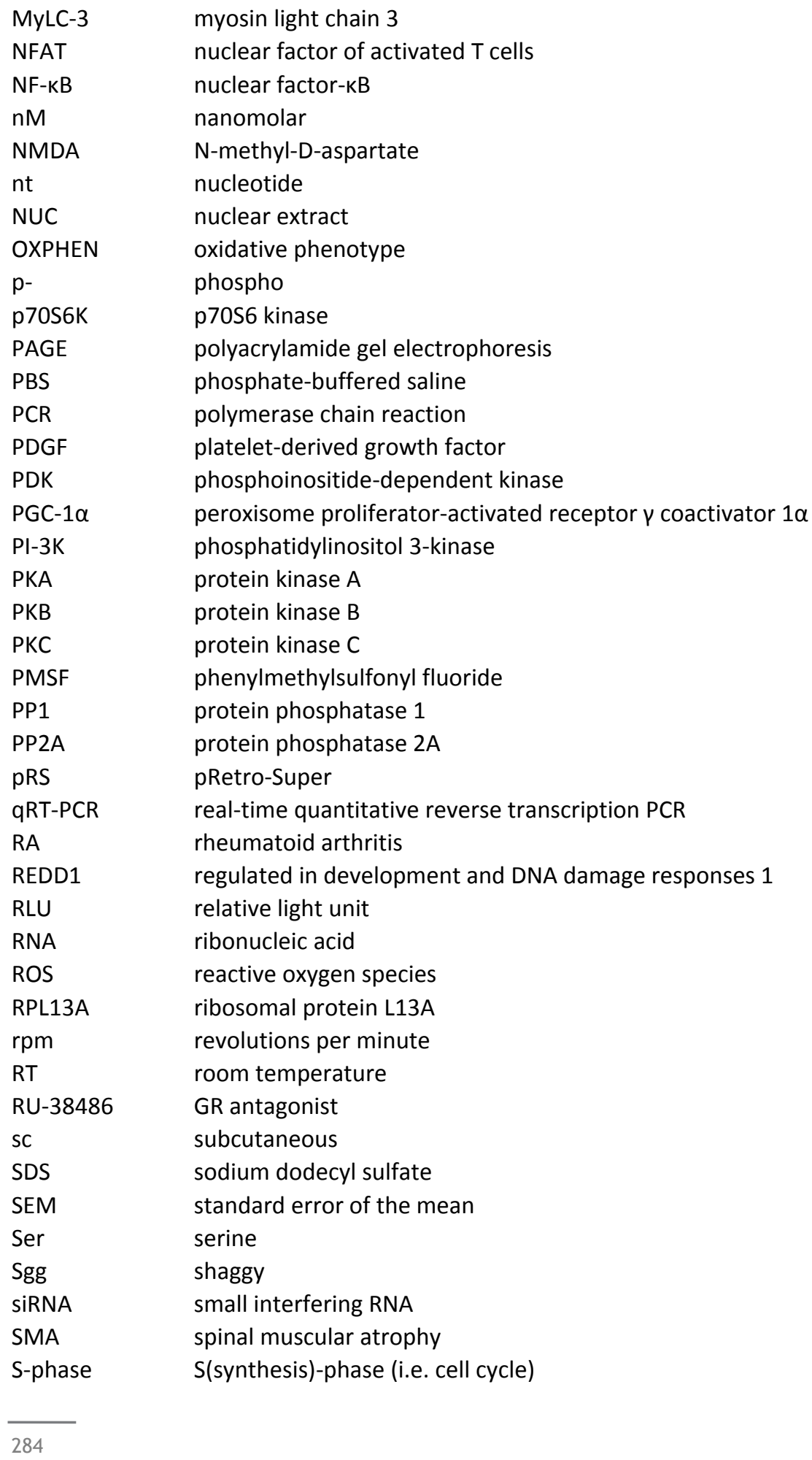


STAT

TBS

Tcf/Lef-1

TDZD

TFA

Thr

T-loop

TNF

Tnl

tPK1

tRNA ${ }^{\text {iMet }}$

$\mathrm{TSC} 1 / 2$

Tyr

U

UPS

$\mathrm{v} / \mathrm{v}$

vc

$w / v$

WCL

Wnt

WT

zw3

BArr2

$\beta$-gal

$\mu \mathrm{M}$

$\mu \mathrm{m}$

signal transducer and activator of transcription

Tris-buffered saline

T-cell factor/lymphocyte-enhancement factor 1

thiadiazolidinone

trifluoroacetic acid

threonine

activation loop (in GSK-3 protein)

tumor necrosis factor

troponin I

human tau protein kinase

initiator methionine transfer RNA

tuberous sclerosis protein 2

tyrosine

units

ubiquitin 26S-proteasome system

volume concentration

vehicle

weight/volume percentage

whole cell lysate

Wingless/int

wild-type

zeste-white 3

$\beta$-arrestin 2

$\beta$-galactosidase

micromolar

micrometer 
usque ad finem 
